\title{
CHINA: THE NEXT TWENTY YEARS OF REFORM AND DEVELOPMENT
}




\title{
Other titles in the China Update Book Series include:
}

\author{
1999 China: Twenty Years of Economic Reform \\ 2002 China: WTO Entry and World Recession \\ 2003 China: New Engine of World Growth \\ 2004 China: Is Rapid Growth Sustainable? \\ 2005 The China Boom and its Discontents \\ 2006 China: The Turning Point in China's Economic Development \\ 2007 China: Linking Markets for Growth \\ 2008 China's Dilemma: Economic Growth, the Environment and \\ Climate Change \\ 2009 China's New Place in a World of Crisis
}




\section{CHINA: THE NEXT TWENTY YEARS OF REFORM AND DEVELOPMENT}

Ross Garnaut, Jane Golley and Ligang Song (eds)

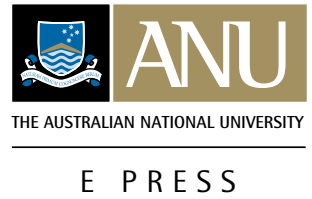

B Brookings Institution Press

(A) 社会科学文献出版社 SOCIAL SCIENCES ACADEMIC PRESS(CHINA) 


\section{ANU}

E PRESS

Published by ANU E Press

The Australian National University

Canberra ACT 0200, Australia

Email: anuepress@anu.edu.au

This title is also available online at: http://epress.anu.edu.au/china_20_citation.html

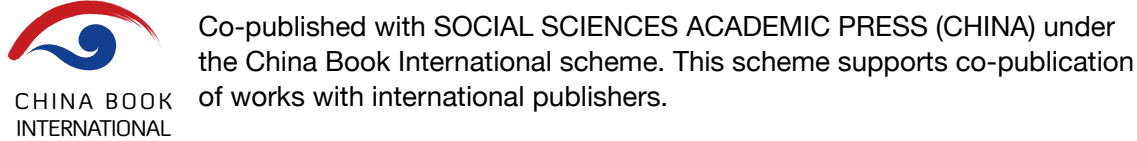
INTERNATIONAL

All rights reserved. No part of this publication may be reproduced, stored in a retrieval system or transmitted in any form or by any means, electronic, mechanical, photocopying or otherwise, without the prior permission of the publisher.

Cover design by Teresa Prowse, Made by Fruitcup

Cover photograph: Nikada. iStockphoto, File Number: 10959874

Printed by Griffin Press

This edition (C) 2010 ANU E Press 


\section{Contents}

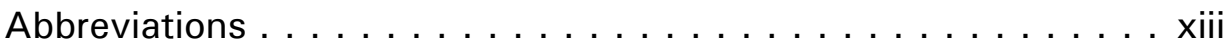

Contributors . . . . . . . . . . . . . . . . . xvii

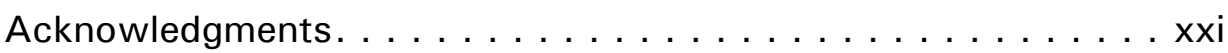

1. Chinese economic reform and development: achievements, ... emerging challenges and unfinished tasks. . . . . . . . 1 Jane Golley and Ligang Song

\section{Part I Long-Term Development: Trends and Issues}

2. The turning period in China's economic development: a conceptual framework and new empirical evidence . . . . . . 19 Ross Garnaut

3. China model and its future $\ldots \ldots \ldots \ldots \ldots \ldots$ Yang Yao

4. How will China's central-local governmental relationships evolve? An analytical framework and its implications . . . . . . . . . . . . . . 53 Yongsheng Zhang

5. China's metal intensity in comparative perspective . . . . 73 Huw McKay, Yu Sheng and Ligang Song

6. Assessing China's energy conservation and carbon intensity: how will the future differ from the past? . . 99 ZhongXiang Zhang

7. Prospects for diminishing regional disparities. . . . . . . . 127 Jane Golley

\section{Part II: Global Integration: Challenges and Opportunities}

8. Exchange rate policy and macroeconomic adjustment $\ldots \ldots 153$ Geng Xiao

9. The real exchange rate and the renminbi $\ldots \ldots \ldots \ldots 163$ Rod Tyers and Ying Zhang 
China: The Next Twenty Years of Reform and Development

10. China and East Asian trade: the decoupling fallacy, crisis and policy challenges. . . . . . . . . . . . . . . . . . . 193 Prema-chandra Athukorala and Archanun Kohpaiboon

11. Asian foreign direct investment and the 'China effect' . . . 221 Chunlai Chen

12. The global financial crisis and rural-urban migration. . . . . 241 Sherry Tao Kong, Xin Meng and Dandan Zhang

\section{Part III: Policy and Reform: Unfinished Business}

13. Avoiding economic crashes on China's road to prosperity . . 269 Wing Thye Woo

14. Rebalancing China's economic structure. . . . . . . . . . . . 293 Yiping Huang and Bijun Wang

15. Urbanisation with Chinese characteristics . . . . . . . . . . 319 Cai Fang and Meiyan Wang

16. Indigenous innovation for sustainable growth . . . . . . . . . 341 Yanrui Wu

17. China's health system and the next 20 years of reform . . . 363 Ryan Manuel

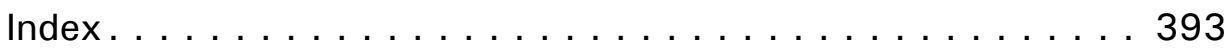




\section{Tables}

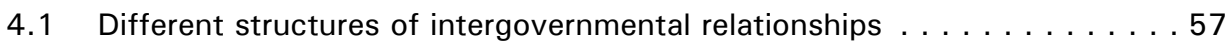

4.2 Share of central and local governments in government revenue

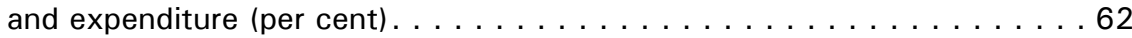

5.1 Major results from simultaneous equation estimation, $1890-2008 \ldots \ldots$. . 88

5.2 China's economy and steel demand per capita, 1980-2008 . . . . . . . 90

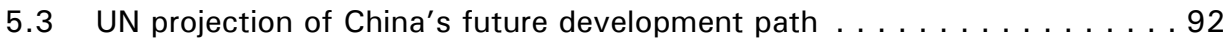

6.1 Consumption tax rates for cars in China (per cent) . . . . . . . . . . . . 104

6.2 Vehicle emission standards and the time to enter into force in China, ASEAN and the European Union. . . . . . . . . . . . . 106

6.3 Preliminary and final values for total primary energy consumption and coal consumption in China, 1990-2008 . . . . . . . . . . . . 114

6.4 Reduction in China's energy intensity: preliminary value versus final value (per cent) . . . . . . . . . . . . . . . . . . . . . . . . . 115

6.5 Differentiated tariffs for eight energy-guzzling industries in China (RMB/kW.h) . . . . . . . . . . . . . . . . . . . . . . . 117

7.1 Regional snapshot, $2007 \ldots \ldots \ldots \ldots$. . . . . . . . . . . . . . 130

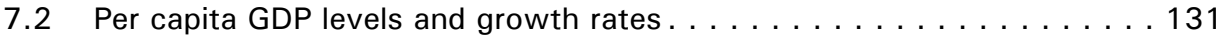

7.3 Industry-wide NRCs and growth rates of industrial output, 2000-07 . . 135

7.4 Regional NRCs and location components by sector, 2000-07 . . . . . 137

7.5 Regional shares of industrial output, 2007 (per cent) . . . . . . . . . 139

7.6 Shift-share analysis of provincial industrial growth . . . . . . . . . . . . 140

9.1 Contributions to China's real exchange rate change 1997-2006 (per cent) . . . . . . . . . . . . . . . . . . . 166

9.2 The balance sheet of the People's Bank of China, ca. 2009 . . . . . . . . 177

9.3 Estimates of the foreign share of total assets, selected countries . . . . 180

9.4 Country rankings on foreign shares of total assets $\ldots \ldots \ldots \ldots$

10.1 Composition of manufacturing exports, 2006-07 (per cent) . . . . . . . 196

10.2 Share of parts and components in manufacturing trade, 1992-03 and 2006-07 (per cent) . . . . . . . . . . . . . . . . . . 198 
China: The Next Twenty Years of Reform and Development

10.3 Share of parts and components in bilateral trade flows, 2006-07 (per cent) . . . . . . . . . . . . . . . . . . . . 199

10.4 China's trade with the rest of East Asia (per cent) . . . . . . . . . . 200

10.5 East Asia-China manufacturing trade . . . . . . . . . . . . . . . 202

10.6 Intra-regional shares of manufacturing trade: total parts and components and final trade, 1992-93 and 2006-07 (per cent) . . . . . . . 203

10.7 East Asia: growth of total merchandise exports and imports, 200701-200903 (year-on-year percentage change) . . . . . . . . . 207

10.8 China: growth of total merchandise exports \& imports by trading partner countries, 200701-20090 year-on-year percentage change,

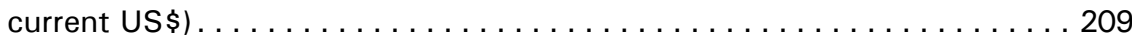

10.9 China: growth of merchandise exports and imports by commodity category, 200801-200903 year-on-year percentage change,

11.1 Regression results of the effects of FDI flows into China on FDI inflows into East, South and South-East Asian developing economies, 1992-2008, fixed-effects . . . . . . . . . . . . . . . . . . . 230

11.2 China's imports of raw materials from Asian economies (US\$ million) . . . . . 231

11.3 Two-way trade between China and Asian economies in electric

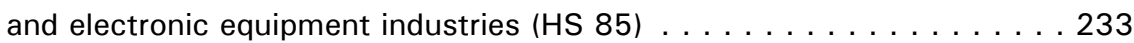

11.A1 Appendix. Variable list of the impact of FDI inflows into China on FDI inflows into other Asian developing host economies. . . . . . . 239

12.1 Summary statistics for migrant and rural samples $\ldots \ldots \ldots \ldots \ldots$

12.2 Employment and earnings of migrants in cities (migrant sample) . . . . 248

12.3 Results from the hours and hourly earnings equations for migrants in cities (migrant sample) . . . . . . . . . . . . . . . . . 252

12.4 Return migration, employment and earnings for rural labour force (rural sample). . . . . . . . . . . . . . . . . . . . . . . . 255

12.5 Migration and off-farm status for a panel of individuals (rural sample) . . . . . . . . . . . . . . . . . . . . . . . . . 257

12.6 Results from hours and hourly earnings equations for rural off-farm work (rural sample) . . . . . . . . . . . . . . . . . . . . 260

12.7 Per capita income comparisons across different type of households . . . . 262

12.A1 Appendix. Migrant survey timing distribution by survey year 
(migrant sample) (per cent) . . . . . . . . . . . . . . . . . . . . . 264

12A2 Appendix. Occupational distribution of self-employed migrants by year (migrant sample) . . . . . . . . . . . . . . . . . . . . . . 264

14.1 Estimated cost distortions in China, 2000-08 (per cent of GDP) . . . . . 307

15.1 Numbers and growth rates of migrant workers and the urban employed . . . . . . . . . . . . . . . . . . . . . . . . . . 324

15.2 Adjustments of urban minimum wages (numbers, per cent) $\ldots \ldots \ldots 332$

15.3 Duration of migrating work and mobility of migrant workers

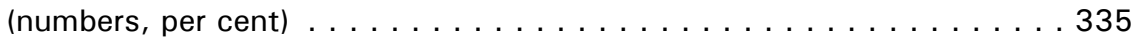

16.1 China's regional research and development statistics 2008 . . . . . . . . 344

16.2 Econometric estimation results . . . . . . . . . . . . . . . . 349

16.3 World's top five research and development spenders $2007 \ldots \ldots . . . .352$

16.4 High-technology sector exports in selected economies 2007 . . . . . . 355

16.5 High-technology sector research and development intensity in selected economies, 2006 (per cent) . . . . . . . . . . . . . 357 

5.1 Competing theories of metal intensity $\ldots \ldots \ldots \ldots \ldots$

5.2 Crude steel output per capita of selected economies, $1890-2008 \ldots \ldots$. . 84

5.3 Crude steel output and GDP, scaled by population, $1890-2008 \ldots \ldots$. . 86

5.4 Urbanisation ratios of selected economies, $1890-2005 \ldots \ldots$. . . . . 86

5.5 Projection of steel demand per capita, extrapolating current trends . . . . . 91

5.6 China's consumption of crude steel, 1978-2008 (million tonnes) . . . . . 93

6.1 Energy use per unit of GDP in China, 1990-2007 (tonnes of coal equivalent per US\$1000 in 1980 prices) . . . . . . . . 102

6.2 Comparison of fuel economy standards for vehicles . . . . . . . . . . . 105

6.3 Cumulative installed wind power capacity by country, 1980-2009 . . . . 109

7.1 Map of China . . . . . . . . . . . . . . . . . . . . . . . . 129

7.2 Regional shares of GVIO (per cent) $\ldots \ldots \ldots \ldots \ldots \ldots \ldots \ldots \ldots$

9.1 Chinese sectoral price indices, $1990-2009 \ldots \ldots \ldots \ldots$. . . . . . 166

9.2 The Mainland China-US real exchange rate on GDP prices . . . . . . . . 167

9.3 The Mainland China-US real exchange rate on producer prices . . . . . . 167

9.4 China's investment-saving and external balances

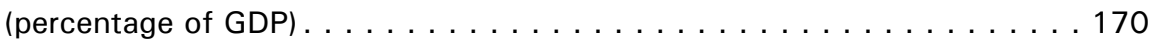

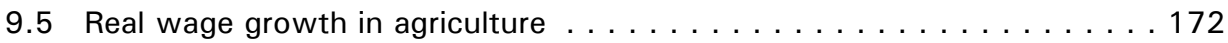

9.6 Dynamics of the PBOC's balance sheet: assets and liabilities as

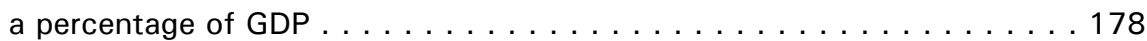

10.1 Growth of merchandise trade: East Asia, developing East Asia, China and ASEAN, January 2008-November 2009 (year-on-year, per cent) . . . . 206

11.1 FDI inflows into China (at current prices) . . . . . . . . . . . 223

12.1 Age distribution of the sample from the migrant and rural surveys. . . . 247

12.2 Wage/salary workers' $\log$ weekly hours worked by industry . . . . . . . 250

123a Wage/salary earners' log hourly earnings by industry (total sample) . . . 251

123b Wage/salary earners' log hourly earnings by industry (panel sample) . . . . . . . . . . . . . . . . . . . . . 251

14.1 Comparison of the investment rate and consumption rate between China and the Chenery Standard, 1990-2008 . . . . . . . . . 296 
14.2 China's current account balances, 1986-2009 (per cent of GDP) . . . . . . . . . . . . . . . . . . . . . . . . . . . 297

14.3 China's saving and investment rate, 1978-2009 (per cent of GDP) . . . . . . . . . . . . . . . . . . . . 298

14.4 Gini coefficient among households and the urban-rural income gap . . . 298

14.5 Proportion of residential, firms' and government income in primary distribution and the urban-rural income gap. . . . . . . . . . . . 299

14.6 China's annual increased loan, $2004-10 \ldots \ldots \ldots \ldots 1$

14.7 Estimated cost distortion and structural imbalances . . . . . . . . . . 309

15.1 Changes in the ratio of physical to labour inputs in Chinese agriculture . 323

15.2 Quantitative relationship between agricultural and non-agricultural

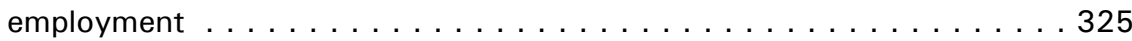

15.3 Usual urban population versus non-agricultural hukou population . . . . . 329

16.1 China's research and development intensity and personnel, 1990-2009. . . . . . . . . . . . . . . . . . . . . . . . . . . 343

16.2 Numbers of patents applied for and accepted, 1995-2009 . . . . . . . 344

16.3 China's research and development intensity and performance, 2008 . . 346

16.4 China's research and development expenditure shares and sources

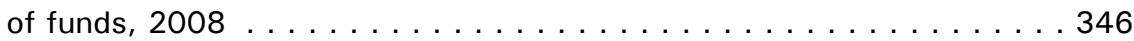

16.5 Research and development intensity and per capita GDP of major

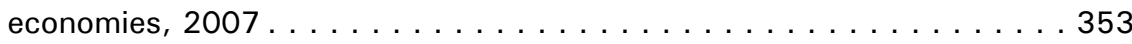

16.6 Research and development spending shares (basic and applied research) in selected economies . . . . . . . . . . . . . . . . . . . . . 354

16.7 High-technology sector value added (in 1995 constant prices) . . . . . . 355

17.1 Levels of healthcare provision in pre-1978 rural China . . . . . . . 365

17.2 Public spending in the post-collectivisation period, 1990-2003 . . . . . 368

17.3 People declining hospitalisation in the post-collectivisation period, 1990-2003 . . . . . . . . . . . . . . . . . . . . 369

17.4 Sources of healthcare spending in the post-collectivisation period, $1990-2003 \ldots \ldots \ldots$. . . . . . . . . . . . . . . . . . 370

17.5 Changes in tax revenues versus expenditures, 1993-2004 (per cent) . . 371

17.6 Urban and rural health profession skills and ratios . . . . . . . . 372 


\section{Abbreviations}

\begin{tabular}{|c|c|}
\hline ACFTA & ASEAN-China Free Trade Area \\
\hline $\mathrm{ADB}$ & Asian Development Bank \\
\hline ASEAN & Association of South-East Asian Nations \\
\hline BMCDR & Beijing Municipal Commission of Development and Reform \\
\hline BMI & Basic Medical Insurance \\
\hline $\mathrm{BPCB}$ & bare-printed circuit boards \\
\hline $\mathrm{BSH}$ & Balassa-Samuelson hypothesis \\
\hline CAFE & corporate average fuel economy \\
\hline CAM & centrally administered municipality \\
\hline $\mathrm{CCP}$ & Chinese Communist Party \\
\hline CDR & country credit rating \\
\hline CHIBOR & China inter-bank offered rate \\
\hline $\mathrm{CIC}$ & China Investment Company \\
\hline CIS & Commonwealth of Independent States \\
\hline CMS & Cooperative Medical Scheme \\
\hline $\mathrm{CNY}$ & yuan \\
\hline COMTRADE & Commodity Trade Statistics Database \\
\hline CPI & consumer price index \\
\hline DPD & Development and Planning Division \\
\hline $\mathrm{EC}$ & European Commission \\
\hline EI & engineering index \\
\hline EIA & Energy Information Administration \\
\hline EU & European Union \\
\hline EW & efficiency wage \\
\hline FAO & Food and Agriculture Organization \\
\hline FDA & Food and Drug Administration \\
\hline FDI & foreign direct investment \\
\hline FTA & free-trade agreement \\
\hline G20 & Group of 20 nations \\
\hline G4 & Group of Four nations \\
\hline GATT & General Agreement on Tariffs and Trade \\
\hline GDP & gross domestic product \\
\hline
\end{tabular}


China: The Next Twenty Years of Reform and Development

\begin{tabular}{|c|c|}
\hline GFC & global financial crisis \\
\hline GR & growth rate \\
\hline $\mathrm{GtCO} 2$ & gigatonnes of carbon dioxide \\
\hline GW & gigawatts \\
\hline ICT & information and communication technology \\
\hline IEA & International Energy Agency \\
\hline ILO & International Labour Organization \\
\hline IMF & International Monetary Fund \\
\hline IPCC & Intergovernmental Panel on Climate Change \\
\hline IPR & intellectual property rights \\
\hline ISSS & Institute of Social Science Survey \\
\hline ISTP & index to scientific and technical proceedings \\
\hline IU & intensity of use \\
\hline KCS & Kuznets curve for steel \\
\hline kW.h & kilowatt hour \\
\hline LMEs & large and medium enterprises \\
\hline MFN & most-favoured nation \\
\hline MNE & multinational enterprise \\
\hline MOF & Ministry of Finance \\
\hline MoHRSS & Ministry of Human Resources and Social Security \\
\hline MST & Ministry of Science and Technology \\
\hline mtce & million tonnes of coal equivalent \\
\hline MW & megawatts \\
\hline NAFTA & North American Free Trade Agreement \\
\hline NBER & National Bureau of Economic Research \\
\hline NBS & National Bureau of Statistics \\
\hline NCMS & New Cooperative Medical Scheme \\
\hline NDRC & National Development and Reform Commission \\
\hline NEA & National Energy Administration \\
\hline NHS & National Health Service (Britain) \\
\hline NIEs & newly industrialised economies \\
\hline NPL & non-performing loan \\
\hline NRC & net relative change \\
\hline OECD & Organisation for Economic Cooperation and Development \\
\hline OLS & ordinary least squares \\
\hline PBOC & People's Bank of China \\
\hline PCBA & printed circuit-board assembly \\
\hline
\end{tabular}




\begin{tabular}{|c|c|}
\hline PPP & purchasing power parity \\
\hline PRC & People's Republic of China \\
\hline $\mathrm{RMB}$ & renminbi \\
\hline ROO & rules-of-origin \\
\hline RUMiCI & Rural-Urban Migration in China and Indonesia Project \\
\hline SAEP & State Agency for Environmental Protection \\
\hline SASAC & $\begin{array}{l}\text { State-Owned Assets Supervision and Administration } \\
\text { Commission }\end{array}$ \\
\hline SC & supercritical power plant \\
\hline $\mathrm{SCB}$ & state-controlled bank \\
\hline SCE & state-controlled enterprise \\
\hline SCI & science citation index \\
\hline SEZ & special economic zone \\
\hline SHI & social health insurance \\
\hline SIC & Standard Industry Classification \\
\hline SITC & Standard International Trade Classification \\
\hline SOE & state-owned enterprise \\
\hline SUR & seemingly unrelated regression technique \\
\hline SUV & sports utility vehicle \\
\hline tce & tonnes of coal equivalent \\
\hline TFP & total factor productivity \\
\hline THC & township health centre \\
\hline TSS & Tax Sharing System \\
\hline TVE & township and village enterprise \\
\hline TW.h & terawatt hours \\
\hline UN & United Nations \\
\hline UNCTAD & United Nations Conference on Trade and Development \\
\hline UNDP & United Nations Development Programme \\
\hline USC & ultra-supercritical power plant \\
\hline VAT & value-added tax \\
\hline WFDIOUT & world total foreign direct investment outflows \\
\hline WRDP & Western Regional Development Program \\
\hline WTO & World Trade Organisation \\
\hline
\end{tabular}





\section{Contributors}

\section{Prema-chandra Athukorala}

Arndt-Corden Division of Economics, Research School of Pacific and Asian Studies, The Australian National University, Canberra.

\section{Chunlai Chen}

Crawford School of Economics and Government, The Australian National University, Canberra.

\section{Cai Fang}

Division of Labour and Human Capital, Institute of Population and Labour Economics, Chinese Academy of Social Sciences, Beijing.

\section{Ross Garnaut}

University of Melbourne, Melbourne and The Australian National University, Canberra.

\section{Jane Golley}

China Economy Program, Crawford School of Economics and Government, The Australian National University, Canberra.

\section{Yiping Huang}

China Centre for Economic Research, Peking University, Beijing and China Economy Program, Crawford School of Economics and Government, The Australian National University, Canberra.

\section{Archanun Kohpaiboon}

Thammasat University, Bangkok.

\section{Sherry Kong}

Research School of Economics, College of Business and Economics, The Australian National University, Canberra. 
China: The Next Twenty Years of Reform and Development

\section{Ryan Manuel}

University of Oxford, Oxford.

\section{Huw McKay}

Westpac Bank, Sydney.

\section{Xin Meng}

Research School of Economics, College of Business and Economics, The Australian National University, Canberra.

\section{Yu Sheng}

Australian Bureau of Agriculture and Resource Economics (ABARE), Canberra.

\section{Ligang Song}

China Economy Program, Crawford School of Economics and Government, The Australian National University, Canberra.

\section{Rod Tyers}

Business School, University of Western Australia, Perth.

\section{Bijun Wang}

China Centre for Economic Research, Peking University, Beijing.

\section{Meiyan Wang}

Division of Labour and Human Capital, Institute of Population and Labour Economics, Chinese Academy of Social Sciences, Beijing.

\section{Yanrui Wu}

Business School, University of Western Australia, Perth.

\section{Wing Thye Woo}

Brookings Institution, Washington DC; University of California (Davis); Central University of Finance and Economics, Beijing.

\section{Geng Xiao}

Brookings-Tsinghua Centre for Public Policy, Tsinghua University, Beijing and Brookings Institution, Washington DC. 


\section{Yang Yao}

China Centre for Economic Research, Peking University, Beijing.

\section{Dandan Zhang}

Research School of Economics, College of Business and Economics, The Australian National University, Canberra.

\section{Ying Zhang}

Business School, University of Western Australia, Perth.

\section{Yongsheng Zhang}

Development Research Centre of the State Council, Beijing.

\section{ZhongXiang Zhang}

East-West Center, Honolulu. 



\section{Acknowledgments}

The China Economy Program gratefully acknowledges the financial support for the China Update 2010 from The Australian Agency for International Development (AusAID) and the assistance provided by Rio Tinto through the Rio Tinto - ANU China Partnership. 



\section{Chinese economic reform and development: achievements, emerging challenges and unfinished tasks}

\section{Jane Golley and Ligang Song}

The economic transformation that has taken place in China since the late 1970s is now regarded as one of the most significant social changes in human history. Within just three decades, China has succeeded in transforming itself from a centrally-planned closed economy into one of the world's most dynamic and globally-integrated market economies. The dynamics unleashed by Deng Xiaoping's reforms, open-door policies and institutional changes have unleashed enormous entrepreneurial energy and propelled continuous capital accumulation, productivity gains and trade and income growth on a scale the world has never seen before. During this period, China's total gross domestic product (GDP), industrial output, foreign trade and, importantly, its per capita income increased respectively by factors of 16, 27, 124 and $12 .^{1}$ As a result, the incidence and severity of poverty have declined dramatically in China. According to a recent World Bank report (2009), between 1981 and 2004, the fraction of China's population consuming less than US\$1 a day in today's purchasing power fell from 65 per cent to 10 per cent and about half a billion people were lifted out of poverty. This achievement has contributed critically to global progress in reducing world absolute poverty and indeed 'a fall in the number of poor of this magnitude over such as short period is without historical precedent' (World Bank 2009:iii). ${ }^{2}$

The fundamental causes of this remarkable performance are by now familiar to most China observers. Market-oriented reforms centred on changes in the price system led to improved resource allocation and allowed the most dynamic private sector to flourish, thereby increasing the overall level of efficiency in the economy. Liberalisation programs allowed trade and foreign direct investment

1 Calculated using the data taken from NBS (2009).

2 The Millennium Poverty Reduction Target aims to halve the proportion of people living in absolute poverty by 2015 compared with the level in 1990 (Thirlwall 2006). 
(FDI) to flourish according to China's underlying comparative advantage, resulting in enormous gains from trade. Decentralisation and ownership transformation helped to solve incentive problems and enhance the performance of firms and local governments. And institutional reforms that abandoned the decades-long restraints on the mobility of labour unleashed an unprecedented scale of urbanisation, with the ratio of the urban in the total population rising from less than 20 per cent in the late 1970s to 46 per cent in 2009. This gradual process of 'reform and opening up' coincided with a surge in the proportion of the working-age population, generating in a 'demographic dividend', which, according to Cai and Wang (2005), accounted for about one-quarter of the growth rate in per capita GDP between 1982 and 2000. The sustained high rates of economic growth that resulted have fundamentally transformed the Chinese economy and its position in the world.

China has also benefited during the past three decades from some favourable internal and external conditions. Internally, there were some positive legacies inherited from the planning system that were conducive to reform and growth, including a basic industrial base and reasonable infrastructure, the irrigation system and a relatively well-developed education system. In the aftermath of the Cultural Revolution, there were overwhelming domestic forces pushing for reform that helped overcome the resistance to change, especially during the early years of reform. The low base from which the economy started enabled China to benefit from low-cost advantages in production that contributed enormously to the rising output and competitiveness of the economy. Moreover, as a latecomer to economic development, China enjoyed the advantage of backwardnessthat is, the ability to adopt the world's more-advanced technologies relatively rapidly.

Externally, China's reforms have coincided with a new era of globalisation, characterised by a more open global trading environment, resulting from significant reductions in tariffs and other forms of trade protection through various rounds of multinational trade negotiations in the post-war period, and from the mid-1980s through unilateral liberalisation in the Western Pacific region. This era has also been characterised by rapid global economic structural adjustment in response to cross-border flows of capital, people and technology; and by rapid reductions in transaction costs stemming from substantial improvements in transport, communication and information management. 'As a result, international markets have provided China with opportunities (and also risks) that far exceed those available at the time of Japan's and Korea's big growth spurts' (Brandt and Rawski 2008:13).

While some of these favourable conditions will remain in place during the next two decades, many of them will no longer yield the sizeable benefits to China's economic growth that they have in the past. If China is to continue along its 
remarkable path of economic reform and development, it will need to adapt to these changing internal and external conditions and to steer skilfully through a number of challenges. This book highlights how the deepening of reforms in critical areas such as domestic factor markets, the exchange rate regime and the health system, combined with the strengthening of channels for effective policy implementation and the rebalancing of economic growth, will enable China to cope with the challenges that lie ahead. These include responding to the pending exhaustion of the unlimited supply of labour; playing a constructive role in reducing global trade imbalances; enhancing firms' ability to innovate and compete in the global economy; coping with migration, urbanisation and rising inequalities on scales unknown in world history; and dealing with rising energy and metal demand in an era in which low-carbon growth has become a necessity rather than a choice.

Evidence presented in this volume and elsewhere indicates that China has entered the turning point - or more accurately, the turning period - in economic development, signalled by the end of surplus labour and the consequent rapid rise in wages in some, albeit not all, sectors of the economy. The tightening of the labour market will be compounded by the combined impact of three decades of the One-Child Policy and rapid income growth on Chinese fertility rates, which has already heralded a rapidly ageing population, with the growth rate of the labour supply predicted to turn negative by about 2020 (Tyers et al. 2009). This will necessitate changes in the industrial structure and composition of trade, as China loses its comparative advantage in the labour-intensive exports that have been an engine of growth in the past. To facilitate these changes, building human capital through education, accelerating technological change through innovation and raising labour productivity through further labour-market reform are becoming increasingly urgent national priorities.

Economic growth in the past has been characterised by extensive growth resulting in a number of structural imbalances, including highly resourceand energy-intensive production. Now China has entered a stage of growth in which metal and energy intensities (that is, consumption per unit of GDP) are exceptionally strong. This will significantly add to the global pressure to balance the supply of, and demand for, resources and energy products, and the impact on world markets for these products is likely to be intense (Garnaut and Song 2006). Confronting this challenge will require China to accelerate its pace of structural change by moving more quickly towards higher valuedadded industrial production and the service sector and by adopting resourceand energy-saving technologies in all productive sectors. Reforming the pricing systems for energy and resources so that prices truly reflect the balance 
between supply and demand will be critical in this regard. Such pricing reforms will enhance supply capacities and encourage resource- and energy-saving technological change, substitutions for resource use and conservation.

As one of the largest economies and the largest carbon emitter in the world, China needs to confront environmental degradation and climate change by moving more rapidly towards a low-carbon growth economy. This is not only for the health and welfare of China's own population, but for the world to stand any chance of achieving the goal of significantly reducing global emissions before catastrophic problems occur (Stern 2007; Garnaut 2008). In so doing, China will need to overcome many difficulties associated with the current level of per capita income, the mid-phase of its industrialisation and the vast regional disparities with respect to the levels of income and industrial development. The transition towards developing a low-carbon economy might not necessarily compromise economic growth, as developing environmentallyfriendly industries can generate new sources of growth. The key challenge is to set up an appropriate system in which all parties involved, including the central government, local governments, firms and households, will have incentives to make the necessary adjustments (Cai and Du 2008). The stark conflict between the contemporary style of industrial development and the health of the biosphere indicates strongly that now is the time for China to make the adjustments that will underpin sustainable long-term growth (McKay and Song 2010).

Enhancing productivity is a crucial component of the shift towards a low-carbon mode of economic growth. Technological progress and innovation hold the key. There is huge potential for China to change the relationship between economic output and carbon emissions through the absorption, mass production and improvement of green technologies from the developed countries. Government will play a crucial role in ensuring that China reaches this potential, most importantly by facilitating the dynamic private sector's active engagement in this endeavour. A concerted effort to generate and commercialise environmentallysound technologies would also enable China to quicken the pace of industrial structural change and alter the current trajectory of its industrialisation path.

Another feature of China's growth strategy has been the reliance on exports and investment, which has contributed to the rise in global imbalances in recent decades and to numerous structural problems within China as well. While not all of the remedies lie in China's hands, there is now widespread recognition that a rebalancing of growth is called for, in the direction of a strategy that relies more heavily on the growth of domestic consumption and productivity. Boosting domestic consumption will take time but there are some clear reform options that will play a positive role. Song et al. (forthcoming), for example, show that an effective way of boosting domestic demand is to accelerate the pace of 'urbanising' migrant workers (estimated to have reached 160 million 
in China in 2009) by granting these workers urban residency, which would change their consumption behaviour. This particular task can be accomplished only by deepening institutional reforms affecting labour mobility and the social security system. Ongoing economic development will also play a role. As China enters the turning period, higher wages will naturally lead to higher domestic consumption, possibly having a greater impact than any institutional reforms. Higher consumption will raise China's import demand, enabling the country to contribute to more balanced growth in the global economy and to become a sustainable engine for global growth. Reforms to China's exchangerate regime and land-management system will also play crucial roles in solving a range of imbalance issues. Low domestic consumption is just one of many indicators that China's growth strategy needs to be readjusted as far as its social impact is concerned. For example, the World Bank (2009) has found that the responsiveness of poverty reduction to economic growth has fallen in recent years. Rising income inequality and widening regional disparities, along with uneven access to health services and social welfare systems, are some of the most undesirable outcomes associated with the rapid economic growth of the past. Failure to deal with these issues could pose the greatest threats to social stability, which in turn could become a serious obstacle for growth and development in the decades ahead. While entering the turning period will offer some respite for income inequality, much more will need to be done. Apart from strengthening the redistributive functions of the government and building a more comprehensive social security system, further reforms to enhance ruralurban migration will be crucial for the continued growth of productivity and income while narrowing the income inequality among different social groups. Strengthening local public finance through reforming the current system of intergovernmental transfer payments and improving the health system will also be critical if the government is to achieve its objective of more equitable development.

Finally, China is likely to become the largest economy in the world by 2030, regardless of the measurement used (Maddison 2001). China's rise as a global economic powerhouse will thrust on it increasing responsibilities in a range of global affairs - whether it wants those responsibilities or not. China will thus be expected, and will surely find it desirable, to contribute positively to global stability, progress and prosperity through cooperation with other players in the global system. High on the agenda for China's strategic engagement are reducing global imbalances, reforming the international financial system, pushing forward with multilateral trade negotiations under the World Trade Organisation (WTO), confronting the challenges of climate change and fighting global poverty. In all of these realms, it is not merely a question of how China manages its external economic relations but how it conducts itself politically. 
China has made tremendous progress in reforming its institutions in the first 30 years of reform and transformation. What has been achieved in the past has laid the groundwork for China to deepen institutional reforms during the next stage of its development. There is reason to be optimistic as far as the link between future institutional change and growth is concerned, since '[o]nce economic growth has begun, institutions change more and more in directions favourable to growth, and so strengthen the forces making for growth' (Lewis 1955:143). China's experience during the past 30 years illustrates this point.

The next two decades of reform and development are likely to be more challenging than the past, as China embraces a new mode of economic growth driven not only by efficiency, but also sustainability and equity considerations. Indeed, the overarching challenge for China in the decades ahead is to successfully shift into this new mode of growth. This will not be possible unless China tackles the overarching task that remains unfinished: completing the transition to a true market economy by further reforming the country's factors markets and carrying out more comprehensive institutional reforms - in the economic system, in governance, in its legal and regulatory systems, as well as in the political system. If successful, the next two decades will see China elevated to a position of global primacy or at least of 'co-primacy' alongside the United States. Success is, however, more easily presumed than achieved. A smooth Chinese ascendancy to global primacy will require many changes from the status quo, as each of the chapters that follow demonstrates from a variety of different angles.

Part I of this book focuses on China's long-term development trends and issues. It begins with Ross Garnaut's (Chapter 2) analysis of the turning period in Chinese development. Garnaut presents a new conceptual framework based on Arthur Lewis's model of economic development in a labour-surplus economy, which provides the basis for understanding China's transition through the end of this period of labour surplus and beyond. He reflects on chapters in the 2006 China Update book, The Turning Point in China's Economic Development, which provided early and partial evidence that China had already begun its entry into the turning period. This is followed by a summary of more recent evidence that the economy has now moved more decisively and deeply into this period, signalled in particular by rapidly rising real wages since 2004. Garnaut sees China's economic success in the future depending on the flexibility of the economy; its openness to foreign trade, investment and ideas; and the quality of human resources and regulatory systems that are required to deal with the more complex economy that is emerging. He argues that, with this flexibility and structural adjustment, the growth of the Chinese economy will not necessarily slow during the Lewis turning period and beyond.

China's gradual and piecemeal approach to economic reform has been heralded by many as an alternative - and preferable — path to economic development, as 
reflected in the discourse about the 'Beijing Consensus' versus the 'Washington Consensus'. Where the Beijing Consensus has often been interpreted as a development model in which an authoritarian government is heavily involved in most economic activities, the Washington Consensus has been interpreted as a development model requiring a relatively rapid transition to a market-based economy as prescribed by neoclassical economics. Yang Yao (Chapter 3) contests both of these interpretations in his analysis of China's development model and sees China's reform and development as being perfectly compatible with the Washington Consensus, and the 'China model' as a process of convergence towards neoclassical ideals. Yao describes the Chinese government as a 'disinterested' government that has managed to remain detached from various social groups within China rather than being captured by exclusive interest groups. This 'disinterest' - rather than its authoritarianism-has enabled growth-enhancing policies, which, while creating winners as well as losers, have collectively delivered higher living standards across the nation in the past three decades. Despite this success to date, Yao concludes that China's future development model will inevitably require explicit political reform, and ideally democratisation, to counterbalance the formation of strong interest groups with increasingly contradictory goals - beyond that of economic growth alone.

Where Yao argues for democratisation in the future as a way of balancing government actions and public interests, Yongsheng Zhang (Chapter 4) sees it as a way to establish effective central-local government relationships, the evolution of which will have a crucial impact on China's future development. He proposes a new analytical framework for intergovernmental relations based on two distinct dimensions - personnel and fiscal - each of which can be either 'top down' or 'bottom up'. This gives rise to four possible structures into which the world's wide range of intergovernmental relations can be categorised. Zhang argues that most industrialised Western countries fall into Structure 1, represented by the combination of bottom-up personnel relationships and top-down fiscal relationships. China's evolving central-local relations during the reform period are then depicted as a journey from Structure 3 (top-down personnel, topdown fiscal) to Structure 4 (top-down personnel, bottom-up fiscal), as a result of fiscal decentralisation between 1978 and 1994, and then back to Structure 3 after the 1994 tax reforms. Zhang suggests that the most likely outcome for China in the foreseeable future is that central-provincial relations continue to be top-down personnel and top-down fiscal (Structure 3), while provinciallocal relations become increasingly bottom-down personnel, top-down fiscal (Structure 1). For the successful evolution towards Structure 1 for all levels of intergovernmental relations in China, Zhang sees two critical requirements: the strengthening of the rule of law and the deepening of grassroots democracy 
over time. Like so much of China's reform and development process, however, Zhang is clear that this process will be gradual and certainly not without Chinese characteristics.

Huw McKay, Yu Sheng and Ligang Song (Chapter 5) revive the theoretical field that relates economic development to metal usage and shed light on China's future path of ferrous-metal demand by referencing the experience of relevant peers over the entire course of the industrialisation process. Their chapter formally identifies the existence of the Kuznets inverted-U curve for steel (KCS) and validates the synthesis view of metal intensity, which sees a role for both technological leapfrogging and evolving consumer preferences in determining changes in metal intensity. Their econometric analysis indicates that China will reach the turning point in its own KCS when its gross domestic product (GDP) per capita exceeds about US\$15 000 - predicted to be about 2024. They conclude that, as China progresses towards high-income status, it is unlikely to continue to closely follow the Korean path characterised by its exceptionally high metal intensity. This is because China will be compelled to alter its mode of economic growth away from the current reliance on heavy industry, investment and export orientation. As a consequence, China's final path of metal intensity is likely to be a blend of certain aspects of the experiences of North America, the Commonwealth of Independent States, Western Europe, Japan and emerging Asia.

The global and local environmental consequences of China's rapid growth and industrialisation during the past three decades have been immense. There is increasing pressure within and outside China for the Chinese leadership to be more ambitious in their plans to combat global climate change and, according to Zhongxiang Zhang (Chapter 6), they are at least beginning to step up to the plate. This is reflected first and foremost in China's target to reduce its carbon intensity by 40-45 per cent by 2020 - a target that goes well beyond 'business as usual'. Zhang is well aware that stating ambitious targets is one thing, while achieving them is another. On this front, he recognises that the (lack of) reliability of China's energy and GDP statistics makes it difficult to assess real progress while raising the issue of credibility as well. Moreover, the conflicting objectives of lower-level governments could result in actions that counteract rather than support national-level environmental objectives. These issues notwithstanding, he provides considerable and detailed evidence of the achievements to date in terms of energy conservation and carbon-intensity reductions. Zhang concludes that the likelihood of China achieving its environmental goals rests on the strengthening of existing policies, industrial restructuring away from highly energy-consuming, polluting and resource-intensive industries and the cooperation of local governments. 
Jane Golley (Chapter 7) reflects on an issue that has plagued Chinese leaders for millennia: regional disparities in development. By 2050, the current leadership has set itself the formidable task of 'considerably reducing' the disparities that exist between western China and the other regions - most prominently, the east, where the vast share of China's industrialisation has occurred throughout time, and in particular, throughout the reform period. Golley's analysis of provincial-level industrial growth rates during the period 2000-07 provides some indication that the glory days of the eastern region could be coming to an end, although its dominance in terms of China's industrial output is still clearly evident. Although she finds some theoretical and empirical reasons for optimism on the likelihood that some industries will spread westward in the next two decades, the balance of evidence suggests this will translate into no more than a minimal reduction in regional disparities during this time. Reducing regional inequalities will remain unfinished business in China for a long time to come.

Part II of the book turns to the challenges and opportunities relating to China's global integration. Xiao Geng (Chapter 8), and Rod Tyers and Ying Zhang (Chapter 9) contribute to the continuing renminbi exchange-rate debate. Both chapters begin by reflecting on the international pressure for renminbi appreciation, which stems from the expectations of the Balassa-Samuelson hypothesis (BSH): a developing country experiencing productivity catchup in its tradable goods sectors is likely to experience a rising real exchange rate as a consequence of the associated rise in wages and non-tradable sector prices. Focusing on the problem of global imbalances, Xiao takes it as given that China will remain reluctant to appreciate the renminbi and considers alternative Chinese policy options - such as privatisation and deregulation - to reduce the excessive savings of the corporate sector and measures to increase domestic consumption. He then turns to what he sees as the key factor driving global imbalances: cheap money. This, he argues, has created property and stock-market bubbles all over the world, including in China, and has also had a significant impact on driving down the prices of Chinese goods (thereby keeping the real exchange rate low). Xiao calls for a higher Chinese interest rate and improved capital-control mechanisms to combat this, by ensuring that capital flows into efficient investments - whether domestic or international-rather than towards speculative and inefficient investments. He closes by noting that the rise in Chinese prices in the future can achieve the necessary real exchange rate appreciation, if and when China is able to tolerate this. The sooner this happens, the sooner external pressure for renminbi appreciation will subside.

Tyers and Zhang look closely at China's real exchange rate movements over time, observing that, despite the expectations of the BSH, it showed no tendency to appreciate until after 2004. Since then, substantial real appreciation has taken place, which they attribute primarily to rising prices and wages in agriculture, 
along with the slowing of trade reforms. They then explain clearly why the setting of the renminbi rate is not as discretionary for the Chinese authorities as suggested by critics and that, should international pressure result in a nominal appreciation either via a monetary contraction or via export disincentives, the consequences would be harmful for Chinese and global interests. Both this chapter and Xiao's demonstrate the importance of understanding the peculiarities of China's transitional economy when entering into one of the world's hottest debates.

Chunlai Chen (Chapter 10) addresses the question of whether China's phenomenal success in attracting foreign direct investment (FDI) during recent decades has been at the expense of other developing economies - in Asia in particular. His econometric analysis of the 'China effect' on FDI into 12 other developing Asian economies during the period 1992-2008 suggests the commonly expressed fears about China's FDI dominance are unfounded. In particular, Chen finds that an increase in FDI inflows into China is positively and significantly related to FDI inflows into other Asian economies. He attributes this investment-creation effect during the period of analysis to the increased resource demand by a rapidly growing Chinese economy and the production-networking activities within Asia. Chen predicts that these positive linkages are likely to strengthen in the next two decades, in light of deepening Asian integration and expectations of continued rapid growth for China. Moreover, with the ageing and increasing wealth of China's population, not only will other Asian economies become more attractive alternative locations for labour-intensive manufacturing, they are likely to be the destinations of choice for China's increasingly large FDI outflows. For developing Asia, on average at least, China's FDI success is a win-win story.

Prema-chandra Athukorala and Archanun Kohpaiboon (Chapter 11) examine the export experience of China and other East Asian economies in the aftermath of the global financial crisis against the backdrop of pre-crisis trade patterns. The analysis is motivated by the 'decoupling' thesis, which posits that the East Asian region has become a self-contained economic entity with the potential for maintaining dynamism regardless of the economic outlook in the industrialised world. Athukorala and Kohpaiboon dispel this thesis by examining the changes in intra and extra-regional trade shares in East Asia since the global financial crisis. Emphasising the importance of including parts and components - as well as final goods - in trade-flow analysis, they show that the rising importance of global production sharing has in fact strengthened, rather than weakened, East Asia's links with the wider global economy. Noting that the global recovery is likely to remain patchy at best in the medium term, they call for an integrated East Asian policy response that emphasises rebalancing growth away from exports and towards domestic markets, particularly in the case of China. Their findings caution against a possible policy backlash against openness to foreign 
trade arising from the newly found enthusiasm for rebalancing growth and they make a strong case for a long-term commitment to non-discriminatory multilateral and unilateral trade liberalisation.

On the impact of the global financial crisis on rural-urban migration, Sherry Tao Kong, Xin Meng and Dandan Zhang (Chapter 12) reveal some unexpected findings. With the global financial crisis leading to a sharp reduction in export orders in the second half of 2008, it was expected that the most significant impacts would fall on rural migrants - in terms of either employment or wage reductions - and indeed millions of laid-off migrants lamented lost jobs and protested over closed factories. Drawing on the panel surveys of rural-urban migrants and rural households in the Rural-Urban Migration in China and Indonesia (RUMiCI) Project, Kong, Meng and Zhang find, however, only very small changes in employment and almost no wage reductions for migrants in cities between 2008 and 2009. Instead, they find that the real effects were felt mainly in the rural sector, to which close to 15 million rural migrants returned in 2009, and with 80 per cent of those taking up jobs in the rural agricultural sector. Thus, it was the agricultural sector that effectively provided an employment buffer for return migrants and also for workers in the rural off-farm sector, which was also hit by the economic downturn. Although this evidence indicates a relatively - and surprisingly - positive outcome for migrants during the global financial crisis, the authors point out that the agricultural sector is unlikely to provide such a buffer in the future, so migrant employment shocks will have to be absorbed in other ways. A universal welfare system and property rights over rural land are seen as crucial in this regard.

Section III of the book focuses on 'Policy and reforms: unfinished tasks'. It begins with Wing Thye Woo's depiction (Chapter 13) of the Chinese economy as a speeding car that is running the risk of three potential types of failure. Fiscal instability and a slowdown in productivity growth are discussed as two potential 'hardware' failures - or breakdowns in a key economic mechanism. Flaws in governance are likened to a crash caused by people fighting in the car - a potential 'software' failure - while severe environmental degradation is seen as a natural or externally imposed limit, a 'power supply' failure analogous to crashing into a wall. After explaining the reasons why each of these particular failures might occur in the foreseeable future, Woo presents a reform agenda to avert the occurrence of these, and other, potential obstacles along China's road to prosperity. His agenda for addressing hardware failures includes the creation of more new entrepreneurs, urbanisation according to the principle of future homeownership and the development of a modern financial system in which the private sector has a greatly enhanced role. Political reforms lie at the heart of his 'software reforms', which require the adoption of free elections, a free press and an independent judiciary. The solution to 'power supply' failures rests on 
China's ability to mobilise international consensus, cooperation and scientific research on key global issues. If adhered to, Woo's reform agenda offers much hope that China's rocky path to prosperity can be smoothed out significantly.

Yiping Huang and Bijun Wang (Chapter 14) examine the evolution of structural imbalances in China and offer one overarching solution: factor-market reform. In particular, they demonstrate that the fundamental cause of China's structural imbalances - reflected in its very high investment share of GDP and current account surplus, inefficient resource use, income inequalities and environmental degradation - lies in the gradual and piecemeal approach to economic reforms in which product markets have been completely liberalised while distortions in factor markets have remained. This has resulted in the repression of prices for labour, land, capital, resources and the environment, which Huang and Wang interpret as providing subsidy equivalents for producers, exporters and investors. While this has clearly been beneficial for China's economic growth in the past, it has also increased the structural risks associated with incomplete reforms, which will threaten the stability, balance and sustainability of China's growth pattern in the future unless adequately addressed. Huang and Wang note that the efforts of the Chinese leadership to date in addressing these issues have been limited and they call for a major shift in policy towards a comprehensive package of factor-market reforms. Only after the successful implementation of these reforms - which is likely to take decades in some areas - will China's transition to a market economy be truly complete.

Almost all aspects of China's economic reform and development process have exhibited uniquely 'Chinese characteristics' and Cai Fang and Meiyan Wang (Chapter 15) show that urbanisation is no exception. Their chapter begins with evidence that China has already reached the Lewis turning 'point', which they point out is in fact more a transitional 'period', beginning in 2004. Their investigation of recent trends in rural-to-urban migration and more general changes in the labour market shows that agriculture no longer serves as a pool of surplus labour, but rather that rural workers' migration to and settlement in urban areas have become irreversible and inevitable. As a consequence, one of their key arguments is that Chinese policymakers need to let go of the 'Todaro dogma', which depicts labour migration in a dual economy as a pattern of 'come and go', rather than of permanent settlement, and which thus results in the implementation of policies that control and even restrict the process of rural-to-urban migration - as exemplified by China's hukou system. While acknowledging progress in reforming the hukou system to date, Cai and Wang explain that impediments in the system have resulted in the transformation of farmers into migrant workers without entitlement to crucial public services and social protection in their urban destinations, thereby driving urbanisation 
with Chinese characteristics. Further hukou reforms are seen as critical for transforming these farmers-turned-migrant workers into migrants-turnedurban residents in the decades ahead.

For Yanrui Wu (Chapter 16), indigenous innovation will be crucial for sustainable growth and development in China in the decades ahead. After reviewing China's achievements in innovation, skills and capacity during the past three decades, $\mathrm{Wu}$ presents an econometric analysis of Chinese innovation at the firm level and then considers China's performance in an international context. After showing that rapid growth in investment in innovation has resulted in a rapid expansion of innovation outcomes, $\mathrm{Wu}$ then demonstrates a significant gap between China and the world's leading innovators and questions whether growth in the quantity of innovations has come at the expense of quality. While closing this gap and promoting quality are two obvious policy recommendations that stem from Wu's analysis, his firm-level analysis presents more of a policy dilemma. In particular, he shows that state-owned enterprises (SOEs) have performed much better than foreign-invested firms and privately owned Chinese firms as far as research and development propensity and efforts are concerned. Wu calls for specific policies to encourage the participation of non-state firms in innovation and to improve the legal system and protection of intellectual property in order to ensure that privatisation does not come at the expense of innovation in the future.

Finally, Ryan Manuel (Chapter 17) focuses on one particular aspect of China's reforms that is sparking much discontent - and with good reason: the healthcare system. Manuel provides some historical context for China's healthcare experience. After noting the achievements of the collective period (1950-79), in which China's public health system was world leading in terms of its high levels of 'bang for your buck', he describes the second, post-collectivisation period (1980-2003) as one that became increasingly inequitable, costly and ineffective. Since then, the introduction of the New Cooperative Medical Scheme (NCMS) and the beginning of the 'cover the countryside' campaign of public finance have resulted in far greater public funds being injected into the healthcare system. Despite this increase in funding, Manuel sees continuing problems during the next 20 years of health reform, unless the Chinese government can effectively address the flawed incentives facing individual health service providers and the lack of supervision, coordination and governance in the system. 


\section{References}

Brandt, L. and Rawski, T. G. 2008, 'China's great economic transformation', in L. Brandt and T. G. Rawski (eds), China's Great Economic Transformation, Cambridge University Press, Cambridge and New York, pp. 1-26.

Cai, F. and Du, Y. 2008, 'The political economy of emissions reduction in China: are incentives for low carbon growth compatible?', in L. Song and W. T. Woo (eds), China's Dilemma: Economic growth, the environment and climate change, ANU E Press and Brookings Institution Press, Canberra and Washington, DC, pp. 226-42.

Cai, F. and Wang, D. 2005, 'Demographic transition: implications for growth', in R. Garnaut and L. Song (eds), The China Boom and Its Discontents, Asia Pacific Press, Canberra, pp. 34-52.

Garnaut, R. 2008, Climate Change Review Report, Cambridge University Press, UK.

Garnaut, R. and Song, L. 2006, 'China's resources demand at the turning point', in R. Garnaut and L. Song (eds), The Turning Point in China's Economic Development, Asia Pacific Press, Canberra, pp. 276-93.

Lewis, W. A. 1955, The Theory of Economic Growth, Unwin University Books, London.

McKay, H. and Song, L. 2010, 'China as a global manufacturing powerhouse: strategic considerations and structural adjustment', China and World Economy, vol. 18, no. 1 (February), pp. 1-32.

Maddison, A. 2001, The World Economy: A millennial perspective, Organisation for Economic Cooperation and Development, Paris.

National Bureau of Statistics (NBS) 2007, China Statistical Yearbook 2007, China Statistics Press, Beijing.

Song, L., Wu, J. and Zhang, Y. (forthcoming), 'Urbanisation of migrant workers and expansion of domestic demand,' Social Sciences in China, vol. XXXI, no. 3 (August).

Stern, N. 2007, The Economics of Climate Change: The Stern review, Cambridge University Press, Cambridge and New York.

Thirlwall, A. P. 2006, Growth and Development with Special References to Developing Countries, Palgrave Macmillan, New York. 
Tyers, R., Golley, J. and Bain, I. 2009, 'Projected economic growth in the People's Republic of China and India: the role of demographic change', From Growth to Convergence: Asia's next two decades, Palgrave, London.

World Bank 2009, From Poor Areas to Poor People: China's evolving poverty reduction agenda, an assessment of poverty and inequality in China, March, East Asia and Pacific Region, The World Bank, Washington, DC. 



\section{Part I}

Long-Term Development: Trends and Issues 



\section{The turning period in China's economic development: a conceptual framework and new empirical evidence}

\section{Ross Garnaut}

China began its era of market reform and sustained strong growth in 1978 as a labour-surplus economy. The rapid growth of the modern industrial economy could be supplied with all of the unskilled labour that it wanted to use at a more or less steady real wage. This supported the familiar characteristics of China's economic development in the later reform period: rapid expansion of exports of relatively labour-intensive goods; rising ratios of savings and investment to gross domestic product (GDP); eventually a tendency towards surplus in trade and current external payments; and increasing inequality of income distribution.

There is now compelling evidence that the period of labour surplus and reasonably steady real wages for unskilled workers - supported by continuing large-scale movement of people from agriculture to industry and from the countryside to the cities - has come to an end. The implications of this change for all aspects of Chinese development will be profound. This chapter explores those implications and reviews some of the recent evidence of the imminence of the structural transformation.

Four years ago, the China Update book carried the title The Turning Point in China's Economic Development (Garnaut and Song 2006). This volume began an intense discussion of the idea that China was at or close to the important transition point from a labour-surplus to a labour-scarce economy (Garnaut 2006; Garnaut and Huang 2006; Cai and Wang 2006; Garnaut and Song 2006:Chs 1, 2, 9). Important contributors to that discussion were brought together in a workshop in Beijing in April 2010, organised by the China Center for Economic Research at Peking University and the Institute of Population and Labour Economics at the Chinese Academy of Social Sciences. Selected and edited papers from this workshop are being published in a special issue of the China Economic Journal in 2010. Cai and Wang (in this volume) suggest a precise date-2004 - for the turning point. 
Chapter 2 in the 2006 volume by Garnaut and Huang (2006), including the macroeconomic survey of the Chinese economy, summarised the accumulating evidence of labour shortages in parts of the country and accelerating rates of wage increases. It touched on West Indian economist Arthur Lewis's theory of the labour-surplus economy that introduced the idea of the turning point in economic development. It presented some demographic and labour-market projections, suggesting that the Chinese economy by 2020 would be structurally transformed by the combination of rapidly growing demand for and diminishing supply of relatively unskilled labour.

Cai Fang and Dewen Wang in Chapter 9 of that volume noted that China's entry into membership of the World Trade Organisation (WTO) in 2001-far from increasing problems of unemployment, as many had feared-contributed to an acceleration of internationally oriented growth. The continued strength of growth in demand for urban labour and China's emerging demographic transition were leading to the emergence of 'a shortage of rural migrant workers [that] signals, to a certain extent, the transition in the rural labour supply from an unlimited to a limited surplus' (Cai and Wang 2006:143).

The notion that labour shortages and rising real wages would soon play central roles in Chinese development was pushed into the background when the recessionary impact of the great crash of 2008 came to China. In late 2008 and early 2009, there was a large and sharp reduction in demand for Chinese exports and an associated decline of demand for labour in China's coastal cities (Garnaut with Llewellyn-Smith 2009, especially Chapter 9).

Although severe, the labour-market reversal in the global financial crisis turned out to be brief. Shortages of unskilled labour and rising real wages returned quickly, with the extraordinary strength of the Chinese economy's response to the expansionary monetary and fiscal policies that were introduced in late 2008 (Du and Wang forthcoming).

So it is time to focus again on the turning point in Chinese economic development.

This chapter provides a conceptual framework for looking at the impact of the turning point in China and examines the empirical evidence of current and prospective tendencies. The conceptual material reproduces the main content of a paper that will be published in the special issue on the turning point in the China Economic Journal (Garnaut forthcoming). The empirical content of the chapter updates Garnaut and Huang (2006) and Cai and Wang (2006) by drawing on and citing mainly other papers in that special issue of the China Economic Journal. 


\section{The surplus-labour economy}

The idea of the 'turning point' comes from a highly stylised model of economic development in a labour-surplus economy, first developed by Arthur Lewis (1954). The model was elaborated on and applied to an East Asian context by Fei and Ranis (1964a, 1964b, 1966; Ranis and Fei 1961, 1963). It was embedded in Minami's $(1973,1986)$ influential books on Japanese economic development.

The labour-surplus economy of the model is dualistic, with a highly productive and dynamic 'modern', 'urban', 'industrial' or 'capitalist' sector and a relatively unproductive and stagnant 'traditional', 'rural' or 'village' sector. In the stylised labour-surplus economy of the model, the marginal product of labour in rural areas is well below the living standards that poor residents of rural areas enjoy. (In some versions of the model, the marginal product of rural labour is zero or even negative in the early stages of modern economic growth.)

Living standards in rural areas can remain above the marginal product of labour because they are supported by village institutions, which leads to some sharing of incomes and employment. There are risks and costs of moving from the rural sector to the urban sector for employment. Assessments of these costs and risks, on top of the customary rural standard of living, establish the 'reserve price' of labour - or the urban wage at which migrants are prepared to migrate. It follows that the marginal product of labour in urban areas is strongly positive.

When a worker moves from rural to urban employment, the total output of the economy rises: there is an increase in urban output, but no or little reduction in rural production. Rural-urban migration is a main source of growth in average productivity and total output. As a matter of arithmetic, average output rises in rural areas with migration (with the same output and less people). In the early stages of expansion of the modern economy, however, and perhaps for a considerable while, there is still redundant rural labour and the marginal product of labour in rural areas remains low or zero. The reserve price of rural labour remains low and for a while is unresponsive to increased urban demand for labour.

The availability of an 'infinitely elastic' supply of labour from rural areas has important implications for the structure of growth in the urban and rural economies.

Rapid expansion can proceed in the urban sector without increases in real wages. The improvements in infrastructure, labour culture and management practices that raise productivity with the passing of time are reflected in a rising rate of 
return on investment and an increasing profit share of modern-sector income. The rising modern-sector share of the economy contributes to a rising profit share in the economy as a whole.

Savings are a much higher share of profits than of wages, so that a rising profit share of income is associated with a higher savings share for the economy as a whole. The higher savings, in turn, support higher levels of investment in the usual situation of home-country bias in investment, with home investment further encouraged by the high and rising rates of return on investment.

A falling consumption share is the other side of the coin to a rising savings share. Also as a matter of arithmetic - although not mentioned in the early theoretical treatments of the subject - and highly relevant to recent Chinese reality, an increasing excess of savings over investment causes the rate of growth of output to be unnecessarily low. In the labour-surplus economy, this does not lead to increasing unemployment of domestic resources. Rather, it leads to economic growth rates that are unnecessarily low, which therefore cause unnecessary delays in the absorption of underemployed labour in the village economy into the modern sector.

On the other hand, if the high and rising returns to investment in the modern sector cause the investment share to rise more rapidly than the savings share, there will be a tendency towards deficits in external trade and current payments. The same outcome will follow if the public sector's claims on resources expand more rapidly than is necessary to absorb any surplus private-sector savings. Such external current payments deficits are sustainable only if the country has ample access to international markets for capital on favourable terms. Where they are sustainable, their presence is likely to raise the sustainable rate of growth and the rate at which underemployed labour in the countryside is absorbed into modern and economically productive activity.

With rising returns on investment and a rising profit and therefore savings share of income, it can be expected that the rate of investment will rise over time. The combination of rising investment rates and the increasing share of the expanding modern sector in the economy is likely to cause the rate of growth in output to accelerate over time.

In the rural sector, the marginal product of labour remains well below the customary minimum income level. Expansion of the modern sector and migration from the village introduce no pressure to economise on the use of labour in production. Average standards of living rise in the village, without noticeably affecting the customary income levels of the low-income workers who are available for emigration to the modern sector. 
In the labour-surplus economy, comparative advantage in international trade is initially in small volumes of commodity exports, before the emergence of a dynamic modern sector. Modern economic growth and the development of the urban economy see comparative advantage in international trade shift to labour-intensive manufactured products; these contribute most of the growth in exports as the modern sector expands and the proportion of exports from the modern sector rises over time. The rapid accumulation of capital in the modern sector, combined with the labour force's learning of industrial disciplines and techniques, makes production of a wider range of traded goods and services profitable in the modern sector. This causes comparative advantage to emerge in some more sophisticated manufactured products, without any weakening of competitiveness in the production of labour-intensive traded goods. At this stage there is no pressure for absolute contraction of labour-intensive industries in the traded-goods sector.

In the labour-surplus economy, the fall over time in the wage share of income is associated with a widening of inequality in the distribution of income. The faster the rates of growth in investment and output, the faster will be the rate of increase in inequality. The faster the rate of growth, however, the greater will be the rate of emigration from rural to urban areas, the quicker will be the absorption of the surplus rural labour into productive modern-sector employment and the earlier will be the turning point from an economy in which labour is in surplus to one in which labour is scarce.

\section{The turning point}

If the rate of economic expansion in the modern sector is fast enough for the rate of emigration from the villages to exceed the natural increase of the rural population that is of working age, sooner or later, there will be no surplus of labour in the rural economy. At this point, any further emigration raises the marginal productivity of labour in rural employment above the rural wage. The real wage rate increases in the rural and urban sectors. This is the 'turning point in economic development'.

From the turning point, the wage share of income rises and the profit share falls. The rate of consumption can be expected to rise with the wage share. The rate of consumption in the whole economy rises and the rate of savings falls.

The increase in urban wages is likely to cause the rate of return on investment in labour-intensive production in the modern sector to fall. The combination of lower profitability of investment, and of lower savings accompanied by the usual home bias in investment, is likely to reduce the share of investment. 
All other things being equal, one would expect the rate of growth of output to fall with the share of investment in expenditure. This is not, however, an inevitable accompaniment of the turning point in economic development. There are two circumstances in which there will be no fall in the rate of growth in output. One of these circumstances could arise if, before the turning point, savings fell short of investment, giving rise to a surplus in external trade and current payments. This would be a case in which the rate of growth before the turning point was unnecessarily low and therefore the turning point of economic development was unnecessarily delayed. In this case, the rebalancing of expenditure from investment demand to consumption associated with the rising wage share of income could occur without any reduction in the rate of growth in the capital stock.

The second circumstance in which there might be no reduction in the rate of growth after the turning point would be if the rate of total factor productivity growth increases to balance a reduced rate of investment and reduced rate of increase in the capital stock. There is a reason to expect some increase in productivity growth beyond the turning point. Higher wages are likely to force economisation in the use of labour and to raise productivity growth in the rural and urban sectors.

It follows that the rate of economic growth could be faster, similar to or slower after the turning point than in the labour-surplus economy.

Whatever the impact of the turning point on the rate of economic growth, the tendencies towards decline in the savings rate are likely to be more powerful than the tendencies for decline in the investment rate, leading to a tendency towards smaller surpluses or larger deficits in foreign trade.

Beyond the turning point, there is a reversal of the tendency for economic growth to exacerbate the widening of income inequalities. At last, rural communities and low-skilled urban workers come to share in the fruits of modern economic growth. The faster the rate of growth in investment, productivity and output after the turning point, the more rapid will be the rise in rural standards of living and workers' income levels in rural and urban areas. The faster the rate of growth after the turning point, the more rapid will be the reduction in income inequalities.

The critical contribution of rapid growth before the turning point to the reduction in inequality is its bringing forward in time the point at which labour becomes scarce and labour incomes rise. The critical contribution of rapid growth after the turning point to the reduction in inequality is to accelerate the increase in real wages and rural living standards relative to incomes from ownership of capital. 
The changes in labour's share of income before and after the turning point are one explanation of the 'Kuznets curve' - the observed tendency for modern economic growth to at first exacerbate and to later reduce inequality in the distribution of income, at least for some time beyond the turning point in economic development.

There is no inevitability about the labour-surplus economy reaching the turning point. It will reach this point only if growth in the modern sector is sufficiently rapid and sufficiently labour intensive to absorb labour from the countryside substantially more rapidly than it is augmented by natural increase. If the modern sector of the labour-surplus economy grows too slowly relative to population increase or policy distortions cause growth to be associated with low increases in demand for labour, modern economic growth can be associated with continued steadiness in real wages and ever-increasing dispersion of the distribution of income.

Real wages rise rapidly with continuing economic growth beyond the turning point in economic development. Whether or not this is inflationary depends on the stance of monetary policy. As long as economic growth continues reasonably strongly, the increase in real wages increases domestic costs relative to the prices of internationally traded goods - that is, it increases the real exchange rate. The increase in the real exchange rate occurs no matter how the nominal exchange rate is managed. The conduct of monetary policy in a way that leads to an increase in the foreign exchange value of domestic currency - that is, to nominal exchange rate appreciation - allows the increase in the real exchange rate to occur with lower inflation than would otherwise occur. The avoidance of inflation as economic growth continues beyond the turning point requires firm monetary policy alongside appreciation of the nominal exchange rate.

Here there are risks of errors in economic policy, which, if they materialise, could unnecessarily diminish the rate of economic growth and the rates of increase in real wages and living standards in rural and urban areas. If the authorities become worried about inflation while wanting to avoid an appreciation of the nominal exchange rate (perhaps in an attempt to protect the labour-intensive industries whose competitiveness is declining), they could seek to tighten expenditure policy in an attempt to hold inflation to low levels. This generates a tendency to surplus in external trade and payments. For a while, this reduces the rate of growth below sustainable levels. The payments surplus generates tendencies to monetary expansion and to the re-emergence of inflationary pressure. In the end, it is likely that the rate of growth will tend towards sustainable levels, with the real appreciation being achieved after a lag through inflation.

Any protection of old, labour-intensive industries that comes with avoidance of appreciation in the foreign exchange value of domestic currency turns out 
to be temporary. The temporary respite comes with potentially large costs: the economy will experience unnecessary inflation and needlessly forgo some increase in economic output, real wages and living standards. In the worst case, the inflation will destabilise aspects of political as well as economic life and indirectly lead to larger losses in economic growth and potential increases in living standards.

Comparative advantage in foreign trade after the turning point shifts out of labour-intensive products into more capital-intensive and technologically more sophisticated goods and services. These more technologically complex products require higher-quality inputs of human resources (education and training) and infrastructure for communications, finance and regulatory arrangements. These requirements make heavy demands on the quality of various services provided by government. Weaknesses in these areas are more likely to emerge as bottlenecks to the continuation of rapid economic growth after rather than before the turning point in economic development.

\section{Real-world variations of the stylised surplus- labour model}

Like any model, the Lewis model of the labour-surplus economy embodies simplifications of reality. Some of these simplifications materially affect its application to analysis of contemporary Chinese economic development. This section examines some of the most important departures of the real from the stylised economy when the model is applied to China's economic development.

The most important departure of reality from the model is in the geographically differentiated nature of the labour market in the huge Chinese economy. Within China, there is imperfect mobility of labour among provinces and regions and differentiated barriers to movement between various rural areas and cities. Imperfect mobility and differentiated barriers are reflected in differing wage levels and material standards of living across the various parts of the country. As a consequence, as urban demand for labour grows, labour could be drawn disproportionately for a while from one source while being drawn less intensively from others. One part of the rural economy could find that its surplus labour has been absorbed fully into the modern economy and that the real wages demanded by potential immigrants from that rural region begin to rise strongly, while there is surplus labour and availability of labour at 'traditional' wages elsewhere. Relatively low-skilled labour could become relatively scarce and real wages could rise in some cities, while it is available at lower costs in others. 
The main consequence of China's geographically differentiated labour market is that there is a 'turning period' during which real wages begin to rise strongly, rather than a 'turning point'. Real wages rise rapidly in some cities, forcing a reduction in the profit share of income, increases in consumption and structural change out of simple, labour-intensive products and techniques, while lower wages persist and labour-intensive production continues to prosper and expand elsewhere. Similarly in the rural economy, labour becomes relatively scarce, living standards rise rapidly and production shifts out of labour-intensive activities in some villages while labour remains abundant in others.

The surplus-labour model's second major departure from reality is the assumption that there is a stable conventional standard of living for potential migrants among rural residents until there has been sufficient emigration to raise the marginal product of rural labour above that standard. Even in the early stages of emigration from part of the rural economy, higher average material living standards and consumption are likely to be reflected in some enhancement of the living conditions of potential emigrants. As a result, the reserve price of rural labour - and therefore the wages of urban workers - rises to some extent from an early stage in modern economic development. Entry into the turning period will be marked by an acceleration of wage increases, rather than by a sharp movement from stable to rapidly increasing real wages.

The third major departure is that in reality, but not in the model, labour is highly differentiated by skills, resulting from differences in education, training and experience in the modern economy. The model focuses on relatively unskilled labour, the availability of which is diminished by increases in education, training and experience. Changes in these factors influence the arrival and duration of the turning period during which relatively unskilled labour becomes scarce and its wages rise. In particular, the high and on average rapidly rising investment in education per student and the accumulation of skills through experience in the modern sector of the economy are reducing the stocks of low-skilled labour available to the urban economy. This has been bringing forward the turning period in China's economic development. In combination with the demographic crunch following from the sharp decline in fertility in the 1970s and 1980s, these factors will cause the rate of increase in real wages during and beyond the turning period to be much sharper than in other labour-surplus economies that have moved through and beyond the turning point.

The fourth major departure is that the real economy does not contain only 'traditional' and 'modern' sectors. There is also a government sector that provides services and modifies demand and supply for various types of labour, and affects living standards in rural and urban areas. The government sector supplies inputs that are critical to economic growth. The government sector's command over resources and also its role in providing essential inputs for development 
are likely to be relatively small in the early stages of development of a laboursurplus economy. The government's potential command over resources expands with the modern sector and its role in continued rapid growth becomes more important over time.

The main effect of the first two departures of reality from the model is to transform the turning point into a turning period.

The main effect of the third departure is to bring forward in time the turning period and to shorten its length.

The effects of the fourth departure are manifold. Improvements in government services in rural areas can raise the reserve price of emigrant labour and therefore the urban wage for unskilled labour. Provision of education services can reduce the pool of surplus labour and bring forward the turning point. Public-sector demand for labour augments demand from the modern industrial sector and brings forward the turning point.

Government policy can affect population growth and, over time, the amount of unskilled labour in the countryside. It can affect the labour intensity of modernsector economic growth. The effectiveness of government provision of various inputs into the development process affects the rate of growth even before the turning period. Its effects are, however, larger during and after the turning period, as growth comes to make larger demands on infrastructure, education and skills, financial services and the sound regulation of private economic activity.

\section{The 2006 evidence of China entering the turning period}

Garnaut and Huang (2006) went through a number of factors influencing the turning point in China's economic development and concluded in a preliminary way that it was not far away. The anecdotal evidence of shortages of labour in some areas and large recent increases in real wages started to make the point. The looming demographic transition deriving from the large and sudden decline in fertility a generation ago, the strength of modern-sector economic growth, the improvement in rural education, including for girls, and the evidence of labour shortages in some rural as well as urban areas all pointed to the imminent arrival of the turning point.

We observed that in the early years of Chinese economic reform after 1978, the large underemployment in the agricultural sector and potential productivity gain from transferring workers from rural to urban employment created the 
conditions for economic growth within the labour-surplus economy. For a couple of decades after the start of reform, real wages of migrant workers had been fairly stable while large numbers of rural residents entered industrial employment. We noted that the reports of shortages of migrant labour seemed odd, given that the standard accounts suggested that there were still 300 million agricultural workers - well above the requirements of agricultural production, even with established agricultural technologies. There were several reasons why the shortages could have reflected temporary influences, rather than the major structural factors that would be associated with China having passed the turning point in economic development. Rising food prices and various government measures to improve rural living conditions had raised the supply price of migrant labour. The absence of an efficient and informed labour market allowed regional shortages to appear even if there was no national shortage. Employers in the cities were seeking to raise productivity and seeking to recruit workers with two to three years' experience, so some reports of labour shortage might not have related to unskilled labour straight from villages. Not all workers from the village were in similarly strong demand: females aged between eighteen and twenty-five were especially valued, and the total pool of about 70 million people in this category was running dry.

Nevertheless, the anecdotal evidence was considerable and was backed up by some relevant statistical data. Migrant workers' cash wages had increased by 20-40 per cent in 2004. Labour fringe benefits were increasing rapidly in scope and size as employers sought to make their employment offers more attractive.

We noted that eventually rising labour costs were a normal phenomenon with successful development of a labour-surplus economy. China's real manufacturing wages in US dollars in 2006 were about 5.6 per cent of those in the United States. Korea's had been a bit below that proportion at 5.2 per cent in 1975, but 29 years later were 49.7 per cent of those in the United States. We asked: will it take more or fewer years for China's labour costs to rise to half of those in the United States?

China's nominal wages had fluctuated with inflation for more than two decades of the reform period with only small increases in real wages. Real wage growth had lifted sharply from about the turn of the century and had remained in double digits from that time. Wage growth had been even more rapid in the less-advanced regions than in the established industrial cities, Guangdong and Shanghai. Until 2003, real wages grew less strongly than average productivity, but in 2004 and 2005 wages growth ran ahead of productivity. This had been reflected in a sharp increase in the share of employee earnings in total industrial value added from the last quarter of 2004 and through 2005, reversing many years of decline. 
These generalisations were based on general wage data, mixing skilled and unskilled elements. A look at the forward-looking data for unskilled labour pointed to a likely special tightening of the market for unskilled migrant labour. China's rapid demographic transformation following the rapid decline in fertility in the late 1970s and 1980s meant that the total labour force was now hardly growing at all, and any significant migration out of the villages caused the rural labour force to decline. These tendencies would strengthen over time. The general decline in the labour force would be especially sharp for unskilled workers, as increasing public investment in education applied to a falling number of children was increasing the proportion of new members of the labour force whose education removed them from the pool of 'unskilled' labour. We noted that all successful labour-surplus economies had passed through a labour-market turning point, with immense implications for the structure of the economy and its relations with the rest of the world. We commented that China would not be an exception, and its time was coming soon.

Cai and Wang (2006) analysed developments in demand and supply for migrant labour, demonstrating that both had contributed strongly to the rapid depletion of surplus labour in the Chinese countryside since the turn of the century.

On the demand side, China's entry into the WTO in 2001 and the accelerated domestic trade liberalisation with which it was associated had lifted growth rates and had also made the pattern of modern-sector growth more labour intensive in line with China's comparative advantage in international trade. Thus, demand for unskilled labour had grown strongly through the early twenty-first century, despite the shedding of large amounts of labour through state-owned enterprise (SOE) reform.

On the supply side, China had entered a period of dramatic contraction of the unskilled labour force. The working-age population would reach a peak in 2016 and then fall steadily. The numbers of younger elements of the labour forcethose available for rural-urban migration - would begin to decline earlier and the proportion of that group available for unskilled work would fall rapidly with expansion and improvement of the quality of education.

Cai and Wang thought that China had reached the turning point.

\section{The evidence in $\mathbf{2 0 1 0}$}

The chapters in The Turning Point in China's Economic Development in 2006 were noting early and partial evidence of China's entry into the turning period. Data and analysis presented in the special issue of the China Economic Journal 
suggest that the Chinese economy has now moved more decisively and deeply into the turning period (Du and Wang forthcoming; Cai and Wang, this volume; Cai forthcoming; Garnaut forthcoming).

The impact of the global financial crisis on China complicates the interpretation of the evidence between 2006 and 2010, but only slightly. The effects of the crisis were quickly overwhelmed by the longer-run tendency for tightening of the labour market. The global financial crisis led to a sharp reduction in demand for labour in the export-oriented coastal cities in late 2008 and early 2009. For a while, the greatest migration in human history went into reverse, as redundant workers returned to the countryside. When retrenched workers returned to work in 2009, there were reports of downward revision of terms of employment.

The Chinese Government responded to the recessionary impact of the global financial crisis by launching the world's greatest exercise in Keynesian expansionary policy, to counteract the effects of global recession (Garnaut with Llewellyn-Smith 2009). The success of the expansionary policies meant that by the middle of 2009, the flow of migrants from rural to urban areas had been restored and then increased beyond pre-crisis levels, hastening movement into and through the turning period in China's economic development.

It is the combined effects of these two developments that we see in the Chinese labour market through 2009 and 2010.

Du and Wang (forthcoming) undertake sophisticated analysis of Chinese labourmarket data in reaching strong conclusions that real wages of unskilled workers have been rising strongly through the early twenty-first century after a couple of decades of relative stagnation, and that the momentum of real wages growth was quickly restored after the shock of the financial crisis. The pre-crisis momentum of growth in real wages of low-skilled migrant workers was so strong that there was an increase of 20 per cent for 2008, which ended in the midst of labourmarket retrenchment. Momentum was briefly lost, but was resumed in time for real wage growth to again be positive for 2009. Real hourly wages for migrant workers increased by 90 per cent from 2001 to 2009 and by 77 per cent from 2003 to 2008 (Du and Wang forthcoming). Non-wage benefits increased more rapidly than wages.

Looking forward, they note that assessments based on the continuing presence of 300 million agricultural workers are misleading. A high proportion of those workers have substantial non-agricultural income; for many, non-farm income is dominant. The economic censuses in 2004 and 2008 show growth of more than 30 million in secondary and more than 50 million in tertiary employment over the four years. Application of employment elasticities of growth to plausible rates of expansion of the secondary and tertiary sectors suggests employment 
increases of about 24 million per annum in the years immediately ahead - if the elasticities or growth are constrained by neither labour shortages nor rising real wages.

Will labour-market realities allow such strong employment growth? The average annual increase in the working-age population is expected to fall from about seven million per annum in 2006-10 to about 3.1 million per annum in 2011-15, and then to decline absolutely by about one million per annum in 2016-20 and five million per annum in 2021-25. The rapidly increasing investment per student in education means that the emerging labour-market squeeze is tightest for low-skilled labour. The focus of government policy in recent years on raising incomes and services in rural areas, along with the rapid expansion of off-farm rural incomes and the absorption in the past of a high proportion of young rural workers - those who are most likely to seek urban employment - further constrain the increased supply of migrant labour.

Du and Wang's analysis draws attention to powerful tendencies to acceleration of real wages growth for labour in general and low-skilled workers in particular.

Cai Fang (forthcoming) raises questions about the bases of the Chinese demographic data and the answers all suggest risks of even greater labourmarket tightening in the period ahead. The periodic survey of agricultural costs suggests that the remaining agricultural labour potentially available for migration to urban employment is less numerous than presumed in any of the widely used studies. As a result, the marginal product of rural labour - and therefore its supply price - is much higher than generally presumed, and rising.

The differences in data from the household survey and the urban unit reporting system suggest that there are 95 million more migrant workers in urban areas than is commonly presumed.

Analysis of the 2000 census and 2005 sample census data suggests that national fertility rates have fallen below those applied to the standard population projections.

The weight of the evidence points to a reasonable expectation of rapidly rising real wages - and more rapidly for low-skilled workers - as the only means of bringing runaway growth in demand for labour back in line with labour's availability. 


\section{Implications of the turning period for Chinese development}

What are the implications of the turning period for China's continuing economic development, for China's interaction with the global economy and for economic policy? I will focus on four of the most important consequences, mention a consequence that is widely anticipated and feared, but which need not eventuate, and briefly discuss one way in which perceptions of China's growth will be affected by its having entered the turning period.

As China enters deeply into the turning period, there will be large and continuing increases in real wages and in the wage share of income. The powerful tendency since the 1980s towards increased inequality in income distribution is likely to be reversed. This is one important consequence. The rise in the wage share of income is likely to be reflected in an increase in the consumption share of expenditure. There will be a reduction in the national savings rate.

It is possible that, at least for a while, the investment rate will in fact rise. Whether or not this is the case, it is likely that China's savings rate will fall more than its investment rate. This will reduce the external surplus in trade and current payments. It will therefore ease current international pressures over payments imbalances and exchange rates. It would be wise for China to ensure that total domestic demand - the sum of demand from private and public investment and consumption - expands enough to ensure that this is the case.

The reduction in Chinese current external payments surpluses is therefore a second important consequence of moving through the turning period. This could ease tensions with other countries - especially the United States - which have identified Chinese surpluses as a principal cause of their own economic problems. Regrettably, the reduction of Chinese surpluses will not help the reality of other countries' economic problems as much as perceptions of them. Indeed, a large fall in Chinese current savings relative to investment would put upward pressure on global long-term interest rates and increase the requirement to reduce domestic expenditure on goods and services in the countries facing large challenges in the management of external and public debt, including the United States. This will make economic management problems in those countries more difficult, not easier.

The third important consequence of China moving through and beyond the turning period is that the centre of China's comparative advantage in international trade will shift rapidly from a fairly narrow range of labour-intensive products to a wider range of more capital-intensive and technologically sophisticated products. This will ease some dimensions of China's trade problems with the rest of the world (perceptions of competitive pressure on other developing countries 
and heavily concentrated pressures for adjustment on particular sectors in industrialised countries) and complicate others (competitive pressures will be felt across a much wider range of industries in industrialised countries). The diversification of China's comparative advantage will probably halt the decline in Chinese export prices that was associated with the heavy concentration of export expansion in a small number of products.

The fourth important consequence of entering the turning period involves a policy risk to economic stability and growth in the period ahead. Rising real wages and the pressure of strong increases in demand for non-traded goods and services will be inflationary unless accompanied by a combination of firm monetary policy and an appreciating renminbi. Nevertheless, the Chinese authorities might be tempted to maintain the fixed exchange rate against the US dollar to avoid adjustment pressures on export-oriented labour-intensive industries, which have played such an important part in Chinese economic growth since the mid 1980s.

To seek to maintain a fixed exchange rate against the US dollar through and beyond the turning period would only postpone and not avoid the structural adjustments that are a necessary accompaniment of the current stage of Chinese economic growth. Payments surpluses would eventually overwhelm the efforts to sterilise their monetary effects. The adjustments would occur through inflation.

It is likely that the authorities would respond to higher inflation by tightening fiscal and monetary policies. This would unnecessarily reduce the rate of economic growth below sustainable levels and postpone the increase in Chinese living standards that can come through and beyond the turning period. The inflation and the delays in inequality reductions could be destabilising to domestic political stability. The delays in reduction in the external payments surplus would certainly be destabilising for China's productive interaction with the international economy and society.

I conclude by pointing to one consequence of moving through and beyond the turning period that is often feared but which is unlikely to be important unless there are mistakes in economic policy, and to one important implication for perceptions of the growth of the Chinese economy.

There is no basis for the expectation that China's rate of growth in output per worker must necessarily fall as it moves through and beyond the turning period. The rise in real wages as China moves through the turning period is likely to lead to an increase in the rate of total factor productivity growth. In the nature of things, this will be concentrated in industries producing relatively sophisticated and capital-intensive products, the competitiveness of which 
is less sensitive to increases in real wages. It is possible that the increase in Chinese domestic demand that is necessary to reduce external current payments surpluses will require an increase in the investment rate for a while. Together with the expected acceleration of productivity growth, this would support an increase in the growth rate in total output per worker, above the high rates of the early twenty-first century. That will surprise the world and also the Chinese authorities, but it might be necessary to maintain internal and external balance in the period ahead.

How successful China is economically in this period of rapidly rising real wages will depend on the flexibility of the economy, its openness to foreign trade and investment and the world's most productive ideas about managing enterprises, the quality of the human resources created by the rapid expansion of the education system in the past couple of decades and the quality of the regulatory systems applied to the more complex economy that is emerging. It is possible that the rate of growth in total output can be maintained at something like the average rates of the decades of reform, until the approach of the industrialised countries' frontiers of productivity and living standards reduces the scope of rapid productivity growth through 'catching up' with the industrialised countries.

Whether or not China succeeds in maintaining such high aggregate rates of growth until it reaches the frontiers of the world economy, most observers will be surprised by how quickly China catches up now that it has entered the turning period. China's real exchange rate will rise rapidly — whether that occurs through inflation, nominal exchange rate appreciation or a combination of the two. The value of China's output when measured in the national accounts and converted into international currency at current exchange rates will converge towards the much higher 'purchasing power' estimates of GDP. People in China and abroad who focus on conventional measures of national output will find that China catches up with the world's most productive economies in output per person - and with the United States in total output - much more quickly than they had been expecting from extrapolation of differentials in national growth rates.

\section{References}

Cai, F. (forthcoming), 'Demographic transition, demographic dividend, and Lewis turning point in China', China Economic Journal, Special Edition. 
Cai, F. and Wang, D. 2006, 'Employment growth, labour scarcity and the nature of China's trade expansion', in R. Garnaut and L. Song (eds), The Turning Point in China's Economic Development, Asia Pacific Press, Canberra, pp. 143-71.

$\mathrm{Du}$, Y. and Wang, M. (forthcoming), 'A discussion on potential bias and implications of Lewisian turning point', China Economic Journal, Special Edition.

Fei, J. C. H and Ranis, G. 1964a, Development of the Labor Surplus Economy: Theory and policy, Richard D. Irwin, Homewood, Ill.

Fei, J. C. H and Ranis, G. 1964b, 'Development of the labor surplus economy: theory and policy', Economic Development and Cultural Change, vol. 41, pp. 147-74.

Fei, J. C. H. and Ranis, G. 1966, 'Agrarianism, dualism and economic development', in I. Adelman and E. Thorbecke (eds), Theory and Design of Economic Development, Johns Hopkins University Press, Baltimore.

Garnaut, R. 2006, 'The turning point in China's economic development', in R. Garnaut and L. Song (eds), The Turning Point in China's Economic Development, Asia Pacific Press, Canberra, pp. 1-11.

Garnaut, R. (forthcoming), 'Macro-economic implications of the turning point', China Economic Journal, Special Edition.

Garnaut, R. and Huang, Y. 2006, 'Continued rapid growth and the turning point in China's economic development', in R. Garnaut and L. Song (eds), The Turning Point in China's Economic Development, Asia Pacific Press, Canberra, pp. 12-34.

Garnaut, R. and Song, L. (eds), 2006, The Turning Point in China's Economic Development, Asia Pacific Press, Canberra.

Garnaut, R. with Llewellyn-Smith, D. 2009, The Great Crash of 2008, Melbourne University Publishing, [Chinese translation published by China Academic Press, Beijing].

Lewis, W. A. 1954, 'Economic development with unlimited supplies of labour', Manchester School of Economic and Social Studies, vol. XXII (May), pp. 139-91.

Minami, R. 1973, The Turning Point in Economic Development: Japan's experience, Kinokuniya Bookstore, Tokyo. 
Minami, R. 1986, The Economic Development of Japan: A quantitative study, Macmillan, London.

Ranis, G. and Fei, J. C. H. 1961, 'A theory of economic development', The American Economic Review, vol. 51, no. 4, pp. 533-65.

Ranis, G. and Fei, J. C. H. 1963, 'The Ranis-Fei model of economic development: reply', The American Economic Review, vol. 53, no. 3, pp. 452-4.

\section{Acknowledgments}

The conceptual core of this chapter is drawn from a forthcoming (2010) paper in the China Economic Journal: 'Macro-economic implications of the turning point.' The author is grateful to the editors of the journal for agreeing to its publication in this form. 



\section{China model and its future*}

\section{Yang Yao}

The Chinese economy's average growth rate of 9.7 per cent per annum from 1978 to $2008^{1}$ places China among just 13 successful economies that have managed to grow at a rate of 7 per cent or higher for 25 years or more since World War II (The Growth Commission 2008). Per capita gross domestic product (GDP) has grown by a factor of 12 in real terms to reach US $\$ 3400$ in $2008 .^{2}$ During this period China moved from a planned economy to a 'mixed economy' with the private sector now accounting for two-thirds of national GDP. How has China managed this profound feat?

One of the prevailing views regarding this question - especially since the financial crisis - seems to suggest that China has benefited from the authoritarian nature of its government; compared with a democratic government, an authoritarian government is able to mobilise large amounts of resources to tackle the most urgent bottlenecks blocking growth and institutional transition. Indeed, the issue is often framed in the context of the 'Beijing Consensus' versus the 'Washington Consensus' - the former being a model of authoritarianism and heavy state involvement in the economy, and the latter being a model of neoliberal and market-oriented doctrines. For example, this contrast has been clearly stated by Bruce Dickson, who has published influential works such as Wealth into Power: The Communist Party's embrace of China's private sector and 'Red capitalists in China: the party, private entrepreneurs, and prospects for political change' (Dickson 2010). Dickson believes that the Washington Consensus 'asserts that state intervention is not conducive to economic development, and that economic freedoms require political liberties associated with democracy to flourish. This neo-liberal model has been the cornerstone of international aid and lending programs for the past two decades.' In contrast,

the 'Beijing consensus' suggests that rapid economic development requires active leadership by political elites committed to growth and

An abridged version of this chapter has been published in Foreign Affairs Online under the title 'The end of Beijing Consensus' (2 February 2010, <http://www.foreignaffairs.com/articles/65947/the-end-ofthe-beijing-consensus $>$ )

1 The National Bureau of Statistics (NBS) website: <www.stats.gov.cn>

2 Ibid. 
that authoritarian rule is necessary to sustain these pro-growth policies and limit demands for greater equity and social welfare. The Beijing Consensus therefore is antithetical to the Washington Consensus and has so far defied the logic that economic development inevitably leads to political change (Dickson, 2010: i)

This characterisation, however, neither captures the original meaning of the Beijing Consensus and the Washington Consensus nor stands the test of reality.

In Joshua Ramo's (2004) original formation, the Beijing Consensus comprises three elements - none of which is related to authoritarianism: 1) innovation; 2) equitable and sustainable development; and 3) self-determination. ${ }^{3}$ China's own history also rejects the thesis of pure authoritarianism and high levels of government involvement in regular economic activity. The Chinese government in the planning period was much more authoritarian and involved in the economy than it is now, but the whole period was characterised more by failures and even disasters than by successes. An authoritarian government might act more quickly than a democratic government, and this would more likely lead to disasters if its policies were wrong.

The Washington Consensus has also been misinterpreted since it was proposed by John Williamson in 1989. When it comes to economic transition, one of the misinterpretations is to treat the Washington Consensus as advocating fast transition and to compare it with the Beijing Consensus, which is often regarded as a model of gradualism. In the first place, Williamson (1990) did not say anything about the speed of transition, although he emphasised market mechanisms as the end result. On the other hand, China's gradualism has its roots in the country's recent history.

To be sure, China is unique in many ways. The Chinese leadership is unusually pragmatic, enabling it to succeed in a complex and constantly changing world. The Chinese transition has followed a gradual trajectory, allowing China to avoid the institutional and organisational disruptions that have plagued most other transitional economies. Equally, China's economic organisations lack the clear-cut features of a standard market economy, yet they have been adaptive in the evolutionary settings of the recent past. The list could go on; however, a serious examination of China's reform process raises the question of whether these features constitute a new model of economic growth or whether they are intermediate yet sometimes necessary steps towards the traditional model

\footnotetext{
3 Ramo's 'Beijing Consensus' itself can be debated. While self-determination can rightfully be used to describe China's dealings with other countries, China's economic growth can hardly be described as 'equitable' and 'sustainable' - nor is it driven by innovations.
} 
of a market economy. The Chinese leadership adopted a gradual approach to transition because of its aversion to the serious risks associated with fast transition. The Chinese Communist Party (CCP) made many serious mistakes during its first 30 years of rule: the grand experiments in social engineering including the aggressive collectivisation of agriculture, the Great Leap Forward and the catastrophic Cultural Revolution. With this legacy, the CCP saw a rapid transition to a full-blown market economy as a risky endeavour best avoided. At the same time, many of China's somewhat unconventional organisational forms can be understood as reactions to the unconventional political and economic circumstances encountered along its transitional path. For example, government ownership of township and village enterprises (TVEs), which was hailed by some as a challenge to conventional private ownership, was a consequence of the government's ambiguous - even conflicted - attitudes towards private firms in the 1980s. After private firms were made legal in the 1990s, TVEs vanished quickly (see Garnaut et al. 2005).

\section{A case for the Washington Consensus}

In terms of economic policy, China has not created a new model. Instead, it has followed closely the teachings of neoclassical economics. Indeed, if we make a list of the reforms that China has undertaken and then compare that list with the recommendations of the Washington Consensus - which in essence is a summary of policies that would be recommended by neoclassical economicswe might be surprised by the similarities in those two lists. In Williamson's (1990) original formulation, the Washington Consensus has the following 10 policy recommendations:

1. financial discipline to avoid an inflation tax

2. public expenditure redirected from redistribution to productive areas, such as primary education, health care and infrastructure

3. tax reform so as to broaden the tax base and cut marginal tax rates

4. financial liberalisation, involving an ultimate objective of market-determined interest rates

5. a unified exchange rate at a level sufficiently competitive to induce rapid growth in non-traditional exports

6. quantitative trade restrictions to be rapidly replaced by tariffs

7. abolition of barriers impeding the entry of foreign direct investment (FDI)

8. privatisation of state enterprises 
9. abolition of regulations that impede the entry of new firms or restrict competition

10. provision of secure property rights.

During the past 30 years, China has closely followed most of these recommendations.

In terms of fiscal discipline, the Chinese government has been very cautious in maintaining a roughly balanced budget. The rate of inflation has been kept in single digits in most years. On the expenditure side, pure redistributive programs have been kept to a minimum; central government transfers have been limited primarily to infrastructure spending. Before 2003, the share of 'social spending' in government budgets had been declining. It has slowly picked up in recent years, but its level is still low.

In terms of taxation, the overall tax burden-measured by the ratio of taxes to GDP - declined dramatically from 31 per cent in 1978 to 12 per cent in 1993, largely because of fiscal decentralisation in the 1980s (Ramo 2004). The 1994 fiscal reform greatly strengthened the central government's taxation capacities, and the amount of government revenue has increased to approximately 24 per cent of GDP. This rate of growth of taxation revenue has, however, begun to concern the government and the general population. The rate of corporate income tax was reduced from 33 per cent to 25 per cent and the allowable deductions for personal income taxes have been raised several times. Even the value-added tax has begun to provide a deduction for capital investment.

On the international front, China has taken a road that leads decisively to the liberalisation of trade and FDI, although it has followed its own pace of opening up. Its special economic zones have served as windows for China to reach the outside world. The export-led growth model was adopted as a national development strategy in the mid 1980s. Joining the World Trade Organisation (WTO) in 2001 marked China's full integration into the world economy. Since then, China's trade dependence ratio - that is, the ratio of imports and exports to GDP - has been maintained at over 60 per cent, which is one of the highest among the large economies.

Domestically, two major themes of Chinese reform since the 1990s have been privatisation and deregulation. After 15 years of privatisation that started in the mid 1990s, most of China's state-owned enterprises (SOEs) have been released into private hands or transformed into publicly listed companies. Only a handful - though powerful - SOEs are still owned by the government. The removal of price controls happened even before privatisation. By the end of the 1990s, government reforms had removed many barriers to the entry and exit of individual firms in specific markets. 
Although protection of property rights is still weak in many arenas (especially intellectual property), China has made noticeable progress in the past 30 years. Several amendments to the constitution and the enactment of the Property Law have established a reasonable - though still incomplete-legal framework for property rights protection. The situation is far from perfect, but the direction has been set decisively for better and stronger protection in the future.

It is noteworthy that the Washington Consensus, as emphasised by Williamson, is different from the so-called 'neo-liberal doctrine' that adds to the list of capital account liberalisation, a floating exchange rate and, above all, the relentless working of the unbridled market, which China has clearly rejected. On the other hand, China has also adopted other policies frequently prescribed by neoclassical economics as essential for economic growth-among which the most significant are high saving and investment rates and an emphasis on primary education.

One area in which China has clearly not followed the Washington Consensus is in financial liberalisation. Interest rates are still controlled by the government. Despite vast deregulation, the State maintains tight controls on what it calls 'the strategic sectors' of the economy, such as petroleum, telecommunications and banking. Controlling interest rates is a tactic that the government believes is essential for its control of the financial sector. This controlled approach-even if it was warranted in the past-now, however, seems problematic. We will return to this point later.

The aim of China's three-decade-long economic reform has been clear-that is, to establish a functioning market economy. It is hard to imagine that China could have managed to grow at 10 per cent per annum without the introduction of the market. Some people might admit the importance of the market, but nevertheless believe that an authoritarian government is necessary to make the market work. This thesis has, however, been rejected by the failures of the Latin American dictatorships, particularly in Chile by Augusto Pinochet's regime of a mixture of military rule and the free market. At the minimum, it blurs the line between an authoritarian government and a regulatory government. Many governments in the industrialised world qualify as regulatory governments, but they are not authoritarian and do not have a heavy and direct hand in the economy. The analysis below will establish that an authoritarian government is not essential for a functioning market economy in China. 


\section{The disinterested government}

We have to ask a further question when we think about China's economic success more carefully: why has the Chinese government adopted the principles of neoclassical economics, particularly when the CCP still claims that Marxism is its ideological anchor?

The answer to this question, I suggest, is that the Chinese government has been a 'disinterested' government. Here the word 'disinterested' is used in one of its three meanings in aesthetics, ${ }^{4}$ which is 'detached' or 'unbiased' when one makes judgments on objective existences. Thus, a disinterested government is taken to mean a government that takes a neutral stance when conflicts of interest arise among different social and political groups. In other words, it is a government that does not consistently represent-and is not captured by-any social or political group in society. This does not mean that such a government is devoid of self-interest; quite the contrary. It can have not only its own interests, but be predatory towards society at large. The key is that its predation is 'identityblind' in the sense that it does not care about the social and political status of its particular prey. As a consequence, it is more likely to adopt growth-enhancing policies than is a government that consistently represents the interests of certain social or political groups.

To understand this assessment, consider that biased governments are obliged to adopt policies that consistently benefit their own favoured groups, and thus create a mismatch between productivity and government allocation of resources because other groups, not similarly favoured, might be more productive. In contrast, a disinterested government is autonomous in the sense that it is free of social and political constraints and is thus more likely to allocate public resources according to sector/group productivity. In that sense, a disinterested government promotes economic growth. It is willing to make this happen for two reasons. First, higher economic growth brings tangible gains (rewards) to its members. Second, higher economic growth brings satisfaction to the people, who in turn might be more willing to acknowledge its legitimacy.

A corollary of the above reasoning is that the policies adopted by a disinterested government are often selective and have the potential to enlarge income gaps in the society. Unless the gaps lead to serious threats to its rule, however, a disinterested government will have little incentive to correct them.

The Chinese government has acted as though it has been disinterested for the past 30 years. This started with the establishment of the 'growth consensus'

4 The other two meanings, according to Rind (2002), are 'uninterested' and 'without self interests' when a person examines an objective existence. 
at the end of the 1970s. This consensus came out of the CCP's realisation that continuing with Stalinist-style socialism would not only retard China's rise in the world, it would endanger its own legitimacy, which was already faltering in the mid 1970s. The need was to discourage growing discontent and put economic growth at the centre of all governmental and societal endeavours.

Looking back, it is clear that the Chinese government intentionally adopted selective policies to promote reform and economic growth - that is, policies that created winners and losers. China's integration into the world economy is a case in point. At the end of the 1970s, the United States was eager to bring China into its camp as a buffer against Soviet hegemony. China quickly grasped the opportunity. Yet that early adoption of the 'Open-Door Policy' was not without domestic resistance. The special economic zones enjoyed an abundance of preferential treatments that other parts of the country envied. The exportled growth model required that China embrace an unbalanced development path that encouraged rapid growth on the east coast and relative neglect of the interior; today, nearly 90 per cent of China's exports come from the nine coastal provinces. China's accession to the WTO in 2001 was also a selective move. Before accession, it was widely believed that China would have to undergo painful structural adjustments in agriculture, automobile manufacturing, banking, telecommunications and retailing if it were to join the WTO. Amid the debate, the central government actually sped up negotiations with WTO members, especially the United States. Despite many detrimental effects, accession to the WTO has greatly accelerated China's growth of exports. Between 2002 and 2007, Chinese exports grew by an annual rate of 28.9 per cent, compared with the average rate of 14.5 per cent in the previous decade. ${ }^{5}$

Privatisation of SOEs provides another case in point of a reform measure that was not welfare improving for every group in society. In the 1990s, during the most dramatic transformations, the CCP had to face new challenges emerging from an increasingly diversified population. Between 1995 and 2004-the peak of privatisation - nearly 50 million SOE workers lost their jobs. This put the CCP in a conundrum: by supporting privatisation it risked losing support from its main power base - the working class; on the other hand, its larger goal of transition to a market economy would be halted if it abandoned privatisation. The CCP finessed this difficult passage by quietly pushing continued privatisation while simultaneously doing all it could to re-employ laid-off workers.

Perhaps the most controversial illustration of the government's selective policies is the urban-rural divide. With urban per capita income standing at 3.5 times rural per capita income, China has the largest urban-rural income differential in the world. There are many explanations for this large gap, some of which are

5 The figures quoted in this paragraph are all from the NBS website: <www.stats.gov.cn $>$ 
related to the institutional barriers inherited from the planning period. From an efficiency point of view, however, this large gap would not be bothersome to the government because cities enjoy much higher productivity and wages than can be found in the countryside.

The government has also been willing to correct mismatches between government resource allocation and the productivity of social groups. The dual-track price system instituted between 1985 and 1994 is a case in point. Under this system, SOEs were given the opportunity to sell their products and buy inputs in the emerging market after they fulfilled their planned quotas. While this system opened up a wide door for economic incentives to play a role in SOE decision making, the increasing gaps between market prices and quota prices created enormous scope for rent seeking. SOE managers and government officials who controlled the quotas of key inputs could easily get rich by selling their quotas to other enterprises and individuals. The brighter side of the dual-track system, however, was that it also created - unintentionally - new elements that benefited only from the market. The TVEs and private firms were particularly helped in this regard. They did not have access to planned resources such as bank credits and key inputs, but instead had to rely on the market to survive. Despite these perils, they had become important players in the Chinese economy by the early 1990s. For example, TVEs contributed 40 per cent to China's industrial growth and 40 per cent of its exports in the early 1990s (Lin and Yao 2001). These new circumstances forced the government to give up the dual-track system so TVEs and private firms were treated equitably with the SOEs. This happened even when the beneficiaries of the system were mostly powerful members of the CCP.

Government policy towards migrant workers is another example of the government's willingness to correct mismatches. Until very recently, free mobility of labour was hampered by various barriers including the household registration system (hukou), which is still in place today. In the 1990s, migrant workers were often treated as second-rate citizens deprived of basic rights to free mobility, workplace safety, health care and even equitable salaries. By the end of the 1990s, however, it had become clear that they were indispensable in the national economy as China became the 'world's factory'. It seems that urban dwellers had gained undue benefits with the government's suppression of migrant workers' rights, and the share of national income going to migrant workers fell below their relative contribution to the national economy. This unequal treatment ignited widespread grassroots rights movements and petitions by intellectuals. The CCP was alarmed by the potential for social unrest. Soon the discriminatory policies towards migrant workers began to wither away after the more equity-minded Hu Jintao-Wen Jiabao government took office in 2003.

The question remains why the Chinese government remained 'disinterested' during the reform era? The CCP's search for legitimacy is one of the major 
reasons. Despite its absolute power, the CCP has never been free to ignore the general wishes of the people. The April Fourth Movement in 1976, the June Fourth Movement in 1989 and numerous protests in subsequent years show that people are quite willing to stage organised resistance. In addition, fiscal decentralisation during the 1980s had considerably weakened the central government's authority over local governments, making it more prudent in carrying out regional policies. International monitoring has also played an important role. As it has emerged as one of the largest international players, China now must care about its legitimacy on the world stage. Since it is not democratically elected, the CCP does not have the legitimacy derived from the set of procedures approved by the people. As a result, it has to seek performancebased legitimacy - that is, legitimacy coming from the delivery of continuous improvements towards people's welfare.

Many other authoritarian regimes, however, also tried to obtain legitimacy through economic growth, yet they often did not enjoy power for long. It has a lot to do with the absence of extreme social inequality in China that the CCP has remained disinterested in the reform era.

In societies with extreme social inequality - such as many of those with authoritarian regimes - forming an alliance with the strongest social groups provides the best chance for the government to survive because those groups can provide sufficient resources for it to suppress any challenges from the unfavoured groups. The biased policies ultimately lead, however, to stagnation of economic growth and the erosion of the regime's legitimacy. In contrast, it is dangerous for the government in an equal society to side with any particular groups because other groups can form an alliance to block the governmentand perhaps even to unseat it.

China was made a socially equal society through a series of revolutions in the twentieth century. The 1911 Xinhai Revolution led by the nationalists ended the Manchu rule of imperial China and established a republic. The communist revolution of 1949 further levelled out Chinese society. Through comprehensive yet brutal land reform, the landed class was effectively eliminated and land distribution became equalised. Large businesses originally tied to the nationalist government were nationalised. By the early 1950s, the Mainland and Taiwan, despite their diametrically opposite ideological outlooks, were surprisingly similar in terms of social structure and government policies. Like the communists on the Mainland, the nationalists in Taiwan carried out a thorough - though peaceful-land reform. Both governments established SOEs and extracted surpluses from agriculture in the hope of speeding up the industrialisation process. Indeed, the Taiwanese industrial sector extracted more surpluses from agriculture through price cuts than its Mainland counterpart in the 1950s. Between 1951 and 1960, 27 per cent of Taiwan's capital formation came from 
net capital outflow from agriculture in the form of price cuts. ${ }^{6}$ In the same period, however, the Mainland government was in fact paying higher prices for agricultural products than the market (Wu 2001). The divergence occurred in 1956 when the Mainland began to eliminate family farming in the countryside and private businesses in the city. Between 1956 and 1978, the Mainland took a long detour and the reform has largely been a process of moving the country back on the track set for it in the early 1950s.

Political scientist Meredith Woo-Cumings (1997) has observed the linkage between an equal social structure and the government's neutrality with regard to society in East Asia. On the one hand, Taiwan and Korea were designated as suppliers of agricultural goods in Imperial Japan's version of the Great East Asian Commonwealth, so urban industrialists were suppressed in those two places. On the other hand, the Japanese colonists intentionally restricted the growth of the landed class in both places because they feared that this class would become a source of nationalist sentiments and organised upheavals against its colonial rule. Woo-Cumings (1997:331) writes: 'This discontinuity had a powerful leveling effect, equalizing incomes more than in most developing countries and providing a fertile ground for instituting effective interventionist states, which were given a relatively free hand to forge a developmental coalition as they saw fit.'

\section{The future?}

The selective and efficiency-biased policies have, predictably, led to large income inequality in China. The overall Gini coefficient has reached 0.47 (Cheng 2007) and the gap between the richest and the poorest is increasing even faster. Worse than that, governments at various levels constantly infringe on people's political and economic rights in order to create short-term growth. Arbitrary land acquisitions are but one example. Political and economic inequality has led to widespread protests in the country. In a sense, China is indeed a 'fragile giant', as Susan Shirk (2007) calls it. Yet it seems that there are no clear signs of an imminent collapse. How has the CCP managed to minimise the downsides of its selective policies?

First, the government has delivered continuous economic growth and rising living standards to the population. One of the curious things about China is that the government has constantly received an approval rating of 70 per cent or above, no matter who does the survey. ${ }^{7}$ The reason behind this is that the

6 Calculated from estimates provided by Lee (1971:Table 3, p. 29).

7 For a recent independent survey, see ISSS (2009). 
majority of the Chinese population is quickly moving into the rank of the middle class, who benefit from the current regime. In China, the middle class - at least for now - is not a force for change, but rather a force for stability.

Second, the government has carried out specific programs that quickly and effectively address early signs of discontent in the population. This includes an urban subsistence maintenance program that covers 20 million low-income people, re-employment centres that provide unemployment benefits to laid-off workers and train them for re-employment, several programs (for example, the Western Region Development Program) that aim to lower regional disparities and the recent New Countryside Movement to improve infrastructure, health care and education in rural areas.

Third, the government has gradually begun to give more respect to people's expressed interests in response to large-scale protests. The policy change for migrant workers is but one example. Other examples include the passage of the Property Law, increased levels of compensation for those who lose land and buildings to urban and industrial expansion and limited transparency of government budgets.

Lastly, the selective policies themselves have certain self-correcting effects. Being disinterested, the government does not consistently favour specific groups, so in the long run favours are likely to be distributed roughly equally - at least in areas where institutional impediments are relatively weak. For example, the Gini coefficients within the city and within the countryside alone are not high — both at the range of 0.35 to 0.37 - which approximates the levels found in South Korea and Japan (Cheng 2007).

Those measures are, however, only 'pain relievers' - being too weak to break down the institutional barriers and correct market imperfections that might stimulate new and threatening social groups. While the private business community is realising the importance of cultivating the government for larger profits, it is the government itself, its cronies and government-controlled SOEs that are quickly forming strong and exclusive interest groups. This is the result of the CCP's two political strategies to improve its chances of continuous control of the society. One is its transformation to become an all-people's party and the other is its intention to follow the Singaporean model to merge itself with the government. The first strategy is aimed at broadening its power base, while the second is aimed at controlling the country in the 'shell' of the government. China is, however, too big for the CCP to follow the Singaporean model even if it is a model worth pursuing. Being an all-people party means that the CCP gives up its political conviction to represent the working class. Since there are no other major political organisations in the country, society is left alone to develop along the trajectory dictated by a 'natural' process - that 
is, a process unmitigated by political contests - in which powerful groups are likely to accumulate more power and weak groups are likely to lose more power. Merging with the government could solve the CCP's organisational issues, but it will deprive it of the autonomy that it used to enjoy when it came to the fight between social groups because it is so involved in the economy that it can no longer avoid taking a biased stance. As a result, there is no assurance that the government can remain disinterested and growth will continue.

The situation has, however, worsened in recent years. In the past several years, government involvement in the economy has increased-most notably with the current CNY4 trillion (US\$586 billion) stimulus plan. Government investment helped China reach a GDP growth rate of nearly 9 per cent in 2009, which many applaud, but in the long run, it could suffocate the Chinese economy by reducing efficiency and crowding out more vibrant private investment.

The economy currently depends heavily on external demand, creating friction among major trading partners. Savings account for 52 per cent of GDP and consumption has dropped to a historic low. Whereas governments in most advanced democracies spend less than 8 per cent of government revenue on capital investment, this figure is close to 50 per cent in China. And household income as a share of national income is declining, making the average citizen feel poorer while the economy expands. As the Chinese people demand more than economic gains as their income increases, it will become increasingly difficult for the CCP to contain or discourage social discontent by administering the medicine of economic growth alone. ${ }^{8}$

More importantly, the government in its current form is cumbersome when dealing with multiple goals that are increasingly being demanded by society. Concerted efforts to promote GDP growth will still result in infringements to people's economic and political rights, which in turn will arouse periodic resistance. Despite its absolute power and recent track record of delivering economic growth, the CCP has still periodically faced resistance from Chinese citizens and, as already noted above, numerous protests have proved that the Chinese people are quite willing to stage organised resistance when their needs are not being met by the State. International monitoring of China's domestic affairs has also played an important role; now that it has emerged as a major global power, China is suddenly concerned about its legitimacy on the international stage.

All this suggests that some form of explicit political transition will be necessary to counterbalance the formation of strong and exclusive interest groups, to allow the government to deal with multiple goals and even to enhance the

8 The figures quoted in this paragraph are from the NBS website: <www.stats.gov.cn $>$ 
CCP's own rule. While the prospect of a multiparty and competitive democracy is not so clear at the moment, societal pressures are forcing the CCP to open up the political process. There is a silent yet steadily growing civil society movement pressing the government to show greater respect for people's rights. The Internet is serving as a platform not just for information sharing among concerned citizens, but for them to coordinate public protests against perceived government wrongdoing. The most powerful resistance, however, is likely to come from marginalised people and the 'rights movements' representing them. They are the people who suffer the most from arbitrary government infringements and benefit the least from the status quo.

The CCP must soon realise that there is no alternative to fuller democratisation if it wishes to maintain both high economic growth and enhanced social stability. The emergence of strong and privileged groups will block equal distribution of the benefits of economic growth in society, which will then render futile the CCP's strategy of trading economic growth for people's consent to its absolute rule. The CCP needs to act now to enable 'ordinary people' to challenge privileged groups on an open and institutionalised platform. Indeed, this will also ease the CCP's own task of controlling the bureaucracy because the democratic institutions will be able to do this instead. Although interest group politics is widespread and often damaging in democratic societies, an open and inclusive political process has been proven to be the most effective way to reach a balance between different groups. Indeed, this is precisely the mandate of a disinterested government - to balance the demands of different social groups. A democratic government can still be disinterested if the right institutions are in place to keep the most powerful groups at bay.

\section{References}

Cheng, Y. 2007, 'The Gini coefficient and its rural-urban decomposition since the reform', Chinese Social Sciences [in Chinese], no. 4, pp. 24-36.

Dickson, B. 2010, Who consents to the 'Beijing Consensus'? Crony communism in China, Manuscript, The Elliott School of International Affairs, George Washington University, Washington, DC.

Garnaut, R., Ligang S., Stoyan T. and Yang Y. 2005, China's Ownership Transformation: Process, Outcomes, Prospects, International Finance Corporation, Washington, DC.

Institute of Social Science Survey (ISSS) 2009, The China Report, Peking University Press, Beijing. 
Lee, T. 1971, Intersectoral Capital Flows in the Economic Development of Taiwan, 1895-1960, Cornell University Press, Ithaca, NY.

Lin, J. and Yao, Y. 2001, 'Chinese rural industrialization in the context of the East Asian miracle', in Joseph Stiglitz and Shahid Yusuf (eds), Rethinking the East Asian Miracle, The World Bank and Oxford University Press, Washington, DC.

Ramo, J. 2004, The Beijing Consensus: Notes on the new physics of Chinese power, Foreign Policy Centre, London, <www.fpc.org.uk>

Rind, M. 2002, 'The concept of disinterestedness in eighteenth-century British aesthetics', Journal of the History of Philosophy, vol. 40, no. 1, pp. 65-76.

Shirk, S. 2007, China, Fragile Superpower, Oxford University Press, New York.

The Growth Commission 2008, The Growth Report: Strategies for sustained growth and inclusive development, The World Bank, Washington, DC.

Williamson, J. 1990, 'What Washington means by policy reform?', in John Williamson (ed.), Latin American Adjustment: How much has happened?, Institute for International Economics, Washington, DC.

Woo-Cumings, M. 1997, 'The political economy of growth in East Asia: a perspective on the state, market, and ideology', in Masahiko Aoki, HyungKi Kim and Masahiro Okuno-Fujiwara (eds), The Role of Government in East Asian Economic Development: Comparative institutional analysis, Clarendon Press, Oxford.

Wu, L. 2001, 'A study of the size of the "price scissors" in China in 1949-1978', Researches in Chinese Economic History [in Chinese], no. 4, pp. 3-12.

\section{Acknowledgments}

I thank Daniel Bromley, Edward Friedman, Ashok Gurung, Yukon Huang, Sanjay Ruparelia and Jianying Zha for their helpful comments and suggestions. 


\section{How will China's central-local governmental relationships evolve? An analytical framework and its implications

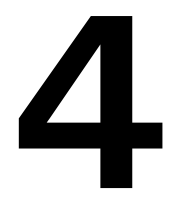

Yongsheng Zhang

\section{Introduction}

The way in which intergovernmental relationships evolve in China is crucial for China's future development. There has been a worldwide trend towards decentralisation of power and responsibilities in large countries since the 1980s. Nonetheless, decentralisation does not necessarily mean a weakened capability of the central (or federal) government to control the behaviour and actions of local governments.

From a fiscal perspective, decentralisation has three related dimensions: responsibility for expenditure; responsibility for raising revenue; and intergovernmental fiscal transfer payments. For each level of government, the relationship between these three items is: expenditure = own-source revenue + intergovernmental fiscal transfer payments.

If decentralisation means an increase in own-source revenue (or taxation autonomy) of lower-level governments then it would result in a reduction of transfer payments. In this situation, the local government's fiscal capability is improved and the central government's is weakened. If decentralisation instead means the devolution of expenditure responsibility then it could be achieved either through an increase in fiscal transfer payments or an increase in the taxation autonomy of lower-level governments. In the former case, the central government's controlling capability is enhanced with decentralisation, while in the latter it is the local government's controlling capability that is enhanced. Therefore, different forms of decentralisation have very different implications for each level of government in terms of controlling capability.

The key principle of decentralisation is broadly accepted: jurisdiction over the delivery of public services should be allocated to the level of government closest to the citizen, unless such delivery can be taken on more effectively by a government that is further away. Accordingly, local governments should have more fiscal autonomy. Nonetheless, it has been a fact that, in most 
countries, higher levels of government control most of the fiscal resources. The worldwide trend towards decentralisation in recent decades is reflected mainly in expenditure, while on the side of revenue it shows a contrary trend of centralisation. The gap between the expenditure and own-source revenue of local governments is filled by fiscal transfer payments. This brings 'vertical fiscal imbalance', in which lower levels of government become financially reliant on transfer payments from higher levels of government. Thus, through increasing transfer payments, the controlling capability of central governments over local governments has been further enhanced rather than weakened.

Why do most countries - including Western countries (either unitary or federal)-purport to value democracy and decentralised markets, yet adopt highly centralised fiscal arrangements? Most of the existing explanations focus on inter-regional externalities relating to infrastructure, spill-overs or regional fiscal equalisation. The solution to these problems is seen to lie in higher levels of government having sufficient fiscal capability (for example, Oates 1972; Seabright 1996). It is not so obvious, however, that central governments need to control most of their country's fiscal revenue in order to solve these problems. For example, trans-regional infrastructure projects could be provided through negotiation between the relevant stakeholders (à la Coase), rather than relying on the central government. Indeed, trans-regional infrastructure projects that are provided by the central government create an additional externality, since in this situation other regions not benefiting from the project bear a part of the tax burden as well. Second, in industrialised countries in which spatial economic imbalances are small, the central governments also control most of the nation's fiscal revenues. As for fiscal equalisation, in industrialised countries in which spatial imbalances are small, the costs of transfer payments often exceed the benefits, particularly when transaction costs are taken into account. Yet even these countries tend to have highly centralised fiscal arrangements. There must be a fundamental explanation for this.

And there is. The fiscal relationship is only one dimension of intergovernmental relationships, and the above explanations fail to take into account the other dimensions, such as the personnel dimension. The objective of this chapter is to provide a new analytical framework for intergovernmental relationships and to investigate its implications for the future evolution of China's central-local governmental relationships. The next section provides a brief review of the relevant literature on intergovernmental relationships. After that, an analytical framework on intergovernmental relationships is presented and some supportive evidence is provided. Subsequent sections consider the current status of China's intergovernmental relationships and how they might evolve in the future. The last section concludes the chapter and suggests how the framework can be applied to a large research agenda in the future. 


\section{Intergovernmental relationships: a brief literature review}

There are three lines of research on intergovernmental relationships from the perspective of vertical fiscal imbalances. First, according to classic fiscal theories (represented by Musgrave 1959 and Oates 1972, among others), a strong central government is necessary to achieve three nationwide goals: efficient resource allocation, equity and economic stability. These theories cannot, however, provide an accurate answer to the question of how much fiscal revenue the central government needs to control, either in absolute terms or as a proportion of all revenue. It seems, according to these theories, that either unbalanced or balanced vertical fiscal relations could occur, since the centre's expenditure responsibility for the three goals might be achieved with a lower central fiscal capability, which makes a balanced vertical fiscal relation possible.

The second research line is related to the optimisation of a nation's aggregate tax revenue. It is argued that vertical fiscal imbalances result from optimising a nation's tax revenue for a given economic and taxation structure, stemming from a range of assumptions about incentive mechanisms, fiscal autonomy, accountability, information, tax competition, tax costs and spill-overs. ${ }^{1}$ The implicit assumption is that vertical fiscal imbalance is pre-designed by a central planner to optimise the nation's tax revenue, so that the move towards a more balanced fiscal structure could cause a fall in aggregate tax revenue, encourage inter-regional transfers of tax resources or increase the taxation costs. There are, however, contradictory findings within this line of research, with some authors emphasising the advantages of decentralisation and others emphasising the advantages of centralisation.

The third line comes from the perspective of constitutional economics. There are three branches in this line. The first emphasises the advantages of decentralisation as a mechanism to control inefficient central governments, in which local governments are like clubs established by the local population to solve common problems (for example, Buchanan 1965; Brennan and Buchanan 1980; North 1987). Beneficial taxation - in which tax is paid according to the benefits received from the system - assures local accountability and there is no case for the central government's financial controls. This branch advocates fiscal autonomy of the local governments, while remaining alert to the potential for their opportunistic behaviour. Implicitly, this means that central governments will not be encouraged to control most fiscal resources and then to refund local governments through transfer payments. The second branch emphasises the

1 See, for instance, Breton (1996); King (1984); Scott (1952); Hicks (1984); Courant et al. (1979); Boadway and Tremblay (2005). 
advantages of federal governments, as represented by Hamilton et al. (1787). In Hamilton's time, the biggest challenge for the American federalists was to establish a federal government from the confederation. They did not propose that the federal government control most of the nation's fiscal revenue; rather they repeatedly vowed that the power of the federal government should be strictly limited. Their basic position, however, was to emphasise the advantages of a strong federal government. We treat their position, then, as being procentralisation.

De Figureiredo and Weingast (2005) and Weingast (2005) represent the third branch. They emphasise the importance of the power balance between federal and state governments for a self-enforcing federalism. They begin their studies with two fundamental dilemmas of federalism: too strong a centre risks overwhelming a federation by acting opportunistically and extracting too many rents; too weak a centre risks a federation's collapse due to free-riding and insufficient provision of public goods. The twin dilemmas make stable federalism problematic - in part because they imply a trade-off in the structure of a federation. Institutions designed to address one of the dilemmas exacerbate the other. To be stable, federalism requires a delicate balance of central government powers combined with mechanisms for limiting the centre's opportunism. Crisis shocks play a key role in achieving the balance of power (Weingast 2005). The perspective emphasising the balance of powers is consistent with the concept of equilibrium in economics.

\section{A new analytical framework and decentralisation}

Based on the theory of self-enforcing federalism (de Figureiredo and Weingast 2005), Zhang $(2005,2008,2009)$ further develops an analytical framework to coordinate the three branches in constitutional economics. He further divides governmental controlling capability into two major dimensions: the personnel dimension (or democratic dimension) and the fiscal dimension. Whether a federation/nation can be sustainable is conditioned on the game between the national and sub-national governments. For instance, in a democratic nation with elections, the federal/central government has no control over the elected officials of the states. To achieve sustainable federalism, an institutional arrangement enhancing the control of the central/federal government over the sub-national governments is needed. Fiscal transfer payments are then used as a hostage by the federal/central government to influence the states/provinces. Vertical fiscal imbalance and transfer payments then work as hostage mechanisms, with lowerlevel governments heavily financially reliant on the higher level. This provides 
an explanation for why, in most countries, the central government controls most of the nation's fiscal resources and for why higher levels of government control most fiscal resources in their jurisdictions.

Since both personnel and fiscal dimensions could be either bottom-up or top-down, the combinations of these two dimensions consist of four basic structures for vertical intergovernmental relationships (Table 4.1). A vertical intergovernmental relationship will not be sustainable if it is unbalanced. Crisis shocks then play a key role in changing the structure making the nation sustainable (Weingast 2005). Vertical balance can be achieved through a twoway arrangement in personnel and fiscal dimensions. Yet, vertical balance is not sufficient for a nation to achieve good economic performance. Horizontal balance between the government and the market must also be established, which could be realised by checks and balances of a government's power through constitutional rule, as pointed out by Buchanan (1965), Brennan and Buchanan (1980), North (1987) and North and Weingast (1989).

Table 4.1 Different structures of intergovernmental relationships

\begin{tabular}{|l|l|l|l|l|l|}
\hline Structures & $\begin{array}{l}\text { Personnel } \\
\text { dimension }\end{array}$ & $\begin{array}{l}\text { Fiscal } \\
\text { dimension }\end{array}$ & Examples & Result \\
\hline Structure 1 & $\begin{array}{l}\text { I. With good rule } \\
\text { of law }\end{array}$ & $\uparrow \uparrow$ & $\downarrow \downarrow$ & $\begin{array}{l}\text { Western } \\
\text { countries }\end{array}$ & $\begin{array}{l}\text { Sustainable, } \\
\text { efficient }\end{array}$ \\
\cline { 2 - 6 } & $\begin{array}{l}\text { Il. Without good } \\
\text { rule of law }\end{array}$ & $\uparrow \uparrow$ & $\downarrow \downarrow$ & $\begin{array}{l}\text { Some Latin } \\
\text { American } \\
\text { countries }\end{array}$ & $\begin{array}{l}\text { Sustainable } \\
\text { but low } \\
\text { efficiency }\end{array}$ \\
\hline Structure 2 & $\uparrow \uparrow$ & $\uparrow \uparrow$ & $\begin{array}{l}\text { European Union, } \\
\text { confederation, } \\
\text { United Nations }\end{array}$ & $\begin{array}{l}\text { Unstable, } \\
\text { inefficient }\end{array}$ \\
\hline Structure 3 & $\downarrow \downarrow$ & $\uparrow \uparrow$ & $\begin{array}{l}\text { Former Soviet } \\
\text { Union-style } \\
\text { countries }\end{array}$ & $\begin{array}{l}\text { Central } \\
\text { planning } \\
\text { regime }\end{array}$ \\
\hline Structure 4 & $\downarrow \downarrow$ & $\uparrow \uparrow$ & $\begin{array}{l}\text { China before } \\
\text { tax-sharing } \\
\text { system reform, } \\
\text { Hong Kong } \\
\text { before 1997 }\end{array}$ & $\begin{array}{l}\text { More } \\
\text { efficient } \\
\text { than } \\
\text { Structure 3 }\end{array}$ \\
\hline
\end{tabular}

Notes: The letter $\downarrow=$ 'top down'; $\uparrow \uparrow=$ 'bottom up'. For instance, if the personnel dimension is $\uparrow \uparrow$, it means local officials are not appointed by higher levels of government. If the fiscal dimension is $\downarrow \downarrow$, it means higher levels of government control most fiscal resources and can put influence on lower-level governments through transfer payments, and vice versa.

Source: Author's own summary.

In Table 4.1, Structure 1 represents the combination of bottom-up personnel relationships and top-down fiscal relationships. In the personnel dimension, the local government has autonomy (although this does not necessarily mean 'election'; autonomy can also happen in a feudal or authoritarian regime), while 
the higher level of government controls most fiscal resources and the lower-level governments have to rely financially on transfer payments. Most industrialisedmarket countries can be classified as Structure 1. This structure is self-enforcing. It can be further classified into two substructures: Structure 1-(I) with, and Structure 1-(II) without, good rule of law.

Structure 2 is one with a weak federal/central government and is neither stable nor efficient - like the American confederation or the early stage of federation in the United States and Australia.

Structure 3 is one with a strong federal/central government, such as the former Soviet Union countries. The central government is too powerful, controlling fiscal revenue and official appointments to lower-level governments. As de Figureiredo and Weingast (2005:127) indicate, 'too strong a centre risks overwhelming a federation by acting opportunistically and extracting too many rents'. This structure is neither stable nor sustainable in the long run.

Structure 4 is a relatively stable structure - such as fiscal federalism in China before 1994 or the UK-Hong Kong relationship before 1997. To some extent, this structure has established a vertical balance on intergovernmental relationships. Nonetheless, since the centre controls official appointments to local governments, local governments do not have real bargaining power against higher levels of government. The central government might easily change the fiscal arrangement. If the higher-level government was a democratic regime, or the higher-level government could not change its fiscal relationship, this structure could be reasonably sustainable.

Different structures have different effects on preventing governmental opportunistic behaviour. Correspondingly, there are two types of governmental opportunistic behaviour in the framework: vertical and horizontal. Vertical governmental opportunistic behaviour refers to the opportunistic behaviour between different levels of government. A balance of intergovernmental relationships is required to prevent this. Horizontal governmental opportunistic behaviour refers to opportunistic behaviour in the market. The horizontal checks and balances of government power are to prevent this type of governmental opportunistic behaviour.

According to Smith (1776), the division of labour is the springboard for economic growth. Yang (2001) developed an 'inframarginal economic framework' in which the evolution of the division of labour was driven by increased transaction efficiency, especially related to institutions. According to North (1987), economic performance is conditioned on the level of endogenous transaction costs resulting from governmental opportunistic behaviour. His idea can be further extended to two types of vertical and horizontal governmental opportunistic 
behaviour in our analytical framework. A sustainable and stable structure, and therefore also a pro-economic development structure, must be a structure that can minimise the two types of governmental opportunistic behaviour. Among the four structures, Structure 1 is the most self-enforcing structure with the least endogenous transaction costs. Structures 2 and 3 are not self-enforcing in the long run. Structure 4 is not as stable as Structure 1.

The framework developed in this chapter can be applied to explain the worldwide decentralisation trend in recent decades. There are good examples of decentralisation, but also bad ones (Martinez-Vazquez and McNab 2003; Fisman and Gatti 2002). Decentralisation has resulted in macroeconomic volatility in some countries but not in others. According to Stein (1999), decentralisation did not increase the fiscal deficits of local governments. According to Fornasari et al. (2000) and de Melo (2000), however, the expansion of local governmental expenditure and deficits after decentralisation results in the expansion of central governmental expenditures and deficits. According to Fisman and Gatti (2000), there is a high correlation between decentralisation and corruption. Simply devolving fiscal power from central governments to regional elites without institutional reforms would encourage corruption. Nonetheless, Treisman (2000) shows no correlation between decentralisation and corruption. Faguet (2004) shows that decentralisation has not increased corruption, but instead makes local governments more responsible.

Why are the apparent effects of decentralisation so varied and contradictory? Why has decentralisation had positive effects in some countries, but not in others? According to our analytical framework, the effectiveness of decentralisation in a nation depends on whether decentralisation makes the intergovernmental structure more sustainable and whether it reduces the endogenous transaction costs resulting from the two types of governmental opportunistic behaviours. Specifically, decentralisation will bring more effectiveness under the following conditions.

First, decentralisation should not change the vertical intergovernmental balance. Within Structure 1(I), decentralisation would be effective. Nonetheless, if decentralisation goes too far and the local government has too much taxation autonomy, Structure 1(I) will jump to Structure 2. Consequently, decentralisation will cause more opportunistic behaviour from local governments and affect the stability and economic performance of the nation. Hence, no matter how decentralised it is, remaining within Structure $1(\mathrm{I})$ is the bottom line of decentralisation for Western countries. Accordingly, the local government's expenditure should be expanded mainly through fiscal transfer payments, rather than through devolving more tax autonomy. Second, government power must 
be limited and checked and balanced in the process of decentralisation, so that the devolved powers do not increase the horizontal governmental opportunistic behaviour of the local governments.

Thiessen (2003) provides evidence of how the effects of decentralisation change with the extent and type of decentralisation. His studies of the Organisation for Economic Cooperation and Development (OECD) show that fiscal decentralisation from a highly centralised starting point results in improved economic performance. Further decentralisation beyond a certain level, however, results in negative effects.

This analytical framework can be used to understand a wide range of decentralisation experiences in time and space, with this section briefly describing just two: the United States and Australia.

Since its independence in 1776, the United States, in its federal-state government relationships, has experienced different stages: confederation without national government $\rightrightarrows$ federation with weak federal government $\rightrightarrows$ strong federal government after the Great Depression and World War II $\rightrightarrows$ decentralisation. During the period 1776-87, there was no federal government in the United States. Before the Great Depression, the federal government was very weak. This was a typical Structure 2 and was not sustainable. From the Great Depression through to the 1980s, the fiscal capability of the federal government has been significantly enhanced and the vertical intergovernmental relationship jumped from Structure 2 to Structure 1. Since the 1980s, the decentralisation of expenditure has become a worldwide trend, including in the United States. Nonetheless, fiscal decentralisation happened mainly for expenditure, rather than with regard to the fiscal autonomy of local governments. US intergovernmental relations have remained in Structure 1 during the process of decentralisation, and the federal government always controls most of the nation's fiscal resources and imposes influence through fiscal transfer payments (Wallin 2001; Fox 2001). Throughout the evolution of intergovernmental relationships in the United States, crises and shocks have been crucial driving forces (Weingast 2005).

The evolution of federal-state relations in Australia has been similar to that in the United States: the capability of the federal government has grown stepby-step and the evolution of Australian federal-state relationships is a process moving from Structure 2 to Structure 1. As the six colonies formed a federation on 1 January 1901, the federal government merely had some enumerated powers on international affairs such as defence, trade and immigration, while its fiscal capability was weak. The states provided crucial public services such as education, health and law and order, and reserved all residual rights (Watts 1999). In this case, most people expected that the Australian Constitution provided a guarantee to make the states financially independent of the federal 
government. Nonetheless, it turned out differently. The early Australian federal-state relationship of Structure 2 was not a self-enforcing federation. It faced the fate of either evolving to Structure 1 or dissolving. The driving force for the evolution was a series of crisis shocks, including two world wars, the Great Depression and a number of domestic crises. In Structure 1, the federalstate relationship became stable and sustainable and the federation became selfenforcing (see Dollery 2002).

\section{China's vertical intergovernmental relations: past and current status}

\section{Central-provincial government relations}

In China, in the planned economy before 1978, the central-provincial relationship fell into Structure 3. The central government was like a command centre. It not only controlled the appointment of major provincial officials, it controlled the fiscal resources of the provinces. The fiscal system was called a 'unified collection and allocation of funds by the state' (Tongshoutongzhi). The central government controlled the collection and allocation of fiscal resources.

Between 1978 and 1994, China adopted a fiscal responsibility system whereby local authorities took full responsibility for their revenues and expenditures, which was known as 'fenzaochifan' - that is 'each province eats the rice in its own bowl' — or fiscal federalism (Qian and Weingast 1997). This changed China's central-provincial relationship from Structure 3 to Structure 4. In Structure 4 , the central government controlled the appointment of major officials in the provinces, but no longer controlled each province's fiscal revenue. According to Qian and Roland (1998), Qian and Weingast (1997) and Shirk (1993), the introduction of fiscal federalism provided strong incentives for the provinces to develop their economies. This resulted in most fiscal resources in China being controlled by the provinces. The fiscal capability of the Chinese central government was insufficient. For instance, in 1993, the share of central government revenue accounted for only 22 per cent of the nation's total tax revenue (Table 4.2). 
China: The Next Twenty Years of Reform and Development

Table 4.2 Share of central and local governments in government revenue and expenditure (per cent)

\begin{tabular}{l|c|c|c|c}
\hline \multirow{2}{*}{ Year } & \multicolumn{2}{|c|}{ Revenue } & \multicolumn{2}{|c}{ Expenditure } \\
\cline { 2 - 5 } & Central & Local & Central & Local \\
\hline 1978 & 15.5 & 84.5 & 47.4 & 52.6 \\
1980 & 24.5 & 75.5 & 54.3 & 45.7 \\
1985 & 38.4 & 61.6 & 39.7 & 60.3 \\
1990 & 33.8 & 66.2 & 32.6 & 67.4 \\
1991 & 29.8 & 70.2 & 32.2 & 67.8 \\
1992 & 28.1 & 71.9 & 31.3 & 68.7 \\
1993 & 22.0 & 78.0 & 28.3 & 71.7 \\
1994 & 55.7 & 44.3 & 30.3 & 69.7 \\
1995 & 52.2 & 47.8 & 29.2 & 70.8 \\
1996 & 49.4 & 50.6 & 27.1 & 72.9 \\
1997 & 48.9 & 51.1 & 27.4 & 72.6 \\
1998 & 49.5 & 50.5 & 28.9 & 71.1 \\
1999 & 51.1 & 48.9 & 31.5 & 68.5 \\
2000 & 52.2 & 47.8 & 34.7 & 65.3 \\
2001 & 52.4 & 47.6 & 30.5 & 69.5 \\
2002 & 55.0 & 45.0 & 30.7 & 69.3 \\
2003 & 54.6 & 45.4 & 30.1 & 69.9 \\
2004 & 54.9 & 45.1 & 27.7 & 72.3 \\
2005 & 52.3 & 47.7 & 25.9 & 74.1 \\
2006 & 52.8 & 47.2 & 24.7 & 75.3 \\
2007 & 54.1 & 45.9 & 23.0 & 77.0 \\
2008 & 53.3 & 46.7 & 21.3 & 78.7 \\
\hline
\end{tabular}

Source: National Bureau of Statistics (NBS) 2009, China Statistical Yearbook 2009, China Statistics Press, Beijing, p. 263.

Since the central government lacked fiscal capability, towards the end of the 1980s and in the early 1990s, it 'borrowed' money from the provinces twice and was eventually unable to repay that money (Sun 2004). Before the introduction of the Tax Sharing System (TSS) reform in 1994, there were some specific topdown fiscal grants from the central government to the provinces, but there were also bottom-up 'transfer payments' from the provinces to the centre. In contrast with Western national governments, the Chinese central government was somehow financially reliant on the provinces to support its expenditure before 1994.

Structure 4 provided a relatively balanced vertical relationship between the centre and provinces, in which the provinces had more autonomy and stronger 
incentives to promote their own economies. Nonetheless, this was not a normal intergovernmental relationship within a nation and the central government had both the incentive and the ability to change it.

Third, having experienced fiscal incapability for more than a decade, the central government eventually became determined to change the bottom-up fiscal arrangement and establish a top-down fiscal arrangement through the TSS reform in 1994. According to the TSS, the ratio of the major tax sources between the central and provincial governments is 75:25. This has resulted in the rapid growth of the central government's revenue (Table 4.2). The relationship between the central government and the provinces jumped from Structure 4 to Structure 3. In Structure 3, the central government not only controls the appointment of major provincial officials, it controls a large share of provincial fiscal revenue through transfer payments. The provinces have to rely heavily on transfer payments from the central government.

The rapid increase of the central government's revenue came mainly from incremental tax revenue, not from redistribution of the existing tax revenue. There was an agreement between the central and provincial governments that the TSS reform would not change the status of fiscal revenue of each province. Since the Chinese economy grows very rapidly and 75 per cent of the valueadded tax belongs to the central government, the central government's fiscal revenue has, however, grown much faster than that of the provinces. Enormous transfer payments have therefore become a new, powerful tool for the central government to influence the provinces.

In addition to tax revenue, the central government's control over the economy comes from the centrally controlled, large state-owned enterprises (SOEs), most of which are monopolistic. According to a release from China's StateOwned Assets Supervision and Administration Commission (SASAC), in 2009, the assets value of central government-controlled SOEs was RMB14.6 trillion (US\$2.14 trillion) - accounting for roughly 40 per cent of China's gross domestic product (GDP) in 2009 — while their profits were RMB980 billion. This further strengthens the capability of the central government.

Since the TSS reform, China's central-provincial government fiscal relationship has converged with that of Western countries. The central government controls most of the nation's fiscal resources and, financially, the provinces rely heavily on transfer payments. The difference between Structure 3 in China and Structure 1 in Western countries is in the personnel dimension. The dual top-down arrangements in personnel and fiscal dimensions have produced a super central government in China. Hence, without changing the status of the top-down personnel dimension, simply changing China's fiscal federalism and 
borrowing the top-down fiscal arrangement from Western countries to jump to Structure 3 from Structure 4 also risks the prevalence of vertical governmental opportunistic behaviour.

\section{Provincial-local government relations}

The TSS reform in 1994 was implemented only at the central-provincial level, not at the provincial-local level. Within a province, all local governments' revenues rely heavily on transfer payments from the provincial government. According to our investigation in 2004, transfer payments from the province accounted for 71.1 per cent of fiscal expenditure in a county in Sichuan. In the personnel dimension, higher-level governments nominate major county officials. This is a typical Structure 3 with strong higher-level government and weak lower-level government. This structure induces both types of governmental opportunistic behaviour, which reinforce each other.

The first is vertical governmental opportunistic behaviour of the provincial governments over the local governments. Due to the dual top-down arrangements in the two dimensions, local governments are too weak to play games with the province. The second is horizontal governmental opportunistic behaviour. Since the horizontal checks-and-balances mechanism for the government has not been well established in China, to solve their fiscal incapability problems resulting from the opportunistic behaviour of the higher-level governments, local governments have a strong incentive to act opportunistically and extract rents from the market. This in turn affects economic performance.

To solve the fiscal incapability problem of local governments in China, some have argued that local governments should have higher tax autonomy to match their expenditure. Nonetheless, as our analytical framework suggests, the universal arrangement is that lower-level governments rely financially on transfer payments from higher-level governments. The main solution is therefore not to devolve more tax autonomy, but rather to reform the top-down personnel arrangement to improve the bargaining power of lower-level governments and to institutionalise the transfer payment process to reduce opportunistic behaviour from higher-level governments. This change can be achieved through the development of grassroots democracy. If local officials could be elected rather than appointed by higher-level governments, and transfer payments could be institutionalised, an effective vertical balance between the provincial and local governments could be established. 


\section{The future evolution of China's intergovernmental relations}

China's intergovernmental relationships are undergoing rapid change. There are many positive changes that are reshaping and re-establishing the relationships. For instance, the Chinese government has officially endorsed 'socialist democratic politics'. Grassroots elections and internal democracy in the ruling Chinese Communist Party (CCP) are being widely practised and developed, and the rule of law and civil society are being established. The evolution of China's vertical intergovernmental relationships will have a profound influence on China's longterm development. How will China's vertical intergovernmental relationship evolve in the future? The framework developed in this chapter sees four major possible scenarios.

\section{Scenario 1: Structure 3-top-down fiscal and personnel dimensions}

This scenario means a continuation of the current intergovernmental relationship in the future. In this structure, the central government not only controls most of the nation's fiscal resources, it controls the appointment of the major officials of the provinces. Within the province, the provincial government also controls the appointment of the major local officials and most of the province's fiscal revenue.

This structure looks similar to that in the former planned economy. The substantive differences are the introduction of rule by law (as seen in the TSS) and the market economy. In Structure 3, the central government has very strong fiscal capability and authority to effectively realise the 'State's will' and to push forward with national reforms and development in areas such as social security, education and trans-regional infrastructure.

Nonetheless, as discussed previously, Structure 3 is not sustainable in the long run and also induces vertical and horizontal governmental opportunistic behaviour. The social cost and pressure of remaining in this structure would also be quite high. At this stage, many current economic and social problems in China - such as massive conflicts, petitions, farmer questions, local governments' huge debts and risks, distorted markets and corruption - are the results of the two types of governmental opportunistic behaviour. Without development of grassroots democracy and improving the checks-and-balances mechanism for government through constitutional rule, these problems might develop into crises. As Weingast (2005) points out, crisis shocks are the driving force for evolution towards a self-enforcing federalism or nation. To avoid possible economic and social crises and to build up the so-called 'harmonious society' in China, a sustainable intergovernmental relationship needs to be established. 


\section{Scenario 2: Structure 1(I)-a good market economy}

As far as we can see from the practices around the world, this structure is probably the most stable and sustainable one. It not only has a stable vertical structure, it has an effective horizontal checks-and-balances mechanism. China already has some of the conditions in place required for evolution to this structure.

In the two vertical dimensions, China's fiscal arrangement at the centralprovincial level is already very similar to that in Western countries. The key for China to shift to Structure l(I) is to reform its arrangement in the personnel dimension, or to develop its democracy. Although grassroots elections are developing steadily in China, they are still at a relatively early stage. To what level, and when, direct elections can develop in the future in China is still unclear.

At the horizontal level, China needs to establish effective checks-and-balances mechanisms at various levels of government through the rule of law, so that the market can function well. The expansion of civil society and liberty with rapid economic growth will allow the rule of law and democracy eventually to be well established in China.

\section{Scenario 3: Structure 1(II) - a bad market economy}

This structure looks sustainable in terms of vertical intergovernmental relationships, but is not an effective one for economic growth. This is an example of a bad market economy, in which the rule of law is not well established and the law institutionalises the privileges of interests groups, even though it has democracy. This would result in the prevalence of horizontal governmental opportunistic behaviour (Liu and Yang, 2001).

At present, vested interests - instead of ideology - have become the biggest impediment to China deepening its economic and political reforms. Corruption and social injustice are serious. The law has already institutionalised some privileges of interest groups and the market has some serious distortions. If this situation does not change, China is likely to evolve to this structure in the future. If constitutional rule cannot be established and liberty cannot be guaranteed, democracy alone will not be sufficient for eradicating corruption and the privileges of interest groups, since horizontal governmental opportunistic behaviour will prevail. This would result in poor economic performance and social injustice. Hence, this is a structure China should try to avoid. 


\section{Scenario 4: Structure 3 at the central-provincial level and Structure 1 at the provincial-local level}

This is a mixed structure with different relations at different levels of government. The central-provincial relationship would be Structure 3, while the provinciallocal relationship would be Structure 1 . This structure is very likely to occur in China in the future.

Since the central-provincial relationship is already at Structure 3, two further steps are needed to shift to this mixed structure. One is that grassroots democracy spreads further - up to the county level from the township and village levelin the near future. Another is that the fiscal relationship between provincial and local governments be institutionalised by the TSS as well. If this were to happen, the vertical intergovernmental relationships within each province would be Structure 1 and substantially similar to those in Western countries.

At the central-provincial level, the vertical relationship would not be substantially changed, but the horizontal checks-and-balances mechanism would be effectively established through a strengthening of the rule of law. This would significantly reduce both types of governmental opportunistic behaviour.

This mixed structure implies that China could develop a unique vertical intergovernmental arrangement deeply rooted in its 5000-year history, tradition, culture and vast population. This mixed structure also provides room for the central-provincial relationship to further evolve to Structure 1 from Structure 3 once conditions mature. This is consistent with China's gradual reform approach since 1978. In this mixed structure, avoiding vertical governmental opportunistic behaviour remains a major challenge and is dependent largely on the rule of law and the moral merit of the top leaders.

\section{Conclusions}

Based on the theory of self-enforcing federalism, this chapter has developed an analytical framework for intergovernmental relationships. A sustainable federal nation is conditioned by whether different levels of government can be balanced to prevent vertical governmental opportunistic behaviour between them. Different arrangements in the fiscal and personnel dimensions have different effects on governmental opportunistic behaviour and therefore on whether a federal nation is sustainable. In a democratic nation, fiscal transfer payments make local governments hostages to federal/national government influence. Meanwhile, it is equally essential to establish a checks-and-balances mechanism through the rule of law and democracy to prevent horizontal governmental 
opportunistic behaviour in the market. Economic performance is conditioned on preventing endogenous transaction costs resulting from these two types of behaviour.

In terms of fiscal arrangements, China's central-provincial relationship is already very similar to that in Western countries. The central government controls most of the nation's fiscal resources and, financially, the provinces rely heavily on transfer payments. The key difference between China and Western countries is in the personnel dimension. The dual top-down arrangements in the personnel and fiscal dimensions in China have resulted in a very strong central government. Preventing vertical governmental opportunistic behaviour is therefore a major challenge for China - and it is not sufficient to simply borrow the top-down fiscal arrangement from the West.

This chapter sees four major possible scenarios for the future evolution of intergovernmental relationships in China. The first is Structure 3-a continuation of the current dual top-down intergovernmental relationships. The second is Structure 1, with good rule of law, which is a structure like those in Western countries. This is probably the most sustainable structure observable in the world today. The third is Structure 1, without good rule of law, which is the structure in some Latin American countries. This is a structure that China needs to avoid. The fourth structure is a mixed one of Structures 1 and 3 , in which the central-provincial relationship is Structure 3 and the provinciallocal relationship is Structure 1. This mixed structure is very likely to emerge as grassroots democracy grows in China. It also provides room for further evolution to a unified Structure 1 with good rule of law in the more distant future.

\section{References}

Boadway, R. and Tremblay, J.-F. 2005, A theory of vertical fiscal imbalance, Working Paper, Queen's University, Kingston, Ontario.

Brennan, J. and Buchanan, J. 1980, The Power to Tax: Analytical foundations of a fiscal constitution, Cambridge University Press, New York.

Breton, A. 1996,Competitive Governments: An economic theory of politics and public finance, Cambridge University Press, Toronto.

Buchanan, J. 1965, 'An economic theory of clubs', Econometrica, vol. 33, pp. $1-14$. 
Courant, P., Gramlich, E. and Rubinfeld, D. 1979, 'The stimulative effects of intergovernmental grants: or why money sticks where it hits', in $\mathrm{P}$. Mieszkowski and W. Oakland (eds), Fiscal Federalism and Grants-in-Aid, The Urban Institute, Washington, DC, pp. 79-95.

de Figureiredo, R. J. and Weingast, B. R. 2005, 'Self-enforcing federalism', Journal of Law, Economics, and Organization, vol. 21, no. 1, pp. 103-35.

de Melo, L. 2000, 'Fiscal decentralization and intergovernmental fiscal relations: a cross-country analysis', World Development, vol. 28, pp. 365-80.

Dollery, B. 2002, 'A century of vertical fiscal imbalance in Australian federalism', History of Economics Review, vol. 36, pp. 26-43.

Faguet, J.-P. 2004, 'Does decentralization increase government responsiveness to local needs? Evidence from Bolivia', Journal of Public Economics, vol. 88, nos 3-4 (March), pp. 867-93.

Fisman, R. and Gatti, R. 2000, Decentralization and corruption: evidence across countries, Development Research Group, The World Bank, Washington, DC.

Fisman, R. and Gatti, R. 2002, 'Decentralization and corruption: evidence from US federal transfer programs', Public Choice, vol. 113, nos 1-2 (October), pp. 25-35.

Fornasari, F., Webb, S. and Zou, H. 2000, 'The macroeconomic impact of decentralized spending and deficits: international evidence', Annals of Economics and Science, vol. 2, pp. 403-33.

Fox, W. F. 2001, Decentralization in the United States: where has the country headed?, Paper submitted to the International Symposium on Fiscal Imbalance, Canada, 13-14 September.

Hamilton, A., Madison, J. and Jay, J. 1787, The Federalist Papers, Online, $<$ http://www.foundingfathers.info/federalistpapers/>.

Hicks, U. K. 1984,Federalism: Success or failure, Macmillan, London.

King, D. 1984,Fiscal Tiers: The economics of multi-level government, Allen \& Unwin, London.

Martinez-Vazquez, J. and McNab, R. M. 2003, 'Fiscal decentralization and economic growth', World Development, vol. 31, no. 9 (September), pp. 1597-616.

Musgrave, R. 1959, Theory of Public Finance: A study in public economy, McGraw, New York. 
China: The Next Twenty Years of Reform and Development

National Bureau of Statistics (NBS) 2009, China Statistical Yearbook 2009, China Statistics Press, Beijing, p. 263.

North, D. 1987, 'Institutions, transaction costs, and economic growth', Economic Inquiry, vol. 25, pp. 419-28.

North, Douglas., and Weingast, Barry, 1989, “Constitutions and Commitment: The Evolution of Institutions Governing Public Choice in SeventeenthCentury England", Journal of Economic History, 49, pp. 803-32.

Oates, W. 1972,Fiscal Federalism, Harcourt Brace Jovanovich, New York.

Qian, Y. and Roland, G. 1998, 'Federalism and the soft budget constraint', American Economic Review, vol. 88, no. 5. pp. 1143 - 62.

Qian, Y. and Weingast, B. 1997, 'Federalism as a commitment to preserving market incentives', The Journal of Economic Perspectives, vol. 11, no. 4 (Autumn), pp. 83-92.

Scott, D. A. 1952, 'The evaluation of federal grants', Economica, vol. 19, no. 2, pp. 377-94.

Seabright, P. 1996, Accountability and decentralization in government: an incomplete contracts model', European Economic Review, vol. 40, pp. 61-89.

Shirk, S. 1993, The Political Logic of Economic Reform in China, University of California Press, Berkeley.

Smith, A. 1776, An Inquiry into the Nature and Cause of the Wealth of Nations, University of Chicago Press.

Stein, Ernesto, 1999, 'Fiscal decentralization and government size in Latin America', Journal of Applied Economics, vol. 2, no. 2. pp. 375 - 91.

Sun, L. 2004, 'A review on tax sharing system at its 10th anniversary' [in Chinese], The 21st Century Report, 10 November.

Thiessen, U. 2003, 'Fiscal decentralization and economic growth in high-income OECD countries', Fiscal Studies, vol. 24, no. 3 (September), pp. 237-74.

Treisman, D. 2000, 'The causes of corruption: a cross-national study', Journal of Public Economics, June.

Liu, W-M., and Yang, X., 2001: “Good Capitalism Versus Bad Capitalism: Effects of Political Monopoly of the Ruling Elite on the Extent of the Market, Income Distribution, and Development", Working Paper, Department of Economics, Monash University, No. 08/01. 
Wallin, B. A. 2001, Forces behind centralization and decentralization in the United States, Paper submitted to the International Symposium on Fiscal Imbalance, Canada, 13-14 September.

Watts, R. L. 1999,Comparing Federal Systems, Second edition, Queen's University, Kingston, Ontario.

Weingast, B. R. 2005, 'The constitutional dilemma of economic liberty', The Journal of Economic Perspectives, vol. 19, no. 3. pp. 89 - 108

Yang, X. 2001,Economics: New classical versus neoclassical framework, Blackwell Publishers Ltd, New York.

Zhang, Y. 2005, The direction of China's reform on fiscal transfer payments learning from international comparison: a theoretical framework on intergovernmental relationship, Research Report of Development Research Centre of the State Council, vol. 32, Beijing.

Zhang, Y. 2008, 'The intergovernmental assignment of expenditure and revenue', Comparison of Economic and Social System [in Chinese], vol. 2.

Zhang, Y. 2009, 'Central-local governmental relationship: a theoretical framework and its application', Comparison of Economic and Social System [in Chinese], vol. 2. 



\title{
China's metal intensity in comparative perspective
}

\author{
Huw McKay, Yu Sheng and Ligang Song
}

\section{Introduction}

This chapter has two aims. The first is to reinvigorate the theoretical field that relates economic development to metal usage, which has been lying fallow for considerable time. The second is to shed light on China's future path of ferrous metal demand by referencing the experience of relevant peers over the entire course of the industrialisation process.

In the past decade, a great deal of effort has gone into long-run forecasting projects in the realm of diet (FAO 2002, 2006), agriculture, food supply and water (Bruinsma 2009), energy (McKibbin 2006), carbon emissions (Garnaut et al. 2008; UNDP 2010) and automobiles (IMF 2005a). Long-run metal demand has surprisingly been neglected. This neglect is particularly surprising given that metals' prices have risen so dramatically in real and nominal terms since 2003. The commodity price boom of the 1970s, which brought issues of resource security to the fore, spawned a proliferation of long-run forecasting projects in the metals arena. Beginning with the pioneering work of the International Iron and Steel Institute (1972) and Malenbaum (1973, 1975), which introduced and popularised the intensity of use curve, a number of studies sought to project the demand for metals in the longer run. Two of the best-known works are Leontief et al. (1983) ${ }^{1}$ and Malenbaum (1978).

In this study, we seek to contribute to the broader discussion by employing a richer set of macroeconomic data than that employed in earlier empirical studies, in addition to providing a projection for China's ferrous metal demand to 2030.

This chapter takes as a starting point the observation that the style of development-expressed in differing industrial structures, household consumption patterns, urbanisation paths and levels of openness to trade and investment - matters a great deal for metals. Since countries achieve economic growth with different mixtures of these factors over the short and long run-

1 One of Leontief's co-authors, Ira Sohn, later wrote a second paper (Sohn 2006:Table 9) scrutinising the published forecasts for the year 2000, finding that all the projections were significant overestimates. 
reflecting comparative advantage or politico-strategic bias-empirical studies in the field seeking generality should recognise that the varied relationship between gross domestic product (GDP) per capita and metal consumption is reflecting these differences and broaden the boundaries of their empirical studies accordingly. Our firm belief is that the relationship between metal use and standard macroeconomic benchmarks is complex and idiosyncratic. The fact that this study accommodates differences across countries is a major advance on previous work. Further, if we wish to claim any generality for our findings, we have met a severe test if we are able to explain the Chinese case - which in the past has confounded expectations drawn from cross-country analysis (for example, IMF 2005b).

We begin by summarising the existing literature on the association between development level and metal intensity and explaining where our approach is different. The intensity-of-use framework, the bottom-up approach applying input-output tables and the 'Kuznets curve for steel' (the KCS, an inverted 'U'shaped curve in steel use per capita and income per capita space), which we introduce, do not automatically translate into neat forecasting frameworks. A sound model of metal demand, whether it is focussed on metals demand per person or per unit of economic output, must simultaneously capture flow, stock, cyclical and developmental/structural influences. Although incorporating all of these variables into a model is a formidable task, the attempt to do so will increase our understanding of the relationship between metal demand and economic development.

The chapter then moves on to discuss the China's demand for metals in particular. It has been noted previously that China's post-1978 history of ferrous metal use has many similarities with the Korean experience (Garnaut and Song 2006; McKay 2008; McKay and Song 2009). Will China continue to follow a path such as Korea's - a nation in which metal intensity of economic activity has remained high for a sustained period; or will the metal intensity of growth only remain high while China is a middle income country en route to the current resting place of the European economies and their offshoots? Will it eventually sit on the more metal-intensive side of the high-income cohort, in a similar place to where Japan resides? These questions are of central importance to China's longrun economic strategy and performance.

A fundamental conclusion of this chapter is that China is unlikely to continue to closely follow the Korean path once it moves deeper into middle-income status. This is due to our contention that China will be compelled to alter its mode of economic growth. China's current reliance on heavy industry, investment vis-avis consumption and high degrees of export orientation will have to be altered if it is to successfully navigate the next phase of its development (McKay and Song 2009). As a consequence, China's final path is likely to emulate certain 
aspects of the experiences of North America, the Commonwealth of Independent States (CIS), Western Europe, Japan and emerging Asia, rather than merely reflecting the course followed by one specific jurisdiction.

\section{The KCS and related theories}

\section{Extant theory and our extension}

Before 1993, the literature on metal usage was divided into two distinct schools: the consumer preference school that pioneered intensity-of-use (IU) analysis, and the leapfrogging school. The consumer preference school argued that IU (defined as the volume of metal consumed per unit of output) increased in low-income economies over time as demand for durable goods created derived demand for metals (International Iron and Steel Institute 1972; Malenbaum 1973). In this view of the world, as economies make the transition towards industrialised status, the consumption basket progressively shifts towards services such as health, education and recreation, at the expense of the metalintensive durable goods market. Thus the development of consumer preferences with rising incomes creates an inverted ' $U$ '-shaped IU curve with a definable turning point.

The leapfrogging school argued that the ability of low-income economies to skip whole generations of technologies gave a downward bias to IU over time (Hwang and Tilton 1990). Essentially, the leapfrogging school argued that a low-income economy's ability to import technology could transplant it to the same point on the hypothesised IU schedule as an advanced economy; or, alternatively, they were able to navigate to lower IU schedules relative to those that previous generations of industrial countries had inhabited at equivalent income levels. The implication was that a low-income economy was just as likely to see a decline in its IU as it moved towards middle-income status, rather than see the rise assumed by the consumer preference school.

The difference between the two schools is best understood by reference to a diagram (Figure 5.1). The leapfrogging school argues that the underlying tendency for low-income economies is to move onto lower IU schedules as they import more advanced technologies (a shift from A on IU2 to B on IU3) or to be conceived immaculately beyond the turning point of the IU schedule, where the parabola is downward sloping. Their adversaries argued that the underlying tendency for low-income economies was to transit along the upward-sloping portion of a single parabola, or in extreme instances to move onto higher IU schedules, as their citizens consumed more sophisticated goods and services (a shift from $\mathrm{A}$ on $\mathrm{IU}_{2}$ to $\mathrm{C}$ on $\mathrm{IU} 1$ ). 
Figure 5.1 Competing theories of metal intensity

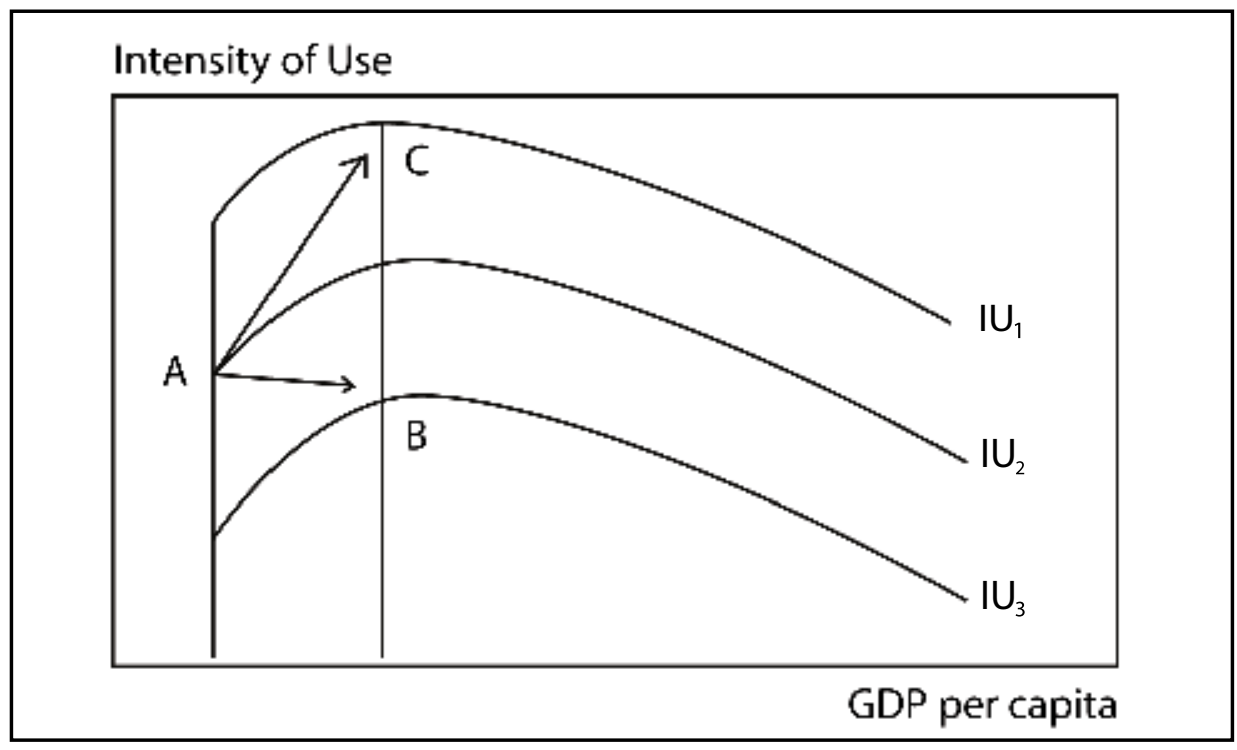

Source: Authors' adaptation of Figure 1 in Hwang, K. H. and Tilton, J. E. 1990, 'Leapfrogging, consumer preferences, international trade and the intensity of metal use in less developed countries', Resources Policy, September, p. 211.

A synthesis was achieved by the work of Lohani and Tilton (1993). They argued that there was partial truth in the teachings of both schools that could be reconciled into a single theory by a relatively simple empirical test. Building on the implications of Hwang and Tilton (1990), Lohani and Tilton studied changes in IU of a cross-section of low-income economies between 1977 and 1988 to test the extant theories and the viability of a synthesis. ${ }^{2}$

Their hypothesis was that IU in the low-income economies was linearly related to income per capita (change in purchasing power and consumption patterns) and time (change in the technological frontier). If the extreme version of the leapfrogging school was correct, the coefficients derived from their crosssectional regression should have been zero for income per capita and negatively related to position on the time trend. If the extreme version of the consumer preference school was correct, the coefficients should have been zero for the time trend and positively related to income per capita. The synthesis would see a positively sign on the coefficient for income per capita and a negative sign on the coefficient for the time trend.

2 Lohani and Tilton assumed a linear relationship for their test, as their sample included only countries gauged to be on the upward-sloping segment of the IU schedule. Note that they were not testing the empirical robustness of the IU schedule itself, which is of course non-linear. Therefore they had nothing to say about the turning point of the IU schedule, which is naturally an important consideration of this chapter. 
The result was that the synthesis view carried the day. More specifically, the authors indicated that a real income growth rate of approximately 1 per cent per annum was required to keep IU stable against the underlying gravity of the leapfrogging phenomenon. Therefore, low-income countries achieving strong rates of economic growth will see a rising IU, but those that are stagnating will see their IU fall due to technological change, or other factors that are captured by the time trend. ${ }^{3}$

These findings reconciled the debate between the opposing schools. The authors noted, however, that their test left about half of the variation in IU across the sample unexplained. The current study extends the analysis in a number of ways as an aid to preparing a long-run projection of China's steel demand.

First, we empirically verify not the IU schedule itself-which measures metal usage per unit of output at various levels of per capita income- - but the Kuznets curve for steel (the KCS), which is scaled by population. Our reason for deciding to move away from the IU framework is that we see the KCS as a summary development metric that will stand alongside other measures of absolute and relative living standards - and these measures are invariably expressed in per capita terms. Using population as the denominator and steel consumption as the numerator of our key ratio also has the benefit of couching the KCS as a demandside concept, whereas the IU framework is a product of the supply side.

Beyond verifying the existence of the KCS, we estimate its turning point in income per capita terms. Second, we use the early and middle industrialisation phases of currently middle and high-income economies to inform the analysis, not just the low-income economies of today. Third, we use long time-series data at five-yearly intervals, rather than a contemporary cross-section from a selection of economies at various development levels. We thereby avoid the problems inherent with cross-sectional analysis, particularly where there are data constraints (McKay 2008). ${ }^{4}$ Finally, we broaden our empirical analysis to incorporate macroeconomic variables such as investment propensity,

\footnotetext{
3 Given the leapfrogging phenomenon relies heavily on foreign capital flow, and economies that do not attract the interest of foreign investors tend to be slow growing, it is arguable whether leapfrogging is a terribly strong downward force on IU in poorly performed jurisdictions. Indeed, a shortage of capital will limit the investment share of GDP in these economies, and if investment efficiency is low (as the absence of foreign investors would attest both ex ante and ex post) then income per capita will expand sluggishly, if at all. Conversely, an economy absorbing large amounts of foreign investment will face a much higher than average drag on its IU from the leapfrogging phenomenon. The virtuous relationship between the availability of investment funds, the rising investment share that accommodates it and the rising efficiency of investment as improving technology replaces the old predict, however, a rapid ascent in income per capita that more than offsets the leapfrogging drag on IU. The Korean example is a classic case (Hwang and Tilton 1993).

4 While cross-sectional metal intensity data of recent vintage are available for a wide variety of countries at various states of engagement with an industrial strategy, using these data alone has the potential to be highly misleading. A focus on comparative time-series data is crucial to define the path from A (entry) to B (peak) to $\mathrm{C}$ (maturity). Cross-sections can help with this task, but they can easily mislead rather than guide. The
} 
urbanisation rates, openness to trade and automobile penetration. We apply this enhanced data-set in a simultaneous equation system, the estimation of which is intended to capture the impact of those key variables on aggregate demand. This allows us to test specifically whether the synthesis view of the changing relationship between economic development and IU holds over time and across countries and regions.

Before proceeding to a discussion of the empirical methodology and the data, it is instructive to consider the IU framework as a simple series of equations and identities. Following Etheridge (1981) and Hwang and Tilton (1990), and where $m=$ level of metal consumption, $I U=$ metal use per unit of output, $Y=$ GDP, $N$ $=$ population, $S_{i}=$ sector $i$ 's share in $Y$ and $i_{i}=$ metal use in output of sector $i$, we have Equation 5.1.

\section{Equation 5.1}

$m \equiv I U * \frac{Y}{N} * N$

Dividing through by $\mathrm{N}$ to cast in per capita terms gives Equation 5.2.

\section{Equation $\mathbf{5 . 2}$}

$$
\frac{m}{N} \equiv I U * \frac{Y}{N}
$$

Going further, we have Equations 5.3 and 5.4.

\section{Equation 5.3}

$$
I U=\frac{m}{Y}
$$

\section{Equation $\mathbf{5 . 4}$}

$$
\frac{m}{Y}=\sum\left(\frac{S_{i}}{Y} * \frac{i_{i}}{S_{i}}\right)
$$

So, $\frac{m}{N}$, our core focus, depends on income per capita and IU, which in turn is a function of the sectoral composition of economic activity with respect to metals.

\footnotetext{
difficulty is that while a cross-section is able to define states of nature at $\mathrm{A}$ and $\mathrm{C}$, the path between these two states might be hidden, and B identified erroneously, if the sample is imperfect. This illustration is not to be confused with the exercise in the text centred on Figure 5.1.
} 
Extending to an open economy, allowing for technological change and dividing $Y$ into its constituent parts yields Equation 5.5.

\section{Equation $\mathbf{5 . 5}$}

$I U=f\left(D D_{I U}, E X P_{I U}, I M P_{I U}, t\right)$

In Equation 5.5, $D D$ is domestic demand, EXP and $I M P$ are exports and imports respectively and $t$ is the prevailing state of technology. ${ }^{5}$

Therefore, metal demand can be altered by a change in income per capita, a change in domestic demand that is occasioned by changes in industrial structure (inter-sectoral and/or intra-sectoral) and a change in the nature of a country's international trade. A change in $I U$ could still be achieved in the absence of structural change or income per capita gains through the mechanism of technological change. ${ }^{6}$ Following the leapfrogging school, we assume $t$ is negatively related to $I U^{7}$

\section{'Kuznets curves' as development metrics and some methodological considerations}

The 'Kuznets curve' - an inverse 'U'-shaped curve relating income distribution to income per capita - was first advanced by Kuznets (1955). The evidence for this original Kuznets curve was some patchy time series for a group of industrial countries (the United States, the United Kingdom and Germany/Prussia/ Saxony) and single observations of a few countries at a spread of lower-income levels from Latin America and South Asia. ${ }^{8}$ The inverted ' $U$ ' was formed by this mixture of time-series and cross-sectional data. The lower-income economies provided the hump in the hypothesised curve, 'corroborating' the patchy timeseries evidence.

Subsequent experience of East Asian development trajectories in the quartercentury after World War II, in which inequality was reduced between the

5 Inventories are ignored here as they are assumed to be neutral for economic structure.

6 A change in relative prices could also bring about a change in IU. If heavy industry is a strategic sector under a developmental state, it is likely that factor prices (for instance, land, labour, energy, capital) will be suppressed to assist the sector. The removal of such distortions will clearly impact on IU. This is particularly pertinent in the situation of China (Huang and Tao 2010).

7 This framework obviously lends itself to input-output (I-O) analysis, in which metal use coefficients can be estimated and applied. This technique is entirely appropriate in industrialised economies with relatively stable structures. Given the inherent delay in the publication of detailed I-O tables, however, and their fiveyear periodicity, it is unlikely that they would provide an accurate 'leaping-off point' for assessing the IU situation in a country developing as rapidly as China.

8 Kuznets used data from India (1949-50), Ceylon (now Sri Lanka; 1950) and Puerto Rico (1948). 
low and middle-income stages of development, has shown that the Latin American and South Asian paths observed by Kuznets are idiosyncratic rather than general. The two regions followed development models that encouraged the super-normal growth of a rent-seeking elite, with predictable outcomes for income distribution. Therefore, the original Kuznets curve is a cautionary tale for scholars of development looking to cross-sectional data for predictive relationships.

In the metals sphere, a contemporaneous cross-section of countries at various income levels can be readily assembled to show an apparent Kuznets-type relationship. The apex of the hump in the curve relating steel demand per person to per capita income is provided by two medium-sized upper middleincome North Asian economies: Korea and Taiwan. They are both relatively new entrants to industrialisation with their engagement occurring within the past half-century. Are these economies typical or atypical? This judgment could validate or invalidate the cross-section as representative, as we do not have readily available middle-income alternatives to substitute for them.

Preliminary investigations by McKay (2008) document the existence of a KCS relationship in a long time series of steel use per capita in the United States. The empirical evidence in favour of a Kuznets relationship in the long-run steel demand per capita in the United States is strong. The finding that steel use per capita in the United States during the twentieth century followed an inverted ' $U$ ' shape 'corroborates' the cross-sectional 'evidence' available from a scatter plot, indicating that the Kuznets framework could be applicable to the entire field of metal demand. Development is, however, a complex process conditioning a rich variety of urbanisation processes, investment approaches and sectoral transformations (and in China's case, ownership transformations [Garnaut et al. 2006] and imperfections in the markets for resources), differing approaches to international trade, foreign investment, financial systems, institutional reform, and so on. It is therefore potentially misleading to reduce an economy's development process to an aerial view of a high-growth phase following initial engagement with industrialisation, followed by a deceleration as the ability to benefit from convergence of productivity levels is reduced as it approaches the frontier. Rather, given the observed heterogeneity of 'pathways from the periphery' (Haggard 1990), it is necessary to build a system that can account for these differences.

In short, while the shortcut of generalising from a narrow potentially unrepresentative sample is tempting, it is not appropriate. What is needed is an approach that allows for national deviations from the average path within a consistent aggregate framework. Our approach, therefore, is to estimate the aggregate KCS relationship and its underlying determinants in a simultaneous procedure. 


\section{Model specification and estimation strategy}

\section{Model specification}

To examine the potential Kuznets relationship between long-term steel demand per capita and economic development, we follow McKay (2008) by assuming that steel demand per capita is a function of income per capita, its square term and a control vector (Equation 5.6).

\section{Equation 5.6}

lncsteel $_{i t}=\beta_{0}+\beta_{1} \operatorname{lncgdp_{it}}+\beta_{2} \ln c g d p_{-} s q_{i t}+\gamma Z_{i t}+\varepsilon_{i t}$

In Equation 5.6, lncsteel $_{\text {it }}$ denotes the logarithm of annual steel consumption per capita and $\operatorname{lncgdp_{it}}$ and $\ln c g d p_{-} s q_{i t}$ the logarithm of GDP per capita and its square term of country $i$ at time $t$ respectively. $Z_{i t}=\left(\operatorname{lnccar}_{i t}^{1}, \mathrm{t}\right)$ is the control vector, accounting for the impact of automobile penetration (defined as the logarithm of the number of passenger cars per 1000 people) and technological progress (defined as the time trend). Thus, the null hypothesis for the Kuznets relationship to be robust is that the estimated coefficients in front of the logarithm of GDP per capita and its square term should be positive and negative in sign, respectively, and statistically significant. Additionally, a negative and statistically significant coefficient assigned to the time trend will provide support for the leapfrogging hypothesis. The degree of automobile penetration is a proxy variable for the consumer preference hypothesis. A positive coefficient is expected here.

This is a major advance on the work of Lohani and Tilton (1993). Positioned in this fashion, our test can offer a comprehensive update and extension of the synthesis view of the relationship between economic development and IU. In addition, this approach can infer the turning point in the KCS - something that is beyond a single equation linear system. It also has some utility as a projection model that we later apply to the question of China's future metal demand.

Equation 5.6 can be directly estimated by various methods, but the results might not be economically robust in isolation. This is because a parsimonious single equation exercise potentially violates the empirical reality that the nature of the industrialisation process is just as important as the development level in determining the path of long-term steel demand per capita. To control for this factor, we choose a simultaneous estimation of three equations (Equations 5.6, 5.7 and 5.8), with steel use per capita, GDP per capita and its squared term, 
respectively, serving as dependent variables. The estimation utilises five-year panel data - essentially smoothed long time-series - for a representative sample of the global economy. The data cover 14 countries and regions from as early as 1890 until 2008.

The variety of local conditions prevailing at the entry point into industrialisation strategies, the different states of local and global technological attainment at each 'time stamp', divergent comparative advantages and a diversity of institutional approaches to the development task have generated substantially different degrees of steel demand per capita at similar income per capita levels. Therefore, in the analysis of the KCS, GDP per capita can be plausibly treated as an intermediate variable that is jointly determined by the broad parameters that characterise a nation's mode of economic development. These factors include the urbanisation process, investment propensity, motorisation and the degree of openness to trade. While these factors are endogenous to the style of economic development adopted, econometrically speaking they are exogenous determinants of GDP per capita in our model.

Equations 5.7 and 5.8 complete the system required for the test.

\section{Equation 5.7}

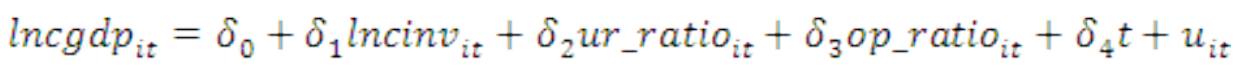

\section{Equation 5.8}

$$
\operatorname{lncgdp_{-}sq_{it}}=\varphi_{0}+\varphi_{1} \operatorname{lncinv}_{i t}+\varphi_{2} u r_{-} \text {ratio }_{i t}+\varphi_{3} \text { op } \text { ratio }_{i t}+\varphi_{4} t+v_{i t}
$$

In both equations, $\operatorname{lncin} v_{i t}$ is the logarithm of total investment per capita, ${ }^{9} \mathrm{ur}_{-}$ratio $_{i t}$ is the urbanisation rate (defined urban population share of the total population) and $o p_{-}$ratio $_{i t}$ is an openness to trade index (defined as exports plus imports over GDP).

Equations 5.6-8 are estimated using the simultaneous equation method. There are two econometric problems to be solved before an unbiased and consistent estimation can be reached.

First, since we use panel data for the exercise, the country-specific effect needs to be eliminated. If there are time-invariant country-specific unobserved factors determining the dependent variable (that is, steel demand per capita) that are

9 We use investment per capita rather than the more usual choice of the investment share of GDP. We do this because while a developing economy might have a high investment share, it is most unlikely to have a large capital stock relative to its workforce. This enables us to capture a prolonged process of capital deepening that will not necessarily be captured by the investment share (especially where the efficiency of investment improves over time) as well as the importance of depreciation expenditures at higher levels of development. 
also correlated with the independent variables (that is, GDP per capita), the estimated coefficients could be either over or underestimated. To deal with this problem, we take the first difference for all variables and use Equations 5.6', $5.7^{\prime}$ and $5.8^{\prime}$.

\section{Equation 5.6'}

dlncsteel $_{i t}=\gamma_{0}+\beta_{1} d \operatorname{lncg} d p_{i t}+\beta_{2} d \operatorname{lncg} d p_{-} s q_{i t}+\gamma_{1} d \operatorname{lnccar} r_{i t}+d \varepsilon_{i t}$

\section{Equation 5.7'}

$$
\text { dlncgdp } i t=\delta_{4}+\delta_{1} d l n c i n v_{i t}+\delta_{2} d u r_{-} \text {ratio }_{i t}+\delta_{3} \text { dop_ratio } i t+d u_{i t}
$$

\section{Equation 5.8'}

$d l n c g d p_{-} s q_{i t}=\varphi_{4}+\varphi_{1} d l n c i n v_{i t}+\varphi_{2} d u r_{-}$ratio $_{i t}+\varphi_{3} d o p_{-}$ratio $i t+d v_{i t}$

In all three equations, $d(\cdot)$ represents first differences.

Second, when the simultaneous equation regression technique is adopted, the potential correlation among the residuals across equations introduces the efficiency problem for the estimated coefficients (Zellner 1962). In other words, if we assume that $d \varepsilon_{i t}, d u_{i t}$ and $d v_{i t}$ are independently and identically distributed (as is normally assumed in statistics), the estimated standard error for all coefficients would be biased since $d \varepsilon_{i t}, d u_{i t}$ and $d v_{i t}$ could be correlated through the dependent variables that are correlated across different equations. Thus, the statistical significance of the regression is rendered dubious. To deal with this problem, we use the seemingly unrelated regression (SUR) technique to adjust the covariance matrix in our estimation.

To test the stability of our results, we carried out two robustness checks. On one hand, we substituted the original dependent variables with other development measures (such as electricity consumption, rail freight and shipping vessels all in per capita and logged form). The results did not differ substantially. We also used a variety of econometric techniques. ${ }^{10}$ Once again, the results were consistent in terms of the expected signs and statistical significance of the estimated coefficients.

10 The substitute variables were electricity consumption, rail freight and shipping vessels (all in per capita and logged form). The alternative methods were a dynamic panel regression (with GDP per capita specified as the endogenous variable) and an IV regression (with different model specifications). 


\section{Data description}

The panel data used for this study cover 14 countries and regions between 1890 and 2008. The sample comprises Canada, the United States, Latin America, Africa, European members of the Organisation for Economic Cooperation and Development (OECD), the Commonwealth of Independent States countries (Russia after 1990), the Middle East, India, China, South-East Asia, Oceania, Japan, Korea and Taiwan. To reduce year-to-year fluctuations, we sampled the data at five-year intervals. The regional definitions are consistent with those used by the International Steel Association.

Figure 5.2 Crude steel output per capita of selected economies, 1890-2008

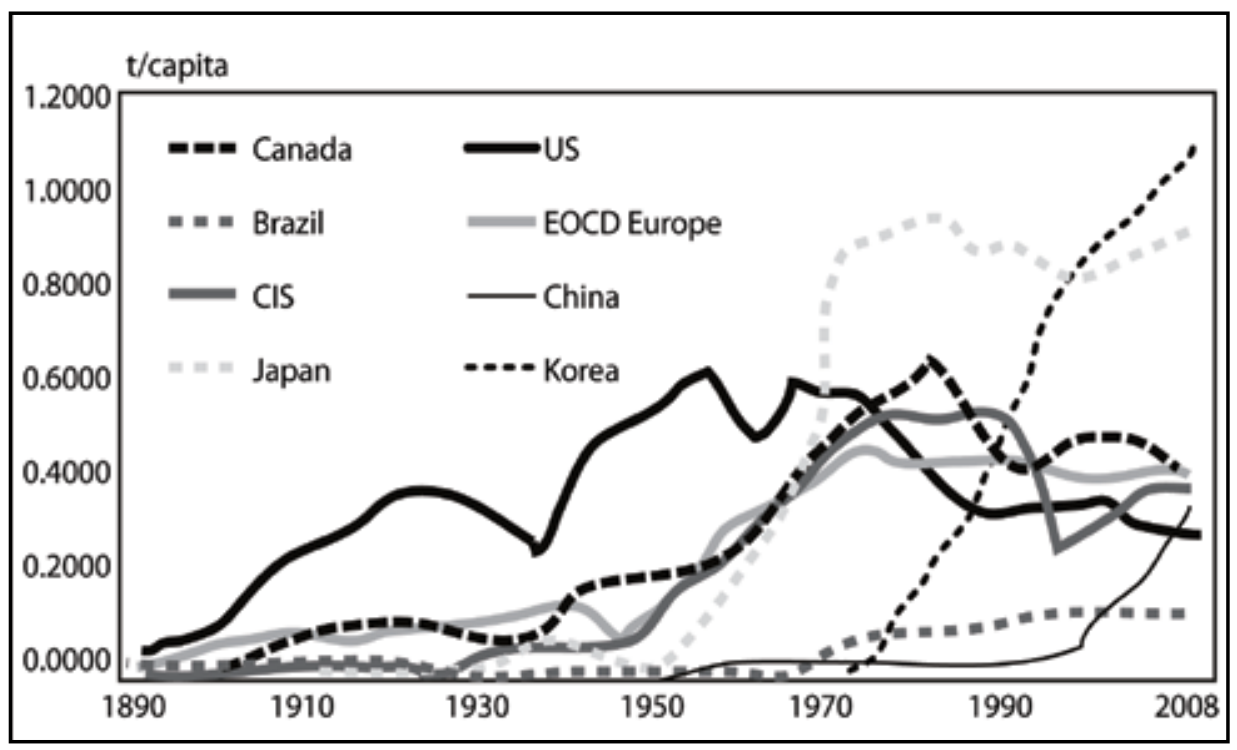

Source: Data from the World Metal Statistics Yearbook, various issues, International Steel Association.

The macroeconomic variables we employ are steel use, GDP, investment, electricity use, private automobile ownership (all scaled by population), openness to trade (scaled by GDP) and the urbanisation rate. The measures of all variables are consistent across countries and over time. Steel use is defined as total crude steel consumption. GDP is measured at 1990 constant price international US dollars. Investment is defined as gross fixed capital formation. The urbanisation rate is the percentage of urban residents in the total population. Openness to trade is defined as exports plus imports over GDP.

The data come from three principal sources. Crude steel production and consumption come from the International Steel Statistics; population data come from Maddison (2003, 2010; the Penn World Table (Centre for International 
Comparisons n.d.) was used for obtaining the national accounts variables and urbanisation rates; and the CHIPs database of the National Bureau of Economic Research (NBER) provided private car registrations per 1000 people, electricity consumption per capita and some other country-specific variables.

There is a clear similarity in terms of the pattern of rising steel output per capita for the United States from the mid 1930s to the end of the Korean War, and for Canada, Europe and the CIS from the 1950s to the 1970s. The experience of Japan from the early 1950s to the 1970s and Korea from the early 1970s to the present day, and China since 2000, are also quite similar (Figure 5.2). While the levels of steel production per capita in the United States and Canada fell steadily after reaching their peaks (thereby tracing an inverted U shape), Europe and the CIS held their peaks for longer.

Japanese steel use per capita has remained steady in the decades after its peak, while Korea is yet to peak, even if the rate of increase has slowed since the 1990s. Japan's and Korea's levels of per capita steel production have reached a point much higher than those reached by other industrialised countries. These levels are thus unprecedented in the Western history of industrialisation. Figure 5.2 also shows that in the case of Japan, the phase of acceleration lasted for about 20 years (1950-70) while the path has been more protracted for Korea at almost 40 years and counting. This illustrates the point made earlier about the unique path of metal consumption in Korea. The question as to what extent the level of per capita steel production of China will rise and how long the phase of acceleration will last is significant and remains to be addressed.

Figure 5.3 illustrates the relationship between steel output per capita and income per capita in the major countries and regions over the long period 1890-2008. The figure presents three features. First, the trajectories of certain countries (especially in East Asia) seem to support the consumer preference view - namely, that steel demand continues to rise along with increases in per capita income. This process is extended even beyond the point where other industrialised countries have reached the peak in their steel intensities. Second, Western economies have demonstrated a pattern of change that is more in support of the leapfrogging view - namely, their steel intensities began to fall after peaking between US\$10 000 and US\$15000 of income per capita. Steel use then stabilises about the US $\$ 20000$ level between one-half and three-quarters of the peak level and thereafter follows a cyclical pattern of change. 
Figure 5.3 Crude steel output and GDP, scaled by population, 1890-2008

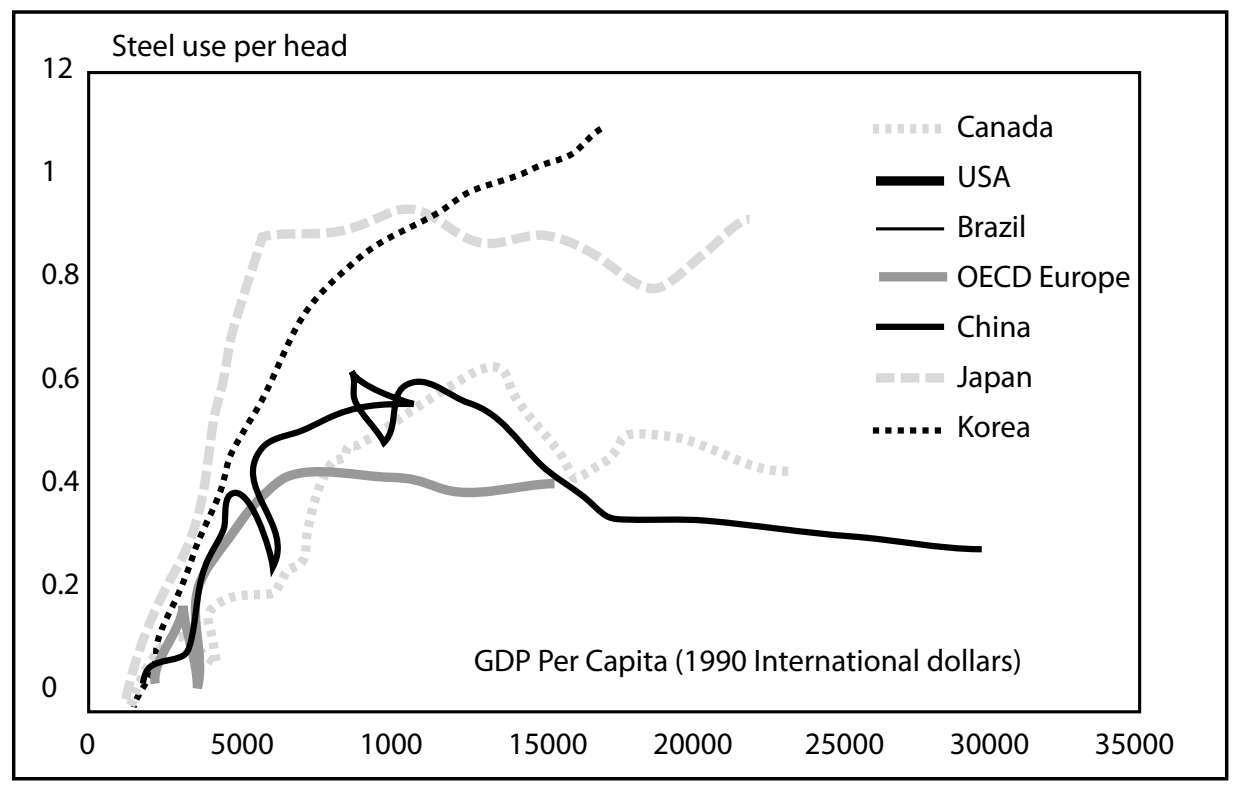

Source: World Metal Statistics Yearbook, various issues, International Steel Association.

These are the basic data that provide the dependent variables for the formal econometric exercise detailed in sections three and four in which we test the validity of the different theories and their synthesis. It is also the context in which the future trajectory of China's steel demand per capita is projected.

Figure 5.4 Urbanisation ratios of selected economies, 1890-2005

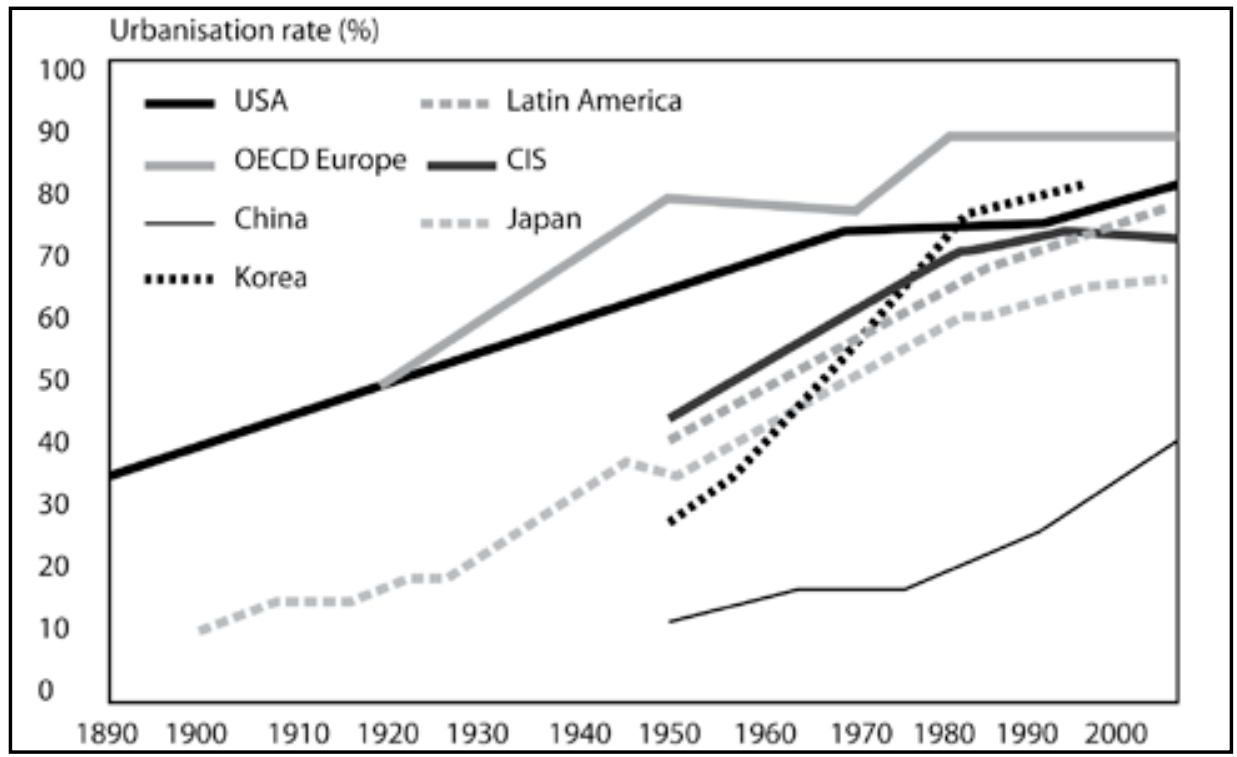

Source: Center for International Comparisons n.d., The Penn World Table,University of Pennsylvania, Philadelphia. 
The difficulty of the modelling task is illustrated with reference to one of the explanatory variables: the urbanisation rate (Figure 5.4). The urbanisation process tends to be associated with rising steel demand per capita as it directly contributes to GDP growth through the well-known Lewisian dynamics of sectoral transfer. It also requires a dwelling and infrastructure-building program to accommodate the population shift. The benefits of agglomeration drive an increase in service sector activity, greater specialisation and the associated productivity gains. Each of these factors generates income growth, which increases effective demand, and so on. As this short description indicates, the urbanisation process is an attractive variable for proponents of the consumer preference view. There is nothing rigid, however, about the relationship between urbanisation and steel use. For example, Brazil's urbanisation ratio is close to 80 per cent, but Brazil has a relatively low level of steel intensity (and income per capita). Brazil also has a rich endowment of ferrous metal resource reserves. At a similar level of urbanisation, Korea's steel intensity is much higher than that of the United States. At a much lower level of urbanisation, China's steel intensity has already surpassed those for the United States and Brazil. China's steel use is converging with that of the CIS, where urbanisation is significantly higher. In the case of Japan, its steel intensity is much higher than that of the United States with a lower level of urbanisation, despite the density of its population and its weak resource endowment (McKay 2008). It is both theoretically and intuitively sound to include urbanisation rates in the empirical test. Yet a quick review of the country-level data highlights the differences between countries in the sample.

\section{Estimation results and projection}

The estimation results from the model presented above capture the interactive relationship between steel consumption per capita, GDP per capita and their common determinants, as summarised in Table 5.1.

The first implication of the test is that the KCS does indeed exist. Our estimation of Equation 5.6' yields results in line with our expectations. As shown in Table 5.1, the coefficients assigned to GDP per capita and its squared term are positive and negative, respectively, and are significant at the 1 per cent level. Further, the motorisation variable also behaves as expected, with a statistically significant positively signed coefficient estimated for the number of automobiles per 1000 people. This corroborates the view that consumer preferences have played an important role in determining steel consumption over time. Generally, the greater the degree of motorisation the higher steel demand per capita is likely to be. The time trend and its square term are significant at the 1 per cent level 
with positive and negative signed coefficients, respectively, correctly signed to corroborate the leapfrogging hypothesis. So, with the consumer preference and leapfrogging views both validated simultaneously, the synthesis view is upheld (Lohani and Tilton 1993) and extended, and a new concept, the KCS (McKay 2008), has been more rigorously identified.

Table 5.1 Major results from simultaneous equation estimation, 1890-2008

\begin{tabular}{|c|c|c|c|c|c|}
\hline \multicolumn{2}{|c|}{ Dependent variable: Insteel } & \multicolumn{2}{|c|}{ Dependent variable: Ingdp } & \multicolumn{2}{|c|}{ Dependent variable: Ingdp_sq } \\
\hline Ingdp & $\begin{array}{l}6.299 * * * \\
(1.325)\end{array}$ & Innewinv & $\begin{array}{l}0.418 * * * \\
(0.056)\end{array}$ & Innewinv & $\begin{array}{l}6.664 * * * \\
(0.959)\end{array}$ \\
\hline Ingdp_sq & $\begin{array}{l}-0.313^{* * *} \\
(0.078)\end{array}$ & urban_ratio & $\begin{array}{l}0.018 * * * \\
(0.006)\end{array}$ & urban_ratio & $\begin{array}{l}0.233 * * \\
(-0.097)\end{array}$ \\
\hline Lncar & $\begin{array}{l}0.118 * \\
(0.057)\end{array}$ & open_ratio & $\begin{array}{l}-0.001 \\
(0.003)\end{array}$ & open_ratio & $\begin{array}{l}0.001 \\
(0.049)\end{array}$ \\
\hline Time trend & $\begin{array}{l}-0.028 * * * \\
(0.011)\end{array}$ & Time trend & $\begin{array}{l}0.009 * \\
(0.005)\end{array}$ & Time trend & $\begin{array}{l}0.145^{*} \\
(0.083)\end{array}$ \\
\hline $\begin{array}{l}\text { Time trend } \\
\text { squared }\end{array}$ & - & $\begin{array}{l}\text { Time trend } \\
\text { squared }\end{array}$ & $\begin{array}{l}- \\
-\end{array}$ & $\begin{array}{l}\text { Time trend } \\
\text { squared }\end{array}$ & $\begin{array}{l}- \\
-\end{array}$ \\
\hline Constant & $\begin{array}{l}0.495 * * \\
(0.208)\end{array}$ & Constant & $\begin{array}{l}-0.128 \\
(0.095)\end{array}$ & Constant & $\begin{array}{l}-1.853 \\
(1.609)\end{array}$ \\
\hline $\begin{array}{l}\text { Adjusted } \\
\text { R-squared }\end{array}$ & 0.48 & $\begin{array}{l}\text { Adjusted } \\
\text { R-squared }\end{array}$ & 0.56 & $\begin{array}{l}\text { Adjusted } \\
\text { R-squared }\end{array}$ & 0.52 \\
\hline $\begin{array}{l}\text { Number of } \\
\text { observations }\end{array}$ & 72 & $\begin{array}{l}\text { Number of } \\
\text { observations }\end{array}$ & 72 & $\begin{array}{l}\text { Number of } \\
\text { observations }\end{array}$ & 72 \\
\hline
\end{tabular}

Note: - zero, ${ }^{* * *} \mathrm{p}<0.01,{ }^{* *} \mathrm{p}<0.05,{ }^{*} \mathrm{p}<0.1$. For simplicity, we do not report the estimation results for Equation 5.8, which are available on request from the authors. The numbers in brackets are standard errors.

Source: Authors' own estimations.

Second, while these results are a major upgrade and extension of previous work in the field of metal demand, they do not enable us to proceed directly from Equation $5.6^{\prime}$ to a projection of China's steel demand. Not only has China's steel demand commonly defied attempts to be explained by cross-country data-sets (for example, IMF 2005b), but GDP per capita alone has been shown to be at best a weak predictor of metal usage per capita across all countries. To cast forward, we must also understand that there are many common factors related to the style of industrialisation driving both IU and GDP per capita.

These common factors are well covered by Equations 5.7' and 5.8', in which GDP per capita and its squared term are regressed on investment per capita, the urbanisation rate and the degree of openness to trade. Each of these factors can affect income per capita and metal consumption per capita. It is the combination of these factors that generates the apparent KCS. In our estimation results, not 
only do both investment per capita and urbanisation positively contribute to GDP per capita (at the 1 per cent level), they explain the square term of GDP per capita (positively related and significant at the 1 per cent level). ${ }^{11}$ Thus, when we substitute Equation 5.7' and Equation 5.8' into Equation 5.6', steel consumption is driven by these three factors in addition to proxies for consumer preferences and technological progress.

\section{A projection: China's metal demand and economic development}

The substitution of these stylistic variables back into Equation 5.6' allows us to use the KCS formulation as a projection model without sacrificing national heterogeneity. The data presented above, taken together with the econometric results and a working knowledge of economic history, lead to the conclusion that while a general relationship between development-related macro variables does exist, substantial national variations from the central path are common. This permits many potential degrees of steel demand per capita at a given level of income per capita. While the KCS is a good starting point for the discussion, it is not the end game. We must also take account of the other factors underlying the macroeconomic dynamics, while factoring in how the institutional framework is most likely to evolve over time.

China has defined its own trajectory in these contexts to form a unique economic history. Its future will also be distinctive. China's future demand for metal will borrow from others - such as Korea and Japan, the United States, the CIS and Western Europe - but the outcomes will reflect China's unique characteristics.

Table 5.2 summarises major economic development indicators for China between 1980 and 2008, which helps to outline how rapid growth in income per capita has been achieved. During the past three decades, investment, resource demand and openness to trade have all expanded at rapid rates. The urbanisation rate has been increasing, but at a slower rate, reflecting the institutional constraints imposed by policy. All these factors will contribute to the future course of income per capita and, combined with technological progress and changing consumption preferences, will determine the path of steel consumption per capita in the period ahead.

11 Although the degree of openness to trade is not significant in our model, we keep it in our regression since we think that it is an important control variable from a conceptual perspective. 
China: The Next Twenty Years of Reform and Development

Table 5.2 China's economy and steel demand per capita, 1980-2008

\begin{tabular}{|c|c|c|c|c|c|c|c|}
\hline Year & $\begin{array}{c}\text { Steel } \\
\text { per } \\
\text { capita } \\
\text { (tonne) }\end{array}$ & $\begin{array}{c}\text { GDP per } \\
\text { capita } \\
\text { (1990 } \\
\text { int'l } \\
\text { dollar) }\end{array}$ & $\begin{array}{c}\text { Investment } \\
\text { share }(\%)\end{array}$ & $\begin{array}{l}\text { Openness } \\
\text { to trade } \\
\text { index }(\%)\end{array}$ & $\begin{array}{c}\text { Urbani- } \\
\text { sation } \\
\text { rate } \\
(\%)\end{array}$ & $\begin{array}{l}\text { Electricity } \\
\text { per capita }\end{array}$ & $\begin{array}{c}\text { Passenger } \\
\text { cars } / 1000 \\
\text { people }\end{array}$ \\
\hline 1980 & 0.0435 & 809 & 25.1 & 31.5 & 19.6 & 307 & - \\
\hline 1985 & 0.0555 & 985 & 34.3 & 32.2 & 23 & 374 & 0.3 \\
\hline 1990 & 0.0644 & 1400 & 40.8 & 25.4 & 27.4 & 565 & 0.7 \\
\hline 1995 & 0.0789 & 1754 & 43.6 & 32.2 & 31.4 & 842 & 2.1 \\
\hline 2000 & 0.1002 & 2718 & 37.1 & 41.9 & 35.8 & 1046 & 4.9 \\
\hline 2005 & 0.2716 & 3297 & 51.7 & 67.3 & 40.4 & 1131 & 14.1 \\
\hline 2008 & 0.3752 & 5449 & 54.4 & 69.0 & 44.9 & 2452 & 21.6 \\
\hline $\begin{array}{l}\text { Compound } \\
\text { annual } \\
\text { growth rate } \\
\text { (since } \\
1980 \text { ) }\end{array}$ & $8.0 \%$ & $7.0 \%$ & $2.8 \%$ & $2.8 \%$ & $3.0 \%$ & $7.7 \%$ & \\
\hline $\begin{array}{l}\text { Compound } \\
\text { annual } \\
\text { growth } \\
\text { rate (since } \\
\text { 1990) }\end{array}$ & $10.3 \%$ & $7.8 \%$ & $1.6 \%$ & $5.7 \%$ & $2.8 \%$ & $8.5 \%$ & $20.8 \%$ \\
\hline
\end{tabular}

Source: National Bureau of Statistics (NBS) various years, China Statistical Yearbook, China Statistics Press, Beijing; except for the investment share, which is from World Bank n.d., World Development Indicators, Online database, The World Bank, Washington, DC.

To begin, we present a scenario in which current trends persist through the projection period. Using the current growth rates in investment per capita, urbanisation and openness to trade indexes, (an admittedly naive baseline), we project the relationship between income per capita and metal intensity for China over time (shown in Figure 5.5) with confidence intervals jointly determined by country-specific characteristics and measured as standard deviations. The method used for this projection is not based on the predetermined KCS relationship but on the contributions of our three core development factors related to GDP per capita and steel consumption separately. Based on a 2008 leaping-off point, we assume that all three factors have a constant marginal impact on GDP per capita and steel consumption (obtained from our simultaneous regressions). The sum of these products is then used to generate the forward trajectories of the two series: GDP per capita and steel consumption.

On this basis, our estimate of the GDP per capita level consistent with the turning point of China's own KCS is US\$15 449. Given the fact that China's level of per capita income was US\$5449 in 2008 (Table 5.2), per capita income must almost triple before peak intensity is attained. Chinese GDP per capita grew at a compound rate of 7 per cent between 1980 and 2008. If that rate were sustained, 
China's steel intensity would peak during 2024. If the somewhat faster post1990 pace of 7.8 per cent is used (a rate consistent with GDP per capita more than doubling each decade) then the turning point is reached three years earlier. The central tendency of the projection indicates that peak demand for steel will be in the upper half of a range of $700-800 \mathrm{~kg}$ per capita at this income per capita level. This peak level of demand for steel in China will be higher than the one reached by the United States in the 1950s or Europe, Canada and the CIS in the 1970s. It would, however, be lower than those reached by Japan in the 1980s and by Korea and Taiwan at the present time.

The usual caveats apply to this projection, which is only as good as the chosen time path of the exogenous variables.

Figure 5.5 Projection of steel demand per capita, extrapolating current trends

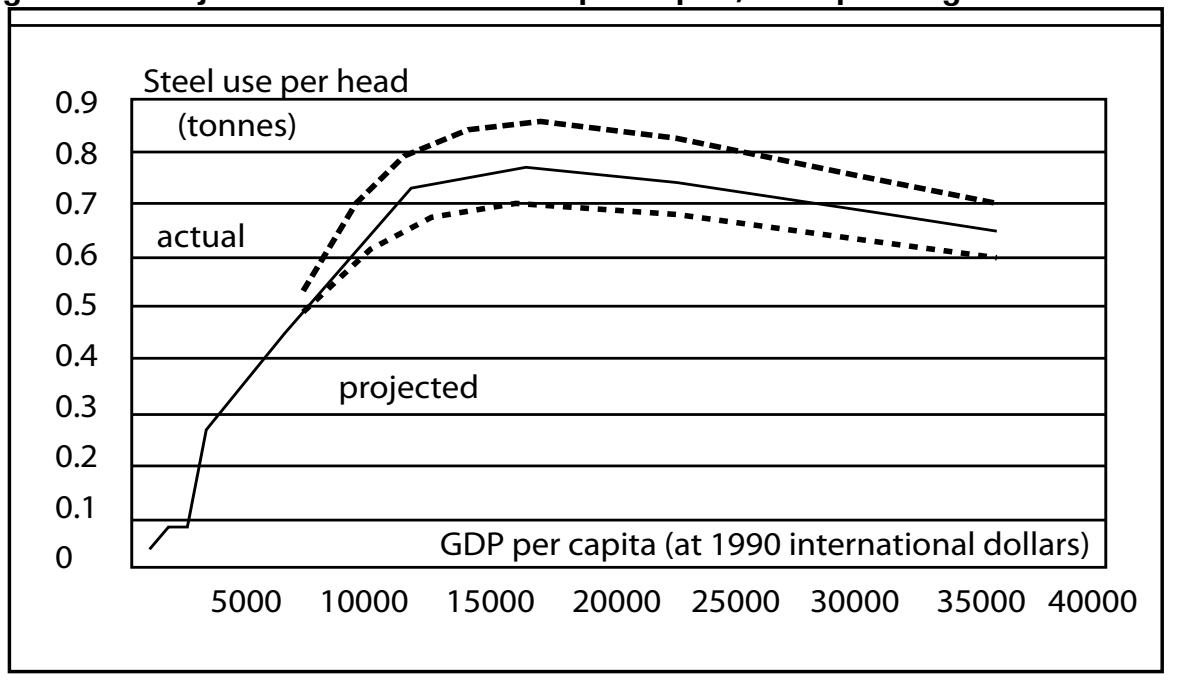

Source: Authors' own projections.

\section{Discussion and critique of the projection}

The projection illustrated in Figure 5.5 is based on the naive assumption that current trends persist into the future. If economic history tells us anything, it is that stasis is the least likely outcome for an economy at China's present stage of development. Table 5.3 shows the forward assumptions utilised in a recent UN report on the future of the Chinese economy (UNDP 2010). The contours of the UN scenario are a decelerating rate of GDP per capita growth, a continuing rise in the urbanisation rate and motorisation that decelerates progressively as 
Chinese levels approach those of high-income economies, a reduced but still high emphasis on secondary industry in overall activity and a peak in steel demand per capita about $630 \mathrm{~kg}$ by 2030 .

Table 5.3 UN projection of China's future development path

\begin{tabular}{|c|c|c|c|c|c|c|}
\hline & 2005 & 2010 & 2020 & 2030 & 2040 & 2050 \\
\hline Urbanisation rate (\%) & 43 & 48 & 56 & 62 & 66 & 70 \\
\hline $\begin{array}{l}\text { Secondary industry } \\
\text { share of GDP }\end{array}$ & 48 & 49 & 48 & 46 & 42 & 38 \\
\hline Cars per 1000 people & 24 & 70 & 190 & 300 & 356 & 400 \\
\hline $\begin{array}{l}\text { Per capita GDP (spliced } \\
\text { to } 1990 \text { int'l dollars)* }^{*}\end{array}$ & 3297 & 4990 & 8868 & 14450 & 22151 & 32079 \\
\hline $\begin{array}{l}\text { GDP growth rate } \\
\text { (decade average) }\end{array}$ & - & 9.5 & 6.6 & 5.5 & 4.5 & 3.5 \\
\hline Population (millions) & 1308 & 1360 & 1450 & 1520 & 1540 & 1500 \\
\hline $\begin{array}{l}\text { GDP per capita growth } \\
\text { rate (decade average)* }\end{array}$ & - & 8.7 & 6.0 & 5.0 & 4.4 & 3.8 \\
\hline $\begin{array}{l}\text { Power generation } \\
\text { Terawatt hours (TWh) } \\
\text { (business as usual) }\end{array}$ & 2494 & 3830 & 6603 & 8880 & 10937 & 12360 \\
\hline $\begin{array}{l}\text { Steel output ( } 100 \\
\text { million tonnes) }\end{array}$ & 3.5 & 5.6 & 8.6 & 9.6 & 9.1 & 8 \\
\hline $\begin{array}{l}\text { Implied steel per capita } \\
\text { (tonnes per capita)* }\end{array}$ & 0.27 & 0.41 & 0.59 & 0.63 & 0.59 & 0.53 \\
\hline
\end{tabular}

* Calculated by the authors from the existing information.

Source: United Nations Development Programme (UNDP) 2010, China Human Development Report 2009/10. China and a sustainable future: towards a low carbon economy and society, China Translation and Publishing Corporation, Beijing, Annexes 3.1, 3.2, 3.3 and 3.4, pp. 107-8, and Table 3.1, p. 52.

Running their assumptions through our system, we find that the United Nation's peak steel output per capita estimate is probably somewhat too low, although the implication that China will remain around its peak levels for a considerable period (at least $590 \mathrm{~kg}$ per capita from 2020 to 2040) seems reasonable. Also, given that the turning point of China's KCS is expected to be reached at a GDP per capita of US\$15 449 - a level that we can deduce the United Nations anticipates being achieved in 2032 - this roughly accords with their assumed timing of the peak in steel demand per capita. In short, the United Nation's steel projections seem rational enough in terms of overall shape and timing, but we would argue for a higher peak demand than that based on their other macroeconomic assumptions.

China has defined its own trajectory in a number of contexts to form a unique economic development path. Its future could also be distinctive if it were to define a path with respect to leapfrogging and consumer preferences that is out of the norm. 
In determining the likelihood that China will reach the peak level of its steel demand per capita in the time frame predicted by our naive projection, which of the upper or lower confidence intervals presents the most likely direction of error from the central tendency or whether China will or will not follow the path of Korea in terms of its long-term path of steel consumption, we need to leave aside empirics and trust judgment. The question is whether China's metal consumption will be influenced more by the consumer preference view or behave more according to the predictions of the leapfrogging view. It is a legitimate question as our model provides empirical evidence supporting the mutual inclusion of each of these views.

If, for example, the consumer preference dynamic operates so strongly that technological leapfrogging is hugely outweighed then there is a high probability that China will either prolong the period before it reaches the peak or it will increase the absolute peak level of steel demand per capita towards the upper confidence interval. Either or both possibilities will raise the chance that China might follow the metal intensity path of Korea.

On the other hand, if the leapfrogging phenomenon operates so strongly that it cancels out a larger than usual portion of the consumer preference dynamic, this will increase the probability that China could either shorten the period leading up to the turning point of the KCS or reduce the peak level of its steel intensity towards the lower confidence interval.

Figure 5.6 China's consumption of crude steel, 1978-2008 (million tonnes)

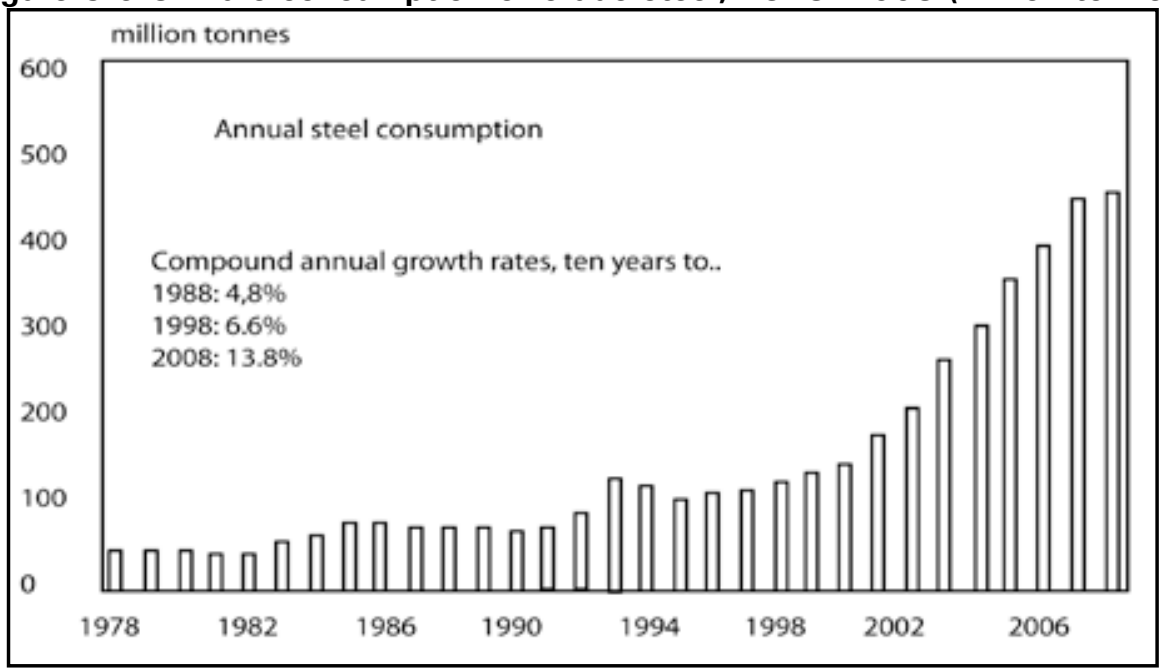

Source: National Bureau of Statistics (NBS) 2009, China Statistical Yearbook, China Statistics Press, Beijing; and author's calculations. 
According to its current level of per capita income, China is still at the mid phase of industrialisation characterised by the relatively high proportion of manufacturing in the total economy and a relatively high share of heavy industries in total industrial output (Chenery et al. 1986). A key feature of this phase of industrialisation is the pattern of extensive growth in which factor inputs - especially physical capital - play an important role. As a result, metal consumption has been accelerating sharply (Figure 5.6). China is far from reaching the saturation point of consumption of durable goods, as illustrated by its low automobile penetration ratio, which is just 5 per cent of the US level. That is especially true if one considers the existence of the vast and untapped rural consumer market. This suggests that there is ample room for increasing the consumption of durable goods in China with the associated rise in demand for metals. On this evidence, we can safely assume that the consumer preference dynamic will play a strong role in the coming decades.

On the other hand, looking beyond the immediate horizon, China is now approaching the end of a long period of extensive growth and will be relying more on technological change and productivity to expand economic activity (Wang 2007; He et al. 2007). China is entering a period in which its pattern of growth will be dictated not only by those fundamental forces that have been working in recent decades, but by the strategies that China has been compelled to adopt at this juncture of its development in order to face the challenges of global imbalances, climate change and the ageing society.

At the core of these strategies is a desire to alter its mode of industrialisation to take account of shifting comparative advantage and the fact that 'business as usual' will put immense pressure on the biosphere going forward. Structural changes will be assisted by altered incentives brought about through institutional changes such as financial system reform and the reform of the pricing system for resources and other factors of production (Huang and Tao 2010). The implementation of these new strategies will accelerate the pace of technological leapfrogging in China, moderating future increases in its metal consumption per capita.

While the desire for environmental amenity has a well-documented relationship to per capita income that is 'Kuznetsian' in shape, in China and elsewhere (Grossman and Krueger 1995; Bao and Peng 2006), no currently wealthy country had to deal with a global environmental backdrop as unpropitious as that of today. This implies that the imperative for China to pursue resourcesaving technological change in the future is greater than that of the individual economies in our historical sample. 
This short discussion highlights only that the consumer preference and leapfrogging dynamics will both be operating at high intensity in the coming decades in China. For now, it is not possible to prioritise one over the other.

Finally, we should sound a further cautionary note with respect to the projection. The objective of this study has been to define a range of potential outcomes for China's steel demand, not to produce a precise forecast. We believe that our confidence intervals are a reasonable approximation of the likely upside and downside risks to the central KCS tendency for China. Needless to say, if the underlying assumptions that generate the central tendency are over or underestimated, the accuracy of the projection will suffer.

\section{Conclusions}

This chapter had two aims. The first was to make a contribution to the theoretical field that related economic development to metal usage by constructing a new analytical framework. The second was to use those insights to shed light on China's future path of ferrous metal demand. The outcomes were as follows. First, a new concept - the Kuznets curve for steel - was formally identified. Second, the synthesis view of IU-that sees a role for both technological leapfrogging and evolving consumer preferences - was validated and updated for the per capita framework we prefer. To accommodate this test, a broader set of data was brought into the discussion than in previous studies, along with a more advanced econometric technique that allowed for the endogeneity of steel demand and income per capita and the heterogeneous nature of individual economic histories. Third, the turning point of China's own KCS was estimated at US\$15 449 GDP per capita - a point that on its post-1980 trajectory of 7 per cent compound growth China would reach during 2024. At that time, China's steel demand per capita is expected to be between 700 and $800 \mathrm{~kg}$, but closer to the latter. That is higher than the peak level reached in the United States, the CIS and Europe, but lower than the peaks seen in Japan, Korea and Taiwan. The eventual accuracy of this projection will depend on a great many factors, chief among them the pace of global technological change and the developing preferences of the Chinese consumer.

\section{References}

Bao, Q. and Peng, S. 2006, 'Economic growth and environmental pollution in China: a simultaneous estimation', Journal of World Economy, vol. 11, pp. 48-59. 
Bruinsma, J. 2009, The resource outlook to 2050: by how much do land, water and crop yields need to increase by 2050?, Paper presented to the Expert Meeting on How to Feed the World in 2050, Food and Agriculture Organization of the United Nations, 24-26 June, Rome, $<\mathrm{ftp}$ //ftp.fao.org/docrep/fao/012/ak97le/ak971e00.pdf >

Center for International Comparisons n.d., The Penn World Table, University of Pennsylvania, Philadelphia.

Chenery, H., Robinson, S. and Syrquin, M. 1986, Industrialisation and Growth: A comparative study, Oxford University Press for The World Bank, New York.

Etheridge, W. S. 1981, 'Demand for metals', Materials in Engineering, vol. 2 (March), pp. 131-40.

Food and Agriculture Organization (FAO) 2002, World Agriculture: Towards 2015/2030-summary report, Food and Agriculture Organization of the United Nations, Rome.

Food and Agriculture Organization (FAO) 2006, World Agriculture: Towards 2030/2050 - interim report, Food and Agriculture Organization of the United Nations, Rome.

Garnaut, R., Howes, S., Jotzo, F. and Sheehan, P. 2008,Emissions in the Platinum Age: the implications of rapid development for climate change mitigation, Garnaut Review Working Paper revised draft, 2 May 2008, $<$ www.garnautreview.org.au>

Garnaut, R., and Song, L. 2006, 'China's resources demand at the turning point,' (with Ross Garnaut), Chapter 14 in R. Garnaut and L. Song (eds), The Turning Point in China's Economic Development, Asia Pacific Press: Canberra, pp. 276-293.

Garnaut, R., Song, L. and Yao, Y. 2006, 'Impact and significance of SOE restructuring in China', The China Journal, no. 55 (January), pp. 35-66.

Grossman, G. and Krueger, A. 1995, 'Economic growth and environment', Quarterly Journal of Economics, vol. 110, no. 2, pp. 353-77.

Haggard, S. 1990, Pathways from the Periphery: The politics of growth in the newly industrialising economies, Cornell University Press, Ithaca, NY.

He, J., Li, S. and Polaski, S. 2007, 'China's economic prospects 2006-2020', Carnegie Papers, no. 83 (April). 
Huang, Y. and Tao, K. 2010, Causes and remedies of China's external imbalances, China Center for Economic Research Working Paper No. E2010002, 25 February 2010, Peking University, Beijing.

Hwang, K. H. and Tilton, J. E. 1990, 'Leapfrogging, consumer preferences, international trade and the intensity of metal use in less developed countries', Resources Policy, September, pp. 210-24.

International Iron and Steel Institute 1972,Projection 85: World steel demand, International Iron and Steel Institute, Brussels.

International Monetary Fund (IMF) 2005a, 'Will the oil market continue to be tight?', World Economic Outlook, April, International Monetary Fund, Washington, DC.

International Monetary Fund (IMF) 2005b, 'Global imbalances: a savings and investment perspective', World Economic Outlook, September, International Monetary Fund, Washington, DC.

Kuznets, S., 1955, 'Economic growth and income inequality', American Economic Review, vol. 45, no. 1, pp. 1-28.

Leontief, W., Koo, J., Nasar, S. and Sohn, I. 1983, The Future of Non-Fuel Minerals in the US and World Economy, Lexington Books, Lexington, Mass.

Lohani, P. R. and Tilton, J. E. 1993, 'A cross-section analysis of metal intensity of use in the less developed countries', Resources Policy, June, pp. 145-54.

McKay, H. 2008, Metal intensity in comparative historical perspective: China, North Asia, the United States \& Kuznets curve, Global Dynamic Systems Centre Working Paper 006, The Australian National University, Canberra.

McKay, H. and Song, L. 2009, 'Global implications of China as the manufacturing powerhouse', in R. Garnaut, L. Song and W. T. Woo (eds), China's New Place in the World in Crisis: Economic, geopolitical and environmental dimensions, ANU E Press and The Brookings Institution Press, Canberra and Washington, DC, pp. 261-302.

McKibbin, W. 2006, 'Global energy and environmental impacts of an expanding China" China and the World Economy vol. 14, no 4, pp. 38-56.

Maddison, A. 2003, The World Economy: Historical statistics, Organisation for Economic Cooperation and Development, Paris.

Maddison, A. 2010, Statistics on world population, GDP and per capita GDP, 1-2008AD, Internet file, <http://www.ggdc.net/maddison/articles/ruggles. $\operatorname{pdf}>$ 
Malenbaum, W. 1973, Material Requirements in the United States and Abroad in the Year 2000, University of Pennsylvania Press, Philadelphia.

Malenbaum, W. 1975, 'Law of demand for minerals', Proceedings of the Council of Economics, 104th Annual Meeting of the American Institute of Mining, Metallurgical and Petroleum Engineers, pp. 145-55.

Malenbaum, W. 1978, World Demand for Raw Materials in 1985 and 2000, McGraw-Hill, New York.

National Bureau of Statistics (NBS) various years, China Statistical Yearbook, China Statistics Press, Beijing.

Sohn, I. 2006, 'Long-term projections of non-fuel minerals: we were wrong, but why?', Resources Policy, vol. 30, pp. 259-84.

United Nations Development Programme (UNDP) 2010, China Human Development Report 2009/10. China and a sustainable future: towards a low carbon economy and society, China Translation and Publishing Corporation, Beijing.

Wang, X. 2007, Pattern and sustainability of China's economic growth towards 2020, Presented at the ACESA 2007 Conference: China's Conformity to the WTO: Progress and Challenges.

World Bank n.d., World Development Indicators, Online database, The World Bank, Washington, DC.

World Metal Statistics Yearbook, various issues, International Steel Association, Brussels, Belgium.

Zellner, A. 1962, 'An efficient method of estimating seemingly unrelated regressions and tests for aggregation bias', Journal of the American Statistical Association, vol. 57, pp. 348-68.

\section{Acknowledgments}

We thank Yixiao Zhou for her help with assembling the data used in the modelling exercise. 


\section{Assessing China's energy conservation and carbon intensity: how will the future differ from the past?}

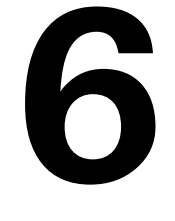

\section{ZhongXiang Zhang}

\section{Introduction}

China's spectacular economic growth since 1978 has been heavily dependent on burning dirty coal. This has given rise to unprecedented environmental pollution and health risks. On top of these domestic environmental stresses, projected global climate change is expected to pose additional threats to China in the foreseeable future.

As the world's largest emitter of carbon dioxide, China is facing great pressure inside and outside international climate negotiations to be more ambitious in combating climate change. China cannot afford to continue on the conventional path of encouraging economic growth at the expense of the environment, whether it looks at the issue from a domestic or international perspective. A range of environmental concerns and pressures has sparked China's determination to improve energy efficiency and to increase the use of clean energy in order to help its transition to a low-carbon economy.

China achieved a quadrupling of its gross domestic product (GDP) with only a doubling of energy consumption between 1980 and 2000 (Zhang 2003). Following the trends of the 1980s and 1990s, the US Energy Information Administration (EIA 2004) estimated that China's carbon dioxide emissions were not expected to catch up with the world's largest carbon emitter until 2030. China's energy use has, however, surged since the turn of this century - almost doubling between 2000 and 2007. Although rates of economic growth were similar in the two periods, the rate of growth in China's energy use during this period (9.7 per cent per annum) was more than twice that of the previous two decades ( 4.25 per cent per annum) (NBS 2009). This change in energy intensity was responsible for an increase of 20 million tonnes of carbon emissions ( $\mathrm{mtc}$ ) during the period 200107, compared with a reduction of 576 mtc during the period 1980-2000 (Zhang 2009d). As a result, China became the world's largest carbon emitter in 2007. 
To reverse this trend, China has incorporated a requirement that energy use per unit of GDP (energy intensity) be cut by 20 per cent during the eleventh five-year-plan period, running from 2006 to 2010. This is widely considered an important step towards building a 'harmonious society' through 'scientific development'. Just before the Copenhagen climate summit, China further pledged to cut its carbon intensity by $40-45$ per cent by 2020 relative to its 2005 levels in order to help reach an international climate change agreement at Copenhagen or beyond.

This chapter focuses on assessing China's energy conservation to date and its proposed carbon intensity target. ${ }^{1}$ It first discusses China's own efforts towards saving energy, cutting pollution and promoting the widespread use of renewable energy. Next, to put China's proposed carbon intensity target into perspective, the chapter seeks to answer a number of issues related to the proposed carbon intensity goal for 2020: is the target as challenging as the energy-saving goals set in the current eleventh five-year economic blueprint; to what extent would it drive China's emissions below projected baseline levels; and if the commitment were met, would China will fulfil its proportionate part of a coordinated global commitment to stabilise the concentration of greenhouse gas emissions in the atmosphere at the level that the Copenhagen meeting agreed was desirable.

As long as China's pledges are in the form of carbon intensity, the reliability of emissions and GDP data matters. The chapter goes on to address reliability issues concerning China's statistics on energy and GDP. Given that China has shifted control over resources and decision-making to local governments during the past three decades, effective environmental protection must be placed in the context of government decentralisation.

The chapter concludes that there is a need to carefully examine those objective and subjective factors that lead to the lack of local officials' cooperation with national policy on the environment, and also that strict implementation and coordination of official policies and measures are of paramount importance in meeting China's existing energy-saving goal in 2010, its proposed carbon intensity target in 2020 and whatever climate commitments China adopts for beyond 2020 .

1 See Zhang $(2000,2009 a, 2009 b, 2009$ c) for detailed discussion of China's climate strategies regarding the format and time frame that it would take on climate commitments. 


\section{Increasing energy efficiency and cutting pollutants}

While China has been calling for energy savings since the early 1980s, the quantitative target on energy efficiency in the current five-year (2006-10) economic plan is an important new development.

China achieved a quadrupling of its GDP with only a doubling of energy consumption between 1980 and 2000 (Figure 6.1). However, from 2002 China experienced faster growth of energy consumption than of economic output, which translates into rising energy intensity. The changing trend on energy efficiency reflects the completion by about the turn of the century of the reductions of energy use associated with the movement towards market pricing of energy as a result of reforms in the 1980s and 1990s. The change in the trajectory of energy intensity that is necessary to meet the new targets suggests that the attainment of the targets will be extremely challenging (Zhang 2005, 2007d).

Industry accounts for about 70 per cent of the country's total energy consumption (Zhang 2003), so that this sector is crucial for China to meet its own goal. The Chinese government has made great efforts towards changing the current energy-inefficient and environmentally unfriendly pattern of industrial growth. China is exploring industrial policies to promote industrial upgrading and energy conservation. With a surge in energy use in heavy industry, the Chinese government started levying export taxes in November 2006 on energy and resource-intensive products to discourage their export and to save scarce energy and resources. These include a 5 per cent export tax on oil, coal and coke; a 10 per cent tax on revenues from sale of non-ferrous metals, some minerals and 27 other iron and steel products; and a 15 per cent tax on revenues from copper, nickel, aluminium and other metallurgical products. ${ }^{2}$

From July 2007, China eliminated or cut export tax rebates under the value added tax for 2831 export items. This is considered the boldest move to rein in exports since China joined the World Trade Organisation (WTO). Among the affected items - which account for 37 per cent of all traded products - are 553 highly energy-consuming, highly-polluting and resource-intensive products, such as cement, fertiliser and non-ferrous metals. The export tax rebates on these products were completely eliminated. This policy will help to enhance energy efficiency and rationalise energy and resource-intensive sectors as well as contribute to macro-economic policy objectives (Zhang 2008).

2 See Zhang (2009c) for discussion of links between China's own export taxes and carbon tariffs proposed in US climate legislation. 
On the energy-saving front, China established the 'Top 1000 Enterprises Energy Conservation Action Program' in April 2006. This program covers 1008 enterprises in nine key energy supply and consuming industrial sub-sectors. These enterprises each consumed at least 180000 tonnes of coal equivalent (tce) in 2004, and together consumed 33 per cent of the national total and 47 per cent of industrial energy consumption in 2004. The program aims to save 100 million tce cumulatively during the period 2006-10, thus making a significant contribution to China's overall goal of a 20 per cent energy intensity improvement (NDRC 2006a). In May 2006, empowered by the State Council, the National Development and Reform Commission (NDRC), China's top economic planning agency, signed energy-saving responsibility agreements with these enterprises. To ensure that the goal is met, achieving energy efficiency improvements has become a criterion for job performance evaluations of the heads of these enterprises. The first year's results of the program's implementation are encouraging, with more than 95 per cent of these enterprises appointing energy managers and the program achieving energy savings of 20 million tce in 2006 (NDRC and NBS 2007). In 2007, 38.2 million tce of energy was saved-almost doubling the amount of energy saved in 2006. If savings continue at the 2007 rate, the top-1000 program will exceed its target (NDRC 2008b).

\section{Figure 6.1 Energy use per unit of GDP in China, 1990-2007 (tonnes of coal equivalent per US\$1000 in 1980 prices)}

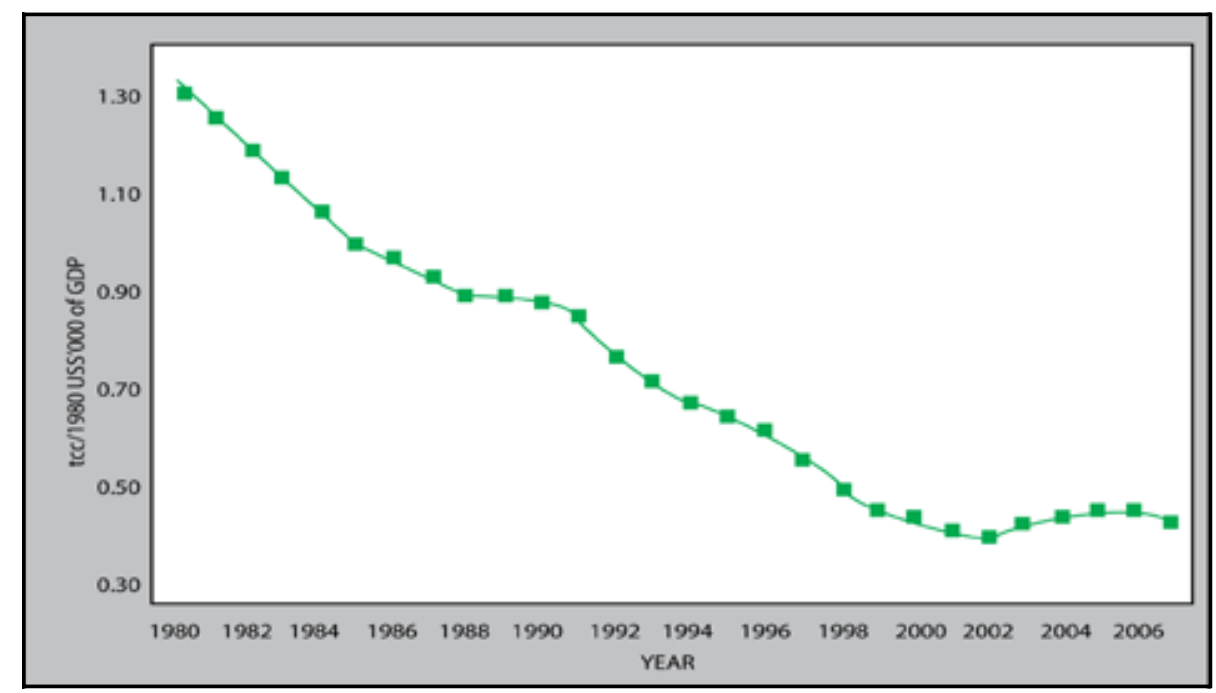

Source: Based on National Bureau of Statistics (NBS) various years, China Statistical Yearbook, China Statistics Press, Beijing. 
Power generation is the largest coal consumer, currently consuming more than half of the total used in China. This share is expected to rise well above 60 per cent in 2020. Thus, efficient coal combustion and power generation is of paramount importance to China's energy savings and pollution reduction. To that end, China has adopted a policy of accelerating the closure of thousands of small, inefficient coal and oil-fired power plants. Units facing closure include those below 50 megawatts (MW), those below $100 \mathrm{MW}$ and in operation for more than 20 years, those below $200 \mathrm{MW}$ and having reached the end of their design life, those with a coal consumption per unit of power output 10 per cent higher than the provincial average or 15 per cent higher than the national average, and those that fail to meet environmental standards. The total combined capacity to be decommissioned is set at 50 gigawatts (GW) during the period 2006-10. By the end of 2008, China had closed small plants with a total capacity of $34.2 \mathrm{GW}$, relative to a total capacity of $8.3 \mathrm{GW}$ decommissioned during the period 2001-05 (NDRC 2008a). By the end of the first half of 2009, the total capacity of decommissioned smaller and older units had increased to $54 \mathrm{GW}$, meeting the 2010 target one and half years ahead of schedule ('SO2 cutting goal expected to come ahead of schedule', 7 July, Sina Net, <http://finance.sina.com. cn/roll/20090707/04346447872.shtml>).

The Chinese government's policy has concurrently focused on encouraging the construction of larger, more efficient and cleaner units. By 30 June 2009, 64 per cent of coal-fired units had capacities of $300 \mathrm{MW}$ or more (Wang and Ye 2009). China's power industry has listed supercritical power generation technology as a key development focus due to its higher thermal efficiency and relatively low unit investment costs. As a result, an increasing number of newly built plants are more efficient supercritical (SC) or ultra-supercritical (USC) plants. By 2007, the share of SC and USC units in total coal-fired generation capacity was about 12 per cent. In comparison, the corresponding share is about 70 per cent in Japan and 30 per cent in the United States. The share of USC plants in total coalfired generation capacity is expected to grow to 15 per cent by 2010 and 30 per cent by 2020 (Huang 2008; IEA 2009a).

For residential buildings, China has taken three steps to improve energy efficiency. The first step requires a 30 per cent cut in energy use relative to typical Chinese residential buildings designed in 1980-81. Second, China requires that new buildings be 50 per cent more efficient by 2010. Third, the energy-saving goal is to be increased to 65 per cent for new buildings by 2020 (Zhang 2005, 2008). Tianjin is the first metropolitan city in China to embark on reform of heat supply and charges. By the end of 2006, 73.5 million square metres of energyefficient residential building space had been built in this city, accounting for 48 per cent of total residential buildings (Zheng and You 2007). In Beijing, the building sector consumed 28 per cent of total energy use in 2004. By the end 
of 2004, 175.2 million sq $\mathrm{m}$ of energy-efficient residential building space had been built in China's capital, 37 per cent of which met the requirement for a 30 per cent increase in energy efficiency. The remaining 62.9 per cent met the '50 per cent more energy-efficient' standards. These energy-efficient buildings in Beijing accounted for 65 per cent of its total residential buildings. Beijing's plan is for all new residential buildings to meet the ' 65 per cent more energy-efficient' standards by 2010 - one decade ahead of the national schedule (BMCDR 2006).

In the transport sector, the excise tax for vehicles has been adjusted over time to provide incentives for the purchase of energy-efficient cars. The excise tax levied at the time of purchase was first introduced in 1994. The rate increases with the size of the engine - set at 3 per cent for cars with engines of 1 litre or less, 8 per cent for cars with engines of more than 4 litres and 5 per cent for cars with engines in between. These tax rates for cars remain unchanged. The new vehicle excise tax, implemented since April 2006, has broadened the tax base from the existing range of 3-8 per cent to 3-20 per cent and to six categories of engine size. Table 6.1 demonstrates clearly the large, upward adjustment in the consumption tax on fuel-guzzling cars over time. Moreover, China cut the purchase tax rate for cars with engines of 1.6 litres or less from the normal rate of 10 per cent to 5 per cent in 2009 and 7.5 per cent in 2010. While this rate cut is motivated by the need to stimulate the economy during the economic crisis, it practically benefits saving energy and cutting pollution as well.

Table 6.1 Consumption tax rates for cars in China (per cent)

\begin{tabular}{lccc}
\hline Engine size (litres) & $\begin{array}{c}\text { Excise tax since } \\
\text { 1 January 1994 }\end{array}$ & $\begin{array}{c}\text { Excise tax since } \\
\text { 1 April 2006 }\end{array}$ & $\begin{array}{c}\text { Excise tax since } \\
\text { 1 September 2008 }\end{array}$ \\
\hline 1.0 or less & 3 & 3 & 1 \\
$1.0<$ engine $\leq 1.5$ & 5 & 3 & 3 \\
$1.5<$ engine $\leq 2.0$ & 5 & 5 & 5 \\
$2.0<$ engine $\leq 2.5$ & 5 & 9 & 9 \\
$2.5<$ engine $\leq 3.0$ & 5 & 12 & 12 \\
$3.0<$ engine $\leq 4.0$ & 5 & 15 & 25 \\
Greater than 4.0 & 8 & 20 & 40 \\
\hline
\end{tabular}

Sources: 'Special topic on paying close attention to adjustments in consumption tax policy, Sina Net, $<$ http://finance.sina.com.cn/focus/gzxfstz/index.shtml>; 'Adjustments for vehicle excise taxes will take place since September 1, up for cars with large engines and down for small cars to 1 per cent', People Net, 14 August, <http://auto.people.com.cn/GB/1049/7663221.html>

China has set fuel economy standards for its rapidly growing passenger vehicle fleet even more stringent than those in Australia, Canada and the United States, although they are less stringent than those in Japan and the European Union (Figure 6.2). Implemented in two phases, the standards classify vehicles into 16 weight classes, covering passenger cars, sports utility vehicles (SUVs) and multipurpose vans. Converted to the US Corporate Average Fuel Economy 
(CAFE) test cycle, new vehicles' average fuel economy standards in China are projected to reach 36.7 miles per gallon (6.5 litres per $100 \mathrm{~km}$ ) in 2008 (An and Sauer 2004).

\section{Figure 6.2 Comparison of fuel economy standards for vehicles}

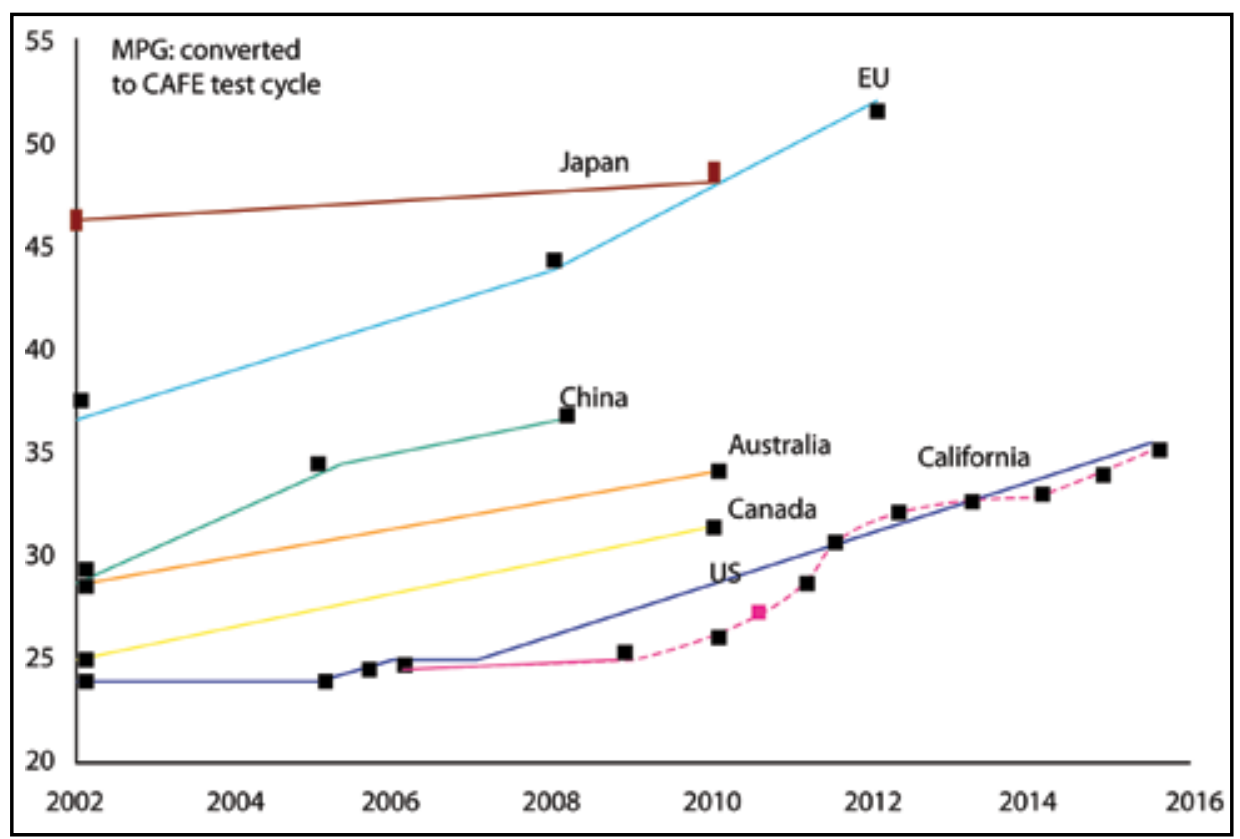

Notes: Dotted lines denote proposed standards; MPG = miles per gallon.

Source: Adapted from An, F. and Sauer, A. 2004, Comparison of Passenger Vehicle Fuel Economy and GHG Emission Standards Around the World, December, Pew Center on Global Climate Change, Arlington, Va, $<$ http://www.pewclimate.org/docUploads/Fuel per cent20Economy per cent20and per cent20GHG per cent20Standards_010605_110719.pdf>

In the meantime, growing Chinese cities are giving priority to public transport and are promoting efficient public transport systems. Given an inevitable increase in the number of vehicles on the road, however, China has also taken significant steps to control vehicle emissions. After the phasing out of leaded gasoline nationwide in July 2000, the State Environmental Protection Agency of China requires all new light-duty vehicles sold after April 2001 to meet State Phase I (similar to Euro I) vehicle emission standards and after 1 July 2004 to meet State Phase II (similar to Euro II) standards across China. Beginning on 1 July 2007, China started implementing State Phase III (similar to Euro III) vehicle emission standards, with State Phase IV (similar to Euro IV) vehicle emission standards scheduled to be introduced on 1 July 2010 (Table 6.2). Pollution from the State Phase III standards is 30 per cent lower than that from State Phase II standards. Pollution from State Phase IV standards goes below 60 per cent of that from State Phase II standards ('Delays in the implementation of state phase 
III vehicle emission standards', Xinhua Net, 7 July, <http://auto.sina.com.cn/ news/2007-07-07/1015290457.shtml>). Clearly, vehicle emission standards in China have become increasingly stringent over time. New vehicles that do not comply with the new standards cannot be sold in China. While China is at about the same levels of vehicle emission standards as India and most Association of South-East Asian Nations (ASEAN) countries, it is a couple of years ahead of these countries in its schedules to implement these regulations. Also, while China still lags behind the European Union's emissions requirements for new vehicles, the gap with the EU requirements has gradually been reduced - from about nine years in 2001 to five and a half years in 2010. Clearly, these new standards will help to reduce substantially environmental costs.

Table 6.2 Vehicle emission standards and the time to enter into force in China, ASEAN and the European Union

\begin{tabular}{|c|c|c|c|c|c|}
\hline Region & Euro I & Euro II & Euro III & Euro IV & Euro V \\
\hline $\begin{array}{l}\text { European } \\
\text { Union }\end{array}$ & $\begin{array}{l}\text { July } \\
1992\end{array}$ & $\begin{array}{l}\text { January } \\
1996\end{array}$ & $\begin{array}{l}\text { January } \\
2000\end{array}$ & $\begin{array}{l}\text { January } \\
2005\end{array}$ & $\begin{array}{l}\text { September } \\
2009\end{array}$ \\
\hline China & $\begin{array}{l}\text { April } \\
2001\end{array}$ & $\begin{array}{l}\text { July } \\
2004\end{array}$ & $\begin{array}{l}\text { July } \\
2007\end{array}$ & $\begin{array}{l}\text { July } \\
2010\end{array}$ & \\
\hline Beijing & 1999 & $\begin{array}{l}\text { August } \\
2002\end{array}$ & $\begin{array}{l}\text { December } \\
2005\end{array}$ & $\begin{array}{l}\text { First half } \\
2008\end{array}$ & \\
\hline India & 2000 & 2005 & 2010 & & \\
\hline ASEAN & & $\begin{array}{l}\text { December } \\
2005 \\
\text { (targeted) }\end{array}$ & & $\begin{array}{l}\text { December } \\
2010 \\
\text { (targeted) }\end{array}$ & \\
\hline Indonesia & & Early 2006 & $\begin{array}{l}\text { First quarter } \\
2007\end{array}$ & 2012 & \\
\hline Malaysia & & Mid 2006 & & 2010 & \\
\hline Philippines & & $\begin{array}{l}\text { December } \\
2006\end{array}$ & & 2010 & \\
\hline Singapore & & 2005 & & $\begin{array}{l}\text { October } \\
2006 \text { (diesel) }\end{array}$ & \\
\hline Thailand & & & $\begin{array}{l}\text { Early } \\
2005\end{array}$ & 2010 & \\
\hline Vietnam & & $\begin{array}{l}\text { July } \\
2007\end{array}$ & & 2012 & \\
\hline
\end{tabular}

Source: Zhang, Z. X. 2008, 'Asian energy and environmental policy: promoting growth while preserving the environment', Energy Policy, vol. 36, pp. 3905-24.

\section{The use of renewable energy}

Concerns about climate change and other environmental problems and health risks have sparked China's plans to pursue alternative energy sources to meet 
the country's increasing energy needs. China has targeted alternative energy sources to meet up to 15 per cent of the nation's energy requirements by 2020 up from 8.9 per cent in 2008. While this is a big step up from the previous goal of 10 per cent by 2020, early success is encouraging officials to develop even more ambitious targets. Under the plan as its stands, China aims to have an installed capacity of $300 \mathrm{GW}$ for hydropower (including large hydropower), 30 GW for wind power and $30 \mathrm{GW}$ for bio-power (power generated from biomass), and to produce 10 million tonnes of ethanol and 2 million tonnes of bio-diesel by 2020 (Zhang 2007b).

The European Union is widely considered to be the world's leader in renewable energy. The European Union is aiming for renewable energy to meet 12 per cent of its primary energy by 2010 and 20 per cent by 2020 from its current level of 6.5 per cent (European Commission 2007a, 2007b). At first glance, the European Union's goal of tripling the share of renewable energy from the current level to 20 per cent by 2020 seems even more ambitious than China's renewable energy goal. Because energy demand in China grows at least three times faster than in the European Union, doubling renewable energy in China's total energy mix by 2020 requires renewable energy in China to grow at a rate four times that in the European Union.

In addition to setting extremely ambitious renewable energy goals, China is making large efforts to meet these goals. China invested US\$34.6 billion in renewable energy in 2009, causing the United States to lose the top spot for the first time in five years, coming in a distant second with a total investment of US\$18.6 billion. In terms of renewable energy investment as a percentage of GDP, China, with 0.39 per cent, invested three times more than the United States, with 0.13 per cent, in 2009 . With an installed capacity of $52.5 \mathrm{GW}$, China ranked second in the world's total renewable energy capacity in 2009-just slightly behind the United States, with 53.4 GW (Pew Charitable Trusts 2010).

With wind power identified as a priority for diversifying China's energy mix, this sector has been the primary recipient of renewable energy investment and favourable policies in recent years. In 2003, China adopted the Wind Power Concession Program as its primary strategy to further promote wind power development. Feed-in tariffs enacted in 2005 took effect on 1 January 2006. This government-run program auctions off development rights for wind power projects of $100 \mathrm{MW}$ or more for a 25-year period, which includes a guaranteed tariff for the first 30000 hours as well as concessionary operation agreements. This on-grid wind power tariff is decided through a competitive bidding process. If the tariff is higher than the reference on-grid tariff of de-sulphurised coal-fired power, the difference will be shared in the selling price at the provincial and national grid levels. For the remainder of the period (namely, after the first 30 000 hours until the ending of the total concession period of 25 years), the wind 
power tariff is set to be equal to the average local on-grid tariff. Other policies have included a halving of the value-added tax (VAT) for wind power, from the normal rate of 17 per cent to 8.5 per cent; lower duty rates levied on domestic investment in wind power (6 per cent compared with the normal rate of 23 per cent); and no duties for equipment imported for renewable energy technologies in joint ventures. Some local governments have provided even more favourable policies. For example, in Inner Mongolia, a VAT of 6 per cent is levied on wind power.

With these favourable policies in place, the total wind power capacity installed doubled between 2003 and 2005, reaching 1.3 GW in 2005. With China's Renewable Energy Law entering into force in January 2006, the pace of installations accelerated considerably. The total installed wind power capacity rose to $2.6 \mathrm{GW}$ in 2006, with new installations in that year alone amounting to more than the combined total in the past 20 years. Wind power capacity in China has doubled in each of the past five years (Figure 6.3). With total installed capacity of $5.9 \mathrm{GW}$ at the end of 2007, China had already surpassed its goal to achieve $5 \mathrm{GW}$ by 2010. With new installations of $6.3 \mathrm{GW}$ and a total installed capacity of $12.2 \mathrm{GW}$ in 2008, China overtook India in wind power installations. During this process, local wind turbine makers - such as Sinovel Wind, Goldwind Science and Technology and Dongfang Electric - accounted for an increasing share of total new installations. Together, they now supply more than 50 per cent of a market dominated by foreign firms until 2008. Sinovel and Goldwind are now among the world's top-five turbine manufacturers.

In its response to the economic crisis, the Chinese government has identified the development of wind power as an area of economic growth. With new installations of $13.8 \mathrm{GW}$ in China-relative to that of $10 \mathrm{GW}$ in the United States - China overtook the United States as the world's top wind power market in 2009. With a total installed capacity of $25.8 \mathrm{GW}$, China slipped past Germany to take second place in total wind power installations in 2009 (Global Wind Energy Council 2010). While the United States continues to have a comfortable lead in terms of total installed capacity, at this growth rate of new capacity installations, China will overtake the United States in 2010 to become the global leader in installed capacity and will have met its 2020 target of $30 \mathrm{GW} 10$ years ahead of schedule. Indeed, since 2008, China has been planning and designing the 'mega-wind power base program', which aims to build a combined wind capacity of $127.5 \mathrm{GW}$ by 2020 in six selected Chinese provinces. This program is expected to increase China's total installed capacity of wind power to $150 \mathrm{GW}$ or more by 2020 - five times the 30 GW target set as late as September 2007. 
Figure 6.3 Cumulative installed wind power capacity by country, 1980-2009

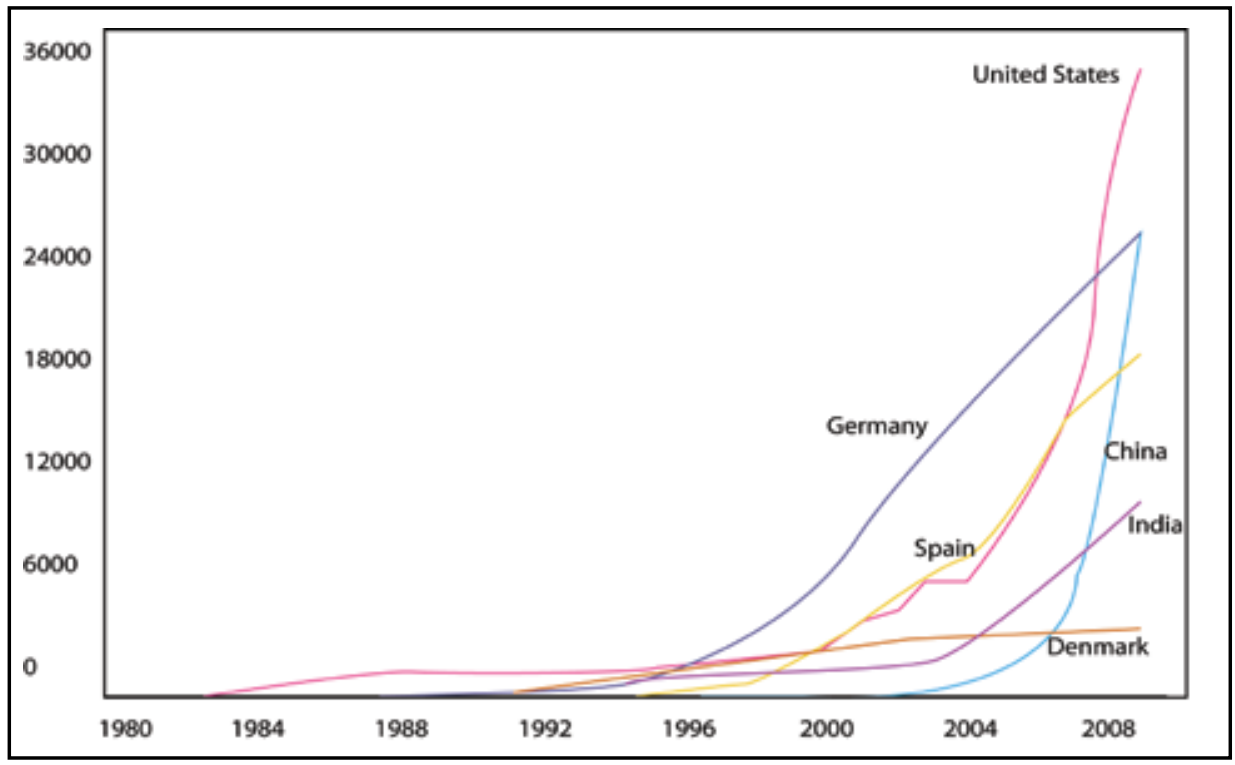

Sources: Based on data from Global Wind Energy Council 2010, Global Wind 2009 Report, March, Global Wind Energy Council, Brussels, <http://www.gwec.net/fileadmin/documents/Publications/Global_ Wind_2007_report/GWEC_Global_Wind_2009_Report_LOWRES_15th. per cent20Apr..pdf >; Earth Policy Institute 2008, Global Wind Power Capacity Reaches 100,000 Megawatts, 4 March, Earth Policy Institute, Washington, DC, <http://www.earth-policy.org/Indicators/Wind/2008.htm>

With both power demand and new installations of wind power capacity increasing faster than planned, and further deterioration of the environment, China is set to raise its wind power target. The country now aims to have at least $100 \mathrm{GW}$ of wind power capacity in operation by 2020. This revised target is $70 \mathrm{GW}$ higher than the current target, four times its current total wind power capacity and more than the United Kingdom's entire current power capacity. In addition, the NDRC enacted feed-in tariffs for wind power, which took effect on 1 August 2009. This means the end of the controversial bidding-based program that had been in place since 2003. According to the quality of wind energy resources and the conditions of engineering construction, four wind energy areas are classified throughout China. Accordingly, on-grid tariffs are set at RMB0.51, RMB0.54, RMB0.58 and RMB0.61 per kilowatt hour (kW.h) as benchmarks for wind power projects across the nation (NDRC 2009). The levels are comparable with the tariffs the NDRC approved in the past several years in most regions and are substantially higher than those set through bidding. By letting investors know the expected rate of return on their projects through announcing on-grid tariffs, the Chinese government aims to encourage the development of wind energy resources of good quality. In the meantime, this will encourage wind 
power plants to reduce the costs of investment and operation and increase their economic efficiency, thus promoting the healthy development of the whole wind industry in China.

It should be emphasised, however, that while China has established a very ambitious wind power target, many local power grids are simply too small to carry all the wind power being generated. Wind turbines often have to wait four months or more before they are hooked up to the power grid. Of $5.9 \mathrm{GW}$ of total installed capacity at the end of 2007, only 4 GW were plugged into the grid (Cyranoski 2009). In the first quarter of 2010, the amount of wind power not used because it was not hooked into the grids reached almost 0.3 terawatt hours (TW.h). This is a significant amount of generation, given that the total wind power generation reached only 0.5 TW.h in the same period (Chen 2010). Thus, China needs to improve its power grids and coordinate the development of wind power with the planning and construction of power grids. New transmission lines will have to be constructed as more wind farms are built. Moreover, given the significantly increased wind power capacity planned for 2020, China should now place more emphasis on companies ensuring the actual flow of power to the grid rather than just meeting capacity. Improving the quality of domestically made turbines is crucial for this endeavour. While less costly, domestic Chinese wind turbines break down more often and have overall capacity factors several percentage points lower than foreign models. This few percentage points difference could make a difference between a wind farm that is economically viable and one that is not.

\section{China's proposed carbon intensity target: ambitious or business as usual?}

Just before the Copenhagen climate summit, China pledged to cut its carbon intensity by 40-45 per cent by 2020 relative to its 2005 levels. A lot of discussion has since focused on whether such a pledge is ambitious or just represents business as usual (for example, Qiu 2009). China considers it very ambitious, whereas some Western scholars (for example, Levi 2009 but not Garnaut et al. 2009) view it as just business as usual. There are several ways to evaluate this issue.

One way is to see whether this proposed carbon intensity goal for 2020 is as challenging as the energy-saving goals set in the current eleventh five-year economic blueprint. This requires first the establishment of why the current 20 per cent energy-saving goal is considered very challenging. As discussed earlier, China set a goal of cutting energy use per unit of GDP by 20 per cent by 2010 relative to its 2005 levels. In 2006 - the first year of this energy efficiency 
drive - while China reversed the rise in its energy intensity in the first half of the year, energy intensity declined by only 1.8 per cent over the entire year. Although this decline was a first since 2003, it was far short of the targeted 4 per cent. Among the 31 Chinese provinces or equivalent, only Beijing met that energy-saving goal in 2006, cutting its energy use per unit of GDP by 5.3 per cent, followed by Tianjin, another metropolitan city in China, with an energy intensity reduction of 4 per cent, Shanghai by 3.7 per cent, Zhejiang by 3.5 per cent and Jiangsu by 3.5 per cent (NBS et al. 2007). ${ }^{3}$ In 2007, despite concerted efforts towards saving energy, the country cut its energy intensity by 4 per cent (NBS et al. 2009). Beijing continued to take the lead, cutting its energy intensity by 6 per cent, followed by Tianjin by 4.9 per cent and Shanghai by 4.7 per cent (NBS et al. 2008). This clearly indicated Beijing's commitment to the 2008 'Green' Olympic Games. In the meantime, however, there were seven provinces whose energy-saving performances were below the national average. The first year in which China exceeded the overall annualised target (4.4 per cent) for energy savings was 2008, when it cut its energy intensity by 4.6 per cent (NBS et al. 2009). This was due partly to the economic crisis that reduced overall demand-in particular, the demand for energy-intensive products. Overall, energy intensity was cut by 10.1 per cent in the first three years of the plan relative to 2005 levels. This suggests that the country needs to achieve almost the same overall performance in the remaining two years as it did in the first three years in order to meet that national energy intensity target. Moreover, as discussed in the next section, these reductions in China's energy intensity have already factored in the revisions of China's official GDP data from the second nationwide economic census - part of the government's continuing efforts to improve the quality of its statistics, the accuracy of which has been questioned by many inside and outside China. Such revisions show that China's economy grew faster and shifted more towards services than previously estimated, thus benefiting the energy-intensity indicator. Even so, it will not be easy for China to achieve its 20 per cent energy-saving goal. The new carbon intensity target set for 2020 requires an additional 20-25 per cent reduction in emissions intensity, on top of the effects of the existing energy intensity target. Achieving this will clearly be even more challenging and costly for China.

How far does this carbon intensity target drive China's emissions below its projected baseline levels? If this is met, does China play its proportionate part in a coordinated global commitment to stabilise the concentration of greenhouse gas emissions in the atmosphere at the desirable level? The World Energy Outlook 2009 (IEA 2009b) has incorporated many policies into the baseline projection that were not incorporated in the World Energy Outlook 2007 (IEA 2007). This projection puts China's baseline carbon emissions at 9.6 gigatonnes

3 See Zhang (2007a, 2007c, 2007d) for detailed discussion of why Beijing recorded the most success in achieving its energy-saving goals. 
of carbon dioxide (GtCO2) in 2020. Under the ambitious 450 parts per million (ppm) of carbon dioxide equivalent scenario, China's carbon dioxide emissions are projected to be 8.4 GtCO2 by $2020-1.2$ GtCO2 less than that in the baseline (IEA 2009b). Now let us put China's proposed carbon intensity target into perspective. My own calculations show that cutting carbon intensity by 40-45 per cent in the period 2006-20 would bring reductions of $0.46-1.2$ GtCO2 in 2020, which is equivalent to a deviation of 4.8-12.7 per cent below the World Energy Outlook 2009 baseline set for China in 2020. Two key points need to be made. First, even the lower end of that range does not represent business as usual, because it represents a deviation of 4.8 per cent below the World Energy Outlook 2009 baseline levels. Second, if China were able to meet its own proposed 45 per cent carbon intensity cut, the country would cut 1.2 GtCO2 of emissions in 2020 from its baseline levels, as is required under the ambitious 450 ppm scenario. That is equivalent to 31.6 per cent of what the world would need to do in 2020 under the 450 ppm scenario - a share higher than China's share of the world's total carbon dioxide emissions (28 per cent in 2020). Clearly, the high end of China's target, if met, aligns with the specified obligation that China needs to fulfil under the $450 \mathrm{ppm}$ scenario.

Arguably, China will claim to meet its carbon intensity target as long as it cuts its carbon intensity by 40 per cent in the period 2006-20. This raises the stringency issue of this proposed intensity reduction. The IEA (2009b) estimates that national policies under consideration in China will bring reductions of about 1 GtCO2 in 2020. This suggests a carbon intensity reduction of 43.6 per cent in 2020 relative to its 2005 levels, implying that the low end of China's carbon intensity target is conservative. Is it a big deal to emphasise this few percentage points difference? It might not matter much for a small country, but for China it matters a great deal.

Is there room for China to achieve additional reductions in carbon intensity by 2020, beyond its own targets? It would be hard, but not impossible. Given that many of the policies considered in the World Energy Outlook 2009 that will cut emissions of $1 \mathrm{GtCO} 2$ in 2020 from its baseline levels are not particularly climate motivated, China could accelerate the speed, and scale up the implementation, of such policies and enact additional policies with explicit considerations of climate mitigation and adaptation. This would bring additional reductions in China's carbon intensity.

What, then, is the yardstick or bound on the energy and carbon intensity of the Chinese economy in 2020? Assuming that China's economy grows at the annual average rate of 7.6 per cent used for the World Energy Outlook 2009 and that China is able to limit the growth of energy use to half the growth rate of the economy between 2006 and 2020, China's energy use per unit of GDP would be cut by 42 per cent by 2020, relative to its 2005 levels. This back- 
of-the-envelope calculation assumes an income elasticity of energy demand of 0.5 between 2006 and 2020 - as it was roughly during the 1980s and 1990s. Given that China experienced faster energy consumption growth than economic growth between 2002 and 2005, this elasticity is, however, likely to be higher in the future, which will result in higher emissions growth. Thus, a 42 per cent cut in China's energy intensity by 2020 relative to 2005 levels is considered an upper bound on China's energy intensity target. With carbon-free energy meeting 7.1 per cent of China's total energy needs in 2005 (NBS 2009) and that share mandated to be increased to 15 per cent, this 42 per cent cut in energy intensity is equivalent to a 50 per cent cut in carbon intensity between 2006 and 2020, implying that there is room for China to increase its own proposed carbon intensity reduction. China should therefore aim for a 46-50 per cent cut in its carbon intensity in the period 2006-20. The Intergovernmental Panel on Climate Change (IPCC 2007) recommends developing countries as a group limit their greenhouse gas emissions to 15-30 per cent below their baseline levels by 2020 . This $46-50$ per cent carbon intensity reduction will lead to China's emissions reductions of 15-21 per cent compared with its baseline levels in 2020. That will put China's absolute emissions reductions very much within the IPCC's recommended levels.

\section{China's energy and GDP statistics: reliability issues}

Having an ambitious commitment is one thing. Fulfilling that commitment is another. While the level of China's commitments is crucial in affecting the level and ambition of commitments from other countries, it is more important to know whether the claimed carbon emissions reductions are real. This raises reliability issues concerning China's statistics on energy and GDP.

China is not known for the reliability of its statistics (for example, Rawski 2001). China's refusal to budge on demands by the United States and other industrialised countries for greater transparency and checks at Copenhagen was cited by negotiator after negotiator as a key block to reaching a deal. As long as China's pledges are in the form of carbon intensity, the reliability of emissions and GDP data matter.

Assuming the fixed carbon dioxide emissions coefficients that convert consumption of fossil fuels into carbon dioxide emissions, the reliability of emissions data depends on energy consumption data. Unlike the energy data in the industrial product tables in the China Statistical Yearbook, the statistics on primary energy production and consumption are usually revised in the year after their first appearance. As would be expected, the adjustments made to 
production statistics are far smaller than those made to consumption statistics, because it is easier to collect information on the relatively small number of energy producers compared with the large number of energy consumers. Table 6.3 shows the preliminary and final values for total primary energy consumption and coal consumption in China between 1990 and 2008. Until 1996, revisions of total energy use figures were several times smaller than in the late 1990s and early 2000s. The preliminary figures for total energy use in 1999-2001 were revised upwards by 8-10 per cent. In all three years, these adjustments were driven by upward revisions of 8-13 per cent made to the coal consumption figures to reflect unreported coal production mainly from small, inefficient and highly polluting coalmines. These coalmines were ordered to shut down in a widely publicised nationwide campaign beginning in 1998, although many had reopened because in many cases local governments had pushed back to preserve local jobs and generate tax revenues as well as for personal pay-offs. In recent years, preliminary figures for energy use are almost the same as the final reported ones.

Table 6.3 Preliminary and final values for total primary energy consumption and coal consumption in China, 1990-2008

\begin{tabular}{l|ccc|ccc}
\hline \multirow{2}{*}{ Year } & \multicolumn{4}{|l|}{ Total primary energy consumption } & \multicolumn{3}{|l}{ Total coal consumption } \\
\cline { 2 - 6 } & $\begin{array}{ccccc}\text { Preliminary } \\
\text { value(mtce) }\end{array}$ & $\begin{array}{c}\text { Final } \\
\text { value } \\
\text { (mtce) }\end{array}$ & $\begin{array}{c}\text { Adjustment } \\
\text { (\%) }\end{array}$ & $\begin{array}{c}\text { Preliminary } \\
\text { value } \\
\text { (mtce) }\end{array}$ & $\begin{array}{c}\text { Final } \\
\text { value } \\
\text { (mtce) }\end{array}$ & $\begin{array}{c}\text { Adjustment } \\
\text { (\%) }\end{array}$ \\
\hline 1990 & 980 & 987 & 0.7 & 741 & 752 & 1.5 \\
1991 & 1023 & 1038 & 1.4 & 777 & 790 & 1.6 \\
1992 & 1089 & 1092 & 0.2 & 816 & 826 & 1.3 \\
1993 & 1117 & 1160 & 3.8 & 814 & 866 & 6.5 \\
1994 & 1227 & 1227 & 0.0 & 921 & 921 & 0.0 \\
1995 & 1290 & 1312 & 1.7 & 968 & 979 & 1.1 \\
1996 & 1388 & 1389 & 0.1 & 1041 & 1038 & -0.3 \\
1997 & 1420 & 1378 & -3.0 & 1044 & 988 & -5.3 \\
1998 & 1360 & 1322 & -2.8 & 974 & 920 & -5.5 \\
1999 & 1220 & 1338 & 9.7 & 819 & 925 & 13.0 \\
2000 & 1280 & 1386 & 8.2 & 858 & 939 & 9.5 \\
2001 & 1320 & 1432 & 8.5 & 884 & 955 & 8.0 \\
2002 & 1480 & 1518 & 2.6 & 978 & 1006 & 2.9 \\
2003 & 1678 & 1750 & 4.3 & 1126 & 1197 & 6.3 \\
2004 & 1970 & 2032 & 3.2 & 1334 & 1382 & 3.6 \\
2005 & 2233 & 2247 & 0.6 & 1539 & 1553 & 0.9 \\
2006 & 2463 & 2463 & 0.0 & 1709 & 1709 & 0.0 \\
2007 & 2656 & 2656 & 0.0 & 1846 & 1846 & 0.0 \\
2008 & $2850 *$ & & & $1958 *$ & & \\
\hline
\end{tabular}

mtce $=$ million tonnes of coal equivalent

* Data for energy and coal consumption in 2008 are preliminary values.

Source: Based on National Bureau of Statistics (NBS) various years, China Statistical Yearbook, China Statistics Press, Beijing. 
Similarly, China first releases its preliminary GDP figures and then revises them. The revised GDP figures for the years 2005-08 are subject to further verification based on the second agricultural census released in February 2008 and the second nationwide economic census released in December 2009. With upward revisions of both GDP and the share of services, there is a big variation between the preliminary value of China's energy intensity and the final reported one. As shown in Table 6.4, such revisions lead to a differential between preliminary and final values as large as 45.5 per cent for energy intensity in 2006 . With the government's continuing efforts to improve the quality of China's statistics, such differentials will become less important.

Table 6.4 Reduction in China's energy intensity: preliminary value versus final value (per cent)

\begin{tabular}{ccccc}
\hline Year & Preliminary value & Revised value & Final value & $\begin{array}{c}\text { Differential between } \\
\text { preliminary and } \\
\text { final values }\end{array}$ \\
\hline 2006 & 1.23 (March 2007) & 1.33 (July2007) & 1.79 (July 2008) & 45.5 \\
2007 & 3.27 (March 2008) & 3.66 (July 2008) & 4.04 (June2009) & 23.5 \\
2008 & 4.59 (June 2009) & $5.2^{\text {a }}$ (Dec 2009) & & 13.3 \\
2009 & $3.98^{\text {b } \text { (March 2010) }}$ & & & \\
\hline
\end{tabular}

a) Based on China's revised 2008 GDP from the second nationwide economic census, which raised the growth rate of GDP to 9.6 per cent from the previously reported 9 per cent for that year and the share of services in GDP.

b) Author's own calculation based on the NDRC's reporting that China's energy intensity was cut by 14.38 per cent in the first four years of the eleventh five-year plan relative to its 2005 levels (Xinhua Net 2010, 'NDRC: the 1lth five-year pollution-cutting goals met ahead of the schedule', Xinhua Net, 10 March, $<$ http://news.sina.com.cn/c/2010-03-10/152019834186.shtml >).

Note: The dates when the corresponding data were released are in parentheses.

From the preceding discussion, it follows that GDP figures are even more crucial to the impacts on energy or carbon intensity than are energy consumption and emissions data. In Copenhagen, China eventually compromised to agree to open its emissions data to international consultation and analysis. The European Union has identified building a robust and transparent emissions and performance accounting framework as a key element of implementing the Copenhagen Accord (European Commission 2010). How all this will be worked out remains to be seen. China has not agreed to open its GDP figures to international consultation and analysis. As long as China's commitments are in the form of carbon intensity, establishing a robust and transparent emissions and performance accounting framework is helpful, but not enough to remove international concern about the reliability of China's commitments. The aforementioned revisions of China's GDP figures reflect part of the government's continuing efforts to improve the accuracy and reliability of China's statistics on economic activity. They are certainly not being calculated to make the energy intensity indicator look good to 
the government's advantage, although practically they do benefit this indicator. Still, such revisions have huge implications for meeting China's existing energysaving goal in 2010 and its proposed carbon intensity target in 2020.

\section{Central-local relations, energy savings and emissions reductions}

Given China's vast size and diversity, it is impossible for the central government in Beijing to operate single-handedly in pursuing nationwide energy savings and environmental outcomes. The ability of, and incentives for, lower-level governments to effectively implement energy-saving and pollution-cutting policies is therefore critical, particularly since the past three decades of economic reforms have witnessed a shift in the control over resources and decision making to local governments and enterprises.

This devolution of decision making to local governments has placed environmental stewardship in the hands of local officials. They are concerned primarily with economic growth, because under the current evaluation criterion for officials in China, local officials typically have been promoted based on how quickly they expand their local economies. This distorted incentive system tempts officials to disregard the environmental costs of growth. Moreover, the current fiscal system in China plays a part in driving local governments to seek higher GDP growth because that system makes it hard to reconcile the interests of the central and local governments (Zhang 2007c, 2007d, 2009a). Since the Tax Sharing System (TSS) was adopted in China in 1994, taxes are grouped into those collected by the central government, those collected by local governments and those shared between the central and local governments. All those taxes that have steady sources and broad bases and are easily collected - such as the consumption tax, tariffs and the vehicle purchase tax-are assigned to the central government. The VAT and income tax are split between the central and local governments, with 75 per cent of VAT and 60 per cent of income tax going to the central government. As a result, central government revenue increased by 200 per cent in 1994 relative to its 1993 level. This led the central government's share in total government revenue to go up to 55.7 per cent in 1994 from 22 per cent in the previous year, while its share in total government expenditure rose by just 2 per cent. By 2008, local governments accounted for only 46.7 per cent of total government revenue, while their expenditure accounted for 78.7 per cent of the total government expenditure in China. To cover their expenditure for culture and education, supporting agricultural production, social security and so on, local governments have little choice but to focus on expanding local 
production. This in turn enables them to enlarge their tax revenue by collecting a range of taxes, including urban maintenance and development tax, contract tax, arable land occupation tax and urban land-use tax.

Another example of distortions associated with the tax-sharing scheme in China is related to differentiated tariffs. The NDRC ordered provincial governments to raise power tariffs for eight energy-guzzling industries from 1 October 2006 onwards (Table 6.5), but many local governments failed to implement the differentiated tariffs that charged more for companies classified as 'eliminated types' or 'restrained types' in these industries, with 14 of them even continuing to offer preferential power tariffs for such industries. The reason for this failure is the lack of incentives for local governments to implement this policy, because all of the revenue collected from these additional charges goes to the central government. To provide incentives for local governments, these revenues should be assigned to local governments, with the central government requiring local governments to use the revenue specifically for industrial upgrading, energy savings and emissions cutting (Zhang 2007c, 2007d, 2008, 2009a).

Table 6.5 Differentiated tariffs for eight energy-guzzling industries in China (RMB/kW.h)

\begin{tabular}{l|l|cccc}
\hline \multicolumn{2}{l|}{} & $\begin{array}{c}\text { Existing } \\
\text { additional } \\
\text { charge }\end{array}$ & $\begin{array}{c}\text { Additional } \\
\text { charge since } \\
\mathbf{1} \text { October } \\
\mathbf{2 0 0 6}\end{array}$ & $\begin{array}{c}\text { Additional } \\
\text { charge since } \\
\text { 1 January } \\
\mathbf{2 0 0 7}\end{array}$ & $\begin{array}{c}\text { Additional } \\
\text { charge since } \\
\text { 1 January } \\
\mathbf{2 0 0 8}\end{array}$ \\
\hline $\begin{array}{l}\text { Eight energy- } \\
\text { guzzling } \\
\text { industries }\end{array}$ & $\begin{array}{l}\text { Eliminated } \\
\text { types }\end{array}$ & 0.05 & 0.10 & 0.15 & 0.20 \\
\cline { 2 - 6 } & $\begin{array}{l}\text { Restrained } \\
\text { types }\end{array}$ & 0.02 & 0.03 & 0.04 & 0.05 \\
\hline
\end{tabular}

Source: National Development and Reform Commission (NDRC) 2006b, Suggestions for improving the policy on differentiated tariffs, September, National Development and Reform Commission, Beijing, <http://www.gov.cn/zwgk/2006-09/22/content_396258.htm>

The evidence above suggests the need to carefully examine those objective and subjective factors that lead to the lack of local officials' cooperation on environmental protection and to provide the right incentives for cooperation. One way to ensure local officials realise that they should take the environmental dimensions of their jobs seriously is developing criteria that incorporate energy conservation and environmental performance into the overall evaluation of local officials' performances. As discussed earlier, to ensure the energy-saving goal under the 'Top 1000 Enterprises Energy Conservation Action Program' is reached, achieving energy efficiency improvements has become a criterion for job performance evaluations of the heads of these enterprises. This performancebased approach should be strengthened and extended to ensure that local officials are held accountable for energy savings and pollution cutting in their 
regions. The evaluation of local officials should abandon the sole focus on GDP. Instead, evaluation needs to look not only at the economic growth of a region, but even more at the model and quality of its development. There are some encouraging signs in this direction, but they fall far short of the needs, given the huge challenges China is facing.

Alleviating the financial burden of local governments is another avenue to provide incentives for them to focus on objectives beyond economic growth alone. Enlarging their tax revenue is the key to helping them cover a disproportionate amount of the aforementioned government expenditure. The central government needs to cultivate steady and sizeable sources of revenue for local governments. Enacting property taxes or real estate taxes for local governments is urgently needed. In the TSS adopted in 1994, resource taxes onshore are assigned to local governments, while the central government collects revenue from resource taxes offshore. Currently, resource taxes in China are levied on the basis of the extracted volume of resources. Starting in 1984, resource taxes have been levied at RMB2-5 per tonne of raw coal and RMB8/t of coking coal, with the weighted average of RMB3.5/t of coal. For crude oil, the corresponding tax is levied at RMB8-30/t. While the prices of coal and oil have increased significantly since 1984, the levels of their resource taxes have remained unchanged for the past 25 years. In addition, current resource taxes are levied on only seven types of resources, including coal, oil and natural gas. This coverage is too narrow, falling far short of what is required to conserve resources and protect the environment. Thus, broadening the current coverage of resource taxation and significantly increasing the levied level based on revenues rather than volumes will also help to increase local governments' revenues while contributing to environmental conservation.

\section{Conclusions}

China achieved a quadrupling of its GDP with only a doubling of energy consumption between 1980 and 2000. Since 2002, however, the country has experienced faster energy consumption growth than economic growth. To reverse this trend, China has incorporated for the first time in its five-year economic plan an input indicator as a constraint - requiring that energy use per unit of GDP be cut by 20 per cent during the eleventh five-year period running from 2006 to 2010. This is widely considered an important step towards building a harmonious society through scientific development. Despite significant efforts towards saving energy, reducing pollution and promoting the widespread use of renewable energy in the past four years, China has had limited success to date in achieving this goal. 
While facing this great challenge at home and international pressure from inside and outside international climate negotiations to be more ambitious in limiting its greenhouse gas emissions, just before the Copenhagen climate summit, China pledged to cut its carbon intensity by $40-45$ per cent by 2020 relative to its 2005 levels. This unilateral commitment clearly indicates China's determination to further decouple its carbon emissions from economic growth. The proposed carbon intensity target certainly does not just represent business as usual, as some Western scholars have argued, because even the lower end of that target represents a deviation of 4.8 per cent below the World Energy Outlook 2009 baseline levels, not to mention a deviation of 12.7 per cent below the World Energy Outlook 2009 baseline levels at the higher end. On the other hand, national policies under consideration in China before the announcement of its carbon intensity target would already have led to a carbon intensity reduction of 43.6 per cent in 2020 relative to its 2005 levels. Given that China is already the world's largest carbon emitter and its share in the world's total emissions continues to rise, even a few additional percentage point reductions in its carbon intensity reduction have important implications for global emissions. It is hard, but not impossible for China to increase its own proposed carbon intensity reduction target. We suggest that China should aim for a 46-50 per cent cut in its carbon intensity in the period 2006-20. That would put China's absolute emissions reductions very much at the IPCC's recommended levels for developing countries.

China's proposed carbon intensity target needs not only to be seen as ambitious, but more importantly it needs to be credible. Ascertaining whether or not it is credible involves two issues. One is whether the claimed carbon emissions reductions themselves are real. This raises reliability issues concerning China's statistics on energy and GDP, given that China is not known for the reliability of its statistics. China's compromise at Copenhagen to agree to open its emissions data to international consultation and analysis is a start, although it remains to be seen how this will work in practice. As long as China's commitments are in the form of carbon intensity, establishing a robust and transparent emissions and performance accounting framework is helpful, but not enough to remove international concern about the reliability of China's commitments. The revisions of China's GDP figures and energy consumption in recent years reflect part of the government's continuing efforts to improve the accuracy and reliability of China's statistics on economic activity and energy use. Such revisions show that GDP figures are even more crucial to the impacts on energy or carbon intensity than are energy consumption and emissions data. They also have huge implications for meeting China's existing energy-saving goal in 2010 and its proposed carbon intensity target in 2020. 
Another issue is whether China is really able to achieve its target, given that China has faced and continues to face great difficulty meeting its own 20 per cent energy-saving goal in 2010. China needs to further strengthen existing policies and measures towards energy savings. China has increased its prices of gasoline and diesel and cut its total energy subsidies in recent years to provide incentives for efficient fuel use and adoption of clean technologies that reduce emissions at sources. Although this is encouraging, removing such subsidies is but a first step in getting the energy prices right. Further steps include incorporating the cost of resources themselves to reflect their scarcity and internalising the costs of externalities. More importantly, China needs to significantly scale up its efforts towards strengthening industrial restructuring in order to keep the frenzied expansion of highly energy-consuming, highly polluting and resourceintensive industries under control. Moreover, given that China has shifted control over resources and decision making to local governments during the past three decades, it is also crucial to ensure that local governments act in accordance with centrally directed policies and have adequate funding to achieve their own policy goals.

Finally, it should be emphasised that enacting the aforementioned policies and measures targeted for meeting China's existing energy-saving goal in 2010 and its proposed carbon intensity target in 2020 signals the goodwill and determination of China's leaders. To really achieve the desired outcomes, however, requires strict implementation and coordination of these policies and measures, as the aforementioned development of wind power and its coordination with the planning and construction of power grids have exemplified. This will be a decisive factor in determining the prospects for whether China will achieve its carbon intensity target. There is no doubt that achieving this target poses a significant challenge for China. The whole world is waiting to see whether China can turn this challenge into a win-win outcome for China and for global climate change.

\section{References}

An, F. and Sauer, A. 2004, Comparison of Passenger Vehicle Fuel Economy and GHG Emission Standards Around the World, December, Pew Center on Global Climate Change, Arlington, Va, http://www.pewclimate.org/docUploads/ Fuel Economy and GHG Standards_010605_110719.pdf

Beijing Municipal Commission of Development and Reform (BMCDR) 2006, The 11 th Five-Year Development Program for Energy Conservation in the Building 
Sector of Beijing Municipality, 8 September, Beijing Municipal Commission of Development and Reform, <http:/www.beijing.gov.cn/zfzx/ghxx/sywgh/ t662751.htm>

Chen, Y. H. 2010, 'NEA mandated wind power to be hooked up with the grids as a result of China's emissions reduction commitments', 21st Century Business Herald, 30 April, <http://finance.sina.com.cn/chanjing/ cyxw/20100430/02257855241.shtml>

Cyranoski, D. 2009, 'Beijing's windy bet', Nature, vol. 457, no. 7228, pp. 372-4.

Earth Policy Institute 2008, Global Wind Power Capacity Reaches 100,000 Megawatts, 4 March, Earth Policy Institute, Washington, DC, <http://www. earth-policy.org/Indicators/Wind/2008.htm>

Energy Information Administration (EIA) 2004, International Energy Outlook 2004, US Energy Information Administration, Washington, DC.

European Commission 2007a, Communication from the commission to the European Council and the European Parliament: an energy policy for Europe, $\operatorname{COM}(2007)$ 1 final, 10 January, European Commission, Brussels, <http://ec.europa.eu/ energy/energy_policy/doc/01_energy_policy_for_europe_en.pdf>

European Commission 2007b, Energy for a Changing World: An energy policy for Europe - the need for action, European Commission, Brussels, <http:// ec.europa.eu/energy/energy_policy/doc/2007_03_02_energy_leaflet_ en.pdf $>$

European Commission 2010, International climate policy post-Copenhagen: acting now to reinvigorate global action on climate change, $\operatorname{COM}(2010) 86$ final, 9 March, European Commission Brussels, <http://ec.europa.eu/environment/ climat/pdf/com_2010_86.pdf>

Garnaut, R. 2008, Climate Change Review Report, Cambridge University Press, Cambridge

Garnaut, R., Jotzo, F., Howes, S. and Sheehan, P. 2009, 'The Implications of Rapid Development for Emissions and Climate Change Mitigation', in D. Helm and C. Hepburn (eds), The Economics and Policy of Climate Change, Oxford University Press, Oxford.

Global Wind Energy Council 2010, Global Wind 2009 Report, March, Global Wind Energy Council, Brussels, http://www.gwec.net/fileadmin/documents/ Publications/Global_Wind_2007_report/GWEC_Global_Wind_2009_ Report_LOWRES_15th. percent20Apr..pdf. 
Huang, Q. L. 2008, 'Cleaner and more efficient coal-fired power generation technologies in China', Huadian Technology, vol. 30, no. 3, pp. 1-8.

International Energy Agency (IEA) 2007, World Energy Outlook 2007, International Energy Agency, Paris.

International Energy Agency (IEA) 2009a, Cleaner Coal in China, International Energy Agency, Paris.

International Energy Agency (IEA) 2009b, World Energy Outlook 2009, International Energy Agency, Paris.

Intergovernmental Panel on Climate Change (IPCC) 2007, Climate change 2007: mitigation of climate change, Working Group III Contribution to the Fourth Assessment Report, Cambridge University Press, Cambridge.

Levi, M. 2009, Assessing China's Carbon Cutting Proposal, 30 November, Council on Foreign Relations, New York.

National Bureau of Statistics (NBS) 2009, China Statistical Yearbook 2009, China Statistics Press, Beijing.

National Bureau of Statistics (NBS) various years, China Statistical Yearbook, China Statistics Press, Beijing.

National Bureau of Statistics (NBS), National Development and Reform Commission (NDRC) and National Energy Administration (NEA) 2008, Bulletin on energy use per unit of GDP and other indicators by region, 14 July, National Bureau of Statistics, National Development and Reform Commission and National Energy Administration, Beijing, <http://www.stats.gov.cn/ tjgb/qttjgb/qgqttjgb/t20080714_402491870.htm>

National Bureau of Statistics (NBS), National Development and Reform Commission (NDRC) and National Energy Administration (NEA) 2009, Bulletin on energy use per unit of GDP and other indicators by region, 30 June, National Bureau of Statistics, National Development and Reform Commission and National Energy Administration, Beijing, <http://www.stats.gov.cn/ tjgb/qttjgb/qgqttjgb/t20090630_402568721.htm>

National Bureau of Statistics (NBS), National Development and Reform Commission (NDRC) and Office of The National Energy Leading Group 2007, Bulletin on energy use per unit of GDP and other indicators by region, 12 July, National Bureau of Statistics, National Development and Reform Commission and Office of The National Energy Leading Group, Beijing, <http://hzs.ndrc. gov.cn/newjn/t20070809_152873.htm> 
National Development and Reform Commission (NDRC) 2006a, The top 1000 enterprises energy conservation action program, NDRC Environment and Resources [2006] no. 571 (April), National Development and Reform Commission, Beijing, <http://hzs.ndrc.gov.cn/newzwxx/t20060414_66220. htm>

National Development and Reform Commission (NDRC) 2006b, Suggestions for improving the policy on differentiated tariffs, September, National Development and Reform Commission, Beijing, <http://www.gov.cn/ zwgk/2006-09/22/content_396258.htm>

National Development and Reform Commission (NDRC) 2008a, China had decommissioned fossil fuel-fired small plants with a total capacity of 25.87 GW since January 1, 2006, 14 July, National Development and Reform Commission, Beijing, <http://nyj.ndrc.gov.cn/sdyx/t20080714_224054. htm $>$

National Development and Reform Commission (NDRC) 2008b, A circular on the evaluation of energy saving in 2007 of the top 1000 enterprises, 27 August, National Development and Reform Commission, Beijing, <http://hzs.ndrc. gov.cn/jnxd/t20080903_234934.htm>

National Development and Reform Commission (NDRC) 2009, A circular on improving on grid feed-in tariffs for wind power, 22 July, National Development and Reform Commission, Beijing, <http://www.fenglifadian. com/zhengce/512169872.html>

National Development and Reform Commission (NDRC) and National Bureau of Statistics (NBS) 2007, Bulletin on energy use of the top 1000 enterprises, 18 September, National Development and Reform Commission and National Bureau of Statistics, Beijing, <http://www.sdpc.gov.cn/zcfb/ zcfbgg/2007gonggao/W020071009598162122784.pdf>

Pew Charitable Trusts 2010, Who's Winning the Clean Energy Race?: Growth, competition and opportunity in the world's largest economies, March, Pew Charitable Trusts, Philadelphia, http://www.pewtrusts.org/uploadedFiles/ wwwpewtrustsorg/Reports/Global_warming/G-20percent20Report. $\mathrm{pdf} ? \mathrm{n}=5939$

Qiu, J. 2009, 'China's climate target: is it achievable?', Nature, vol. 462, pp. $550-1$.

Rawski, T. G. 2001, 'What is happening to China's GDP statistics?', China Economic Review, vol. 12, no. 4, pp. 347-54. 
Wang, P. and Ye, Q. 2009, 'China about to release new energy development plan by the end of 2009', Xinhua Net, 9 August, <http://news.sina.com.cn/ c/2009-08-09/140918397192.shtml>

Zhang, Z. X. 2000, 'Can China afford to commit itself to an emissions cap? An economic and political analysis', Energy Economics, vol. 22, no. 6, pp. $587-614$.

Zhang, Z. X. 2003, 'Why did the energy intensity fall in China's industrial sector in the 1990s? The relative importance of structural change and intensity change', Energy Economics, vol. 25, no. 6, pp. 625-38.

Zhang, Z. X. 2005, Sustainable energy development in China: challenges ahead to 2020, Keynote address at the International Conference on Staying Ahead of the Energy Scenarios, Bangkok, 11 November.

Zhang, Z. X. 2007a, 'China's reds embrace green', Far Eastern Economic Review, vol. 170, no. 5, pp. 33-7.

Zhang, Z. X. 2007b, 'China is moving away from the pattern of "develop first and then treat the pollution"', Energy Policy, vol. 35, pp. 3547-9.

Zhang, Z. X. 2007c, Greening China: can Hu and Wen turn a test of their leadership into a legacy?, Presented at the Plenary Session on Sustainable Development at the first Harvard College China-India Development and Relations Symposium, New York, 30 March - 2 April.

Zhang, Z. X. 2007d, Energy and environmental policy in mainland China, Keynote address at the Cross-Straits Conference on Energy Economics and Policy, organised by the Chinese Association for Energy Economics, Taipei, 7-8 November.

Zhang, Z. X. 2008, 'Asian energy and environmental policy: promoting growth while preserving the environment', Energy Policy, vol. 36, pp. 3905-24.

Zhang, Z. X. 2009a, 'Is it fair to treat China as a Christmas tree to hang everybody's complaints? Putting its own energy-saving into perspective', Energy Economics, 3 December, <doi:10.1016/j.eneco.2009.03.012>

Zhang, Z. X. 2009b, 'In what format and under what timeframe would China take on climate commitments? A roadmap to $2050^{\prime}$, International Environmental Agreements: Politics, law and economics, Social Sciences Research Network, $<$ http://papers.ssrn.com/sol3/papers.cfm?abstract_id=1415123>

Zhang, Z. X. 2009c, 'The US proposed carbon tariffs, WTO scrutiny and China's responses', International Economics and Economic Policy, DOI:10.1007/ s10368-010-0166-8. 
Zhang, Z. X. 2009d, China in the transition to a low-carbon economy, Invited presentation at the Second International Colloquium on Sustainable Growth, Resource Productivity and Sustainable Industrial Policy, Wuppertal, Germany, 10-12, September, <http://www.eastwestcenter.org/fileadmin/ stored/pdfs//econwpl09.pdf>

Zheng, X. and You, S. 2007, Heat reform in Tianjin China, Unpublished manuscript, School of Environmental Engineering, Tianjin University. 



\section{Prospects for diminishing regional disparities}

Jane Golley

\section{Introduction}

In the three decades since Deng Xiaoping declared that China's economic development would necessarily involve some people becoming rich before others, inequalities have risen steadily across (and within) China's provinces and regions. To some extent, this outcome has been the natural consequence of market forces in a large developing economy in which the numerous historical and geographical advantages of the eastern region ensured that industrialisation would occur there ahead of the rest of the country. Deng's Open Door Policy and, later, the Coastal Development Strategy, compounded these advantages with a range of preferential policies that explicitly promoted the development of the eastern region above all else. Yet Deng insisted that there would be 'no polarisation of rich and poor' in the longer term and that people elsewhere simply needed a little patience, referring to the 'two great situations' in which coastal provinces would be given advantages during the early reform years but would subsequently be expected to subordinate their interests to interior areas (Deng 1987).

In late 1999, Jiang Zemin announced the Western Regional Development Program (WRDP; ' $x i b u$ da kai $\mathrm{fa}^{\prime}$ ), declaring that its implementation 'is an important move to carry out Comrade Deng Xiaoping's strategic thinking of "two great situations", eliminate regional disparities gradually, consolidate the unity of ethnic groups, ensure border stability and social stability and promote social progress'. Taken from the 'Overall Plan of Western Regional Development During the Tenth Five-Year Plan Period' (2001-05). A seemingly endless list of policies and projects has been introduced under the WRDP, including policies to promote infrastructure and investment, protect the west's fragile ecology and environment, improve the quality of the workforce, push ahead with enterprise and structural reform, encourage east-west cooperation and accelerate development in specific industrial sectors and key projects such as the WestEast Power Transmission Project and West-East Gas Pipeline Project.For further details, see the 'Overall Plan'; Lai (2002); and Golley (2007). The time frame 
for achieving the ambitious set of policy goals has been set as the middle of the twenty-first century, by which time the intention is for regional disparities between the western and other regions to be 'diminished considerably'.

In 2002, the newly appointed Hu Jintao endorsed the WRDP as an important component of his drive for a 'harmonious and balanced society'. As if this 'colossal systemic campaign' was not enough — and perhaps partly to ensure that he could lay claim to his own regional policy initiative as had his predecessors - Hu and his team formally launched the 'Revive the North-East' ('zhen xing dongbei') scheme in 2004, which they intend to run alongside the WRDP through to 2020. In addition, the 'Rise of the Central Region' ('zhongbu jue $q i^{\prime}$ ) scheme was officially pronounced in late 2005, although there appears to have been little to follow in terms of substantive or identifiable programs within it (Chung et al. 2009). With every province bar the most developed eastern ones being targeted in one way or another, the Chinese Communist Party appears to be taking the regional issue seriously - on paper at least.

Uneven development is not only an economic issue but an ethical one, particularly for a regime whose legitimacy has long been based on egalitarian principles. Deng Xiaoping might have succeeded in convincing the Chinese people that some would have to get rich before everyone else could, but if the gap between those fortunate some and the rest of the country continues to widen, and if the government fails to do anything about this, 'the moral foundations of the regime will be shaken' (Wang and Hu 1999:201). This, in turn, makes the question of regional imbalance an issue of great political significance.

It is impossible to say with any degree of certainty how China's regional pattern of development will unfold in the next two decades, hinging as it does on the complex interaction of a multitude of uncertain market forces and uncertain policy choices. Instead, this chapter first provides a snapshot of China's regional situation as it stands and reflects on some recent trends in industrial development. It then considers some of the theoretical and empirical reasons for optimism and pessimism regarding the likelihood that the Chinese leadership will achieve just one of its regional policy goals - that of stimulating industrial development in China's vast interior, and in the west in particular. While the chapter provides some indication that the process of industrial relocation from the east westwards has already begun in some sectors, the balance of evidence presented here suggests that by 2030, in the absence of significant policy adaptation, disparities between the western and other regions are likely to have 'diminished marginally' at best. 


\section{Regional snapshot}

At present, China comprises 31 'provincial units', or provinces, centrally administered municipalities (CAMs) and autonomous regions (Figure 7.1). The four centrally administered municipalities are Beijing, Tianjin, Shanghai and Chongqing. The five (designated ethnic) autonomous regions are Guangxi (Zhuang), Inner Mongolia, Ningxia (Hui), Tibet and Xinjiang (Uighur). The term 'province' will be used generically to denote all of these. There are also two special administrative regions - Hong Kong and Macau — which will be excluded from the analysis. While many alternative regional breakdowns are possible, the discussion here focuses mainly on the three macro-regions: east, centre and west. The east comprises the coastal provinces of Liaoning, Beijing, Tianjin, Hebei, Shandong, Jiangsu, Shanghai, Zhejiang, Fujian, Guangdong and Hainan. The centre comprises Heilongjiang, Jilin, Shanxi, Henan, Anhui, Hubei, Jiangxi and Hunan, while the west comprises Xinjiang, Gansu, Ningxia, Shaanxi, Qinghai, Sichuan, Guizhou, Yunnan, Tibet, Inner Mongolia and Guangxi.Inner Mongolia and Guangxi were reclassified into the 'west' at the start of the WRDP in late 1999. All of the calculations below are based on this new classification. Alternatively, there is some reference to 'the coast' equivalent to the east-and 'the interior', comprising the west and the centre.

\section{Figure 7.1 Map of China}

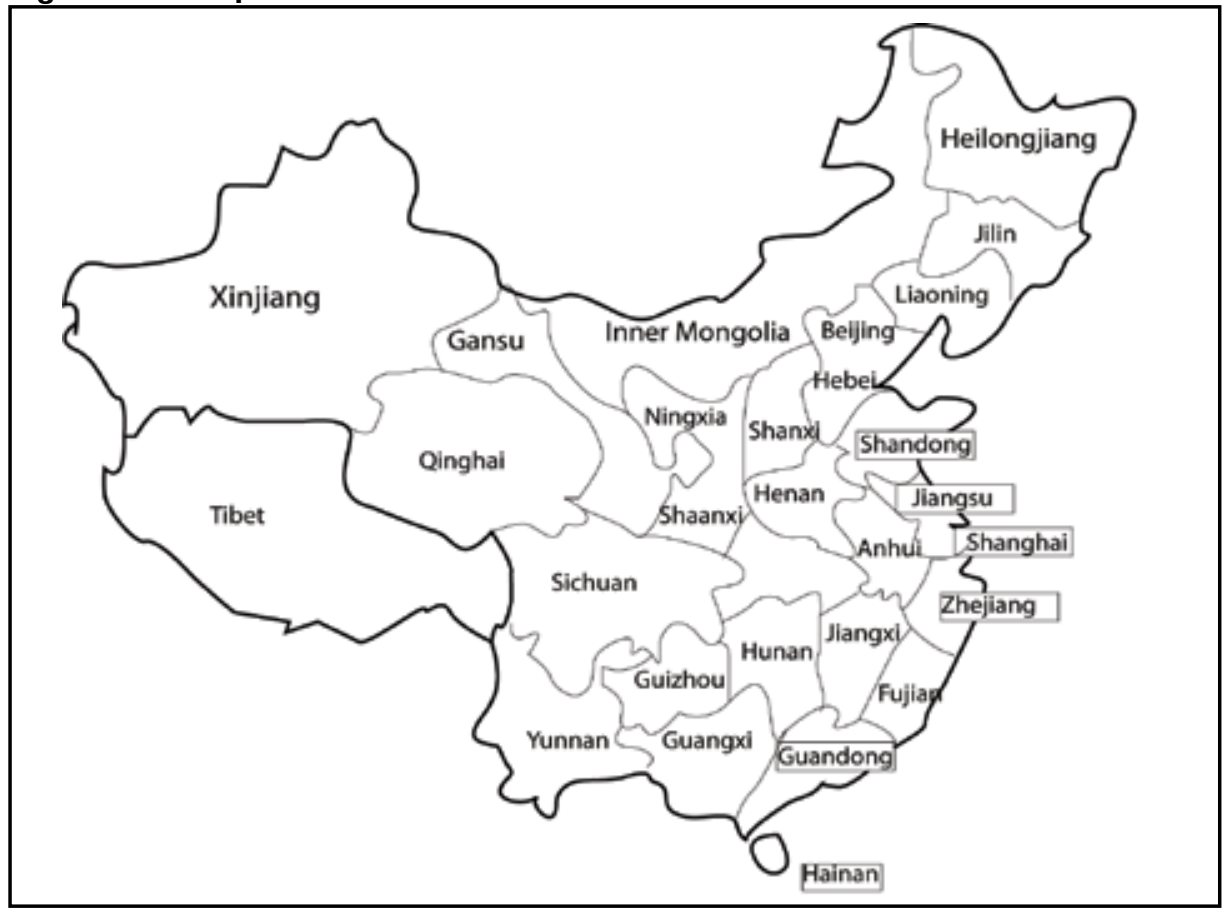


Table 7.1 provides a snapshot of some key indicators for the east, centre and west in 2007. The east outperforms the other two regions in all the indicators seen here (and virtually any other indicator one might choose). The ranking from east to centre to west is also consistent, with the west home to the least urbanised, least educated, poorest people with the lowest life expectancy. It is also the region most dominated by state ownership of industry, producing a miniscule share of national exports and with a tiny share of foreign direct investment (FDI) - three indicators that reveal it to be the least reformed of China's regions.

\section{Table 7.1 Regional snapshot, 2007}

\begin{tabular}{lccc}
\hline Indicator & East & Centre & West \\
\hline Population (million) & 474.8 & 461.5 & 363.0 \\
Share of national population (\%) & 36.5 & 35.5 & 27.9 \\
Urban proportion of population (\%) & 55.0 & 43.3 & 37.0 \\
Percentage of population aged 6+ with: & & & \\
Primary schooling or less & 35.8 & 36.7 & 49.0 \\
Senior secondary schooling or higher & 23.0 & 20.3 & 15.6 \\
Life expectancy (in 2000) & 74.3 & 71.6 & 68.4 \\
Per capita GDP (RMB) & 30131 & 15939 & 12229 \\
Regional share of industrial output produced by (\%): & & & \\
State-owned and shareholding enterprises & 20.3 & 44.6 & 53.0 \\
Private enterprises & 23.7 & 23.7 & 19.5 \\
Hong Kong, Macau, Taiwan and foreign-funded & & & \\
enterprises & 41.1 & 14.5 & 10.0 \\
Share of national exports produced in (\%) & 88.2 & 8.0 & 3.8 \\
Share of foreign direct investment going to (\%) & 77.2 & 14.5 & 6.1 \\
Share of national total budgetary revenue (\%) & 59.6 & 23.1 & 17.3 \\
Share of national total budgetary expenditure (\%) & 44.2 & 30.1 & 25.7 \\
\hline
\end{tabular}

Sources: Author's calculations and National Bureau of Statistics (NBS) 2008, China Industrial Economic Statistical Yearbook 2008, China Statistics Press, Beijing.

Of course, there are significant differences in performance within regions, as demonstrated for per capita gross domestic product (GDP) in Table 7.2. In 2007, the per capita GDP of Shanghai, the richest province, was nearly 10 times that of the poorest province, Guizhou. Inner Mongolia, only recently reclassified into the west, had more than twice the per capita GDP of Anhui and Jiangxi in the centre - just one illustration of the non-linear association between regions and income levels. It is worth noting here that while all of the western provinces with the exception of Tibet had below-average rates of per capita GDP growth during the period 1994-2007 (and indeed during the first three decades of reform), with the exception of Xinjiang and Yunnan, they all performed above average 
during the period 2000-07. Moreover, the increase in the west's aggregate per capita GDP growth-from 11.3 per cent to 15 per cent-is larger than the increase for the other two regions, although on average this resulted in virtually equivalent growth rates for all three regions in the latter period, rather than the west outperforming the others. It is impossible to say whether this boost to growth rates has been caused by the shift in regional policy or other factors, but it does seem to suggest that something has changed for the region in aggregate. Whether this change will translate into sustainable differences in growth rates over the longer term remains to be seen.

Table 7.2 Per capita GDP levels and growth rates

\begin{tabular}{|c|c|c|c|c|c|}
\hline \multirow[t]{2}{*}{ Region } & \multirow{2}{*}{$\begin{array}{l}\text { Per capita GDP } \\
\text { (RMB) } 2007\end{array}$} & \multicolumn{4}{|c|}{ Average annual growth rates (current prices) } \\
\hline & & 1994-2000 & Rank & 2000-07 & Rank \\
\hline \multicolumn{6}{|l|}{ East } \\
\hline Beijing & 58204 & 13.9 & 7 & 14.6 & 19 \\
\hline Tianjin & 46122 & 14.1 & 4 & 14.4 & 22 \\
\hline Hebei & 19877 & 14.3 & 3 & 14.6 & 18 \\
\hline Liaoning & 25729 & 10.7 & 24 & 12.6 & 24 \\
\hline Shanghai & 66367 & 14.7 & 2 & 9.8 & 31 \\
\hline Jiangsu & 33928 & 12.6 & 13 & 16.3 & 8 \\
\hline Zhejiang & 37411 & 13.9 & 6 & 15.7 & 12 \\
\hline Fujian & 25908 & 13.6 & 8 & 12.2 & 28 \\
\hline Shandong & 27807 & 13.5 & 10 & 16.5 & 6 \\
\hline Guangdong & 33151 & 12.4 & 14 & 14.5 & 20 \\
\hline Hainan & 14555 & 6.1 & 30 & 11.3 & 30 \\
\hline \multicolumn{6}{|l|}{ Centre } \\
\hline Shanxi & 16945 & 10.5 & 25 & 18.6 & 2 \\
\hline Jilin & 19383 & 10.8 & 23 & 16.0 & 10 \\
\hline Heilongjiang & 18478 & 11.6 & 18 & 11.6 & 29 \\
\hline Anhui & 12045 & 11.6 & 19 & 13.8 & 23 \\
\hline Jiangxi & 12633 & 12.6 & 12 & 14.7 & 16 \\
\hline Henan & 16012 & 14.0 & 5 & 16.7 & 5 \\
\hline Hubei & 16206 & 13.6 & 9 & 12.3 & 27 \\
\hline Hunan & 14492 & 13.1 & 11 & 14.4 & 21 \\
\hline \multicolumn{6}{|l|}{ West } \\
\hline Guangxi & 12555 & 7.7 & 29 & 16.5 & 7 \\
\hline Inner Mongolia & 25393 & 11.8 & 16 & 23.3 & 1 \\
\hline Chongqing & 14660 & - & - & 16.1 & 9 \\
\hline Sichuan & 12893 & 11.3 & 20 & 15.2 & 14 \\
\hline Guizhou & 6915 & 9.4 & 28 & 14.6 & 17 \\
\hline
\end{tabular}


China: The Next Twenty Years of Reform and Development

\begin{tabular}{lccccc} 
Yunnan & 10540 & 10.9 & 22 & 12.4 & 26 \\
Tibet & 12109 & 14.9 & - & 15.0 & 15 \\
Shaanxi & 14607 & 11.7 & 17 & 18.1 & 3 \\
Gansu & 10346 & 12.2 & 15 & 15.2 & 13 \\
Qinghai & 14257 & 9.8 & 27 & 15.9 & 11 \\
Ningxia & 14649 & 10.3 & 26 & 17.1 & 4 \\
Xinjiang & 16999 & 11.2 & 21 & 12.5 & 25 \\
\hline Average & 18934 & 12.3 & & 13.4 & \\
\hline -zero & & &
\end{tabular}

Sources: Author's calculations and National Bureau of Statistics (NBS) various years, China Industrial Economic Statistical Yearbook, China Statistics Press, Beijing

In 2007 the west had an average annual per capita GDP of RMB12 229 - just 40 per cent of the east's RMB30 131. Between 2000 and 2007, the two regions had almost identical average rates of per capita GDP growth (albeit with significant variation across provinces in both regions) of about 15 per cent in current price terms. In order to close the east-west income gap completely by 2050 , the west would need to grow substantially faster each year than the east. To illustrate this point, from their respective levels in 2007, eastern and western per capita incomes would be equalised in 2050 if the east grew at 10 per cent per annum throughout the period while the west grew at 12.33 per cent per annum. With these average growth rates, by 2030 the west would still have a per capita income equal only to two-thirds of the east's. Obviously, narrowing the gap more quickly would require a greater divergence in regional growth rates. This begs the key question: is there any reason to expect the west (and the centre) to grow faster than the east during the next two decades, thereby narrowing the per capita income gap between regions?

\section{Recent trends in industrial development}

Disparities in industrial development have been a critical component of the rising regional inequalities since 1978. Figure 7.2 illustrates the dominance of the eastern region in producing China's gross value of industrial output (GVIO). From 59.2 per cent of the total in 1978, the east's share rose steadily to a peak of 72.4 per cent in 2005, dropping marginally to 70.4 per cent in 2007. With just 36.4 per cent of the population, this translates into significantly higher per capita industrial output in the east than in the rest of the country. Is it possible that the improvement in the western growth rate of per capita GDP in recent years reflects more rapid growth of industrial output in the west and a consequent change in the regional distribution of industrial output? 
Figure 7.2 Regional shares of GVIO (per cent)

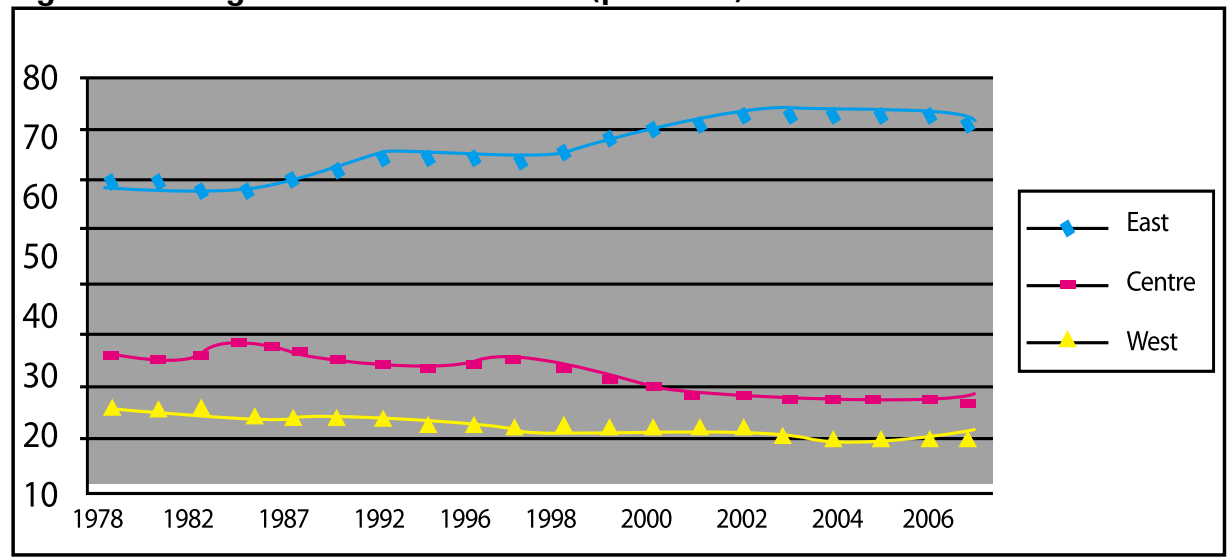

Shift-share analysis sheds some light on this question. As explained in an earlier China Update (Golley 2003), shift-share analysis decomposes provincial rates of industrial output growth into three components. In particular, let $\Delta \mathrm{Y}_{i j}$ denote the change in output for sector $i$ in region $j$ from the base period to the end period. By definition, this is equal to total output of sector $i$ in region $j$ in the base period, $\mathrm{Y}_{i j 0}$, multiplied by the growth rate of sector $i$ in region $j$ over the whole period, $\mathrm{R}_{i j}$ (Equation 7.1).

\section{Equation 7.1}

$\Delta \mathrm{Y}_{i j}=\mathrm{Y}_{i j o \mathrm{R}} \mathrm{R}_{i j}$

Denoting the national growth rates of total output and of sector $i$ as $\mathrm{R} k$ and $\mathrm{R} i k$ respectively, Equation 7.1 can be decomposed into three components (Equation 7.2).

\section{Equation 7.2}

$\Delta \mathrm{Y}_{i j}=\mathrm{Y}_{i j o \mathrm{R}} k+\mathrm{Y}_{i j o}\left(\mathrm{R}_{i k}-\mathrm{R}_{k}\right)+\mathrm{Y}_{i j o}\left(\mathrm{R}_{i j}-\mathrm{R}_{i k}\right)$

The first term on the right-hand side of Equation 7.2 is called the national component of growth, as it shows the growth that would have resulted had sector $i$ in region $j$ exactly matched the national trend $\left(\mathrm{R}_{k}\right)$. The second term in Equation 7.2 is the structural component, reflecting the extent to which the change in sector $i$ can be attributed to the region's industry mix; if a region's industrial structure is dominated by industries that are experiencing aboveaverage rates of growth (higher $\mathrm{R}_{i k}$ ), it will experience faster output growth than the rest of the country. The third term in Equation 7.2 is the location (or residual) component, as it measures the extent to which sector $i$ in region $j$ grew faster or slower than the national growth rate for that sector, thereby reflecting how the local characteristics of a given province influenced its growth 
performance. Rearranging Equation 7.2 gives the net relative change (NRC) for sector $i$ in province $j$, which is the difference between the real change and the national component (Equation 7.3).

\section{Equation 7.3}

$\mathrm{NRC}_{i j}=\Delta \mathrm{Y}_{i j}-\mathrm{Y}_{i j o \mathrm{R}} k=\mathrm{Y}_{i j o}(\mathrm{R} i k-\mathrm{R} k)+\mathrm{Y}_{i j}\left(\mathrm{R}_{i j}-\mathrm{R}_{i k}\right)$

The NRC shows whether sector $i$ in region $j$ experienced faster or slower growth of industrial output than the national average, with a positive value reflecting the former. The NRC can therefore be regarded as an index of relative performance, which the right-hand side seeks to explain. It is also possible to calculate an industry-wide NRC for each province (Equation 7.4).

\section{Equation 7.4}

$\mathrm{NRC}_{j}=\Delta \mathrm{Y}_{j}-\mathrm{Y}_{j} \mathrm{R}_{k}=\mathrm{Y}_{j o}\left(\mathrm{R}_{k}-\mathrm{R}_{k}\right)+\mathrm{Y}_{j}\left(\mathrm{R}_{j}-\mathrm{R}_{k}\right)$

In Equation 7.4, $\mathrm{NRC}_{j}$ is the $\mathrm{NRC}$ for province $j$, and so on. As Equation 7.4 shows, the industry-wide NRC is accounted for entirely by the province's industry-wide location component, since the structural component becomes zero. Data are drawn from the China Industrial Economic Statistical Yearbook (NBS 1995, 2001, 2008) for 30 provincesBecause Chongqing became an independent provincial unit only in 1997, it is included in Sichuan for this analysis so that the two periods can be compared. and 36 industrial sectors, as listed in the tables below, in order to conduct two shift-share analyses for the periods 19942000 and 2000-07. A number of interesting points emerge.

Table 7.3 presents the industry-wide NRCs and average annual growth rates for each province and region during the period 2000-07. This demonstrates the first key message contained in shift-share analysis: a positive NRC is equivalent to a provincial growth rate that is above the national average annual rate of growth (of 22.3 per cent in current prices). The east's and the west's growth rates are identical and marginally above the national average compared with the centre's, which is marginally below. Thus, it does not appear to be the case that relatively higher growth rates of industrial output in the west have underpinned the improvement in its rates of economic growth. These regional aggregates obviously obscure provincial-level results and it is worth noting that of the eight provinces in the centre, five provinces recorded positive NRCs, while of the 11 eastern provinces, five recorded negative NRCs. The geographic proximity of these eastern and central provinces provides some indication (although far from pure evidence) that industrial relocation in line with theoretical expectations could already have begun (discussed further below). The results for the western provinces are much less promising, with just three of the 11 provinces recording positive NRCs. 
Table 7.3 Industry-wide NRCs and growth rates of industrial output, 2000-07

\begin{tabular}{|c|c|c|}
\hline Region & $\begin{array}{c}\text { NRC } \\
\text { (RMB100 000) }\end{array}$ & Average annual growth rate $(\%)$ \\
\hline East & 2458.3 & 22.4 \\
\hline Beijing & -2526.4 & 18.9 \\
\hline Tianjin & -2250.5 & 19.4 \\
\hline Hebei & 876.4 & 23.0 \\
\hline Liaoning & -1870.0 & 20.9 \\
\hline Shanghai & -7043.3 & 18.3 \\
\hline Jiangsu & 3920.7 & 23.3 \\
\hline Zhejiang & 4533.9 & 24.2 \\
\hline Fujian & 349.4 & 22.7 \\
\hline Shandong & 10426.9 & 25.6 \\
\hline Guangdong & -3999.8 & 21.2 \\
\hline Hainan & 41.1 & 22.9 \\
\hline Centre & -2968.0 & 21.7 \\
\hline Shanxi & 2125.3 & 26.8 \\
\hline Jilin & -1324.8 & 19.6 \\
\hline Heilongjiang & -5255.8 & 13.4 \\
\hline Anhui & 69.2 & 22.4 \\
\hline Jiangxi & 1783.3 & 27.1 \\
\hline Henan & 3862.7 & 25.3 \\
\hline Hubei & -4950.8 & 16.3 \\
\hline Hunan & 722.9 & 23.5 \\
\hline West & 509.6 & 22.4 \\
\hline Guangxi & -121.2 & 21.9 \\
\hline Inner Mongolia & 2436.0 & 30.0 \\
\hline Sichuan & 889.1 & 23.1 \\
\hline Guizhou & -495.1 & 19.7 \\
\hline Yunnan & -741.6 & 20.0 \\
\hline Tibet & -38.5 & 11.9 \\
\hline Shaanxi & 178.5 & 22.7 \\
\hline Gansu & -674.8 & 19.5 \\
\hline Qinghai & -106.9 & 20.5 \\
\hline Ningxia & -65.4 & 21.4 \\
\hline Xinjiang & -750.2 & 19.3 \\
\hline National total & 0.0 & 22.3 \\
\hline
\end{tabular}

Sources: Author's calculations and National Bureau of Statistics (NBS) 2001, China Industrial Economic Statistical Yearbook 2001, China Statistics Press, Beijing; National Bureau of Statistics (NBS) 2008, China Industrial Economic Statistical Yearbook 2008, China Statistics Press, Beijing.

Table 7.4 provides a different slant, by presenting the NRC and location components for the east, centre and west for each of the 36 industrial sectors 
for the period 2000-07. Note that all regions can record a positive NRC for sectors that are growing above the national average rate of growth of industrial output (that is, those sectors with positive structural components), while the regional sum of location components for each sector must be zero, reflecting as they do the location advantages for a particular region in a particular industry. The number of negative NRCs for the eastern region, 22, indicates that not all industrial sectors are performing above average in the region-and likewise the number of negative location components for the east, 18, indicates that the east is not completely dominating in every sector. The 18 and 15 sectors recording positive location components in the centre and west, respectively, also indicate that the two regions have something positive to offer with regard to these sectors at least. Still, for the other regions to begin making a dent in the east's industrial dominance - accounting as it does for more than 80 per cent of output in 13 sectors and for more than 50 per cent of output in 32 sectors (Table 7.5) - they need to be recording positive NRCs in sectors in which the east is not. For the centre, this was the case for five sectors during the period 2000-07: non-ferrous metal mining and dressing, non-metal mineral mining and dressing, food processing, food manufacturing and special-purpose equipment. In all of these sectors other than non-ferrous metal mining and dressing, the east's share of output far exceeds the centre's, suggesting that it will be a long time before any kind of balanced regional distribution of output is achieved, let alone a concentration of any of these industries in the centre. As for the west, this was also the case for five industries: food processing, food manufacturing, leather and furs, petroleum processing and coking and special-purpose equipmentsectors in which the region produces between 4.5 and 15.7 per cent of total output, with the exception of leather and furs. Notably, none of these sectors is particularly labour intensive but rather dominates the capital-intensive end of the industrial spectrum - a point returned to further below. The share of 'compensation to employees' in total value added for each sector is used as a measure of labour intensity, calculated using China's input-output table for 44 sectors in 2005. These sectors do not perfectly map onto the 36 industrial sectors used here, but the calculations ranging from 0.477 for garments to 0.091 for crude petroleum and natural gas are at least indicative of labour intensity by sector. Nor are any of these potentially promising sectors for the centre and west particularly large in terms of their contribution to national output, with none of them being in the top-10 industrial sectors.

Table 7.4 Regional NRCs and location components by sector, 2000-07

\begin{tabular}{l|cc|cc|cc}
\hline \multirow{2}{*}{ Sector } & \multicolumn{2}{|c|}{ East } & \multicolumn{2}{c}{ Centre } & \multicolumn{2}{c}{ West } \\
& NRC Location & NRC Location & NRC Location \\
\hline
\end{tabular}




\begin{tabular}{|c|c|c|c|c|c|c|}
\hline Coal mining and dressing & 425.7 & -660.0 & 1618.6 & 94.1 & 1089.6 & 565.9 \\
\hline $\begin{array}{l}\text { Petroleum and natural gas } \\
\text { extraction }\end{array}$ & -2866.9 & -212.7 & -3045.2 & -614.5 & -646.5 & 827.2 \\
\hline $\begin{array}{l}\text { Ferrous metal mining } \\
\text { and dressing }\end{array}$ & 812.2 & -0.6 & 264.4 & -86.4 & 264.9 & 87.0 \\
\hline $\begin{array}{l}\text { Non-ferrous metal mining } \\
\text { and dressing }\end{array}$ & -40.7 & -164.4 & 305.4 & 187.8 & 98.4 & -23.4 \\
\hline $\begin{array}{l}\text { Non-metal mineral mining } \\
\text { and dressing }\end{array}$ & -263.3 & -71.8 & 10.8 & 94.8 & -84.9 & -23.0 \\
\hline Food processing & -446.5 & -337.7 & 89.1 & 131.9 & 181.9 & 205.8 \\
\hline Food manufacturing & -1142.2 & -601.2 & 120.7 & 281.8 & 244.8 & 319.4 \\
\hline Beverages & -2312.8 & -407.3 & -589.0 & 125.3 & -334.2 & 282.0 \\
\hline Tobacco & -566.3 & 321.8 & -857.4 & 28.1 & -1689.2 & -349.9 \\
\hline Textiles & -3615.1 & 896.0 & -1527.8 & -695.8 & -567.5 & -200.1 \\
\hline Garments & -3027.1 & -19.4 & -192.3 & 28.3 & -56.2 & -8.9 \\
\hline $\begin{array}{l}\text { Leather, furs and down } \\
\text { products }\end{array}$ & -1199.7 & -104.1 & -91.6 & 16.7 & 52.3 & 87.4 \\
\hline Wood products & 96.7 & -201.1 & 221.7 & 144.9 & 80.4 & 56.1 \\
\hline Furniture & 657.5 & 120.2 & -16.8 & -108.7 & 26.7 & -11.5 \\
\hline Paper making & -728.1 & 170.6 & -213.1 & -1.3 & -282.9 & -169.2 \\
\hline $\begin{array}{l}\text { Printing and recording } \\
\text { medium production }\end{array}$ & -504.4 & 67.9 & -128.6 & -6.4 & -177.1 & -61.5 \\
\hline $\begin{array}{l}\text { Cultural, educational } \\
\text { and sports articles }\end{array}$ & -829.3 & -23.2 & -3.4 & 22.4 & -1.9 & 0.8 \\
\hline $\begin{array}{l}\text { Petroleum processing } \\
\text { and coking }\end{array}$ & -2651.8 & -533.1 & -1479.2 & -701.0 & 956.7 & 1234.1 \\
\hline Chemical materials & 762.4 & 1096.0 & -933.8 & -835.6 & -320.4 & -260.3 \\
\hline $\begin{array}{l}\text { Medical and pharmaceutical } \\
\text { products }\end{array}$ & -1222.8 & 24.6 & -448.7 & 44.0 & -422.8 & -68.6 \\
\hline Chemical fibres & -1290.7 & 198.1 & -405.4 & -169.3 & -95.7 & -28.7 \\
\hline Rubber & -215.7 & 100.9 & -78.0 & -21.4 & -109.6 & -79.5 \\
\hline Plastic & -747.6 & 19.0 & -83.4 & 6.8 & -70.0 & -25.8 \\
\hline Non-metal mineral products & -1208.9 & 57.1 & -284.1 & 173.8 & -477.4 & -230.9 \\
\hline $\begin{array}{l}\text { Smelting and pressing } \\
\text { of non-ferrous metals }\end{array}$ & 8073.5 & 857.9 & 2184.7 & -120.7 & 978.7 & -737.3 \\
\hline $\begin{array}{l}\text { Smelting and pressing of } \\
\text { non-ferrous metals }\end{array}$ & 3456.2 & -55.0 & 2621.6 & 534.5 & 1604.6 & -479.5 \\
\hline Metal products & -415.2 & 109.6 & -103.1 & -46.7 & -90.6 & -62.9 \\
\hline Universal machines & 3474.3 & 367.8 & 389.2 & -130.0 & 88.1 & -237.8 \\
\hline Special-purpose equipment & -261.3 & -396.5 & 117.3 & 82.2 & 327.5 & 314.4 \\
\hline Transportation equipment & 2335.0 & 1360.8 & -939.8 & -1423.1 & 285.4 & 62.3 \\
\hline $\begin{array}{l}\text { Electrical equipment } \\
\text { and machinery }\end{array}$ & 901.0 & -1.4 & 120.6 & 9.7 & 47.3 & -8.3 \\
\hline
\end{tabular}


China: The Next Twenty Years of Reform and Development

\begin{tabular}{l|cc|cc|cc}
$\begin{array}{l}\text { Electronic and } \\
\text { telecommunications } \\
\text { equipment }\end{array}$ & 4950.3 & 1907.1 & -603.1 & -750.2 & -967.5 & -1157.0 \\
$\begin{array}{l}\text { Instruments and meters } \\
\begin{array}{l}\text { Electric power, steam } \\
\text { and hot water }\end{array}\end{array}$ & 228.6 & 66.1 & 11.9 & -1.4 & -53.7 & -64.6 \\
$\begin{array}{l}\text { Production and supply } \\
\text { of gas }\end{array}$ & 2344.2 & -332.5 & 1212.9 & 103.5 & 1010.6 & 229.0 \\
$\begin{array}{l}\text { Production and supply } \\
\text { of tap water }\end{array}$ & -53.3 & -93.2 & -2.8 & -33.8 & 146.3 & 127.0 \\
\hline
\end{tabular}

Sources: Author's calculations and National Bureau of Statistics (NBS) 2001, China Industrial Economic Statistical Yearbook 2001, China Statistics Press, Beijing; National Bureau of Statistics (NBS) 2008, China Industrial Economic Statistical Yearbook 2008, China Statistics Press, Beijing.

Finally, Table 7.6 provides a comparison of provincial-level results for the two different periods: 1994-2000 and 2000-07. Rather than presenting the detailed numerical results for each province and sector, the table shows for each province the number of sectors that had a positive NRC (whether driven largely by structure or location) and the number of sectors in which location made a positive contribution to growth. While it is difficult to make regional generalisations given provincial-level variations in performance, it certainly appears that the eastern provinces have generally recorded fewer positive NRCs and positive location contributions to growth in the 2000s compared with the 1990s. Guangdong stands out, with the number of sectors with positive NRCs falling from 22 to 12 while the number of sectors with positive location components fell from 29 to 13. It is not alone, however, with Beijing, Tianjin, Hebei, Shanghai, Zhejiang and Hainan also recording fewer positive NRCs and location components. Liaoning is the most dramatic outlier of this trend, with the number of sectors benefiting from locating there increasing from just three in 1994-2000 to 22 in 2000-07. (Note that Liaoning is one of the three provinces included in the north-east, which has had its own regional policy since 2003.) In sum, this provides some evidence that the glory days of the eastern region's industrial dominance could be coming to an end-particularly when contrasted with the results presented in Golley (2003).

Table 7.5 Regional shares of industrial output, 2007 (per cent)

\begin{tabular}{lccc}
\hline Sector & East & Centre & West \\
\hline Coal mining and dressing & 27.5 & 49.7 & 22.9 \\
Petroleum and natural gas extraction & 37.9 & 29.7 & 32.4 \\
Ferrous metal mining and dressing & 60.6 & 22.1 & 17.4
\end{tabular}


Non-ferrous metal mining and dressing

Non-metal mineral mining and dressing

Food processing

Food manufacturing

Beverages

Tobacco

Textiles

Garments

Leather, furs and down products

Wood products

Furniture

Paper making

Printing and recording medium production

Cultural, educational and sports articles

Petroleum processing and coking

Chemical materials

Medical and pharmaceutical products

Chemical fibres

Rubber

Plastic

Non-metal mineral products

Smelting and pressing of ferrous metals

Smelting and pressing of non-ferrous metals

Metal products

Universal machines

Special-purpose equipment

Transportation equipment

Electrical equipment and machinery

Electronic and telecommunications equipment

Instruments and meters

Electric power, steam and hot water

Production and supply of gas

Production and supply of tap water

Total industrial output

\begin{tabular}{|c|c|c|}
\hline 26.9 & 40.6 & 32.5 \\
\hline 51.5 & 31.9 & 16.7 \\
\hline 60.1 & 25.1 & 14.8 \\
\hline 59.8 & 25.4 & 14.9 \\
\hline 50.9 & 24.5 & 24.6 \\
\hline 37.1 & 29.2 & 33.8 \\
\hline 83.8 & 10.9 & 5.4 \\
\hline 91.6 & 7.1 & 1.3 \\
\hline 86.4 & 9.1 & 4.5 \\
\hline 68.9 & 23.4 & 7.7 \\
\hline 85.5 & 9.3 & 5.3 \\
\hline 76.1 & 17.3 & 6.6 \\
\hline 73.9 & 14.8 & 11.4 \\
\hline 95.5 & 4.2 & 0.4 \\
\hline 63.8 & 20.6 & 15.7 \\
\hline 71.9 & 16.8 & 11.2 \\
\hline 59.9 & 24.2 & 15.8 \\
\hline 87.9 & 9.1 & 3.0 \\
\hline 81.4 & 13.4 & 5.2 \\
\hline 85.3 & 10.1 & 4.6 \\
\hline 64.6 & 24.4 & 11.0 \\
\hline 66.8 & 20.2 & 13.1 \\
\hline 45.4 & 30.1 & 24.5 \\
\hline 87.1 & 8.9 & 4.0 \\
\hline 80.6 & 12.4 & 7.0 \\
\hline 70.0 & 19.9 & 10.1 \\
\hline 63.0 & 23.5 & 13.5 \\
\hline 84.4 & 10.4 & 5.2 \\
\hline 94.9 & 2.4 & 2.7 \\
\hline 88.5 & 7.1 & 4.3 \\
\hline 57.3 & 24.7 & 18.0 \\
\hline 62.4 & 13.9 & 23.7 \\
\hline 68.6 & 17.4 & 14.1 \\
\hline 70.4 & 18.1 & 11.5 \\
\hline
\end{tabular}

Sources: Author's calculations and National Bureau of Statistics (NBS) 2008, China Industrial Economic Statistical Yearbook 2008, China Statistics Press, Beijing.

Table 7.6 Shift-share analysis of provincial industrial growth

\begin{tabular}{lcccc}
\hline & \multicolumn{2}{c}{ Positive NRC } & \multicolumn{2}{c}{ Positive location } \\
Region & $1994-2000$ & $2000-07$ & $1994-2000$ & $2000-07$ \\
\hline East & & &
\end{tabular}


China: The Next Twenty Years of Reform and Development

\begin{tabular}{|c|c|c|c|c|}
\hline Beijing & 12 & 7 & 11 & 8 \\
\hline Tianjin & 18 & 6 & 22 & 8 \\
\hline Hebei & 18 & 10 & 20 & 9 \\
\hline Liaoning & 8 & 16 & 3 & 22 \\
\hline Shanghai & 19 & 5 & 14 & 5 \\
\hline Jiangsu & 16 & 15 & 16 & 19 \\
\hline Zhejiang & 24 & 22 & 27 & 26 \\
\hline Fujian & 21 & 21 & 22 & 22 \\
\hline Shandong & 16 & 26 & 15 & 27 \\
\hline Guangdong & 22 & 12 & 29 & 13 \\
\hline Hainan & 18 & 8 & 18 & 6 \\
\hline \multicolumn{5}{|l|}{ Centre } \\
\hline Shanxi & 6 & 13 & 7 & 13 \\
\hline Jilin & 11 & 11 & 9 & 13 \\
\hline Heilongjiang & 11 & 4 & 5 & 5 \\
\hline Anhui & 9 & 15 & 5 & 12 \\
\hline Jiangxi & 5 & 26 & 4 & 27 \\
\hline Henan & 18 & 25 & 22 & 30 \\
\hline Hubei & 18 & 2 & 17 & 2 \\
\hline Hunan & 11 & 21 & 7 & 21 \\
\hline \multicolumn{5}{|l|}{ West } \\
\hline Guangxi & 6 & 13 & 2 & 15 \\
\hline Inner Mongolia & 9 & 21 & 6 & 26 \\
\hline Sichuan & 11 & 21 & 8 & 27 \\
\hline Guizhou & 13 & 10 & 13 & 10 \\
\hline Yunnan & 11 & 11 & 9 & 11 \\
\hline Tibet & 12 & 2 & 12 & 4 \\
\hline Shaanxi & 9 & 12 & 8 & 14 \\
\hline Gansu & 13 & 7 & 12 & 9 \\
\hline Qinghai & 10 & 14 & 11 & 17 \\
\hline Ningxia & 15 & 12 & 16 & 15 \\
\hline Xinjiang & 13 & 13 & 13 & 13 \\
\hline
\end{tabular}

Sources: Author's calculations and National Bureau of Statistics (NBS) 2001, China Industrial Economic Statistical Yearbook 2001, China Statistics Press, Beijing; National Bureau of Statistics (NBS) 2008, China Industrial Economic Statistical Yearbook 2008, China Statistics Press, Beijing.

Of the eight provinces in the centre, five increased the number of sectors with positive NRCs and positive location contributions - most markedly in Jiangxi (up from 5 to 25 and from 4 to 27, respectively). These are the same five provinces that recorded positive NRCs at the industry-wide level. The results for the west are mixed. Curiously, the two biggest improvements over time in terms of the number of sectors with above-average rates of growth are Guangxi and Inner 
Mongolia - the two provinces redefined as western only in the early 2000salthough in the case of Guangxi this was not enough to ensure a positive NRC at the industry-wide level. Sichuan (including Chongqing) also appears to be on the move, and to a lesser extent Qinghai and Shaanxi, while Tibet, Gansu, Guizhou and Ningxia all performed worse on both counts. Based on these results, there is little to suggest that the WRDP is providing the impetus for industrial development in the region to date. Of course, this does not imply that it cannot provide the impetus in the future.

\section{Reasons for optimism}

There are numerous reasons - theoretical and real-why Chinese regional inequalities could diminish in the course of the next two decades. According to neoclassical growth theory, the high rates of investment growth underpinning the east's rapid growth of industrial output reduce the marginal productivity of capital there and result in firms directing their investment elsewhere in China, where the relative rates of return to investment will be higher. Models of 'new' economic geography, while underpinned by different mechanisms, tend to predict likewise that firms will eventually relocate to less-developed regions in order to take advantage of lower costs there (as long as transport costs between regions fall below a certain critical level and there is some labour immobility between regions) (Krugman 1991; Puga and Venables 1996). These models are based on the more traditional arguments of Hirschman (1958) and Myrdal (1957), who describe respectively how development in the most industrialised centres will ultimately trickle down or spread to less-developed peripheral areas. The 'flying geese' model developed by Akamatsu (1962) similarly describes a process of industrial transfer among countries (or regions), which has subsequently been used to describe the transfer of labour-intensive industries out of Japan (the lead goose) to South Korea, Taiwan, Singapore and Hong Kong and later to the Association of South-East Asian Nations (ASEAN) economies and coastal China (the following geese). Dynamic changes in each region's comparative advantage generated in the presence of substantial interregional diversity create the incentives for relocation with the result that, in the long run at least, all the geese industrialise! Finally, the Lewis model applied to a regional context also predicts a long-term equalisation of incomes between regions. In particular, consider that one region (the coast) is home to the modern 'capitalist' or industrial sector that draws in perfectly (or highly) elastic labour from the other region (the interior), which specialises largely in the subsistence sector. Once this surplus labour is exhausted (or prevented from free movement because of impediments in the labour market), the model predicts that wages and per capita income will rise throughout the economy (Lewis 1952). In essence, 
all of these theories predict an equalisation of regional incomes in the long run. Deng Xiaoping appeared to be well versed in most, if not all, of these theories when he adopted the Open Door Policy and asked the non-coastal provinces to have a little bit of patience.

Cai and Wang (2006) and Cai et al. (2009) provide some evidence to support the claim that the agglomeration of industry along China's coastline will soon reach its peak-if it has not already done so. In their 2006 China Update chapter, they point out that the emergence of a shortage of rural migrant workers and the consequent rapid rise in rural wages in the eastern provinces signal the end of China's unlimited labour surplus. This suggests the potential, although by no means a guarantee, that firms will begin looking to alternative locations for production within Chinese borders - namely, in the centre and west. In their 2009 China Update chapter, Cai et al. take this idea a step further and assert that China is likely to sustain its labour-intensive industries for the next few decades as rising costs along the coast lead to industrial upgrading there and industrial relocation into the interior. In particular, they draw on labour productivity and wage data of 310000 manufacturing firms between 2000 and 2007 to argue that the reduction in labour costs in the centre and west relative to the east will enable 'flying geese within Chinese borders'.

Linked to Cai et al.'s (2009) argument that labour-intensive industries will soon relocate westward is the notion that China has already reached its 'Lewisian turning point' - signalled by the end of the rural surplus that has played such a critical role in the industrialisation of the eastern region. Garnaut and Huang (2006) examine the supply and demand for skilled and unskilled labour across China's regions and sectors and conclude that:

The dynamic coastal regions will graduate surprisingly quickly from labour-intensive activities and re-specialise in capital or technologyintensive sectors of the production process. Rising opportunity costs of labour in the countryside and wages in towns would be helpful in containing the increase in income inequality - a source of growing tension and concern. (Garnaut and Huang 2006:32)

If their argument is correct - and to the extent that labour is also able to migrate across provinces - the rise in wages in coastal areas would likewise increase the opportunity cost of labour elsewhere, while migrants to the east could benefit from the higher wages, hence underpinning an improvement in the regional income distribution as well. Combined with Cai et al.'s depiction of increasing cost advantages in the centre and west, and more recent evidence that China has already reached its turning point (in Garnaut and Cai and Wang's chapters in this volume) the future for China's regional development looks bright. 
Regional policies have the potential to make a positive contribution to the realisation of this outcome. As Lai (2002) notes, the Western Development Strategy was introduced not only to try to reduce regional inequality and discontent, but in order to support necessary state-owned enterprise (SOE) reforms in the wake of World Trade Organisation (WTO) entry and to encourage the opening up of the west more generally. To the extent that these efforts succeed, in combination with extensive improvements in infrastructure within the west and between regions, the region is likely to become an increasingly attractive place for firms to locate production. The Revive the North-East policy can equally - to the extent that it succeeds in promoting much needed enterprise reforms - make the north-eastern region increasingly attractive, while the central provinces could benefit naturally from their proximity to the east, as the shift-share analysis above indicated is happening to some extent already. Policies to ensure that surplus labour can migrate to the most productive areas, combined with substantial efforts to raise education levels and labour quality in the centre and west, are also crucial. Of course, it is highly unlikely that all of these regions will industrialise and grow equally rapidly simultaneously, but success in any of them will play a positive role in bringing regional disparities down.

Finally, another reason for optimism is that industrial development is clearly not the only thing that matters for regional development. Western China is home to a large share of China's mineral and energy resources, which are key inputs into many of the industrial sectors concentrated in eastern China and the rest of the world. To the extent that the West is able to capture the rents associated with these resources, it could support higher than average per capita incomes with lower than average industrial output (as in Western Australia today).

\section{Reasons for pessimism}

For each of the theories above that predict income convergence in the long run, and for each piece of evidence suggesting that this long run might not be all that far off, there are contradictory theories and evidence.

There is a vast literature on the sources of China's rapid growth, in which the key debate has been over whether growth has been primarily extensive-fuelled by rapid labour and capital accumulation - or intensive, based on productivity increases deriving from technological advances, innovation and diffusion, and human capital growth. See, for example, Jefferson et al. (1996) and Borensztein and Ostry (1996), who were among the early authors to claim that total factor productivity growth was the key determinant of China's rapid economic growth - in contrast with others, such as Wu (2003) and Chow and Lin (2002), 
who argued that capital investment was the dominant factor. To the extent that growth is driven by capital investment, standard growth theory predicts conditional convergence across regions as investors eventually seek higher returns in places where capital stocks are low. Yet Chi (2008) shows that this idea is overly simplistic, given the role of human capital stock, and presents clear theoretical and empirical reasons why regional inequality is likely to worsen in the foreseeable future. In particular, he shows that when technological change is skill biased, rather than factor neutral, as assumed in standard growth theory, provinces with higher stocks of human capital will continue to attract higher levels of physical capital investment. This skill-capital complementarity implies that, contrary to the neoclassical prediction of capital flowing west, it will continue to flow east. Chi's evidence demonstrates that tertiary-level education is the most important determinant of this skill-capital link and, furthermore, provincial government expenditure on education has done little to increase tertiary-level stocks in the central and western provinces (while having some impact on reducing the percentage of primary-level attainment and raising secondary-level attainment). Essentially, the conclusion is that, until interior provinces can raise their human capital stock significantly, capital flows will continue to support more rapid growth in the east, with regional inequalities rising accordingly.

To the extent that China's growth is instead driven by productivity increases, regional differences in total factor productivity (TFP) could offer some promise for regional equalisation of incomes. Cai et al. (2009) calculated that TFP accounted for between 18 and 28 per cent of industrial output growth between 2000 and 2007, with higher contributions found in the north-east, centre and west. The highest TFP was recorded for the central region-offering some hope for catch-up there - while the TFP of the east and the west was very similar. This is encouraging in the sense that the west does not appear to be substantially behind the east in productivity terms, but offers little hope for catch-up unless the west's TFP can be raised even higher.

Krugman's (1991) depiction of the spatial pattern of industrial development in a market economy implies that the process of industrial agglomeration followed by dispersal is likely to occur first for the most cost-sensitive, labour-intensive, 'footloose' industries that are not tied to location-specific raw materials, because these are the industries for which relocation first becomes profitable in the face of rising wages in the industrial core and improving transport linkages between regions. If the shift-share analysis for 2000-07 had indicated that these were the types of industries starting to perform well in the centre and westparticularly industries that rank highly in terms of industrial output shares, such as electronic and telecommunication equipment, at 9.8 per cent of total industrial output, and one of the most labour-intensive sectors - there would 
be some cause for optimism that this process had started in China. Instead, as discussed above, the few sectors that were performing well in these regions were generally non-footloose (the mining and dressing sectors) and capital intensive. In turn, this could relate to the central government's clearly stated preferential policies for certain 'priority' sectors in the western region, which could contradict the forces of the market and prove unsustainable in the longer term. This is an issue that remains open for further investigation - for which there is no space to expand on here. See Golley (2007:Ch. 8) for further details.

In reference to the theories mentioned above, another reason for pessimism, with regard to industrial relocation providing the key to regional income equalisation in the long run, is that theory and reality are rarely one and the same. It is neither likely, nor indeed desirable, that China's industrial output will ever be evenly distributed across its vast and diverse landscape. In reality, as observed in the United States, Australia and Italy, to name a few, certain regions will always remain relatively poor, providing sources of out-migration for better-developed regions in the rest of the country, and possibly the rest of the world.

Not everyone supports the claim that China has already exhausted its vast pool of surplus labour. Meng and Bai (2007) examined the wages of unskilled workers from seven factories in Guangdong for the period 2000-04 and concluded that over that period average wage growth was either negative or zero and that 'with such small wage increases, one could hardly argue that China has reached the Lewisian turning point' (p. 172). Similarly, while Athukorala et al. (2009) show that wage growth in rapidly growing coastal provinces (Guangdong, Shanghai and Guangxi) has been faster than in labour-sending interior provinces (Sichuan, Gansu and Qinghai), they still conclude that 'even the official data when analysed at the disaggregate level suggest significant continuing duality and surplus labour conditions in the Chinese labour market' (p. 199). As they note, apart from the more than 100 million people who have migrated from rural to urban areas in China - and largely in the direction of west to east - industrial reforms have released more than 40 million workers from the state sector available for potential employment in the rapidly growing non-state sector. The continuing rise in the share of the working-age population (projected to continue through to 2015) and increases in labour participation rates provide further sources of urban labour supply growth (Golley and Tyers 2006), as do the hundreds of millions of workers still underemployed in agricultural activities and the conservative estimate of 7.1 million registered unemployed urban workers countrywide (NBS 2008). There is clearly room for further debate about when the turning point will be reached, and until that point it is unlikely that regional inequalities will begin to fall. 
On the policy side, there is perhaps more reason for pessimism than optimism at this stage, despite the large amount of rhetoric among the top levels of the Chinese leadership. Naughton (2004) points out that many of the key projects of the WRDP - most obviously the transnational (east-west) energy projectsare essentially national and not regional goals and are unlikely to be income equalising in any significant way, if at all. He also notes the incentive problems inherent in a centrally directed regional strategy that lead provincial and lowerlevel leaders to plead poverty and appear needy in order to compete for the limited pool of WRDP funds. Moreover, the mind-set of leaders in the west and north-east is described as conservative and reliant on central government support, which, in combination with ample evidence of corruption and misuse of allocated funding, is a major constraint on regional policy efficacy (Lai 2002; Chung et al. 2009). Golley (2007) describes the WRDP as a 'developmental state' approach to regional policy, in which the central government seems to be controlling development through state ownership and decree rather than by adopting policies that are likely to succeed in stimulating self-sustaining growth in the region. As one illustration of this policy approach, a white paper released in 2003 states that large numbers of university graduates, scientists, technicians and highly trained professionals have been 'assigned' to Xinjiang ('White paper on "the important role of Xinjiang Production Construction Corps"', Xinhua News, 26 May, viewed 6 September 2003, <http://news. xinhuanet.com/english $>$ ). If this is how a State Council member can claim that the 'phenomenon of the peacock flying to the southeast will be replaced by the phenomenon of the peacock flying west' (Goodman 2004:327), it has little to do with the market and a lot to do with the State. It also contradicts what for Naughton (2004) is the single factor most likely to reduce poverty in western China and hence reduce regional inequalities: out migration. And yet extensive out migration - while offering a solution for the migrants and simultaneously relieving certain areas that are not either economically or ecologically viablealso brings with it the threat of brain drain, making it even more difficult for backward areas to develop industrial capacity in the longer term. Moreover, a continual source of migrants to the east will help to keep wages down there, prolonging the decisions of industrial firms to look elsewhere for lower costs. Combine this with the depiction of recent trends in industrial development presented above and the numerous historical and geographical disadvantages of the west - and to a lesser extent the centre as well-and there seems to be a multitude of reasons why the central government will struggle to achieve its regional policy goals in the next two decades. 


\section{Conclusions}

China has entered its fourth decade as a developing, market economy with significant and rising regional inequalities. This chapter has investigated the possibility that relatively rapid industrial development in the less-developed centre and west could offer one of the keys to reducing these inequalities in the next two decades.

An optimistic response to this is, yes, it is possible. The shift-share analysis for the period 2000-07 indicated that the glory days of the east's industrial dominance could be coming to an end, with the region no longer performing above the average across the broad spectrum of industrial sectors. Combine this evidence with claims that China is close to exhausting its labour surplus and it is possible that rising costs in the east will provide the impetus for industrial upgrading there coupled with the incentives for firms to relocate towards the centre and west. A serious and committed pro-west (or at least non-pro-east) regional policy with substantial funding well spent on infrastructure and education could play a positive role in triggering self-sustaining industrial development outside the eastern region. Rising incomes in the east could provide a crucial source of demand for non-eastern products, with the east possibly becoming for western China what the industrialised world has been for the eastern region during its own industrial take-off. The chances that all of this translates into western growth rates being sustained at 2 percentage points or more above the eastand thus achieving the regional policy objective of 'considerably diminishing' regional disparities - are miniscule. That is not to say, however, that some dent will not be made, particularly when other non-industrial factors are taken into account, such as the potential for out-migration and resource rents to raise the per capita incomes of those who remain in the western region.

Taken to its extreme, the pessimistic response would be no, it is impossible. Even if rising costs in labour-intensive manufacturing in the east led to industrial upgrading there, industrial relocation could occur not inwards to the rest of China but rather would occur outwards to competitor nations such as India and Vietnam. Western China would then be characterised by substantial pockets of poverty and underdevelopment - although surely with a few industrialised cities in the mix. A lack of domestic integration could make the east increasingly integrated into the global economy, while the west became increasingly isolated from the rest of the world and the east. This outcome would pose a serious threat to the legitimacy of the Chinese Communist Party - and yet they could fail to effectively implement policies that reverse the situation.

It is unwise - because it is impossible - to look backward in order to try to project future outcomes with any kind of precision or certainty, short of asserting that 
the real path of Chinese regional industrial development during the next two decades will lie somewhere in between these two extremes. To go out on slightly more of a limb, the balance of evidence presented here, in combination with my research on this topic during the past decade or so, suggests that the next two decades will witness limited improvements in the distribution of regional per capita incomes underpinned partially by limited redistribution of industry towards some but not all of China's non-coastal provinces. To be categorical, there is no doubt that regional inequalities in some form or other will continue to plague China's policymakers until the long run is reached-and that time is a very long way off indeed.

\section{References}

Akamatsu, K. 1962, 'A historical pattern of economic growth in developing countries', Journal of Developing Economies, vol. 1, no. 1, pp. 3-25.

Athukorala, P.-c., Fukao, K. and Yuan, T. 2009, 'Economic transition and labour market integration in China', in R. Garnaut, L. Song and W. T. Woo (eds), China's New Place in a World in Crisis, ANU E Press, Canberra.

Borensztein, E. and Ostry, J. D. 1996, 'Accounting for China's growth performance', American Economic Review, vol. 86, no. 2, pp. 224-8.

Cai, F. and Wang, D. 2006, 'Employment growth, labour scarcity and the nature of China's trade expansion', in R. Garnaut and L. Song (eds), The Turning Point in China's Economic Development, Asia Pacific Press, Canberra.

Cai, F., Wang, D. and Yue, Q. 2009, 'Flying geese within borders: how does China sustain its labour-intensive industries?', in R. Garnaut, L. Song and W. T. Woo (eds), China's New Place in a World in Crisis, Asia Pacific Press, Canberra.

Chi, W. 2008, 'The role of human capital in China's economic development: review and new evidence', China Economic Review, vol. 19, pp. 421-36.

Chow, G. and Lin, A.-l. 2002, 'Accounting for economic growth in Taiwan and Mainland China: a comparative analysis', Journal of Comparative Economics, vol. 30, pp. 507-30.

Chung, J. H., Lai, H. and Joo, J.-H. 2009, 'Assessing the "Revive the Northeast" (zhenxing dongbei) programme: origins, policies and implementation', The China Quarterly, vol. 197 (March), pp. 108-25. 
Deng, X. 1987, Fundamental Issues in Present Day China, Foreign Languages Press, Beijing.

Garnaut, R. and Huang, Y. 2006, 'Continued rapid growth and the turning point in China's development', in R. Garnaut and L. Song (eds), The Turning Point in China's Economic Development, Asia Pacific Press, Canberra.

Golley, J. 2003, 'Industrial location and regional development', in R. Garnaut and L. Song (eds), China 2003: New engine for growth, Asia Pacific Press, Canberra.

Golley, J. 2007, The Dynamics of Chinese Regional Development: Market nature, state nurture, Edward Elgar, Cheltenham, UK.

Golley, J. and Tyers, R. 2006, 'China's growth to 2030: demographic change and the labour supply constraint', in R. Garnaut and L. Song (eds), The Turning Point in China's Economic Development, Asia Pacific Press, Canberra.

Goodman, D. S. G. 2004, 'Qinghai and the emergence of the west: nationalities, communal interaction and national integration', China Quarterly, Special Issues New Series, no. 5, pp. 379-99.

Hirschman, A. 1958, The Strategy of Economic Development, Yale University Press, New Haven, Conn.

Jefferson, G., Rawski, T. and Zheng, Y. 1996, 'Chinese industrial productivity trends', Journal of Comparative Economics, vol. 23, pp. 146-80.

Krugman, P. 1991, Geography and Trade, Leuven University Press and MIT Press, Cambridge, Mass.

Lai, H. H. 2002, 'China's Western Development Program: its rationale, implementation and prospects', Modern China, vol. 28, no. 4, pp. 432-66.

Lewis, W. A. 1952, 'Economic development with unlimited supplies of labour', Manchester School, vol. 22, no. 2, pp. 139-91.

Meng, X. and Bai, N. 2007, 'How much have the wages of unskilled workers in China increased? Data from seven factories in Guangdong', in R. Garnaut and L. Song (eds), China: Linking markets for growth, Asia Pacific Press, Canberra.

Myrdal, G. 1957, Economic Theory and Underdeveloped Regions, Gerald Duckworth, Essex, UK.

National Bureau of Statistics (NBS) 1995, China Industrial Economic Statistical Yearbook 1995, China Statistics Press, Beijing. 
National Bureau of Statistics (NBS) 2001, China Industrial Economic Statistical Yearbook 2001, China Statistics Press, Beijing.

National Bureau of Statistics (NBS) 2008, China Industrial Economic Statistical Yearbook 2008, China Statistics Press, Beijing.

National Bureau of Statistics (NBS) various years, China Industrial Economic Statistical Yearbook, China Statistics Press, Beijing.

Naughton, B. 2004, 'The western development program', in B. Naughton and D. Yang (eds), Holding China Together: Diversity and national integration in the post-Deng era, Cambridge University Press, UK.

Puga, D. and Venables, A. 1996, The spread of industry: spatial agglomeration in economic development, CEPR Discussion Paper No. 1354, Centre for Economic Policy Research, London.

Wang, S. and Hu, A. 1999, The Political Economy of Uneven Development: The case of China, M. E. Sharp, Armonke, NY.

Wu, Y. 2003, 'Has productivity contributed to China's growth?' , Pacific Economic Review, vol. 8, no. 1, pp. 15-30. 


\section{Part II}

Global Integration: Challenges and Opportunities 



\section{Exchange rate policy and macroeconomic adjustment}

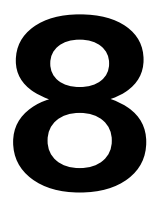

Geng Xiao

\section{China's exchange rate policy and what it means for the dollar}

The debate over the exchange rate between the renminbi (RMB) and the US dollar is usually framed in terms of global imbalances: excessive US consumption beyond its savings on the one hand and excessive Chinese production and savings beyond its own spending on the other. This quickly leads to the view that the United States should export and save more and China should import and spend more. The debate centres on how to achieve this rebalancing. The focus in the West is on short-term appreciation of the renminbi, while the emphasis in China is on longer-term structural and institutional reform (Xiao 2008). ${ }^{1}$

Leaders in the United States would like the renminbi to appreciate significantly and quickly to encourage an expansion of US exports and employment. Chinese leaders, however, regard the pressure to revalue the renminbi and various protectionist trade policies from the West as unfair, and believe they threaten China's development. ${ }^{2}$ What accounts for this considerable gap between the views of China and the West? What is the economic rationale for China's insistence on a stable renminbi?

The argument for a sustained appreciation of the renminbi is rooted not only in short-term concerns about China's large current account surplus, but in longerterm trends of China's economic fundamentals, including high growth, rapid urbanisation and industrialisation, low national debt and low fiscal deficits. These trends are the result of three decades of reform in China that have opened the country to trade with the rest of the world and led to strong productivity gains. Based on the experience of other fast-growing industrialising economies, these forces will increase Chinese wages, the value of the renminbi and China's price level-over time.

1 Some of the key results are summarised and restated in this chapter.

2 On 30 November 2009, in his meeting with European leaders, Chinese Premier, Wen Jiabao, said some countries on the one hand demanded renminbi appreciation and on the other hand adopted various trade protection meaures. 


\section{China's stance}

China views its renminbi peg with the US dollar as a crucial link for its trade and investment flows with US and world markets. China is concerned that a premature end to this nominal link with the dollar would bring about financial instabilities such as speculative capital inflows, associated asset bubbles and short-term nominal shocks to employment and business in the external sector.

China has not forgotten how the large appreciation of the Japanese yen brought about by the 1985 Plaza Accord created massive asset bubbles that burst in 1989, creating a two-decade-long period of sustained deflation without eliminating Japan's trade surplus.

China is also wary of how currency appreciation might encourage destabilising capital inflows. From 2005 to 2008, the renminbi appreciated steadily against the United States dollar by over 5 per cent a year and China's stock-market index increased from about 1500 to 6000 before falling to 2000 because of large speculative capital inflows especially from Hong Kong. If China were to use renminbi appreciation to reach a balance in trade and to stop speculative capital inflows, the renminbi could overshoot its equilibrium level, leading to bubbles and deflation.

Another reason for not having predictable renminbi appreciation relates to China's outward investment. For a country with a large net surplus savings and trade surplus, a well-functioning financial system should support orderly private or non-state capital outflows of the same order of magnitude as the trade surplus. Private firms and financial institutions would, however, be reluctant to buy dollar assets if they were likely to continually depreciate in terms of the renminbi. Because fear of dollar depreciation - and the near-zero short-term interest rates in the United States - reduces outward investment by privatesector investors, the People's Bank of China (PBOC) has to finance virtually all of China's trade surplus by building up official exchange reserves, making its monetary control difficult. ${ }^{3}$

In any case, it is not clear that nominal renminbi appreciation is necessary. The real exchange rate between the renminbi and the US dollar should be selfadjusting. This is because the change in China's price level relative to that in the United States (the 'real exchange rate') is technically the sum of renminbi appreciation against the dollar and China's extra inflation above US inflation. This real exchange rate is determined largely by China's productivity growth. If China appreciates its currency in excess of its productivity gains, it will

\footnotetext{
3 See a series of articles by Ronald McKinnon about the exchange-rate policy in Japan and Chinaparticularly McKinnon et al. (2009).
} 
experience deflation. If, however, China refuses nominal appreciation against its productivity gains, the country will experience some structural inflation related to the increase of wages and prices in the non-tradable sector, which will keep the real exchange rate compatible with its productivity changes. If China experiences inflation higher than its productivity gains, the renminbi will face depreciation pressure.

Indeed, if China makes the mistake of continually appreciating the renminbi against the dollar - ostensibly to reflect its higher productivity growth in manufacturing - then wage growth could well slow by roughly the amount of the anticipated exchange appreciation. Manufacturing firms would risk bankruptcy if they raised wages in the face of an ever-higher renminbi. Indeed, in Japan's very high growth phase in the 1950s and 1960s, when the yen was fixed at 360 to the dollar, Japanese wages grew very rapidly - at about the same pace as domestic productivity growth in manufacturing. Then, when Japan was forced by the US government to appreciate in the 1970s and afterwards, wage growth slumped to virtually zero and remains at zero today. ${ }^{4}$ China does not want to repeat Japan's experience of deflationary stagnation by allowing excessive renminbi appreciation.

It should also be noted that recent research by Hong Qiao (2007) has shown that currency appreciation has an ambiguous impact on the net trade balance. Qiao's (2007) research is clearly consistent with Japan's experiences and supports China's current exchange-rate policy.

When it comes to rebalancing, what really matters is the real exchange rate: the relative price levels between economies in international currency, which determine the relative costs of production, exports and imports of trading partners. Hence, if China pegs the renminbi to the dollar, it can still achieve a rapid increase in its real exchange rate against the United States by having an inflation rate 5 percentage points higher than that of the United States. Many formerly fast-growing industrialising economies - such as Japan, South Korea, Taiwan and Hong Kong - kept inflation about 5-8 per cent during their fastgrowth phases as a way to make nominal wages and general price levels converge towards global standards.

Hence, both inflation and nominal appreciation can adjust the real exchange rate. The Chinese approach to exchange-rate stability thus far has focused on inflation first and appreciation second, which makes the longer-term objectives of creating employment, productivity gains, wage growth and price liberalisation the priorities rather than addressing trade imbalances through adjustments for exchange-rate change.

4 See detailed analysis in McKinnon (2006). 


\section{Policy alternatives}

Given the fact that China is cautious about using large nominal appreciation to rebalance the Chinese and global economies - at least for the time being - it is important to consider some alternative policy options. A widely held view in China is that the rebalancing should focus on reducing the net savings surplus by shifting disposable income to households, paying corporate dividends, increasing governments' fiscal spending, and so on-and not simply on adjusting the exchange rate.

China is well known for its high savings rate, which reached about 55 per cent of gross domestic product (GDP), with a current account surplus of about 10 per cent of GDP, during 2007-08. One of the key sources of China's high national savings rate is its state-owned enterprises (SOEs), as corporate savings contribute about half of China's national savings (Prasad 2009). Historically, these large SOEs could not pay high salaries or wages to their employees due to tight control by the government. They did not distribute dividends. Even after they were reformed into a modern corporate format in the 1990s, the primary focus was on reducing losses, not sharing dividends. They also did not generate private purchasing power when the prices of their shares increased, which created huge capital gains with, as it happens, only small wealth effects on consumption. The high savings of SOEs are prone to investment in sectors with tendencies to overcapacity. Hence, privatisation and deregulation are necessary to reduce savings and inefficient investment by the large SOEs. ${ }^{5}$

While China clearly must increase its current consumption, consumption is ultimately limited by income. China has a long way to go in raising the wages and productivity of its workforce. Right now, household income accounts for only 35 per cent of national income. The low disdposable income is especially acute for migrant workers, who do not receive high-quality education in rural villages. Their wages were stagnant at a level of about US\$120-200 a month for the first several decades of reform due to steady high underemployment for unskilled labour.

Chinese savings are also high because the average Chinese household is faced with a very high return on investment, such as in residential property. In one of our studies (Sun et al. 2009) of the comparative long-term return on capital for China, Japan and the United States, we found that China's return on capital is about 20 per cent, compared with about 10 per cent for Japan and 5 per cent for the United States in the past three decades. Moreover, Chinese households save to meet very high future expenditures, such as college education for their single child and medical and retirement expenditures.

5 For more on China's SOEs, see the discussion by Xiao et al. (2009). 


\section{Addressing the West's concerns}

Chinese and foreign observers alike have expressed concerns about inefficient investment in China's export-manufacturing sector and in some local government-sponsored projects. As a result, China's central government has recently tightened monitoring and control of all new projects, especially those likely to lead to overcapacity. The Chinese authorities have not, however, changed their overall stimulus policy and continue to focus on generating more efficient investment, employment and imports so as to contribute positively to global rebalancing and global recovery.

For those who worry about China's US $\$ 2.2$ trillion foreign exchange reserves, it is worth looking at a case that illustrates China's need for foreign exchange. The number of self-financed Chinese students studying abroad increased from 102 247 in 2002 to 161600 in 2008, which is a compound rate of about 8 per cent a year. If we assume the number of such students will increase 8 per cent a year for the next 10 years, the number of students studying abroad will reach 348 882 by 2018 . If each outgoing student spends four years overseas, with US $\$ 60$ 000 in expenditure per annum for tuition, living expenses and travel, the total accumulated expenditure for those Chinese students going abroad will reach US $\$ 606.8$ billion - amounting to about 30 per cent of China's current foreign exchange reserves. It is no secret that even high and middle-income Chinese parents need to save for many years or decades to pay for their children's expensive overseas education.

\section{Price distortions and global rebalancing}

One of the key factors driving the global imbalances has been cheap money, which, together with weak regulation of high-risk investment, led to property and stock-market bubbles in the United States and other economies. The bubbles brought temporary capital gains that reduced Americans' savings and increased their consumption to levels beyond their sustainable income. This is well known now; but what has been overlooked in the public discussion is that this same cheap money also flowed into China through foreign direct investment (FDI) and other capital flows. Cheap foreign money, combined with cheap Chinese land, energy and natural resources, has led to huge overcapacity in China's manufacturing sector, driving down the prices of made-in-China products.

The United States' current zero-interest-rate policy might be necessary for the US economy now, but it is likely to create a carry trade as a by-product that is, where investors borrow currencies with low interest rates and invest 
in currencies with high interest rates to make profits when the interest rate differential is larger than the anticipated exchange rate change. This brings capital flows into China in anticipation of higher investment returns compared with the United States. If managed well, China can combine this foreign capital and its own savings to improve the efficiency of its investment, so as to allow higher levels of domestic investment for future domestic consumption. This would certainly help global rebalancing.

Rising Chinese household income and large official reserves mean that there will be rising demand for diversification by Chinese investors into foreign assets. Over time, the amount of cross-border capital flows could be much larger than the amount of trade flows. To facilitate these future cross-border capital flows, it would be helpful for China to maintain a stable exchange rate and large foreign exchange reserves - both of which are critical in reducing the Chinese and foreign investors' uncertainty that would result from a volatile exchange rate. Having a stable exchange rate to facilitate cross-border investment is also important for the large number of US multinational corporations with extensive and growing investments in China that generate high value-added complementary jobs in the United States.

\section{The future for China and the dollar}

The biggest challenge for Chinese policymakers now is how to deal with the property and stock-market bubbles being formed by cheap money in China and around the world. As asset prices and the consumer price index (CPI) rise, it is important for China to raise its interest rate - as India has done very successfully - to keep the real interest rate at a stable and positive level. A higher interest rate would attract greater capital inflows. It is therefore necessary for China to improve its capital-control mechanisms, to allow orderly crossborder capital flows for more efficient investments with higher returns both domestically and internationally, while limiting the speculative flow of capital and the inefficient and low-return investments.

So what does China's policy stance mean for the dollar? There are some clear implications.

Given the institutional and structural constraints in China, it does not seem likely that nominal renminbi appreciation will become a key policy variable in rebalancing China and the global economy in the near future. This means it will be difficult for the United States to pursue a weak-dollar policy. Without depreciation against the renminbi, any further depreciation of the dollar against the euro and yen would do little to help global rebalancing - and could instead cause shocks to the European and Japanese economies. 
Given the huge potential for cross-border investment and debt financing between the United States and China, a stable renminbi-dollar exchange rate seems to fit both countries' long-term national interest. If the United States and China can cooperate effectively in maintaining the stability of the exchange rate and orderly cross-border flows of capital, there is little reason to believe the dollar-based international currency system will collapse in the foreseeable future.

In the longer term - certainly after 2020 and perhaps during 2025-35-the renminbi is likely to become an international currency when it becomes fully convertible and the Chinese economy completes its structural and institutional transformation into a fully modernised market economy with a more democratic political system. By that time, the integration of the US, European, Japanese and Chinese economies will be so deep that the dollar, euro, yen and renminbi are likely to become leading reserve currencies of the world, with fully floating exchange rates.

Rebalancing the world economy can be accomplished without revaluing the renminbi. For this to happen without major dislocations, however, structural and institutional reforms must occur both in China and in the United States. Higher inflation in China and deflation or lower inflation in the United States can bring about the needed adjustment in real, rather than nominal, exchange rates. This implies a stronger dollar, but also requires de-leveraging in the United States, including reduction of US fiscal deficits.

\section{Challenges in the next two decades}

During the next 20 years of reform and development, the key macroeconomic challenge is to determine how to manage the exchange rate, interest rate and inflation rate in order to facilitate sustainable, stable, efficient and harmonious growth of China's real economy in the context of a world economy in which the weight of the Western economies will shrink relative to the emerging market economies.

To appreciate the extent of this challenge, it is essential to recognise that China's high growth in the past 30 years is a story largely of rapid productivity growth and catching up. The productivity story is likely to continue for the next two decades if China continues its market-oriented reform and its trend of rapid industrialisation and urbanisation. As a result, China's non-tradable goods prices - such as wages for unskilled labour and property prices - are likely to continue to rise (see the chapter in this volume by Ross Garnaut), relative to the prices of tradable goods, which are set by global markets. 
In the next two decades, rising non-tradable goods prices in China will lead to a gradual but steady convergence of China's price levels towards those in Hong Kong and the United States, through structural inflation or structural renminbi appreciation - or both. It is essential for China's policymakers and Chinese people to tolerate the structural inflation and/or currency appreciation associated with this productivity catch-up.

More importantly, since inflation and currency appreciation can cause distortions, shocks and income redistribution, it is necessary for policymakers to use appropriate policy mixes to mitigate potential dislocation that might be created in the adjustment process.

For example, when structural inflation emerges, it will be critical to raise nominal interest rates so as to avoid asset bubbles that are caused by negative real interest rates as well as to protect the value of bank deposits held by the lowincome households who cannot afford to invest or speculate in property markets in order to hedge against the structural inflation. Since 1991, China's urban residential real estate prices have grown on average about 9 per cent a year, but the mortgage rate is only about 5 per cent and the one-year fixed-deposit rate is only about 2 per cent. The structural inflation in property and low mortgage and deposit rates implies a very serious problem of negative real interest rates in terms of investing in property. This is the root of China's property bubbles and the associated huge income redistribution from depositors (usually the poor) to mortgage holders (usually the rich).

If China cannot maintain a positive real interest rate, its boom and bust cycles in the property sector are likely to continue, leading to serious inefficiency in investment as well as social instability. On the other hand, if China does raise interest rates to a level higher than its structural inflation, it then needs adequate capital control to deal with speculative capital inflows.

The importance of keeping the real interest rate positive cannot be overemphasised for China in the next two decades, as China's key challenge in macroeconomic adjustment is to improve its investment and consumption efficiency so that it can absorb more of its current account surplus. Otherwise, China will face serious international trade protection pressure.

On the other hand, this chapter shows that it is not necessary for China to rely only on nominal exchange rate flexibility to facilitate its rising price level if it can instead tolerate higher structural inflation and the associated real appreciation. In fact, it is much easier for China to implement a flexible exchange rate regime when it allows reasonable structural inflation. With inflation, there will be potential for the currency to depreciate when inflation runs beyond productivity growth. So, a mixture of inflation and nominal appreciation could 
create a regime in which the market exchange rates could go up or downreducing the incentive for massive speculative holdings of the renminbi, which has become one of the key drivers of China's foreign exchange reserve bubble.

It should also be pointed out that when China pegs its renminbi to the US dollar, it should not worry too much about runaway inflation since the peg has the stabilisation function. If the inflation rate goes beyond China's underlying productivity growth, the market will expect the renminbi to depreciate, which will lead to capital outflows and the tightening of money supply. Given China's huge foreign exchange reserves, it is easy for China to defend its peg and avoid runaway inflation.

As soon as China starts to tolerate reasonable structural inflation and the associated real appreciation, the pressure for nominal appreciation will be reduced.

This chapter has also highlighted the fact that the exchange rate is a price not just for trade but for assets. In fact, the volume of the asset markets is much bigger than that of trade. Maintaining stable exchange rates for facilitating stable and efficient cross-border capital flows could be more important than using the exchange rate to balance trade. It could be more productive to use trade policies such as reducing the transaction costs for imports to balance China's trade.

\section{References}

McKinnon, R. 2006, 'China's exchange rate trap: Japan redux?', American Economic Review, vol. 6, no. 2, pp. 427-31.

McKinnon, R. Lee, B. and Wang, Y. D. 2009, The global credit crisis and China's exchange rate, Stanford Center for International Development Working Paper no. 391, Stanford University, Calif.

Prasad, E. 2009, 'Rebalancing growth in Asia', Finance \& Development, vol. 46, no. 4, pp. 19-22.

Qiao, H. 2007, 'Exchange rates and trade balances under the dollar standard', Journal of Policy Modeling, vol. 29, no. 5, pp. 765-82.

Sun, W., Yang, X. and Xiao, G. 2009, Investment rate and FDI: a comparative analysis of return to capital among China, US and Japan, Paper presented at the joint symposium of US-China Advanced Technology Trade and Industrial Development, Beijing, 23-24 October. 
Xiao, G. 2008, 'China's exchange rate and monetary policies: structural and institutional constraints and reform options', Asian Economic Papers, vol. 7, no. 3, pp. 31-49.

Xiao, G., Yang, X. and Janus, A. 2009, 'State-owned enterprises in China: reform dynamics and impacts', in R. Garnaut, L. Song and W. T. Woo (eds), China's New Place in a World in Crisis: Economic, geopolitical and environmental dimensions, ANU E Press, Canberra, pp. 155-78.

\section{Acknowledgments}

This chapter consists of two sections. Section one is a reprint of an article by the author published on 13 January 2010 at 'What Matters' web forum hosted by the McKinsey Quarterly (<http://whatmatters.mckinseydigital.com/currencies/ china-s-exchange-rate-policy-and-what-it-means-for-the-dollar $>$ ). Section two includes additional comments prepared specially for this chapter. The author is grateful to the McKinsey Quarterly for permission to include the previously published contents in this chapter. The author would also like to thank Ronald McKinnon, Andrew Sheng, Pieter Bottelier, Wing Thye Woo, Jeffrey Sachs, Barry Bosworth, Harry Broadman, David Dollar, David Loevinger, David Meale, David Skilling, Jonathan Woetzel, Kenneth Lieberthal, Cheng Li, Xingdong Chen, Chunlai Chen, Min Zhu, Qiren Zhou and Hong Liang for helpful comments and discussions on this work. Jonathan Delikat and Will Hobbs provided excellent research assistance. 


\title{
The real exchange rate and the renminbi
}

\author{
Rod Tyers and Ying Zhang
}

\section{Introduction}

China's renminbi (RMB) has been at the centre of political debates over current account imbalances for more than a decade. In scholarly circles, while a few, including McKinnon (2006), argue that a renminbi appreciation would not address the imbalances of concern to the United States, numerous studies have supported the view that the currency is undervalued-by margins ranging from 'small' to as high as 50 per cent ${ }^{1}$ - and some conclude that a unilateral appreciation of the renminbi is essential (for example, Cline 2005). Expectations that China's exchange rate should be appreciating are based commonly on the Balassa (1964) - Samuelson (1964) hypothesis (BSH). This implies a positive relationship between economic growth and the underlying real exchange rate, driven by productivity catch-up in developing countries' tradable sectors and, in association, rising wages and prices in their non-tradable sectors.

Empirical evidence from studies by Lu (2006), Fogel (2006) and Tyers et al. (2008) suggests that China's tradable productivity growth has been double that of the United States since the early 1990s (Gordon 2003, 2006). The productivity pattern therefore appears to support a real appreciation relative to the United States consistent with the BSH. More controversial, however, is the expectation that the productivity gains force relative growth in real wages. That this is true to some degree is clear from the official statistics (Garnaut and Huang 2006). The real wages of non-hukou workers were, however, less formally recorded and Meng and Bai (2007), among others, suggested that these grew more slowly, if at all, at least until the mid 2000s. The BSH then posits that faster Chinese growth in both tradable productivity and real wages should cause a rise in relative nontradable (mainly service) prices, which is also observed through the mid 2000s (Lu 2006; Tyers et al. 2008). In spite of all this evidence supporting the BSH, there was no significant real appreciation between the mid 1990s and 2004.

1 See, for example, Frankel (2004); Wang (2004); Goldstein (2004); Coudert and Couharde (2005); Tyers et al. (2008); and Cheung et al. (2007a, 2007b). 
The resolution of this puzzle requires a number of generalisations of the $\mathrm{BSH}$, most significant among which is the relaxation of the assumption that the law of one price applies for all traded goods. This greatly broadens the set of determinants of the real exchange rate. The net effect of China's rapid economic growth on its real exchange rate is, then, seen to depend on the sources of that growth and the consequent pattern of endowment changes and sectoral distributions of productivity growth and tradability. Of considerable importance in the decade to the mid 2000s is the short-run impact of China's widening current account surplus, which stemmed from its extraordinarily high total saving rate and the World Trade Organisation (WTO) accession trade reforms.

We show that a strong reversal of the earlier tendency for the real exchange rate to depreciate occurred after 2004, raising China's production costs by onethird, relative to the United States, by 2008 . We explore this change and discuss its determinants, noting mounting evidence not for a return to the dominance of the BSH but instead for a tightening labour market associated, at least in part, with improved rural terms of trade. Turning to macroeconomic policy, we then examine the controversy over China's extensive holdings of official foreign reserves, finding these to be a consequence of its capital controls and its high saving rate. We show, however, that, by international standards, they do not appear to represent extraordinary holdings of generic foreign assets. We then examine the exchange rate target as monetary policy, concluding that, should the Chinese government respond to international pressure with a premature nominal revaluation or some form of constraint on its exports, the consequences would be harmful to both Chinese and global interests.

The next section offers a brief summary of an analysis of China's real exchange rate path to the mid 2000s, showing the importance of the saving rate and trade reforms in this period. This is followed by a review of evidence of the reasons for the more recent appreciating trend and then a discussion of the role of China's macroeconomic policy. A summary of policy implications concludes the chapter.

\section{The 1994-2004 puzzle}

If the average product of labour in the non-tradable (largely services) industries is the same across countries while the corresponding average product in tradable industries, $A T$, is lower in poor countries, the BSH yields the following elegant relationships between the underlying real exchange rate, $e R$, and the ratios of home and foreign values of $A T$, non-traded prices, $p N$, and wage rates, $W$ (Equation 9.1). ${ }^{2}$

2 For the derivation of this relationship, see Golley and Tyers (2007). 


\section{Equation 9.1}

$e_{i}^{R}=\left(\frac{p^{N}}{p_{i}^{N}}\right)^{\theta}=\left(\frac{A^{T}}{A_{i}^{T}}\right)^{\theta}=\left(\frac{W}{W_{i}}\right)^{\theta}$

Here, the real exchange rate is defined as the value of the home product bundle relative to a corresponding bundle in foreign region $i$. It is the number of foreignsourced product bundles that can be obtained if one home product bundle is traded away. According to the BSH, an economy that is growing faster than its trading partners also has:

1. faster tradable productivity growth, $\hat{A}^{T}>\hat{A}_{i}^{T}$

2. faster wage growth $\hat{W}>\hat{W}_{i}$

3. relative service price inflation $\hat{p}^{N}>\hat{p}_{i}^{N}$

4. an appreciating real exchange rate $\left(\hat{e}_{R}>0\right)$.

The hypothesis then implies that, if developing countries are poorer because their tradable labour productivity is lower, their comparatively rapid growth should be associated with real appreciations against their richer trading partners. Given that this is a widely discussed theory of the real exchange rate, it is not surprising that China's growth surge since the early 1990s has been accompanied by the widespread anticipation of a real appreciation.

While wider empirical evidence in support of the BSH is mixed, when price levels are compared through time and across large numbers of countries, the pattern of real appreciation among the more rapidly growing countries is observed (Cheung et al. 2007b; Bergin et al. 2006). For the case of China, we observe convincing evidence of faster tradable productivity growth (Table 9.1) and higher price inflation in the service sector ('tertiary' industry and construction) through the mid 2000s (Figure 9.1). Yet, as Figure 9.2 shows, no real appreciation was observed until after 2003. For a reflection of this, we use monthly data for Chinese and US producer price indices in Figure 9.3, which shows the same real depreciating trend through the mid 2000s with a subsequent sharp real appreciation in the lead-up to the global financial crisis. Clearly, to understand the path of China's real exchange rate, we require a generalisation of the $\mathrm{BSH}$, and this means relaxing its key assumptions. 
China: The Next Twenty Years of Reform and Development

Table 9.1 Contributions to China's real exchange rate change, 1997-2006 (per cent)

\begin{tabular}{l|l}
\hline Faster tradable productivity growth-Balassa Samuelson & +1.6 \\
\hline Faster skill growth & -0.6 \\
\hline WTO accession trade reforms & -4.2 \\
\hline Influx on the financial/capital account of North America & -0.4 \\
\hline Efflux on the financial/capital account (high saving rate) & -4.8 \\
\hline Net effect over 1997-2006 & -8.1 \\
\hline
\end{tabular}

Source: Tyers, R. and Golley, J. 2008, 'China's real exchange rate puzzle', Journal of Economic Integration, vol. 23, no. 3, pp. 547-74.

Figure 9.1 Chinese sectoral price indices, 1990-2009
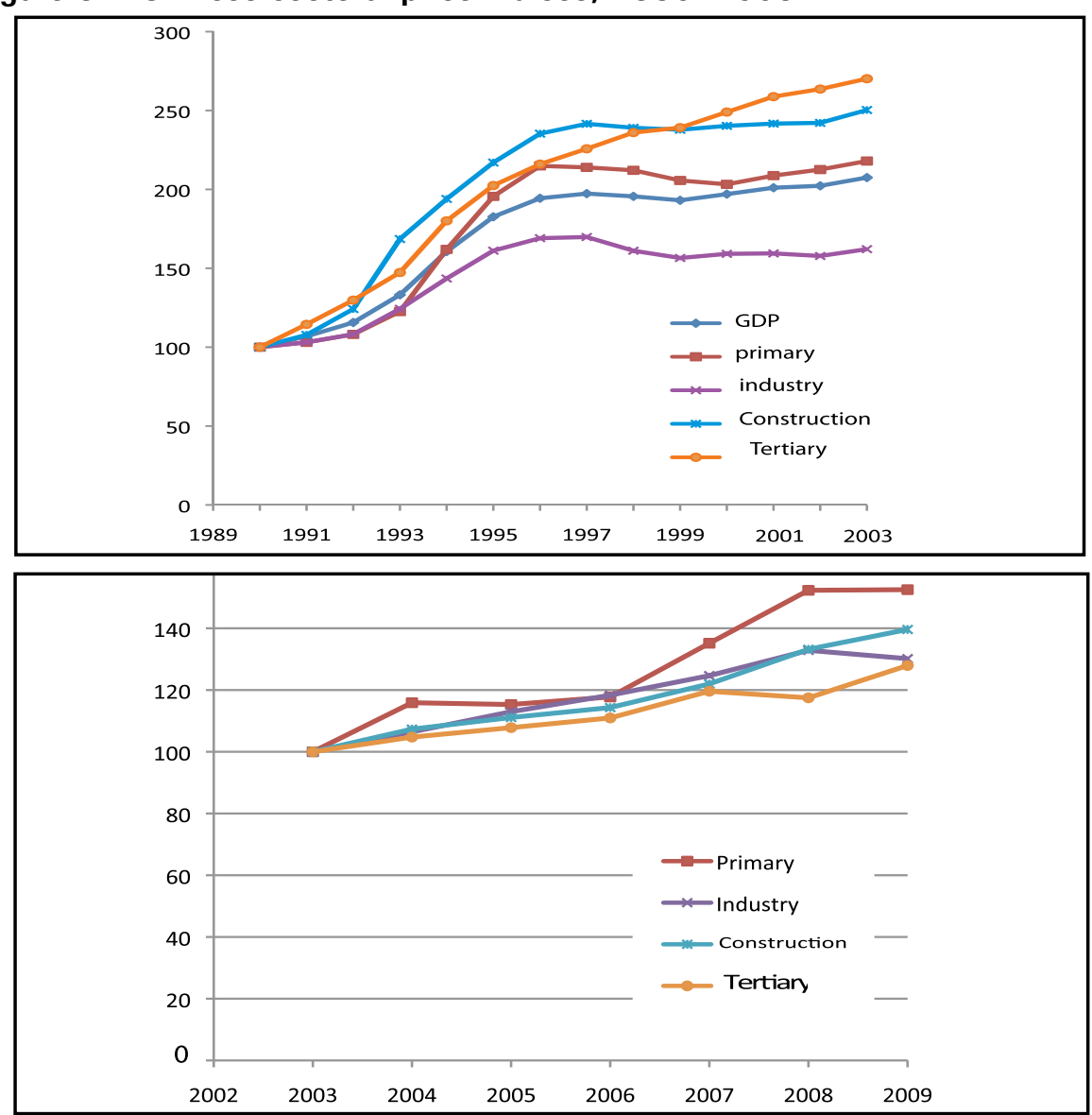

Note: These are sectoral price indices for 'primary industry', which is agriculture and rural services, 'industry', which is primarily manufacturing and 'construction' (the latter two making up the 'secondary' sector); and 'tertiary industry', which is other services.

Source: The price indices are implied by volume and value data from National Bureau of Statistics (NBS) 2009, China Statistical Yearbook 2009, China Statistics Press, Beijing. 
Figure 9.2 The Mainland China-US real exchange rate on GDP prices

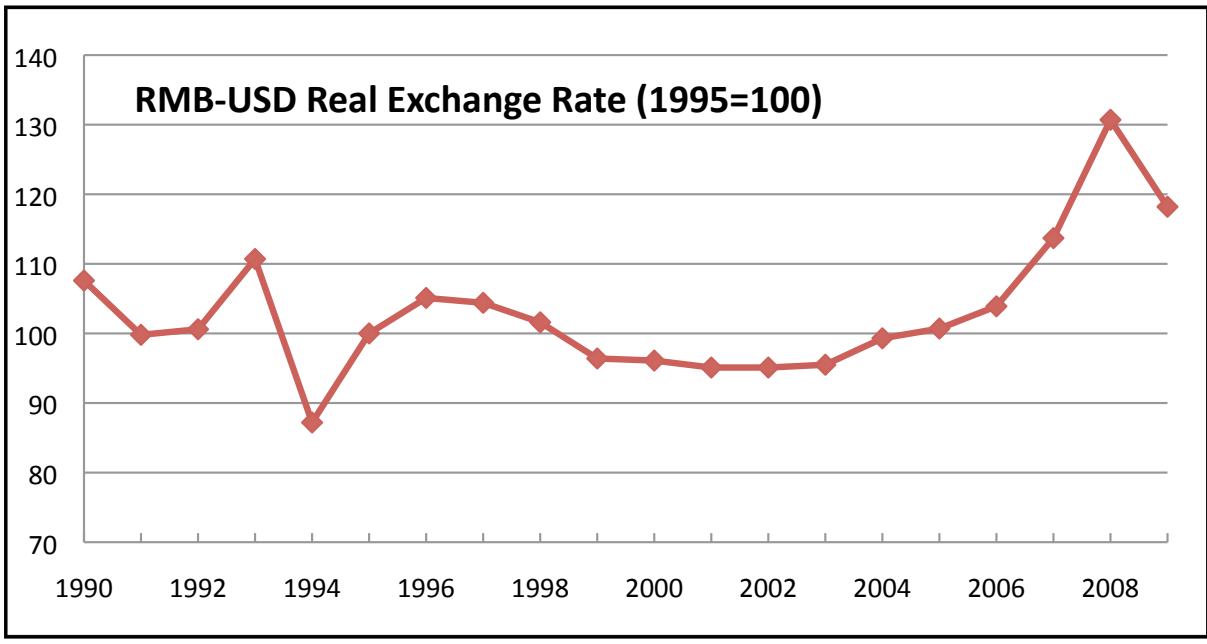

Note: These are indices of nominal bilateral rates between Mainland China and the United States, deflated according to $e_{R}=E \times P_{Y} / P_{Y}^{U S}$, where $E$ is the nominal exchange rate in US dollars per unit of local currency, $P_{Y}$ is the local GDP price and $P_{Y}$ is the corresponding US GDP price.

Source: International Monetary Fund (IMF) 2009a, International Financial Statistics, International Monetary Fund, Washington, DC.

\section{Figure 9.3 The Mainland China-US real exchange rate on producer prices}

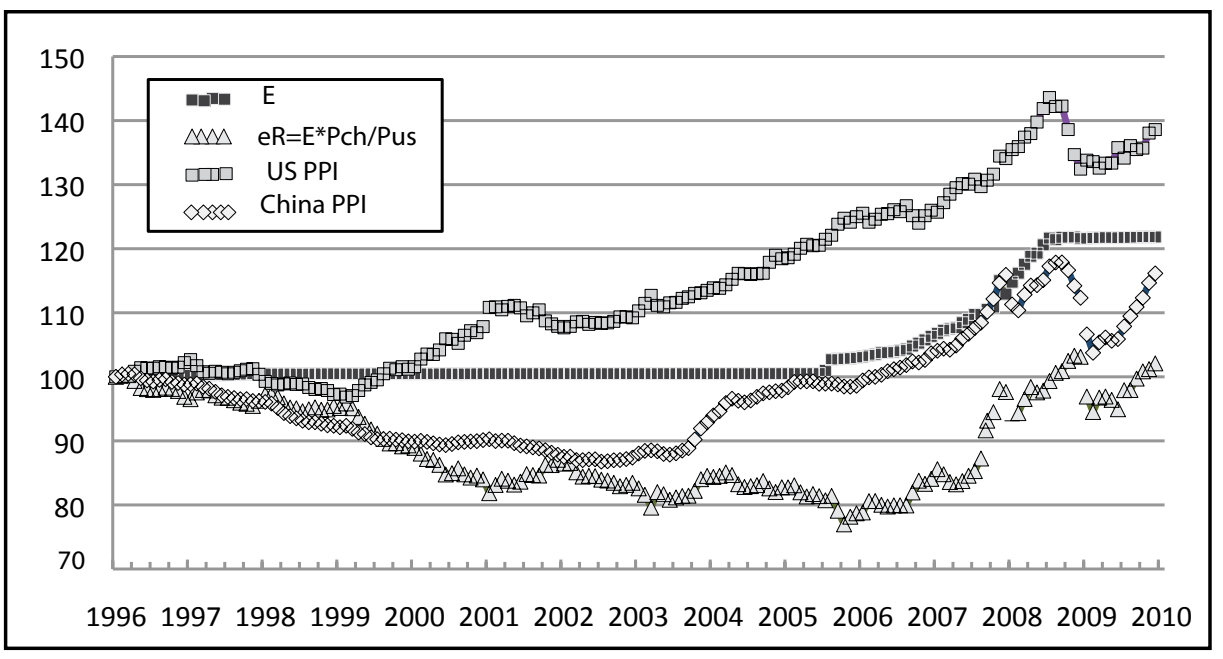

Notes: Here the home prices are, for the United States, the producer price index and, for China, the corporate goods price index. The Chinese index has more coverage of commodities and services, so this is a less than perfect comparison. The implied real exchange rate is in black.

Sources: International Monetary Fund (IMF) 2009a, International Financial Statistics, International Monetary Fund, Washington, DC; National Bureau of Statistics (NBS) 2009, China Statistical Yearbook 2009, China Statistics Press, Beijing; the Bureau of Labor Statistics, USA. 


\section{The law of one price for tradable goods}

Failures of the law of one price have been observed for tradable goods in specific instances (for example, Bergin et al. 2006; Crucini et al. 2005; Drine and Rault 2005). Goods and services are not homogeneous across countries but are differentiated at minimum by country of origin. ${ }^{3}$ Supply and/or demand-side shocks that raise the volume of tradable production move the home country down the global demand curves for its product varieties, reducing its supply prices and resulting in deterioration in its terms of trade and a depreciation of its real exchange rate. Home factor endowment growth and changes in policy that lead to substitution in demand away from home products therefore also depreciate real exchange rates.

\section{Labour arbitrage}

In most developing economies, there is a Harris-Todaro gulf between wages in the modern and rural sectors. If labour mobility between the rural and industrial sectors is inferior to that between the rural and service sectors (particularly the construction sector), industrial productivity growth does not necessarily drive up service wages or service costs — at least not to the same extent on average. ${ }^{4}$

\section{Closed capital account ${ }^{5}$}

The assumption that the real exchange rate depends only on interactions among countries associated with trade in merchandise is clearly violated in many of today's developing countries - and particularly in China. Its violation, in concert with failures of the law of one price for tradable goods, means that any influx of payments (in the form of a foreign direct investment, portfolio capital flow or a repatriation of official foreign reserves) raises home aggregate demand. Since tradable goods are supplied more elastically via imports than are non-tradable goods - which depend on home resources - such an influx must raise relative non-tradable prices and therefore appreciate the real exchange rate. Conversely, effluxes such as China's extraordinary foreign reserve accumulations cause real depreciations.

Using a multi-region, multi-product dynamic simulation model of the world economy, Tyers and Golley (2008) evaluate the implications of a variety of shocks for China's real exchange rate. They find that, in the short run, the real

3 This is a standard assumption in the most widely used numerical models of open economies and global trade. See, for example, Dixon et al. (1982); McKibbin and Sachs (1991); Hertel (1997); and Dixon and Rimmer (2002).

4 Chang and Tyers (2008) offer evidence for this.

5 Here we adopt a working definition of the capital account as broadly including all flows on the balance of payments associated with asset acquisition. As such, it encompasses the more narrowly defined capital account, the financial account and official reserve transactions. 
exchange rate is most responsive to financial capital flows, so that China's excess saving tends to depreciate the real exchange rate. In the medium run, the BSH force (relative productivity growth in tradable industries) is strong, as is the effect of trade reforms that divert domestic demand away from home products and therefore depreciate the real exchange rate. In the long run, the real exchange rate depends sensitively on factors affecting the cost of non-traded services. They then employ their model to decompose the real depreciating trend between the mid 1990s and the mid 2000s. The particular real exchange rate chosen for this analysis is that between China (including Hong Kong and Taiwan) and North America. This rate depreciated by 8 per cent in the period of interest. Its decomposition is summarised in Table 9.1.

Higher Chinese productivity growth is seen to have offered the expected BSH appreciating force. Net financial outflows on China's balance of payments and inflows on the North American balance of payments both tend to depreciate the Chinese real exchange rate. Similarly, skill acquisition (which reduces the cost of supplying mainly skill-intensive services) and trade reform offer the expected depreciating forces. In combination, the current account imbalances in China and North America contribute a real depreciation of more than 5 per cent. Surprisingly significant, however, is the depreciating effect of WTO accession trade reforms, which contribute more than 4 per cent to the overall real depreciation. In the end, these current account imbalances prove to be, in combination, the most important depreciating forces to the mid 2000s.

The significance of this for China is clear from Figure 9.4, which shows that the saving-investment gap (the current account surplus) expanded substantially after the East Asian financial crisis. This expansion in net outflows diverted domestic demand abroad and placed downward pressure on China's real exchange rate. To see this, note that the equality of net inflows of payments on the capital account (net outflows on the current account) ${ }^{6}$ to the investment-saving gap follows from the standard aggregate expenditure and disposal identities. ${ }^{7}$ Defining net inflows as positive, the capital account surplus can be written as: $K A=S_{N F}-\Delta R=I-S_{D}$, in which $I$ is investment, $S D$ is total domestic saving, $S N F$ (net foreign saving) is net private inflow on the financial account and $\Delta R$ is the annual addition to official foreign reserves. In the presence of capital controls, $S_{N F}$ was roughly equal to officially approved inward foreign direct investment (FDI). Both sides of the equation are negative in the case of China, indicating net outflows. Extraordinarily, even though investment accounts for

6 For our working definition of the 'capital account', KA, see the next note.

7 The right-hand side of this identity stems from the combination of aggregate expenditure on GDP, $Y=C+$ $I+G+X+\mathrm{M}$; the fact that GNP is $Y N=Y+\mathrm{N}$, where $\mathrm{N}$ is net factor income from abroad; the GNP disposal identity, $Y N=C+T+\mathrm{S}$, and the balance of payments, $B o P=O=K A+C \mathrm{~A}$, where the current account is $C A=X-M+\mathrm{N}$. 
45 per cent of China's GDP, more than half of its GDP is saved. In explaining the real depreciating trend, however, the key observation is that the savinginvestment gap was increasing through the mid 2000s.

Figure 9.4 China's investment-saving and external balances (percentage of GDP)

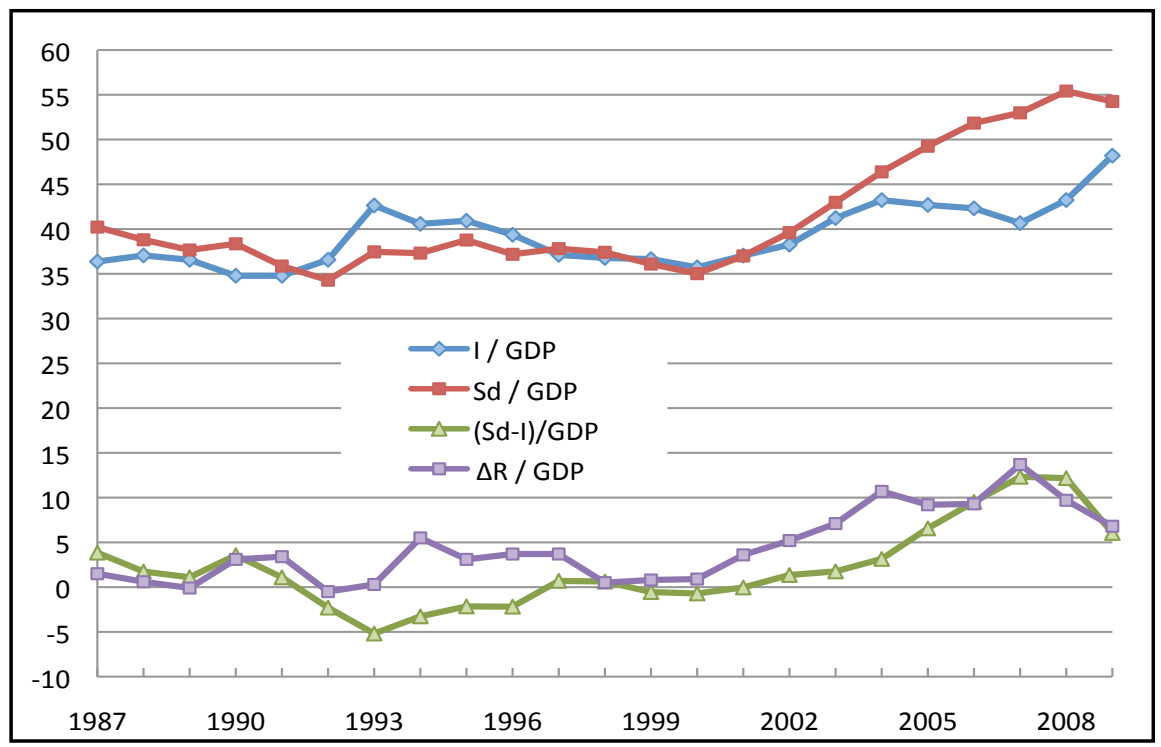

Note: Since errors and omissions are large, we have adjusted the least accurately measured items in each sub-account (usually net factor income and net private flows on the financial account) to ensure balance.

Sources: International Monetary Fund (IMF), 2009a, International Financial Statistics, International Monetary Fund, Washington, DC; International Monetary Fund (IMF), 2009b, World Economic Outlook Database, April, International Monetary Fund, Washington, DC; National Bureau of Statistics (NBS) 2009, China Statistical Yearbook 2009, China Statistics Press, Beijing.

\section{The real appreciation after 2004}

The exchange rate reforms launched by the Chinese authorities in July 2005 were intended to at least demonstrate a departure from the de facto fixed US dollar peg, nominally allowing the currency to fluctuate by up to 0.3 per cent each day. The appreciation accelerated in 2007 amounting to an accumulated 20 per cent by July 2008, after which the global financial crisis induced the Chinese government to return to the de facto US dollar peg. The 2004-2008 round of revaluation was accompanied by significant domestic inflation, implying a substantially larger appreciation of the underlying real exchange rate (Figure 9.2)-amounting to at least 30 per cent. As is evident from Figure 9.3, the difference between the bilateral nominal and real appreciations was associated with faster growth of China's producer prices than those of the United States. 
More recently, as Figure 9.3 shows, the underlying real appreciating trend has resumed. Accordingly, to control domestic inflation, official "flexibility" was restored as of June 2010.

Changes in the path of the real exchange rate since 2004 are too recent for a detailed decomposition. The GFC aside, a clear tendency toward real appreciation is evident, however. In what follows, we discuss a number of alternative explanations for this appreciating trend.

\section{Decreasing current account surplus}

After a rapid increase in the early 1990s, household saving rates fluctuated between 20 and 25 per cent during 1997-2006 (Tyers and Lu 2009). The initial surge in household saving was associated with the 1990s round of privatisation and restructuring, which increased household funding responsibilities for health, education and retirement expenses. In more recent years, the government has embarked on national schemes for health and retirement insurance, including the extension of medical pension insurance to cover rural areas and the establishment of urban subsistence security systems (Chamon and Prasad 2008; Wen 2008). These have lessened this concern, leading to at least the stabilisation of household saving rates. At the same time, a surge in government spending began with the onset of the global financial crisis in 2007. This reduced the government's contribution to national saving. As shown in Figure 9.5, the Chinese current account surplus has stabilised since 2005 and recently contracted. The previous period of real depreciation was associated with the expansion of this surplus and hence the diversion of increasing shares of Chinese income into expenditures abroad. The cessation of this trend would at least stem further real depreciation.

\section{Increasing oligopoly rents}

$\mathrm{Lu}$ et al. (2008) point out that Chinese state-owned enterprises (SOEs) still dominate industries such as metals, motor vehicles, aircraft, transport, telecommunication, finance and insurance and that they became extremely profitable during the 2000s. Tyers and Lu (2009) attribute these profits to oligopolistic behaviour and see the associated rents as having expanded with the post-WTO accession growth surge, financing the huge corporate savings of the period. The effect of these rents on China's real exchange rate has two channels. First, higher mark-ups in largely non-traded industries raise prices and hence cause appreciation. Second, the rents gained by SOEs make up a primary part of corporate saving, which has tended to divert Chinese expenditure abroad and thus to depreciate the real exchange rate. As Tyers and Lu showed, the latter effect was dominant to 2005. The more recent decline in the corporate saving rate (Bayoumi et al. 2009) could have shifted this balance towards the appreciating effect of mark-ups. 
Figure 9.5 Real wage growth in agriculture

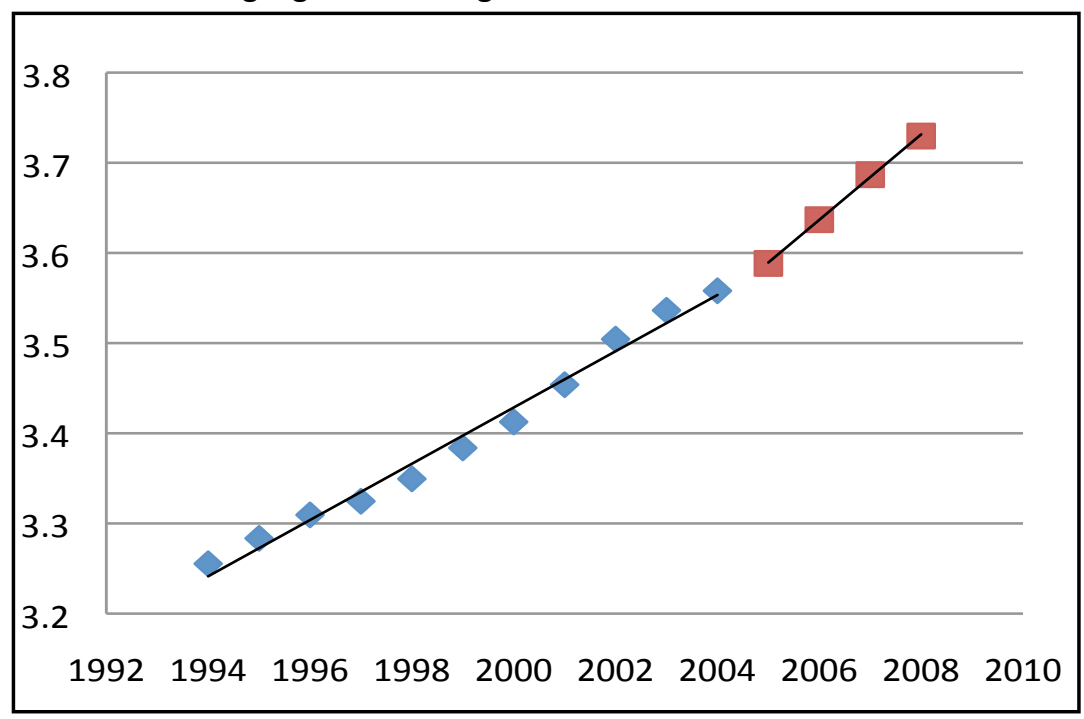

Note: The vertical axis is the log of the real wage index where the agricultural nominal wage is deflated by the consumer price index (CPI).

Source: The nominal wage by sector and the CPI are from National Bureau of Statistics (NBS) 2009, China Statistical Yearbook 2009, China Statistics Press, Beijing.

\section{Slowdown of trade reform}

China's 2001 WTO accession saw a wide range of tariff cuts and market-opening policy changes. Since then trade reform has slowed. ${ }^{8}$ As discussed previously, trade liberalisation depreciates the real exchange rate so this slowdown might be seen as at least relaxing pressure for depreciation. Yet trade reforms are never Pareto improving without compensation. The sector bearing the most negative effects from WTO accession has been agriculture, the stagnation of which in the early years after accession probably contributed to the substantial rural-urban migration of the period (Chang and Tyers 2008; Rees and Tyers 2008). Since then a major concern of the central government has been the welfare of farmers and other rural dwellers. Unlike the corresponding experiences of Japan, Korea and Taiwan during their growth surges, in China, because of its WTO commitment, it has not been able to address the rural-urban divide using trade protection (Anderson and Hayami 1986; Anderson 2009; Duncan et al. 2008). A consequence has been a trend from negative assistance to agriculture in the early reform period to positive and significant protection today, channelled via domestic marketing, transport, storage and other budgetary measures - allowed

8 According to the World Trade Organisation's Trade Policy Review (WTO 2008), the tariff is still one of China's main trade policy instruments. The overall average applied MFN tariff was 9.7 per cent in 2007-the same as in 2005. The average applied MFN tariff rates for agricultural and non-agricultural products were 15.3 per cent and 8.8 per cent, respectively — also the same as in 2005. 
under WTO rules for developing countries. ${ }^{9}$ Beyond agriculture, a number of trade-biased policies have emerged that cut against the spirit of the preaccession reforms. Since 2005, the value-added tax (VAT) rebate for exporting firms has been raised nine times - up to 17 per cent - covering approximately 3800 export products, including textiles, clothing, toys, machinery, electric appliances, medicines, communication devices and steel (Ministry of Commerce of the People's Republic of China 2009). Such export-encouraging policies divert home supplies abroad, raising the relative prices of domestic goods and hence appreciating the real exchange rate.

\section{Rising relative wage costs}

The sectoral price indices in Figure 9.1 are revealing in that, since the mid 2000s they do not show any rise in the price of services (the 'tertiary' and construction sectors) relative to the tradable-goods sectors. This suggests that the appreciation since 2004 is not due to the BSH force (relatively high productivity growth in China's tradable sectors). Indeed, the striking change is in the price index for primary products, indicating a substantial improvement in the agricultural terms of trade. While this is due in part to higher prices of import-competing commodities, we have already seen that there have been a number of favourable changes to policies affecting agriculture and the rural sector generally. These changes would have raised the marginal product of rural labour and therefore the incentive required for rural workers to migrate to eastern cities.

Regression results suggest a structural change in real wage growth for the agricultural and construction sectors about 2004, as indicated in Figure 9.5. The labour forces in these sectors are mainly unskilled and the rural labour market is the source of most non-hukou workers in construction, other services and manufacturing. The official agricultural real wage grew at 3.1 per cent per annum (with a standard error of 0.0012) in the period 1994-2004 and at 4.7 per cent per annum (with a standard error of 0.002) in the period 2005-08. ${ }^{10}$

In their study of the real wages of unskilled factory workers in Guangdong, Meng and Bai (2007) used payroll data to ensure the inclusion of non-hukou workers. They show a much smaller annual growth rate of between 0.5 and 1.5 per cent per annum up to 2004, controlling for education and firm tenure. The

9 Huang et al. (2009) show the trend in assistance to agriculture clearly in their Table 3.5. More recently, the speech by Wen (2010) indicates the central government's plans to raise the agricultural subsidy to RMB133 billion in 2010. The same speech indicates that agricultural tax reductions were carried out in Anhui Province in 2000 and were then extended to 30 provinces in 2003. By 2005, agricultural production taxes were completely cancelled in 28 provinces. Farmers' benefits were estimated at RMB133.5 billion per annum. 10 The growth rates were obtained from a simple ordinary least squares (OLS) regression of the log of the nominal agricultural wage deflated by the consumer price index (CPI) against time. The standard errors on the growth rate coefficients in both regressions are very small, suggesting that the growth rates are significantly different. 
take-off in rural wages after that time suggests, however, that real non-hukou rates have increased since and this is to be expected from the improvements in net returns from agricultural activity. Increasingly, it is likely that potential 'floating workers' are choosing to continue their rural employment. Anecdotal indications of tightening labour markets have been abundant, including of increased labour unrest suggesting improved labour-market power in manufacturing provinces. ${ }^{11}$ What is evident is a slowing of urban labour supply growth, which drives up the cost of tradable and non-tradable goods relative to China's trading partners and hence causes the real exchange rate to appreciate. While this seems to be associated with agricultural incentives in the short termalong with improvements in infrastructure that have boosted local services sectors - in the long term, the prospect can only be for a continuation. This is because demographic change already long in train will see China's total labour force begin to decline during the next decade (Cai and Wang 2006; Golley and Tyers 2006). In short, this change could be heralding the end of the era of the Dooley et al. (2003) 'revived Bretton Woods trade account' regions generating export growth on the back of surplus rural labour - at least as far as China is concerned (Feenstra and Hong 2007).

\section{Macroeconomic policy and the renminbi}

The real and nominal exchange rates are linked by definition as $e_{R}=P_{Y} /\left(E P_{Y}^{*}\right)=E \cdot P_{Y} / P_{Y}^{*}$, where $E$ is the nominal exchange rate (in foreign currency per unit of home currency), $P_{Y}$ is the price of the home product bundle (the GDP price) and $P^{*}{ }_{Y}$ is the corresponding foreign gross domestic product (GDP) price. Since the foreign price level is outside the realm of home monetary policy, changes in the real exchange rate (determined as discussed in the previous sections) are transmitted domestically through changes in either the nominal exchange rate or the home price level. The choice as to how these are combined is a matter for home monetary authorities. At one extreme, a real appreciation can be transmitted as a nominal appreciation (inflation targeting) or, at another, as inflation (exchange rate targeting). This is complicated, particularly in China's case, by the dependence of the real exchange rate on capital account flows, which are dominated by reserve accumulation, where the choice of reserves is also an instrument of monetary policy.

11 Strikes at key joint-venture plants and other activism led to substantial increases in manufacturing wages in 2009 in the engine-room provinces of Guangdong and Zhejiang (Gardner 2010). 


\section{Reserve accumulation and monetary mercantilism}

China's reserve accumulation has led to allegations of 'monetary mercantilism' (Aizenman and Lee 2006). It is implied that reserve accumulation is chosen freely in order to keep the real exchange rate low. In our view, the monetary mercantilist critique is misplaced. The root of its unfairness is evident from the identity derived previously, $K A=S_{N F}-\Delta R=I-S_{D}$, and therefore, $\Delta R=S_{D}-I+S_{N F}$, in which $S_{N F}$ includes approved FDI and illegal private inflows. As long as total domestic savings exceed investment and capital controls prevent the matching of inward FDI by private outflows, $\Delta R$ must be positive. Indeed, we can state that China's current account surplus must be matched by reserve accumulation and the imbalance is not amenable to feasible changes in macroeconomic policy, narrowly defined, ${ }^{12}$ if:

- the capital controls are justified on stability grounds

- the high private saving rate is impervious to macroeconomic policy in the short run

- as it approaches 50 per cent of GDP (Figure 9.4), investment must be near absorptive capacity.

- government revenue is increasing so quickly that the government cannot easily offset private saving with public 'dis-saving'.

Consider each of these four conditions in turn. The capital controls are conceptually simplest. They stem from 'fear of floating' and short memories of the currency run with which China was threatened in the late 1990s during the East Asian financial crisis. Moreover, some suspicions remain in the People's Bank of China (PBOC) as to the prudential reliability of China's commercial banks in exchanging large volumes of foreign currency. Financial institutions are perceived variously as not sufficiently distant from decades of soft budget constraints associated with the channelling of government subsidies to stateowned enterprises (SOEs) through accumulated debt. And there are concerns that the commercial banks lack access to or sufficient experience with derivative markets for currency and debt instruments to do the necessary hedging. Though Ma and McCauley (2007) vouch for their continued effectiveness, the controls are slowly being relaxed.

As indicated earlier, China's high private saving rate is due to comparatively high household saving and extraordinarily high corporate saving. While the former has ceased to rise and is expected to decline slowly with time as health and retirement insurance systems develop (Chamon and Prasad 2008), the latter,

12 This is a general view also taken by Xiao (2006), who posits that 'structural factors' and transaction costs cause China's economy to adjust with a lag, implying that the current account surplus is not amenable to macroeconomic policy in the short run. 
as argued by Tyers and Lu (2009), is due to the profitability of key SOEs and is therefore an issue for industrial policy, which will take time to resolve. The causes of high saving are therefore deeply structural and the subject of longterm programs of microeconomic policy reform. None is amenable to action by the central bank alone.

As noted by Xiao (2006), it has been suggested that the surplus of saving over investment implies that the rate of investment is too low. At more than 45 per cent of its GDP, however, China's investment is extraordinarily high. It is difficult to imagine how additional projects might be conceived and implemented given service sector planning and facilitation constraints. ${ }^{13}$ Moreover, China's low official domestic financing rates notwithstanding, recent surveys by the PBOC show that a very substantial proportion of investment still takes place through the informal sector at rates that remain high by international standards. It will take some time yet for financial intermediation costs in China to fall to industrialised-country levels, so financing costs must continue to be a brake on investment. ${ }^{14}$

Finally, before the global financial crisis, China's fiscal policy maintained a tight balance between revenue and expenditure. During the crisis, the government committed to a substantial fiscal expansion, including an ambitious program of infrastructural investments, with a view to reducing the national saving rate and raising private consumption expenditure. This prospect faces two difficulties. First, public infrastructure investment to that point already absorbed a larger share of GDP in China than in any other developing country of comparable income per capita (Roland-Holst et al. 2005). Second, revenue collections have grown faster than China's GDP as its tax system has improved in effectiveness and as more of China's economic activity has occurred in the relatively taxable 'modern' sectors. It is yet unclear whether the accelerated spending has outpaced revenue collection. Certainly, there has yet been no dramatic rise in government bond issues. ${ }^{15}$

This support of the 'four ifs' suggests that the Chinese government has little true discretion over its rate of reserve accumulation and therefore over the rate at which domestic income is diverted into expenditure abroad, weighing on its

\footnotetext{
13 Evidence of "white elephant" projects notwithstanding, this is a point over which there is much disagreement.

14 Tyers and Golley (forthcoming) model the effect of high financial intermediation costs on China's growth rate.

15 According to the Ministry of Finance, during 2006-09, the Chinese government issued bonds worth RMB888 billion (2006), RMB798 billion (2007), RMB862 billion (2008) and RMB778 billion (2009) — showing no increasing trend. Besides this, RMB1550 billion in special bonds were issued in 2007 and exchanged with the $\mathrm{PBOC}$ for the equivalent from its stock of reserves. The result was a substitution on the asset side of about 8 per cent of GDP from reserves to domestic credit.
} 
underlying real exchange rate. The extent to which the national saving rate has stabilised very recently suggests, however, that reserve accumulation could be a more neutral force in future.

\section{Liquidity and sterilisation}

Through 2008 at least, the PBOC absorbed foreign currency inflows (export revenue) net of import costs because - short of long-term reforms affecting financial depth and while capital controls remained - the Chinese commercial banks could not move the required volume of foreign currency. This required acquisition of the foreign currency surplus with newly minted domestic currency. To avoid excess liquidity, annual reserve increments were sterilised. PBOC holdings of domestic credit were insufficient for this sterilisation, however, so 'sterilisation bonds' were issued on the debit side of the balance sheet shown in Table 9.2.

Table 9.2 The balance sheet of the People's Bank of China, ca. 2009

\begin{tabular}{l|l}
\hline Assets & Liabilities \\
\hline $\begin{array}{l}\text { Domestic credit, DC Central bank } \\
\text { claims on depository and other financial } \\
\text { corporations and on the central } \\
\text { government } 13 \text { per cent GDP }\end{array}$ & $\begin{array}{l}\text { The monetary base, MBCurrency and bank } \\
\text { reserves 43 per cent of GDP }\end{array}$ \\
\hline $\begin{array}{l}\text { Official foreign reserves, R55 per cent } \\
\text { of GDP }\end{array}$ & $\begin{array}{l}\text { Sterilisation bonds, SBDebt to the Chinese public } \\
13 \text { per cent of GDP } \\
\\
\text { Other liabilities, OLIncludes government } \\
\text { ownership 12 per cent of GDP }\end{array}$ \\
\hline
\end{tabular}

Source: People's Bank of China (PBOC) 2009, Balance Sheet of Monetary Authority, People's Bank of China, Beijing.

Just as the reserves have come to dominate the asset side of the balance sheet, sterilisation bonds have assumed significance on the debit side. In effect, the PBOC has acted as a conduit for domestic savers who might otherwise acquire foreign assets but are restricted from doing so by capital controls. The pressure from abroad to revalue therefore creates two difficulties for the PBOC. First, since the assets of the PBOC are primarily in US dollars and its liabilities are in renminbi, too prompt an appreciation of the renminbi would result in substantial losses that would need to be covered in renminbi from the government budget. This concern was addressed in 2007 with the issue of US $\$ 200$ billion 
in government debt to be exchanged with the PBOC for reserve assets - the latter to be maintained by China's 'sovereign wealth fund': the state-run China Investment Company (CIC). ${ }^{16}$

As shown in Figure 9.6, this sterilisation process kept a lid on the monetary base as a proportion of GDP until the mid 2000s. Liquidity growth was substantial thereafter. It is our view that this has stemmed from continuing financial reforms, which have greatly expanded commercial bank intermediation (in place of preexisting and relatively costly informal credit structures and credit cooperatives). This has been valuable but the associated expansion in deposits has also boosted overall money supply growth, contributing since 2006 to inflationary pressure. The PBOC responded with higher bank reserve requirements and higher short interest rates. The latter added to speculative (illegal) private inflows driven by the expectation that the renminbi would be allowed to appreciate further, bringing upward pressure on the real exchange rate in the lead-up to the global financial crisis and since. As Figures 9.2 and 9.3 show, however, during the crisis the drop in export demand caused a temporary real depreciation. The return to the de facto peg then necessitated contractionary monetary policy and temporary deflation.

Figure 9.6 Dynamics of the PBOC's balance sheet: assets and liabilities as a percentage of GDP

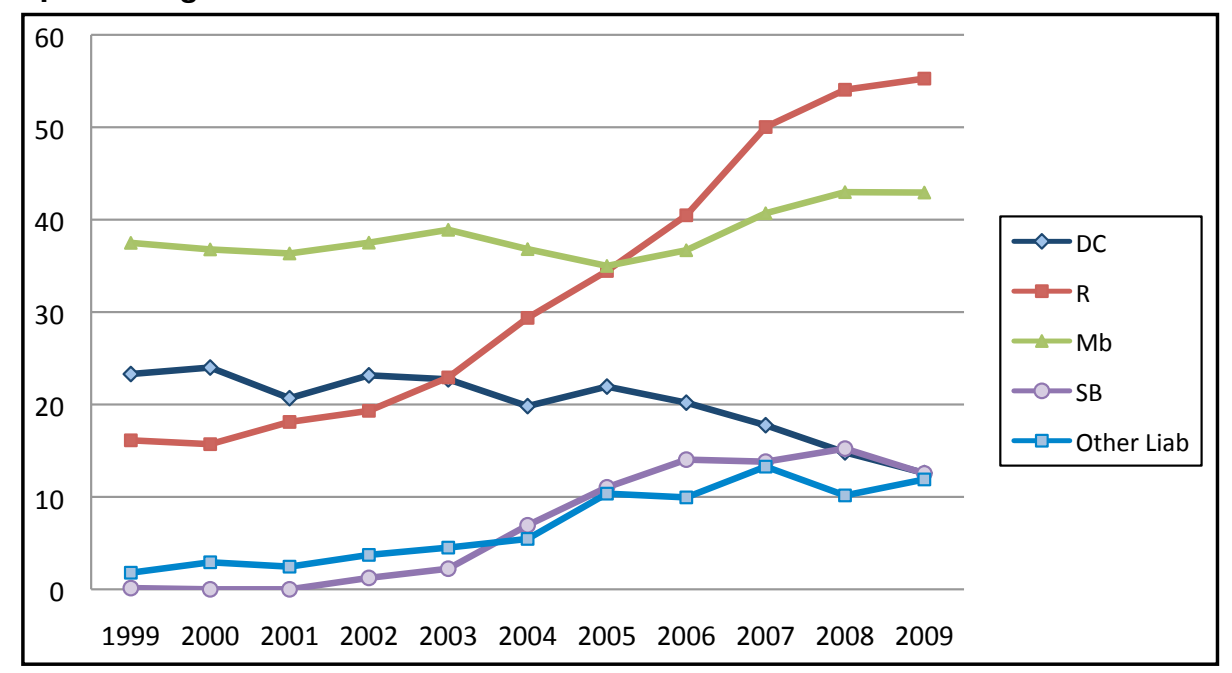

Source: The People's Bank of China.

16 The CIC takes the formerly established 'foreign exchange financial investment company' (the Hui Jin Co: literally translated as foreign exchange and gold) as its subsidiary. Hui Jin does mainly equity investment in domestic financial industries while its parent company, CIC, focuses on overseas investment. Thanks are due to the PBOC for this detail. 


\section{The effect of relaxing capital controls}

As capital controls are relaxed, a key issue will be the extent of private outflows on the financial account. Prasad et al. (2005) point to the potential for this to create a depreciating force as Chinese private investors seek to diversify their portfolios. The scale of this force depends on whether the PBOC's existing foreign reserves are the equivalent of the private sector's desired foreign holdings. A crude assessment of this can be made by comparing the foreign shares of collective portfolios across industrialised and developing countries. Assets are, however, many and various and net positions are poorly documented. For a sample of countries, we have constructed a crude approximation of foreign shares in collective portfolios using estimates of capital stocks and recorded flows on balances of payments. The results require a sceptical eye since capital stocks are measured differently across countries and foreign shares can be expected to be higher in smaller and more open economies irrespective of their levels of development - as in the cases of Hong Kong, Singapore and the United Kingdom.

The resulting foreign asset shares are listed in Table 9.3. The countries are then ranked on their estimated foreign shares in Table 9.4. Most striking is that, large official foreign reserves notwithstanding, China ranks rather low on the list, even when compared with other Asian developing countries. Its foreign share appears to have doubled between 2000 and 2005 and its ranking rose. By 2005, it ranked above Japan, Korea, Thailand, India and Brazil but below the other industrialised countries and Malaysia, Taiwan and Chile. Its ranking above Japan and the other two of the world's very large developing countries, India and Brazil, suggests that its foreign share could be on the high side, though none of these economies is as open as China already is to foreign trade and ownership (Lardy 2006). On the other hand, its ranking below the industrialised countries suggests that continued growth, combined with comparative openness, will take its share higher. At the very least, these results do not lend clear weight to the thesis that financial liberalisation will automatically raise private inflows and appreciate the renminbi. Moreover, a surge in private rebalancing outflows could prove a healthy outcome since the PBOC could readily offset this by repatriating its reserves and sterilising the inflow by liquidating its 'sterilisation bonds'. This would take the pressure off the CIC by restoring the PBOC's balance sheet to something more conventional as well as stabilising the home financial capital market. 
China: The Next Twenty Years of Reform and Development

Table 9.3 Estimates of the foreign share of total assets, selected countries

\begin{tabular}{|c|c|c|c|c|c|c|}
\hline \multirow[t]{2}{*}{ Country } & \multicolumn{6}{|c|}{ Ratio of foreign to total assets (\%) } \\
\hline & 2000 & 2001 & 2002 & 2003 & 2004 & 2005 \\
\hline $\begin{array}{l}\text { China } \\
\text { Ch }\end{array}$ & 10 & 9 & 9 & 12 & 14 & 18 \\
\hline Hong Kong & 55 & 56 & 55 & 59 & 60 & 64 \\
\hline Japan & 9 & 12 & 12 & 14 & 14 & 17 \\
\hline Taiwan & 11 & 14 & 17 & 21 & 22 & 24 \\
\hline Korea & 11 & 13 & 13 & 15 & 17 & 16 \\
\hline Malaysia & 22 & 27 & 28 & 38 & 36 & 41 \\
\hline Singapore & 48 & 50 & 51 & 57 & 57 & 58 \\
\hline Thailand & 18 & 20 & 19 & 19 & 17 & 17 \\
\hline India & 6 & 9 & 9 & 11 & 12 & 11 \\
\hline Brazil & 5 & 6 & 8 & 8 & 7 & 5 \\
\hline Mexico & 7 & 8 & 7 & 8 & 9 & 9 \\
\hline Chile & 21 & 23 & 22 & 26 & 25 & 25 \\
\hline Australia & 15 & 17 & 17 & 18 & 19 & 21 \\
\hline United States & 22 & 19 & 18 & 22 & 25 & 35 \\
\hline European Union 15 & 30 & 33 & 30 & 34 & 36 & 47 \\
\hline United Kingdom & 63 & 63 & 52 & 54 & 54 & 68 \\
\hline
\end{tabular}

Notes: Shares are approximated as the quotient of foreign financial and physical assets and total financial and physical assets. The numerator is the stock of capital owned abroad plus official foreign reserves. The denominator is official foreign reserves plus the home capital stock plus the stock of capital owned abroad less that part of the home capital stock that is foreign owned plus M2 plus gold stocks. International capital ownership is approximated, in turn, by dividing current account net factor income flows by long-term bond rates.

Sources: For most countries, foreign reserves, money supplies, gold stocks, net factor income flows on current account balances and long-term bond rates are from the International Monetary Fund (IMF) various issues, International Financial Statistics, International Monetary Fund, Washington, DC. For Taiwan, these are from the Taiwan Statistical Data Book, 2006. For Chile, the money supply is from the Central Bank of Chile; for Australia, it is from the Reserve Bank of Australia; and for Singapore, it is from the Monetary Authority of Singapore. For China and India, bond rates are from Datastream and, for the European Union 15, Malaysia and Chile, the bond rates are from the Economist Intelligence Unit. All capital stock estimates are from the GTAP global database.

Table 9.4 Country rankings on foreign shares of total assets

\begin{tabular}{llllll}
\hline $\mathbf{2 0 0 0}$ & $\mathbf{2 0 0 1}$ & $\mathbf{2 0 0 2}$ & $\mathbf{2 0 0 3}$ & $\mathbf{2 0 0 4}$ & $\mathbf{2 0 0 5}$ \\
\hline $\begin{array}{l}\text { United } \\
\text { Kingdom } \\
\text { Hong Kong }\end{array}$ & $\begin{array}{l}\text { United } \\
\text { Kingdom }\end{array}$ & Hong Kong & Hong Kong & Hong Kong & $\begin{array}{l}\text { United } \\
\text { Kingdom }\end{array}$ \\
& Hong Kong & $\begin{array}{l}\text { United } \\
\text { Kingdom }\end{array}$ & Singapore & Singapore & Hong Kong \\
Singapore & Singapore & Singapore & $\begin{array}{l}\text { United } \\
\text { Kingdom }\end{array}$ & $\begin{array}{l}\text { United } \\
\text { Kingdom }\end{array}$ & Singapore \\
European & European & European & Malaysia & Malaysia & European \\
Union 15 & Union 15 & Union 15 & & & Union 15
\end{tabular}




\begin{tabular}{|c|c|c|c|c|c|}
\hline Malaysia & Malaysia & Malaysia & $\begin{array}{l}\text { European } \\
\text { Union } 15\end{array}$ & $\begin{array}{l}\text { European } \\
\text { Union } 15\end{array}$ & Malaysia \\
\hline $\begin{array}{l}\text { United } \\
\text { States }\end{array}$ & Chile & Chile & Chile & $\begin{array}{l}\text { United } \\
\text { States }\end{array}$ & United States \\
\hline Chile & Thailand & Thailand & $\begin{array}{l}\text { United } \\
\text { States }\end{array}$ & Chile & Chile \\
\hline Thailand & $\begin{array}{l}\text { United } \\
\text { States }\end{array}$ & $\begin{array}{l}\text { United } \\
\text { States }\end{array}$ & Taiwan & Taiwan & Taiwan \\
\hline Australia & Australia & Australia & Thailand & Australia & Australia \\
\hline Korea & Taiwan & Taiwan & Australia & Korea & China \\
\hline Taiwan & Korea & Korea & Korea & Thailand & Japan \\
\hline China & Japan & Japan & Japan & China & Thailand \\
\hline Japan & China & India & China & Japan & Korea \\
\hline Mexico & India & China & India & India & India \\
\hline India & Mexico & Brazil & Brazil & Mexico & Mexico \\
\hline Brazil & Brazil & Mexico & Mexico & Brazil & Brazil \\
\hline
\end{tabular}

Source: Rankings on the foreign asset shares in Table 9.3.

\section{Unilateral appreciation scenarios}

If the tendency towards real appreciation since 2004 - as shown in Figure 9.2is indeed due to labour-market tightening, it heralds a long-term appreciating trend. This will make it easy for the PBOC to allow a corresponding appreciation in the renminbi. Any decision to revalue faster than the underlying rate of real appreciation would require further monetary tightening and possibly a return to the growth-sapping deflation of the late 1990s.

McKinnon's (2004) sage preference for an East Asian dollar standard notwithstanding, the bilateral pressure from the United States for a renminbi revaluation is understandable in one respect. Despite the benefits accruing to the US economy from Chinese investment, its government perceives a substantial current account imbalance, a proportion of which stems from its bilateral trade with China, and it expects that a US dollar depreciation will help to correct it (Woo 2006). Not only does the inflexibility of the renminbi rate frustrate the US government-inciting the critical rhetoric (Bernanke 2006) and the draft legislation to 'punish' China (Callan 2007) - it causes frustration in Europe, where the burden of appreciation against the US dollar is greatest. ${ }^{17}$

Ironically, while the refusal by some other Asian countries to appreciate their currencies significantly against the renminbi might well be motivated by 'monetary mercantilism', as argued previously, we believe that the sluggishness

17 See RGE Monitor (2007a). European rhetoric also represents this view, as in a speech by Pascal Lamy, then EU Trade Commissioner, on 23 December 2003. 
of China's appreciation against the US dollar is motivated internally. The sticking point is a fear of financial (including exchange rate) volatility, confirmed by adherence to the peg during the global financial crisis. Were the Chinese government nonetheless to agree to revalue faster than the underlying rate of real appreciation, it could either undertake a substantial monetary tightening, and hence further deflation, or accelerate the underlying real appreciation with a return to distorted trade.

\section{Appreciation by monetary contraction}

In the absence of any substantial upward movement in the underlying real exchange rate, the PBOC could simply declare a higher US dollar/renminbi rate. This is the option advocated by Tung and Baker (2004), who suggest a 15 per cent one-off revaluation and argue that the risk of consequent deflation is minimal, due to inflationary pressure from other sources. In the absence of an underlying appreciation of the real exchange rate, this argument lacks foundation.

The defence of the stronger renminbi would require a contraction of the domestic money supply (or a slowdown in its growth) and a boost to domestic short-term interest rates and other financing barriers. If the revaluation were large enough, the result would likely be a return to the deflation of the late 1990s and this would hurt employment in the tradable-goods sector. Income would decline (or grow more slowly), as would consumption and saving. Slower employment growth in the modern sector would reduce capital returns and, combined with higher financing costs, this would also contract investment (or reduce its growth), so the implications for China's external imbalance would then depend on the relative size of the saving contraction. For external balance there are, therefore, two cases to consider.

First, if Chinese households are optimistic, they expect that the contraction is temporary and unrestrained growth will be restored in the future. Faced with reduced current income, they would then smooth consumption by reducing current saving. Even with such a reduction in the saving rate, however, simulations presented by Tyers and Zhang (2010) show that the effect of lower employment growth on capital returns also causes a fall in investment. The value of the saving decline is larger in magnitude, however, and the net effect is to reduce China's current account surplus. There is therefore a real appreciation against North America and a slight reduction in the latter's current account deficit. In addition, there is a slight increase in North America's politically sensitive industrial employment, though this comes at the expense of a servicesector employment contraction due to North America's real depreciation against China. Both China and North America suffer losses in overall GDP and real income per capita. The loss in China is substantial, however, amounting to almost a year's growth. 
A second possibility is that Chinese households are pessimistic and believe that the contraction is permanent. In response to the monetary contraction and reduced income, they would then exhibit behaviour seen in Japan in the 1990s - smoothing their consumption forward and raising their saving rate. ${ }^{18}$ This exacerbates the contraction in Chinese economic activity and income. Moreover, because saving does not fall and investment does, China's current account surplus is raised. The additional financial outflow causes a real depreciation, suggesting that, to achieve a particular nominal appreciation target, the monetary contraction in this case would need to deliver a larger deflation than before. Internationally, this shock reduces global interest rates and raises North America's current account deficit. Even though there are small gains in North America's terms of trade and real income, the exacerbation of current account imbalances and the associated decline in industrial employment would further frustrate the United States politically. It is difficult to conclude other than that there is little to be gained from renminbi appreciation by monetary contraction.

\section{Taxing trade}

The other 'unhealthy' approach to a unilateral appreciation is via trade distortions. We can dismiss a rise in import tariffs since China's WTO accession conditions offer very little room between applied and bound tariff rates. Export restraints are possible, however - of the type followed by Japan in the late 1980s when it was under similar pressure from the United States. These are not directly protectionist and hence would not attract mercantilist objections from abroad. In principle at least, like import tariffs, they might be expected to divert domestic demand from foreign to home products and thereby appreciate the real exchange rate, allowing the central bank to also appreciate the nominal exchange rate. The downside is that they would also be a tax on the most rapidly expanding sectors in the economy so they would sacrifice growth in urban employment and income.

The corresponding Tyers and Zhang (2010) simulation is of the short-run impacts of an export tax of 15 per cent graduated over 2007-09 and levied only on industrial exports. As previously, they consider scenarios with optimistic and pessimistic households. Surprisingly, in both cases, China experiences robust real depreciations against North America. This is because China's current account surplus rises even in the optimistic case, in which the saving rate falls temporarily. This contradicts the expected story because that emphasises substitution in final demand. The true story is about intermediate

18 Ito (2001:Ch. 11, pp. 329-33) shows that, in the post-Plaza Accord period, the yen appreciated substantially against the US dollar and Japan's current account surplus rose at the same time, even while real investment also rose. 
demand. China's export-manufacturing sector relies to an extraordinary extent on imported components - mostly from Asian trading partners. ${ }^{19}$ When the export tax contracts this sector, imports are similarly contracted. Total exports, in fact, contract by a smaller proportion because there is offsetting expansion in agricultural and service exports that are not intensive in imported inputs. The net effect is an expansion in China's trade surplus.

In North America, the current account deficit rises and, as before, there are only small changes in real GDP and real per capita income. Importantly, however, China's export restraints do raise North American industrial employmentagain, at the expense of services employment - even though North America experiences a real appreciation against China that would otherwise advantage the services sector. In either case, at least in the short run, export restraints would not make it easier for the PBOC to appreciate the renminbi; in fact, quite the opposite.

\section{Conclusions}

Relative to the United States, Chinese productivity has grown faster in tradable than in non-tradable sectors, real wages have also grown faster and there has been relative service-price inflation. The flat trajectory of its real exchange rate between 1990 and 2004 is therefore a contradiction of the $\mathrm{BSH}$, the resolution of which requires generalisation to incorporate failures of the law of one price for tradable goods, open financial capital markets and a more sophisticated representation of the labour market. This opens the way for depreciating forces that have offset the $\mathrm{BSH}$, including net financial outflows on the balance of payments associated with China's excess saving along with trade and other microeconomic reforms. Decomposition of the flat trajectory of the real exchange rate during 1997-2004 reveals that the BSH was offset most strongly by the excess saving and the associated expansion of net outflows on its capital account, along with a significant additional contribution from WTO accession trade reforms. China's real exchange rate began appreciating in the mid 2000s when the national saving rate stabilised and trade reforms were exhausted. An examination of the trends in relative product prices and real wages in this period suggests that the real appreciation is not due to the resumption in the dominance of the BSH. Instead it appears to be due to tightening rural labour markets associated with improvements in the agricultural terms of trade, combined with slowing overall labour force growth.

19 An important empirical literature is developing around China's role as an assembler of components made in other Asian countries. Part of the reason for China's bilateral trade surplus with the United States is that this intra-Asian trade is reducing the bilateral surpluses of other Asian economies with the United States while it exacerbates that of China. See, for example, Athukorala $(2005,2007)$. 
While much attention is paid in the literature to the past decade's 'undervaluation' of the renminbi, it is in our view incorrect to blame this on China's monetary policy - narrowly defined to include the exchange rate target and the accumulation of foreign exchange reserves. The key constraints were capital controls, motivated by concern about financial (and exchange rate) stability in the face of the relative immaturity of its commercial banking sector, and structurally determined high savings. These constraints will eventually be relaxed but, while they remain, reserves will accumulate and exchange rate adjustment will not address the current account imbalance. The only 'healthy' way to appreciate the renminbi will be to follow the path of the underlying real exchange rate. We show that defiance of this principle in the form of a unilateral appreciation by monetary contraction would be very costly to China - and it would most likely hurt the rest of the world by tightening capital markets and changing the terms of trade adversely. Moreover, if Chinese households were to react pessimistically to the shock, the current account surplus could be enlarged, backfiring on those who clamour for an appreciation to address global imbalances. The other conceptually feasible, but no more healthy, approach to a unilateral appreciation is via the imposition by China of a tax on manufactured exports. As it turns out, because China's export-manufacturing sector relies so heavily on imported components, such a tax would in fact exacerbate the trade surplus by cutting imports in proportion with manufactured exports while expanding other less import-dependent exports. This would increase China's current account surplus while sacrificing considerable growth. It would hurt the North American economy overall.

In the near term, with an apparently labour market-driven appreciating trend in the underlying real exchange rate, it is reasonable for the central bank to allow a unilateral nominal appreciation of the renminbi to ease domestic inflation pressure. To the extent that this appreciating trend is not fast enough for political equilibria in China's trading partners, international pressure would best be focused on the remaining financial reforms, including smooth transitions to policies that better regulate large SOEs and address the need for uniform systems of retirement and health insurance. In the long term, whether there is a sustained upward trend in China's real exchange rate will depend on the relative strengths of appreciating forces, including tradable productivity growth, reduced savings and labour force decline, and depreciating forces, including productivity growth in its services sector. 


\section{References}

Aizenman, J. and Lee, J. 2006, Financial versus monetary mercantilism: long run view of large international reserves hoarding, IMF Working Paper WP/06/280, International Monetary Fund, Washington, DC.

Anderson, K. (ed.) 2009, Distortions to Agricultural Incentives: A global perspective, 1955-2007, Palgrave Macmillan and The World Bank, London and Washington, DC.

Anderson, K. and Hayami, Y. 1986, Political Economy of Agricultural Protection: The experience of East Asia, Chinese Academy of Social Sciences, Beijing [1996 publication in Chinese based on the original, Allen \& Unwin, Sydney].

Athukorala, P.-C. 2005, 'Components trade and implications for Asian structural adjustment', in R. Garnaut and L. Song (eds), The China Boom and Its Discontents, Asia Pacific Press, Canberra.

Athukorala, P.-C. 2007, The rise of China and its consequences for East Asia: is the fear of export competition warranted?, Conference on Reforms for Korea's Sustained Growth, East West Centre and Korea Development Institute, Honolulu, 12-13 July.

Balassa, B. 1964, 'The purchasing power parity doctrine: a reappraisal', Journal of Political Economy, vol. 72, no. 6, pp. 584-96.

Bayoumi, T., Tong, H. and Wei, S. J. 2009, The Chinese corporate savings puzzle: a firm-level cross-country perspective, Columbia Business School Working Paper, December, Columbia University, New York.

Bergin, P. R., Glick, R. and Taylor, A. M. 2006, 'Productivity, tradability and the long run price puzzle', Journal of Monetary Economics, vol. 53, no. 8, pp. 41-66.

Bernanke, B. 2006, Speech to the Chinese Academy of Social Sciences, Beijing, 15 Friday December, <www.federalreserve.gov/BoardDocs/ Speeches/2006/20061215>

Cai, F. and Wang, D. 2006, 'Employment growth, labour scarcity and the nature of China's trade expansion', in R. Garnaut and L. Song (eds), The Turning Point in China's Economic Development, Asia Pacific Press, Canberra.

Callan, E. 2007, 'Clinton and Obama back China crackdown', The Financial Times, 5 July. 
Chamon, M. and Prasad, E. 2008, Why are saving rates of urban households in China rising?, Global Economy and Development Working Paper 31, December, Brookings Institution, Washington, DC.

Chang, J. and Tyers, R. 2008, 'Trade reform, macroeconomic policy and sectoral labour movement in China', in C. Chen and R. Duncan (eds), The Impact of WTO Accession and Regional Trade Arrangements on China's Agricultural Sector and Food Security, Asia Pacific Press, Canberra, pp. 268-304.

Cheung, Y.-W., Chinn, M. and Fuji, E. 2007a, China's current account and exchange rate, Center for Economic Studies CESifo Working Paper Series no. 2587, Ludwig Maximilian University of Munich.

Cheung, Y.-W., Chinn, M. and Fuji, E. 2007b, 'The overvaluation of renminbi undervaluation', Journal of International Money and Finance, vol. 26, pp. $762-85$.

Cline, W. 2005, The case for a new Plaza agreement, Policy Briefs 05-4, Institute for International Economics, Washington, DC.

Coudert, V. and Couharde, C. 2005, Real equilibrium exchange rate in China, CEPII Working Paper No. 2005-01, CEPII, Paris.

Crucini, M. J., Telmer, C. I. and Zachariadis, M. 2005, 'Understanding European real exchange rates', American Economic Review, vol. 95, no. 3, pp. 724-38.

Dixon, P. B. and Rimmer, M. T. 2002, Dynamic General Equilibrium Modelling for Forecasting and Policy: A practical guide and documentation of Monash, North Holland, Amsterdam.

Dixon, P. B., Parmenter, B. R., Suttonand, J. and Vincent, D. P. 1982, ORANI: A multi-sectoral model of the Australian economy, North Holland, Amsterdam.

Dooley, M. P., Folkerts-Landau, D. and Garber, P. 2003, An essay on the revived Bretton Woods system, NBER Working Paper 9971, National Bureau of Economic Research, Cambridge, Mass.

Drine, I. and Rault, C. 2005, 'Can the Balassa-Samuelson theory explain long run real exchange rate movements in OECD countries?', Applied Financial Economics, vol. 15, no. 8, pp. 519-30.

Duncan, R., Rees, L. and Tyers, R. 2008, 'Revisiting the economic costs of food self-sufficiency in China', in C. Chen and R. Duncan (eds), The Impact of WTO Accession and Regional Trade Arrangements on China's Agricultural Sector and Food Security, Asia Pacific Press, Canberra, pp. 203-28. 
Feenstra, R. C. and Hong, C. 2007, China's exports and employment, NBER Working Paper 13552, October, National Bureau of Economic Research, Cambridge, Mass.

Fogel, R. 2006, Why is China likely to achieve its growth objectives?, NBER Working Paper W12122, National Bureau of Economic Research, Cambridge, Mass.

Frankel, J. 2004, On the renminbi: the choice between adjustment under a fixed exchange rate and adjustment under a flexible rate, NBER Working Paper 11274, National Bureau of Economic Research, Cambridge, Mass.

Gardner, B. 2010, 'China's labor situation is changing, not for the worse', Roubini Global Economics - Asia EconoMonitor, 1 June.

Garnaut, R. and Huang, Y. 2006, 'Mature Chinese growth leads the global Platinum Age', in R. Garnaut and L. Song (eds), China: Linking markets for growth, Asia Pacific Press, Canberra.

Golley, J. and Tyers, R. 2006, 'China's growth to 2030: demographic change and the labour supply constraint', in R. Garnaut and L. Song (eds), The Turning Point in China's Economic Development, Asia Pacific Press, Canberra.

Goldstein, M. 2004, Adjusting China's foreign exchange rate, International Monetary Fund seminar on China's Foreign Exchange Rate System, Dalian, China.

Gordon, R. 2003, 'Exploding productivity growth: context, causes and implications', Brookings Papers on Economic Activity, vol. 2, pp. 207-97.

Gordon, R. 2006, The US productivity growth 'explosion': dimensions, causes, consequences and aftermath, 48th Annual Meeting of the NABE, NBER Session, Boston, 11 September.

Hertel, T. W. (ed.) 1997, Global Trade Analysis Using the GTAP Model, Cambridge University Press, New York.

Huang, J., Rozelle, S., Martin, W. and Liu, Y. 2009, 'China', in K. Anderson (ed.), Distortions to Agricultural Incentives: A global perspective, 1955-2007, Palgrave Macmillan and The World Bank, London and Washington, DC.

International Monetary Fund (IMF) 2009a, International Financial Statistics, International Monetary Fund, Washington, DC.

International Monetary Fund (IMF) 2009b, World Economic Outlook Database, April, International Monetary Fund, Washington, DC. 
International Monetary Fund (IMF) various issues, International Financial Statistics, International Monetary Fund, Washington, DC.

Ito, T. 2001, The Japanese Economy, MIT Press, Cambridge, Mass.

Lardy, N. 2006, 'China's interaction with the global economy', in R. Garnaut and L. Song (eds), The Turning Point in China's Economic Development, Asia Pacific Press, Canberra.

Lu, F. 2006, China's productivity growth: an international comparison, China Centre for Economic Research Working Paper C200604, Peking University, Beijing.

Lu, F., Song, G., Tang, J., Zhao, H. and Liu, L. 2008, 'Profitability of Chinese industrial firms (1978-2006)', China Economic Journal, vol. 1, no. 1, pp. 1-31.

Ma, G. and McCauley, R. N. 2007, 'How effective are China's capital controls?', in R. Garnaut and L. Song (eds), China: Linking markets for growth, Asia Pacific Press, Canberra.

McKibbin, W. J. and Sachs, J. 1991, Global Linkages: Macroeconomic independence and cooperation in the world economy, Brookings Institution, Washington, DC.

McKinnon, R. I. 2004, 'The East Asian dollar standard', China Economic Review, vol. 15, pp. 325-30.

McKinnon, R. I. 2006, 'China's exchange rate appreciation in the light of the earlier Japanese experience', Pacific Economic Review, vol. 11, no. 3, pp. 287-98.

Meng, X. and Bai, N. 2007, 'How much have the wages of unskilled workers in China increased? Data from seven factories in Guangdong', in R. Gaunaut and L. Song (eds), China:Linking markets for growth, Asia Pacific Press, Canberra.

Ministry of Commerce of the People's Republic of China 2009, China Foreign Trade and Economic Cooperation Gazette 2005-2009, Ministry of Commerce of the People's Republic of China, Beijing.

National Bureau of Statistics (NBS) 2009, China Statistical Yearbook 2009, China Statistics Press, Beijing.

People's Bank of China (PBOC) 2009, Balance Sheet of Monetary Authority, People's Bank of China, Beijing.

People's Bank of China (PBOC) various issues, Balance Sheet of Monetary Authority, People's Bank of China, Beijing. 
Prasad, E., Rumbaugh, T. and Wang, Q. 2005, Putting the cart before the horse: capital account liberalization and the exchange rate in China, Policy Discussion Paper 05/01, International Monetary Fund, Washington, DC.

Rees, L. and Tyers, R. 2004, 'Trade reform in the short run: China's WTO accession', Journal of Asian Economics, vol. 15, no. 1, pp. 1-31.

RGE Monitor (2007), 'Excessive Liquidity and Credit Growth in Emerging Markets', 11 May, info@rgemonitor.com.

Roland-Holst, D., Brooks, D. and Zhai, F. 2005, Asia's long term growth and integration: reaching beyond trade policy barriers, ADB Policy Brief No. 38, Asian Development Bank, Manila.

Samuelson, P. 1964, 'Theoretical notes on trade problems', Review of Economics and Statistics, vol. 46, no. 2, pp. 145-54.

Tung, C. Y. and Baker, S. 2004, 'RMB revaluation will serve China's self-interest', China Economic Review, vol. 15, pp. 331-5.

Tyers, R. and Golley, J. 2008, 'China's real exchange rate puzzle', Journal of Economic Integration, vol. 23, no. 3, pp. 547-74.

Tyers, R. and Golley, J. (forthcoming), 'China's growth to 2030: the roles of demographic change and investment reform', Review of Development Economics, [earlier version in Chinese published in China Labour Economics, vol. 4, no. 1 (2007), pp. 6-30].

Tyers, R. and Lu, F. 2009, Competition policy, corporate saving and China's current account surplus, Working Papers in Economics and Econometrics No. 496, July, College of Business and Economics, The Australian National University, Canberra.

Tyers, R. and Zhang, Y. 2010, Appreciating the renminbi, Working Paper, Business School, University of Western Australia, Perth.

Tyers, R., Golley, J., Bu, Y. and Bain, I. 2008, 'China's economic growth and its real exchange rate', China Economic Journal, vol. 1, no. 2, pp. 123-45.

Wang, T. 2004, 'Exchange rate dynamics', in E. Prasad (ed.), China's growth and integration into the world economy: prospects and challenges, IMF Occasional Paper 232, International Monetary Fund, Washington, DC.

Wen, J. 2008, Report on the work of the government, Speech, Beijing.

Wen, J. 2010, Report on the work of the government, Speech, Beijing. 
Woo, W. T. 2006, 'China's macroeconomic imbalances: the liquidity tango mechanism', in J. J. Teunissen and A. Akkerman (eds), Global Imbalances and the US Debt Problem: Should developing countries support the US dollar?Volume 1, Forum on Debt and Development, The Hague.

World Trade Organisation (WTO) 2008, Trade Policy Review: China, WT/ TPR/G/199, World Trade Organisation, Washington, DC.

Xiao, G. 2006, What is special about China's exchange rate and external imbalance: a structural and institutional perspective, Asian Economic Panel 2007, Brookings-Tsinghua Center and Brookings Institution, Beijing and Washington, DC.

US Bureau of Labor Statistics various issues, Producer Price Index Detailed Reports, US Bureau of Labor Statistics, Washington, DC.

\section{Acknowledgments}

Funding for the research described in this chapter came from the Australian Research Council Discovery Grant No. DP0557889. Thanks are due to Iain Bain and Pingkun Hsu for their assistance with the analysis presented in an earlier draft and to Jane Golley, Yongxiang Bu, Huang Yiping, Ross Garnaut, Yanrui Wu and Wing Thye Woo for useful discussions on the topic. 



\section{China and East Asian trade: the decoupling fallacy, crisis and policy challenges}

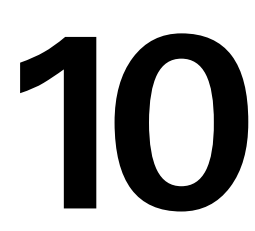

\section{Prema-chandra Athukorala and Archanun Kohpaiboon}

The 'decoupling' thesis - the notion that the East Asian region has become a self-contained economic entity with the potential for maintaining its own growth dynamism independent of the economic outlook for the traditional industrialised-market economies - was a popular theme in Asian policy circles in the first decade of the new millennium until the onset of the recent global financial crisis. ${ }^{1}$ The empirical basis for this was provided by studies of trade patterns based on readily available trade data, which revealed a continuous increase in trade among the countries in the region (intra-regional trade) since the late 1980s - a process that received added impetus from the subsequent emergence of China as a world export powerhouse. A few studies questioned the validity of this inference in a context in which international production fragmentation and the related network trade had been rapidly expanding with East Asia as its centre of gravity (Roach 2009:Ch. 1; Bergsten et al. 2006; Athukorala 2005; Garnaut 2003). The decoupling thesis continued to dominate the policy scene, however, presumably because it fitted well with the East Asian growth euphoria of the day.

The global financial crisis has served to reveal the fragility of the decoupling thesis since all major East Asian countries, including China, have experienced precipitous trade contractions. Consequently, the policy debate in East Asia has made a U-turn from the complacency of the decoupling thesis to a call for the rebalancing of East Asian growth with a view to reducing its susceptibility to the vicissitudes of the global business cycle (ADB 2010; IMF 2010).

\footnotetext{
1 See Urata (2006), Yoshitomi (2007) and Park and Shin (2009) and the works cited therein. All these authors are concerned with 'trade decoupling' as opposed to the ability of large Asian economies like India and China to continue to grow strongly on the basis of domestic demand expansion even if growth in the developed world slows down. This chapter focuses solely on the 'trade decoupling' debate.
} 
What went wrong with the decoupling thesis? Was the trade-integration story that underpinned the decoupling thesis simply a statistical artefact, resulting from a failure to incorporate the realities of an era of global production sharing? What are the policy challenges faced by the East Asian economies in the postglobal financial crisis era? Is there room for an integrated policy response that marks a clear departure from the pre-crisis policy stance favouring outwardoriented development strategies? This chapter aims to probe these and related issues through a comparative analysis of the export experiences of China and other East Asian economies in the aftermath of the crisis against the backdrop of a systematic analysis of pre-crisis trade patterns.

The decoupling thesis is based on the traditional notion of horizontal specialisation, according to which international trade is an exchange of goods that are produced from start to finish in just one country. It ignores the implications for trade-flow analysis of the continuing process of global production sharing ${ }^{2}$ the breaking up of the production processes into separated stages, with each country specialising in a particular stage of the production sequence - and the increasingly important role played by China and other East Asian countries in the resultant global production network. In a context in which production sharingbased trade is growing rapidly, trade-flow analysis based on the assumption of horizontal specialisation can lead to misleading inferences about the nature and extent of trade integration among countries for three reasons.

First, in the presence of global production sharing, trade data are doublecounted because goods-in-process cross multiple international borders before becoming embodied in the final product. Thus, the total amount of recorded trade could be a multiple of the value of final goods. Second, and perhaps more importantly, trade shares calculated using reported data can lead to wrong inferences as to the relative importance of the 'region' and the rest of the world for the growth dynamism of a given country, even controlling for doublecounting in trade. This is because 'fragmentation trade' and trade in related final goods ('final trade') are unlikely to follow the same patterns. Third, the intra-regional trade ratio estimated by lumping together imports and exports tends to hide a significant asymmetry in regional trade patterns of imports and exports in a context in which network-related trade is growing rapidly.

Given these concerns, a meaningful analysis of trade patterns requires systematic separation of parts and components (henceforth referred to as 'components') from final (assembled) products in reported trade data. We do this through a careful disaggregation of trade data based on Revision Three of the Standard International Trade Classification (SITC, Rev. 3) extracted from the United Nations trade-data reporting system (UN n.d.). ${ }^{3}$ 
For the purpose of this chapter, East Asia is defined to include Japan and developing East Asia, which covers the newly industrialised economies (NIEs) of North Asia (South Korea, Taiwan and Hong Kong), China and members of the Association of South-East Asian Nations (ASEAN). Among the ASEAN countries, Myanmar is not covered because of a lack of data and Brunei, Cambodia and Laos are treated as a residual group because of data gaps. The East Asian experience is examined in the wider global context, focusing specifically on the comparative experiences of the North American Free Trade Agreement (NAFTA) and the European Union.

This chapter is structured as follows. The first section examines trade patterns in East Asia in the global context, paying attention to the nature and extent of production sharing and network-based trade, East Asia's role in this new form of international exchange and its implications for regional versus global economic integration. In the next section, the latest available data are used to examine the impact of the global financial crisis on the export performance of East Asian economies. The next section deals with post-crisis policy challenges, focusing on the emerging debate regarding rebalancing (or reshaping) development strategies. The final section summarises the key findings and draws some general inferences.

\section{Pre-crisis trade patterns}

Rapid export growth has been the hallmark of East Asia's rise in the global economy. The combined share of East Asian countries in world non-oil exports recorded a threefold increase between 1969-70 and 2006-07-from 11 per cent to 33 per cent. ${ }^{4}$ The region accounted for more than 40 per cent of the total increment in world exports in this period. In the 1970s and 1980s, Japan dominated the region's trade, accounting for nearly 60 per cent of its exports and imports. The picture has changed dramatically in the past two decades, with the share of developing East Asian countries increasing rapidly in the face of a relative decline in Japan's position in world trade. By the middle of this decade, these countries accounted for more than 80 per cent of total regional trade. The rise of China has been the dominant factor behind this structural shift, ${ }^{5}$ but the other countries in the region (Taiwan, Korea, Malaysia, Singapore, the Philippines, Thailand and, more recently, Vietnam) have also increased their world market shares.

\footnotetext{
4 Trade magnitudes throughout the chapter are measured in current US dollars unless otherwise indicated. Inter-temporal comparison calculations are made for the two-year averages relating to the end points of the period under study, so as to reduce the impact of year-to-year fluctuations of trade flows. All data reported, unless otherwise stated, are compiled from the UN Comtrade database (UN n.d.).

5 For details on China's rise as a major trading nation and the implications of this for the other countries in the region, see Athukorala (2009a, 2009b).
} 
China: The Next Twenty Years of Reform and Development

Rapid export growth in East Asia has been underpinned by a pronounced shift in the region's export structure away from primary commodities and towards manufacturing. By 2006-07, manufacturing accounted for 92 per cent of total exports from Asia - up from 78 per cent four decades ago. Within manufacturing, machinery and transport equipment (SITC 7)-particularly information and communication technology (ICT) products and electrical goods - has played a pivotal role in this structural shift. The share of Asia in world machinery and transport equipment exports increased from 14.5 per cent in 1994-05 to 42.4 per cent in 2006-07, with developing East Asia accounting for more than four-fifths of the increment. By 2006-07, more than 58 per cent of total world ICT exports originated from Asia, with China alone accounting for 23 per cent (Table 10.1). In electrical goods, China's world market share increased from 3.1 per cent to 20.6 per cent between these two years. Export dynamism in these product lines has been driven by the continuing process of global production sharing and the increasingly deep integration of East Asian countries into global production networks.

Table 10.1 Composition of manufacturing exports, 2006-07 (per cent)

\begin{tabular}{|c|c|c|c|c|c|c|c|c|c|}
\hline $\begin{array}{l}\text { Commodity } \\
\text { group }\end{array}$ & EA & Japan & DEA & China & $T W+K$ & ASEAN & NAFTA & EU15 & World \\
\hline $\begin{array}{l}\text { Chemicals } \\
\text { (SITC 5) }\end{array}$ & 0.1 & 0.1 & 0.1 & 0.1 & 0.1 & 0.0 & 0.2 & 0.2 & 0.2 \\
\hline $\begin{array}{l}\text { Resource-based } \\
\text { products } \\
\text { (SITC 6 - SITC 68) }\end{array}$ & 1.2 & 1.8 & 0.9 & 1.0 & 1.0 & 0.7 & 2.1 & 2.8 & 2.0 \\
\hline $\begin{array}{l}\text { Machinery } \\
\text { and } \\
\text { transport } \\
\text { equipment } \\
\text { (SITC 7) }\end{array}$ & 89.7 & 87.5 & 90.3 & 91.6 & 84.0 & 94.7 & 86.0 & 87.9 & 88.1 \\
\hline $\begin{array}{l}\text { Power- } \\
\text { generating } \\
\text { machines } \\
\text { (SITC 71) }\end{array}$ & 1.8 & 3.8 & 1.1 & 1.1 & 1.1 & 1.2 & 9.0 & 6.6 & 4.9 \\
\hline $\begin{array}{l}\text { Specialised } \\
\text { industrial } \\
\text { machines } \\
\text { (SITC 72) }\end{array}$ & 2.1 & 3.5 & 1.7 & 1.8 & 1.1 & 2.3 & 2.6 & 3.5 & 2.7 \\
\hline $\begin{array}{l}\text { Metal-working } \\
\text { machines } \\
\text { (SITC 73) }\end{array}$ & 0.3 & 0.6 & 0.2 & 0.2 & 0.3 & 0.1 & 0.4 & 0.7 & 0.5 \\
\hline $\begin{array}{l}\text { General } \\
\text { industrial } \\
\text { machinery } \\
\text { (SITC 74) }\end{array}$ & 1.3 & 1.7 & 1.2 & 1.4 & 0.9 & 1.2 & 2.4 & 3.5 & 2.3 \\
\hline ICT products & 60.5 & 33.2 & 68.9 & 69.2 & 59.7 & 78.3 & 27.6 & 22.9 & 41.1 \\
\hline
\end{tabular}




\begin{tabular}{|c|c|c|c|c|c|c|c|c|c|}
\hline $\begin{array}{l}\text { Office/ } \\
\text { automatic } \\
\text { data-processing } \\
\text { machines } \\
\text { (SITC 75) }\end{array}$ & 19.6 & 8.2 & 23.1 & 29.0 & 8.7 & 27.0 & 7.2 & 7.6 & 12.4 \\
\hline $\begin{array}{l}\text { Telecommu- } \\
\text { nication } \\
\text { and sound- } \\
\text { recording } \\
\text { equipment } \\
\text { (SITC 76) }\end{array}$ & 18.7 & 9.0 & 21.7 & 28.3 & 16.1 & 14.9 & 9.6 & 7.9 & 13.1 \\
\hline $\begin{array}{l}\text { Semiconductors } \\
\text { and } \\
\text { semiconductor } \\
\text { devices } \\
\text { (SITC772+776) }\end{array}$ & 22.2 & 16.0 & 24.2 & 11.8 & 34.9 & 36.4 & 10.8 & 7.5 & 15.7 \\
\hline $\begin{array}{l}\text { Electrical } \\
\text { goods } \\
\text { (SITC 77-772-776) }\end{array}$ & 9.7 & 8.1 & 10.2 & 14.2 & 6.1 & 6.4 & 8.2 & 8.5 & 9.3 \\
\hline $\begin{array}{l}\text { Road } \\
\text { vehicles } \\
\text { (SITC 78) }\end{array}$ & 12.7 & 35.0 & 5.9 & 3.2 & 12.6 & 4.4 & 26.5 & 36.4 & 23.0 \\
\hline $\begin{array}{l}\text { Other } \\
\text { transport } \\
\text { equipment } \\
\text { (SITC 79) }\end{array}$ & 1.3 & 1.6 & 1.2 & 0.7 & 2.3 & 0.9 & 9.3 & 5.7 & 4.4 \\
\hline $\begin{array}{l}\text { Miscellaneous } \\
\text { manufacturing } \\
\text { (SITC 8) }\end{array}$ & 9.1 & 10.6 & 8.7 & 7.3 & 14.9 & 4.6 & 11.8 & 9.1 & 9.8 \\
\hline $\begin{array}{l}\text { Professional } \\
\text { and scientific } \\
\text { equipment } \\
\text { (SITC 87) }\end{array}$ & 5.5 & 5.8 & 5.4 & 4.0 & 11.0 & 2.6 & 8.2 & 5.9 & 6.3 \\
\hline $\begin{array}{l}\text { Photographic } \\
\text { apparatus } \\
\text { (SITC 88) }\end{array}$ & 2.3 & 3.6 & 1.9 & 2.4 & 1.2 & 1.3 & 1.3 & 1.8 & 2.1 \\
\hline $\begin{array}{l}\text { Total } \\
\text { manufacturing } \\
\text { exports }\end{array}$ & 100 & 100 & 100 & 100 & 100 & 100 & 100 & 100 & 100 \\
\hline US\$billion & 1826 & 428 & 1398 & 656 & 359 & 348 & 739 & 1366 & 4517 \\
\hline
\end{tabular}

Notes: Standard International Trade Classification (SITC) codes are given in parentheses. EA = East Asia; DEA = developing East Asia; $\mathrm{TW}+\mathrm{K}=$ Taiwan and Korea; ASEAN6 = six main ASEAN countries; EU15 $=15$ member countries of the European Union; NAFTA = countries in the North American Free Trade Agreement (United States, Canada and Mexico).

Source: Compiled from United Nations (UN) n.d., Comtrade database, United Nations, New York.

The best available indicator of the intensity of global production sharing is the share of parts and components in total manufacturing trade. ${ }^{6}$ Reflecting

6 Henceforth, for the sake of brevity, we use the term 'components' in place of 'parts and components'. 
the rapid growth of global production sharing, the share of components in manufacturing trade has sharply increased across all major countries in the region (Table 10.2). In 2006-07, components accounted for 34.1 per cent of East Asian manufacturing exports (42.1 per cent of manufacturing imports) compared with a world average of 27.1 per cent (27.3 per cent of imports). The share of components is particularly high among the ASEAN countries. There is a remarkable similarity in component share figures in exports and imports across countries, reflecting overlapping specialisation patterns in component assembly among countries in the region.

Table 10.2 Share of parts and components in manufacturing trade, 1992-03 and 2006-07 (per cent)

\begin{tabular}{lcccc}
\hline & \multicolumn{2}{c}{ Exports } & \multicolumn{2}{c}{ Imports } \\
Region & $\mathbf{1 9 9 2 - 9 3}$ & $\mathbf{2 0 0 6 - 0 7}$ & $\mathbf{1 9 9 2 - 9 3}$ & $\mathbf{2 0 0 6 - 0 7}$ \\
\hline East Asia & 20.2 & 34.1 & 27.2 & 42.1 \\
Japan & 23.9 & 34.4 & 19.3 & 29.9 \\
Developing East Asia & 17.3 & 34 & 29 & 44.2 \\
China (PRC) & 7.4 & 25.6 & 20.4 & 44 \\
Hong Kong, China & 15.8 & 33.3 & 24.1 & 48.5 \\
Taiwan & 24.7 & 44.2 & 29.5 & 38.9 \\
Republic of Korea & 18.1 & 47.3 & 30.1 & 31.9 \\
ASEAN & 22.7 & 44.2 & 36 & 47.9 \\
Indonesia & 3.8 & 21.5 & 27 & 21.8 \\
Malaysia & 27.7 & 53.6 & 40.5 & 50 \\
The Philippines & 32.9 & 71.7 & 32.6 & 61.3 \\
Singapore & 29 & 49.3 & 39.9 & 60.4 \\
Thailand & 14.1 & 29.9 & 30.6 & 36.1 \\
Vietnam & $\mathrm{n.a.}$ & 11.0 & $\mathrm{n} . \mathrm{a}$. & 19.1 \\
South Asia & 2.3 & 8.2 & 16.6 & 23.8 \\
India & 3 & 10.4 & 17.5 & 22.9 \\
NAFTA & 28.4 & 31.2 & 37.4 & 28.8 \\
Mexico & 42.1 & 34.6 & 29.4 & 36.1 \\
EU15 & 18.3 & 22.4 & 21.2 & 23.2 \\
Industrialised countries & 20.4 & 25.2 & 22.6 & 23.4 \\
Developing countries & 14.6 & 29.2 & 11.9 & 33.6 \\
World & 19.3 & 27.1 & 19.6 & 27.3 \\
\hline
\end{tabular}

n.a. not available

Source: Compiled from United Nations (UN), n.d., Comtrade database, United Nations, New York.

The rapid increase in component intensity (percentage shares of parts and components) in East Asian trade is closely associated with cross-border component trade within regional production networks. As can be seen in Table 10.3, components account for a much larger share of intra-regional trade in East Asia than these countries' shares of world trade and trade with the European 
Union and NAFTA. Moreover, the share of components in total intra-regional imports is much larger than in exports - and has increased at a faster rate. This reflects the fact that the region relies on the rest of the world more as a market for final goods than as a market for components. Within East Asia, ASEAN countries stand out for the high share of components in their intra-regional trade flows (more than 60 per cent in 2006-07). According to country-level data, the share of components in manufacturing exports and imports amounted to more than four-fifths in Singapore, Malaysia and the Philippines and more than two-thirds in Thailand. South Korea and Taiwan are also involved in sizeable trade in components with other countries in the region. In 2006-07, components accounted for 59.2 per cent and 74 per cent of China's imports from developing Asia and ASEAN countries, respectively, compared with 44 per cent in total imports.

Table 10.3 Share of parts and components in bilateral trade flows, 2006-07 (per cent)

\begin{tabular}{|c|c|c|c|c|c|c|c|c|}
\hline $\begin{array}{l}\text { Reporting } \\
\text { country }\end{array}$ & EA & Japan & DEA & PRC & ASEAN & NAFTA & EU15 & World \\
\hline \multicolumn{9}{|l|}{ (a) Exports } \\
\hline East Asia & 47.6 & 32.9 & 50.1 & 51.6 & 54.5 & 25.1 & 24.1 & 34.1 \\
\hline Japan & 42.0 & 0.0 & 42.0 & 41.5 & 47.9 & 31.5 & 30.4 & 34.4 \\
\hline $\begin{array}{l}\text { Developing } \\
\text { East Asia }\end{array}$ & 48.1 & 33.4 & 53.9 & 0.0 & 65.2 & 22.7 & 21.6 & 34.0 \\
\hline China (PRC) & 36.2 & 25.2 & 40.6 & 0.0 & 49.1 & 17.1 & 16.3 & 25.6 \\
\hline Korea & 61.9 & 51.5 & 63.5 & 57.3 & 63.7 & 36.6 & 26.8 & 44.2 \\
\hline Taiwan & 51.5 & 59.0 & 50.5 & 39.5 & 61.2 & 35.0 & 37.6 & 44.2 \\
\hline ASEAN10 & 58.2 & 39.9 & 61.4 & 64.0 & 56.0 & 32.1 & 33.9 & 44.2 \\
\hline NAFTA & 46.7 & 36.5 & 49.8 & 34.8 & 67.9 & 28.8 & 30.6 & 31.2 \\
\hline EU15 & 31.4 & 18.7 & 34.8 & 30.4 & 46.5 & 22.1 & 22.0 & 22.4 \\
\hline \multicolumn{9}{|l|}{ (b) Imports } \\
\hline East Asia & 51.7 & 48.8 & 52.8 & 34.8 & 68.3 & 54.7 & 33.1 & 42.1 \\
\hline Japan & 34.2 & 0.0 & 34.2 & 23.1 & 44.9 & 41.0 & 18.9 & 29.9 \\
\hline $\begin{array}{l}\text { Developing } \\
\text { East Asia }\end{array}$ & 55.5 & 47.7 & 59.5 & 0.0 & 74.3 & 40.3 & 31.7 & 44.2 \\
\hline China (PRC) & 55.2 & 47.5 & 59.2 & 0.0 & 74.0 & 40.1 & 31.6 & 44.0 \\
\hline Korea & 33.0 & 26.6 & 38.1 & 26.1 & 55.7 & 38.9 & 22.9 & 31.9 \\
\hline Taiwan & 46.7 & 33.8 & 58.3 & 44.1 & 68.8 & 40.2 & 28.0 & 38.9 \\
\hline ASEAN10 & 50.3 & 47.2 & 51.4 & 40.1 & 55.9 & 67.5 & 41.7 & 47.9 \\
\hline NAFTA & 29.4 & 39.3 & 26.0 & 17.7 & 40.5 & 36.3 & 25.1 & 28.8 \\
\hline EU15 & 25.0 & 33.6 & 22.8 & 14.9 & 37.9 & 34.1 & 22.1 & 23.4 \\
\hline
\end{tabular}

Notes: EA = East Asia; DEA = developing East Asia; ASEAN6 = six main ASEAN countries; EU15 = 15 member countries of the European Union; NAFTA = countries in the North American Free Trade Agreement (United States, Canada and Mexico). 


\section{China in East Asian trade}

Manufacturing products dominate China-East Asia trade flows, accounting for nearly 90 per cent of imports and exports (Table 10.4). In China's total manufacturing imports from East Asia, the share of components increased from 18 per cent in 1994-05 to more than 44 per cent in 2006-07. Within manufacturing, the share of components is much larger in machinery and transport equipment imports, at nearly three-quarters in 2006-07. The shares of components in manufacturing exports also have increased over the years, but the magnitudes are significantly lower compared with those in total imports. Interestingly, although China's importance as a market for the rest of East Asia has increased during the period under study (see below), the importance of the region for China's export expansion has declined notably, as it absorbed only 33.7 per cent of China's total merchandise exports in 2006-07-down from 55.8 per cent in 1993. East Asia's share in China's total imports increased marginally from 21.3 per cent in 1992-03 to 28.8 per cent in 2006-07.

Table 10.4 China's trade with the rest of East Asia (per cent)

\begin{tabular}{|c|c|c|c|c|}
\hline \multirow[b]{2}{*}{ A: Commodity composition } & \multicolumn{2}{|c|}{ Exports } & \multicolumn{2}{|c|}{ Imports } \\
\hline & 1994-95 & 2006-07 & 1994-95 & 2006-07 \\
\hline A1: Total trade & 100 & 100 & 100 & 100 \\
\hline Primary products & 16.2 & 10.4 & 23.5 & 13.5 \\
\hline Manufacturing & 83.4 & 89.2 & 76.1 & 86.3 \\
\hline Machinery and transport equipment (SITC 7) & 20.8 & 46.6 & 26.4 & 49.7 \\
\hline Electronics and electrical goods $(75+76+77)$ & 16.7 & 40.6 & 15.0 & 43.0 \\
\hline Miscellaneous manufacturing (SITC 8) & 43.3 & 25.5 & 7.7 & 12.5 \\
\hline Apparel (84) & 18.5 & 10.3 & 1.3 & 0.4 \\
\hline A2: Parts and components & 100 & 100 & 100 & 100 \\
\hline Machinery and transport equipment (SITC 7) & 90.2 & 95.5 & 92.1 & 95.1 \\
\hline Electronic and electrical goods $(75+76+77)$ & 81.0 & 87.7 & 74.6 & 85.7 \\
\hline Transport equipment (78) & 3.7 & 2.3 & 0.7 & 1.8 \\
\hline Other & 9.8 & 4.5 & 3.8 & 3.3 \\
\hline \multicolumn{5}{|c|}{ B: Parts and component share in manufacturing trade } \\
\hline Total manufacturing & 7.5 & 25.6 & 17.9 & 44.4 \\
\hline Machinery and transport equipment (SITC 7) & 6.8 & 24.4 & 46.1 & 73.3 \\
\hline Electronic and electrical goods $(75+76+77)$ & 30.3 & 49.3 & 73.1 & 82.5 \\
\hline Transport equipment & 25.4 & 50.1 & 16.3 & 79.0 \\
\hline Other & 1.4 & 4.0 & 18.0 & 14.4 \\
\hline
\end{tabular}




\begin{tabular}{lcccc}
\hline C: Trade with East Asia in China's world trade & & & & \\
C1: Total trade & 55.8 & 33.7 & 21.3 & 28.4 \\
Primary products & 74.6 & 59.2 & 27.9 & 15.5 \\
Manufacturing & 53.3 & 32.2 & 19.9 & 32.7 \\
Machinery and transport equipment (SITC 7) & 53.7 & 33.1 & 13.4 & 32.0 \\
Electronic and electrical goods (75 + 76 + 77) & 60.4 & 34.6 & 53.0 & 52.0 \\
Miscellaneous manufacturing (SITC 8) & 50.1 & 29.1 & 27.2 & 36.0 \\
Apparel (84) & 59.1 & 38.1 & 45.1 & 52.9 \\
C2: Parts and components & 60.1 & 44.7 & 22.4 & 38.7 \\
Machinery and transport equipment (SITC 7) & 59.8 & 44.6 & 21.7 & 38.6 \\
Electronic and electrical goods (75 + 76 + 77) & 61.2 & 46.0 & 68.9 & 56.2 \\
Transport equipment & 44.2 & 23.2 & 5.6 & 21.7 \\
Miscellaneous manufacturing (SITC 8) & 62.2 & 45.7 & 30.3 & 40.7 \\
\hline
\end{tabular}

Note: East Asia = developing East Asia and Japan.

Source: Compiled from United Nations (UN) n.d., Comtrade database, United Nations, New York.

Table 10.5 summarises data on China-East Asia trade relations at the individual country level. Data on the geographic profile of China's manufacturing imports from the region are in Panel A. Panel B gives data on the relative importance of China as an export destination of the East Asian economies. Nearly 60 per cent of China's manufacturing imports originate in East Asia. The bulk of these imports come from Japan, Korea and Taiwan. The share of imports coming from the other East Asian countries is small, although growing fast. In 2007, China accounted for only 21.2 per cent of total manufacturing exports from the rest of East Asia. At the individual country level, China accounted for 33 per cent and 27 per cent of exports from Taiwan and Korea, respectively. China was also one of the most important export destinations of the Philippines, accounting for more than one-fifth of total exports. For all other ASEAN countries, the figures are much smaller - varying from 8 per cent to 13.5 per cent. Clearly, aggregate data hide some significant differences among East Asian countries in trade links with China, with China's intra-regional trade concentrated largely in trade with Japan, Korea and Taiwan. 
China: The Next Twenty Years of Reform and Development

Table 10.5 East Asia-China manufacturing trade

\begin{tabular}{lcccc}
\hline Region & \multicolumn{2}{c}{$\begin{array}{c}\text { A: Geographic profile } \\
\text { of China's imports }\end{array}$} & \multicolumn{2}{c}{$\begin{array}{c}\text { B: Exports to China relative } \\
\text { to total exports by country/ } \\
\text { region }\end{array}$} \\
& $\mathbf{1 9 9 4 - 9 5}$ & $\mathbf{2 0 0 6 - 0 7}$ & $\mathbf{1 9 9 4 - 9 5}$ & $\mathbf{2 0 0 6 - 0 7}$ \\
\hline East Asia & 58.2 & 58.6 & 7.6 & 21.2 \\
Japan & 20.9 & 16.4 & 5.5 & 17.3 \\
Developing East Asia & 37.1 & 42.2 & 8.2 & 21.6 \\
Hong Kong & 17.3 & 2.0 & 29.6 & 19.5 \\
Korea & 4.3 & 13.4 & 5.8 & 27.2 \\
Taiwan & 10.7 & 14.0 & 10.3 & 32.6 \\
ASEAN & 3.7 & 13.8 & 2.5 & 13.7 \\
Indonesia & 1.0 & 1.1 & 3.3 & 8.4 \\
Malaysia & 1.1 & 3.4 & 3.2 & 13.5 \\
The Philippines & 0.2 & 2.1 & 1.5 & 21.3 \\
Singapore & 0.8 & 2.3 & 1.8 & 12.2 \\
Thailand & 0.7 & 2.3 & 1.8 & 11.2 \\
Vietnam & 0.1 & 0.1 & 2.5 & 4.1 \\
Other countries & 41.8 & 41.4 & 1.5 & 3.7 \\
World & 100 & 100 & 2.7 & 6.7 \\
\hline
\end{tabular}

Sources: Compiled from United Nations (UN) n.d., Comtrade database, United Nations, New York; and Council for Economic Planning and Development n.d., Trade Data, CD-ROM, Council for Economic Planning and Development, Taipei (for data on Taiwan).

\section{Intra-regional trade patterns}

The previous section reveals three important features of the emerging trade patterns in East Asia compared with overall patterns of global trade. First, component trade has played a more important role in trade expansion in East Asia. Second, trade in components accounts for a much larger share in intraregional trade than is the case for the rest of the world. Third, China's rapid trade expansion largely reflects its role as an assembly centre within global production networks; China's trade links with the rest of East Asia are dominated by components for assembling final products, which are destined predominantly for markets in the rest of the world. Given these three peculiarities, conventional trade-flow analysis is bound to yield a misleading picture of the relative importance of intra-regional trade - compared with global trade - for growth in East Asia.

To illustrate this point, intra-regional trade shares are estimated separately for total manufacturing, components and final goods (total manufacturing net of components) (Table 10.6). The table covers trade in East Asia and three 
sub-regions therein, which relate to contemporary Asian policy debates on regional integration. Data for NAFTA and the European Union are reported for comparative purposes. Estimates are given for total trade (imports plus exports) as well as for exports and imports separately in order to illustrate possible asymmetries in trade patterns resulting from East Asia's increased engagement in fragmentation-based international exchange. ${ }^{7}$

Table 10.6 Intra-regional shares of manufacturing trade: total, parts and components and final trade, 1992-93 and 2006-07 (per cent)

\begin{tabular}{|c|c|c|c|c|c|c|}
\hline & East Asia & $\begin{array}{l}\text { Developing } \\
\text { East Asia }\end{array}$ & ASEAN $+3^{1}$ & ASEAN & NAFTA & EU15 \\
\hline \multicolumn{7}{|c|}{ Total trade } \\
\hline \multicolumn{7}{|l|}{ Exports } \\
\hline $1986-97$ & 28.4 & 25.1 & 17.3 & 17.4 & 49.1 & 65.5 \\
\hline $1992-93$ & 47.2 & 38.2 & 15.3 & 20.7 & 44.4 & 61.2 \\
\hline 2006-07 & 43.9 & 33.4 & 21.9 & 18.4 & 48.1 & 56.9 \\
\hline \multicolumn{7}{|l|}{ Imports } \\
\hline $1986-97$ & 48.6 & 22.9 & 34.4 & 11.0 & 29.9 & 69.7 \\
\hline $1992-93$ & 58.2 & 34.9 & 43.0 & 15.5 & 36.3 & 64.1 \\
\hline $2006-07$ & 64.4 & 46.7 & 49.3 & 20.8 & 32.0 & 57.9 \\
\hline \multicolumn{7}{|c|}{ Trade (exports + imports) } \\
\hline $1986-97$ & 35.8 & 24.0 & 22.9 & 13.5 & 37.1 & 67.5 \\
\hline $1992-93$ & 53.2 & 36.5 & 27.0 & 17.8 & 39.9 & 62.6 \\
\hline $2006-07$ & 55.1 & 40.0 & 30.4 & 20.1 & 38.4 & 57.4 \\
\hline \multicolumn{7}{|c|}{ Parts and components } \\
\hline \multicolumn{7}{|l|}{ Exports } \\
\hline $1992-93$ & 50.2 & 42.6 & 33.7 & 30.3 & 43.5 & 62.3 \\
\hline 2006-07 & 61.1 & 53.9 & 35.3 & 25.4 & 46.9 & 55.9 \\
\hline \multicolumn{7}{|l|}{ Imports } \\
\hline 1992-93 & 65.9 & 35.3 & 39.6 & 20.2 & 39.5 & 58.0 \\
\hline 2006-07 & 66.9 & 50.9 & 47.8 & 22.9 & 39.9 & 55.2 \\
\hline \multicolumn{7}{|l|}{ Trade } \\
\hline $1992-93$ & 57.0 & 38.7 & 35.4 & 24.2 & 41.4 & 60.1 \\
\hline 2006-07 & 62.9 & 52.1 & 40.2 & 23.1 & 43.2 & 55.5 \\
\hline \multicolumn{7}{|c|}{ Final goods $^{2}$} \\
\hline \multicolumn{7}{|l|}{ Exports } \\
\hline $1992-93$ & 46.0 & 36.8 & 11.4 & 16.1 & 44.7 & 60.9 \\
\hline 2006-07 & 36.9 & 28.3 & 17.0 & 15.9 & 48.7 & 57.0 \\
\hline
\end{tabular}




\begin{tabular}{|c|c|c|c|c|c|c|}
\hline \multicolumn{7}{|l|}{ Imports } \\
\hline 1992-93 & 55.4 & 34.7 & 43.4 & 12.9 & 35.3 & 65.6 \\
\hline $2006-07$ & 63.0 & 42.8 & 50.2 & 20.6 & 30.2 & 58.5 \\
\hline \multicolumn{7}{|l|}{ Trade } \\
\hline $1992-93$ & 50.3 & 35.7 & 25.4 & 14.3 & 39.4 & 63.2 \\
\hline $2006-07$ & 46.4 & 34.0 & 29.1 & 18.0 & 37.3 & 57.7 \\
\hline \multicolumn{7}{|c|}{ l ASEAN + Japan + Korea + China } \\
\hline \multicolumn{7}{|c|}{2 Total trade - parts and components. } \\
\hline \multicolumn{7}{|c|}{$\begin{array}{l}\text { Note: Intra-regional trade shares have been calculated excluding bilateral flows between China and Hong } \\
\text { Kong. }\end{array}$} \\
\hline \multicolumn{7}{|c|}{$\begin{array}{l}\text { Sources: Compiled from United Nations (UN) n.d., Comtrade database, United Nations, New York; and } \\
\text { Council for Economic Planning and Development n.d., Trade Data, CD-ROM, Council for Economic } \\
\text { Planning and Development, Taipei (for data on Taiwan). }\end{array}$} \\
\hline
\end{tabular}

Trade patterns depicted by the unadjusted (standard) trade data affirm the perception underlying the decoupling thesis that Asia, and in particular East Asia, has become increasingly integrated through merchandise trade. In 200607, intra-regional trade accounted for 55.1 per cent of total manufacturing trade - up from 35.8 per cent in 1986-87. The level of intra-regional trade in East Asia was higher than that in NAFTA throughout this period and was rapidly approaching the level of the European Union 15. For developing East Asia (Asia excluding Japan) and ASEAN+3, the ratios are lower than the aggregate regional figure, but they have increased at a much faster rate. The intra-regional trade share of ASEAN has been much lower than the other two sub-regions.

The picture changes significantly, however, when components are netted out: the intra-East Asian share in final trade in 2006-07 was 46.4- down from 50.3 per cent in 1992-93. The estimates based on unadjusted data and data on final trade are vastly different for East Asia, particularly for developing East Asia and ASEAN. The level of trade in the two given years and the change over time in intra-regional trade shares are significantly lower for estimates based on final trade. Interestingly, we do not observe such a difference in estimates for NAFTA and the European Union.

The intra-regional shares calculated separately for imports and exports clearly illustrate the risk of making inferences about regional trade integration based on total (imports plus exports) data. There is a notable asymmetry in the degree of regional trade integration in East Asia. Unlike in the European Union and NAFTA, in East Asia, the increase over time in the intra-regional trade ratio (both measured using unadjusted data and data for final trade) has emanated largely from the rapid increase in intra-regional imports; the expansion in intra-regional exports has been consistently slower. The dependence of East Asia (and country sub-groups therein) on extra-regional markets (in particular, those in NAFTA 
and the European Union) for export-led growth is far greater than is revealed by the standard intra-regional trade ratios commonly used in the debate on regional economic integration. For instance, in 2007, only 43.9 per cent of total East Asian manufacturing exports was absorbed within the region, compared with an intra-regional share of 64.4 per cent in total manufacturing imports. For developing East Asia, the comparable figures were 33.4 per cent and 46.7 per cent, respectively. This asymmetry is clearly seen across all sub-regions within East Asia. The asymmetry between intra-regional shares of import and exports is much sharper when components are netted out. This is understandable given the heavy 'component bias' in Asian intra-regional trade and the multiple border crossing of parts and components within regional production networks. On the export side, the intra-regional share of final goods declined continuously from 46 per cent in 1995 to 37 per cent in 2007, whereas the intra-regional import share increased from 56 per cent to 63 per cent between these two time points.

In sum, these data support the hypothesis that, in a context in which global production sharing is expanding rapidly, standard trade flow analysis can generate misleading inferences regarding the process of economic integration through trade. When data on component trade are excluded from trade flows, these estimates suggest that extra-regional trade is much more important than intra-regional trade for continued growth in East Asia, whether or not Japan is included. Thus, the rising importance of global production sharing seems to have strengthened, rather than weakened, East Asia's link with the wider external economy. As we will see in the next section, this inference is basically consistent with the behaviour of trade flows in East Asia after the onset of the global financial crisis.

\section{Trade performance in the aftermath of the crisis}

A striking feature of the global economy since the onset of the global financial crisis in late 2007 has been the precipitous drop in global trade - at a rate faster than that during the Great Depression (Almunia et al. 2010; Krugman 2009). From April 2008 to June 2009, world trade contracted by about 20 per cent, which amounted to almost the total contraction in world trade during the first 30 months of the Great Depression (starting in April 1929). ${ }^{8}$ Interestingly, the trade contraction experienced by the East Asian countries during this period has been even greater than the contraction in total world trade (Figure 10.1 and Table 10.7).

8 Numbers derived from Almunia et al. (2010:Figure 5). 
China: The Next Twenty Years of Reform and Development

Figure 10.1 Growth of merchandise trade: East Asia, developing East Asia, China and ASEAN, January 2008 - November 2009 (year-on-year, per cent)

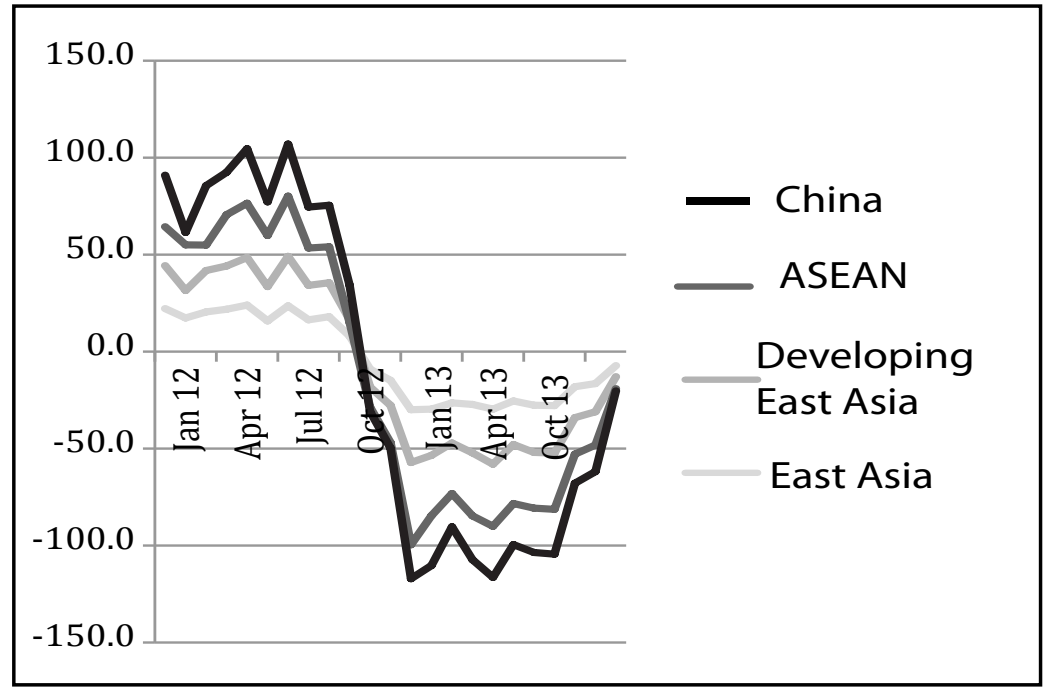

a) Exports

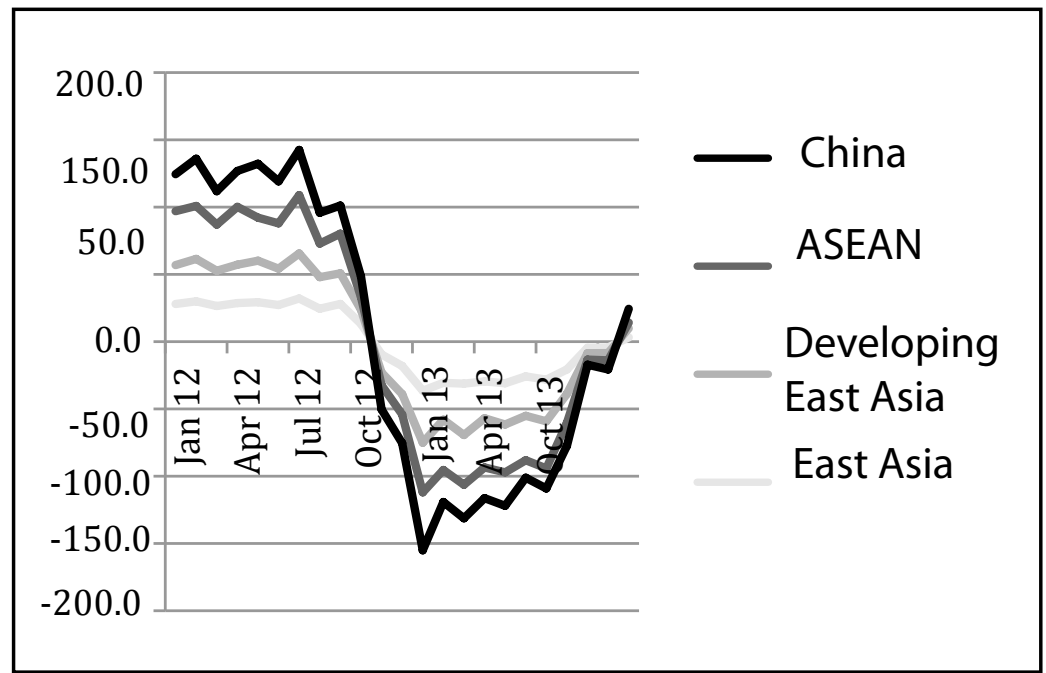

b) Imports

Source: Based on data compiled from CEIM database. 
Table 10.7 East Asia: growth of total merchandise exports and imports, 200701 - 200903 (year-on-year percentage change)

\begin{tabular}{|c|c|c|c|c|c|c|c|}
\hline & 200801 & 200802 & 200803 & 200804 & 200901 & 200902 & 200903 \\
\hline \multicolumn{8}{|l|}{ Exports } \\
\hline East Asia & 20.6 & 21.0 & 19.3 & -5.6 & -30.1 & -32.5 & -30.2 \\
\hline Japan & 22.9 & 16.4 & 15.2 & -8.1 & -42.1 & -41.1 & -38.2 \\
\hline $\begin{array}{l}\text { Developing } \\
\text { East Asia }\end{array}$ & 19.0 & 21.3 & 19.9 & -4.7 & -26.6 & -27.2 & -24.2 \\
\hline Hong Kong & 10.5 & 8.3 & 5.7 & -2.1 & -21.0 & -23.4 & -20.1 \\
\hline China & 21.1 & 22.4 & 23.0 & 4.6 & -20.1 & -22.7 & -20.3 \\
\hline Korea & 17.4 & 23.2 & 27.1 & -9.9 & -24.5 & -20.1 & -20.3 \\
\hline Taiwan & 17.4 & 18.2 & 7.6 & -24.6 & -35.9 & -28.3 & -18.5 \\
\hline ASEAN & 18.9 & 26.9 & 22.9 & -10.3 & -36.8 & -39.3 & 34.2 \\
\hline Indonesia & 31.9 & 29.4 & 27.9 & -5.3 & -32.5 & -33.2 & 31.1 \\
\hline Malaysia & 19.4 & 28.5 & 21.6 & -12.6 & -27.6 & -28.2 & 3.8 \\
\hline Philippines & -2.0 & -0.6 & 2.0 & -22.3 & -33.9 & -36.3 & -37.2 \\
\hline Singapore & 21.7 & 26.4 & 21.2 & -12.9 & -30.7 & -31.2 & -33.2 \\
\hline Thailand & 25.5 & 25.5 & 27.2 & -10.2 & -23.0 & -24.4 & -26.3 \\
\hline Vietnam & 27.7 & 31.8 & 37.5 & 6.0 & -14.8 & -11.7 & -7.3 \\
\hline \multicolumn{8}{|l|}{ Imports } \\
\hline East Asia & 29.6 & 29 & 29.8 & -4.1 & -32.5 & -33.1 & 30.7 \\
\hline Japan & 25.6 & 26.8 & 35.8 & 8.3 & -29.0 & -28.5 & -28.1 \\
\hline $\begin{array}{l}\text { Developing } \\
\text { East Asia }\end{array}$ & 29 & 28.9 & 26.6 & -8.0 & -32.1 & -34.2 & -33.2 \\
\hline Hong Kong & 12.0 & 9.6 & 7.0 & -4.0 & -20.8 & -22.3 & -25.2 \\
\hline China & 29.4 & 32.9 & 25.9 & -8.0 & -30.8 & -31.7 & -30.3 \\
\hline Korea & 29.0 & 30.5 & 42.9 & -8.8 & -32.8 & -35.6 & -11.9 \\
\hline Taiwan & 26.1 & 19.2 & 20.3 & -21.9 & -45.9 & -46.3 & -47.2 \\
\hline ASEAN & 37.9 & 36.2 & 32.6 & -5.0 & -37.2 & -36.7 & -35.3 \\
\hline Indonesia & 91.6 & 96.1 & 82.3 & 33.3 & -35.9 & -36.2 & -34.2 \\
\hline Malaysia & 16.1 & 17.3 & 14.5 & -17.1 & -36.8 & -36.1 & 4.8 \\
\hline Philippines & 22.1 & 8.4 & 4.5 & -23.4 & -30.3 & -31.3 & -32.1 \\
\hline Singapore & 32.1 & 35.4 & 32.9 & -9.3 & -30.0 & -28.1 & -29.2 \\
\hline Thailand & 39.6 & 25.7 & 37.8 & 3.8 & -39.7 & -40.5 & -37.3 \\
\hline Vietnam & 69.0 & 61.0 & 22.8 & -8.2 & -36.5 & -34.1 & -31.1 \\
\hline
\end{tabular}

Note: Growth rates calculated using current US dollar values.

Source: Compiled from CEIC Data Company.

Krugman (2009) points to the increased vertical integration of global production (the rise of global production sharing) as a possible explanation for the surprisingly large trade contraction in the present crisis compared with that in the Great Depression. Vertical integration of production implies that a given degree 
of contraction in demand for a final (assembled) product has ramifications for trade flows between the many countries involved in the production chain. Also, demand for components is susceptible to rapid stock adjustment by producers compared with final goods. Given that global production sharing is much more important for trade expansion in East Asia, this explanation also seems relevant for East Asia's greater trade contraction compared with overall trade contraction at the global level. A number of other factors are, however, also relevant for explaining the larger contraction in trade volume in the current crisis. These include the much larger contraction of trade credit, a greater share of consumer durables in contemporary global trade compared with the 1930s and the effect of recent advances in communication technology on inventory cycles and justin-time procurement practices. The current state of datum availability does not permit us to systematically delineate the impact of production sharing on trade contraction while appropriately controlling for these other possible factors. Instead, this section puts together some readily available data that have some bearing on this issue in order to set the stage for further analysis.

All major East Asian countries - including China, which was expected by the decoupling enthusiasts to cushion the rest of East Asia against a global economic collapse - experienced a precipitous trade contraction from about the last quarter of 2008 (Table 10.7). The remarkably synchronised nature of the trade contraction across countries in the region - in imports and exports - is generally consistent with the close trade ties in East Asia forged within regional production networks and the unique role of the region within global production networks.

Among the East Asian countries, Japan has been by far the worst hit. A large share of Japan's exports consists of capital goods and high-end durable consumer goods, such as cars and electrical machinery, machine tools and their components. Exports of capital goods and high-end consumer durables are concentrated heavily in the United States and other industrialised-country markets and are therefore directly exposed to the global economic decline. On the other hand, contrary to the predictions of the decoupling enthusiasts, Japan's growing exports to China have been indirectly affected by declining final (assembled) exports from China (Fukao and Yuan 2009). The degree of export contraction suffered by Taiwan and Korea has been smaller than that in Japan, but, on average, notably higher than in the other East Asian countries. As in the case of Japan, growing exports to China do not seem to have provided a cushion against collapse in world demand for these two countries. The relatively lower degree of export contractions experienced by Korea, Taiwan and the second-tier exporting countries in the region compared with Japan could possibly reflect consumer preferences for price-competitive low-end products in the crisis context. 
An inspection of growth rates of exports of individual East Asian countries by destination provides no support for the view that East Asian economies have become less susceptible to the worldwide trade contraction because of regional growth dynamism. ${ }^{9}$ Intra-East Asian trade flows have in general contracted at a faster rate than these countries' exports to the United States and the European Union.

Exports to China from most countries in the region have contracted at a much faster rate than their imports from China-perhaps an indication of de-stocking of components by Chinese firms given the gloomy outlook for exports (Table 10.8). China's imports from Japan, Korea and Taiwan have shrunk more rapidly (at an average rate of 23.5 per cent) than imports from other countries. This is not surprising, given the dominant role played by these countries in the supply of components to ICT assembly activities in China, which are heavily exposed to contractions in import demand in the United States and other industrialised countries. Overall, China's intra-regional imports have contracted at a much faster rate than imports from the United States and the European Union.

Table 10.8 China: growth of total merchandise exports \& imports by trading partner countries, 200701 - 200904 (year-on-year percentage change, current US\$)

\begin{tabular}{lcccccccc}
\hline & $\mathbf{2 0 0 8}$ & $\mathbf{2 0 0 8}$ & $\mathbf{2 0 0 8}$ & $\mathbf{2 0 0 8}$ & $\mathbf{2 0 0 9}$ & $\mathbf{2 0 0 9}$ & $\mathbf{2 0 0 9}$ & $\mathbf{2 0 0 9}$ \\
& $\mathbf{0 1}$ & $\mathbf{0 2}$ & $\mathbf{0 3}$ & $\mathbf{0 4}$ & $\mathbf{0 1}$ & $\mathbf{0 2}$ & $\mathbf{0 3}$ & $\mathbf{0 4 1}$ \\
\hline Exports & & & & & & & & \\
East Asia & 23.7 & 25.1 & 28.2 & 4.5 & -23.4 & -24.2 & -18.0 & 8.2 \\
Japan & 12.1 & 18.0 & 18.1 & 7.9 & -16.7 & -23.8 & -16.3 & -6.7 \\
Developing & 31.2 & 29.2 & 33.9 & 2.7 & -24.1 & -24.5 & -28.7 & 7.5 \\
East Asia & & & & & & & & \\
Korea & 33.1 & 38.3 & 52.9 & 7.5 & -29.2 & -36.6 & -35.0 & -3.0 \\
Taiwan & 15.4 & 21.1 & 17.3 & -10.4 & -34.5 & -38.8 & -21.4 & 20.1 \\
Hong Kong, & 10.8 & 6.5 & 11.0 & -9.9 & -24.0 & -21.6 & -16.6 & 12.2 \\
China & & & & & & & & \\
ASEAN & 34.2 & 26.0 & 27.4 & 2.8 & -22.6 & -16.8 & -9.6 & 23.0 \\
Indonesia & 33.2 & 41.5 & 54.8 & 20.2 & -26.4 & -21.0 & -24.0 & 21.3 \\
Malaysia & 33.3 & 28.2 & 20.8 & 7.1 & -23.9 & -12.2 & -9.1 & 9.2 \\
Philippines & 30.4 & 22.8 & 34.5 & 1.3 & -11.8 & -18.7 & -8.5 & 18.6 \\
Singapore & 15.3 & 5.9 & 17.1 & -0.6 & -17.1 & -12.3 & -16.2 & 21.4 \\
Thailand & 37.2 & 42.1 & 38.3 & 5.9 & -27.3 & -29.6 & -14.3 & 21.1 \\
Vietnam & 88.8 & 45.1 & 16.0 & -11.1 & -30.0 & -15.9 & 36.3 & 58.9 \\
United & 5.4 & 12.2 & 15.3 & 0.7 & -15.4 & -18.5 & -16.7 & 1.4 \\
States & & & & & & & &
\end{tabular}

9 This inference is based on monthly export data extracted from the CEIC Data Company (not reported here for want of space). 
China: The Next Twenty Years of Reform and Development

\begin{tabular}{|c|c|c|c|c|c|c|c|c|}
\hline $\begin{array}{l}\text { European } \\
\text { Union }\end{array}$ & 25.0 & 29.7 & 23.5 & 4.1 & -22.6 & -26.6 & -23.6 & -4.2 \\
\hline $\begin{array}{l}\text { Total } \\
\text { exports }\end{array}$ & 16.3 & 19.0 & 20.2 & 0.9 & -21.1 & -23.5 & -20.3 & 7.2 \\
\hline \multicolumn{9}{|l|}{ Imports } \\
\hline East Asia & 18.8 & 24.1 & 13.2 & -18.1 & -33.7 & -23.1 & -12.5 & 30.2 \\
\hline Japan & 17.0 & 23.7 & 18.7 & -5.0 & -29.8 & -21.4 & -13.4 & 15.6 \\
\hline $\begin{array}{l}\text { Developing } \\
\text { East Asia }\end{array}$ & 19.6 & 24.3 & 10.8 & -23.6 & -35.3 & -23.8 & -12.1 & 37.7 \\
\hline Korea & 14.9 & 25.0 & 14.8 & -18.5 & -26.6 & -18.8 & -10.2 & 33.6 \\
\hline Taiwan & 24.5 & 24.2 & 5.0 & -33.3 & -43.9 & -29.9 & -14.9 & 43.8 \\
\hline Hong Kong & 26.0 & -2.5 & 11.0 & -21.4 & -49.1 & -32.9 & -33.3 & -7.7 \\
\hline ASEAN & 19.9 & 23.8 & 12.7 & -18.9 & -33.8 & -22.1 & -8.9 & 12.2 \\
\hline Indonesia & 31.7 & 30.3 & 17.3 & -13.5 & -38.0 & -18.4 & -6.3 & 69.6 \\
\hline Malaysia & 18.4 & 29.5 & 22.4 & -16.1 & -25.0 & -17.0 & -3.5 & 60.3 \\
\hline $\begin{array}{l}\text { The } \\
\text { Philippines }\end{array}$ & 12.7 & 5.7 & -23.2 & -48.6 & -61.3 & -51.7 & -30.3 & 17.6 \\
\hline Singapore & 6.7 & 35.5 & 27.4 & -9.3 & -23.7 & -28.2 & -11.9 & 27.2 \\
\hline Thailand & 26.0 & 22.9 & 15.8 & -5.6 & -29.2 & -6.6 & -0.9 & 29.7 \\
\hline Vietnam & 64.3 & 19.0 & 69.4 & 6.8 & -7.9 & 23.6 & -8.3 & 47.7 \\
\hline $\begin{array}{l}\text { United } \\
\text { States }\end{array}$ & 29.7 & 23.0 & 15.7 & 3.7 & -17.7 & -13.1 & -6.4 & 19.3 \\
\hline $\begin{array}{l}\text { European } \\
\text { Union }\end{array}$ & 25.9 & 33.0 & 22.7 & 2.3 & -14.7 & -11.2 & -2.2 & 14.9 \\
\hline $\begin{array}{l}\text { Total } \\
\text { imports }\end{array}$ & 21.2 & 25.0 & 15.1 & -12.2 & -28.3 & -19.6 & -11.9 & 10.2 \\
\hline
\end{tabular}

1 Average for October and November

Note: Growth rates calculated using current US dollar values.

Source: Compiled from CEIC Data Company.

Data on export growth by major commodity categories for Chinese imports and exports are summarised in Table 10.9. A notable pattern is the relatively sharper contraction in the category of machinery exports (in which network trade is heavily concentrated) compared with other product categories - in particular, traditional labour-intensive products (textiles and garments, footwear and other miscellaneous manufactures). Exports belonging to this commodity categoryin particular, ICT products and consumer electronics - are also predominantly consumer durables, which, as already noted, are generally more susceptible to income contraction. In traditional labour-intensive products, developingcountry producers have the ability to perform better purely on the basis of cost competitiveness even in the context of depressed demand. 
Table 10.9 China: growth of merchandise exports and imports by commodity category, 200801 - 200903 (year-on-year percentage change, current US\$)

\begin{tabular}{|c|c|c|c|c|c|c|c|}
\hline & $\begin{array}{c}2008 \\
01\end{array}$ & $\begin{array}{c}2008 \\
02\end{array}$ & $\begin{array}{c}2008 \\
03\end{array}$ & $\begin{array}{c}2008 \\
04\end{array}$ & $\begin{array}{c}2009 \\
01\end{array}$ & $\begin{array}{c}2009 \\
02\end{array}$ & $\begin{array}{c}2009 \\
03\end{array}$ \\
\hline \multicolumn{8}{|l|}{ Exports } \\
\hline Total exports & 16.3 & 19.0 & 20.2 & 0.9 & -21.1 & -23.5 & -20.3 \\
\hline Primary & 16.3 & 24.9 & 29.9 & 8.6 & -17.9 & -13.6 & -14.2 \\
\hline Manufacturing & 21.2 & 23.8 & 22.0 & 2.6 & -20.7 & -18.2 & -17.2 \\
\hline $\begin{array}{l}\text { Products of chemical or } \\
\text { allied industries }\end{array}$ & 48.5 & 54.0 & 42.2 & 3.1 & -25.2 & -24.9 & -23.4 \\
\hline $\begin{array}{l}\text { Plastics and articles } \\
\text { thereof, rubber and rubber } \\
\text { articles }\end{array}$ & 13.8 & 10.1 & 16.1 & 10.7 & -21.1 & -17.1 & -17.3 \\
\hline Textiles and textile articles & 22.5 & 5.3 & 4.1 & 8.0 & -11.4 & 2.6 & 4.2 \\
\hline $\begin{array}{l}\text { Footwear, headgear, } \\
\text { umbrellas, etc. }\end{array}$ & 14.7 & 14.4 & 19.7 & 21.3 & -1.3 & 7.2 & 8.2 \\
\hline $\begin{array}{l}\text { Base metals and articles } \\
\text { of base metal }\end{array}$ & 23.3 & 18.5 & 26.4 & 22.0 & -9.0 & -1.5 & -4.3 \\
\hline $\begin{array}{l}\text { Machinery and mechanical } \\
\text { appliances, etc. }\end{array}$ & 15.9 & -15.7 & 20.9 & 4.3 & -31.6 & -38.8 & -42.1 \\
\hline Electronics & 6.2 & 12.5 & 61.5 & 17.2 & -33.5 & -36.5 & -37.3 \\
\hline $\begin{array}{l}\text { Electrical machinery and } \\
\text { equipment }\end{array}$ & 20.3 & 27.0 & 20.4 & -1.1 & -21.5 & -19.5 & -20.2 \\
\hline $\begin{array}{l}\text { Miscellaneous manufactured } \\
\text { articles }\end{array}$ & 41.5 & 39.0 & 31.7 & 9.1 & -17.0 & -19.7 & -6.2 \\
\hline Imports & $\begin{array}{c}2008 \\
01\end{array}$ & $\begin{array}{c}2008 \\
02\end{array}$ & $\begin{array}{c}2008 \\
03\end{array}$ & $\begin{array}{c}2008 \\
04\end{array}$ & $\begin{array}{c}2009 \\
01\end{array}$ & $\begin{array}{c}2009 \\
02\end{array}$ & $\begin{array}{c}2009 \\
03\end{array}$ \\
\hline Total imports & 21.2 & 25.0 & 15.1 & -12.2 & -28.3 & -19.6 & -11.9 \\
\hline Primary & 73.5 & 74.9 & 72.5 & 5.2 & -40.7 & -35.3 & -27.2 \\
\hline Manufacturing & 16.3 & 19.1 & 11.4 & -12.1 & -26.2 & -21.1 & -19.2 \\
\hline $\begin{array}{l}\text { Products of chemical or allied } \\
\text { industries }\end{array}$ & 19.6 & 23.5 & 19.6 & -10.5 & -23.9 & -18.2 & -16.3 \\
\hline $\begin{array}{l}\text { Plastics and articles thereof, } \\
\text { rubber and rubber articles }\end{array}$ & 16.3 & 22.5 & 22.7 & -15.6 & -29.2 & -20.1 & 15.2 \\
\hline Textiles and textile articles & 6.3 & 2.7 & -3.4 & -9.2 & -22.8 & -22.8 & -23.2 \\
\hline $\begin{array}{l}\text { Footwear, headgear, } \\
\text { umbrellas, etc. }\end{array}$ & 47.5 & 47.7 & 24.8 & 12.6 & -2.8 & -18.7 & -22.2 \\
\hline $\begin{array}{l}\text { Base metals and articles of } \\
\text { base metal }\end{array}$ & 14.1 & 5.8 & 8.3 & -15.0 & -26.3 & -16.9 & -2.7 \\
\hline $\begin{array}{l}\text { Machinery and mechanical } \\
\text { appliances, etc. }\end{array}$ & 11.7 & 18.0 & 9.8 & -10.7 & -24.1 & -17.9 & -8.2 \\
\hline Electronics & 16.3 & 19.9 & 15.0 & -1.0 & -19.8 & -19.5 & -3.2 \\
\hline $\begin{array}{l}\text { Electrical machinery and } \\
\text { equipment }\end{array}$ & 9.5 & 17.1 & 7.4 & -15.2 & -26.3 & -17.4 & -6.7 \\
\hline $\begin{array}{l}\text { Miscellaneous manufactured } \\
\text { articles }\end{array}$ & 11.6 & 20.8 & 1.4 & -8.1 & -5.4 & 1.6 & 2.2 \\
\hline
\end{tabular}




\section{Policy options}

At the time of writing this chapter (mid June 2010), 'the global recovery is proceeding better than expected' (IMF 2010:1). Industrial production in the United States and other major industrialised countries has begun to recover and the downward spiral in world trade volume has abated. The economic forces unleashed by the crisis will, however, probably run rampant for years. The recovery has so far been driven largely by unprecedented fiscal and monetary stimulus and there is considerable downside risk to sustainability stemming from fiscal fragility. In the medium term, the United States and other crisisaffected industrialised countries will have to save more and spend less in order to wind down the massive accumulated household and public debt. Given this global economic outlook, what are the policy options available to governments in China and other East Asian countries that have hitherto depended largely on export-driven growth?

There has been a growing emphasis in Asian policy circles on the need for rebalancing growth: engineering a structural shift in aggregate demand away from exports and towards domestic markets (ADB 2010). The policy measures under consideration include measures to redress the export bias in the incentive structure, to reduce high saving propensities with a view to boosting domestic consumer demand and to promote domestic non-tradable (services) production. The major focus of this policy advocacy is on China.

China's degree of export dependence is unusually high for a continental economy of China's size. China's export to gross domestic product (GDP) ratio (about 40 per cent) grossly exaggerates its export dependence because of the heavy import dependence of assembly exports, which account for more than two-thirds of total merchandise exports. Even the available adjusted estimates (about 20 per cent), however, seem too high for China's potential economic size. Moreover, the unusually high domestic saving rates, the vast population base, highly repressed domestic financial system and excessively high urban-rural household income gap all indicate the vast potential for policy-induced domestic demand-led growth in China. Growth rebalancing will not only enable China to deal effectively with massive external imbalances while cushioning growth momentum against external demand shocks, it will engineer a critical shift in the focus of national development policy from the quantity to the quality of growth, with a view to redressing urban-rural disparities and achieving social harmony.

The need to embark on a major structural transition from export-led to domestic demand-led growth was recognised by the Chinese leadership well before the onset of the global financial crisis (Roach 2009:229-33). The eleventh Five- 
Year Plan enacted in March 2006 stressed the imperatives of an enhanced, broad-based social safety net (encompassing not just social security but rural health care and education) to improve income security, thereby reducing the excess precautionary savings that continue to inhibit the expansion of private consumption. Chinese authorities have, however, so far failed to put this policy into action, presumably because of strong domestic political pressure to maintain the momentum of employment-intensive growth through export orientation (Yu 2007; Fan 2008).

Success on the rebalancing front will naturally involve an appreciation of China's real exchange rate ${ }^{10}$ — that is, a reduction in the profitability of tradable production relative to non-tradable production. But this is unlikely to impedeat least in the medium term - China's role as the premier assembly centre within regional production networks. Even after three decades of rapid growth, the average hourly wage rate for Chinese manufacturing of US\$3.20 is still (as in 2007) only 13 per cent of the US hourly wage rate of US\$24.40. ${ }^{11}$ About half of China's massive labour force (about 745 million people) is still engaged in agriculture, where productivity is, on average, barely one-eighth of that in industry and about one-quarter of that in the service sector. This, coupled with the high skilled-unskilled wage differential — which, according to Blanchard and Giavazzi (2006), has risen from 1.3 to 2.1 in the past decade - suggests that China still has much potential for moving unskilled workers out of agriculture and into manufacturing and other productive urban-sector activities. ${ }^{12}$

The pressure for maintaining export competition in a context of slow-growing world demand could provide a fertile setting for the rise of trade frictions and protectionism (Bhagwati 1988; Erixson and Razeen 2009). Fortunately, there has not yet been a protectionist backlash in the form of erecting tariff walls, as happened during the Great Depression. There are, however, already signs that countries are resorting to protection 'disguises' in the form of filing antidumping complaints and imposing stringent implementation of technical, sanitary and phyto-sanitary standards, in addition to the massive financial support extended by the United States and some other countries to automobile manufacturers (Gamberoni and Newfarmer 2009). The number of legislative measures introduced in the US Congress that involve some form of sanction on China's trade has multiplied in recent years (Roach 2009:241). There is

10 Whether it would be preferable to achieve this by adjustments to the nominal exchange rate rather than by adjustment of domestic prices remains a subject of controversy, which is beyond the scope of this chapter. See the chapters by Xiao Geng, and Rod Tyers and Ying Zhang in this volume.

11 Data from the US Bureau of Labor Statistics web site $(<\mathrm{ftp}$.bls.gov $>)$.

12 In recent years, there have been many scattered cases of rising wages and worker shortages in industrial cities in China. One cannot, however, realistically infer this evidence as indicative of a broader macroeconomic trend of emerging labour shortages given that the Chinese economy is still a long way from having a fully functioning labour market. These cases could well reflect skill mismatches and frictional dislocations in a highly imperfect labour market rather than genuine labour shortages. 
therefore a strong case for devising strategies to fight new protectionism as part of a long-term commitment to non-discriminatory multilateral and unilateral liberalisation. The Information Technology Agreement, which came into force in 1997, seems to be a promising example to follow (Elek 2008). There is also a case for Asia's Group of 20 (G20) countries and the ASEAN Secretariat to consolidate their positions against protectionist tendencies. As part of its efforts to keep export markets open, China should resist the temptation to use export subsidies and other selective policies to support its export sector. In an era of rising unemployment and the resultant backlash against globalisation in the United States and other industrialised countries, giving in to such temptation could be a recipe for anti-China trade sanctions.

One option under consideration in Asian policy circles for supporting regional trade growth in the face of slow growth in world demand is to form a regionwide free-trade agreement (FTA), encompassing ASEAN, China, Japan and Korea (and possibly India) (Kawai and Wignaraja 2009; ADB 2009). The logic behind this proposal in relation to the network trade in the region is that trade within global production networks (both in components and final assembly) is generally more sensitive to tariff changes than is final trade (or total trade as captured in published trade data) (Yi 2003). Normally a tariff is incurred each time a good-in-process crosses a border. Consequently, a 1 percentage point reduction in tariffs leads to a decline in the cost of production of a vertically integrated good by a multiple of this initial reduction - in contrast with a 1 per cent decline in the cost of a regular traded good. Tariff reductions can also make it more profitable for goods that were previously produced entirely in one country to become vertically specialised. Consequently, in theory, the tradestimulating effect of FTAs would be higher for network trade than for normal trade, other things remaining unchanged.

In our view, however, this is a risky strategy, given Asia's heavy reliance on extra-regional markets for its export dynamism. Such a move would invite swift retaliation by the United States and the European Union, and possibly others. A firm commitment as part of the FTA to not increase existing tariff and non-tariff barriers against non-members is unlikely to avert this threat because an Asiawide FTA - given that it would encompass a number of significant world trading nations - is likely to involve significant trade diversion even under the existing extra-regional tariffs. In any case, the chances of negotiating a region-wide FTA look rather slim in the context of the continuing crisis. In particular, China might not want to get involved in such an endeavour, not only because of its new emphasis on domestic-oriented growth but because of its official commitment to averting protectionist backlashes in industrialised countries. ${ }^{13}$ Governments

13 See, for instance, the recent article written by the Chinese Minister of Trade for the Wall Street Journal (Deming 2009). 
in South-East Asian countries are also concerned that any region-wide attempt to liberalise trade would give China an unfair advantage in attracting foreign direct investment (FDI) involved in global production networks, given its vast domestic economy characterised by regional differences in costs of production. ${ }^{14}$

In reality, the trade effects of any FTA would depend very much on the nature of the rules-of-origin (ROO) built into it. In particular, there are three main complications involved in bringing network trade under FTAs (or other preferential trading arrangements). First, formulating ROOs for network-related trade is a rather complicated business. The conventional value-added criterion is not virtually applicable to this trade because the products involved are low value added by their very nature. The only viable option is to go for ROOs based on 'change in tariff lines', but this leads to insurmountable administrative problems because trade in electrical and electronic goods and the related components belongs to the same tariff code at the HS- 6 digit level, which is the normal basis for designing this type of ROO (Kohpaiboon 2008:App. 2). For example, electrical appliance assembly plants in Thailand that use imported bare-printed circuit boards (BPCB) together with other locally procured electronic components (for example, diodes, integrated circuits, semi-conductors) for printed circuit-board assembly (PCBA) for export are not eligible for FTA concessions because BPCBs and PCBAs belong to the same HS code (853690).

Second, the process of network-based global production sharing is characterised by the continuous emergence of new products. Given the obvious administrative problems involved in revising ROOs in tandem, these product inventions and innovations naturally open up room for unnecessary administrative delays and/or the tweaking of rules as a means of disguised protection (Elek 2008). Moreover, given the importance of extra-regional markets for final goods for the growth dynamism of production networks in Asia, maintaining barriers to trade against non-members (while allowing free trade among members) can thwart the 'natural' expansion of global production sharing. Third, twisting ROOs for the purpose of import-competing industries becomes easier when the production process involves procuring components from a number of sources; tightening ROOs on the procurement of one critical input would suffice to protect competing domestic producers of the final (assembled) product. ${ }^{15}$

14 This point is based on interviews with high-ranking officials in the Thai Ministry of Foreign Affairs.

15 ROOs relating to television sets (HS852812) in the Thailand-Australia Free Trade Agreement (Annex 4.1) can be used to illustrate this point. To become eligible for preferential tariffs, television producers must source three parts (HS701120, 854011 and 854091) locally. Television picture tubes (HS854011) are not, however, produced in Thailand and Thai colour-television assembly is viable only if this item is procured from Japan, Taiwan or Korea. Thus, even though a preferential tariff on televisions under the FTA (20 per cent) is very attractive, the Thailand-Australia FTA is virtually irrelevant for television assembly plants located in Thailand. 
Finally, it is important to note that the available evidence on the operation of FTAs in operation in the region (and beyond) does not augur well for the potency of a new region-wide FTA. Presumably because of the operational complications noted above, the real utilisation rates of tariff concessions provided under these FTAs are rather low - ranging from about 5 per cent to 20 per cent across different product categories (Takahashi and Urata 2008; Kawai and Wignaraja 2009; Kohpaiboon 2008). Moreover, there is evidence that utilisation rates are often firm or industry specific and are higher in large firms, firms with close trade and FDI ties and firms located in particular industries in which meeting ROO requirements is simple and straightforward. The upshot is that FTAs are unlikely to have the potential to promote trade in a neutral and broad-based fashion.

\section{Conclusions}

Intra-regional trade shares based on conventional trade data are generally consistent with the view that East Asia has become increasingly integrated through merchandise trade. When the continuing process of global production sharing and East Asia's unique role in China-centred global production networks are appropriately taken into account, it is clearly evident, however, that the increase over time in intra-regional trade ratios has emanated largely from the rapid increase in intra-regional imports, while intra-regional export expansion has persistently lagged behind. The asymmetry in intra-regional shares between imports and exports is much sharper when reported trade data are adjusted for trade in parts and components. Clearly, the region's dependence on the rest of the world for its trade expansion has in fact increased over time.

This inference is basically consistent with the behaviour of trade flows since the onset of the global financial crisis. The remarkably synchronised nature of the trade contraction across countries in the region is generally consistent with the close trade ties within East Asia-forged within regional production networks. While many had hoped that China would provide a cushion for this export contraction - as would have been consistent with the decoupling thesis - this did not turn out to be the case.

The rise of global production sharing has strengthened the case for a global, rather than a regional, approach to trade policymaking. Given the global orientation of the region's economies, we question whether there would be any significant positive pay-off from forming a region-wide FTA. In any case, it is doubtful whether an FTA approach to trade liberalisation is feasible in a context in which global production networks are rapidly expanding, seamlessly encompassing many industries and countries. 
The recent and prospective developments in the global economy since the global financial crisis make a strong case for China to go ahead with the speedy implementation of the growth-rebalancing policy embodied in its eleventh Five-Year Plan. Given the nature of domestic factor-market conditions and the continuing changes in the process of global production sharing, promoting domestic demand-oriented growth and engagement in global production sharing is not a mutually exclusive policy priority for China in the medium term. Successful growth rebalancing has the potential to facilitate the further expansion of network trade by averting trade friction and retaliation. An enlarged domestic market would also have the potential to improve the international competitiveness of exporting firms within production networks by reducing unit costs of production. Looking further ahead, increases in domestic income and wages under a successfully balanced growth strategy would provide the setting for China to move up the value ladder within global production networks. After all, the bulk (more than 60 per cent) of international exchange within global production networks takes place among industrialised countries and, in the future, China will surely become one of these.

\section{References}

Asian Development Bank (ADB) 2009, Asian Development Outlook 2009: Rebalancing Asia's growth, Asian Development Bank, Manila.

Asian Development Bank (ADB) 2010, Asian Development Outlook 2010: Macroeconomic management Beyond he Crisis, Asian Development Bank, Manila.

Almunia, M., Benetrix, A., Eichengreen, B., O'Rourke, K. H. and Rua, G. 2010, 'From Great Depression to great credit crisis: similarities, differences and lessons', Economic Policy, April, pp. 219-65.

Athukorala, P.-c. 2005, 'Product fragmentation and trade patterns in East Asia', Asian Economic Papers, vol. 4, no. 3, pp. 1-27.

Athukorala, P.-c. 2009a, 'The rise of China and East Asian export performance: is the crowding-out fear warranted?', World Economy, vol. 32, no. 2, pp. 234-66.

Athukorala, P.-c. 2009b, 'China and Southeast Asia in the new division of labour', in L. Yueh (ed.), The Future of Asian Trade and Growth: Economic development with the emergence of China, Routledge, London, pp. 406-31. 
Athukorala, P.-c. 2009c, Production networks and trade patterns: East Asia in a global context, Trade and Development Discussion Paper 2009/08, Division of Economics, Research School of Pacific and Asian Studies, The Australian National University, Canberra.

Bergsten, C. F., Gill, B., Lardy, N. R. and Mitchell, D. 2006, China: The balance sheet, Public Affairs, New York.

Blanchard, O. and Giavazzi, F. 2006, 'Rebalancing growth in China: a threehanded approach', China and World Economy, vol. 14, no. 4, pp. 1-20.

Bhagwati, J. 1988, Protectionism, MIT Press, Cambridge, Mass.

CEIC Data Company, New York. Data downloaded from www.ceicdata.com

Council for Economic Planning and Development n.d., Trade Data, CD-ROM, Council for Economic Planning and Development, Taipei.

Deming, C. 2009, 'China calls on the world's governments to learn from history', Wall Street Journal, 20 February.

Elek, A. 2008, Immunizing future protectionists: preventing the emergence of more sensitive sectors, Asia Pacific Economic Papers 372, Australia-Japan Research Centre, The Australian National University, Canberra.

Erixson, F. and Razeen, S. 2009, 'Fighting the urge for protectionism', Far Eastern Economic Review, vol. 172, no. 1 (January/February), pp. 28-31.

Fan, G. 2008, 'Renminbi revaluation and US dollar depreciation', in M. Goldstein and N. R. Lardy (eds), Debating China's Exchange Rate Policy, Peterson Institute for International Economics, Washington, DC.

Fukao, K. and Yuan, T. 2009, 'Why is Japan so heavily affected by the global economic crisis?', voxeu.org, 8 June.

Gamberoni, E. and Newfarmer, R. 2009, 'Trade protection: incipient but worrisome trends', voxeu.org, 4 March 2009.

Garnaut, R. 2003, Australia and Japan: time to be important to each other again, Address to the Australia-Japan Business Committee Conference, Kyoto, 5 October 2003.

International Monetary Fund (IMF) 2010, Global Economic Outlook: Rebalancing growth, International Monetary Fund, Washington, DC.

Kawai, M. and Wignaraja, G. 2008, The Asian noodle bowl: is it serious for business?, ADBI Working Paper 136, Asian Development Bank Institute, Tokyo. 
Kawai, M. and Wignaraja, G. 2009, 'Multilateralising Regional Trading Agreements in Asia', in Multilateralizing Regionalism: Challenges for the Global Trading System, edited by Richard Baldwin and Patrick Low. Cambridge UK: Cambridge University Press.

Krugman, P. 2009, The return of depression economics, Lionel Robbins Lecture, London School of Economics, <http/cep.lse.ac.uk/_new/events/special_ post.asp>

Kohpaiboon, A. 2008, Exporters' response to AFTA tariff preferences: evidence from Thailand, Paper presented at the East Asian Economic Congress, Manila.

Park, Y. C. and Shin, K. 2009, 'Economic integration and changes in the business cycle in East Asia: is the region decoupling from the rest of the world?', Asian Economic Papers, vol. 8, no. 1, pp. 107-40.

Roach, S. 2009, The Next Asia: Opportunities and challenges for a new globalization, John Wiley, Hoboken, NJ.

Takahashi, K. and Urata, S. 2008, On the use of FTAs by Japanese firms, RIETI Discussion Paper 08-E-002, Graduate School of Asia-Pacific Studies, Waseda University, Japan.

United Nations (UN) n.d., Comtrade database, United Nations, New York.

Urata, S. 2006, A shift from market-driven to institution-driven regionalization in East Asia, Paper presented to Conference on Economic Policy Reform in Asia, Stanford University, California., June.

Yoshitomi, M. 2007, 'Global imbalances and East Asian monetary cooperation', in D.-K. Chung and B. Eichengreen (eds), Towards An East Asian Exchange Rate Regime, Brookings Institution Press, Washington, DC, pp. 22-48.

Yi, K. 2003, 'Can vertical specialization explain the growth of world trade', Journal of Political Economy, 111 (1), 52-102.

Yu, Y. 2007, 'Global imbalances and China', The Australian Economic Review, vol. 40, pp. 3-23. Geng Xiao. 



\section{Asian foreign direct investment and the 'China effect'}

\section{Chunlai Chen}

\section{Introduction}

Since the 1990s and especially after China's accession to the World Trade Organisation (WTO), China has become one of the most-favoured destinations for foreign direct investment (FDI). In 2008, FDI inflows into China reached US\$92.4 billion. In 2009, despite the global economic recession, which severely affected world FDI flows, China still attracted US $\$ 90$ billion of FDI inflows. By the end of 2009, China had attracted a total of US\$760 billion in FDI inflows, ${ }^{1}$ making it by far the largest FDI recipient among the developing countries in the world.

There are, however, increasing concerns that China's FDI success has been excessive, thereby crowding out FDI inflows into other countries. Several of China's neighbouring Asian economies have raised concerns that the emergence of China has not only diverted FDI away from them but has encouraged their own domestic investors to leave their economies, resulting in a continuous loss of manufacturing industries and jobs, and further weakening their economies.

A growing China can add to other countries' FDI inflows by creating more opportunities for production networking and by raising the demand for raw materials and resources. At the same time, low Chinese labour costs can lure multinational enterprises (MNEs) away from other Asian economies when the MNEs consider alternative locations for low-cost export platforms. Theoretically, competition for any resource flow can obviously occur when the resource in question is available in limited amounts. This 'zero-sum' hypothesis is, however, difficult to justify in the case of FDI. For example, FDI inflows accounted for only 12.3 per cent of world gross fixed capital formation in 2008 (UNCTAD 2009), and additional FDI resources can be easily diverted from domestic resources and other international capital flows should investment opportunities arise.

1 At constant 1990 US dollar prices. 
This chapter examines empirically the question of whether the success of China in attracting FDI inflows has diverted FDI away from-or has been complementary to FDI inflows into - other Asian economies. The next section presents an overview of FDI inflows into China during the past three decades and discusses the current literature on the effects of FDI inflows into China on FDI inflows elsewhere. The subsequent section sets out the framework of analysis, the hypotheses, the empirical model and the variable specification. Following this is a presentation and discussion of the regression results, before some conclusions are drawn.

\section{The growth of FDI inflows into China}

As shown in Figure 11.1, the growth of FDI inflows into China from 1982 to 2009 can be broadly divided into three phases: the experimental phase from 1982 to 1991, the boom phase from 1992 to 2001 and the post-WTO phase from 2002 to 2009.

During the experimental phase, FDI inflows into China were at a low level but grew steadily. They were concentrated mainly in the south-eastern coastal areas, particularly in the four special economic zones (SEZs). ${ }^{2}$ In the second phase, FDI inflows into China increased rapidly during 1992-96, but slowed after 1997 and declined in 1999 and 2000, followed by a moderate recovery in 2001. The slowdown of FDI inflows into China during 1997-2000 was caused mainly by the East Asian financial crisis. After China's entry into the WTO, with the implementation of its WTO commitments and broader and deeper liberalisation in trade and investment, FDI inflows into China increased rapidly-from US $\$ 46.9$ billion in 2001 to US $\$ 92.4$ billion in 2008 , before decling to US $\$ 90$ billion in 2009 in the aftermath of the global financial crisis.

China's success in attracting FDI inflows, particularly after its WTO accession, has caused increasing concerns that it has come at the expense of other developing countries, particularly its neighbouring Asian developing economies. An increasing number of empirical studies have focussed on the effects of FDI inflows into China on those into other countries (see, for example, Chantasasawat et al. 2004; Cravino et al. 2007; Eichengreen and Tong 2005; Resmini and Siedschlag 2008; Mercereau 2005; Zhou and Lall 2005; Wang et al. 2007). These studies differ in the measurement of FDIflows and in estimation techniques.

Chantasasawat et al. (2004) use data for eight Asian economies-Hong Kong, Taiwan, Republic of Korea, Singapore, Malaysia, Philippines, Indonesia and

2 The four special economic zones are Shenzhen, Zhuhai, Shantou in Guangdong Province and Xiamen in Fujian Province. 
Thailand - in addition to China for the period 1985-2001. They estimate equations for China's FDI inflows and other Asian economies' FDI inflows using two-stage least squares. They find that the level of China's FDI is positively related to the levels of these economies' inward FDI, although this 'China effect' is generally not the most important determinant of inward FDI into these economies. Policy and institutional factors such as openness, corporate tax rates and the level of corruption tend to be more important. Zhou and Lall (2005) and Wang et al. (2007) estimate panel models to investigate the effect of FDI inflows into China on FDI inflows into other Asian economies. They also find that, on average, FDI inflows into China have raised rather than diverted FDI inflows into neighbouring economies.

\section{Figure 11.1 FDI inflows into China (at current prices)}

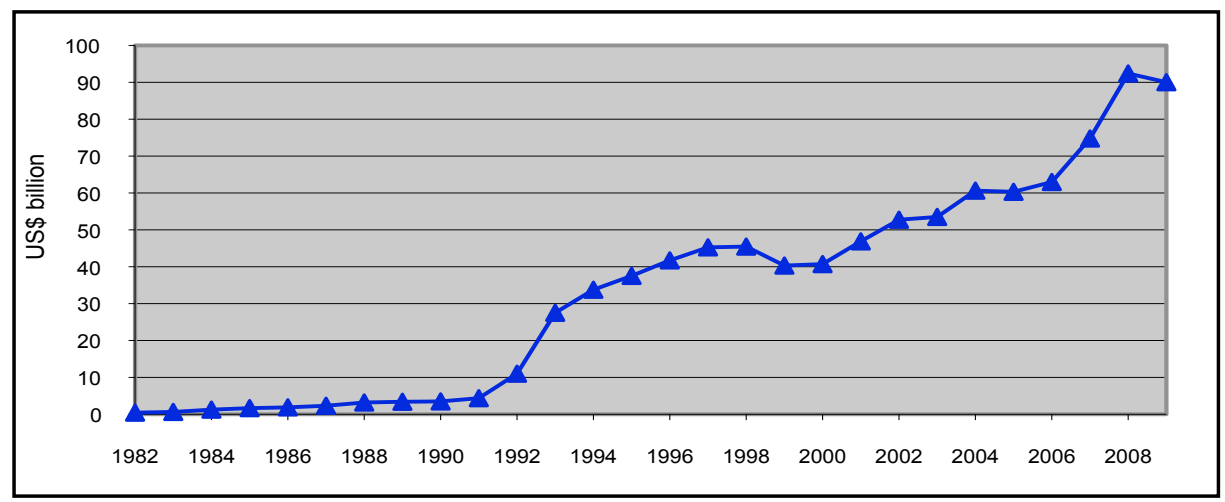

Note: The data do not include FDI inflows into the finance sector.

Sources: National Bureau of Statistics (NBS) various years, China Statistical Yearbook, China Statistics Press, Beijing.

Mercereau (2005) also investigates the impact of China's emergence on FDI inflows into Asia, using data from 14 Asian economies from 1984 to 2002 and using a number of econometric methods, including ordinary least squares (OLS) with fixed country effects, dynamic panels with a lagged endogenous variable and instrumental variables. In contrast with the above studies, he does not find a positive relationship between China's FDI inflows and FDI inflows into other Asian economies. He does not find evidence, however, that China's success in attracting FDI has been at the expense of other economies in the region - with the exception of Singapore and Myanmar. Low-wage economies, which compete with China for low-wage investment, do not appear to have been particularly affected by China's emergence. Low levels of education or scientific development are not associated with increased crowding out by China either. Some economic fundamentals, such as healthy government balances and low inflation, help explain the allocation of FDI inflows among Asian economies. 
Eichengreen and Tong (2005) employ a gravity model and show that the emergence of China as a leading FDI destination has encouraged FDI inflows into other Asian economies via supply-chain production linkages. They also find evidence, however, suggesting that FDI inflows into China have diverted FDI inflows away from Europe. They explain this diversion effect by the negative impact of distance on supply-chain production linkages. In contrast, Resmini and Siedschlag (2008) estimate an augmented gravity model to analyse the effects of FDI inflows into China originating in Organisation for Economic Cooperation and Development (OECD) economies on FDI inflows into the European Union and other economies for the period 1990-2004. Their results suggest that on average, FDI inflows into China have been complementary to FDI inflows into other host countries and into the European Union as well. This complementary relationship is, however, not constant across countries, but is instead weaker in Europe than outside it; also these complementarities follow a decreasing trend over the analysed period.

Finally, Cravino et al. (2007) examine the effect of foreign capital stock in China on the Latin American and Caribbean countries and find no evidence of FDI diversion from OECD countries - in particular from the United States-into China at the expense of the Latin American and Caribbean countries. While the growth of capital stocks in China originating from the OECD was faster than in Latin American and Caribbean countries for the period 1990-97, this relative growth has slowed since then.

The above empirical studies indicate that there is little to suggest that China's FDI success has crowded out FDI inflows into other countries. On the contrary, there is strong empirical evidence that, on average, FDI inflows into China have been complementary to FDI inflows into other host countries, especially into China's neighbouring economies.

\section{Framework of analysis and the empirical model}

This study uses a gravity model to investigate the impact of FDI inflows into China on FDI inflows into other Asian developing economies. Apart from being used extensively in studies of trade flows, the gravity model has been used in studies of FDI flows. As elaborated by Dunning's (1993) 'OLI' explanation of FDI, many factors influence the flows of FDI. Since these factors are located in different areas, the general argument for the use of the gravity model in line with the OLI framework is that each factor can be categorised as a sourcecountry factor (reflected in ownership and internalisation advantages) or a hosteconomy factor (reflected in location advantages). Source-country factors reflect 
the capacity of a source country to conduct FDI in all possible host economies, while host economy factors are characteristics of the overall attractiveness of a host economy for FDI inflows from all source countries.

Based on the gravity model and the OLI framework in explaining FDI, the fundamental model used here can be written as Equation 11.1.

\section{Equation 11.1}

$\ln \operatorname{FDI}_{* \mathrm{j}}=\beta_{0}+\beta_{1} \ln \mathrm{X}_{*}+\beta_{2} \ln \mathrm{X}_{\mathrm{j}}$

In Equation 11.1, $\mathrm{FDI}_{* \mathrm{j}}$ is the magnitude of total FDI inflows from all source countries into host economy $\mathrm{j}, \mathrm{X}_{*}$ are the aggregate source country variables and $\mathrm{X}_{\mathrm{j}}$ are host economy variables.

Since source country i's variables, $\mathrm{X}_{\mathrm{i}}$ - which measure the overall outward investment potential of source country $\mathrm{i}$ - are determined by its own technological and economic development levels, the key feature of these variables is that they are common to all outward FDI of source country $i$ and are independent of factors in the destination countries. Therefore, the aggregate source-country variables, $\mathrm{X}_{*}$, become a constant for each of the host economies - although one that changes over time. In the real implementation, we use the world total FDI outflows (WFDIOUT) of all source countries to capture the effects of sourcecountry variables, $X_{*}$. We adopt the log-linear form as the basic functional form to connect the magnitude of FDI inflows from all source countries to host economy $\mathrm{j}$ to the relevant explanatory variables (aggregate source-country variables and host economy variables).

\section{The hypotheses}

As shown in many studies, the location factors determining FDI inflows into developing economies are mainly market size, economic growth, per capita income, labour costs, resource endowments, economic and political stability, and investment incentives offered by the host country government. In the following, we examine briefly how each of these location factors plays an important role in determining the magnitude of FDI inflows into developing host economies.

\section{Market size and economic growth of host economies}

The main argument for the importance of market size as a location factor in the determination of inflows of FDI is based primarily on economies of scale: larger economies can provide more opportunities to realise and explore economies of scale, to realise the specialisation of productive factors and to absorb more 
efficiently the technology that foreign investors desire to introduce. Therefore, we expect that the magnitude of FDI inflows will be greater the larger is the market size of the developing host economy. The significance of this argument is, however, debatable in open economies. This is because in open economies, enterprises and industries can realise and explore economies of scale through international markets instead of relying only on the domestic market - and this point is especially relevant in the East and South-East Asian economies. As a result, instead of using gross domestic product (GDP) or per capita GDP as the measure of market size, we use the real rate of economic growth to capture this location variable.

A high rate of economic growth is an indicator of development potential, which is expected to be an important location determinant affecting FDI inflows. First, the higher level of economic growth represents a better overall economic condition of the host economies, which is attractive to foreign investors. Second, a higher level of economic growth is an indicator of improving conditions in local infrastructure, which is fundamental for attracting FDI inflows. Third, a higher level of economic growth implies a fast expansion of the market size, a rapid rise in domestic demand and a growing purchasing power of the host economies' consumers, which is an important determinant of market-oriented FDI. Clearly, markets that are expected to grow faster will tend to attract higher levels of inward FDI. Therefore, the hypothesis is that there is a positive relationship between inward FDI and economic growth in the developing host economy. In this study, the real GDP growth rate, denoted by GR, is used as the comprehensive measure of development potential in the host economy under study.

\section{Factor costs in host economies}

In the FDI literature, the most important factor cost in the determination of FDI inflows is the wage rate, especially when FDI is export oriented. Therefore, the relevant factor cost in the decision to locate FDI in the host economy is that of labour costs. In particular, lower labour costs are expected to induce higher levels of FDI inflows, especially for export-oriented FDI. A lower wage rate could, however, also be accompanied by lower productivity, and thus the efficiency wage might not in fact be low. Therefore, the best measure of labour costs is the 'efficiency wage' rather than the absolute wage rate. The efficiency wage can be measured directly as Equation 11.2.

\section{Equation 11.2}

$$
E W_{j}=\frac{W_{j}}{\Pi_{j}}
$$


In Equation 11.2, $\mathrm{EW}_{\mathrm{j}}$ is the average efficiency wage in host economy $\mathrm{j}, \mathrm{W}_{\mathrm{j}}$ is the absolute wage rate in host economy $j$ and $\Pi_{j}$ is the average productivity of labour in host economy $\mathrm{j}$. The efficiency wage as a measure of labour costs has the advantage of being unit free.

There are two major problems involved in international cross-country comparisons of wage rates and labour productivity. One is the different price level in different countries and another is the different exchange rate, especially in developing countries. To avoid these problems, this study uses total labour earnings as a percentage of total value added in each developing economy as the corresponding measure of the efficiency wage. ${ }^{3}$ In fact, according to the above definition for the efficiency wage, the measure of total earnings as a percentage of total value added is exactly the average efficiency wage in the developing host economies. ${ }^{4}$ In this study, we expect the efficiency wage to be negatively related to the level of FDI inflows into host developing economies.

\section{Country risk (country credit rating)}

Studies of FDI in developing countries have put particular emphasis on indicators of economic and political risk (such as Lucas 1993; Singh and Jun 1995). Country risk comprises three main elements: macroeconomic stabilityfor example, economic growth, inflation and exchange rate risk; institutional stability, such as policies towards FDI, tax regimes, the transparency of legal regulations, intellectual property protection and the scale of corruption; and political stability, ranging from indicators of political freedom to measures of surveillance and revolutions. While there is a variety of ways in which country risk can be approximated for empirical studies, a common approach relies on country credit ratings, which provides information available to firms at the time of their investment decision.

Country credit ratings are developed by Institutional Investors, which has published credit ratings twice a year since 1979 to assess the creditworthiness of about 150 countries, based on a survey of some 100 international bankers' perceptions of creditworthiness, including economic, financial and sociopolitical stability criteria. The resulting score scales from zero (very high chance of default) to 100 (least chance of default). Participants' responses are adjusted according to their institutions' assets, with heavier weights on those institutions with worldwide exposure and sophisticated country-analysis

\footnotetext{
3 Total labour earnings are calculated as the wage rate multiplied by total employment. The data for wage rates and employment are from ILO (n.d.). The data for total value added are from United Nations Statistical Division (n.d., National Accounts). The calculation is based on local currency and current prices.

4 The derivation of the average efficiency wage is as follows: $\mathrm{EW}=\mathrm{W} / \Pi=(\mathrm{Y} / \mathrm{L}) /(\mathrm{V} / \mathrm{L})=\mathrm{Y} / \mathrm{V}$, in which EW is efficiency wage, $\mathrm{W}$ is the wage rate, $\Pi$ is labour productivity, $\mathrm{Y}$ is total labour earnings, $\mathrm{V}$ is total value added and $\mathrm{L}$ is total labour.
} 
systems. This study uses the credit rating of the host country to measure the investor's perception of country-specific risk. The hypothesis is that the lower is the country risk (the higher is the country credit rating) the higher will be the level of FDI inflows. The country credit rating, denoted as CDR, is compiled from various issues of Institutional Investor magazine.

\section{The empirical model and variable specification}

To investigate the effects of FDI inflows into China on FDI inflows into other Asian developing economies, we add FDI inflows from all source countries into China - denoted as FDICHN - as an independent variable into the equation.

There are at least two aspects that need to be considered here. First, in examining in which low-wage export platform to locate, MNEs can choose between investing in China versus investing in another developing Asian economy. In this case, the MNEs will study all the factors that will make an economy desirable as a site for low-cost production. Investing in China will then reduce the FDI inflows into another Asian developing economy. The sign of FDICHN, according to this argument, is negative. We call this the 'investment-diversion effect'.

The second aspects are the production and resource linkages between a growing China and the other Asian developing economies. In manufacturing, this takes the form of further specialisation and growing fragmentation of the production processes. An investor sets up factories in both China and another Asian developing economy to take advantage of their respective competitiveness in distinct stages of the production process. Components and parts are then traded among China and other Asian developing economies. An increase in FDI inflows into China is then positively related to an increase in FDI inflows into other Asian developing economies. A different but complementary argument is that as China grows, its market size increases and its demand for minerals and resources rises accordingly. Subsequently, MNEs rush into China to produce and to sell in China. At the same time, other MNEs also invest in other Asian developing economies to extract minerals and resources to export to China. This line of reasoning leads to the prediction that the sign of FDICHN will be positive. We call this the 'investment-creation effect'. Theoretically, we cannot determine $a$ priori the net effect of investment creation and investment diversion for China. It is thus important to examine this issue empirically.

To investigate the China effect on FDI inflows into other Asian developing economies, we use Equation 11.3 as the empirical model. 


\section{Equation 11.3}

$\operatorname{lnFDI} *_{\mathrm{j}, \mathrm{t}}=\beta_{0}+\beta_{1} \ln \mathrm{FDICHN}_{* \mathrm{t}-\mathrm{k}}+\beta_{2} \ln \mathrm{WFDIOUT}_{\mathrm{t}}+\beta_{3} \operatorname{lnGR}_{\mathrm{j}, \mathrm{t}-\mathrm{k}}+\beta 4 \ln \mathrm{LW} \mathrm{j, \textrm {t } - \mathrm { k }}$ $+\beta 5 \operatorname{lnCDR} \mathrm{R}_{\mathrm{j}, \mathrm{t}-\mathrm{k}}+\mathrm{v}_{\mathrm{j}}+\varepsilon_{\mathrm{j}, \mathrm{t}}$

The dependent variable, denoted as $\mathrm{FDI}^{*} \mathrm{j}, \mathrm{t}$, is the aggregate inflow of FDI from all source countries into Asian developing host economy $\mathrm{j}$ in year t. The value of FDI - and all the relevant following variables - is measured in constant 1990 US dollar prices. There are five independent variables. The independent variables of GR, EW and CDR are hypothesised and defined in the above section. We include the world total FDI outflows (WFDIOUT) as an independent variable to control the aggregate supply-side effect of FDI on FDI inflows into Asian developing host economies. The dependent and independent variables are summarised in Appendix Table 11.1.

The independent variables, except WFDIOUT, are lagged $\mathrm{k}$ years. This model assumes that the effect of the independent variables at time t-k appears only within period $\mathrm{t}$ and is fully completed within that period. The relationship shown in Equation 11.3 will be examined for $\mathrm{k}=1$ - the most likely appropriate lag. The independent variable WFDIOUT, which is world total FDI outflows, is determined by the source-side factors and is independent from host-economy determinants; therefore, the current value $(\mathrm{k}=0)$ will be employed in the regression equation. The estimated coefficients of $\operatorname{lnFDICHN}{ }^{t}-\mathrm{k}, \ln \mathrm{WFDIOUT}^{*}{ }_{\mathrm{t}}$,

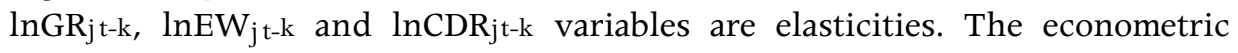
regression analysis below uses panel data and a fixed-effects model in order to eliminate the economy-specific and time-invariant factors that could affect FDI inflows.

\section{Regression results and explanations}

In this empirical study, there are 12 Asian developing economies in the sample and the time period is from 1992 to 2008. The 12 economies are Bangladesh, Hong Kong, India, Indonesia, Malaysia, Pakistan, the Philippines, Singapore, South Korea, Sri Lanka, Taiwan and Thailand. The fixed-effects regression results are reported in column 1 of Table 11.A1. The model fits the data well. All the independent variables have the expected signs and are statistically significant.

As a robustness check, the regression is also run without the four South Asian developing economies: Bangladesh, India, Pakistan and Sri Lanka. The regression results remain very similar to those with the four South Asian developing economies in the sample and are reported in column 2 of Table 11.1. The model performs well: the independent variables have the expected signs and, except for the variable GR, are statistically significant. 
Our main variable of interest, FDICHN, is positive and highly significant in both regressions. A 10 per cent increase in the FDI inflows into China would raise FDI inflows into the East, South and South-East Asian economies by about 4.8 per cent. Despite considerable concerns that an increase in FDI inflows into China has been at the expense of other Asian economies, this suggests that flows into those economies have increased as a result of DFI flows to China during the period of analysis.

Table 11.1 Regression results of the effects of FDI inflows into China on FDI inflows into East, South and South-East Asian developing economies, 1992-2008, fixed-effects (dependent variable FDI*j, t)

\begin{tabular}{lcc}
\hline Variables & $(1)$ & $(2)$ \\
\hline Constant & -7.61 & -12.84 \\
LFDICHN & $(-1.72)^{*}$ & $(1.96)^{*}$ \\
& 0.48 & 0.47 \\
LWOFDI & $(2.73)^{* * *}$ & $(2.44)^{* *}$ \\
& 0.23 & 0.21 \\
LGR & $(4.33)^{* * *}$ & $(3.07)^{* * *}$ \\
& 0.48 & 0.36 \\
LEW & $(2.17)^{* *}$ & $(1.24)$ \\
& -1.00 & -1.02 \\
LCDR & $(-2.40)^{* *}$ & $(-2.02)^{* *}$ \\
& 2.42 & 3.86 \\
No. of observations & $(2.42)^{* *}$ & $(2.15)^{* *}$ \\
No. of groups & 170 & 108 \\
R2: within & 12 & 8 \\
between & 0.54 & 0.43 \\
overall & 0.82 & 0.42 \\
F-statistics & 0.76 & 0.40 \\
\hline
\end{tabular}

* statistically significant at 0.10 level (two-tail test)

** statistically significant at 0.05 level (two-tail test)

${ }^{* * *}$ statistically significant at 0.01 level (two-tail test)

Notes: Standard errors adjusted for clustering on group; t-statistics are in parentheses.

The observed relationship could be linked to the increased resource demand by a rapidly growing Chinese economy and the production-networking activities among the Asian economies. As Table 11.2 shows, Asian economies have become increasingly important suppliers of China's growing demand for raw materials. For some resources, the Asian economies are the major suppliers to China - for example, Indonesia and Malaysia for animal, vegetable fats and oils, Taiwan, India and Pakistan for textiles and India, Indonesia and South Korea for mineral products. Therefore, China's fast economic growth associated with high demand for raw materials could generate great opportunities for MNEs to conduct resource-based FDI in Asian economies. 
Table 11.2 China's imports of raw materials from Asian economies (US\$ million)

\begin{tabular}{|c|c|c|c|c|}
\hline & 1995 & 2000 & 2005 & 2008 \\
\hline \multicolumn{5}{|l|}{ All 12 Asian economies } \\
\hline Animal, vegetable fats and oils (HS 15) & $\begin{array}{l}954 \\
(36)\end{array}$ & $\begin{array}{l}804 \\
(67)\end{array}$ & $\begin{array}{c}2131 \\
(64)\end{array}$ & $\begin{array}{l}7092 \\
(63)\end{array}$ \\
\hline Mineral products (HS 25, 26, 27) & $\begin{array}{c}2958 \\
(41)\end{array}$ & $\begin{array}{l}5614 \\
(23)\end{array}$ & $\begin{array}{c}16433 \\
(18)\end{array}$ & $\begin{array}{c}43072 \\
(17)\end{array}$ \\
\hline \multirow{2}{*}{$\begin{array}{l}\text { Pulp of wood and paper products } \\
\text { (HS } 47,48 \text { ) } \\
\text { Textiles (HS 52, 54, 55) }\end{array}$} & $\begin{array}{l}1367 \\
(43)\end{array}$ & $\begin{array}{l}2684 \\
(40)\end{array}$ & $\begin{array}{c}2386 \\
(23)\end{array}$ & $\begin{array}{l}2495 \\
(15)\end{array}$ \\
\hline & $\begin{array}{c}5290 \\
(53)\end{array}$ & $\begin{array}{c}5893 \\
(62)\end{array}$ & $\begin{array}{c}5932 \\
(42)\end{array}$ & $\begin{array}{l}5830 \\
(43)\end{array}$ \\
\hline \multicolumn{5}{|l|}{ Indonesia } \\
\hline $\begin{array}{l}\text { Animal and vegetable fats } \\
\text { (HS 15) }\end{array}$ & $\begin{array}{l}70 \\
(3)\end{array}$ & $\begin{array}{l}245 \\
(21)\end{array}$ & $\begin{array}{l}749 \\
(23)\end{array}$ & $\begin{array}{c}2482 \\
(22)\end{array}$ \\
\hline Mineral products & 766 & 1104 & 2282 & 5269 \\
\hline (HS 25, 26, 27) & (11) & (5) & $(2.5)$ & $(2)$ \\
\hline Pulp of wood and paper products & 180 & 928 & 893 & 1068 \\
\hline (HS 47, 48) & (6) & $(14)$ & (8) & (7) \\
\hline \multicolumn{5}{|l|}{ Malaysia } \\
\hline $\begin{array}{l}\text { Animal and vegetable fats } \\
\text { (HS 15) }\end{array}$ & $\begin{array}{l}732 \\
(28)\end{array}$ & $\begin{array}{l}471 \\
(39)\end{array}$ & $\begin{array}{l}1271 \\
(38)\end{array}$ & $\begin{array}{l}4084 \\
(36)\end{array}$ \\
\hline \multicolumn{5}{|l|}{ Singapore } \\
\hline Mineral products (HS 27) & $\begin{array}{l}1123 \\
(24)\end{array}$ & $\begin{array}{c}852 \\
(4)\end{array}$ & $\begin{array}{l}2206 \\
(3)\end{array}$ & $\begin{array}{l}4325 \\
(3)\end{array}$ \\
\hline \multicolumn{5}{|l|}{ South Korea } \\
\hline Mineral products (HS 27) & $\begin{array}{l}398 \\
(8)\end{array}$ & $\begin{array}{c}2016 \\
(10)\end{array}$ & $\begin{array}{c}3506 \\
(6)\end{array}$ & $\begin{array}{c}9945 \\
(6)\end{array}$ \\
\hline \multicolumn{5}{|l|}{ Taiwan } \\
\hline Textiles (HS 54) & $\begin{array}{c}1046 \\
(31)\end{array}$ & $\begin{array}{l}1268 \\
(35)\end{array}$ & $\begin{array}{l}1359 \\
(36)\end{array}$ & $\begin{array}{l}1120 \\
(31)\end{array}$ \\
\hline \multicolumn{5}{|l|}{ Thailand } \\
\hline Mineral products (HS 27) & $\begin{array}{c}7.6 \\
(0.2)\end{array}$ & $\begin{array}{l}383 \\
(2)\end{array}$ & $\begin{array}{l}806 \\
(1)\end{array}$ & $\begin{array}{l}1803 \\
(1)\end{array}$ \\
\hline \multicolumn{5}{|l|}{ India } \\
\hline Mineral products (HS 26) & 153 & 373 & 5509 & 14314 \\
\hline Textiles (HS 52) & (8) & $(12)$ & $(21)$ & $(17)$ \\
\hline & 24 & 186 & 275 & 1130 \\
\hline & (1) & (7) & (4) & (15) \\
\hline \multicolumn{5}{|l|}{ Pakistan } \\
\hline Textiles (HS 52) & $\begin{array}{l}173 \\
(5)\end{array}$ & $\begin{array}{l}398 \\
(14)\end{array}$ & $\begin{array}{l}581 \\
(8)\end{array}$ & $\begin{array}{l}599 \\
(8)\end{array}$ \\
\hline
\end{tabular}

Notes: Figures in parentheses are shares in China's total imports of the commodities. HS $15=$ animal, vegetable fats and oils, cleavage products, and so on; HS $25=$ salt, sulphur, earth, stone, plaster, lime and cement; HS 26 = ores, slag and ash; HS 27 = mineral fuels, oils, distillation products, and so on; HS $47=$ pulp of wood, fibrous cellulosic material, waste, and so on; HS 48 = paper and paperboard, articles of pulp, paper and board; HS 52 = cotton; HS 54 = manmade filaments; HS 55 = manmade staple fibres.

Source: Author's calculations using data from United Nations Statistics Division n.d., COMTRADE, Commodity Trade Statistics Database, United Nations, New York and Geneva, <http://unstats.un.org/ unsd/comtrade/default.aspx>

The evidence of production networking among China and other Asian economies can be found in the substantial two-way trade in intermediate and final goods 
in the same industries among those economies. Many of the Asian economiesparticularly those in East and South-East Asia-are heavily involved in vertical specialisation, particularly in the industries of electronics equipment (HS 85). As shown in Table 11.3, the value and shares of two-way trade in the electronic equipment industries between China and Asian economies have been substantial. The economic ties of mutual dependence among them have been deepening rapidly since the 1990s. The significance of the China effect in the level of FDI inflows into Asian economies could reflect such interdependence.

It is impossible to ascertain from the above regression results whether the China effect is driven primarily by resource demand or by production networking; this remains a topic for further research. The central result, however, still holds: an increase in FDI inflows into China is positively and significantly related to FDI inflows into other Asian economies. In other words, in recent decades, the investment-creation effect has dominated the investment-diversion effect, so Chinese and Asian FDI inflows have been complementary.

As for the location variables, the regression results provide strong support for the hypotheses. The market growth rate (GR) is a positive and statistically significant location determinant in affecting the magnitude of FDI inflows into Asian economies, with the results implying that the higher and faster the growth of an economy, the higher will be the level of FDI inflows.

A host economy's efficiency wage (EW) - the proxy for labour cost - is a negative statistically significant determinant of the magnitude of FDI inflows that a country receives. This indicates that FDI is responsive to differences in efficiency wages across Asian economies. It also reveals that taking advantage of Asian economies' cheap labour is one of the main motives for foreign investors in Asian developing economies.

A country's credit rating (CDR) is found to exert a large influence on the magnitude of FDI inflows into Asian economies. Economic, financial, institutional, social and political stabilities with high creditworthiness can be considered the most influential tools to promote FDI since they have a direct impact on the security and profitability of FDI projects.

Finally, the variable of world total FDI outflows (WFDIOUT) is positive and statistically significant. This signifies the impact of an overall supply-side effect on the inflows of FDI to Asian economies.

It is also interesting to note that, although FDI inflows into China have a positive and statistically significant effect on FDI inflows into other Asian economies, the China effect is not the most important factor determining FDI inflows into these Asian economies. The empirical regression results suggest that, all else being equal, the marginal effect of the host economies' location variables on FDI inflows into their economies is much larger than that of the china effect. 
The marginal effect of the efficiency wage is approximately two times and the country credit rating is five to eight times as large as that of the China effect, respectively.

Table 11.3 Two-way trade between China and Asian economies in electric and electronic equipment industries (HS 85)

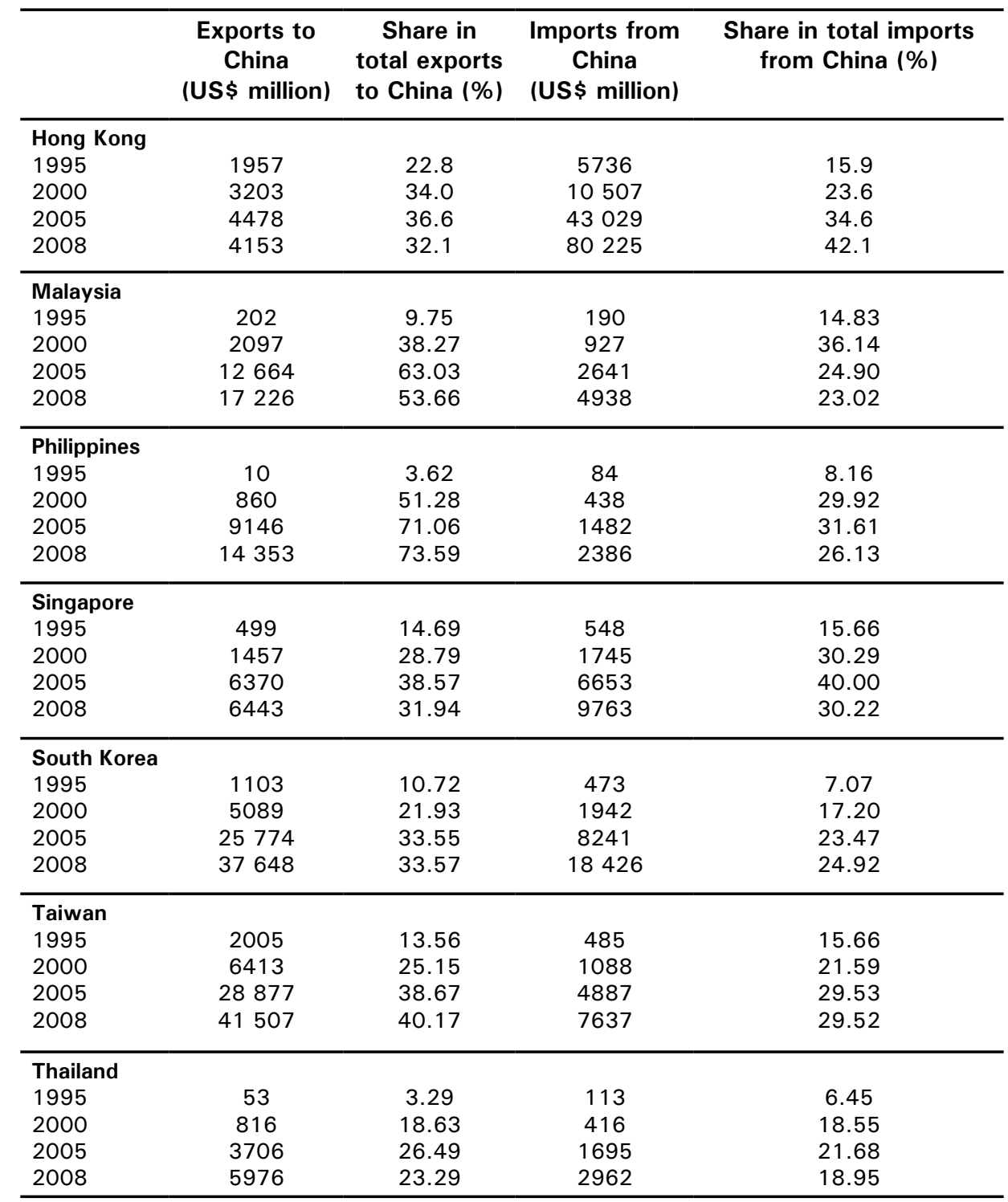

Source: Author's calculations using data from United Nations Statistics Division n.d., COMTRADE, Commodity Trade Statistics Database, United Nations, New York and Geneva, <http://unstats.un.org/

unsd/comtrade/default.aspx> 


\section{Implications for future FDI inflows into China and Asian economies}

The results in the previous section imply that the positive impact of the China effect on FDI inflows into Asian economies could be linked to the increased resource demand by a rapidly growing Chinese economy and the productionnetworking activities among the Asian economies. These two channels generating the positive China effect on FDI inflows into the Asian economiesespecially into the Association of South-East Asian Nations (ASEAN) - will be strengthened in the next two decades.

First, with the creation and implementation of the ASEAN-China Free Trade Area (ACFTA) on 1 January 2010, the economic relationship between ASEAN and China entered a new era. The ACFTA covers agreements on trade in goods and services and investment, which will accelerate and intensify the economic integration and result in rapid development and expansion in trade and investment between ASEAN and China. Apart from the ACFTA, China has bilateral free-trade agreements with a number of Asian economies, including Pakistan, Thailand, Singapore, Hong Kong and Macao, and is proposing to negotiate bilateral free-trade agreements with India, South Korea and Taiwan. The reduction and elimination of barriers to trade and investment - to the extent that preferential trading agreements actually have this effect - will not only lead to an expansion of trade and investment among China and other Asian economies, it will create investment opportunities for third parties to invest in Asia - in China and elsewhere - in order to get into and take advantage of the enlarged Asian free-trade areas.

Second, one of the major driving forces behind the economic integration of the Asian economies is the fast growth of the Chinese economy. China's economic growth and strong investment expansion are energising the region and providing the Asian economies with an expanding and diversified market. According to a report by the Cabinet Office of the Japanese Government (NIKKEI.com 2010), the Chinese economy is predicted to grow 9.1 per cent annually in the decade from 2010 and 7.9 per cent annually in the 2020s. As a result, China is expected to generate 23.9 per cent of the world's GDP in 2030-becoming the largest economy in the world. The fast growth of the Chinese economy will continue to have a substantial impact on the Asian economies. On the one hand, as China's economy grows, it will increase the demand for consumer goods as the income of the Chinese people increases. On the other hand, China's rapid growth will also increase demand for resources and raw materials to support the continuing expansion of production. Both will generate great opportunities not only for 
Asian economies to increase exports to the Chinese markets, but for MNEs to invest in Asian economies in order to produce goods and extract resources to supply the Chinese markets.

Third, with the fast and deep integration among the Chinese and other Asian economies, production-networking activities-particularly in vertical specialisation - will intensify with each of the economies specialising in the production of those goods in which it has a comparative advantage. Currently, China and other Asian economies have already developed substantial two-way trade in the electric and electronic equipment industries. In the years ahead, with the upgrading and restructuring of the industrial structures in China and Asian economies, it is highly likely that the two-way trade between China and other Asian economies will expand into other industries - for example, automobiles and machinery and equipment. This structural change and upgrading of industries throughout Asia will provide huge opportunities for MNEs to invest in China and other Asian economies based on their comparative advantages and competitiveness.

Fourth, with rapid economic growth, a high rate of capital accumulation and a huge accumulation of foreign reserves, China has gradually become an increasingly important supplier of outward FDI. During the period 2004-08, China's outward FDI increased from US\$5.5 billion to US\$55.9 billionincreasing more than nine times. Most of China's outward FDI flowed into Asian economies - accounting for 71.4 per cent of China's total outward FDI stock at the end of 2008. With rapid economic growth, the next two decades will witness a rapid increase in FDI outflows from China. On the one hand, China will accelerate industrial restructuring and upgrading. Some labour-intensive manufacturing activities and industries will gradually lose competitiveness due to the combined effects of increasing labour costs and shrinking labour forces with an ageing population. As a result, these labour-intensive industries will move out of China and invest in other economies, with other Asian developing economies the most likely candidates. On the other hand, China's rapid economic growth will continue to increase the demand for resources and raw materials. To meet this demand, China will increase investment overseas to expand and secure the supply of resources and raw materials. Asian economies with rich resource endowments will be the primary destinations for China's outward investment, with China becoming an increasingly important investor in Asia as a consequence. Overall, then, the relationship between China and Asian economies in terms of FDI is likely to remain complementary in the next 20 years. 


\section{Conclusions}

The vast volume of FDI inflows into China in the past three decades has been a source of celebration for some and of concern for others. Has China really crowded out FDI inflows into other Asian economies or has it been more of a win-win story? This chapter has built on an extensive literature seeking to answer this question by conducting an empirical analysis to test the hypotheses based on the location advantages of the OLI explanation of FDI. The three main findings can be summarised as follows.

First, for the location determinants of FDI inflows into Asian developing economies, the regression results provided strong support for the acceptance of our hypotheses. The main findings are: economies with faster economic growth, higher creditworthiness or lower country risk in terms of economic, financial, institutional, social and political stability attracted relatively more FDI inflows, while higher efficiency wages or lower labour productivity deterred FDI inflows during the period of analysis: 1992-2008.

Second, the regression results have shown that FDI inflows into China have a statistically significant positive effect on FDI inflows into other Asian economies. This positive and complementary effect of FDI inflows into China on FDI inflows into other Asian economies could be linked to the increased resource demand in a growing China and the production-networking activities among the Asian economies. While the results did not allow the relative strength of these two linkages to be determined, it is likely that this positive China effect stems from a combination of both, leading to the central result that this effect is about investment creation, not investment diversion. This complementarity implies that much of the concern about Chinese FDI is unfounded.

Third, although FDI inflows into China have had a positive and statistically significant impact on FDI inflows into other Asian economies, the China effect is not the most important factor determining FDI inflows into the Asian economies. The empirical regression results suggest that, all else being equal, the marginal effect of the host economies' location variables on FDI inflows into their economies is much larger than that of the China effect. Host economies' location variables - such as fast economic growth, lower labour costs accompanied with higher labour productivity, lower country risk with economic, financial, institutional, social and political stability-play the fundamental role in attracting FDI inflows.

In the next two decades, China's economic growth and strong investment expansion will energise the region and will provide the Asian economies and other countries with an expanding and diversified integrated Asian market. 
Overall, with the rapid and deepening integration among the Chinese and other Asian economies, the positive China effect on FDI inflows into other Asian economies will continue.

\section{References}

Chantasasawat, B., Fung, K., Iizaka, H. and Siu, A. 2004, Foreign direct investment in China and East Asia, Hong Kong Institute of Economics and Business Strategy, viewed 30 May 2010, <http://www.hiebs.hku.hk/working_paper_ updates/pdf/wp1 135.pdf>

Cravino, J., Lederman, D. and Olarreaga, M. 2007, Foreign direct investment in Latin America during the emergence of China and India: stylized facts, Policy Research Working Paper 4360, The World Bank, Washington, DC, viewed 30 May 2010, <http://ideas.repec.org/p/wbk/wbrwps/4360.html>

Dunning, J. 1993, Multinational Enterprises and the Global Economy, AddisonWesley, Wokingham, UK.

Eichengreen, B. and Tong, H. 2005, Is China's FDI coming at the expense of other countries?, NBER Working Paper 11335, National Bureau of Economic Research, Cambridge, Mass., viewed 30 May 2010, <http://www.nber.org/ papers/w11335>

International Labour Organization (ILO) n.d., LABORSTA, International Labour Organization, Geneva, <http://laborsta.ilo.org/>

Lucas, R. 1993, 'On the determinants of direct foreign investment: evidence from East and Southeast Asia', World Development, vol. 21, no. 3, pp. 391-406.

Mercereau, B. 2005, FDI flows to Asia: did the dragon crowd out the tigers?, IMF Working Paper, WP/05/189, September 2005, International Monetary Fund, Washington, DC, viewed 30 May 2010, <http://zunia.org/uploads/media/ knowledge/wp051891.pdf>

National Bureau of Statistics (NBS) various years, China Statistical Yearbook, China Statistics Press, Beijing.

NIKKEI.com 2010, 'China's GDP 4 times Japan's in '30: govt', The Nikkei, 29 May, Morning edition, viewed 1 June 2010, <http://e.nikkei.com/e/fr/tnks/ Nni20100528D28JFA12.htm> 
Resmini, L. and Siedschlag, I. 2008, Is FDI into China crowding out the FDI into the European Union?, Working Paper, European Trade Study Group, Johannes Kepler University, Linz, and University of Strathclyde, viewed 30 May 2010, <http://www.etsg.org/ETSG2008/Papers/Siedschlag.pdf>

Singh, H. and Jun, K. W. 1995, Some new evidence on determinants of foreign direct investment in developing countries, Policy Research Working Paper, no. 1531, The World Bank, Washington, DC, viewed 30 May 2010, <http://ideas. repec.org/p/wbk/wbrwps/1531.html>

United Nations Conference on Trade and Development (UNCTAD) various years, World Investment Report, United Nations, New York and Geneva.

United Nations Statistics Division n.d., COMTRADE, Commodity Trade Statistics Database, United Nations, New York and Geneva, < http://unstats. un.org/unsd/comtrade/default.aspx>

United Nations Statistical Division n.d., National Accounts, United Nations, New York and Geneva, <http://unstats.un.org/unsd/snaama/dnllist.asp>

Wang, C., Wei, Y. and Liu, X. 2007, 'Does China rival its neighbouring economies for inward FDI', Transnational Corporation, vol. 16, no. 3, pp. 35-60.

Zhou, Y. and Lall, S. 2005, 'The impact of China's surge on FDI in South-East Asia: panel data analysis for 1986-2001', Transnational Corporation, vol. 14, no. 1 , pp. 41-65. 
Appendix Table 11.A1 Variable list of the impact of FDI inflows into China on FDI inflows into other Asian developing host economies

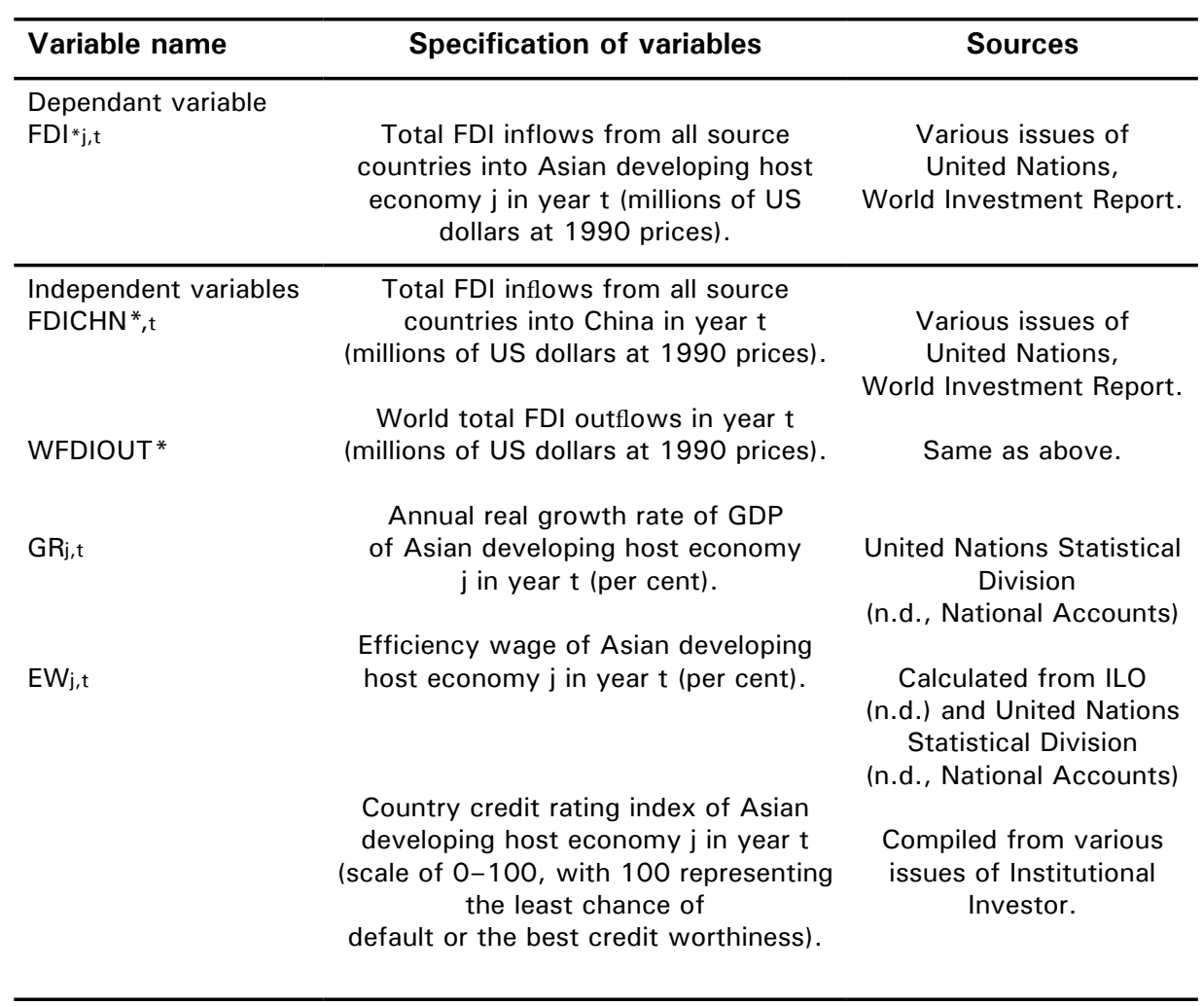





\title{
The global financial crisis and rural-urban migration
}

\author{
Sherry Tao Kong, Xin Meng \\ and Dandan Zhang
}

\section{Introduction}

Since the second half of 2008, the global financial crisis (GFC) reduced export orders sharply and led to a decline in China's economic growth. As China's exporting industries are labour intensive and most likely to employ rural migrants, it is widely believed that the global financial crisis has had significant negative impacts on the employment and/or wages of rural migrants. At the height of the crisis, laid-off Chinese migrant workers protested outside closed factories and millions lamented lost jobs and embarked on journeys home much earlier than the usual Chinese New Year visit. Many were apprehensive, worrying that the worst was yet to come. At that time, policymakers and academics alike were convinced there would be a significant, adverse labour-market adjustment for rural migrants (Chen 2009; NBS 2009; Kong et al. 2009). In last year's China Update volume, we estimated that the total employment impact of the global financial crisis was between 13 and 19 per cent. We also emphasised, however, that the adverse shock to employment was in fact the joint outcome of the global financial crisis and China's domestic policy stance - most prominently, the contractionary macroeconomic policy and the implementation of the New Labour Contract Law (Kong et al. 2009).

With the fiscal and monetary expansions in response to the global financial crisis and the gradual recovery of external demand, China bounced back forcefully from a gross domestic product (GDP) growth rate of 6.1 per cent in the year to the first quarter to 7.8 per cent to the second quarter of 2009. By the end of 2009 , the growth rate exceeded the 8 per cent target. Now that the immediate crisis is over, it is time to evaluate how much the global financial crisis has affected migrant labour-market outcomes and whether these effects were short lived or long lasting.

Using the panel surveys of rural-urban migrants and rural households in the Rural-Urban Migration in China and Indonesia (RUMiCI) Project, this chapter 
compares the labour-market outcomes of migrants in cities in 2008 and 2009. Much to our surprise, we observe small employment effects and virtually no reduction in working hours or wages for migrants. We try to understand the logic behind our findings. We find that the real adverse effect of the global financial crisis is felt mainly by the rural sector-to where the unemployed migrant workers from cities returned - and the multiplier effect of the reduction in income of unemployed migrant workers, which suppressed demand in the rural sector, which, in turn, further suppressed rural off-farm jobs. This multiplier effect is very large and has not received attention in the literature before.

The chapter is structured as follows. The next section reviews the literature and hypothesises about the types of labour-market adjustment we might expect to observe. This is followed by a discussion of the data and an examination of labour-market adjustments from the urban and rural labour-market perspectives. The final section concludes the chapter.

\section{Earlier findings and our hypothesis}

There have been two important studies of the impact of the global financial crisis on rural-urban migrants: Kong et al. (2009) and Huang et al. (2010). Using a representative sample of 1200 households in six provinces in rural China, Huang et al. (2010) find that the initial negative impact of the crisis on rural migrants' employment has been significant. They estimate that between September 2008 and April 2009, 17 per cent (up to 45 million) of rural dwellers with off-farm employment either lost their jobs or delayed their move out of the agricultural sector. Farmers, however, adapted to the crisis more quickly than expected. By April 2009, 25 million of those rural workers who initially lost their off-farm jobs had found new positions and by August this number had increased to 32 million. To explain this phenomenon, Huang et al. (2010) suggest that the quick recovery was a result of the improved flexibility of China's labour market and rural workers' willingness to accept lower wages. They estimate that the average monthly earnings of the employed off-farm workers fell by 2.4 per cent-from RMB1086 in 2008 to RMB1062 in January-April 2009.

Two other reports from the Ministry of Human Resources and Social Security of China (MoHRSS) show an even more optimistic picture. A report entitled 'The response of China's employment of rural migrants to the GFC' (MoHRSS 2009) shows that, between the end of 2008 and April 2009, 70 million rural migrants moved from the city back to their home villages, including 20 million rural migrants who lost their jobs in cities due to the global financial crisis. Among the 70 million returning migrants, 95 per cent obtained new employment in 
cities. The unemployment rate for rural migrants in Chinese cities was less than 3 per cent. The total number of rural migrant workers in cities in fact increased from 140 million in 2008 to 150 million in 2009.

The other report (MoHRSS 2010) focuses on the employment situation of migrants in 2009 and is based on a survey conducted in 90 counties throughout 27 provinces in early 2010. The survey interviewed 9081 rural migrants and collected information including their employment situation, wage remuneration, willingness to work in cities and employment expectations. The survey data showed that the average monthly earnings of rural migrants increased by 12.9 per cent from 2008 to 2009, with 6.7 and 11.5 per cent increases for wage/salary earners and the self-employed, respectively.

These studies revealed that for rural migrants, who bore most of the initial brunt of the economic downturn, their employment levels had essentially recovered from the crisis by late 2009. These studies provide conflicting evidence, however, on changes in earnings. In addition, all the above studies are based on surveys conducted at the sending (or migrant-source) areas and on retrospective data, which might not accurately reflectwhat happened to rural migrants in their destination cities. In this chapter, we use consistent surveys of rural households as well as city migrants to re-examine this issue and to paint a more complete picture of the effect of the global financial crisis.

In a modern labour market, a negative economic shock will generate unemployment or depressed wages in the market in which the shock occurs. In a developing economy, however, a demand shock to the 'modern sector' labour market might not be directly detected in that market because of the dual labourmarket structure of the economy. With a dual economic structure, the 'traditional sector' provides a 'fallback' position for most migrant workers. Whenever the wages in the modern sector fall below the reservation wage, workers will move back to the 'traditional sector' provided that the cost of moving is not too high (Lewis 1954; Ranis and Fei 1961). This process happened during the East Asian financial crisis in Indonesia, where millions of workers moved back to the agricultural sector and very little unemployment was detected in the modern sector (Hugo 2000; Manning 2000; Fallon and Lucas 2002).

This relationship between the modern and traditional sectors is even stronger in China for the following reasons. First, migrants often come to cities alone due to the restrictions on welfare access in cities for families and children. Consequently, the cost of returning to rural areas is relatively low. Second, migrants normally do not have unemployment insurance and do not have health or pension insurance in cities. Without a job, it is very hard for them to survive in cities, whereas the agricultural sector provides a subsistence level of welfare (housing and food). The migrants might see this difference between the two 
sectors either as a lower effective urban sector wage or a higher reservation wage set in the traditional sector. The end result is to increase the probability of making a return migration decision. In effect, the only way that migrants can cushion the adverse effects of economic shocks that affect their employment or earnings is to return to rural areas and seek alternative employment.

Considering this special institutional setting of rural-urban migration in China, the effect of any economic shock on migrant labour-market outcomes should be examined from two directions. First, when economic shocks come, many affected migrant workers move back to rural hometowns where they find offfarm jobs or become underemployed farmers, which, in turn, could suppress agricultural productivity. Second, for those affected migrants who are unwilling to move back to their rural hometowns, we could observe an increase in open unemployment, shifting to informal employment or a reduction in wage rates.

Thus, to provide a more complete picture of the effect of the global financial crisis on migrant workers, we examine urban and rural labour markets using survey data for sending rural regions and receiving urban cities from the RUMiCI surveys of 2008 and 2009. Given the 'buffer' role that the rural sector plays, we expect that most of the impact of the global financial crisis is felt by the rural sector.

\section{Data}

The RUMiCI survey started in 2008. The sampling strategy and survey instruments can be found on the Internet (<http://rumici.anu.edu.au $>$ ). The uniqueness of the survey in China is that it surveys three groups of households: 5000 rural-urban migrant households who worked in 15 designated cities (migrant survey); 5000 urban households in the same cities ${ }^{1}$ (urban survey); and 8000 rural households from nine provinces where the 15 cities are located (rural survey). RUMiCI was designed to be a panel survey and the second wave was conducted in 2009.

Due to the high mobility of rural migrants (especially during the economic downturn), the attrition rate for the migrant sample is extremely high (about 60 per cent). Thus, in 2009, in addition to the 40 per cent of tracked households, a group of new households was randomly selected based on the same sampling frame and added into the second wave of the survey. As a result, the urban migrant sample in 2009 contains 40 per cent of the households sampled in 2008

\footnotetext{
1 The urban survey covers all 15 cities included in the migrant survey plus four additional cities. Thus, we have a total of 19 cities for the urban survey.
} 
that were successfully tracked in 2009 (that is, the panel) and 60 per cent of households newly sampled in 2009. In contrast, the attrition rates for rural and urban resident households are much lower (below 10 per cent).

We believe the impact of the global financial crisis was concentrated from the second half of 2008 to the first half of 2009. The two waves of RUMiCI data cover the period before and during this period. The migrant survey in 2008 started in March and ended in June. About 93 per cent of interviews were finished by the end of May. The survey in 2009 was conducted over six months starting from March and ending in August, with 73 per cent of households interviewed by the end of May (see Appendix Table 12.Al for a distribution of survey times in the two years). The rural household survey was conducted between March and May 2008 and April and June 2009. Thus, we use the 2008 data to indicate the pre-global financial crisis situation while using 2009 data to indicate the global financial crisis period. A comparison between the two survey years will enable us to identify changes in migrant labour-market outcomes before and during the crisis.

Here we focus on individuals who are aged sixteen to sixty-five and are in the labour market. ${ }^{2}$ The total number of observations in our migrant sample is 7153 and 7567 for the first and second waves, respectively. The number of observations for the rural sample is 20451 and 20408 for the two waves, respectively. Note that in the rural survey, all household members are reported in the survey, including those who were not present at the time of the survey. For individuals who were not present at the time of the survey, other household members who were present reported their information. In most cases, the respondent was the household head. We are therefore able to examine the difference in characteristics between current migrants and non-migrants from the rural survey. The data for migrants could suffer, however, from larger measurement errors. Due to this inaccuracy, it is important to complement the information on migrant workers from their rural origin with information collected from the migrants themselves in the cities. Table 12.1 presents the summary statistics of the basic demographic characteristics of the two samples for both waves.

On average, the migrant sample is 31.3 years of age in 2008 and increased by about one year to 32.2 in 2009. About 58 per cent are males, and the proportions who are married or cohabitate are 63 and 66 per cent for the two years, respectively. The average years of schooling are about nine years and slightly higher $(0.17$ years) for the 2009 sample. This increase seems to come from the slightly higher proportion of senior high school graduates in the sample for 2009.

2 An individual is defined to be in the labour force if he/she is between sixteen and sixty-five years of age and is stated to be currently working (including re-employed retired people), an unpaid family worker, unemployed or waiting to be assigned to a job. This definition applies to migrant and rural samples. 
China: The Next Twenty Years of Reform and Development

Table 12.1 Summary statistics for migrant and rural samples

\begin{tabular}{|c|c|c|c|c|c|c|c|c|}
\hline & \multirow{2}{*}{\multicolumn{2}{|c|}{ Migrant sample }} & \multicolumn{6}{|c|}{ Rural sample } \\
\hline & & & \multicolumn{2}{|c|}{$\begin{array}{c}\text { Total } \\
\text { sample }\end{array}$} & \multicolumn{2}{|c|}{$\begin{array}{l}\text { Migrant } \\
\text { sample }\end{array}$} & \multicolumn{2}{|c|}{$\begin{array}{l}\text { Non-migrant } \\
\text { sample }\end{array}$} \\
\hline & 2008 & 2009 & 2008 & 2009 & 2008 & 2009 & 2008 & 2009 \\
\hline Age & 31.3 & 32.2 & 40.0 & 40.6 & 29.3 & 29.8 & 42.9 & 43.3 \\
\hline $\begin{array}{l}\text { Percentage } \\
\text { of males }\end{array}$ & 58.3 & 57.9 & 53.9 & 52.8 & 61.8 & 60.6 & 51.8 & 50.8 \\
\hline \multicolumn{9}{|c|}{ Marital status (\%): } \\
\hline $\begin{array}{l}\text { First } \\
\text { marriage }\end{array}$ & 62.0 & 63.9 & 77.2 & 77.3 & 54.9 & 55.8 & 83.2 & 82.7 \\
\hline $\begin{array}{l}\text { Second } \\
\text { marriage }\end{array}$ & 0.8 & 0.9 & 2.2 & 2.8 & 1.5 & 1.8 & 2.3 & 3.0 \\
\hline Cohabitation & 0.3 & 0.7 & 0.4 & 0.4 & 0.1 & 0.4 & 0.5 & 0.4 \\
\hline Divorced & 1.0 & 1.2 & 0.4 & 0.5 & 0.6 & 0.7 & 0.3 & 0.4 \\
\hline Widowed & 0.4 & 0.6 & 1.0 & 1.0 & 0.3 & 0.1 & 1.2 & 1.3 \\
\hline Single & 35.4 & 32.7 & 18.8 & 18.0 & 42.5 & 41.3 & 12.4 & 12.2 \\
\hline $\begin{array}{l}\text { Years of } \\
\text { schooling }\end{array}$ & 9.1 & 9.2 & 7.5 & 7.5 & 8.5 & 8.5 & 7.2 & 7.2 \\
\hline \multicolumn{9}{|c|}{ Level of schooling (\%): } \\
\hline Illiterate & 2.1 & 4.0 & 4.9 & 4.9 & 0.7 & 0.8 & 6.1 & 6.0 \\
\hline $\begin{array}{l}\text { Primary } \\
\text { school }\end{array}$ & 12.9 & 12.1 & 17.6 & 17.7 & 7.6 & 7.4 & 20.3 & 20.3 \\
\hline $\begin{array}{l}\text { Junior high } \\
\text { school }\end{array}$ & 55.6 & 49.7 & 63.9 & 63.4 & 75.0 & 74.9 & 60.9 & 60.5 \\
\hline $\begin{array}{l}\text { Senior high } \\
\text { school }\end{array}$ & 25.5 & 27.6 & 13.5 & 13.9 & 16.7 & 16.8 & 12.7 & 13.1 \\
\hline $\begin{array}{l}\text { Post- } \\
\text { secondary }\end{array}$ & 4.0 & 6.6 & 0.0 & 0.0 & 0.0 & 0.1 & 0.0 & 0.0 \\
\hline $\begin{array}{l}\text { Total no. of } \\
\text { observations }\end{array}$ & 7153 & 7563 & 20451 & 20408 & 4317 & 4110 & 16134 & 16298 \\
\hline
\end{tabular}

Source: Authors' own survey.

Compared with the migrant sample surveyed in urban cities, the rural total labour force (including migrants and non-migrants) is much older. On average, they were forty and forty-one years of age in 2008 and 2009, respectively. Consistent with the migrant survey, the average age of the migrant population is about thirty years, while the non-migrant sample is much older (about fortythree). This age differential indicates that young people are more likely than older people to migrate. We present the age distributions from different samples in Figure 12.1, where it is clearly indicated that migrants are more concentrated in the twenty-thirty age group, whereas non-migrants are more concentrated in the late-thirty to fifty age group. 
Figure 12.1 Age distribution of the sample from the migrant and rural surveys
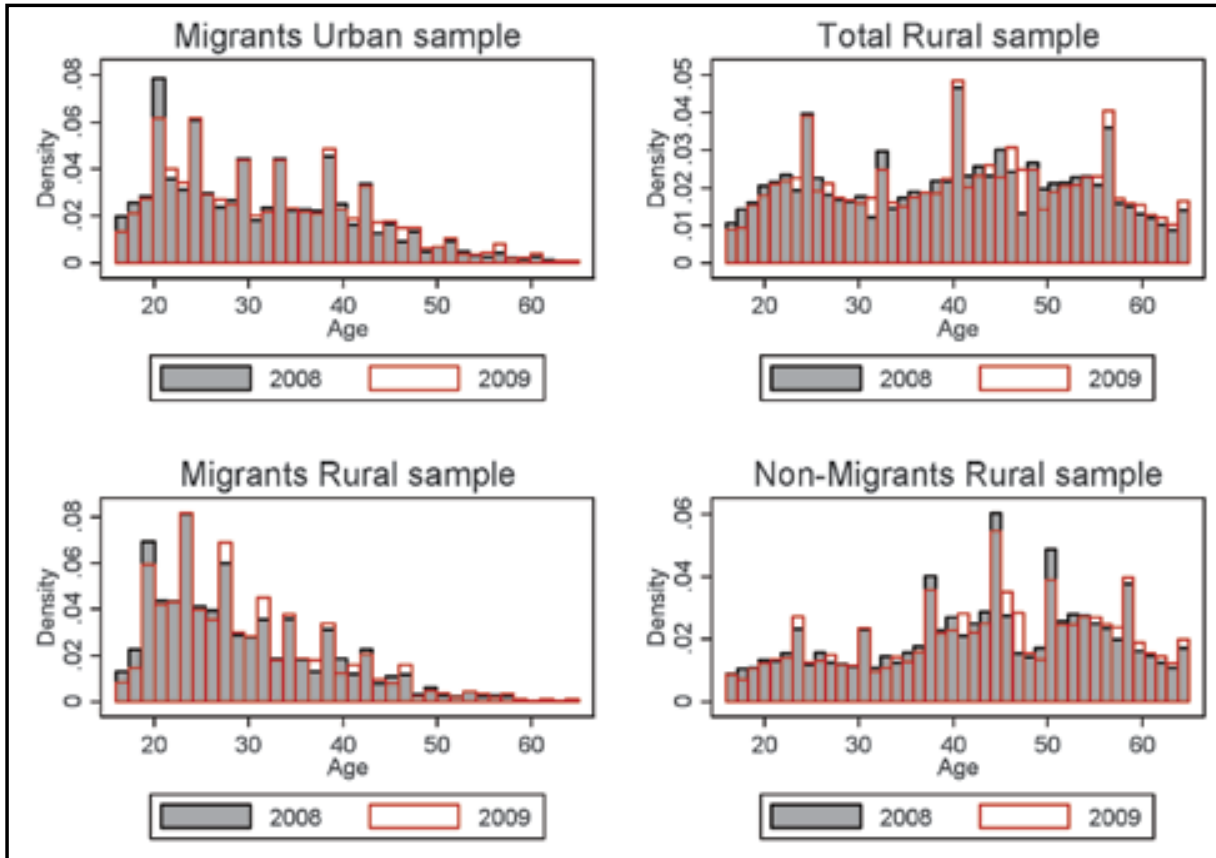

Source: Authors' own survey.

Migrants are also most likely to be males. In the total rural sample, about 53-54 per cent are males, while for the migrant sample the proportion is about 58 per cent; and for migrants in the rural sample it is even higher at about 61 per cent. Migrants are also more likely to be singles and divorcees. Finally, migrants are better educated than those who are non-migrants.

\section{The effect of the global financial crisis on labour-market outcomes: urban perspective}

In this section, we investigate the extent to which the global financial crisis affected the employment and wages of rural-urban migrants who stayed in cities during 2009.

Table 12.2 presents summary statistics of employment and wages for the two years as well as the differences in outcomes between the two years. The first panel of Table 12.2 shows that the employment rate for the total sample fell from 98.7 in 2008 to 96.6 in 2009 - that is, an increase in the unemployment rate by 2.1 percentage points. If we look at the panel sample, the increase in the unemployment rate is marginally higher-at 2.7 percentage points. Considering the huge reduction in exports during 2009, this increase in unemployment looks rather trivial. 
China: The Next Twenty Years of Reform and Development

Table 12.2 Employment and earnings of migrants in cities (migrant sample)

\begin{tabular}{|c|c|c|c|c|c|c|c|}
\hline & \multicolumn{3}{|c|}{ Total sample } & \multicolumn{3}{|c|}{ Panel sample } \\
\hline & & 2008 & 2009 & Difference & 2008 & 2009 & Difference \\
\hline \multirow{6}{*}{$\begin{array}{l}\text { Panel } \\
1\end{array}$} & Employed (\%) & 98.7 & 96.6 & -2.1 & 98.8 & 96.1 & -2.7 \\
\hline & Self-employed (\%) & 22.5 & 28.1 & 5.6 & 31.6 & 38.3 & 6.7 \\
\hline & $\begin{array}{l}\text { Wage and salary } \\
\text { earners }(\%)\end{array}$ & 72.1 & 69.7 & -2.4 & 61.5 & 59.3 & -2.2 \\
\hline & Family workers(\%) & 5.4 & 2.2 & -3.2 & 6.9 & 2.4 & -4.5 \\
\hline & $\begin{array}{l}\text { Total no. of } \\
\text { labour force }\end{array}$ & 7153 & 7567 & 414 & 2829 & 2714 & -115 \\
\hline & & 2008 & 2009 & $\begin{array}{l}\text { Percentage } \\
\text { change }(\%)\end{array}$ & 2008 & 2009 & $\begin{array}{l}\text { Percentage } \\
\text { change }(\%)\end{array}$ \\
\hline \multirow[t]{8}{*}{$\begin{array}{l}\text { Panel } \\
2\end{array}$} & $\begin{array}{l}\text { Weekly hours } \\
\text { worked (hour) }\end{array}$ & 63.1 & 63.1 & 0.0 & 65.8 & 65.5 & -0.5 \\
\hline & $\begin{array}{l}\text { Wage and } \\
\text { salary earners }\end{array}$ & 58.4 & 57.3 & -1.9 & 58.9 & 57.7 & -2.0 \\
\hline & Self-employed & 78.3 & 77.6 & -0.9 & 79.3 & 77.7 & -2.0 \\
\hline & Weekly hours n & prked b & industr & & & & \\
\hline & Construction & 62.2 & 61.5 & -1.1 & 61.7 & 61.5 & -0.3 \\
\hline & Manufacturing & 54.6 & 55.2 & 1.1 & 55.7 & 55.0 & -1.3 \\
\hline & $\begin{array}{l}\text { Retail/wholesale } \\
\text { trade }\end{array}$ & 59.2 & 57.7 & -2.5 & 59.6 & 58.2 & -2.3 \\
\hline & Service & 58.8 & 57.4 & -2.4 & 59.1 & 58.5 & -1.0 \\
\hline \multirow[t]{7}{*}{$\begin{array}{l}\text { Panel } \\
3\end{array}$} & $\begin{array}{l}\text { Monthly } \\
\text { earnings } \\
\text { or net revenue } \\
\text { (RMB) }\end{array}$ & 1598 & 1820 & 13.9 & 1648 & 1842 & 11.8 \\
\hline & $\begin{array}{l}\text { Wage and } \\
\text { salary } \\
\text { earners }\end{array}$ & 1411 & 1631 & 15.6 & 1417 & 1661 & 17.2 \\
\hline & Self-employed & 2200 & 2297 & 4.4 & 2098 & 2128 & 1.4 \\
\hline & $\begin{array}{l}\text { Hourly earnings } \\
\text { or net revenue } \\
\text { RMB) }\end{array}$ & 6.4 & 7.5 & 17.2 & 6.41 & 7.64 & 19.2 \\
\hline & $\begin{array}{l}\text { Wage and } \\
\text { salary } \\
\text { earners }\end{array}$ & 6.2 & 7.4 & 19.4 & 6.2 & 7.6 & 22.6 \\
\hline & Self-employed & 7.3 & 7.9 & 8.2 & 6.8 & 7.7 & 13.2 \\
\hline & $\begin{array}{l}\text { First month } \\
\text { earnings or } \\
\text { net revenue } \\
\text { (RMB) }\end{array}$ & 899.6 & 978.1 & 8.7 & & & \\
\hline
\end{tabular}


The global financial crisis and rural-urban migration

\begin{tabular}{llccc|ccc}
\hline $\begin{array}{l}\text { Panel } \\
\mathbf{4}\end{array}$ & $\begin{array}{l}\text { Percentage } \\
\text { of workers } \\
\text { receiving } \\
\text { welfare } \\
\text { insurance (\%) }\end{array}$ & $\mathbf{2 0 0 8}$ & $\mathbf{2 0 0 9}$ & Difference & $\mathbf{2 0 0 8}$ & $\mathbf{2 0 0 9}$ & Difference \\
$\begin{array}{l}\text { Unemployment } \\
\text { insurance }\end{array}$ & 11.9 & 12.2 & 0.3 & 11.8 & 11.9 & 0.1 \\
& 18.9 & 20.6 & 1.7 & 19.7 & 20.8 & 1.1 \\
$\begin{array}{l}\text { Pension } \\
\text { insurance }\end{array}$ & 55.9 & 68.2 & 12.3 & 59.8 & 67.9 & 8.1 \\
$\begin{array}{l}\text { Health } \\
\text { insurance }\end{array}$ & 17.5 & 16.8 & -0.7 & 16.6 & 16.8 & 0.2 \\
$\begin{array}{l}\text { Work injury } \\
\text { insurance }\end{array}$ & 7.0 & 7.0 & 0 & 6.5 & 7.2 & 0.7 \\
\hline
\end{tabular}

Source: Authors' own survey.

Of the total employed, the proportion of self-employed increased by 5.6 percentage points for the total sample. This increase could, however, to some extent be a result of sample attrition bias, because self-employed individuals are less mobile than their wage/salary-earning counterparts and hence are more likely to be tracked in the second wave. To gauge the extent to which sample attrition could contribute to this increase in the share of self-employment, we further examine the panel sample. For the sample of the same individuals, we find that in 2008, 32 per cent were self-employed and by 2009, 38 per cent were self-employed - an increase of 6 percentage points. Switching from being a wage/salary earner to self-employment could have been a strategy to cope with the economic downturn generated by the global financial crisis. During the East Asian financial crisis (1998), many migrant workers in Indonesia switched from the formal sector to the informal sector (Hugo 2000). Indeed, when we compare occupational distributions for the self-employed in 2008 and 2009, we find that the biggest reduction between the two years is for small-shop or factory owners, while the biggest increases in 2009 are for street vendors, garbage collectors and shop assistants (see Appendix Table 12.A2). This last group is more likely to be categorised as informal-sector employment.

Another way to adjust employment in response to the economic shock is to reduce working hours. The second panel of Table 12.2 summarises the average weekly hours worked by total employed workers as well as by self-employed and wage/salary earners, separately. On average, there is hardly any change in weekly hours worked for the total sample and the panel sample. Self-employed workers in general work longer hours than wage/salary earners and this phenomenon did not change over time. More importantly, weekly hours worked did not fall much for either self-employed or wage/salary earners in 2009 relative to 2008. For the self-employed, there is a 1 per cent reduction in hours worked while the proportion for wage/salary earners is 1.9 per cent. Given the fact that the global financial crisis is more likely to have affected manufacturing rather than 
other industries, we also examine hours worked by industry (also see Figure 12.2). Here the same story is observed: the largest reduction in hours worked is 2.5 per cent for the retail/wholesale trades. The manufacturing industry had no observable decline in hours but rather a 1 per cent increase. Clearly, no job sharing occurred in the Chinese labour market during the recession, unlike the situation in some Western labour markets. This is understandable because in a country with an abundant labour supply at the unskilled level, employers would not have been worried about hiring when the recession was over.

\section{Figure 12.2 Wage/salary workers' log weekly hours worked by industry}

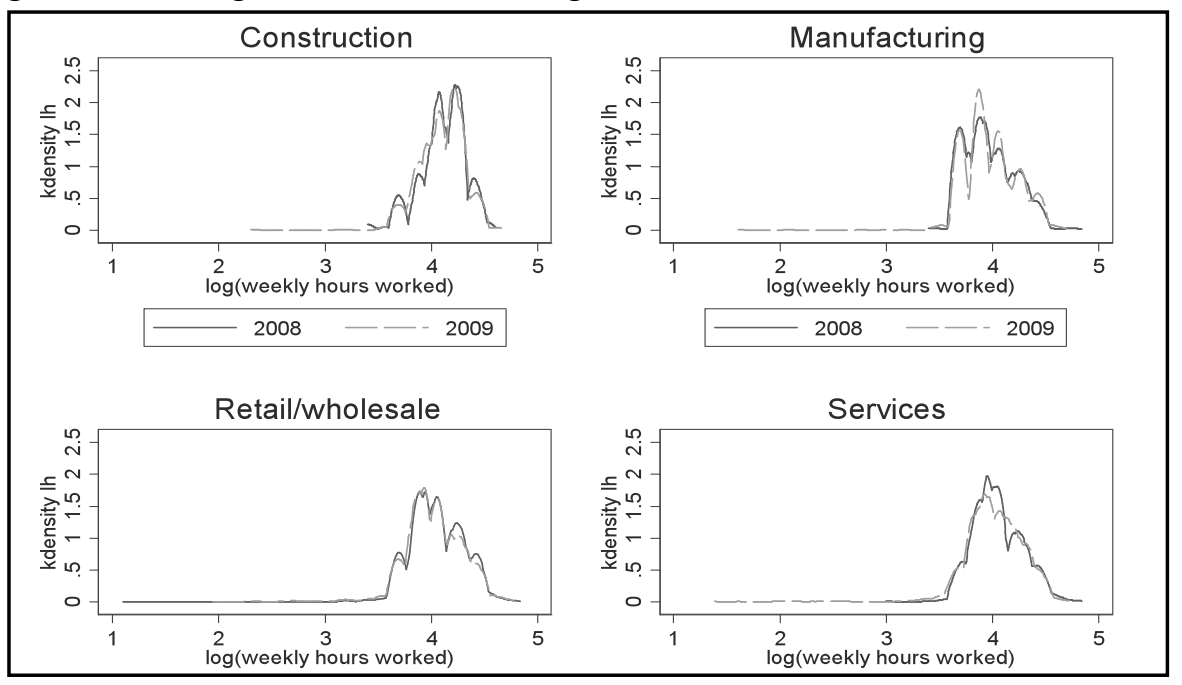

Source: Calculated based on authors' own survey.

The small change in the unemployment rate and the small change in hours worked between 2008 and 2009 suggest that the average employment situation for migrants who stayed in cities was not significantly affected. This is rather puzzling to us. Given the 20 per cent reduction in exports (MoHRSS 2009), one would have expected a much larger employment effect. Perhaps, as the labour market for migrant workers is flexible, the demand shock can be absorbed by the wage flexibility. If so, we should observe a downward change in earnings.

Panel 3 of Table 12.2 presents the change in monthly and hourly earnings for the total, wage/salary earners and self-employed workers for the total and panel samples. For monthly or hourly earnings, we observe no reduction, but rather an increase in earnings in 2009. Even more surprisingly, the largest increase in earnings occurred among wage/salary earners, who should have been the group most negatively affected by the global financial crisis shock. The average hourly earnings increase for wage/salary earners was 19 per cent, while for the selfemployed it was 8 per cent. Figure 12.3 presents the distribution of earnings by industries for wage/salary earners. It is clear that every industry had an hourly earnings increase between 2008 and 2009 and it is particularly so for the panel sample. 
Figure 12.3a Wage/salary earners' log hourly earnings by industry (total sample)

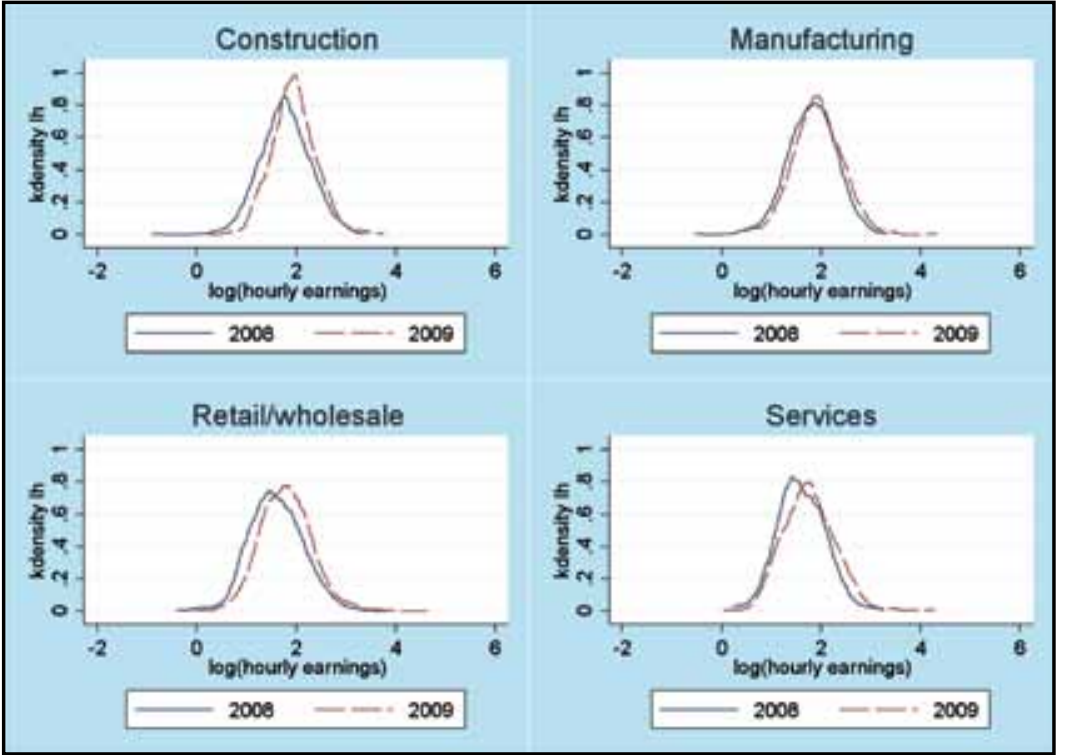

Figure 12.3b Wage/salary earners' log hourly earnings by industry (panel sample)

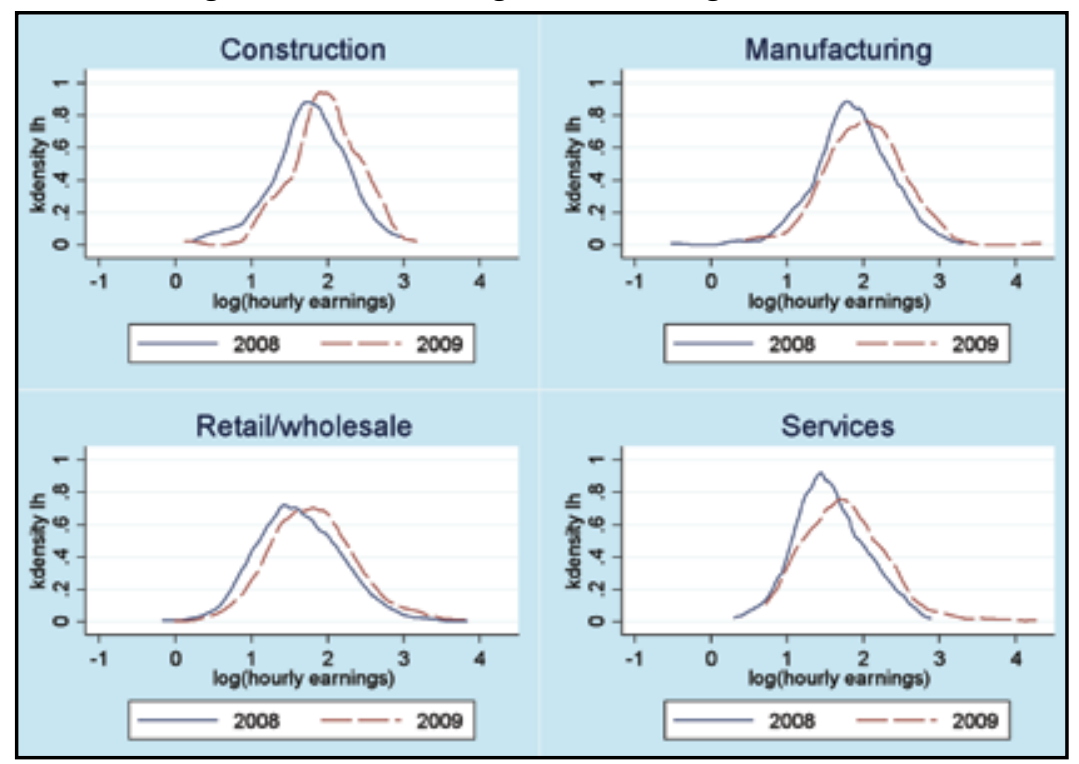

Source: Calculated based on authors' own survey.

We also examine whether monthly earnings for new arrivals changed between the two years in Panel 3 of Table 12.2. This is interesting because this group represents the most unskilled workers without any work experience. In the RUMiCI survey, we collect information on earnings in the first month of the first job. For those whose arrival month and survey month are the same or plus/ minus one month, we use their current monthly earnings. Many individuals did not report first-month earnings, especially those who arrived within the survey 
year. Thus, we have a rather small sample, with a total of 93 new arrivals for 2008 and 26 for 2009. On average, the first monthly pay for the first job is about 9 per cent higher in 2009 than in 2008.

Finally, we examine whether employer-provided social insurance has fallen as part of the adjustment for earnings levels (Panel 4 of Table 12.2). Here again we did not find much change and, if anything, the changes are positive.

The above analysis examines only average unconditional hours and earnings changes. To ascertain whether these results are due to the change in the distribution of different types of workers and their working locations between the two years, we estimate hours and earnings equations, which control for individual characteristics and industry and regional variations. Table 12.3 presents the regression results for log weekly work hours (first three columns) and log hourly earnings (columns 4-6). We estimate these regressions for the total sample and the sample of wage/salary earners and self-employed, separately.

Table 12.3 Results from the hours and hourly earnings equations for migrants in cities (migrant sample)

\begin{tabular}{|c|c|c|c|c|c|c|}
\hline & \multicolumn{3}{|c|}{ log (weekly work hours) } & \multicolumn{3}{|c|}{ log (hourly earnings) } \\
\hline & Total & $\begin{array}{l}\text { Wage/ } \\
\text { salary }\end{array}$ & $\begin{array}{c}\text { Self- } \\
\text { employed }\end{array}$ & Total & Wage/salary & $\begin{array}{c}\text { Self- } \\
\text { employed }\end{array}$ \\
\hline \multirow[t]{2}{*}{ Age } & -0.011 & -0.015 & 0.010 & 0.039 & 0.044 & 0.007 \\
\hline & {$[0.002] * * *$} & {$[0.002]^{* * *}$} & {$[0.005]^{*}$} & {$[0.004]^{* * *}$} & {$[0.003]^{* * *}$} & [0.012] \\
\hline \multirow{2}{*}{$\begin{array}{l}\text { Age } \\
\text { squared/ } \\
100\end{array}$} & 0.014 & 0.021 & -0.013 & -0.062 & -0.069 & -0.021 \\
\hline & {$[0.003]^{* * *}$} & {$[0.003]^{* * *}$} & {$[0.006]^{* *}$} & {$[0.005]^{* * *}$} & {$[0.005]^{* * *}$} & [0.015] \\
\hline \multirow{2}{*}{$\begin{array}{l}\text { Years of } \\
\text { schooling }\end{array}$} & -0.016 & -0.018 & -0.007 & 0.048 & 0.053 & 0.036 \\
\hline & {$[0.001]^{* * *}$} & {$[0.002]^{* * *}$} & {$[0.004]^{* *}$} & {$[0.003]^{* * *}$} & {$[0.003]^{* * *}$} & {$[0.008]^{* * *}$} \\
\hline \multirow{2}{*}{$\begin{array}{l}\text { Years of } \\
\text { schooling* } \\
\text { dummy } \\
\text { for } 2009\end{array}$} & -0.005 & -0.013 & -0.004 & 0.069 & 0.009 & 0.073 \\
\hline & [0.019] & [0.020] & {$[0.046]$} & {$[0.038]^{*}$} & {$[0.036]$} & [0.110] \\
\hline \multirow{2}{*}{$\begin{array}{l}\text { Dummy } \\
\text { for males }\end{array}$} & 0.016 & 0.027 & -0.023 & 0.130 & 0.126 & 0.123 \\
\hline & {$[0.005]^{* * *}$} & {$[0.005]^{* * *}$} & {$[0.012]^{* *}$} & {$[0.010]^{* * *}$} & {$[0.009]^{* * *}$} & {$[0.028]^{* * *}$} \\
\hline $\begin{array}{l}\text { Dummy } \\
\text { for married }\end{array}$ & $\begin{array}{c}0.013 \\
{[0.007]^{*}}\end{array}$ & $\begin{array}{c}0.011 \\
{[0.007]}\end{array}$ & $\begin{array}{c}0.034 \\
{[0.021]}\end{array}$ & $\begin{array}{l}-0.006 \\
{[0.015]}\end{array}$ & $\begin{array}{l}-0.004 \\
{[0.013]}\end{array}$ & $\begin{array}{l}-0.059 \\
{[0.051]}\end{array}$ \\
\hline
\end{tabular}


The global financial crisis and rural-urban migration

\begin{tabular}{|c|c|c|c|c|c|c|}
\hline $\begin{array}{l}\text { Year since } \\
\text { first } \\
\text { migration }\end{array}$ & $\begin{array}{c}0.003 \\
{[0.001]^{* *}}\end{array}$ & $\begin{array}{c}0.004 \\
{[0.001]^{* * *}}\end{array}$ & $\begin{array}{c}0.002 \\
{[0.003]}\end{array}$ & $\begin{array}{c}0.027 \\
{[0.003]^{* * *}}\end{array}$ & $\begin{array}{c}0.025 \\
{[0.002]^{* * *}}\end{array}$ & $\begin{array}{c}0.026 \\
{[0.007]^{* * *}}\end{array}$ \\
\hline $\begin{array}{l}\text { Year } \\
\text { since first } \\
\text { migration } \\
\text { squared/ } \\
100\end{array}$ & $\begin{array}{c}-0.010 \\
{[0.005]^{* *}}\end{array}$ & $\begin{array}{c}-0.014 \\
{[0.005]^{* * *}}\end{array}$ & $\begin{array}{l}-0.004 \\
{[0.011]}\end{array}$ & $\begin{array}{c}-0.079 \\
{[0.010]^{* * *}}\end{array}$ & $\begin{array}{c}-0.064 \\
{[0.010]^{* * *}}\end{array}$ & $\begin{array}{c}-0.090 \\
{[0.026]^{* * *}}\end{array}$ \\
\hline $\begin{array}{l}\text { Dummy } \\
\text { for self- } \\
\text { employed }\end{array}$ & $\begin{array}{c}0.243 \\
{[0.007]^{* * *}}\end{array}$ & & & $\begin{array}{c}0.042 \\
{[0.013]^{* * *}}\end{array}$ & & \\
\hline $\begin{array}{l}\text { Dummy } \\
\text { for } 2009\end{array}$ & $\begin{array}{l}-0.014 \\
{[0.018]}\end{array}$ & $\begin{array}{l}-0.005 \\
{[0.020]}\end{array}$ & $\begin{array}{l}-0.023 \\
{[0.040]}\end{array}$ & $\begin{array}{c}0.056 \\
{[0.036]}\end{array}$ & $\begin{array}{c}0.153 \\
{[0.035]^{* * *}}\end{array}$ & $\begin{array}{l}-0.051 \\
{[0.096]}\end{array}$ \\
\hline $\begin{array}{l}\text { Industry } \\
\text { dummies }\end{array}$ & Yes & Yes & Yes & Yes & Yes & Yes \\
\hline $\begin{array}{l}\text { City } \\
\text { dummies }\end{array}$ & Yes & Yes & Yes & Yes & Yes & Yes \\
\hline $\begin{array}{l}\text { Obser- } \\
\text { vations }\end{array}$ & 13149 & 9777 & 3372 & 13149 & 9777 & 3372 \\
\hline R-squared & 0.23 & 0.11 & 0.05 & 0.22 & 0.33 & 0.13 \\
\hline
\end{tabular}

* significant at 10 per cent

${ }^{* *}$ significant at 5 per cent

*** significant at 1 per cent

Note: Standard errors are in brackets.

Source: Authors' own estimations.

Controlling for city and industry effects, most of the demographic characteristics seem to exhibit normal patterns in both the hours and earnings equations. We discuss the hours equation first. For the total sample, age has a U-shaped relationship with hours worked. This is the same as for wage/salary earners, but for self-employed the relationship is reversed. The more educated an individual is the fewer hours he/she works and this relationship does not change between the two years. Males work 2-3 per cent more hours than their female counterparts if they are a wage/salary earner, but 2 per cent less if they are selfemployed. Married workers work slightly longer hours and the relationship between years since migration and hours worked is inverse U-shaped. Selfemployed workers on average work 24 per cent more than wage/salary earners. Finally, standardising for individual, industry and regional effects, workers in 2009 worked almost the same number of hours a week as they did in 2008. 
Moving to the log hourly earnings equations, we find the normal inverse U-shaped relationship between age and earnings. An additional year of schooling increases earnings for wage/salary earners by 5.3 per cent and for the selfemployed by 3.6 per cent. These rates of return do not seem to change over time. The number of years since migration also has an inverse U-shaped relationship with earnings. The self-employed earn 4.2 per cent more hourly earnings than wage/salary earners. Controlling for all these characteristics, hourly earnings in 2009 do not seem to be statistically different from those in 2008 for the total sample. This, however, is not the case for wage/salary earners. For this group of workers, their hourly earnings increased by 15 per cent conditional on other co-variates. The self-employed, on the other hand, earned 5 per cent less but the point estimate is not statistically significant.

Combining the stories on unemployment, hours worked and earnings changes, it seems that at the time of the global financial crisis, those migrant workers who did not lose their jobs or could find other jobs were not adversely affected in terms of hours worked - and their earnings were not adversely affected. In fact, for wage/salary earners, their earnings increased by 15 per cent. This seems to suggest that the labour-market flexibility for migrant wage/salary earners could be reflected in hiring and firing. On the other hand, the self-employed sector does seem to have more labour-market flexibility, where we observe increased informal employment, slight reduction in hours worked and slight reduction in hourly earnings.

\section{The effect of the global financial crisis on labour-market outcomes: rural perspective}

In the previous section, we examined labour-market outcomes for migrants who remained in cities during the global financial crisis. In this section, we use the rural household sample to investigate the possible effect of the global financial crisis on return migration, rural off-farm employment and earnings.

Table 12.4 presents summary statistics on employment and migration. Between 2008 and 2009, the total number of the rural labour force in our sample fell by only 42 people. Note that here 'rural labour force' is defined as those aged sixteen to sixty-five who are either employed or unemployed, including those who have already migrated but still have household registration in their rural village, which is the majority of migrants. Of those in the labour force, 97.7 and 98.9 per cent are employed in the two years, respectively - that is, a reduction in the unemployment rate of 1.2 percentage point for that period (Panel 1 of Table 12.4). ${ }^{3}$ 
The global financial crisis and rural-urban migration

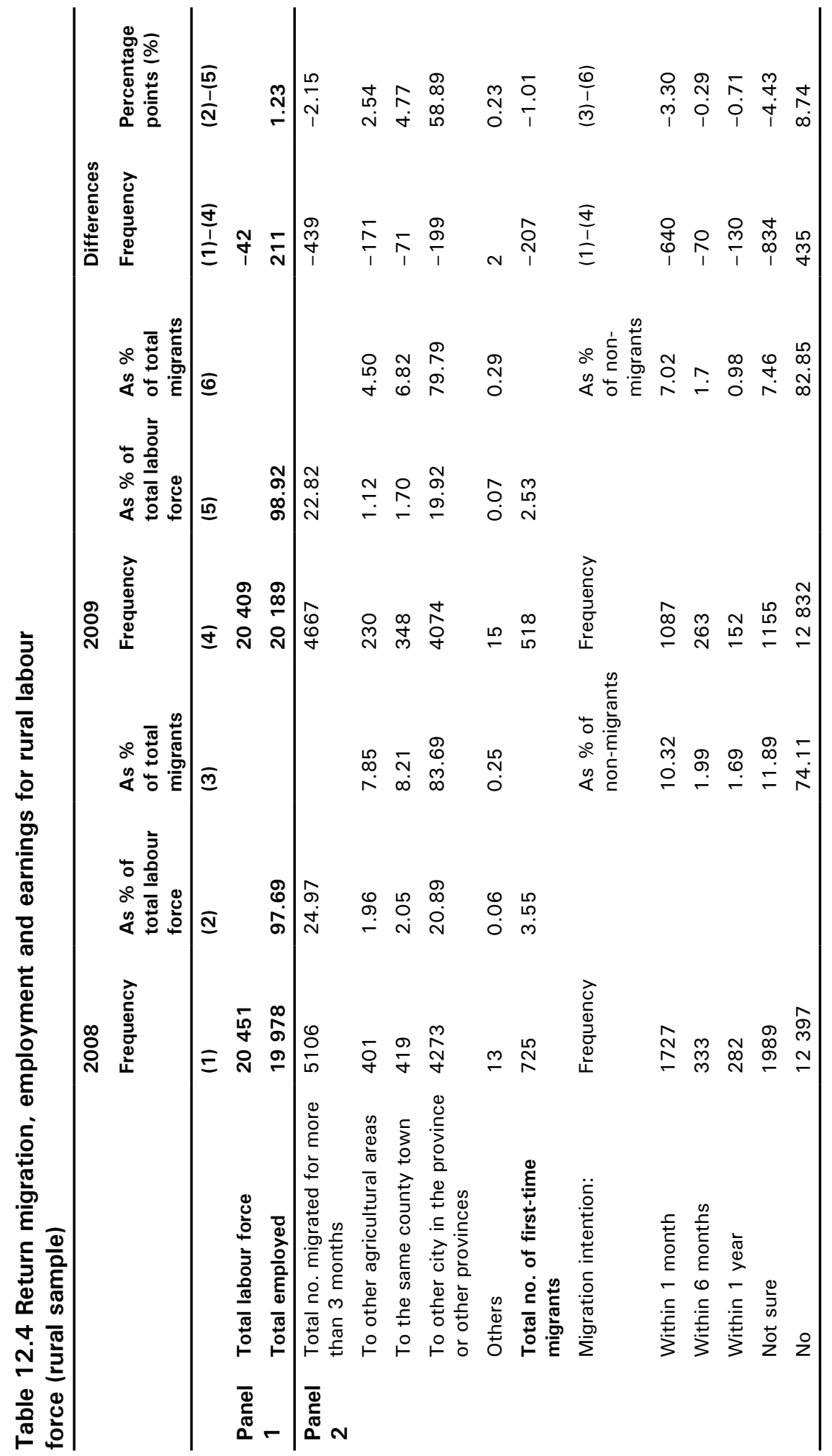




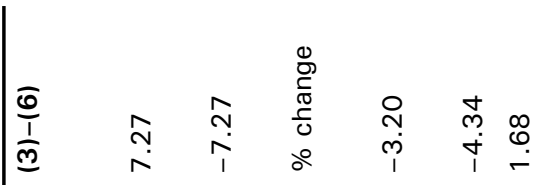

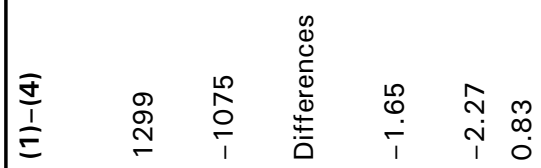

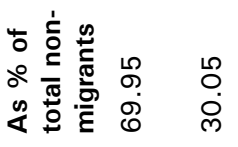

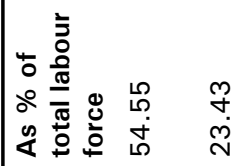

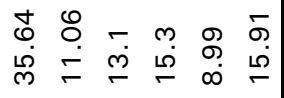

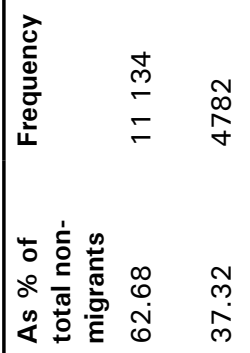

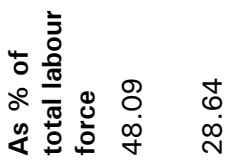

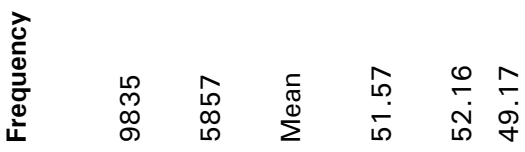

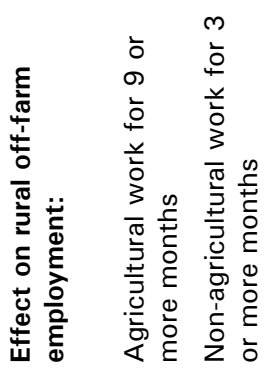

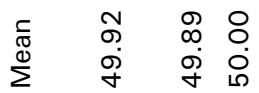

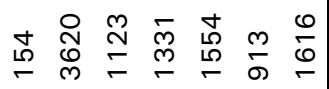

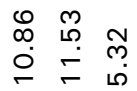

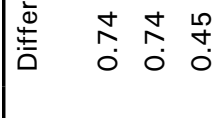

$$
\begin{aligned}
& \text { กุ } \\
& \text { ๑ } \stackrel{\infty}{\sim} \stackrel{g}{\circ} \\
& \begin{array}{lll}
0 & 0 & \infty
\end{array} \\
& \text { 㐫 }
\end{aligned}
$$

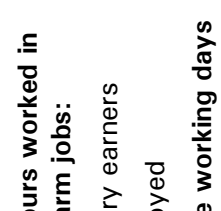

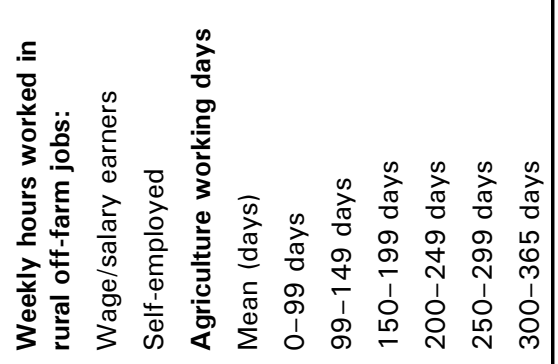

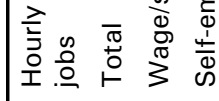

$$
\begin{aligned}
& \text { ब }
\end{aligned}
$$


Of the total labour force, about 25 per cent in 2008 and 23 percent in 2009 migrated to other places to work - a total 2.2 percentage point reduction. Relative to 2008, in 2009, the proportion of migrants fell by 8.6 per cent from 5106 to 4667 . We further divide the migrants into four different categories: those who migrated to other rural regions, to local county towns, to other cities in the province or other provinces, and to other places. In both years, the largest group is those who migrated to other cities within the province or other provinces and this is the group we use to identify migrants in our urban migrant sample. This group accounted for 84 and 80 per cent of the total migrants in 2008 and 2009, respectively, or a reduction of 4 percentage points (Panel 2 of Table 12.4).

Because of the panel nature of our data, we are able to examine the number of people who migrated in 2008 but did not migrate in 2009 and those who migrated in 2009 but did not migrate in 2008 (the top panel of Table 12.5). The former has 1371 individuals and the latter has 1189 individuals. Thus, we have a net return migration of 182 people, which accounted for 4.3 per cent of the total migrants in 2009, translating to about 6.5 million people at the national level. Note that in a normal year we would have observed a net increase in migration. For example, based on the World Bank (2009), between 2004 and 2005 the number of migrants increased-from 118.2 million to 125.8 millionan increase of 6.4 per cent. Therefore, the 6.5 million observed net reduction in migration is only a lower-bound estimate of the effect of the global financial crisis on migration. If we regard the change between 2004 and 2005 as a normal year, the real return migration between 2008 and 2009 should be no lower than 10 per cent of the total migrants - or a total of no less than 14-15 million migrants. Note that this estimate excludes temporary return migrants. Perhaps this is why this estimate is slightly lower than Kong et al.'s (2009) lower-bound estimate of the effect of the global financial crisis of 13 per cent.

Table 12.5 Migration and off-farm status for a panel of individuals (rural sample)

\begin{tabular}{lccc}
\hline & $\begin{array}{c}\text { No in 2009/ } \\
\text { yes in 2008 }\end{array}$ & $\begin{array}{c}\text { Yes in 2009/ } \\
\text { no in 2008 }\end{array}$ & Net difference \\
\hline Migration & $(1)$ & $(2)$ & $(3)=(1)-(2)$ \\
Frequency & 1371 & 1189 & 182 \\
$\begin{array}{l}\text { As percentage of } 2009 \\
\text { migrated labour }\end{array}$ & 32.5 & 28.2 & 4.3 \\
$\begin{array}{l}\text { Off-farm } \\
\text { Frequency }\end{array}$ & 2537 & & 1106 \\
$\begin{array}{l}\text { As percentage of } 2009 \text { off- } \\
\text { farm labour }\end{array}$ & 53.0 & 1431 & 23.1 \\
$\begin{array}{l}\text { As percentage of } 2009 \text { total } \\
\text { labour force }\end{array}$ & 12.4 & 29.9 & 5.4 \\
\hline
\end{tabular}

Source: Based on authors' own surveys.

Of the reduction in out-migration, we further investigate the effect of the global financial crisis on first-time migration and on migration intention (the second 
block in Panel 2 of Table 12.4). RUMiCI data include information on the year of first migration. Comparing the two periods-January 2007 to mid 2008 and January 2008 to mid 2009 - the number of first-time migrants dropped from 725 to 518 people, equivalent to a decrease of 1 percentage point of the total rural labour force. ${ }^{4}$ The former period can reasonably be considered as normal circumstances and used as a benchmark to compare with the latter, which covers the short period leading up to the height of the crisis through until the power of the crisis started to subside. The drop of 1 percentage point implies a decline of about five million first-time rural migrants. ${ }^{5}$

With regard to migration intentions, the survey asks individuals who were present at the time of the survey to indicate their plan to out-migrate. Compared with a year earlier, the numbers of adults who expected to migrate within one month, six months and one year all fell, while those indicating that they would not migrate increased substantially, from 74 to 83 per cent (the third block in Panel 2 of Table 12.4). As the 2009 survey was conducted mainly in the first half of the year, it is likely that the memory of the negative shock at the end of 2008 and the bleak prospects for employment discouraged rural labourers from becoming migrant workers.

The data presented above indicate a substantial effect of the global financial crisis on migration outflow. A net effect of no less than 10 per cent of the total migrants returned to their hometowns during late 2008 and stayed there through the first half of 2009.

What did these migrants do after they returned to the rural areas? Was it rural farming or off-farm employment that eventually absorbed these return migrants? How did the switching from out-migration to rural off-farm or farm work affect their earnings?

First, we investigate whether the 2009 return migrants were employed in farming or off-farm sectors. We find that 80 per cent of the migrants returned to a farming job and only 20 per cent returned to work in an off-farm job.

Second, we examine the change in farming and off-farm employment over the two years (the first block in Panel 3 of Table 12.4). We find that for those who did not migrate, the proportion working in the agricultural sector relative to the total non-migrated labour force increased by 7.27 percentage points (or 6.24 percentage points in terms of the total labour force with rural hukou) and the same degree of reduction is found for those who worked in the off-farm sector. Among those who worked in rural areas, we also utilise the panel nature

4 In this chapter, we define total rural labour as the labour force with rural household registration.

5 This is calculated based on the total labour force with rural household registration (rural hukou) using 20051 per cent population survey data. This number in 2005 was 505 million. 
of the data to examine the number of people who switched from an off-farm job in 2008 to farming employment in 2009 (the bottom panel of Table 12.5). There are 2537 individuals working in off-farm jobs in 2008 who switched to farm jobs in 2009, while only 1431 individuals moved from farming jobs to offfarm jobs - a net switch to farming jobs of 1106 individuals or 5.4 per cent of the total rural hukou labour force, which is equivalent to 27.3 million people. This, however, might be a lower-bound estimate. Assuming that in the preglobal financial crisis period rural off-farm employment increased annually by 2 percentage points, the real effect of the global financial crisis on rural offfarm jobs should be no less than 7.5 per cent of the total labour force with rural hukou - equivalent to 38 million rural hukou holders. This is a much bigger effect than the direct return migration effect. Perhaps, in addition to the direct demand shock of the global financial crisis, there is a secondary multiplier effect of return migration. When a large number of migrants lost jobs in the cities and returned to home villages, their income level fell, which in turn reduced demand for non-agricultural goods and services in the rural areas, leading to the multiplier effect on rural off-farm employment.

Based on our panel estimates, if we add the impact of the global financial crisis on return migration and on the switching from rural off-farm to farming jobs, total off-farm employment fell by 53 million (15 million return migrants plus 38 million switching from off-farm jobs to farming jobs) in $2009 .^{6}$ This is a substantial employment effect.

Next, we consider whether for rural off-farm jobs there were any hourly adjustments (the second block in Panel 3 of Table 12.4). We find that there were slight reductions in the number of hours worked weekly in 2009 relative to 2008 for the wage/salary earners, but not for self-employed. For the former, the reduction was about 2.3 hours, or 4 per cent. This slight reduction in hours worked for wage/salary earners does not, however, take into account changes in individual characteristics or industry and regional distributions. Once controlling for these changes, there was no change in hours worked for either group (see Table 12.6 for the regression results).

6 The lower-bound estimate is 34 million (the 6.5 million return migration plus 27 million reduction in rural off-farm jobs). 
China: The Next Twenty Years of Reform and Development

Table 12.6 Results from hours and hourly earnings equations for rural off-farm work (rural sample)

\begin{tabular}{|c|c|c|c|c|c|c|}
\hline \multicolumn{4}{|c|}{ log(weekly hours worked) } & \multicolumn{3}{|c|}{ log(hourly earnings) } \\
\hline & Total & $\begin{array}{l}\text { Wage/ } \\
\text { salary }\end{array}$ & $\begin{array}{c}\text { Self- } \\
\text { employed }\end{array}$ & Total & Wage/salary & $\begin{array}{c}\text { Self- } \\
\text { employed }\end{array}$ \\
\hline \multirow[t]{2}{*}{ Age } & -0.004 & -0.006 & 0.007 & 0.037 & 0.03 & 0.073 \\
\hline & [0.003] & [0.004] & [0.011] & {$[0.005]^{* * *}$} & {$[0.005]^{* * *}$} & {$[0.015]^{* * *}$} \\
\hline \multirow{2}{*}{$\begin{array}{l}\text { Age squared } \\
/ 100\end{array}$} & -0.002 & 0.001 & -0.015 & -0.052 & -0.044 & -0.095 \\
\hline & [0.004] & [0.004] & [0.013] & {$[0.006]^{* * *}$} & {$[0.006]^{* * *}$} & {$[0.017]^{* * *}$} \\
\hline \multirow{2}{*}{$\begin{array}{l}\text { Years of } \\
\text { schooling }\end{array}$} & 0.004 & 0.002 & 0.012 & 0.024 & 0.028 & 0.002 \\
\hline & {$[0.002]^{*}$} & [0.003] & {$[0.007]^{*}$} & {$[0.004]^{* * *}$} & {$[0.004]^{* * *}$} & {$[0.010]$} \\
\hline $\begin{array}{l}\text { Years of } \\
\text { schooling* } \\
\text { dummy } \\
\text { for } 2009\end{array}$ & $\begin{array}{c}-0.007 \\
{[0.004]^{*}}\end{array}$ & $\begin{array}{c}-0.007 \\
{[0.004]^{*}}\end{array}$ & $\begin{array}{l}-0.001 \\
{[0.011]}\end{array}$ & $\begin{array}{c}0.013 \\
0.005]^{* *}\end{array}$ & $\begin{array}{c}0.012 \\
{[0.005]^{* *}}\end{array}$ & $\begin{array}{c}0.018 \\
{[0.014]}\end{array}$ \\
\hline $\begin{array}{l}\text { Dummy for } \\
\text { males }\end{array}$ & $\begin{array}{c}0.01 \\
{[0.011]}\end{array}$ & $\begin{array}{c}0.006 \\
{[0.011]}\end{array}$ & $\begin{array}{c}0.012 \\
{[0.030]}\end{array}$ & $\begin{array}{c}0.274 \\
{[0.015]^{* * *}}\end{array}$ & $\begin{array}{c}0.259 \\
{[0.016]^{* * *}}\end{array}$ & $\begin{array}{c}0.319 \\
{[0.040]^{* * *}}\end{array}$ \\
\hline $\begin{array}{l}\text { Dummy } \\
\text { for married }\end{array}$ & $\begin{array}{c}0.052 \\
{[0.020]^{* * *}}\end{array}$ & $\begin{array}{c}0.047 \\
{[0.019]^{* *}}\end{array}$ & $\begin{array}{c}0.081 \\
{[0.077]}\end{array}$ & $\begin{array}{c}0.007 \\
{[0.028]}\end{array}$ & $\begin{array}{c}0.037 \\
{[0.028]}\end{array}$ & $\begin{array}{l}-0.134 \\
{[0.103]}\end{array}$ \\
\hline $\begin{array}{l}\text { Dummy for } \\
\text { self- } \\
\text { employed }\end{array}$ & $\begin{array}{c}-0.058 \\
{[0.013]^{* * *}}\end{array}$ & & & $\begin{array}{c}0.239 \\
{[0.019]^{* * *}}\end{array}$ & & \\
\hline $\begin{array}{l}\text { Dummy } \\
\text { for } 2009\end{array}$ & $\begin{array}{c}0.043 \\
{[0.031]}\end{array}$ & $\begin{array}{c}0.026 \\
{[0.032]}\end{array}$ & $\begin{array}{c}0.064 \\
{[0.088]}\end{array}$ & $\begin{array}{l}-0.013 \\
{[0.044]}\end{array}$ & $\begin{array}{l}-0.006 \\
{[0.046]}\end{array}$ & $\begin{array}{c}-0.05 \\
{[0.118]}\end{array}$ \\
\hline Observations & 9508 & 7444 & 2064 & 9508 & 7444 & 2064 \\
\hline R-squared & 0.06 & 0.06 & 0.06 & 0.13 & 0.13 & 0.12 \\
\hline
\end{tabular}

* significant at 10 per cent

** significant at 5 per cent

*** significant at 1 per cent

Note: Standard errors are in brackets.

Source: Authors' own estimations.

Considering that the land-labour ratio is very low in rural China and is probably fixed over the two-year period, an increase in the agricultural labour force should imply an increase in under-employment. To illustrate the level of under-employment among agricultural labour, we utilise the 2009 survey question, 'How many days in 2008 did you work on the farm?'. On average, 
those who identified themselves as having a farming job worked 154 days or 42 per cent of the year on the farm if using 365 days as the denominator and 52 per cent if using 300 days $^{7}$ as the denominator. Among the agricultural workers, 36 per cent worked only between zero and 99 days on the farm, while those who worked more than 200 days accounted for 40 per cent. The average total number of days this group worked on off-farm activities was 8.4 days (the third block in Panel 3 of Table 12.4). If we restrict the sample to those who identified themselves as working in the farming sector in both 2008 and 2009-a stronger indication of the agricultural workers - the average hours worked in the farming sector increased slightly to 172 , or 57 per cent of the year, using 300 days as the denominator. These data are indicative of the level of under-employment there has been in the rural agricultural sector.

The last important point to be investigated is whether wages for rural off-farm jobs were affected by the global financial crisis (see Panel 4 of Table 12.4). Interestingly, hourly earnings of both wage/salary earners and self-employed increased during this period. For the former, the hourly earnings increased by almost 12 per cent, while for the latter the increase was about 5 per cent. Once we control for demographic, industry and regional characteristics, however, the earnings change for rural off-farm workers between two years disappears (see Table 12.6).

It would be interesting to examine household-level income effects of the global financial crisis, but unfortunately our survey records only household income for previous years. Thus, we have only household income for 2007 and 2008, which does not allow us to investigate the effect of the global financial crisis. Using household income for 2008 for different types of households, we could, however, provide some indicative information of the impact of the reduction in migration and off-farm jobs on household per capita income. Table 12.7 presents these data. In 2008, rural households on average had a per capita income level of RMB9428. We divide these households into four types: 1) those with both migrants and rural off-farm workers; 2) those with rural off-farm workers but no migrants; 3) those with migrants but no off-farm workers; and 4) those with only farm workers. Comparing the average per capita household income for the first three types of households with households that have only farm workers, we find that farm work provides the lowest income. Surprisingly, though, rural off-farm workers seem to provide higher income to households than migrants. This perhaps is because rural off-farm workers are mainly living at home and hence all their income is counted as part of household income, whereas only the remittance component of migrant income is counted as part of household income. On average, the first three types of households have per capita income between 7 and 27 per cent higher than households with only farm workers.

7 That is, 300 working days is a normal migrant worker's annual working days in a city. 
Table 12.7 Per capita income comparisons across different type of households

\begin{tabular}{|c|c|c|c|c|}
\hline & \multirow[t]{2}{*}{$\begin{array}{c}\text { No. of } \\
\text { households }\end{array}$} & \multirow[t]{2}{*}{$\begin{array}{c}\text { Per } \\
\text { capita } \\
\text { income } \\
\text { (RMB) }\end{array}$} & \multicolumn{2}{|c|}{$\begin{array}{l}\text { Difference to } \\
\text { households } \\
\text { with only farm } \\
\text { workers }\end{array}$} \\
\hline & & & $\begin{array}{l}\text { Value } \\
\text { (RMB) }\end{array}$ & $\%$ difference \\
\hline Total households & 7912 & 9428 & 1001 & 11.9 \\
\hline $\begin{array}{l}\text { Households with both } \\
\text { off-farm and migrant } \\
\text { workers (1) }\end{array}$ & 657 & 10688 & 2261 & 26.8 \\
\hline $\begin{array}{l}\text { Households with off-farm } \\
\text { workers but no migrants (2) }\end{array}$ & 2896 & 10237 & 1810 & 21.5 \\
\hline $\begin{array}{l}\text { Households with migrants } \\
\text { but no off-farm workers (3) }\end{array}$ & 2004 & 9024 & 597 & 7.1 \\
\hline $\begin{array}{l}\text { Households with neither } \\
\text { off-farm nor migrant } \\
\text { workers (4) }\end{array}$ & 2355 & 8427 & & \\
\hline \multicolumn{5}{|l|}{2009 household type } \\
\hline 2008 household type & $\begin{array}{l}\text { Households } \\
\text { with both off- } \\
\text { farm and migrant } \\
\text { workers (1) }\end{array}$ & $\begin{array}{l}\text { Households } \\
\text { with off-farm } \\
\text { workers but } \\
\text { no migrants(2) }\end{array}$ & $\begin{array}{l}\text { Households } \\
\text { with } \\
\text { migrants } \\
\text { but no } \\
\text { off-farm } \\
\text { workers (3) }\end{array}$ & $\begin{array}{l}\text { Households } \\
\text { with neither } \\
\text { off-farm nor } \\
\text { migrant } \\
\text { workers (4) }\end{array}$ \\
\hline $\begin{array}{l}\text { Households with both } \\
\text { off-farm and migrant } \\
\text { workers (1) }\end{array}$ & 237 & 106 & 249 & 69 \\
\hline $\begin{array}{l}\text { Households with } \\
\text { off-farm workers but no } \\
\text { migrants (2) }\end{array}$ & 104 & 1803 & 265 & 748 \\
\hline $\begin{array}{l}\text { Households with migrants } \\
\text { but no off-farm workers (3) }\end{array}$ & 188 & 136 & 1353 & 367 \\
\hline $\begin{array}{l}\text { Households with neither } \\
\text { off-farm nor migrant } \\
\text { workers (4) }\end{array}$ & 30 & 430 & 174 & 1759 \\
\hline $\begin{array}{l}\text { Total no. of } \\
\text { households }\end{array}$ & 559 & 2475 & 2041 & 2943 \\
\hline $\begin{array}{l}\text { Percentage transited } \\
\text { from other types of } \\
\text { households }\end{array}$ & 57.6 & 27.1 & 33.7 & 40.2 \\
\hline
\end{tabular}

Source: Authors' own survey.

To gauge the degree of the income effect of the reduction in migration and rural off-farm jobs, we also present the transition matrix between 2008 and 2009 across the four types of households (second panel of Table 12.7). The bottom line is that in 2008, 2393 households had only agricultural workers and this figure increased to 2943 in 2009. In addition, 40 per cent (1184) of these 2943 
households had off-farm or migrant workers in 2008. It can be expected that these 1184 households suffered from the global financial crisis in terms of their reduced income levels.

\section{Conclusions}

This chapter examines the effect of the global financial crisis on the labourmarket outcomes of migrants from the perspective of those who remained in cities during the crisis and those who returned to their rural home villages.

Surprisingly, we found that migrants who decided to stay in cities in 2009 suffered very little in terms of employment, working hours and earnings.

To resolve this puzzle, we searched further and examined the employment and earnings conditions of the rural labour force. It was here in rural villages that we observed the most significant employment effect of the global financial crisis: no less than 15 million rural migrants (more than 10 per cent of total migrants) returned to rural villages in 2009. About 80 per cent of them went back to the rural farming sector, where they worked, on average, 52 per cent of the year. In addition to the effect of the global financial crisis on return migration, we found that rural off-farm employment fell by about 38 million - or 7.5 per cent of the total rural hukou labour force. Once again, for those employed in rural off-farm jobs, no downward adjustment to hours or earnings was detected.

Based on these findings, we are inclined to believe that the rural agricultural sector provided the employment buffer for return migration and rural off-farm employment during the global financial crisis. Because of this buffer effect, no open unemployment can be observed. In the current environment, this is certainly a good thing for political stability, although it has come at the expense of a reduction in agricultural productivity.

In the long run, however, it must be expected that small-scale farming will give way to large landholding and higher agricultural productivity. This inevitably will lead to the consolidation of farmland and many small landholders will need to sell their land. Thus, their future employment shocks will have to be cushioned by other means. The question is how will this be done? How will China move towards a universal welfare system and give migrants the rights to sell their land, effectively trading an inefficient land-based traditional welfare system for one that is more appropriate for a modern economy? In the decades ahead, policymakers' responses to this question will have a serious impact on the wellbeing of Chinese migrants - all hundreds of millions of them! 
China: The Next Twenty Years of Reform and Development

Appendix Table 12.A1 Migrant survey timing distribution by survey year (migrant sample, per cent)

\begin{tabular}{lcc}
\hline & $\mathbf{2 0 0 8}$ & $\mathbf{2 0 0 9}$ \\
\hline March & 3.4 & 18.3 \\
April & 33.1 & 35.5 \\
May & 56.7 & 19.7 \\
June & 6.8 & 8.9 \\
July & 0 & 9.4 \\
August & 0 & 8.1 \\
Total no. of observations & 6687 & 7199 \\
\hline
\end{tabular}

Appendix Table 12.A2 Occupational distribution of self-employed migrants by year (migrant sample)

\begin{tabular}{|c|c|c|c|c|c|}
\hline & \multicolumn{2}{|c|}{2008} & \multicolumn{2}{|c|}{2009} & \multirow{2}{*}{$\begin{array}{l}\text { Difference } \\
\quad \text { in } \%\end{array}$} \\
\hline & Frequency & $\%$ & Frequency & $\%$ & \\
\hline Semi-professional & 21 & 0.01 & 27 & 0.01 & 0.00 \\
\hline Owners & 968 & 0.61 & 867 & 0.42 & -0.19 \\
\hline $\begin{array}{l}\text { Street vendors/garbage } \\
\text { collectors }\end{array}$ & 185 & 0.12 & 357 & 0.17 & 0.06 \\
\hline Shop assistants & 147 & 0.09 & 394 & 0.19 & 0.10 \\
\hline Hospitality service workers & 29 & 0.02 & 104 & 0.05 & 0.03 \\
\hline Domestic helpers & 4 & 0.00 & 4 & 0.00 & 0.00 \\
\hline Hairdressers & 39 & 0.02 & 52 & 0.03 & 0.00 \\
\hline $\begin{array}{l}\text { Repair/removal/transport } \\
\text { workers }\end{array}$ & 63 & 0.04 & 84 & 0.04 & 0.00 \\
\hline Chefs/kitchen hands & 36 & 0.02 & 47 & 0.02 & 0.00 \\
\hline Drivers & 30 & 0.02 & 14 & 0.01 & -0.01 \\
\hline Other services labourers & 11 & 0.01 & 8 & 0.00 & 0.00 \\
\hline Construction labourers & 19 & 0.01 & 38 & 0.02 & 0.01 \\
\hline Other labourers & 38 & 0.02 & 74 & 0.04 & 0.01 \\
\hline Total no. of observations & 1590 & & 2070 & & \\
\hline
\end{tabular}

\section{References}

Chen, X. 2009, 'Around 20 million rural migrants lost their jobs, need to confront these social problems', Caijing.com.cn, 2 February 2009, <http:// www.caijing.com.cn/2009-02-02/110051988.html>

Fallon, P. R. and Lucas, R. E. B. 2002, 'The impact of financial crises on labor market, household incomes and poverty: a review of evidence', The World Bank Research Observer, vol. 17, no. 1, p. 21. 
Huang, J., Zhi, H., Huang, Z., Rozelle, S. and Giles, J. 2010, Impact of the global financial crisis on off-farm employment and earnings in rural China, Unpublished manuscript.

Hugo, G. 2000, 'The impact of the crisis on internal population movement in Indonesia', Bulletin of Indonesian Economic Studies, vol. 36, no. 2, pp. 115-38.

Kong, T., Meng, X. and Zhang, D. 2009, 'Impact of economic slowdown on migrant workers', in R. Garnaut, L. Song and W. T. Woo (eds), China's New Place in a World in Crisis: Economic, geopolitical and environmental dimensions, ANU E Press and Brookings Institution Press, Canberra and Washington, DC, pp. 233-60.

Lewis, W. A. 1954, 'Economic development with unlimited supplies of labour', Manchester School, vol. 22, no. 2, pp. 1139-91.

Manning, C. 2000, 'Labour market adjustment to Indonesia's economic crisis: context, trends and implications', Bulletin of Indonesian Economic Studies, vol. 36, no. 1, pp. 105-36.

Ministry of Human Resources and Social Security (MoHRSS) 2009, The response of China's employment of rural migrants to the GFC, Series of reports on China's employment strategies against the global financial crisis, Unpublished manuscript.

Ministry of Human Resources and Social Security (MoHRSS) 2010, An investigation on employment demand of enterprises in Spring 2010 and employment situation of rural migrants in 2009, Unpublished manuscript.

National Bureau of Statistics (NBS) 2009, The total number of rural migrants (in China) was 225.42 million by the end of 2008, Press release, National Bureau of Statistics, Beijing, viewed 25 March 2009, < http://www.cpirc.org.cn/tjsj/ tjsj_cy_detail.asp?id=10471>

Ranis, G., and Fei, J.C.H. 1961. 'A theory of economic development', American Economic Review, Vol. 51 No. 4:533-65.

World Bank (2009) From poor areas to poor people: China's evolving poverty reduction agenda: An assessment of poverty and inequality in China World Bank, Washington D.C, Chunlai Chen. 



\section{Part III}

Policy and Reform: Unfinished Business 



\section{Avoiding economic crashes on China's road to prosperity}

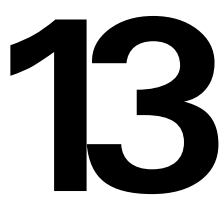

\section{Wing Thye Woo}

\section{Introduction}

There is a long tradition of predictions of gloom and doom among China economists. For example, in the mid 1990s, Nicholas Lardy (1998) of the Peterson Institute for International Economics started highlighting the de facto insolvency of the Chinese banking system with the implication that a bank run leading to financial-sector ruin was a strong possibility in the medium term. The twenty-first century began with the claim by Gordon Chang (2001) that China's imminent accession to the World Trade Organisation (WTO) would cause such widespread unemployment within China's already alienated population that the country's economic and political systems would collapse.

These two dire predictions have turned out to be wrong. China, in fact, accelerated its annual gross domestic product (GDP) growth to double-digit rates after 2001 . Lardy was wrong because, while the banks were indeed bankrupt, the Chinese government that owned them was not bankrupt and could afford to bail out the banks when necessary. The fiscal strength of the government made it irrational for depositors to contemplate a bank run. Chang was wrong because WTO membership quickened the pace of job creation in China by greatly increasing the volume of foreign direct investment (FDI) inflow. WTO membership made China more attractive to FDI because it guaranteed the access of Chinese goods to the US market by eliminating the need for China to received most-favoured nation (MFN) status annually from the US Congress (McKibbin and Woo 2003).

The fact that the doomsayers have been wrong so far does not mean that their dire predictions are guaranteed not to happen in the future. It also does not mean that gloom and doom can be ruled out because the doomsayers could simply have been wrong in their specific identifications of where they would come from. This chapter is, first, an assessment of some of the obstacles that China could stumble into on its development path; and, second, a proposal for how these obstacles could be overcome. 


\section{The rocky road to prosperity}

The tradition of forecasting gloom and doom for China is quite surprising given China's economic performance in the past 30 years and, indeed, it is becoming more common to hear glowingly optimistic assessments of China's future than dismissively pessimistic ones. For example, Jim O'Neill et al. (2005) of Goldman Sachs have predicted that China's GDP will surpass that of the United States in 2040 even after assuming that China's GDP growth rate will slow steadily from its average annual rate of 10 per cent during 1979-2005 to 3.8 per cent during $2030-40 .^{1}$

A good guide to how one should regard the new optimism and the traditional pessimism can be found in the discussions of the Sixth Plenum of the Sixteenth Central Committee of the Communist Party of China (CPC) in October 2006. The sixth plenum passed a resolution to commit the CPC to establish a harmonious society by 2020. The obvious implication is that the present major social, economic and political trends within China might not lead to a harmonious society or, at least, not rapidly enough.

Among the disharmonious features mentioned in the 'resolutions of the CPC Central Committee on major issues regarding the building of a harmonious socialist society' were serious imbalances in social and economic development across (and within each of) China's 31 provinces; worsening population and environmental problems; grossly inadequate social safety nets and healthcare systems; and serious corruption. The harmonious socialist society would encompass a democratic society under the rule of law; a society based on equality and justice; an honest and caring society; a stable, vigorous and orderly society; and a society in which humans live in harmony with nature.

China's economy during the past three decades can be likened to a speeding car. The CPC leadership in 2006 saw that the car could crash in the future because there were several high-probability failures that might occur and cause economic collapse. To be specific, there are three classes of failures that could occur: hardware failure, software failure and power supply failure.

A hardware failure refers to the breakdown of an economic mechanism-a development that is analogous to the collapse of the chassis of a car. Probable hardware failures include a banking crisis that causes a credit crunch, a budget crisis that necessitates reductions in important infrastructure and social

1 For a review of the debate on how to interpret China's high growth in 1978-2000 and why China - unlike the economies of the former Soviet bloc - did not experience a recession when it made the switch from a centrally planned economy to a market economy, see Sachs and Woo (2000) and Woo (2001). 
expenditure (and possibly generates high inflation and balance-of-payments difficulties as well) and a serious slowdown in productivity growth from the accumulation of micro-inefficiencies created by state intervention.

A software failure refers to a flaw in governance that creates frequent widespread social disorders that disrupt economy-wide production and discourage private investment. This situation is similar to a car crash that results from a fight among the people inside the speeding car. Software failures could come from the present high-growth strategy creating enough inequality and corruption to generate severe social unrest, and from the State not being responsive enough to rising social expectations, hence causing social and economic disorder.

A power supply failure refers to the economy being unable to move forward because it hits either a natural limit or an externally imposed limit - a situation that is akin to the car running out of fuel (a natural limit) or into a roadblock erected by foreigners (an externally imposed constraint). Examples of power supply failures are an environmental collapse and a collapse in China's exports because of a trade war.

There are many events within each type of failure that could make China's high growth unsustainable is beyond the scope of this chapter. We limit the discussion here to those that seem most likely in June 2010.

\section{Potential hardware failure}

China will face two potential hardware failures in the aftermath of the global financial crisis: a weakening of the fiscal position and a slowdown in productivity growth. To see the source of our concern, we have to recall, first, the nature of the global financial crisis and the manner in which it impacted on China; and second, the kind of economic mechanisms that were used to generate the stunning 8.7 per cent GDP growth rate in 2009.

The global financial crisis burst onto the world scene on 15 September 2008 when investment bank Lehman Brothers filed for bankruptcy. This action sparked a wholesale flight to liquidity that caused a meltdown of financial markets globally. This widening financial crash, in turn, became a negative 
feedback loop to the level of aggregate income. GDP growth (year-on-year) turned negative in the fourth quarter of 2008 in the United States ( -1.9 per cent) and the United Kingdom (-2.1 per cent).

This abrupt decline in GDP of the major advanced economies translated into a large, abrupt negative external shock to China that had two components: a negative export shock and a negative inward FDI shock. ${ }^{2}$ This prolonged contractionary external impulse hit China at a time when its economy was already slowing from the tightening of monetary policy that was implemented immediately after the conclusion of the seventeenth CPC congress in October 2007. In the run-up to the party congress, easy monetary policy had steadily boosted GDP growth from 10.4 per cent in 2005 to 11.6 per cent in 2006 and 13 per cent in 2007. GDP growth, which had been brought down by tighter monetary policy to 10.4 per cent in the second quarter of 2008 , fell to 9.6 per cent in the fourth quarter of 2008, and then further to 6.1 per cent in the first quarter of 2009, under the additional squeeze from the large drop-off in export and foreign investment.

The Chinese government responded with very aggressive fiscal and monetary policies to offset the external deflationary policies. It announced in early November 2008 that a fiscal stimulus of RMB4 trillion would be undertaken in 2009-10 - an annual stimulus of about 7 per cent of GDP. Monetary easing has been even more dramatic, with broad money (M2) increased by 28 per cent in 2009.

While consumer price index (CPI) inflation in 2009 was reassuringly low at -0.7 per cent, 'land prices...doubled in 2009 on a nationwide basis' ('China tells banks to restrict loans to local governments', The New York Times, 25 February 2010). The value of residential property transactions in 2009 was 80 per cent higher than in 2008 ('Market defies fear of real estate bubble in China', The New York Times, 4 March 2010). ${ }^{3}$ The first quarter of 2010 saw even more rapid increases in land prices, especially in the major coastal cities. ${ }^{4}$ In mid April 2010, the government sought to stabilise property prices by imposing restrictions on mortgage applications to buy second and third homes.

The roaring real estate market and the use of non-market means (for example, bans on purchases) to tame it are symptoms of some deep economic problems that

2 On a year-on-year basis, the growth rate of exports turned abruptly negative $(-2.2$ per cent) in 2008 (11 months) and remained negative through 2009 (11 months). The growth rate of FDI also turned abruptly negative in 2008 (11 months) - to -36 per cent from 35 per cent in 2008 (10 months); remained negative through 2009 (seven months); and recovered to historically low levels in 2009 (eight months) to 2010 (four months).

3 The article also reported that some duplexes in Shanghai were selling for US\$45 million each.

4 In 2009, land prices had gone up 200 per cent in Shanghai, 400 per cent in Guangzhou and 876 per cent in Wenzhou ('China: no one home', Financial Times, 21 February 2010). 
China has to address in order to sustain growth over the long run. Specifically, the real estate boom is part of a generalised investment boom unleashed by the RMB4 trillion stimulus program implemented since November 2008. The fact that the central government would fund only one-third of the proposed expenditure might prompt one to think of the stimulus program as a work agenda for the government to create the incentives to induce investment to reach the stated level, but such an interpretation would be wrong. The stimulus should be properly understood as permission by the central government to allow additional investments up to the stated level.

This different understanding is based on the reality that a large part of China's economy is still state controlled ${ }^{5}$ and that this segment pursues other objectives besides the ideal of profit maximisation. Because state-controlled enterprises (SCEs) are usually bailed out when their investments turn out to be based on over-optimistic projections or are derailed by bad luck, the outcome is the well-known interest-inelastic phenomenon of a 'thirst for investment' by SCEs and local governments. The state-appointed SCE manager is always in favour of expanding the scale and range of the operation of the SCE because it yields three major benefits to him or her: higher likelihood of promotion based on the proven ability to handle bigger things; greater patronage power to build a political base; and more resources that could potentially be diverted for personal gain. Similarly, local government leaders also share the enthusiasm of SCE managers for economic growth in their administrative regions for the same three reasons.

Whenever the state-controlled banks (SCBs), which dominate China's financial sector, extend loans to accommodate the high demand for investment loans by SCEs and local governments, a 'liquidity tango' is generated. The inevitable outcome of a protracted liquidity tango is high inflation followed by nonperforming loans (NPLs). ${ }^{6}$ The notable period when such liquidity tangos were rare was 1996-2001 when Zhu Rongji was prepared to punish the managers of SCBs severely for the appearance of new NPLs. The key is that whenever a SCB manager feels they are operating under a soft-budget constraint, they extend loans readily because a scaling-up of lending brings the three benefits mentioned previously.

At present, the central government has two lines of institutional defence to prevent the liquidity tango from getting out of hand in China's partially reformed

\footnotetext{
5 State-controlled firms include state-owned firms and publicly listed firms in which the State and its intermediaries hold the controlling share.

6 See Woo (2006) for a more detailed discussion of how the frequent rescue of state firms (also known as the soft-budget practices of the government) has made the economy inflation prone since economic decentralisation began in 1978.
} 
economy. The first line is that all large projects need the approval of the National Development and Reform Commission (NDRC; formerly, the State Planning Commission). The second line is that all banks are assigned credit quotas.

So, when Premier Wen Jiabao approved the stimulus program and covered only one-third of its cost, he was giving permission: 1) to the SCEs and local governments to invest more in order to offset the spending slump in the private sector; and 2) to the SCBs to extend the necessary loans to fund the approved projects. Herein lies the mechanism for the success of the stimulus program: the use of capacity-maximising state-controlled production and financial units to boost aggregate demand. Because the SCEs and SCBs are implementing a stateassigned mission, their managers cannot rightly be held responsible should the assigned projects turn out to be financial busts in the future.

Not surprisingly, the public media carries occasional anecdotes about new investments in industries plagued by overcapacity (for example, steel, cement and aluminium), trophy investments (for example, grand town centres, highspeed rail and stately administrative buildings) and spontaneous privatisation of project funds (for example, massive purchases of cars by state bodies). ${ }^{7}$ Another common concern about China's stimulus program was that the SCBs were channelling the flood of liquidity to the SCEs and neglecting the increased financing needs of the private sector brought on by the global financial crisis. Pressed for working capital, two well-known large private companies, Rizhao (a steel firm) and Mengniu (a dairy), agreed to be acquired by their state-owned counterparts.

While it is clear that China's massive macro-stimulus program has been successful in warding off deflation from the negative external shocks, we see this program as creating two potential hardware failures in the future.

The first is a weakening of the future fiscal position of the State. Many of the industrial and infrastructure investments in 2009 were undertaken by the 8000 local investment companies established by local governments. It has been estimated that the loans of these investment vehicles amounted to 51 per cent of GDP in 2009. ${ }^{8}$ (The present debt of the central government amounts to 20 per cent of GDP.) Adding in the large loans to the SCEs, the recent stimulus program has the potential of generating a huge number of NPLs. It is important to see

\footnotetext{
7 See, for example, Forsythe (2009); 'China: no one home', Financial Times, 21 February 2010; 'China audit finds misuse of funds tied to stimulus', Financial Chronicle, 29 December 2009, <http://www.mydigitalfc. com/news/china-audit-finds-misuse-funds-tied-stimulus-821>; and 'China boosts auditors' power as stimulus package spending prompts corruption concerns', People's Daily, 21 February 2010, <http://english. peopledaily.com.cn/90001/90776/90785/6898354.html>

8 The 51 per cent figure is from combining information in Shih (2010), who reported the debt of the central government to be 20 per cent of GDP, with information in the Financial Times ('China warned of growing "land loan" threat', 28 March 2010) that reported the combined figure was 71 per cent.
} 
that NPLs are not just a financial-sector problem; they are a fiscal problem. The US and UK bailouts of their financial systems in 2008-09 make this point most clearly.

Given China's history of liquidity tangos, it is reasonable to worry that most of the bank loans to the stimulus program will end up as NPLs. ${ }^{9}$ The resulting financial crisis would cause China to crash much like the United States and the United Kingdom did in 2009 unless the Chinese government stepped in againas it did in the 1998-2003 period to recapitalise the banks. Such a large-scale recapitalisation would inevitably mean that state expenditure in other categories would have to be reduced. ${ }^{10}$

The second potential hardware failure that could result from the 2009-10 macrostimulus program is a slowdown in the productivity growth of the economy. Unless the 2008-10 expansion of the state sector (sometimes occurring at the expense of the private sector) is balanced by a larger expansion in the private sector, the post-1949 economic history of China does not give ground for optimism that Premier Wen's way of imparting the needed boost to capacity utilisation during the global financial crisis will not become a drag on future productivity growth ('Communist Party needs to loosen its grip on China', The New York Times, 2 March 2010). ${ }^{11}$

\section{Potential software failure}

The satisfactory functioning of a market economy requires a wide array of regulatory institutions that ranges from straightforward law-and-order administration to complicated legal adjudication. China's strategy of incremental reform combined with the fact that institution building is a time-consuming process means that many of its regulatory institutions are either absent or ineffective. The result has been governance failure on many fronts, with the most well-known recent ones being violations of the welfare of consumers and workers.

There have been significant regulatory failures in keeping China's food supply and pharmaceutical products safe. The misuse of chemicals to lower production

\footnotetext{
9 Some observers have pointed out that the NPL ratio has stayed low since the second round of recapitalisation in 2003 and, hence, have claimed that the SCBs have improved their internal incentives and risk-assessment ability so much that large NPL ratios are a thing of the past. We, however, think that it is premature to pronounce victory on state-owned bank (SOB) reforms because the 2003-09 period has been one of high growth.

10 See Tong and Woo (2006) for an analytical discussion of the undermining of fiscal stability by the constant recapitalisation of SCBs.

11 This debate over the growth of the state firms at the expense of private ones is conducted over the heading of 'guojin mintui' (the state sector advances, and the private sector withdraws).
} 
costs has resulted in the addition of poisonous substitutes to toothpaste ('China investigates contaminated toothpaste', The New York Times, 22 May 2007; 'China prohibits poisonous industrial solvent in toothpaste', The New York Times, 12 July 2007), cough medicine ('From China to Panama, a trail of poisoned medicine', The New York Times, 6 May 2007) and animal feed ('Filler in animal feed is open secret in China', The New York Times, 20 April 2007; 'Another chemical emerges in pet food case', The New York Times, 9 May 2007); the application of lead paint to children's toys ('As more toys are recalled, the trail ends in China', The New York Times, 19 June 2007; 'Train wreck', The New York Times, 19 June 2007; 'Fisher-Price recalls 1.5m China-made toys', Financial Times, 2 August 2007); ${ }^{12}$ and the overuse of antifungals and antibacterials in fish farming ('FDA curbs sale of 5 seafoods farmed in China', The New York Times, 29 June 2007; 'A slippery, writhing trade dispute', The New York Times, 3 July 2007). Dereliction of duty by government officials is the fundamental reason for such governance failures. The most well-known recent case was the conviction of Zheng Xiaoyu, the former director of China's food and drug safety agency, for accepting bribes to approve production licences for pharmaceutical and food companies ('Ex-chief of China food and drug unit sentenced to death for graft', The New York Times, 30 May 2007; 'For 2 children, ban of a drug came too late', The New York Times, 13 July 2007).

There have also been significant regulatory failures in the treatment of labour, especially in the areas of occupational safety and wage payments. One of the most recent horrifying accounts involved the forced labour of kidnapped children in the brick kilns of Shanxi and Henan Provinces ('China to investigate into "slave labour" incident', China Daily, 16 June 2007). ${ }^{13}$ The official China Daily reported that 'as many as 1,000 children may have been sold into slave labour in central China' ('China brickwork slave children may number 1,000', China Daily, 15 June 2007). A parent visiting the brick kilns in her quest to find her son found that the local police were not only unwilling to help but demanded bribes ('Reports of forced labour unsettle China', The New York Times, 16 June 2007). In one case, the son of the village party secretary owned the brick kiln ('5 Chinese arrested in enslavement case', The New York Times, 18 June 2007).

Perhaps the two most dismaying revelations from the news reports on the brick kiln slavery are that this sad state of affairs has been going on for a decade ${ }^{14}$ and the 'forced labour and sexual exploitation have increased as the trend in

12 The first article also reported the recall of a ghoulish fake eyeball that was filled with kerosene and of an infant's wrist rattle that presented a choking hazard.

13 The New York Times ('China slave scandal brings resignation calls', 18 June 2007) reported that ' $[\mathrm{t}]$ he workers endured prison-like confinement with fierce dogs and beatings...Released workers were shown on television with festering wounds and emaciated bodies.'

14 This point was made by the popular tabloid Southern Metropolis Daily; see The New York Times ('China slave scandal brings resignation calls', 18 June 2007). 
human trafficking in China has taken a turn for the worst' ('More forced into prostitution, labour', China Daily, 27 July 2007). Yin Jianzhong, the senior official at the Ministry of Public Security who identified the worsening trend in human trafficking in China, recognised a reason for the negative development to be 'the loopholes in the legal and labour systems... [Specifically,] the Criminal Law on human trafficking protects women and children only and leaves out grownup and teen males. It doesn't have provisions for punishing those trafficking people for forced labour or prostitution' ('More forced into prostitution, labour', China Daily, 27 July 2007). The fact that such legal loopholes exist supports our contention that the main cause of the governance failures in China is the 'dereliction of duty by government officials'. ${ }^{15}$

Inadequate institutions of governance are not, however, the only cause of social tensions in China. The present economic development strategy, despite its ability to generate high growth, also generates high social tensions because, in the past 10 years, it has failed to reduce extreme poverty and to improve significantly the rural-urban and regional income distributions (Woo et al. 2004; Démurger et al. 2002). In an Asian Development Bank (ADB 2007) study of income inequality in 22 Asian countries, in 2004, only Nepal had a Gini coefficient (47.3) that was higher than China's (47.3). Meanwhile, in 2004, China's income ratio of the richest 20 per cent to the poorest 20 per cent (11.4) of the population was the highest in Asia - significantly higher than the next highest income ratio ( 9.5 for Nepal). China is probably the most unequal country in Asia today.

In the first phase of China's economic development, the provision of more jobs was enough to lower poverty significantly. At present, however, many of the people who are still poor require more than just job opportunities. They first need an infusion of assistance (for example, empowering them with human capital through education and health interventions) in order to be able to take up these job opportunities. Effective governance for equitable growth has now become even more challenging, so the probability of improving social harmony has been diminished.

Furthermore, the present mode of economic development also generates immense opportunities for embezzlement of state assets, seizure of farmlands for industrial development and corruption because of the absence of effective mechanisms to supervise government employees (Woo 2001). These features certainly make social harmony hard to sustain.

15 This point was made by the Shanxi Governor, Yu Youjun, who said: ‘For a long time, relevant government departments did little to regulate rural workshops, small coal mines and small factories, and they are basically out of control and are not being supervised... The dereliction of duty by civil servants and the corruption of individuals have made it possible for illegal labour to exist, particularly the abductions of migrant workers, and forced labour of children and mentally disabled people.' See 'Fears linger over child slaves at kilns', South China Morning Post, 23 June 2007. 
The data on social unrest are consistent with the hypothesis of rising social disharmony. First, the incidence of public disorder - labelled 'social incidents' has risen steadily from 8700 in 1993 to 32500 in 1999, and then to 74000 in 2004. Second, the average number of people involved in mass incidents has also risen greatly - from eight in 1993 to 50 in 2004.

Clearly, the number of mass incidents would have been lower if China had better governance. There would have been more pre-emptive efforts at conflict mediation by the government and less abuse of power by government officials if the government's actions had been monitored closely by independent mechanisms - and also if the government had been held more accountable for its performance.

\section{Power supply failure}

The two most probable power supply failures that China faces are trade protectionism and environmental crises. While we think that trade protectionism is the likelier of the two to cause growth failure in the medium run, we will limit ourselves to some brief remarks on this type of power supply failure just before concluding the chapter because we have analysed this issue at length in Woo and Xiao (2007) and Woo (2008).

The present mode of economic development has given China the dirtiest air in the world, is polluting more and more of its water resources and is, possibly, changing the climate patterns within China. The reality is that the CPC's new objective of living in harmony with nature is not a choice because the Maoist adage of 'man conquering nature' is just as unrealistic as creating prosperity through central planning. There is no doubt that China's rapid growth in the past two decades has done substantial damage to the environment (Economy 2004).

Water shortages appear to pose the most immediate environmental threat to China's continued high growth. ${ }^{16}$ Presently, China uses $67-75$ per cent of the 800-900 billion cubic metres of water available annually, and present trends in water consumption project the usage rate in 2030 to be $78-100$ per cent ('Top official warns of looming water crisis', South China Morning Post, 7 November 2006). The present water situation is already fairly critical because of the uneven distribution of water and the lower than average rainfall in the past 15 years.

16 Air pollution is also a serious problem. Of the 20 cities in the world identified by the World Bank as having the dirtiest air, 16 are in China. It is shocking that lead and mercury poisoning are more common than expected; see 'China's economic miracle contains mercuric threat', Financial Times, 18 December 2004; and 'A poison spreads amid China's boom', The Wall Street Journal, 30 September 2006. 
Right now, about '400 of China's 660 cities face water shortages, with 110 of them severely short' ('China may be left high and dry', The Straits Times, 3 January 2004). ${ }^{17}$

The extended period of semi-drought in northern China combined with economic and population growth have caused more and more water to be pumped from the aquifers, leading the water table to drop 3-6 metres a year ('Northern cities sinking as water table falls', South China Morning Post, 11 August 2001; Becker 2003). A study using measurements from satellites has established that the part of China north of the thirty-sixth parallel has been 'sinking at the rate of 2 mm a year' ('Northern China sinking... as the south rises', The Straits Times, 18 March 2002). ${ }^{18}$ Specifically, 'Shanghai, Tianjin, and Taiyuan are the worst hit in China, with each sinking more than two metres (6.6 feet) since the early 1990s' ('Chinese cities, including Olympic host Beijing, slowly sinking', Agence FrancePresse, 23 July 2004). The overall water situation in northern China is reflected in the fate of the Yellow River, 'which started drying up every few years from 1972, did so for increasing periods of time over longer distances in the 1990s until 1997, when it dried up for almost the entire year over a stretch of several hundred kilometres' ('China may be left high and dry', The Straits Times, 3 January 2004).

Water shortages and the increasing pollution of water are not the only serious environmental threats to the economy of northern China ${ }^{19}$. The desert is expanding (possibly, at an accelerating pace) and humans appear to be the chief culprits. The State Forestry Administration reported that 28 per cent of the country's landmass was affected by desertification in 1999 and 37 per cent was affected by soil erosion. The report identified about 65 per cent of the desert as having been created by 'over-cultivation, overgrazing, deforestation and poor irrigation practices' ('Quarter of land now desert-and man mostly to blame', South China Morning Post, 30 January 2002). One direct upshot is a great increase in the frequency of major sandstorms ${ }^{20}$ that play 'havoc with aviation in northern China for weeks, cripples high-tech manufacturing and worsens respiratory problems as far downstream as Japan, the Korean peninsula and even the western United States' ('Billions of trees planted, and nary a dent

\footnotetext{
17 The shortage is reported to be most acute in Taiyuan in Shanxi and Tianjin (Becker 2003).

18 According to Becker (2003): 'Some 60 per cent of the land in Tianjin municipality is plagued by subsistence.'

19 Examples of reports about serious water pollution include: 'Main rivers facing a "pollution crisis"', South China Morning Post, 6 June 2003; 'Booming cities polluting scarce water supplies', The Straits Times, 18 September 2003; 'Rivers run black, and Chinese die of cancer', The New York Times, 12 September 2004; “'Cancer villages" pay heavy price for economic progress', South China Morning Post, 8 May 2006; and 'Rules ignored, toxic sludge sinks Chinese village', The New York Times, 4 September 2006.

20 The number of major sandstorms in China was five in the period 1950-59, eight in 1960-69, 13 in 197079, 14 in 1980-89, 23 in 1990-99, 14 in 2000, 26 in 2001, 16 in 2002 and 11 in 2003, according to Yin Pumin ('Sands of time running out: desertification continues to swallow up "healthy" land at an alarming rate', Beijing Review, 16 June 2005).
} 
in the desert', The New York Times, 11 April 2004). In the assessment of Chen Lai, Vice-Minister of Water Resources: 'It will take nearly half a century for China to control the eroded land and rehabilitate their damaged ecosystems in accordance with China's present erosion-control capabilities' ('Quarter of land now desert - and man mostly to blame', South China Morning Post, 30 January 2002).

While northern China has been getting drier and experiencing desertification, nature - as if in compensation (or in mockery) - has been dousing southern China with heavier rains, causing heavy floods that have brought considerable deaths and property damage almost every summer since $1998 .^{21}$ The sad possibility is that the northern droughts and southern floods might not be independent events but a combination caused by pollution that originates in China. We will have more to say about this possibility later.

Clearly, without water, growth cannot endure. In response to this, the government began implementation in 2002 of Mao Zedong's 1952 proposal for three canals to be built to take water from the south to the north: an eastern coastal canal from Jiangsu to Shandong and Tianjin, a central canal from Hubei to Beijing and Tianjin, and a western route from Tibet to the north-western provinces ('Ambitious canal network aims to meet growing needs', South China Morning Post, 27 November 2002). Construction of the eastern canal (to be built on a part of the existing Grand Canal) started in 2002 and of the central canal in 2003. Work on the western canal is scheduled to begin in 2010 on completion of the first stage of the central canal.

This massive construction project will be not only technically challenging but extremely sensitive politically and fraught with environmental risks. The central canal will have to tunnel through the foot of the huge dyke that contains the elevated Yellow River and the western canal will have to transport water through regions susceptible to freezing. The number of people displaced by the Three Gorges Dam was 1.1 million and this water-transfer scheme is a bigger project. Moving people involuntarily is certainly potentially explosive politically. The project could also be politically explosive on the international front. One plan for the western canal calls for 'damming the Brahmaputra River and diverting

\footnotetext{
21 The National Development and Reform Commission (NDRC 2007) reported: 'The regional distribution of precipitation shows that the decrease in annual precipitation was significant in most of northern China, [the] eastern part of the north-west, and north-eastern China, averaging 20-40 mm/10a, with [the] decrease in northern China being most severe; while precipitation significantly increased in southern China and southwestern China, averaging 20-60 mm/10a...The frequency and intensity of extreme climate/weather events throughout China have experienced obvious changes during the last 50 years. Drought in northern and northeastern China, and flood in the middle and lower reaches of the Yangtze River and south-eastern China have become more severe.'
} 
200 billion cubic metres of water annually to feed the ageing Yellow River' - a scenario that is reportedly 'giving sleepless nights to the Indian government' ('China's river plan worries India', Times of India, 23 October 2006).

Many opponents of the water-transfer project have argued that water conservation could go a long way towards addressing China's water problems because currently a tremendous amount of water is wasted ('Alert sounded over looming water shortage', The Straits Times, 10 June 2004). The most important reason for this inefficient use of water lies in the fact that 'China's farmers, factories and householders enjoy some of the cheapest water in the world' ('Water wastage will soon leave China high and dry', South China Morning Post, 8 March 2006), even though China's per capita endowment of water is onequarter of the world average ('Alert sounded over looming water shortage', The Straits Times, 10 June 2004).

There is, however, the unhappy possibility that neither the price mechanism nor the three canals can solve China's water problems, making its growth unsustainable unless the present mode of economic development is drastically amended.

\section{A reform agenda for avoiding crashes on the road to prosperity}

\section{Dealing with potential hardware problems}

We identified two potential hardware problems arising from the large dose of SCE-SCB-based macro-stimulus that Prime Minister, Wen Jiabao, has administered to maintain full utilisation of production capacity: NPLs that could cause either the SCBs to collapse or a fiscal crisis from the bailout of the SCBs, and lower productivity growth in the future from the crowding out of the private sector by the state sector. China's instruments of macro-stimulus have created a trade-off between maintenance of full capacity utilisation in the short run and sustenance of a high rate of capacity expansion in the long run.

Our recommendation is that China eliminates this trade-off by replacing its macro-stimulus with three new growth drivers that are interrelated: 1) creation of more new entrepreneurs; 2) urbanisation according to the principle of future homeownership; and 3) development of a modern financial system in which the private sector has a greatly enhanced role.

The State can partly offset the expanded state sector by mobilising inland migrant workers laid-off from the coastal provinces into an entrepreneurial 
force. Many of these migrants have sufficient work experience to start their own factories/workshops to take advantage of the increased cost competitiveness of the inland provinces created by the explosive extension of the national transportation network during the global financial crisis. Because the primary barrier to the emergence of this group of owner-operators is the availability of credit, the government should legalise small and medium private banks, as they have comparative advantage over the four large state banks in catering to the needs of these new entrepreneurs. The healthy development of the new private banks would require that the system of prudential supervision be strengthened and that interest rates be deregulated. Farmland should also be privatised so that the new businesses can have the collateral to access credit from the new private banks. As most of the migrants are from the western provinces, the government could unleash this first driver of growth in the western provinces on an experimental basis.

The creation of a new large group of private entrepreneurs will bring three major benefits

- expenditure by this new group will substitute for the present macro-stimulus program in keeping aggregate demand high

- private firms are likely to have higher productivity growth than SCBs

- these small and medium private enterprises will be more labour intensive than SCEs.

The second new growth driver is urbanisation based on the principle of affordable future homeownership. The fast growth of the real estate sector-not only recently but in the past decade - reflects not just speculative demand but genuine pent-up demand for housing and genuine accommodation to meet the high rate of the joint industrialisation-urbanisation process. ${ }^{22}$ The bulk of the new arrivals from the countryside cannot qualify for bank mortgages, so many investors have been buying multiple housing units to rent to new arrivals with the intention of raising the rents over time in line with the income growth of the renters. In this sense, much of the recent housing demand has been speculative.

We propose that China studies the low-cost public housing schemes in Hong Kong and Singapore and establishes a national housing program under which the new arrivals would rent homes for seven years and then have the first right to buy these units at a price based on construction costs. This 'future ownership' form of urbanisation would prevent the problem of empty housing

22 If speculative demand had been the overwhelmingly dominant cause of the property boom, house rents would not have risen substantially (because the speculative investors would tend to rent out their extra units). Instead, rent in Beijing in March 2010 was 19.6 per cent above that in March 2009; see 'Survey shows house prices still too high', China Daily, 12 May 2010, < http://www.chinadaily.com.cn/metro/2010-05/12/ content_9839054.htm> 
held for speculative reasons escalating into NPLs. China can afford a massive public housing program because the expensive part of such programs in other countries is the cost of land and not the cost of the structures - and land in China is mostly owned by the State. ${ }^{23}$

Our proposed form of urbanisation will support China's growth in three ways

- through the maintenance of real estate investment to supply the needed housing and to help maintain the existing level of aggregate demand

- through the redirection of bank loans to new rural migrants, with the new housing agency as the intermediary, to prevent the appearance of NPLs

- this housing scheme will redistribute income to the rural migrants (which helps in reducing the threat of software failure), with the positive side effect that consumption will rise to help offset the elimination of the macrostimulus program.

We note that the first and second new growth drivers are mutually reinforcing. The new enterprises of the former rural migrants would inevitably be located in or near towns and cities to take advantage of infrastructure and positive spillovers from agglomeration. We note that the main institutional adjustments that must be made to enable the working of the second new growth driver are the same as those that would help the development of the first new growth driver: privatisation of farmland, termination of the household registration system and liberalisation of the financial system.

The third interrelated new growth driver is the true legalisation of privately owned financial institutions. ${ }^{24}$ The emergence of a strong small-medium banking sector would reduce the dominance of the SCBs and hence make the economy less vulnerable to their collapse from potential NPLs. The entry of private banks (domestic and foreign) will reduce the probability that any one of the big four state banks would remain too big to fail-and hence reduce the soft-budget protection enjoyed by the now monopoly state banking system. The privatisation of some units of the SCBs, and the emergence of large domestic private banks, will also help in strengthening the budget constraints perceived by the managers of SCBs. The development of a modern banking system with a major role for the private sector will thence increase the quality of bank loans

23 It should be noted that housing construction is relatively labour intensive and that home decoration is highly labour intensive.

24 We do not consider listed banks in which the State holds the controlling share (often through statecontrolled intermediaries - for example, 'legal persons') to be private banks in the true sense. 
along with the increase in the quantity of bank loans-helping to reduce the appearance of NPLs along with market-directed investments replacing the macro-stimulus program. ${ }^{25}$

\section{Dealing with potential software problems}

The important realisation about hardcore poverty is that, in today's China, introducing more of the same economic policies will not produce the same salubrious results on every front because the development problems have changed. This was illustrated above with the example that, during the first phase of economic development, the provision of more jobs (through economic deregulation) was enough to lower poverty significantly, while more recently job opportunities alone have proved insufficient.

Complicating matters is that there have not just been rising expectations about the performance of the State in its traditional functions (for example, coordinating water use); there are also new expectations about the participation of the State in some additional areas (for example, reducing income inequality). In this new situation, the greater use of democratic procedures, the establishment of an independent judiciary and the restoration of a free press might be inevitable if the CPC is to successfully accommodate the rising social expectations and mediate the emerging differences in social expectations.

One main source of recent social unrest in rural China has been the conversion of farmland to industrial parks without adequate compensation for the farmers. It is interesting therefore that the 'No. 1 Document' issued in January 2006 jointly by the CPC Central Committee and the State Council pledged to not only 'stabilise and regulate the transfer of land-use rights and accelerate land acquisition reforms', but 'expand channels to express public opinions in the countryside and improve the mechanism to resolve social conflicts' ('New pledge to give farmers a louder voice', South China Morning Post, 30 January 2007). ${ }^{26}$

The desire by the Hu-Wen leadership to improve the institutions of governance is also borne out by the following report from the South China Morning Post about what Premier Wen said when he met a group of Chinese citizens in Japan in April 2007:

During 30 minutes of impromptu remarks, he said the key to pursuing social justice, the mainland's most important task, was to 'let people be masters of their houses and make every cadre understand that power is invested in them by the people'...Mr Wen is known for being careful

25 The management of state assets and the regulation of the financial sector should also be reformed to eliminate the phenomenon of repeated recapitalisation of the SCBs.

26 The No. 1 Document designation is designed to show that this is the most important task in the new year. 
about what he says, whether in prepared remarks or speaking off the cuff. The fact that he highlighted, in the presence of Hong Kong and overseas journalists, the need for political reform is uncharacteristic and interesting... There have been signs that the leadership under President $\mathrm{Hu}$ Jintao is under increasing pressure to undertake drastic political reforms to consolidate the party's grip on power and stamp out widespread corruption. ('Impromptu remarks reveal the party's pressure for reforms', South China Morning Post, 16 April 2007)

While there are reasonable grounds for an analyst to doubt either the sincerity of Premier Wen's words or his ability to act on them, the analyst cannot doubt that Premier Wen is at least aware that democracy is one way to solve many of China's problems of governance. The embrace of the harmonious society program by the $\mathrm{Hu}$-Wen leadership reveals the CPC's acknowledgment that democracy, the rule of law, a reduction in corruption, land reform and improved income distribution make an indivisible combination that is necessary to ensure the social stability that will keep the economy on the high-growth path needed to catch up with the United States (a vision that acts as the bedrock of the CPC's legitimacy to rule).

Warding off software failure is of course much more difficult than warding off hardware failure because political reforms lie at the heart of successful reconfiguration of the software of governance. The modernisation of China's administrative software will require the adoption of free elections, a free press and an independent judiciary.

\section{Dealing with power supply failure caused by environmental degradation}

The general point is that effective policymaking on the environmental front is a very difficult task because much of the science about the problem is not known. For example, there is now persuasive evidence that China's voluminous emissions of black carbon (particles of incompletely combusted carbon) have contributed significantly to the shift to a climate pattern that produces northern droughts and southern floods of increasing intensity (Menon et al. 2002; Streets 2005). The biggest source of what has been called in the popular media the 'Asian brown cloud' is burning of coal and bio-fuels in China and India. This link between pollution and water shortages further reduces the possibility that either the price mechanism or the three canals can solve China's water problems unless the present mode of economic development is drastically amended.

China must no longer select its water strategy and it energy strategy separately. A systems approach to policymaking is necessary because the interaction among the outcomes from the different sectoral policies can generate serious unintended 
environmental damage. If part of the shift in China's climate is integral to global climate change, a sustainable development policy would require a complete rethinking of the location of population centres and the types of enhanced international cooperation on global environmental management.

The uncomfortable reality for China is that unless ecological balance is restored within the medium term, environmental limits could choke off further economic growth. And the uncomfortable reality for the rest of the world is that the negative consequences of large-scale environmental damage within a geographically large country are seldom confined within that country's borders. The continued march of China's desertification first brought more frequent sandstorms to Beijing and then, beginning in April 2001, sent yellow dust clouds not only across the sea to Japan and Korea but across the ocean to the United States. China's environmental management is a concern not only for China's welfare but for global welfare.

In discussing the environmental aspects of the water-transfer plan, it is important to note that there is now open controversy in China involving a key government infrastructure project - and this controversy is not limited to members of the technocracy. The very public nature of the controversy - and the involvement of more than just scientists, engineers and economists in it-reveals how very far social attitudes have progressed. The important point is that this change in social expectations will require any government in China to live in harmony with nature. Any government will, however, have great difficulties in doing so even if it wants to because a green growth policy involves a systems approach, and scientific understanding of many ecological subsystems and the nature of their interactions is still rather incomplete.

The global environment is an important area in which China can help to build a harmonious world system. ${ }^{27}$ Specifically, China should be mobilising international consensus to form an international research consortium to develop ways to burn coal cleanly because China is now building a power station a week and hence is able to facilitate extensive experimentation on prototype plants to burn coal cleanly. Furthermore, given the growing water shortages in China (especially in the north) and in many of its neighbouring countries, China should start a regional forum on the joint use of water from the Tibetan Plateau before the situation becomes too critical. China should also be mobilising an international scientific research effort on the desalination of seawater for drinking. If global cooperation on clean energy research and desalination research is successful, it will unleash sustainable development in the whole world.

27 See McKibbin et al. (2008) for an example of an efficient global carbon dioxide emission compact that China and the rest of the world could adopt. 


\section{Dealing with power supply failure caused by trade protectionism}

Finally, we consider briefly how to reduce the probability of the speeding car (that is, China) crashing into a roadblock that takes the form of trade protectionism. There is no denying that international tensions over China's large chronic trade surpluses have increased greatly since 2004, and have been exacerbated by the global financial crisis. China has been accused of misconduct on many international fronts - for example, causing the global financial crisis by forcing cheap loans on US consumers ${ }^{28}$ and engaging in beggar-thy-neighbour devaluations by keeping a fixed renminbi-US dollar exchange rate ('Will China listen?', The New York Times, 17 March 2010).

The root of China's chronic current account surplus is that the sum of savings by SCEs and the private sector exceeds the sum of their investment expenditures. This chronic large trade surplus reveals a deep-seated and serious problem in China's economy: its dysfunctional financial system (Liu and Woo 1994). China generates the current account surplus because of inadequate financial intermediation and the surplus grows over time because the dysfunctional financial system fails to pool risks to reduce uncertainty-induced savings and fails to provide loans to reduce investment-motivated saving. The optimal solution to China's excess saving is to establish an improved intermediation mechanism for coordinating private savings and private investments.

It must be mentioned in fairness, however, that a trade imbalance reflects the economic situation in two countries: China could not have over-saved if the United States had not under-saved. US profligacy is to be blamed for the trade tensions just as much as Chinese thriftiness. Furthermore, as Woo (2008) has pointed out, even if China's trade balance were zero, the pains of structural adjustment and income redistribution caused by technological innovations in the United States, institutional changes in the United States, globalisation and immigration into the United States would still be there- and the amount of US worker anxiety generated collectively would be much larger than the additional worker anxiety generated by the widening trade deficit.

The reduction of trade tensions between the United States and China would be helped if the United States now strengthened its social safety nets to lower the cost of changing jobs. Specifically, the US Congress should speed up the reduction of fiscal imbalances and expand trade adjustment programs - especially those

\footnotetext{
28 Nicholas Lardy has described China as being in a co-dependent relationship with the United States in which ' $[\mathrm{t}]$ he United States is the addict. We are addicted to consumption. China is the dealer. They're supplying the credit that makes it possible for us to over-consume' ('Winter Institute: China and US joined at the hip', News release, 2 March 2009, From conference at St Cloud State University, Minnesota, 27 February 2009, <http://www.stcloudstate.edu/news/pressreleases/default.asp?storyID=28126>).
} 
that upgrade the skills of younger workers. The important point is that USChina trade tensions would be lower if both countries undertook corrective policies rather than if China acted alone.

Apart from what the United States and China can each do independently to reduce international tensions over the trade imbalance, they should also work together to prevent the General Agreement on Tariffs and Trade (GATT)-WTO free-trade regime from weakening. Specifically, China has benefited immensely from the WTO system, yet it has, up to this point, played a very passive role in pushing the Doha Round of negotiations forward to completion. By default, Brazil and India have assumed the leadership of the developing economies' camp in the trade negotiations. According to Susan Schwab, the US Trade Representative at the Group of Four (G4: the United States, European Union, Brazil and India) meeting in Potsdam in June 2007, Brazil and India retreated from their earlier offers to reduce their manufacturing tariffs in return for cuts in agricultural subsides by the industrialised economies because of 'their fear of growing Chinese imports' ('Schwab surprised by stance of India and Brazil' and 'China's shadow looms over Doha failure', Financial Times, 22 June 2007).

With the United States weakening in its resolve to protect the multilateral freetrade system (Woo 2008), China should now become more active in the Doha Round negotiations to deregulate world trade further. Such a role will be very much in China's interest because Brazil is now bypassing multilateral trade liberalisation by entering into free-trade negotiations with the European Union. The fact is that a growing number of nations such as Brazil 'are increasingly wary of a multilateral deal because it would mandate tariff cuts, exposing them more deeply to low-cost competition from China. Instead, they are seeking bilateral deals with rich countries that are tailored to the two parties' needs' ('Brazil, others push outside Doha for trade pacts', The Wall Street Journal, 5 July 2007). It is time for China to show that it is a responsible stakeholder by joining in the stewardship of the multilateral free-trade system. Such an international stance would also reduce the threat of this type of power supply failure to China's own growth.

\section{Conclusions}

Our assessment is that the probabilities of either a software failure or a power supply failure are higher than the probability of a hardware failure because the first two are harder problems to deal with. For most hardware problems, China can learn from the experiences of the rest of the world, especially those of the richer countries in East Asia, as long as ideological constraints on methods of economic management continue to wither. The 1868 insight of the Meiji 
reformists that success in economic catch-up largely involves willingness to adopt and adapt to 'best international practices' will continue to apply to China until its per capita GDP converges with that of Japan and Western Europe.

Dealing with software failure is harder than dealing with hardware failure for two major reasons. The first is that development policymaking in China has become more challenging because popular expectations of administrative performance have risen dramatically with income growth and, more importantly, with increasing knowledge of the outside world. A Chinese government that consistently fails to produce results in line with the rise in social expectations runs the increasing risk of being challenged by internal factions within the CPC, culminating in an open split, with each side seeking the support of non-party groups.

The second reason is that successful reconfiguration of the administrative software requires not just highly developed political skills but favourable circumstances in the domestic political arena and a benign international environment - both of which are normally beyond the reach of most politicians to manipulate. What happens in the future will depend on whether the CPC is sufficiently confident and politically skilful enough to lead the democratic transition and emerge afterwards as the most important political force. History tells us that the French and British monarchies reacted very differently to popular requests for reform of the administrative software - and the outcomes were very different in each case. The practical issue is whether the CPC can do a better job in political transition than the Kuomintang did in Taiwan during the period 1983-88.

Dealing with power supply problems is much harder than dealing with hardware problems because it often involves working on issues of which the world has few (mostly, no) successful experiences (for example, a global carbon dioxide emission pact) or it involves working with powerful foreign partners where differentiation between cultural misunderstanding (for example, a bombastic 
national but nevertheless well-meaning demeanour) and unstated national rivalry (for example, keeping shipping lanes open) is not easy — or it involves working with both of these difficult conditions. As most solutions to power supply failures require a high degree of mobilisation of international effortwhich China has historically been too weak to participate in meaningfully-

China and the other major powers will need to converge in their rethinking of China's responsibilities in the world economy before there can be significant cooperation on common problems. ${ }^{29}$

China's economy has now become an important shaping force of the global economy and, along with it. Chinese civil society has come to possess more and more of the middle-class aspirations common in the industrialised world. China's continued high growth now necessitates a new development strategy that also emphasises the creation of a harmonious society and a harmonious world - and this will require an improvement in its administrative software and the sustenance of the global power supply.

\section{References}

Asian Development Bank (ADB) 2007, Key Indicators: Inequality in Asia, Asian Development Bank, Manila.

Becker, Jasper, 2003, "The death of China's rivers," Asian Times Online, August 26.

Chang, G. G. 2001, The Coming Collapse of China, Random House, New York.

Démurger, S., Sachs, J. D., Woo, W. T., Bao, S., Chang, G. and Mellinger, A. 2002, 'Geography, economic policy and regional development in China', Asian Economic Papers, vol. 1, no. 1 (Winter), pp. 146-97.

\footnotetext{
29 A timely discussion about China's role in the future world economy is found in the collection of papers in Garnaut et al. (2009) - for example, Woo (2009). The present dispute between China and its biggest trading partners over its exchange-rate regime illustrates very well the difficulties of handling a power supply problem. The proposed - and highly contentious - solution of a significant renminbi appreciation is typical of the narrowly focused solutions that have been proposed for power supply failures (for example, only building canals to transfer water from south to north when China should also reduce black carbon and concentrate urbanisation in southern China). Specifically, an economically more efficient - and politically more amicablesolution to the trade imbalance problem would require: 1) more than one policy instrument to be used to reduce the trade imbalance (that is, not just appreciation of the renminbi, but, at least, liberalisation of the Chinese government's procurement policy and export promotion by the United States); 2) more than one party to adjust its policies when the situation is the product of policies in at least two countries (that is, the United States and China must take corrective policies, not just China); and 3) more than the pursuit of a single policy target but achievement of a range of more direct welfare objectives as well (that is, going beyond reduction in the size of China's trade surplus to include objectives such as strengthening the WTO system of adjudication, and keeping GDP growth rates high in all countries).
} 
Economy, E. C., 2004, The River Runs Black: The environmental challenge to China's future, Cornell University Press, Ithaca, NY.

Forsythe, M. 2009, 'Is China's economy speeding off the rails?', The New York Times, 23 December 2009.

Garnaut, R., Song, L. and Woo, W. T. (eds) 2009, China's New Place in a World in Crisis: Economic, geopolitical and environmental dimensions, ANU E Press and Brookings Institution Press, Canberra and Washington, DC.

Lardy, N. R. 1998, China's Unfinished Economic Revolution, Brookings Institution Press, Washington, DC.

Liu, L.-Y. and Woo, W. T. 1994, 'Saving behavior under imperfect financial markets and the current account consequences', Economic Journal, vol. 104, no. 424 (May), pp. 512-27.

McKibbin, W. J. and Woo, W. T. 2003, 'The consequences of China's WTO accession on its neighbours', Asian Economic Papers, vol. 2, no. 2 (Spring/ Summer), pp. 1-38.

McKibbin, W. J., Wilcoxen, P. J. and Woo, W. T. 2008, 'China can grow and help prevent the tragedy of the CO2 commons', in L. Song and W. T. Woo (eds), China's Dilemma: Economic growth, the environment and climate change, Asia Pacific Press and Brookings Institution Press, Canberra and Washington, DC, pp. 190-225.

Menon, S., Hansen, J., Nazarenko, L. and Luo, Y. 2002, 'Climate effects of black carbon in China and India', Science, vol. 297, no. 27 (September), pp. 2250-3.

National Development and Reform Commission (NDRC) 2007, China's National Climate Change Programme, June, National Development and Reform Commission, Beijing.

O'Neill, J., Wilson, D., Roopa, P. and Stupnytska, A. 2005, How solid are the BRICs?, Global Economics Paper No. 134, 15 December, Goldman Sachs, New York.

Sachs, J. D. and Woo, W. T. 2000, 'Understanding China's economic performance', Journal of Policy Reform, vol. 4, no. 1, pp. 1-50.

Shih, Victor, 2010, "China's 8,000 Credit Risks," The Wall Street Journal, February 8, 2010.

Streets, D. 2005, 'Black smoke in China and its climate effects', Asian Economic Papers, vol. 4, no. 2 (Spring/Summer), pp. 1-23. 
Tong, J. and Woo, W. T. 2006, 'Keeping fiscal policy sustainable in China', in R. Garnaut and L. Song (eds), The Turning Point in China's Economic Development, Asia Pacific Press, Canberra.

Woo, W. T. 2001, 'Recent claims of China's economic exceptionalism: reflections inspired by WTO accession', China Economic Review, vol. 12, nos 2-3, pp. 107-36.

Woo, W. T. 2006, 'The structural nature of internal and external imbalances in China', Journal of Chinese Economic and Business Studies, vol. 4, no. 1 (February), pp. 1-20.

Woo, W. T. 2008, 'Understanding the sources of friction in US-China trade relations: the exchange rate debate diverts attention away from optimum adjustment', Asian Economic Papers, vol. 7, no. 3 (Fall), pp. 65-99.

Woo, W. T. 2009, 'China and international financial reform', in R. Garnaut, L. Song and W. T. Woo (eds), China's New Place in a World in Crisis: Economic, geopolitical and environmental dimensions, ANU E Press and Brookings Institution Press, Canberra and Washington, DC, pp. 15-32.

Woo, W. T. and Xiao, G. 2007, 'Facing protectionism generated by trade disputes: China's post-WTO blues', in R. Garnaut and L. Song (eds), China: Linking markets for growth, Asia Pacific Press, Canberra.

Woo, W. T., Li, S., Yue, X., Wu, H. X. and Xu, X. 2004, The poverty challenge for China in the new millennium, Report to the Poverty Reduction Taskforce of the Millennium Development Goals Project of the United Nations, United Nations, New York. 


\section{Rebalancing China's economic structure}

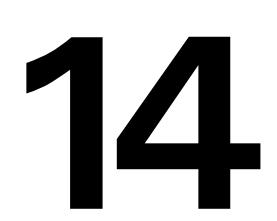

\section{Yiping Huang and Bijun Wang}

\section{Introduction}

Chinese Premier, Wen Jiabao, warned in early 2010 that 'the Chinese economy is still imbalanced, inharmonic and unsustainable'. This is not the first time that Premier Wen has expressed concerns about growth quality. He first raised the issue when he took office in 2003 and repeated the warning when the economy showed signs of overheating in 2007. It is probably fair to rank transformation of the growth model as one of the top policy priorities under Wen's government.

Indeed, despite its continuous success maintaining strong growth, the Chinese economy has exhibited worsening structural imbalances in recent years. Some of the growth quality problems highlighted by Premier Wen and other policymakers include the very high investment share of gross domestic product (GDP), the very large current account surplus, inefficient resource use, unequal income distribution, serious pollution and corruption among local government officials. If these problems persist, China's strong economic growth will probably not be sustainable.

The government has undertaken a range of policy measures to adjust China's economic structure during the past seven years. For instance, it has provided large subsidies to agriculture to boost rural income and it has tightened controls over investment projects to reduce overcapacity in certain industries. It has adjusted export tax rebates and revalued the currency in order to slow export growth and narrow current account surpluses. It has required all provinces to lower the energy intensity of GDP by 20 per cent during the eleventh Five-Year Plan to improve energy efficiency and curb pollution. And it has even adopted a new strategy to respond to global climate change.

All these policy efforts, however, have failed to reverse the overall trend of a worsening economic structure. Between 2003 and 2008, the investment share of GDP increased while the consumption share fell, the current account surplus became larger, income distribution became more unequal and pollution probably 
became more serious. These do not imply that all policy efforts were ineffective; but deteriorating problems of imbalance certainly raise an important question about what more needs to be done to alleviate the growing risks.

In this chapter, we take a close look at the evolution of structural imbalances in China and their possible remedies. We argue that most of the policy measures implemented so far have addressed the symptoms, but not the root cause. For instance, the over-investment problem was probably caused by the expected high returns to investment. Therefore, unless the incentive structure is corrected, administrative measures controlling investment projects are unlikely to be effective. Marx once said that if the profit rate was above 100 per cent, capitalists would be willing to risk their lives. In this sense, Chinese entrepreneurs are no less likely than others to prove him right.

We further propose that the fundamental cause of structural imbalance lies in the unique pattern of market liberalisation during the reform period: complete liberalisation of product markets but with distortions remaining in factor markets. Such a reform approach generally represses prices for labour, land, capital, resources and the environment. These distortions have the effect of subsidy equivalents for producers, exporters and investors. This is probably why growth has been so strong in China, but exports and investment have been even stronger. If our analysis is right, correction of the structural imbalance problems in China is dependent on the liberalisation of factor markets.

The remainder of this chapter is organised as follows. The next section summarises the major manifestations of China's structural imbalances and then reviews what the government has done to alleviate these imbalances in the past five years. The next section discusses the asymmetric liberalisation of product and factor markets. Subsequently, the effects of factor-market distortion on the structural imbalance problem are presented, before some final conclusions are drawn.

\section{China's growing imbalance problems}

Structural imbalance is a broad and subjective concept, although international experience provides some useful references. We focus our discussion on imbalance problems in three broad areas: shares of investment and consumption in GDP; income distribution among households; income distribution across households, the corporate sector and the government; and current account imbalances. 


\section{Over-dependence on investment}

One of the most widely identified imbalance problems is the rising share of investment in GDP, which rose from 38.2 per cent in 1978 to 49.3 per cent in 2008. In contrast, the consumption rate decreased from 62.1 per cent to 46.1 per cent during the same period. In 2008, household consumption accounted for only about 36 per cent of GDP. This share is extraordinarily low compared with most developing and industrialised countries.

A high and rising investment share in itself might not be a problem, as investment is a necessary driver of economic growth. A very high investment share, however, increases the risk of excess capacity and low returns. East Asian economies traditionally have very high investment shares, especially during periods of economic take-off. China's current investment share is, however, high even compared with its East Asian neighbours. During the past several decades, only three economies experienced above-40 per cent investment shares. The first was Singapore in the early 1980s - but its share collapsed in the mid 1980s when structural adjustment was forced on the country. The other two were Malaysia and Thailand in the 1990s. Unfortunately, financial crisis quickly followed in both countries. These previous incidents highlight the potential risks for the Chinese economy should its investment share remain at extraordinarily high levels.

We are not certain that there is an optimal range for the investment share, since it probably varies according to individual economies' particular conditions. Chenery and Syrquin (1975), however, examined the empirical relationship between a country's consumption rate and its per capita national income using data from 101 countries. Applying the empirical relationship implied by their study - known as the Chenery Standard - we find that China's investment share of GDP is roughly 20 percentage points higher than the benchmark, while its consumption rate is about 20 percentage points lower (Figure 14.1).

Sources: National Bureau of Statistics (NBS) various years, China Statistical Yearbook, China Statistics Press, Beijing; Chenery, H. and Syrquin, M. 1975, 'Patterns of development, 1950-1970', Oxford University Press, UK; He, G. 2009, A study on the unbalance between investment and consumption and its impact on China's economic growth, Doctoral dissertation, Huazhong University of Science and Technology. 
Figure 14.1 Comparison of the investment rate and consumption rate between China and the Chenery Standard, 1990-2008

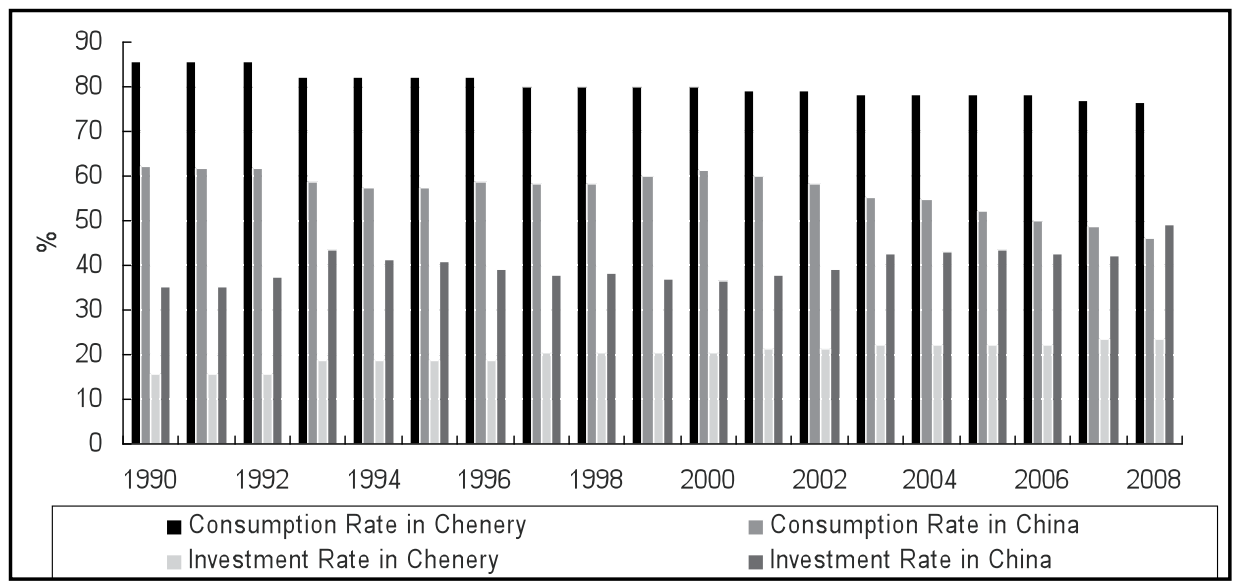

Sources: National Bureau of Statistics (NBS) various years, China Statistical Yearbook, China Statistics Press, Beijing; Chenery, H. and Syrquin, M. 1975, 'Patterns of development, 1950-1970', Oxford University Press, UK; He, G. 2009, A study on the unbalance between investment and consumption and its impact on China's economic growth, Doctoral dissertation, Huazhong University of Science and Technology.

\section{Current account surpluses}

The rapid growth of China's current account surplus is a relatively recent phenomenon. The sharpest rise in the current account surplus occurred after 2004. Within three years, the surplus jumped from 3.5 per cent of GDP, in 2004, to the highest in history at 10.8 per cent in 2007. The soaring trend moderated in 2008 and 2009 as a result of seriously dampened external demand affected by the current global financial crisis (Figure 14.2). The surplus shrank further to 3.5 per cent of GDP due to much faster growth of imports than of exports. This further downward shift could, however, prove to be temporary in the absence of more decisive policies for structural adjustment.

By definition, the current account surplus is equivalent to the excess of a country's savings over its investment. A persistent current account surplus means that China, as a low-income economy, has been exporting capital to other countries through financial intermediaries. This is obviously odd since China still has many areas where investment is badly needed. More importantly, most of the current account surplus ends up as foreign exchange reserves. Returns to such investment, such as US Treasury bonds, are relatively low. If the central bank pays a higher rate for domestic bills then the holding of foreign exchange reserves could imply a net loss. This still does not take into account exchange rate risk. 
The current account surplus has recently been closely tied to the renminbi (RMB) exchange rate policy debate. American politicians have repeatedly argued that the RMB is substantially undervalued and that China takes jobs away from the United States. China's current account surpluses are often used to provide 'hard evidence' to support this argument. Large current account surpluses also cause economic problems domestically. In addition to exporting capital to rich countries, the surpluses indicate the degree to which Chinese growth is dependent on external demand. This was precisely why Chinese growth was seriously affected by the US sub-prime crisis nearly two years ago.

Figure 14.2 China's current account balances, 1986-2009 (per cent of GDP)

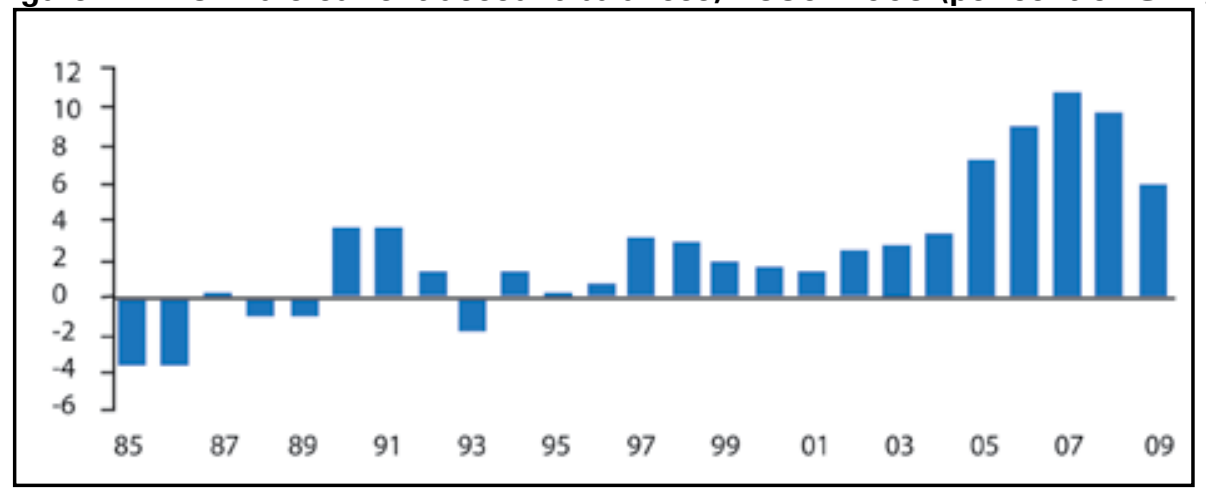

Source: CEIC Data Company.

It is important to note that the increase in net savings in China in recent years was the result of a faster rise in the saving rate, not a decline in the investment rate. In fact, as already noted, the investment rate rose by nearly 10 percentage points during the past decade (Figure 14.3). Since the investment rate is already at such a high level, it is reasonable to expect that any efforts to deal with the large current account surplus will have to try to reduce the saving rate.

\section{Income inequality}

As the most important result of economic reform, household income has increased dramatically during the past three decades. Rapid income growth has lifted hundreds of millions of people out of poverty and the living standards of rural and urban residents have improved significantly. Income distribution has, however, also deteriorated sharply. This change was understandable initially since the 'very equal' income distribution pattern in the pre-reform period did not provide any incentives for hard work. Over time, however, income inequality has become a major political as well as economic concern. 
Perhaps the most striking measure of income inequality is the Gini coefficient among households, which rose from 0.25 in 1985 to 0.47 in 2008 (Figure 14.4). The latest reading of the coefficient is among the highest in the world and probably indicates high risks of social and economic instability.

Figure 14.3 China's saving and investment rate, 1978-2009 (per cent of GDP)

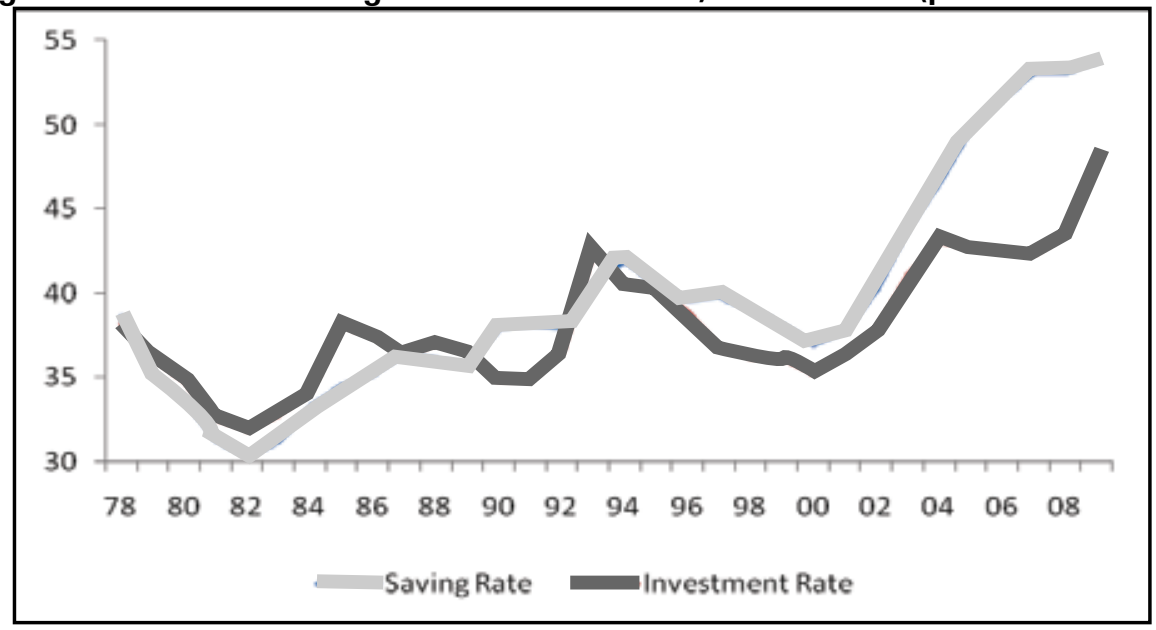

Source: CEIC Data Company.

Figure 14.4 Gini coefficient among households and the urban-rural income gap

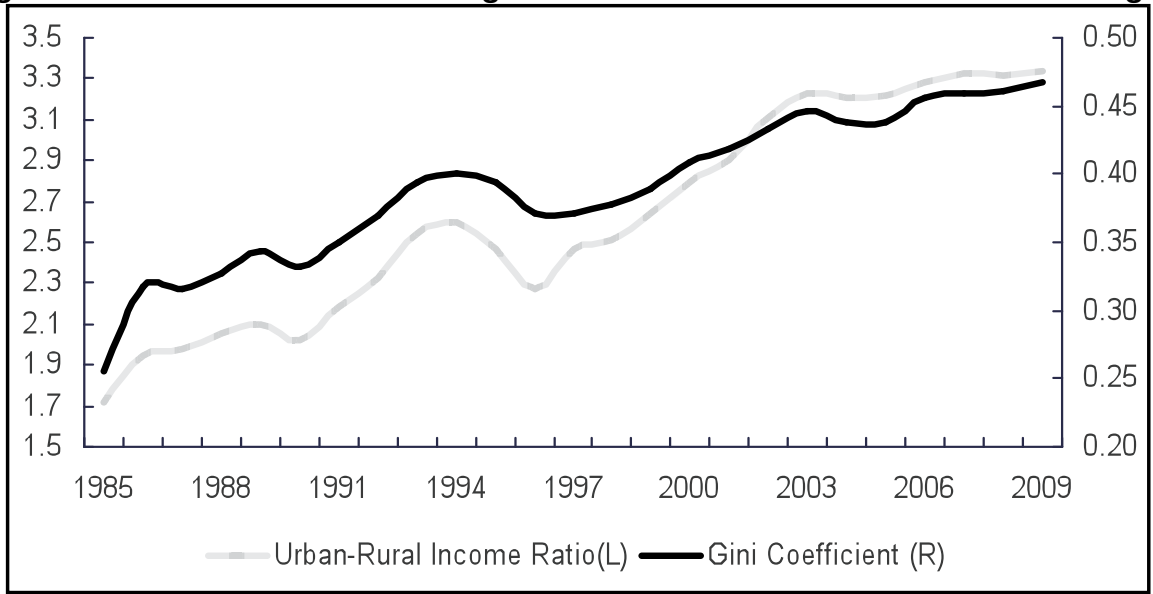

Source: National Bureau of Statistics (NBS) various years, China Statistical Yearbook, China Statistics Press, Beijing.

A related problem is the widening gap between rural and urban income. At the beginning of the 1980s, the rural-urban income gap in fact narrowed, since agricultural income was boosted by the implementation of the household responsibility system in the countryside while urban reforms were slow to gather momentum. Over time, however, the gap has widened sharply. In 1981, urban 
income was on average about two times that of rural income. In 2005, this ratio rose to 3.2. On the surface, this trend appears to contradict the increasing trend of rural-urban migration. In reality, it is probably the result of institutional restrictions on migration and faster productivity growth in the urban economy.

From the perspective of macroeconomic imbalance, one of the most important indicators is the distribution of national income among households, the corporate sector and the government. Between 1995 and 2007, the shares of the corporate sector and the government in total national income increased steadily. As a result, the income share of households decreased from 68 per cent to 50 per cent (Figure 14.5). This trend could be important for explaining the declining share of consumption in GDP.

Figure 14.5 Proportion of residential, firms' and government income in primary distribution and the urban-rural income gap

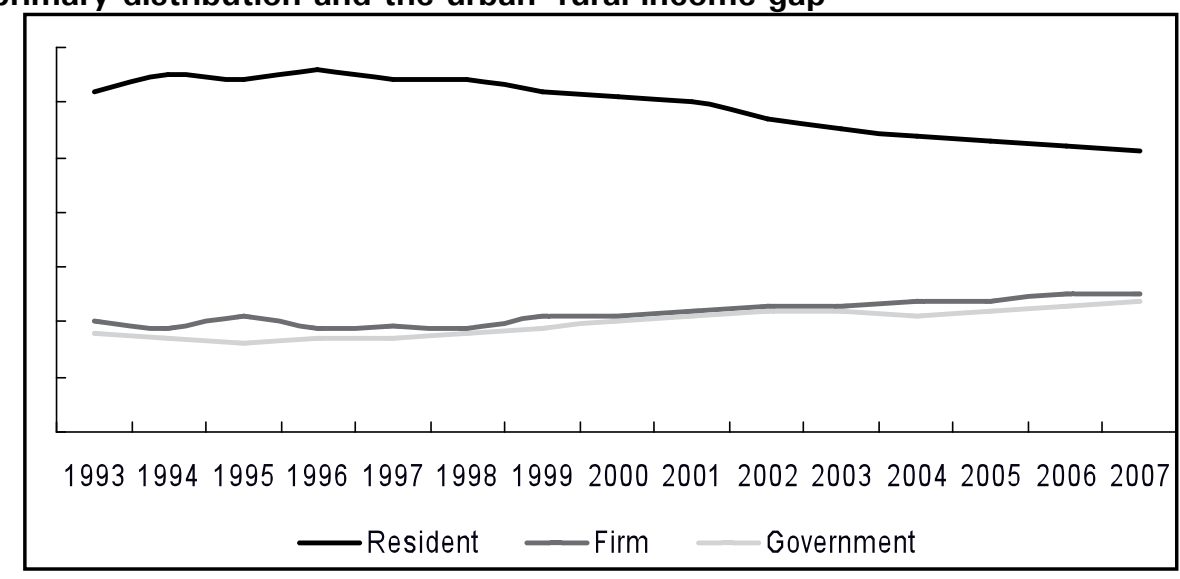

Sources: Bai, C.-E and Qian, Z. 2009, 'Factor income share in China: stories behind statistics', Economic Research Journal [Jing Ji Yan Jiu], vol. 3; National Bureau of Statistics (NBS) various years, China Statistical Yearbook, China Statistics Press, Beijing.

\section{Policy efforts to rebalance the economy}

Between 2003 and 2010, the Chinese economy experienced almost two full cycles. Economic momentum accelerated in the years after China's accession to the World Trade Organisation (WTO) in late 2001. In 2004, the economy started to show signs of overheating, with the consumer price index (CPI) exceeding the 5 per cent benchmark in July and August of that year, although it cooled off quickly as the government adopted various tightening measures. In 2007, the economy entered another cycle of overheating, with the increase in the CPI 
reaching 8.7 per cent in early 2008. This momentum was, however, reversed abruptly by the global financial crisis from mid 2008. Again, in early 2010, the economy began to show initial signs of overheating.

While the priorities of macroeconomic policies shift over time, one consistent policy theme throughout this period has been the transformation of the growth model. The Chinese government has become increasingly uncomfortable with the growing imbalance problems. Premier Wen and his government take the improvement of the quality of growth as a top policy priority, and during the past seven years they have adopted various measures to achieve this objective, including administrative controls, monetary instruments and fiscal tools (see Appendix 14 for detailed policy measures during the past six years).

Industrial policy has played an important role in the government's efforts to transform the growth model. The idea is to promote high-tech, high value-added and environmentally friendly industries. This has been done in various ways, with the most important tools including fiscal subsidies and administrative controls. The National Development and Reform Commission (NDRC) is the coordinating authority for industrial policy. At the beginning of every year, it sets out plans for investment for the coming year. It also identifies the industries where excess capacity risks are high.

Perhaps the most powerful policy tool of the NDRC is its approval and termination authority. For instance, in 2004-05, the NDRC closed a large steel plant in Jiangsu Province called 'Tie Ben' and terminated another 70600 investment projects in an effort to cool the economy. Since 2007, when the economy showed initial signs of overheating, the NDRC has been granted the authority to approve any investment projects larger than RMB50 million.

In addition to its responsibilities for managing the overall size of investment, the NDRC is responsible for optimising the industrial structure. It regularly publishes lists of industries with high overcapacity risk and promotes investment in other industries. In 2009, for instance, the NDRC stopped approving new projects in certain industries, including the hydropower development project on the Jinsha River and steel industry projects in Shandong Province. The NDRC also raised the capital requirement in 2005 for investment projects in iron and steel, cement, aluminium and real estate and again in 2009 for energyintensive industries.

The government has also made efforts to promote industrial upgrading, such as localising the production of large nuclear power equipment in 2006, revitalising the equipment manufacturing industry in 2007, restructuring the 
telecommunications and airline industries in 2008 and subsidising sales of electronics, motorbikes, cars and agricultural machinery in the countryside in 2009.

Credit expansion is often an important policy instrument for the authorities to regulate macroeconomic conditions, with the scale of loans fluctuating according to economic performance. For instance, as part of the effort controlling economic overheating, the People's Bank of China (PBOC) reduced loan growth from 21.1 per cent in 2003 to 9.3 per cent in 2005 (Figure 14.6). As the global financial crisis hit the Chinese economy, however, the PBOC significantly boosted credit expansion in order to support growth, raising loan growth from 15.9 per cent in 2008 to 31.8 per cent in 2009. Indeed, the new loans extended in 2009RMB9.6 trillion - doubled the annual target for that year.

Figure 14.6 China's annual increased loan, 2004-10

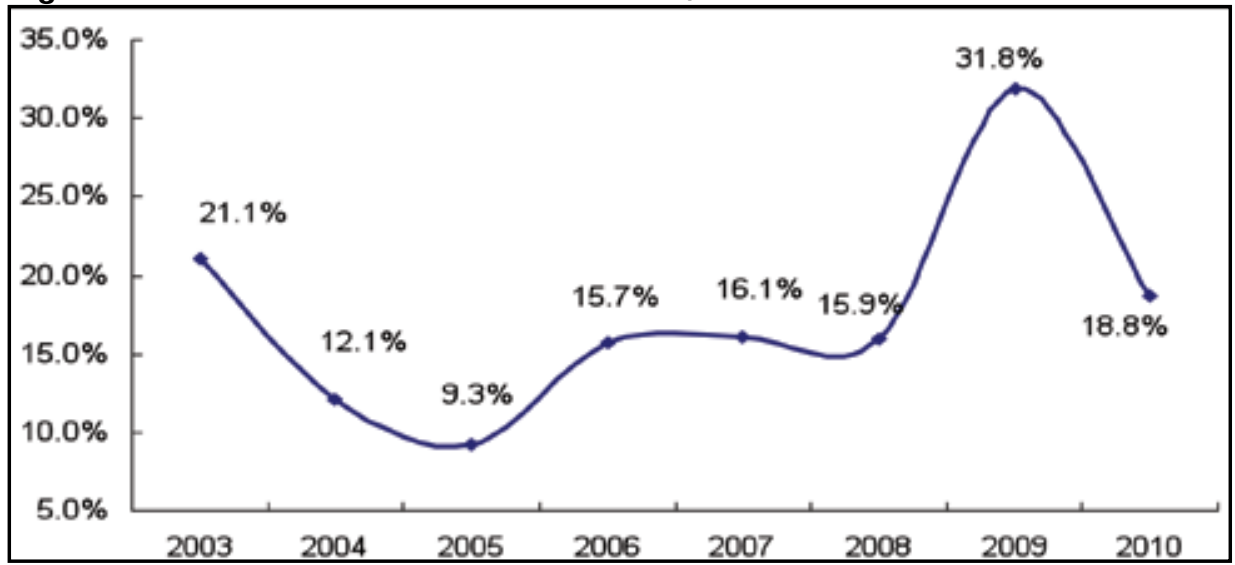

Note: The data for 2010 are the official targets.

Source: National Bureau of Statistics (NBS) various years, China Statistical Yearbook, China Statistics Press, Beijing.

The authorities frequently change their credit policies. For instance, the State Council published 'Regulations on strengthening control of investment in fixed assets and newly started projects' in June 2006. This policy required the commercial banks to tighten controls over loan extensions for investment projects. Meanwhile, financing demands from strategic emerging industries, small enterprises, trade and residential consumption are the highest priorities. Beside these areas, loan demands from newly started projects, heavy polluters, heavy energy consumption and resource-related industries, industries with excess capacity and real estate investment have been listed within the scope of strict control.

In addition to credit policy, the PBOC raises or lowers the reserve requirement ratio and base interest rates to adjust the monetary policy environment. In the 
wake of the global financial crisis, the PBOC lowered the reserve requirement four times to ease liquidity conditions. This was an important factor behind the extraordinary loan growth during that period. On the other hand, between 2004 and mid 2008, the PBOC continuously raised the reserve requirement ratio - from 7 per cent in early 2004 to 17.5 per cent in the first half of 2008.

Unlike other central banks around the world, the PBOC does not target a particular market interest rate. Instead, it directly adjusts the benchmark interest rates, such as one-year base lending and deposit rates. Commercial banks are allowed to float the rates as long as they observe floors for lending rates and ceilings for deposit rates. Adjustments of interest rates, though, are often less frequent, reflecting the policymakers' greater confidence in quantitative measures.

The government has also adopted a number of other policies to reduce the imbalance problems. For instance, to boost consumption, the authorities increased spending on social welfare systems, including medical insurance for rural residents and social security funds in the urban areas. The logic is that development of the social welfare systems can probably reduce the household saving rate and therefore increase total consumption. The Ministry of Finance (MOF) raised the minimum thresholds for personal income taxes and also abolished agricultural taxes.

To narrow external account surpluses, the MOF has frequently lowered export tax rebates to discourage exports. The PBOC also allowed the RMB to appreciate gradually for three years between 2005 and 2008.

In recent years, policymakers began new initiatives to develop a resource-saving and environmentally friendly society. They started 178 energy-saving, watersaving and resource-efficient projects. They required all provinces to reduce energy intensity annually by 4 per cent and the discharge of major pollutants by 2 per cent in 2006. In 2009, the government published a new policy on 'China's responses to climate change: policy and action', announcing an explicit target of reducing the carbon intensity of GDP by 40-45 per cent by 2020 .

\section{Asymmetrical market liberalisation}

Despite the government's deep concerns and its continuous efforts, the imbalance problems have worsened steadily in recent years. This is indeed puzzling. Theoretically, there could be only two possibilities: the wrong policies, or the right policies, but not implemented aggressively enough. In our view, most of the policy measures implemented so far have not directly addressed the incentive 
structure that caused the imbalance problems - a peculiar incentive structure that is associated with China's unique asymmetrical market liberalisation approach. This approach has caused serious distortions in most factor markets.

\section{Product-market liberalisation}

The most fundamental change during the reform period has been the introduction of free markets. In retrospect, the introduction of the market system includes at least three dimensions: 1) creating autonomy and incentives at the micro level; 2) liberalising restrictions in markets; and 3) building the institutional infrastructure necessary for a market economy (Huang forthcoming). Of these, the liberalisation of markets is essential, including the reintroduction of marketdetermined prices and the liberalisation of trade in goods and services.

For the sake of progressive reform, the initial dual-track price system represented the coexistence of state prices alongside market prices. One price was set by the State for planned activities and the other was determined by demand and supply in free markets. The dual-track system served an important purpose in the reforms: allowing free markets to allocate resources without seriously affecting the groups with vested interests. This dual-track price system was applied mainly to grain and production goods as well as capital goods such as foreign exchange and stock.

Price liberalisation started in the agricultural sector. State purchase prices were raised from the end of the 1970s and free markets for agricultural surpluses were also reopened in urban and rural areas. In 1984, the mandatory state purchase of grain was converted to a contract system, parties to which were farmers and the State. The mandatory nature was not phased out, however, until 1992.

The liberalisation of non-agricultural prices started with consumer goods and was then extended to industrial materials. The coupon system, which was used to allocate consumer goods during the central planning system, was phased out completely in the early 1990s. Free markets for most consumer goods came into existence during the 1980s. By the late 1990s, transactions of almost all consumer goods were completely liberalised with prices freely determined by the market mechanism.

\section{Distortions of factor markets}

Compared with product markets, factor markets have not yet been liberalised completely. From the production function, there are four major sources of output: labour, capital, natural resources and technology. Given technology, prices for the other three factors are distorted. 


\section{Labour}

Abundant and cheap labour is known as a key factor behind China's success in labour-intensive manufacturing exports. Because of the segmentation of rural and urban labour markets, however, as well as the underdevelopment of social welfare systems, labour costs in China are distorted.

The main source of labour-market segmentation is the Household Registration System, which differentiates agricultural and non-agricultural registered permanent residence, resulting in the formation of a separated structure of town and country. During the pre-reform period, no labour mobility was permitted between agricultural and non-agricultural residences, unless there was special approval by the government. This restriction has been loosened in recent years with the growth of the non-state sector, evidenced by the large number of migrant workers roaming the cities. At the end of 2009, there were about 150 million migrant workers across the country.

Although restrictions on rural-urban migration have been loosened, the location of an individual's household registration makes a significant difference in terms of payment and other social welfare benefits; even when migrant workers have been working in cities for years, they are normally not entitled to pensions, medical care and housing subsidies, and their children cannot attend local public schools. In short, it is very difficult for them to settle down. For this reason, migrant workers' pay is sometimes only half the pay of urban residents, even if they do the same job.

Scepticism about distorted wage costs derives from the argument that labour should be cheap given China's massive surplus labour in the countryside. This is not necessarily so. If urban employers made social welfare contributions for their migrant workers, their payrolls could rise by about 35-40 per cent, which includes contributions to pensions (20 per cent of payroll), medical insurance (6 per cent), unemployment benefits ( 2 per cent), work injury insurance ( 1 per cent), maternity benefits ( 0.8 per cent) and housing entitlements (5-10 per cent). ${ }^{1}$ If social welfare policies were implemented properly and the Household Registration System was abolished, migrant workers would be likely to receive significantly higher compensation.

\section{Capital}

Distortions in capital markets exist in two respects. Domestically, the financial system remains repressed, as evidenced by highly regulated interest rates and state influences on credit allocation, and externally, the currency has been undervalued.

1 These estimates for a typical year were provided to the author by Zhai Fan, a former official of China's 
Generally, market-oriented interest rates have been introduced in the wholesale market. The China inter-bank offered rate (CHIBOR) was formed in 1996 and the inter-bank market was liberalised accordingly; the loan rates and deposit rates for foreign currency were liberalised in 2000 and 2004, respectively. Worried about possible vicious competition among banks, however, the PBOC still controls RMB deposit and loan interest rates by setting an upper limit for deposit rates and a lower limit for loan rates, based on the announced benchmark rates.

Under such regulation, interest rates are depressed, as in many other developing countries. From 1990 to 2008, the average loan and deposit interest rates were 7.63 per cent and 5.26 per cent, respectively. The average loan and deposit interest rates were only 5.85 per cent and 2.45 per cent between 2000 and 2008 . These seem low for a developing country with great opportunities for productive investment. The interest rate has become increasingly distorted since 2000 .

Underestimation of the domestic cost of capital is underscored by the existence of financial repression (Wang 2010). A World Bank study suggests that financial liberalisation in emerging market economies often raises domestic interest rates by a couple of percentage points (Caprio et al. 1994). This could be interpreted as financial repression reducing interest rates by a couple of percentage points.

As for the exchange rate, when reforms began, the official RMB exchange rate against the US dollar was 1.5 , which was probably overvalued. In subsequent years, the authorities frequently devalued the currency in order to promote exports. At the beginning of 1994, the PBOC unified the official and swap market exchange rates at 8.7, substantially devaluing the official rate from 5.3. The exchange rate strengthened slowly to 8.27 at the end of 1997. In response to the East Asian financial crisis, the PBOC adopted a conventional peg by fixing the exchange rate at 8.27 .

On 21 July 2005, the PBOC appreciated the currency by 2.1 per cent and adopted a managed float with reference to a basket of currencies. The RMB showed slow but steady appreciation against the US dollar, reaching 6.84 at the end of 2008. With the exception of brief periods when the currency experienced mild depreciation pressure, the $\mathrm{PBOC}$ has generally resisted pressures to appreciate faster. Today, most economists believe that the RMB remains undervalued, although they disagree on the degree of undervaluation (Goldstein and Lardy 2008), with the normal range of the undervaluation estimated to lie between 5 and 50 per cent (Clive and Williamson 2008).

\section{Natural resources}

Natural resources such as land, energy and the environment are important production factors, but their prices are also distorted. In China, land is owned by the State in the cities and by the collectives in the countryside. The Land 
Administration Law, promulgated in 1999, classifies land into agricultural, development and unutilised land. Land transfer for non-agricultural uses has to be approved by the government.

In the past, local authorities decided land fees. To attract more investment, they often provided concessions on land-use fees. In recent years, however, the government has turned to more market-oriented land transfer mechanisms, such as auctions and negotiations. This practice, however, applies mainly to property development. There is no market mechanism for determining land prices for industrial use and it is still common for the government to apply land-use fees, the average of which is only about 16 per cent of the costs through auction (Huang and Tao 2010). Manufacturers, therefore, receive implicit subsidies on land inputs.

Institutional distortions in domestic energy markets are widespread, although the magnitude of cost distortions has varied over the years. Of the different types of energy products, coal prices are the closest to market prices. Electricity tariffs are different for agricultural, industrial and residential uses and are set by the NDRC, although the authorities sometimes hold public hearings to improve the quality of decisionmaking. Electricity prices have been under upward pressure in recent years, as the costs of oil and coal have risen significantly.

The most visible and sometimes most volatile distortions are in oil products. In 1998, in an important step towards oil price liberalisation, the State Council announced a formula linking domestic prices to the weighted average of prices in New York, Singapore and Rotterdam. The NDRC would adjust domestic prices, with a couple of months' delay, if the international weighted average moved by more than 8 per cent. In 2000, the NDRC raised oil prices seven times in order to bring domestic prices closer to international levels. When international prices moved sharply upwards, however, the NDRC was reluctant to follow for fear of disrupting domestic economic growth. For instance, when international crude prices reached their recent peak in 2008 - at close to US\$150 a barrel-domestic prices remained at about US $\$ 80$ a barrel.

The environment is not regarded as a conventional production factor; however, compensation for pollution should be counted as an integral part of production costs. While China has introduced a series of environmental laws and regulations, the problem is the big gap between the intent of these policies and their implementation, as the various levels of government continue to give priority to economic growth.

According to a joint study by the National Bureau of Statistics (NBS) and the State Agency for Environmental Protection (SAEP), an incomplete count of the costs of environmental damage amounted to about 3.05 per cent of GDP in 
2004. Since producers do not always fully compensate for their damage to the environment, this reduces short-term production costs at the expense of longterm development.

\section{Crude estimation of factor cost distortions}

What is the magnitude of these distortions? Huang (forthcoming) made his first attempts to measure factor-market distortions and found that they amounted to RMB2.1 trillion in 2008 - or about 7 per cent of GDP. His estimation, however, was made for only one year. In a follow-up study, Huang and Tao (2010) refined some of the methods and extended the estimation to include nine years from 2000 to 2008 (Table 14.1).

The task of estimating these distortions is quite difficult, as in most cases there is no information about undistorted equilibrium factor prices. The purpose of the estimation, however, is not to provide accurate estimates, but rather to get some idea of the possible magnitude of the distortions and, more importantly, changes in their impact over time.

Despite potential problems, the estimation results reveal some important patterns. First, labour-market distortions have in fact grown in recent years, despite loosening policy controls and increasing rural-urban migration. This is a result both of the rising number of migrant workers and persistent, widening income gaps between migrant workers and urban workers. Indeed the statistics suggest that while labour demand has increased in recent years, migrant workers' pay has not kept pace with that of urban workers, especially when social welfare benefit contributions are taken into account.

Table 14.1 Estimated cost distortions in China, 2000-08 (per cent of GDP)

\begin{tabular}{lccccccccc}
\hline & $\mathbf{2 0 0 0}$ & $\mathbf{2 0 0 1}$ & $\mathbf{2 0 0 2}$ & $\mathbf{2 0 0 3}$ & $\mathbf{2 0 0 4}$ & $\mathbf{2 0 0 5}$ & $\mathbf{2 0 0 6}$ & $\mathbf{2 0 0 7}$ & $\mathbf{2 0 0 8}$ \\
\hline Labour & 0.1 & 0.2 & 0.8 & 1 & 2 & 2.4 & 2.7 & 3.2 & 3.6 \\
Capital & 4.1 & 3.9 & 3.9 & 3.8 & 3.1 & 3 & 3.1 & 3.6 & 3.4 \\
Natural & 4.3 & 4 & 3.7 & 4.4 & 4.5 & 6 & 6.4 & 5.2 & 3.6 \\
resources & & & & & & & & & \\
\hline Total & 8.5 & 8.1 & 8.4 & 9.2 & 9.5 & 11.4 & 12.2 & 12 & 10.6 \\
\hline
\end{tabular}

Source: Huang and Tao (2010), page 18.

Second, of all the distortions, capital-market distortions are by far the most important, ${ }^{2}$ contributing about 40 per cent of total cost distortions on average. This helps to explain the persistent problem of over-investment in China and also the rapid development of capital-intensive industries despite continued job-market pressures.

2 Natural resource distortions include land distortion, energy distortion and environmental distortion. Compared with the three elements, as well as labour distortion, capital-market distortions are the largest. 
Third, natural resource distortions have fluctuated widely over the years, reflecting volatilities in components, energy-especially international oil prices - and the varying responses of the Chinese authorities to these changes. China has already adopted a price mechanism that closely tracks changes in international energy prices, but the authorities hold down domestic prices when international prices surge rapidly. Therefore, energy cost distortions are sometimes asymmetrical. When international prices are low, there is little distortion. When international prices are high, distortions increase rapidly.

Finally, the aggregate estimates of cost distortions show significant increases since 2004 - consistent with the observation that structural imbalances have worsened during this period. The trends of continuous liberalisation and recent increases in the total impact of cost distortions are not necessarily contradictory. These trends could arise because of a slower rise in distorted prices than undistorted prices, despite loosening controls overall. They could also arise because the quantity of factors has grown rapidly even though unit distortions have declined. The moderation of the impact of total distortions since 2006, however, suggests that the worst of the imbalance problems are already behind us.

\section{Structural imbalances: consequences of factor- market distortions}

We donot intend to analyse the various structural imbalance phenomena one by one, since they in fact share the same root cause: asymmetrical market liberalisationleads to structural problems.

In fact, some economists have also realised the distortions on some production factors: Wang Xiaolu regards the lack of social security to be responsible for relatively low incomes, and hence, the low consumption of the labour force, Zhang Xiang blames the weakness in financial system reform for the economic structural imbalances, while Xu Xiaonian blames the strict controls on the service sector.

We, however, think it is not a problem that can be traced to a single market or factor. More importantly, there are distortions in all factor markets and such distortion is in fact a production subsidy: labour is cheap; capital is cheap; land is cheap; energy is cheap; producers have further enjoyed tax exemptions; and there has been no real charge for pollution.

Such a production subsidy improves the international competitiveness of China's products and promotes exports, resulting in trade surpluses. Close to 70 
per cent of Chinese GDP is externallyoriented (exports plus imports), compared with 20-30 per cent for the United States and Japan. In fact, our factor-cost distortion estimates provide a reasonably good fit with the current account balance during the past nine years (Figure 14.7, bottom right).

\section{Figure 14.7 Estimated cost distortion and structural imbalances}
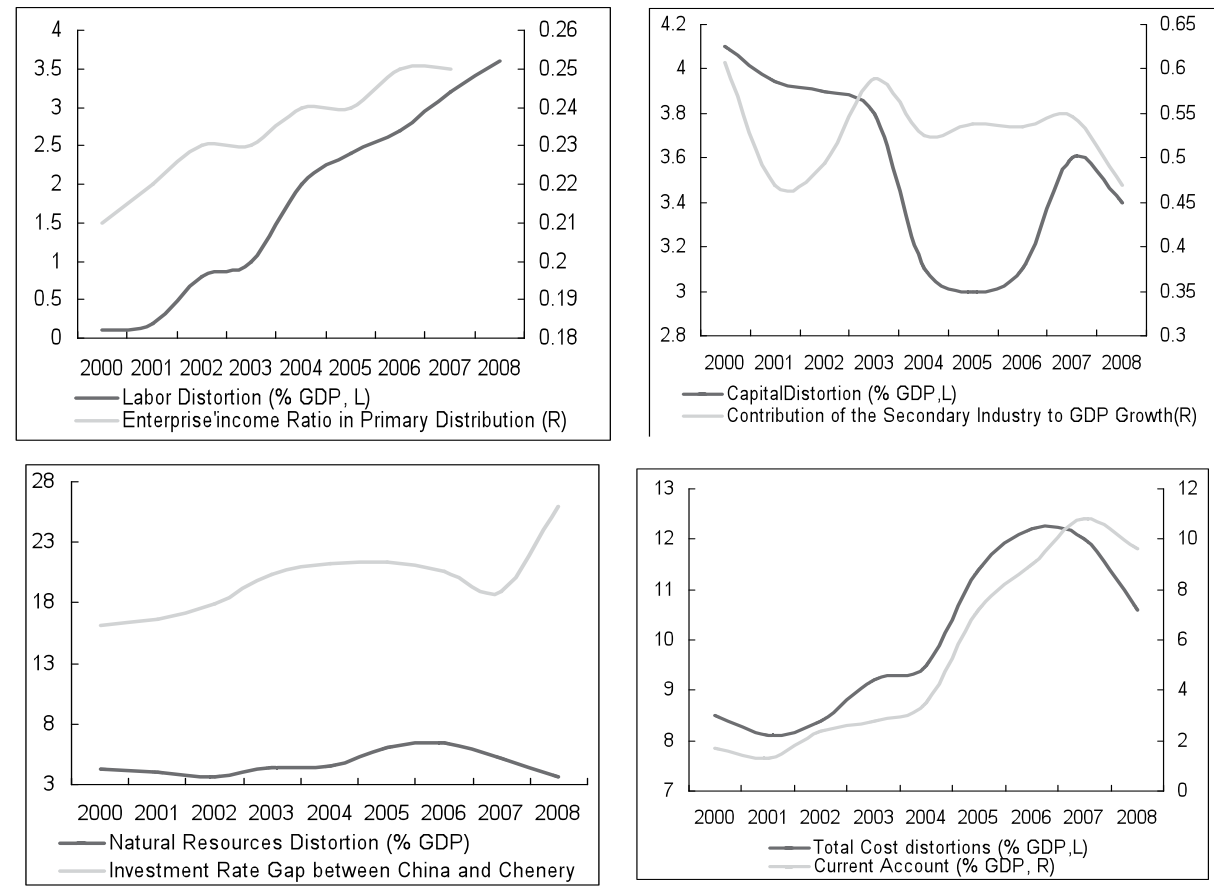

Sources: National Bureau of Statistics (NBS) various years, China Statistical Yearbook, China Statistics Press, Beijing; CEIC Data; and authors' estimation.

Low costs have also stimulated investment. According to the estimates, capital was by far the most important item in total cost distortions during the period analysed. Thus, it has been almost impossible for the government to control the over-investment problem. The estimated factor-cost distortionfor capital estimates shows a proper fit with the contribution of secondary industry to GDP growth (see Figure 14.7, upper right). When potential investment returns are so high, any NDRC initiatives to slow investment are bound to fail. This explains why China moved into heavy industries so quickly in the early twentyfirst century even though the government was still hoping to create more jobs. Perhaps it is also easy to understand why urban infrastructure is so advanced in a country where per capita GDP is only slightly above US $\$ 3000$.

While cost distortions have been positive for production, investment and exports - that is, they have the effect of subsidy equivalents for producers, exporters and investors - correspondingly, these distortions are equivalent to 
taxes on the owners of these factors, mainly households and consumers. It can be seen that the rising share of the enterprise sector's income in national income has been accompanied by rising labour-market distortions (see Figure 14.7, upper left).

Distorted incentives have significantly inflated investment and export activities. At the same time, as household income relative to GDP declined over time, consumption also weakened inevitably in relative terms. All these suggest that factor-cost distortions have been a fundamental force behind China's structural imbalances, which alongside other problems such as inefficient resource use and pollution could seriously affect China's ability to sustain its rapid growth in the future.

\section{Conclusions}

With the reform of its policies and modernisation of its economy since the late 1970s, China has quickly transformed from a large and poor economy into a globally influential economic power. Structural risks have, however, also increased significantly. Premier Wen and other senior leaders have repeatedly pointed out that the existing growth pattern is unstable, unbalanced and unsustainable.

In fact, the government has tried to address the problems of growth quality and structural imbalances - for instance, taking various steps to stimulate consumption, contain investment growth and reduce external account surpluses. Overall, however, limited progress has been made despite these policy efforts. One explanation is that China's gradualist reform approach means that changes can happen only slowly. Meanwhile, as growth has remained very strong, the government has been reluctant to do anything drastic to change the course of the economy. More importantly, the paramount value of social stability in Chinese policy thinking probably also discourages any policy change that might threaten social order.

In order to alleviate the existing structural risks, the authorities need to change their policy course. It is critical to understand that the root cause of the imbalances and inefficiency problems is factor-market distortions. Such distortions have artificially increased profits from manufacturing production and quickly turned China into a global manufacturing centre through the supply of cheap labour, cheap capital, cheap land and cheap resources. Cost distortions have also contributed to oversized investment and exports.

Therefore, the fundamental solution to deal with the imbalance problem is to implement a comprehensive package of factor-market reforms. This essentially 
calls for an end to the asymmetrical approach to market liberalisation. Steady liberalisation of factor markets and the elimination of cost distortions should be the top priorities for the next stage of reform.

In fact, the Chinese government has already started its process of factor-market liberalisation.

Labour-market liberalisation is a fundamental way to stimulate consumption and such liberalisation is already in progress. The government has planned to make new breakthroughs in reforming the Household Registration System and propelling urbanisation in 2010. It also intends to extend the social welfare systems to all rural residents. The complete removal of distortions and therefore of discrimination against rural workers will, however, still take some time.

The breakthrough of capital-market liberalisation could be the introduction of market-based interest and exchange rates. The CHIBOR has been a good starting point for trying to form a market-based term structure for interest rates. The financial system, however, needs to cater better for the needs of the private sector, which will be the backbone of the Chinese economy. In addition, the exchange rate regime should at least be more flexible, even if it is still too early for an absolutely free-floating exchange rate regime.

Clearly defined landownership in the countryside could reduce distortions to land use. Collective ownership is vague, creating room for corruption and hindering the modernisation of the rural economy. In the cities, the government should at least stay out of the direct negotiation of land prices and private property development.

The market should determine energy prices. Fluctuations of energy prices cause difficulties for the economy but international experience suggests that these costs are much smaller than the costs of inefficiency caused by price distortions. From late 2009, the authorities began to make efforts in adjusting prices for fuel, gas, electricity and water. If the government needs to support particular groups for special reasons, it should use fiscal subsidies, not mess about with prices.

Other related reforms are also needed as a supplement to abolish cost distortions. The state sector needs further reforms so as to share profits with households. One way is for the State to collect more taxes from the state-owned enterprises (SOEs) and then redistribute the gains to broader society. More thoroughly, the state sector should gradually give up much of its monopoly power or be privatised. 
The complete liberalisation of factor markets and the elimination of cost distortions are likely to take years to complete. When completed, they will genuinely signal China's full transition to a market economy and will also help lock China's growth onto a more sustainable path for the long run.

\section{Appendix 14}

\section{The Chinese government's policy to adjust the economic structure}

\section{April 2004 - June 2005}

Chinese real GDP growth accelerated from 7.6 per cent in 1999 to 10 per cent in 2003. Total fixed-asset investment grew by 43 per cent during the first quarter of 2004.

\section{1) Industrial policy}

- reducing agricultural taxes for all products except tobacco

- subsidising grain farmers directly

- implementing minimum purchase prices for certain grain products

- raising capital requirements for investment projects in iron and steel, ${ }^{3}$ cement, aluminium and real estate. ${ }^{4}$

\section{2) Land supply}

- suspending the conversion of farmland for non-farm uses for six months

- tightening controls over land for construction purposes

- reducing a total of 4813 development zones (2.49 million hectares).

\section{3) Project approval}

- closing 'Tie-Ben' steel plant in Jiangsu Province

- nine central government groups inspecting investment projects in steel, cement, aluminium, government office buildings and training centres, urban fast trains, golf courses, conference and exhibition centres, logistics parks, large shopping centres and development zones

- NDRC terminating 70600 projects, with total investment of CNY17.3 trillion.

3 Raising the least capital requirement ratio from 25 per cent to 40 per cent.

4 Raising the least capital requirement ratio from 20 per cent to 35 per cent. 


\section{4) Loan controls}

- loan growth slowing from 21.1 per cent in 2003 to 12.1 per cent in 2004 .

\section{5) Monetary policy}

- raising reserve requirement by 0.5 percentage point, to 7.5 per cent, on 25 April 2004

- increasing one-year base lending rate by 0.27 percentage point to 5.58 per cent on 29 October 2004, and lending rates in other terms adjusted accordingly

- removing ceilings for lending rates.

\section{6) Environmental protection}

- government proposal to develop a resource-saving society

- starting 178 key projects for energy saving, water saving and efficient use of resources.

\section{June 2005 - June 2006}

From May 2005, the value added of industrial production began to decelerate. Year-on-year growth of industrial profits slowed by more than 20 percentage points. Loan growth also weakened substantially.

\section{1) Industrial policy}

- abolishing agricultural taxes and taxes for animal husbandry in 28 provinces in 2005 and then in the whole country in 2006

- closing a large number of companies with high energy consumption, high pollution and failing production safety requirements

- localising production of certain important products, including large nuclear power equipment and novel-type craft

- implementing restructuring measures for 11 industries including steel, coal and cement. Eliminating backward production capacity of 110 million tonnes and 1.2 million tonnes in coal and electrolytic aluminium, respectively.

\section{2) Loan controls}

- loan growth accelerating from 9.3 per cent in 2005 to 15.5 per cent in 2006.

\section{3) Environmental protection}

- central government requiring all provinces to reduce energy intensity by 4 per cent and the discharge of major pollutants by 2 per cent in 2006 (most failed in the end) 
- setting up a system of targets for energy conservation and reduction of pollutant emissions

- conducting a number of circular economy pilots.

\section{April 2006 - June 2008}

Again, the economy showed signs of overheating. During the first quarter of 2006, real GDP growth reached 10.2 per cent and new loans reached CNY1.25 trillion - more than half of the annual target.

\section{1) Industrial policy}

- revitalising equipment manufacturing industries

- lowering or abolishing export tax rebates for high energy consumption, high pollutant and resource-intensive industries.

\section{2) Project approval}

- new policy-tightening controls over new investment projects and construction projects list

- raising capital requirements for certain construction projects

- central government approval required for all local government projects with investment of more than CNY50 million.

\section{3) Loan control}

- publishing 'Regulations on strengthening control of investment in fixed assets and newly started projects' and requiring commercial banks to tighten controls over loan extension for investment projects.

\section{4) Monetary policy}

- raising the reserve requirement three times and base lending and deposit rates twice in 2006

- raising the reserve requirement 10 times in 2007-to 14.5 per cent at the end of the year-and raising the one-year base deposit rate six times, to 7.47 per cent at the end of 2007

- raising the reserve requirement another five times - to 17.5 per cent in the first half of 2008 .

\section{5) Fiscal policy}

- transitioning from proactive to neutral fiscal policy.

\section{6) Environmental protection}


- closing a large number of ftactories, including 11200 coalmines, 46.6 million tonnes production capacity of iron, 37.5 million tonnes production capacity of steel and 87 million tonnes production capacity of cement

- starting 10 key energy-conservation projects

- making a breakthrough in coal-fired power plant desulphurisation project.

\section{July 2008 - December 2009}

At the beginning of 2008, the government set clear policy goals of preventing overheating and avoiding high inflation; however, the economy cooled rapidly in the second half of 2008 as the impacts of the global financial crisis hit China.

\section{1) Industrial policy}

- raising export tax rebates seven times ${ }^{5}$ in 2008 and 2009, especially for labour-intensive products

- restructuring telecommunications and airline industries

- closing small power generators (1669 kilowatts) and 1054 coalmines

- spending CNY45 billion to subsidise sales of electronics, motorbikes, cars and agricultural machinery in the countryside

- reducing 50 per cent of purchase tax on small cars and supporting selfoccupation of housing consumption

- planning for revitalisation of 10 industries, closing 26 megawatt small power generators, 16.9 million tonnes of steel production capacity, 74.2 million tonnes of cement production capacity, and so on

- allocating CNY20 billion to promote 4441 technological transformation projects

- introducing new capital requirements for fixed-asset investment projects, which raised 5 percentage points for energy-intensive industries.

\section{2) Project approval}

- Ministry of Environmental Protection stopped approving a number of new projects $^{6}$ on 11 June 2009 in order to preserve the environment.

\section{3) Loan controls}

- loosening controls over new loans from August 2008, with the total of new loans reaching CNY9.6 trillion in 2009 - almost doubling the annual target.

\footnotetext{
51 August 2008; 1 November 2008; 1 December 2008; 1 January 2009; 1 February 2009; 1 April 2009; 1 June 2009.

6 Including a hydropower development project on the Jinsha River, construction projects of the Huanneng and Huadian Group and steel industry projects in Shandong Province.
} 
China: The Next Twenty Years of Reform and Development

\section{4) Monetary policy}

- lowering reserve requirements four times and reducing the base lending rates five times in 2008.

\section{5) Fiscal policy}

- announcing CNY4 trillion fiscal stimulus package in October 2008; spending on investment, consumption, imports and exports, real estate and stock markets

- public investment reaching CNY923 billion in 2009-an increase of CNY504 billion from a year earlier.

\section{6) Environmental protection}

- continuing efforts on energy saving and ecological protection, with a total of CNY42.3 billion spent by the central government in 2008

- allocating a budget to support 2983 energy-saving and circular economy projects

- releasing 'China's responses to climate change: policy and action'

- announcing explicitly the targets ${ }^{7}$ and policy measures to cap greenhousegas emissions by 2020 .

\section{References}

Bai, C.-E and Qian, Z. 2009, 'Factor income share in China: stories behind statistics', Economic Research Journal [Jing Ji Yan Jiu], vol. 3.

Caprio, G. jr, Atiyas, I. and Hanson, J. A. 1994, Financial Reform: Theory and practice, Cambridge University Press, New York and Melbourne.

CEIC Data Company, New York. Data downloaded from www.ceicdata.com.

Chenery, H. and Syrquin, M. 1975, 'Patterns of development, 1950-1970', Oxford University Press, UK.

Clive, William R. and John Williams, 2008, "Estimates of the Equilibrium Exchange Rate of Renminbi: Is There a Consensus and If Not, Why Not?", in Morris Goldstein and Nick Lardy (eds.), Debating China's Exchange Rate Policy, Peterson Institute of International.

Goldstein, M. and Lardy, N. (eds) 2008, Debating China's Exchange Rate Policy, Peterson Institute for International Economics, Washington, DC.

7 Reduce by $40-45$ per cent from that of 2005. 
He, G. 2009, A study on the unbalance between investment and consumption and its impact on China's economic growth, Doctoral dissertation, Huazhong University of Science and Technology.

Huang, Y. (forthcoming), 'China's great ascendancy and structural risks: consequences of asymmetric market liberalization', Asian-Pacific Economic Literature.

Huang, Yiping and Tao Kunyu, 2010, “Causes and Remedies of China's External Imbalances", Working Paper Series No. 2010002, Beijing: China Center for Economic Research, Peking University.

National Bureau of Statistics (NBS) various years, China Statistical Yearbook, China Statistics Press, Beijing.

Wang, X. 2010, An index of financial repression for China, Unpublished note, China Center for Economic Research, Peking University, Beijing.Wing Thye Woo. 



\section{Urbanisation with Chinese characteristics}

\section{Cai Fang and Meiyan Wang}

\section{Introduction}

It is universally acknowledged by economists that agricultural shares in aggregate output and the workforce tend to decline as an economy grows. Economists agree, however, only on the existence and inevitability of this phenomenon as a result of general economic growth, while arguing about questions such as how the transformations of production and employment happen during the economic development process, what characterises each stage of the transformation and what changes are indicative in the transformations. In China, there is little agreement on the way these transformations take place from either a theoretical or an empirical perspective, for the following reasons.

First, the explanations and predictions of development economics vary. For example, while Lewis $(1954,1958)$ considered rural-to-urban migration an integral part of dual economy development in developing countries, he in fact assumed that this process was a one-way movement, whereas Todaro (1969) and Harris and Todaro (1970) viewed it as a circular movement following a repetitive 'come-and-go' pattern.

Second, there have been dissimilarities with respect to the pattern of these transformations among countries and across time, which have made it difficult to determine any stylised facts about the two types of transformations. While Japan, Korea and some other countries accomplished their modernisation through massive rural-to-urban migration decades ago, many developing countries - especially in Latin America and East Asia - have been trapped by 'urban diseases' such as extreme poverty and slums in urban areas.

Third, the changes in China have been too fast for scholars and practitioners to keep pace with. Conventional wisdom - such as the notion of a longstanding and everlasting excessive labour force in rural areas - prevents observers from understanding the potential for changing situations in labour demand and supply. This is particularly relevant in China's case. 
The reality and dynamics of China's rural labour shift, and of its turning point in particular, can be observed through the theoretical framework of Lewisian development economics. Equally important is to apply the theory of demographic transition to China to understand the changes in demographic structure that have happened in the past decade. Due to the implementation of strict population control policy and social and economic developments in China in the past three decades, in combination with reform and opening up, rapid economic growth has been underpinned by a rapid demographic transition from high to low fertility, and the consequent increase in the labour force as a proportion of the population. Econometric analysis shows that the declining dependence ratio has accounted for 26.8 per cent of per capita gross domestic product (GDP) growth during the period 1982-2000 (Cai and Wang 2005).

However, in recent years the main source of growth of the urban working-age population has been in-migration of the rural labour force, and it is predicted that by about 2015, the out-migrating working-age population in rural areas will not be able to meet the demand for the working-age population in urban areas. That is, the total working-age population of the country as a whole will stop growing by this time and begin to shrink afterwards. The dependence ratio of the population will then begin increasing dramatically and the conventionally recognised demographic dividend is expected to vanish. The tension between this population structural change and strong economic growth has been reflected in the recent phenomena of rising wages and a shortage of unskilled migrant workers.

Setting the Lewis turning point as a milestone of development, a theoretical and empirical recognition of the end of an unlimited labour supply in China can help to identify the potential areas in which efforts can be made to sustain economic growth and harmonise the society in the near future. Migrant workers undoubtedly are at the centre of the theoretical cognition and the policy focus. ${ }^{1}$ In a sense, changes in the status of migrant workers will determine the future vision of economic growth and social stability in China. In the 20 years to 2030, the consequences of China's demographic transition will be further revealed, as the working-age population stops growing in 2015 and the total population reaches its peak in 2030. For a country such as China, which has realised its rapid economic growth through fully utilising an abundant and cheap labour force, the challenges brought about by the demographic transition have to be tackled so the country can exploit the potential of the demographic dividend in the short and medium run and transform its growth pattern in the long run.

1 This is true not only for China but for the world, as is implied by the fact that Chinese workers were chosen as 'People of the Year 2009' by Time magazine. 
This chapter is organised as follows. The next section explains the implications of the Lewis turning point for the labour supply and hence for economic growth. Investigating the trends of rural-to-urban migration and more general labour market changes shows that agriculture no longer serves as a pool of surplus labour; rather rural workers' migration to and settlement in urban areas has become irreversible and inevitable. The next section discusses the outdated policy implications of the Todaro paradox in the circumstances of the Lewis turning point. This suggests that there is no reason to expect a comeand-go pattern of rural labour migration and that the appropriate policy choice is to push forward with urbanisation by transforming migrant workers into urban residents. The subsequent section shows the urgency and feasibility of including migrant workers in the urban social security system from the viewpoint of government policy orientation. The chapter concludes with some policy suggestions.

\section{The irreversibility of rural-urban migration}

There has been much disagreement about whether (or when) China has reached (or will reach) its Lewis turning point (Garnaut and Huang 2006; Cai 2008a, 2008b; Garnaut 2010). This is not all that surprising when, according to Lewis (1972) and other authors (for example, Ranis and Fei 1961), there are in fact two turning points as a consequence of development in a dual economy. The period when the growth of labour demand exceeds the growth of labour supplyand hence the wage rate of unskilled workers begins to rise - is the first Lewis turning point. At this point, the agricultural wage is not yet determined by the marginal productivity of labour, so a productivity differential between the agricultural and modern sectors still exists. Subsequently, the point at which wages in the agricultural and modern sectors are determined by their respective marginal productivities of labour and are equal to each other is the second Lewis turning point, which is referred to also as the commercial point. When an economy reaches the latter point, it is no longer a dual economy. This chapter intends to discuss the first of these two turning points.

The Lewis turning point is not, and should not be, a black-and-white watershed distinguishing between two stages of development, but is rather a transitional period bridging them - or it can be viewed as the starting point of a new historical trend in the course of economic development (Minami 1968). In this regard, while 2004 was a significant year signalling the turning point, the longer period around it is the focus of this study. In what follows, we examine the different characteristics of the labour market before and after the turning point. 
During the stage long before the Lewis turning point, since there was a large reservoir of surplus labour in agriculture and the marginal productivity of labour in that sector was very low, the shift of workers from agricultural to nonagricultural sectors did not impact on agricultural production - that is, labour migration at this stage did not cause a significant change in the production mode in agriculture. On the other hand, because non-agricultural sectors during this stage absorbed the transferred labour force only marginally and sporadically, and the urban authorities frequently dispelled migrant workers when urban labour markets came under pressure (Cai et al. 2001), the agricultural sector still served as a pool of surplus labour. With the arrival of the Lewis turning point, however, circumstances have shown some fundamental changes, which we explain as follows.

First, the methods of agricultural production have changed in response to the massive and unremitting outflow of workers. Such outflow, given its large scale and steady growth, has accelerated agricultural mechanisation and modernisation and has pushed a transformation of agricultural technological change from being of the labour-use type to the labour-saving type. Examining the changes in agricultural mechanisation clearly shows this trend. During the first three decades of economic reform, the total power of agricultural machinery has strengthened, and even with the enlarged base the growth has shown no sign of decline in recent years. What is more notable is the changed composition of different sized agricultural tractors and tractor-towing machinery. In the period 1978-98, when there was surplus labour in agriculture, the annual growth in the capacity of large and medium-sized tractors was 2 per cent annually, while that of small-sized tractors was 11.3 per cent. In the period 1998-2008, as the mass labour force shifted from agricultural to non-agricultural sectors and, as a result, there emerged stronger demand for labour-saving technological changes, the capacity of large and medium-sized tractors increased by 12.2 per cent annually and that of small-sized tractors decreased by 5.2 per cent. Changes in the growth rates of different sizes of tractor-towing machinery show a similar trend, with the annual growth rate of large and medium-sized tractor-towing machinery increasing from zero per cent in the period 1978-98 to 13.7 per cent in 1998-2008, whereas the annual growth rate of small tractor-towing machinery declined from 12.1 per cent to 6.9 per cent in the same period.

As a result of falling labour inputs and rising physical capital inputs in production, Chinese agriculture's capital-labour ratio - which is denoted by the ratio of physical inputs to labour inputs - has risen rapidly since 2004 (Figure 15.1). According to the theory of induced technological changes (Hayami and Ruttan 1980), this labour-saving tendency during the rapid process of agricultural mechanisation is the natural result of the ultimate abatement of the surplus labour force in agriculture. It is hardly surprising that the total 
factor productivity (TFP) of the agricultural sector has also witnessed a rapid rise during the same period-increasing by 38 per cent between 1995 and 2008, with a sudden rise after 2004 (Zhao 2010).

\section{Figure 15.1 Changes in the ratio of physical to labour inputs in Chinese agriculture}

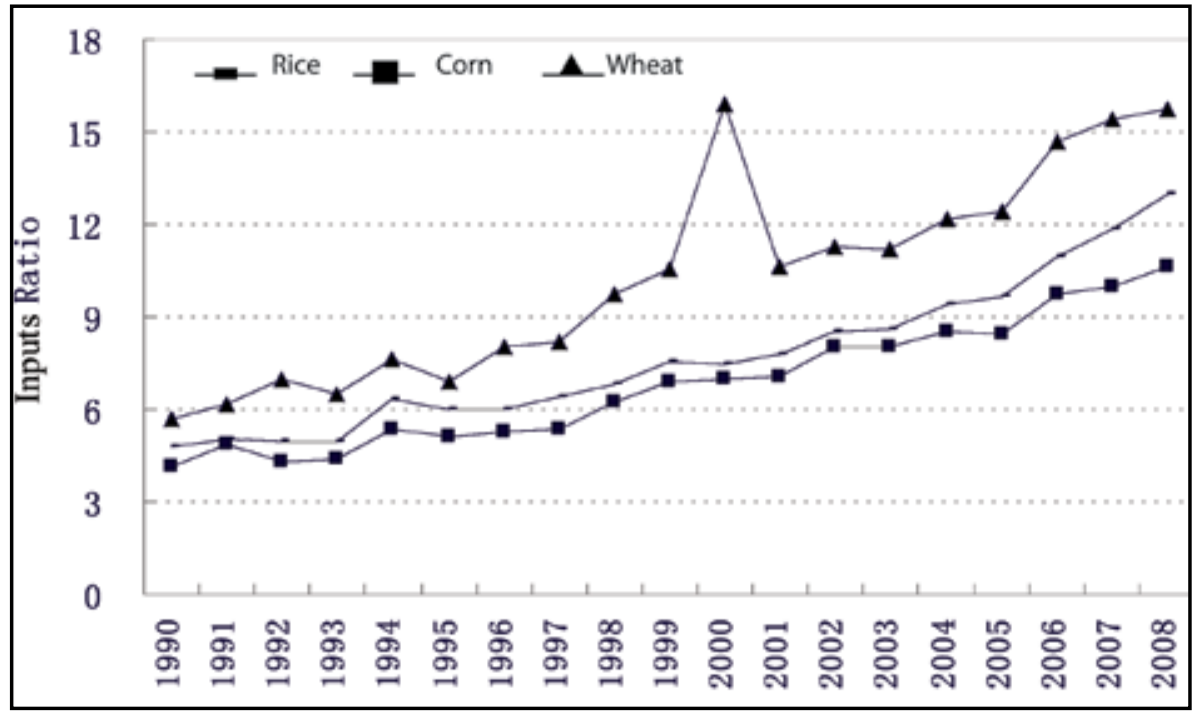

Source: National Development and Reform Commission various years, Compilation of Farm Product CostIncome Data of China, China Statistics Press, Beijing.

Second, urban demand for migrant workers has become increasingly rigid. As the result of demographic transition, during which process the urban age structure changes faster than the rural age structure, economic growth in urban sectors depends heavily on labour supply through migration. And yet, as shown in Table 15.1, while the total number of migrant workers from rural to urban areas for six months or longer continued to grow from 78.5 million in 2000 to 145 million in 2009, the growth rate decreased over time. In the meantime, the employment of urban locals continued to increase, and its growth rate remained constant. In 2009, nearly one-third of urban employees were rural migrants and they were dominant in some sectors such as construction. At the same time, migrant workers tend to reside and work in cities secularly (Zhang et al. 2009). In any event, urban sectors can no longer afford a retreat of such a large proportion of the labour force.

According to a survey conducted by the National Bureau of Statistics (NBS) in early 2009, at the end of 2008 rural workers working in non-agricultural sectors for more than six months totalled 225 million, of which 140 million were migrant workers across townships, accounting for 62.3 per cent of total farmers-turnedworkers, and 85 million, or 37.7 per cent, worked in non-agricultural sectors 
within home townships. Among migrant workers, 112 million still had family members in home villages, accounting for 79.6 per cent of all migrants, while 28.6 million migrated from home villages with their entire families, accounting for 20.4 per cent (Sheng 2009).

Table 15.1 Numbers and growth rates of migrant workers and the urban employed

\begin{tabular}{lcccc}
\hline Year & \multicolumn{2}{c}{ Migrant workers } & \multicolumn{2}{c}{ Urban employed } \\
& Number(million) & $\begin{array}{c}\text { Annual growth } \\
(\%)\end{array}$ & Number(million) & $\begin{array}{c}\text { Annual growth } \\
(\%)\end{array}$ \\
\hline 2001 & 84.0 & 7.0 & 239.4 & 3.4 \\
2002 & 104.7 & 24.7 & 247.8 & 3.5 \\
2003 & 113.9 & 8.8 & 256.4 & 3.5 \\
2004 & 118.2 & 3.8 & 264.8 & 3.3 \\
2005 & 125.8 & 6.4 & 273.3 & 3.2 \\
2006 & 132.1 & 5.0 & 283.1 & 3.6 \\
2007 & 137.0 & 3.7 & 293.5 & 3.7 \\
2008 & 140.4 & 2.5 & 302.1 & 2.9 \\
2009 & 145.0 & 3.3 & 313.1 & 3.6 \\
\hline
\end{tabular}

Source: Data for 2001-08 from: National Bureau of Statistics (NBS) various years, China Statistical Yearbook, China Statistics Press, Beijing; Department of Rural Surveys various years, China Yearbook of Rural Household Survey, National Bureau of Statistics, China Statistics Press, Beijing. Data for 2009 from National Development and Reform Commission 2010, The Report on the Implementation of the 2009 Plan for National Economic and Social Development and on the 2010 Draft Plan for National Economic and Social Development, The Third Session of the Eleventh National People's Congress, Beijing.

The two trends described above have altered the characteristics of labour migration after the Lewis turning point. In the period before the turning point, the cyclical changes of demand of the urban and non-agricultural sectors for labour often bring about a reverse rise and fall of the labour force engaged in agriculture. The amount of agricultural employment is not determined by the sector's need per se but statistically is a residual term and thus agriculture still serves as a pool of surplus labour. After the turning point, however, fluctuations in the labour demand of urban and non-agricultural sectors no longer cause reverse changes in agricultural employment, because the urban and nonagricultural sectors gain the capacity to accommodate short-term labour market fluctuations. As a result, agriculture no longer provides a pool of surplus labour.

As shown in Figure 15.2, the correlation between growth rates of non-agricultural employment and of agricultural employment differs statistically before and after the turning-point years. In the period before the mid1990s, growth rates of nonagricultural and agricultural employment showed drastically fluctuating and positive growth rates, because the labour force continued to grow. While the rural surplus labour force faced the pressure of transfer and the constraints of 
non-agricultural employment opportunities, the two employment growth rates showed no stable correlation. After the mid1990s, while growth rates of nonagricultural and agricultural employment became more stable, they also became significantly and negatively correlated. During the period 1998-2008, the correlation coefficient between the growth rate of non-agricultural employment and the growth rate of one year lagged agricultural employment was -0.748 , with declining agricultural employment in most years. The most significant change happened in 2004 when the high growth rate of non-agricultural employment and the negative growth rate of agricultural employment were highly correlated. In conclusion, while we consider the Lewis turning point to in fact be a transitional period, the year 2004 is still indicative of that period beginning.

Figure 15.2 Quantitative relationship between agricultural and non-agricultural employment

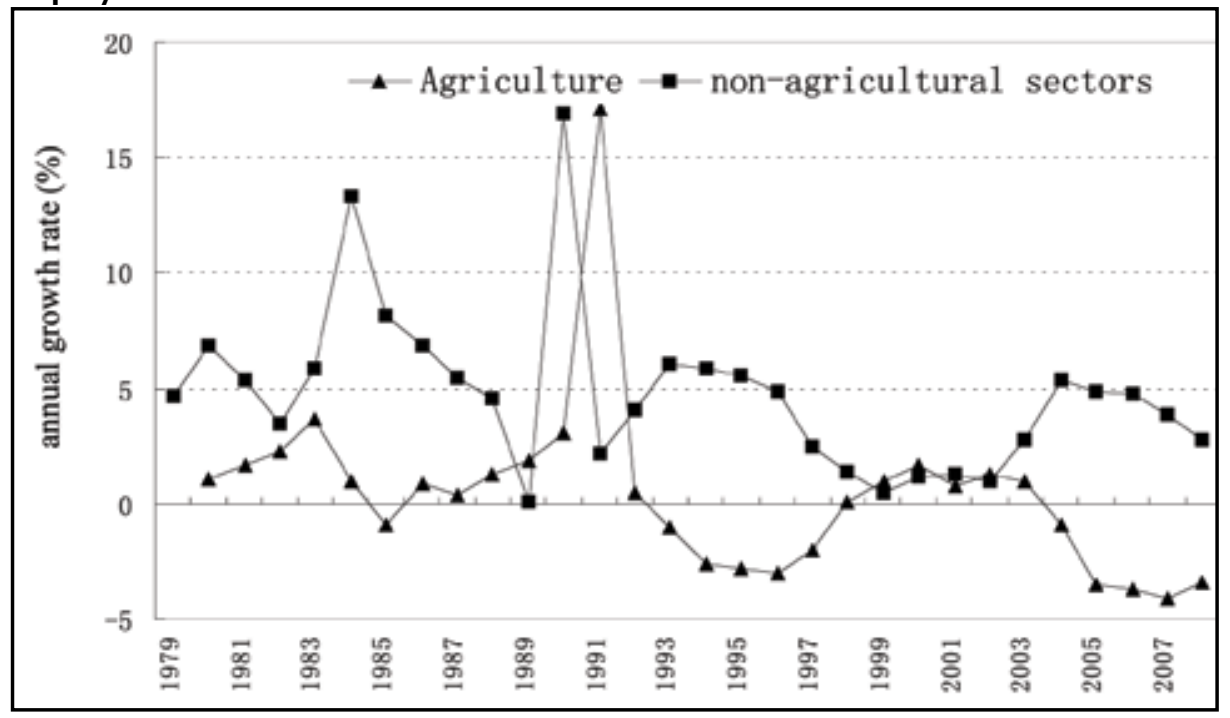

Source: National Bureau of Statistics (NBS) various years, China Statistical Yearbook, China Statistics Press, Beijing.

\section{The end of the 'Todaro dogma'}

Michael Todaro is widely known for his profound research on internal migration in developing countries. His most influential theory is the so-called 'Todaro paradox' (Todaro 1969; Harris and Todaro 1970). He argues that it is the differential of expected wages between the rural and urban sectors that encourages rural workers to migrate. Since the urban expected wage is adjusted by the urban unemployment rate, the paradox is this: efforts made by the government to reduce the unemployment rate will increase the difference 
of expected wages between rural and urban sectors and thus motivate more migration, which in turn can lead to more unemployment. A further implication is that any efforts made to improve the status of migrants working in urban areas can encourage more migration, thereby deteriorating the potential for migrants to find employment and residencein urban areas. Accordingly, the 'Todaro paradox' has been translated into a 'Todaro dogma', which views labour migration as a pattern of 'comeand go', rather than of permanent settlement, and thus the implementation of policies aiming to control and even restrict the process of rural-to-urban migration is regularly implied. ${ }^{2}$

The Todaro paradox rests on the assumption that there is no unemployment in the agricultural sector-namely, that agriculture is a pool for depositing the surplus labour force. Correspondingly, the Todaro dogma tends to mitigate the social risks potentially raised by labour migration, through balancing the push and pull forces between the rural and urban sectors, and especially through strengthening the role of rural areas in absorbing surplus workers. From the viewpoint of economic development, such an assumption is insufficient to conduct a dynamic analysis, because it fails to take into account the fact that the agricultural share of employment declines over time in the development of the dual economy.

As mentioned previously, the Chinese economy is already inthe stage of development expressed by the Lewis turning point, which suggests that the Todaro paradox might no longer hold. Thus there is a need to revise the policy orientation implied by the Todaro dogma. Before the Lewis turning point arrived, during each period when urban sectors suffered a cyclical downturn, migrant workers frequently returned to their rural homes and their contracted land provided them with shelter and some employment support. That mechanism prevented floating workers from becoming unemployed and hence falling into absolute poverty. Given the lack of social protection for migrant workers, this has indeed served as a buffer against economic and social risks. Once agriculture does not serve as a pool of surplus labour, however, and labour migration no longer follows a come-and-go pattern, this mechanism for risk alleviation no longer exists.

The employment adjustment of Chinese migrant workers in the face of the global financial crisis resonates with international experience. After a short break during the Chinese New Year period in early 2009, migrant workers immediately returned back to their urban jobs, and through relocation from manufacturing to service and construction sectors, they achieved comparatively full employment — so much so that a migrant worker shortage occurred shortly

2 For an explanation of the Todaro dogma and the policy implications of the Todaro paradox, see Todaro (1985:Ch. 9). 
afterwards. This evidently suggests that the management mode of labour migration based on the Todaro dogma and the conventional wisdom of a comeand-go pattern no longer characterise the new stage of development.

In contrast with the period before the Lewis turning point, when urban governments regularly drummed out migrant workers each time their cities had employment pressure (Cai et al. 2001), during the years 2008-09, as countermeasures to cope with the negative impacts of the financial crisis on employment, urban administrators relaxed the restriction on ambulatory pitchmen, which helped migrant workers shift their jobs to the informal service sector in the first place. Then, as the government-led stimulus plan was implemented, and since the structure of investment had become more biased towards infrastructure and services, more and diversified job opportunities were created (Cai et al. 2010).

This is very similar to Japan's experience in that, after the arrival of its Lewis turning point, the massive outflow of rural workers who settled and found jobs in urban areas in the 1960s has never been reversed, despite upsurges and recessions in the urban economy since then. During urban economic downturns in the country, workers originating from rural areas have not returned to agricultural production. Instead, in coping with each of the economic crises, their employment has been adjusted from the manufacturing to the service sector and has become more diversified. As a result, those workers have settled to become urban residents.

On the other hand, Chinese migrant workers' willingness and tendency to live and work permanently in urban areas can conflict with the reality that they lack legitimate urban residential identities. When urban enterprises encounter difficulties, migrant workers are the first group of employees to be affected. Therefore, while being vulnerable in job and wage security and inadequately covered by social safety nets, they also suffer the worst labour relations. According to a survey conducted in 2009 (Ru et al. 2009:7-8), labour dispute cases accepted and heardby courts had increased by 30 per cent in the country as a whole and by 40 to 150 per cent in coastal provinces. Migrant workers became the dominant accusers in those cases, ranging from wage arrears to social security entitlements. This indicates the existence of social risks caused by employment and income insecurity, on the one hand, and the urgent need for revising the conventional mode of regulating the labour market, on the other. That is, in the new stage of development after reaching the Lewis turning point, urbanisation should be deepened through a strategy of transforming farmersturned-workers into migrants-turned-residents.

The manifestation of the end of the Todaro dogma is rapid urbanisation, which is attributed overwhelmingly to migrant workers becoming secular residents 
in urban areas. Such a rapid urbanisation rate, however, is more statistical than material under the unique circumstance of China's hukou (household registration) system. The difference between statistical and real urbanisation suggests that while farmers have turned to migrant workers and have counted as urban residents, they are not real citizens in urban areas.

In the planning period, when strict hukou control prevented spontaneous migration, the division of agricultural and non-agricultural hukou identities became a practical method to define who were counted as urban residents and who were counted as rural residents. For example, the second and third National Censuses, conducted in 1964 and 1982, respectively, both defined people with non-agricultural hukou as urban residents and people with agricultural hukou as rural residents.

With rural-to-urban migration becoming more and more common through the reform period, and since hukou reforms have not kept pace with the expansion of migration, hukou identity no longer accurately reflects real residence in rural and urban areas. In response to this, the fourth National Census used the concept of 'usual residence' to distinguish between rural and urban residents by defining people who left their rural home village and lived in an urban area for more than one year as usual residents of that urban area. After the 1990 census, the National Bureau of Statistics adjusted all data between 1982 and 1990 based on the criterion of one-year residence. The fifth National Census shortened permanent residence to six months - that is, those rural migrants who lived in cities for more than six months were considered urban usual residents, regardless of their place of household registration. As a consequence, there appears to be a large difference between the proportion of the urban population and the proportion of the non-agricultural hukou population-a difference as large as 12 percentage points in 2007 (Figure 15.3).

Due to the fact that a large proportion of the statistically defined urban population is still engaged in agricultural activity, Chan (2009) claims that China's urbanisation level is overestimated by 10 per cent. Although urbanisation involves a shift from agricultural to non-agricultural activities, it is more typically characterised by population concentration and industry agglomeration. Hence, the engagement of fractional urban residents in agriculture is not sufficient evidence to conclude that urbanisation is overestimated. Because the hukou system is a unique institutional arrangement of China's and there are ample welfare implications behind it, it is more meaningful to understand Chinesestyle urbanisation within the context of the hukou system and its public service content. 


\section{Figure 15.3 Usual urban population versus non-agricultural hukou population}

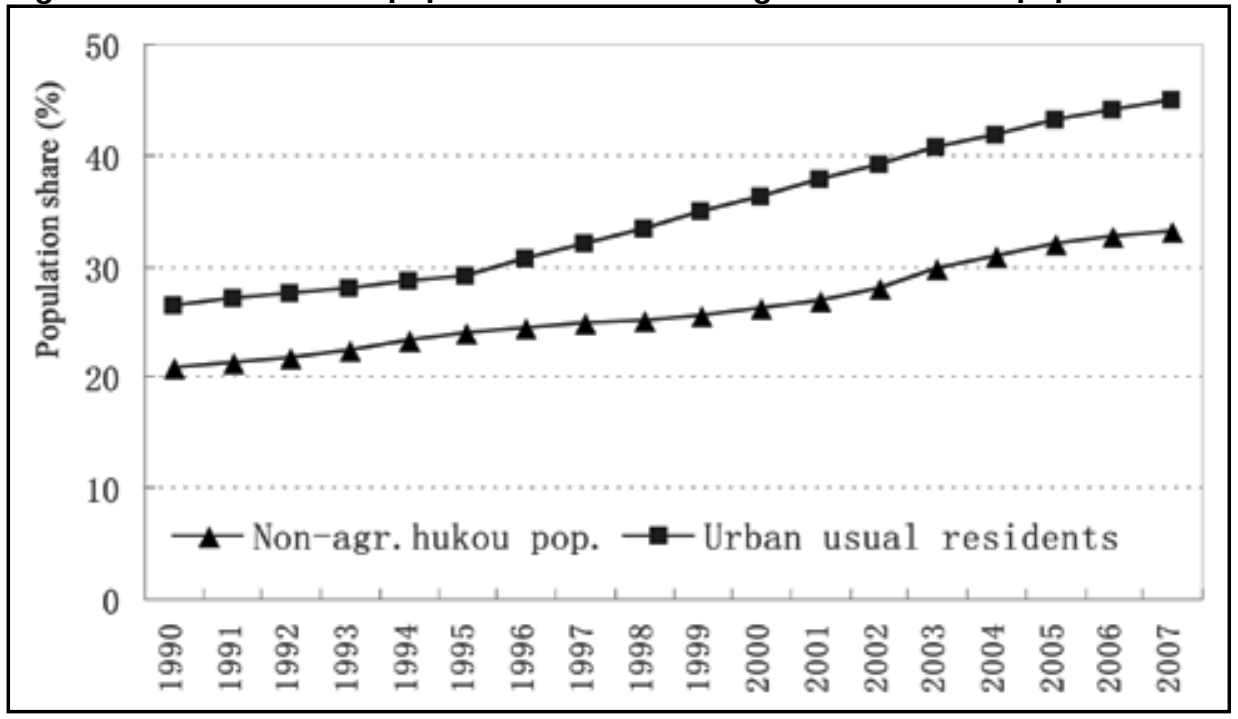

Source: National Bureau of Statistics (NBS) various years, China Population and Employment Statistical Yearbook, China Statistics Press, Beijing.

The fact that rural workers can now freely migrate to and work in cities signifies important progress in reforming the hukou system - to which the current level of urbanisation can be largely attributed. In this sense, the present urbanisation level should not be considered an overestimate. Accordingly, I do not agree with the arguments by Chan and Buckingham (2008) that suggest that the cumulative effect of the new round of hukou reform has nothing to do with the abolition of the hukou, but makes migration harder than before. One can hardly conclude that, given the widespread employment of migrant workers in urban sectors, the entitlements of free residence in urban areas and, as a result, the substantial expansion of migrant numbers in cities.

The significant increase in the share of the population with non-agricultural hukou, especially in recent years, is an indication of hukou reform progress. Compared with the period 1990-99, in which the annual growth rate of the non-agricultural population share was 2.3 per cent and that of the urban 'usual' population share was 3.1 per cent, in the period 1999-2007 the annual growth rate of the non-agricultural population share increased to 3.2 per cent and that of the urban 'usual' population share increased to 3.2 per cent. Both these growth rates were fast compared with the world average (Cai 2010). However, since there is still a difference between the two population groups - which is reflected in the gap of access to public services between farmers-turned-workers and migrants-turned-residents - there is great potential for further urbanisation through narrowing the difference between the 'usual' urban population and real urban residents. 
This urbanisation pattern is an atypical one in terms of equal access to public services. Those migrant workers and their accompanying family members, though counted as usual urban residents, are not fully covered by social security and more widely by other forms of social protection. They do not enjoy equal entitlements to public services such as subsidised housing and children's elementary education. This incomplete urbanisation has depressed the effect of urbanisation on economic growth and social development. More concretely, because migrant workers without urban residence identity still consider their rural home as their final destination, they behave like rural residents, who consume less and save more owing to comparatively low income and the lack of social protection. At the same time, urban construction does not take into account migrants' demand for public infrastructure. Therefore, individual and public consumption, which would have become demand sources for spurring economic growth, especially in the service sector, have been held back.

\section{Requisite conditions for equalising access to public services}

One of the changes brought about by the Lewis turning point is manifested in the government's policy orientation towards labour migration. The Chinese central government has been conceptualised as a typical developmental or entrepreneurial state (Oi 1999; Walder 1995), while Chinese local governments are seen as being competitive (Herrmann-Pillath and Feng 2004). It is well documented that under the decentralised fiscal system, local governments have had strong incentives to spur local economic development and have thus tried to ensure that government functions in an efficient way.

Local governments have various ways of trying to reach their development goals - from intervention in economic activities to the provision of public policies. Through a 'vote with their feet' model, Tiebout (1956) explained local governments' behaviour of providing public services, trying to find a 'markettype' solution for public goods provision. This hypothesis implies that given particular potential migrants' needs and preferences for public services, they choose their destinations based on information available to them on public services provided by local governments. Similarly, by deciding and adjusting how to provide public goods and create positive externalities, local governments try to attract or deter potential migrants in accordance with their own demand and preferences for the number and composition of local dwellers.

Although there has been extensive debate about the Tiebout model, this hypothesis does provide a powerful tool for our analysis of the incentive compatibility of local governments in making policies towards migrant workers, 
as they recognise the increasing importance of migrant workers to local economic development. In the development of a dual economy characterised by an unlimited supply of labour, any number of workers demanded can be met without a noticeable increase in the wage rate - namely, the labour force does not become a bottleneck limiting economic growth. Therefore, the main arena in which local governments - even of a developmental type-intervene in economic development is not in labour markets but in attracting physical capital inflows.

After the Chinese economy reached its Lewis turning point, and labour shortages had begun to occur regularly, while employers began competing for workers by increasing wages, improving work-related welfare and working conditions, local governments utilised various measures to create a better environment for local cities to attract workers. One notable practice is to include migrant workers under the umbrella of labour market institutions and social protection, which includes raising minimum wage standards and enhancing the coverage of social security and other public services.

For example, adjusting the level of minimum wages is a mechanism that has been used frequently in recent years by local governments to intervene in wage setting. The minimum wages scheme has been put into practice since The Regulation on Minimum Wages in Enterprises was issued in 1993 and the Labour Law in 1994. The Labour Law authorised local governments to decide their standards in accordance with locallydifferentiated standards of living. Early on in its implementation, minimum wage levels were low and rarely enhanced, and the scheme was rarely applied to migrant workers. The levels of minimum wages and the frequency of their adjustment slowly increased, however, in the late 1990s, and further noticeable changes have occurred in the new century. Since the migrant labour shortage became widespread in 2004, the central government has called for a frequency ofadjustment of minimum wages of no more than two years. At the same time, local governments, pressured by local labour shortages, have leapfrogged to increase minimum wages (Table 15.2), which are now applied to migrant workers also. In the same period, minimum wages have been adjusted in an attempt to keep pace with the increase in market wages. ${ }^{3}$

3 Cai et al. (2009) depict in detail the trends of increases in migrant workers' wages, which we take as representative of market-determined wage rates of unskilled workers. 
China: The Next Twenty Years of Reform and Development

Table 15.2 Adjustments of urban minimum wages (numbers, per cent)

\begin{tabular}{ccccc}
\hline Year & $\begin{array}{c}\text { No. of } \\
\text { sampled } \\
\text { cities }\end{array}$ & $\begin{array}{c}\text { No. of cities } \\
\text { involved in } \\
\text { adjustment }\end{array}$ & $\begin{array}{c}\text { Average MWR } \\
\text { growth rates of } \\
\text { sample cities }\end{array}$ & $\begin{array}{c}\text { Average MWR } \\
\text { growth rates of } \\
\text { involved cities }\end{array}$ \\
\hline 1996 & 129 & 32 & $3.6(7.2)$ & $14.4(7.2)$ \\
1997 & 142 & 80 & $7.6(8.0)$ & $13.5(5.9)$ \\
1998 & 209 & 31 & $2.4(6.4)$ & $15.9(7.7)$ \\
1999 & 227 & 152 & $16.9(14.2)$ & $25.3(9.4)$ \\
2000 & 255 & 79 & $8.8(15.9)$ & $28.7(15.8)$ \\
2001 & 274 & 122 & $9.2(16.8)$ & $20.7(20.0)$ \\
2002 & 286 & 167 & $9.8(11.4)$ & $16.8(10.3)$ \\
2003 & 286 & 77 & $4.4(8.3)$ & $16.3(7.7)$ \\
2004 & 286 & 186 & $15.6(16.6)$ & $24.0(14.9)$ \\
2005 & 286 & 132 & $10.9(15.5)$ & $23.6(14.9)$ \\
2006 & 286 & 253 & $18.4(14.4)$ & $20.7(13.6)$ \\
2007 & 286 & 154 & $10.8(14.3)$ & $20.0(13.9)$ \\
2008 & 286 & 200 & $13.6(11.9)$ & $19.4(9.4)$ \\
\hline
\end{tabular}

MWR minimum wage rate

Note: Standard deviations are in parentheses.

Source: Authors' calculations based on Institute of Population and Labour Economics n.d., Urban Minimum Wages Database, Institute of Population and Labour Economics, Chinese Academy of Social Sciences, Beijing.

Migrant workers are, however, still left behind when it comes to social security coverage, particularly pension and unemployment insurance. According to the Employment Contract Law issued in 2008 and other regulations, migrant workers are entitled to be included in urban basic social security. The participation rate of migrant workers in social security programs is, however, rather low. A survey conducted by the NBS in 2009 shows that only 9.8 per cent of migrant workers living in cities for more than six months participated in basic pension programs and 3.7 per cent in unemployment insurance programs (Sheng 2009). Since there is no legal handicap for migrant workers to participate in various social security programs, the willingness of workers and employers to join rests largely on each scheme's design. Before conceptions of scheme design can be decisively altered, local governments can find some alternatives if they are willing to expand the coverage of public services in order to attract more labour, and that can also bring forth social security reform for the central government. It is therefore important to consider the interaction between the right conditions for equalising migrant workers' rights to public services created by the arrival of the Lewis turning point and the practices of the central and local governments in related arenas.

The general concerns about including migrant workers in the urban social security system have been threefold. First, authorities have long been concerned 
with the burden of migrants' participation on the affordability of social security funds. Second, as for the migrant workers' and employers' incentives to participate in the programs, the fact that not all social security schemes are portable and transferable across regions has deterred migrant workers and their employers from participating, since migrant workers' employment is not stable. Third, the high contribution rates required have reduced affordability and hence the incentives for employers to participate in the programs.

Turning to pensions, the conditions for an inclusive basic pension system have mellowed. The current basic pension system for urban enterprises has two parts: social pooling and individual accounts. The system was formed in 1997 and it has long mixed up the pooling and individual accounts, because the inadequacy of social pooling was required to be compensated by individual account collection. That caused a problem of empty individual accounts, and the system is indeed a pay-as-you-go type with only a nominal fullyfunded component. The problem of inadequacy of the social pooling accounts is twofold. First, a huge historic debt was accumulated during the pre-reform period, during which there was no accumulation for workers' pension funds, since the State guaranteed retirement support for all state-owned enterprises' employees, who overwhelmingly dominated urban employment. Second, the dependence ratio has increased since the initiation of reform and is expected to grow over time, according to demographic predictions made by the United Nations (UN 2009).

There have, however, been some significant changes in the system in recent years. First, many of the 'middlemen' (those who had not yet retired in 1997) retired and were well supported by the social pooling pension, alongside with the 'old men' (those who retired before 1997). That is, a large portion of historical debt is disappearing as time passes. Second, as the pilot program for basic pension system reform aimed at substantiating individual accounts in Liaoning Province has been completed and extended to 11 more provinces, individual accounts have accumulated, which is reflected in the current positive balance of more the RMB700 billionin the revenues and expenditures of the basic pension fund. Third, migrant workers whose ages are concentrated between twenty and thirty have become widely engaged in urban activity, which significantly reduces the dependence ratio of the retired to working population - that is, migrant workers not only contribute to social pooling, they build a full individual account if they can be included. With all these changes reflecting positive improvements in the basic urban pension system, when a fuller inclusion of migrant workers in the system can be reached, the financial difficulties of the system will not be aggravated but substantially eased (Cai and Meng 2003).

The lack of portability has been the decisive constraint on migrant workers' incentives to participate in the basic pension system. The basic pension fund was not built at the provincial level in 19 provinces and it was not even at the 
municipal level in some regions until 2007. The low levels of social pooling have restricted the portability of basic pensions and prevented highly mobile migrant workers from transferring their pension contributions. As a result, when a migrant worker changes his workplace, he has to surrender his pension contribution; and when labour market shocks happen, a mass of migrant workers retreats from the program. Given that only the individual accumulation but not the pooled contribution is refundable, neither the migrant workers nor their employers have much incentive to participate.

In order to tackle this problem, the central government has recently issued 'Interim Measures on the Transfer of Continuation of Basic Pension for Urban Enterprises Employees', which stipulates that all workers who participate in the basic pension program, when migrating across provincial boundaries, will be guaranteed a transfer of their individual and pooling accounts to their new workplace. This new regulation provides institutionallyguaranteed portability for migrant workers' pension entitlements.

A small fraction of migrant workers has so far participated in the unemployment insurance program. While the Employment Contract Law came into effect in 2008 - requiring employers to sign contracts with migrant workers so that the latter could be included in various social security programs - government departments holding on to the Todaro dogma and hence considering migrant workers a highly mobile group of workers have not had a strong incentive to enforce this regulation. That is, the authorities expect that such high mobility might cause circumstances in which migrant workers contribute less to and benefit more from the program. As discussed earlier, the Todaro dogma is preventing an accurate understanding of migrant workers' real status in the labour market.

The current unemployment insurance program requires a minimum contribution period of one year and warrants a period before benefiting of one to two years. Migrant workers' employment features are not incompatible with this regulation. According to a recent survey (Zhang et al. 2009), only those migrant workers who entered cities for less than one year, and account for 11 per cent of all samples, changed their jobs and cities within a year. All others who migrated out of rural areas for more than one year changed jobs and cities of employment less than once within a year. And the longer the migrants stayed in a city, the less frequently they changed their jobs or cities (Table 15.3). Furthermore, migrant workers usually accept low reservation wages and less satisfying jobs, so they take less time to find a new job once encountering unemployment. In conclusion, the labour market status of migrant workers can perfectly meet the requirements of the minimum time of contributing and the warranted time of benefiting. 
Table 15.3 Duration of migrating work and mobility of migrant workers (numbers, per cent)

\begin{tabular}{lllll}
\hline Years & $\begin{array}{l}\text { Effective nos of } \\
\text { people surveyed }\end{array}$ & $\begin{array}{l}\text { Proportion } \\
\text { of total }\end{array}$ & $\begin{array}{l}\text { Numbers of } \\
\text { annual job } \\
\text { change }\end{array}$ & $\begin{array}{l}\text { Numbers of } \\
\text { annual city } \\
\text { change }\end{array}$ \\
\hline$<\mathbf{1}$ & 362 & 11 & 4.00 & 3.89 \\
$\mathbf{1 - 3}$ & 658 & 20 & 0.87 & 0.76 \\
$\mathbf{3 - 5}$ & 454 & 14 & 0.50 & 0.42 \\
$\mathbf{5 - 8}$ & 475 & 15 & 0.34 & 0.27 \\
$\mathbf{8}$ & 1268 & 39 & 0.18 & 0.14 \\
\hline Total & 3217 & 100 & 0.82 & 0.75 \\
\hline
\end{tabular}

Source: Zhang, X., Tian, M., Liu, F., Gao, Y., Chen, L. and Hu, X. 2009, Survey report of migrant workers' pension system, International Conference on Migrant Workers' Pension System, Ministry of Human Resources and Social Security, Beijing, 15-16 September.

Since 2003, the revenue of the unemployment insurance fund has significantly outweighed the expenditure of the fund, so the balance accumulated to RMB128.8 billion by 2008, which was five times the total expenditure of the same year. As a pay-as-you-go type fund, consecutive excesses of revenue over expenditure are not necessarily advisable, particularly when a huge surplus has been accumulated. It is such an overrun that causes an asymmetry between the contributions and benefits of potential participants and reduces the incentive to participate. Therefore, it is feasible to adjust the contribution rate of unemployment insurance in order to enhance incentives to participate and to expand the coverage of the program. This is an example of strengthening the levels of social protection for migrant workers.

In fact, as local governments have begun to recognise the need to increase social protection to increasingly scarce workers, local government authorities for labour and social security have tended to flexibly adjust the contribution rates of various social security programs, which the central government is legally required to adjust. While tackling the global financial crisis, the central government introduced a series of employment support policies, which allowed qualified enterprises to postpone their payments of social security contributions and reduce workers' contributions to social security funds. Taking advantage of the temporary flexibility, local governments in some regions - especially those where labour shortages had been strongly felt before the financial crisis occurred-increased the social security coverage of migrant workers by debasing the contribution rates during the period.

Moreover, one can observe a host of phenomena that had rarely happened before the shortage of ordinary workers became widespread across the country. First, local governments in labour-migration destinations have tried to establish 
formal coordination mechanisms with their counterparts in labour-sending regions in order to help local enterprises secure a stable supply of labour. Second, some municipal governments have relaxed certain criteria-such as the size of purchased housing, the length of employment contracts and accumulative years of contributing to social security programs - for migrants to obtain urban hukou. All these efforts have been made mainly by local governments and indicate incentive compatibility in people-centred urbanisation.

\section{Conclusions}

The combination of a rapid demographic transition from high to low fertility, an institutional transition from a planned to a market economy and a continuing transition from a dual society to an integrative one has contributed significantly to the 'Chinese miracle' that has received worldwide attention. Such a compressed process of socioeconomic development and institutional transition provides an interesting case for studies of development in a dual economy. The fact that China's development of a dual economy is passing through the Lewis turning point has injected new life into the economic development theory coined by Arthur Lewis. The application of other relevant paradigms in development economics to the China case helps us to assess the stage of, and to identify challenges and opportunities facing, China's socioeconomic development.

As a result of the arrival of the Lewis turning point, migrant workers have become an indispensable source of labour for urban sectors - in other words, non-agricultural sectors' demand for migrant workers has become unvarying, or rigid. Since agriculture no longer provides a pool of surplus labour and labour migration no longer demonstrates a come-and-go pattern, there is a need for synchronisation between urbanisation and industrialisation. While China has urbanised at the world's fastest pace in recent decades, this speed can be attributed to counting migrants as de facto urban residents, who live in cities for more than six months but have no formal access to public services due to their lack of local hukou.

Now that the existing exclusiveness of urban public services provision is rooted in the hukou system, the extension of those provisions to migrant workers should logically initiate from hukou system reform. Because many municipalities have little financial capability to cover all migrants with equal provision of public services - such as social security, migrant children's compulsory education and entrance to higher education and subsidised housing - and while there has been some hukou reform in some cities, there has not been a significant breakthrough overall. The hukou system is, however, significant only because of its affiliation with various urban public services that favour residents with 
local hukou identity. Under the circumstance of labour shortage, and in pursuit of attracting and keeping migrant workers, developmental local governments will change their function to focus more on equal public services provision. When non-hukou migrant workers and their accompanying families can enjoy more equal rights to urban basic public services, the hukou per se becomes less meaningful. That is, real hukou reform can be embodied in the process of transforming farmers-turned-workers into migrants-turned-residents.

Compared with other developing and transitional countries, in China, the hukou system is unique. China's development of a dual economy has therefore been characterised by the transformation of farmers to urban workers without entitlement to public services, particularly regarding access to social protection, which has driven rapid urbanisation with Chinese characteristics. As reaching the Lewis turning point brings about a labour shortage, a new round of urbanisation with Chinese characteristics will be shifting towards transforming migrant workers into entitled residents. Just as China's development has already created the largest number of farmers-turned-migrant workers in human history, it can also be expected to create the largest number of migrants-turned-urban residents in the world in the next two decades.

\section{References}

Cai, F. 2008a, Approaching a triumphal span: how far is China towards its Lewisian turning point?, UNU-WIDER Research Paper, No.2008/09, United Nations University World Institute for Development Economics Research, Helsinki.

Cai, F. 2008b, Lewis Turning Point: A coming new stage of China's economic development, Social Sciences Academic Press, Beijing.

Cai, F. 2010, 'How migrant workers can contribute to urbanization: potentials of China's growth in post-crisis era', Chinese Journal of Population Science, no.1, pp.2-10.

Cai, F. and Meng, X. 2003, 'Demographic transition, system reform, and sustainability of pension system in China', Comparative Studies, vol.10.

Cai, F. and Wang, D. 2005, 'China's demographic transition: implications for growth', in R. Garnaut and L. Song (eds), The China Boom and Its Discontents, Asia Pacific Press, Canberra.

Cai, F., Du, Y. and Wang, M. 2001, 'What determines hukou system reform? A case of Beijing', Economic Research Journal, vol. 12. 
Cai, F., Du, Y. and Wang, M. 2009, Migration and labour mobility in China, Human Development Research Paper, no.9, United Nations Development Programme, Human Development Report Office, New York.

Cai, F., Wang, D. and Zhang, H. 2010, 'Employment effectiveness of China's economic stimulus package', China \& World Economy, vol.18, no.1, pp.33-46.

Chan, K. W. 2009, Urbanization in China: what is the true urban population of China? Which is the largest city in China?, Unpublished memo.

Chan, K. W. and Buckingham, W. 2008, 'Is China abolishing the Hukou system?', The China Quarterly, vol. 195, pp. 582-606.

Department of Rural Surveys various years, China Yearbook of Rural Household Survey, National Bureau of Statistics, China Statistics Press, Beijing.

Garnaut, R. 2010, Chapter 2 in this volume.

Garnaut, R. and Huang, Y. 2006, 'Continued rapid growth and the turning point in China's development', in R. Garnaut and L. Song (eds), The Turning Point in China's Economic Development, Asia Pacific Press, Canberra.

Harris, J. and Todaro, M. 1970, 'Migration, unemployment and development: a two sector analysis', American Economic Review, no.40, pp.126-42.

Hayami, Y. and Ruttan, V. 1980, Agricultural Development: An international perspective, Johns Hopkins University Press, Baltimore and London.

Herrmann-Pillath, C. and Feng, X. 2004, 'Competitive governments, fiscal arrangements, and the provision of local public infrastructure in China: a theory-driven study of Gujiao municipality', China Information, vol. 18, no. 3, pp. 373-428.

Institute of Population and Labour Economics n.d., Urban Minimum Wages Database, Institute of Population and Labour Economics, Chinese Academy of Social Sciences, Beijing.

Lewis, A. 1954, 'Economic development with unlimited supplies of labour', The Manchester School, vol. 22, no.2, pp. 139-91.

Lewis, A. 1958, 'Unlimited labour: further notes', The Manchester School, vol.26, no.1, pp. 1-32.

Lewis, A. 1972, 'Reflections on unlimited labour', in L. Di Marco (ed.), International Economics and Development, Academic Press, New York, pp. 75-96. 
Minami, R. 1968, 'The turning point in the Japanese economy', The Quarterly Journal of Economics, vol.82, no.3, pp.380-402.

National Bureau of Statistics (NBS) various years, China Population and Employment Statistical Yearbook, China Statistics Press, Beijing.

National Bureau of Statistics (NBS) various years, China Statistical Yearbook, China Statistics Press, Beijing.

National Development and Reform Commission 2010, The Report on the Implementation of the 2009 Plan for National Economic and Social Development and on the 2010 Draft Plan for National Economic and Social Development, The Third Session of the Eleventh National People's Congress, Beijing.

National Development and Reform Commission various years, Compilation of Farm Product Cost-Income Data of China, China Statistics Press, Beijing.

Oi, J. C. 1999, 'Local state corporatism', in J. C. Oi (ed.), Rural China Takes Off: Institutional foundations of economic reform, University of California Press, Berkeley.

Ranis, G. and Fei, J. C. H. 1961, 'A theory of economic development', The American Economic Review, vol. 51, no. 4, pp. 533-65.

Ru, X., Lu, X. and Li, P. 2009, Analysis and Prospects of China's Social Situation, 2009, Social Sciences Academic Press, Beijing.

Sheng, L. 2009, New challenges migrants are faced with on employment during the financial crisis, Paper presented to Urban-Rural Social Welfare Integration Conference, Chengdu, Sichuan Province, 16 April.

Tiebout, C. M. 1956, 'A pure theory of local expenditures', The Journal of Political Economy, vol. 64, no. 5, pp. 416-24.

Todaro, M. P. 1969, 'A model of labour migration and urban unemployment in less developed countries', American Economic Review, vol.59, no.1, pp. $138-48$.

Todaro, M. P. 1985, Economic Development in the Third World, Longman, New York and London.

United Nations (UN) 2009, The World Population Prospects: The 2008 revision, United Nations, New York. <http://esa.un.org/unpp/>

Walder, A. 1995, 'Local governments as industrial firms: an organizational analysis of China's transitional economy', American Journal of Sociology, vol.101, no.2, pp.263-301. 
Zhang, X., Tian, M., Liu, F., Gao, Y., Chen, L. and Hu, X. 2009, Survey report of migrant workers' pension system, International Conference on Migrant Workers' Pension System, Ministry of Human Resources and Social Security, Beijing, 15-16 September.

Zhao, W. 2010, Analysis on potentials of China's agricultural growth after Lewis turning point, Unpublished working paper. 


\section{Indigenous innovation for sustainable growth}

Yanrui Wu

\section{Introduction}

After three decades of rapid growth, the Chinese economy is now at the crossroads heading to the next phase of development. While China's economic growth has indeed been phenomenal, it has also been resource intensive and environmentally damaging. To sustain high growth in the coming decades, the role of technological progress has to be boosted. Technological progress within a country can be due to technology transfer from abroad or indigenous innovation. The former has been widely discussed in the literature on the Chinese economy. For example, Wei and Liu (2006) examine productivity spill-overs from exports and foreign direct investment (FDI) in the Chinese manufacturing sector, Tian (2007) and Liu et al. (2009) investigate technology spill-overs from FDI and multinational corporations and Kuo and Yang (2008) analyse knowledge spillovers and regional economic growth. The innovation capacity and achievements of indigenous firms in China are, however, under-documented. ${ }^{1}$ The objective of this chapter is to examine China's indigenous innovation capacity and to explore the potential for innovation to provide a key source of sustainable growth in the future. The chapter begins with a review of China's innovation capacity and achievements. This is followed by an analysis of innovation at the firm level. Subsequently, China's innovation is examined from an international perspective, before discussing the implications for sustainable growth in the country.

\section{China's innovation capacity and achievements}

China has adopted an active science and technology development program since the foundation of the People's Republic in 1949. The program has long been biased towards technological advancement in defence-related sectors. Science

1 General surveys of China's research and development sectors are available in Gao and Jefferson (2007); OECD (2009); and Zhang et al. (2009). Wei and Liu (2006) and Jin et al. (2008) also cover research and development marginally. 
and technology as important sources of economic growth more generally have been recognised and promoted only recently. This is clearly envisaged in the country's 'National Medium and Long-term Program for Science and Technology Development (2006-2020)' released in early 2006 (hereafter, the '2020 program'). ${ }^{2}$ The aim of the 2020 program is to make China an innovation-oriented society by 2020 and one of the world's leading innovators in the longer term.

The key goals and priorities in China's science and technology development in the coming decade are detailed in the 2020 program document. According to this document, China will:

- give priority to technological development in 11 major sectors such as energy, water resources and environmental protection in the coming 15 years

- further improve the national intellectual property rights (IPR) system and strengthen the enforcement of IPR protection laws and regulations

- encourage enterprises to play the key role in innovation through their involvement in state projects and the provision of tax incentives and other financial support

- boost investment in science and technology; by 2020, China's research and development expenditures will account for about 2.5 per cent of the country's gross domestic product (GDP)

- by 2020, derive 60 per cent or more of its economic growth from technological progress; the numbers of patents granted to and total citations of journal articles by Chinese nationals are expected to be ranked among the top five in the world.

To provide an assessment of China's indigenous innovation capacity, several indicators can be considered. The most important factor underlying indigenous innovation is research and development spending. Associated with the implementation of the 2020 program has been a dramatic increase in research and development expenditure in recent years. For example, during 2005-09, research and development expenditure grew at an average real rate of 19.4 per cent - twice as fast as the growth of China's GDP. ${ }^{3}$ As a result, research and development expenditure as a proportion of GDP (or research and development intensity) in China rose from 0.71 per cent in 1990 to 1.62 per cent in 2009 (Figure 16.1). The same figure also illustrates that China's research and development personnel increased from about 670000 (full-time equivalent) people in 1992 to 1.9 million in 2008. This growth was particularly rapid in recent years, with an

2 The 2020 program was released by the State Council, People's Republic of China, on 9 February 2006 $(<$ www.gov.cn $>$ ).

3 The average growth rate of research and development expenditure is calculated using data from NBS $(2009,2010)$ and YST $(2009)$. 
average rate of 13.4 per cent during 2005-08. In addition, the number of fresh graduates in science, engineering and medicine increased from 476110 in 1995 to 2.7 million in 2008 (NBS 2009).

Figure 16.1 China's research and development intensity and personnel, 19902009

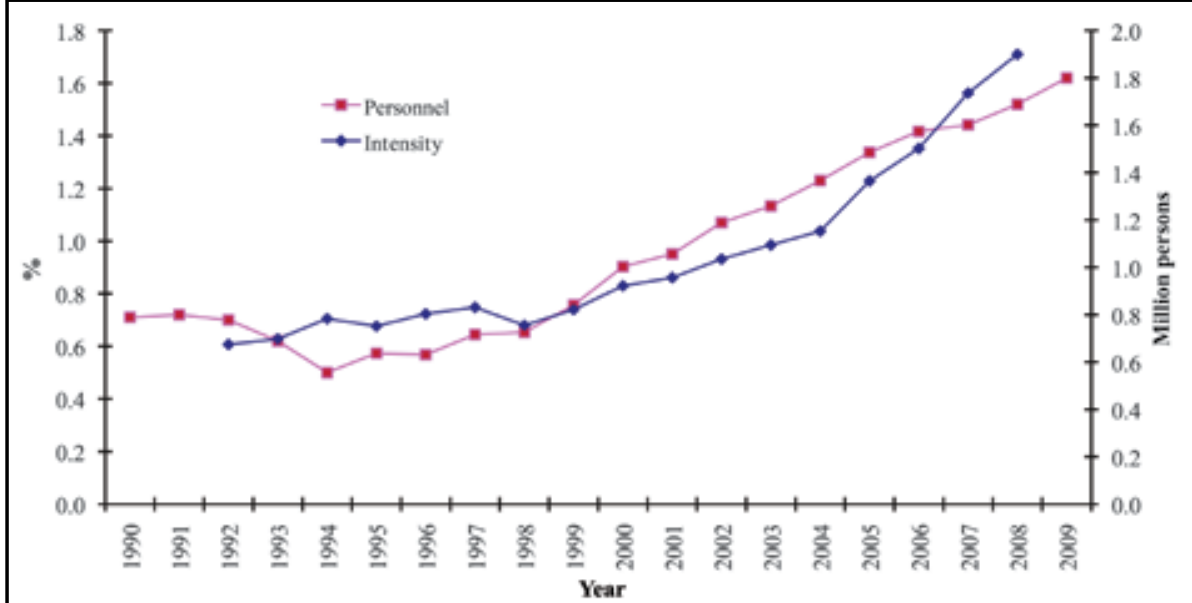

Sources: National Bureau of Statistics (NBS) 2009, China Statistical Yearbook 2009, Chtina Statistics Press, Beijing; National Bureau of Statistics (NBS) 2010, 2009 Statistical Communiqué of National Economic and Social Development, National Bureau of Statistics, Beijing; YHT 2009, China Statistical Yearbook of High Technology Industry 2009, National Bureau of Statistics and Ministry of Science and Technology, China Statistics Press, Beijing.

With the expansion of research and development inputs, China's innovation capability and outcomes have increased too. For example, the numbers of domestic patent applications and registrations grew from 69535 and 41881 items in 1995 to 878000 and 502000 items in 2009, respectively (Figure 16.2). During the same period, the number of Chinese applications for patent registration offshore also increased-from 13510 to about 99000 items, with the number of registered patents rising from 3183 to 80000 (NBS 2009; MST 2010). In addition, it is reported that the number of publications by Chinese scientists and engineers increased from 65000 to 208000 between 1995 and $2007 .^{4}$

There are considerable variations among the Chinese regions. Among the 31 administrative regions in China, research and development intensity varied from less than 0.5 per cent in six regions to more than 2 per cent in four regions in 2008 (Table 16.1). In terms of human resources, the number of research and development scientists and engineers per million people ranged from 161

4 Those numbers are based on the science citation index (SCI), engineering index (EI) and index to scientific and technical proceedings (ISTP) databases, according to YST (2009). 
in Tibet to 9833 in Beijing. Table 16.1 also shows that the number of patent registrations per million people was between 32 in Tibet and 1296 in Shanghai in 2008. In general, large disparities exist between the coastal regions and the rest of the country (that is, the central and western regions). Furthermore, if the number of patent registrations per 1000 scientists and engineers is defined as an indicator of research and development performance then, in general, provincial-level performance and inputs are positively related-as expected and as depicted in Figure 16.3. The figure also highlights, however, two clear outliers, with Beijing underperforming and Zhejiang achieving an excellent performance in 2008 at least.

Figure 16.2 Numbers of patents applied for and accepted, 1995-2009

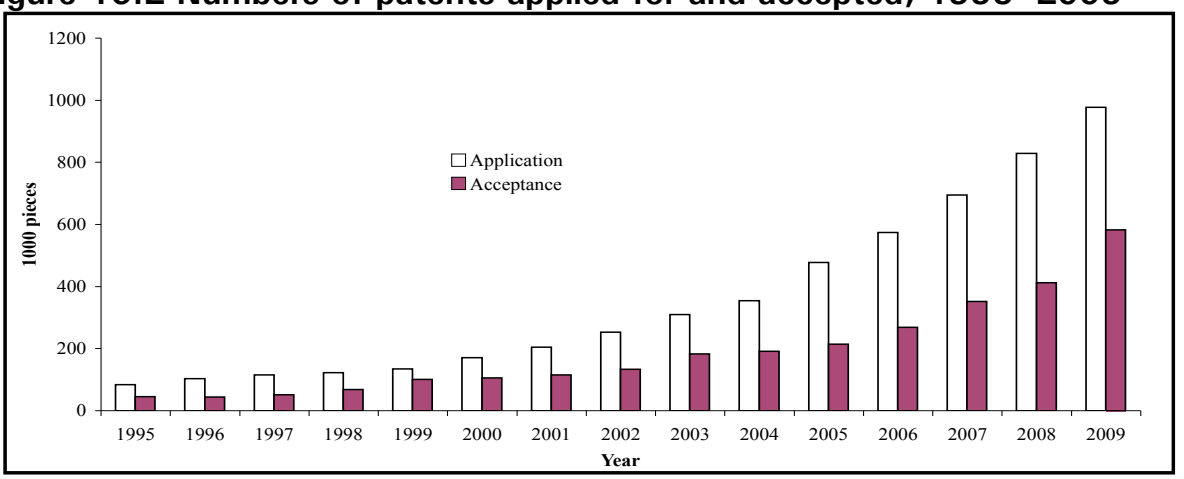

Sources: National Bureau of Statistics (NBS) 2009, China Statistical Yearbook 2009, China Statistics Press, Beijing; National Bureau of Statistics (NBS) 2010, 2009 Statistical Communiqué of National Economic and Social Development, National Bureau of Statistics, Beijing; Ministry of Science and Technology (MST) 2010, China Science \& Technology Statistics, Ministry of Science and Technology, Beijing, <www.most.gov.cn>

Table 16.1 China's regional research and development statistics, 2008

\begin{tabular}{lccc}
\hline Regions & $\begin{array}{c}\text { Expenditure over } \\
\text { GRP (\%) }\end{array}$ & $\begin{array}{c}\text { Scientists and } \\
\text { engineers per } \\
\text { million population }\end{array}$ & $\begin{array}{c}\text { Number of } \\
\text { patents per million } \\
\text { population }\end{array}$ \\
\hline Coastal mean & 1.96 & 2830 & 601 \\
Beijing & 5.25 & 9833 & 1047 \\
Shanghai & 2.59 & 4212 & 1296 \\
Tianjin & 2.45 & 3293 & 577 \\
Jiangsu & 1.92 & 1887 & 579 \\
Zhejiang & 1.60 & 2067 & 1034 \\
Liaoning & 1.41 & 1538 & 247 \\
Guangdong & 1.41 & 2186 & 650 \\
Shandong & 1.40 & 1408 & 283 \\
Fujian & 0.94 & 1345 & 220 \\
Hebei & 0.67 & 535 & 79 \\
Middle mean & 0.85 & 731 & 84
\end{tabular}




\begin{tabular}{lccc} 
Hubei & 1.31 & 1103 & 147 \\
Anhui & 1.11 & 655 & 71 \\
Heilongjiang & 1.04 & 1168 & 120 \\
Hunan & 1.01 & 604 & 96 \\
Jiangxi & 0.97 & 540 & 52 \\
Shanxi & 0.90 & 974 & 67 \\
Jilin & 0.82 & 1085 & 109 \\
Henan & 0.66 & 583 & 97 \\
Guangxi & 0.46 & 426 & 46 \\
Hainan & 0.23 & 172 & 40 \\
Western mean & 0.81 & 597 & 80 \\
Shaanxi & 2.09 & 1352 & 117 \\
Sichuan & 1.28 & 768 & 164 \\
Chongqing & 1.18 & 995 & 170 \\
Gansu & 1.00 & 593 & 40 \\
Ningxia & 0.69 & 694 & 98 \\
Guizhou & 0.57 & 257 & 46 \\
Yunnan & 0.54 & 357 & 44 \\
Inner Mongolia & 0.44 & 647 & 55 \\
Qinghai & 0.41 & 377 & 41 \\
Xinjiang & 0.38 & 366 & 70 \\
Tibet & 0.31 & 161 & 32 \\
\hline
\end{tabular}

Sources: National Bureau of Statistics (NBS) 2009, China Statistical Yearbook 2009, China Statistics Press, Beijing; YST (2009).

\section{Innovation at the firm level}

Chinese enterprises have played an important role in promoting growth in the country's innovation capacity. Since the mid 1990s, Chinese enterprises have become the leading players in research and development investment and execution (NBS 2009). By 2008, they were accounting for more than 70 per cent of the country's research and development investment and spending (Figure 16.4). This growth is also reflected in the changing share of patents registered by the enterprise sector compared with the national total. This share increased from 12 per cent in 1995 to 34 per cent in 2008. ${ }^{5}$ The expanded role of Chinese enterprises could, however, have led to more market-driven research and development investment. This is reflected in the movement of two indicators. First, the share of basic and applied research expenditure over total research and development spending declined from 32 per cent in 1995 to 17 per cent in 2008

5 Those share figures are calculated using China's patent data (NBS 2009). 
(NBS 2009). Second, the share of 'invention' patents over total domestic patents registered peaked at 25.9 per cent in 2004 and has since fallen, reaching 22.7 per cent in 2008 (NBS 2009). ${ }^{6}$ The challenge ahead for policymakers is to ensure that market-oriented research and development activities do not grow at the expense of long-term innovation capacity building in the country.

Figure 16.3 China's research and development intensity and performance, 2008

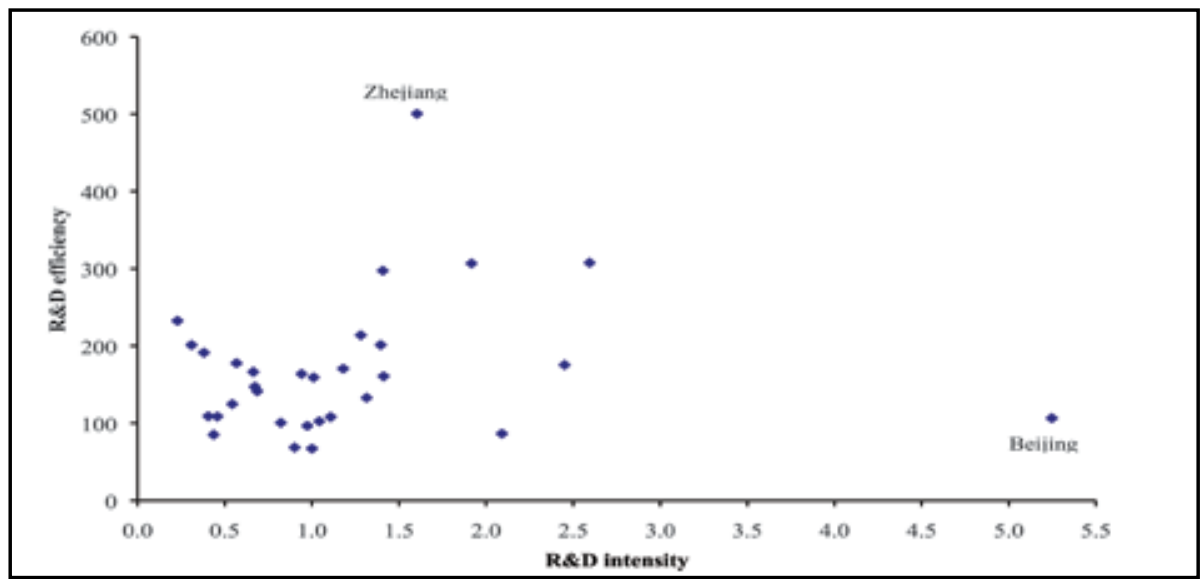

Note: Research and development efficiency is defined as the number of patent registrations per million scientists and engineers.

Sources: Research and development intensity and efficiency values are calculated using data from National Bureau of Statistics (NBS) 2009, China Statistical Yearbook 2009, China Statistics Press, Beijing; YST 2009, China Statistical Yearbook of Science and Technology 2009, National Bureau of Statistics and Ministry of Science and Technology, China Statistics Press, Beijing.

\section{Figure 16.4 China's research and development expenditure shares and sources of funds, 2008}

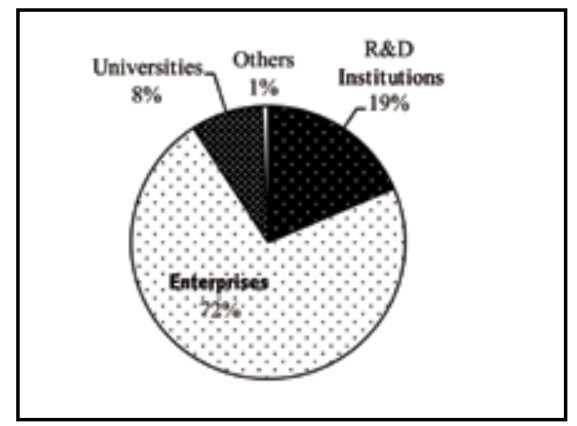

Expenditures shares

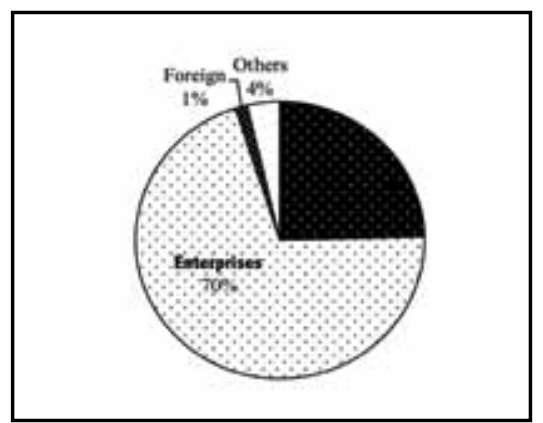

Sources of fund

Source: National Bureau of Statistics (NBS) 2009, China Statistical Yearbook 2009, China Statistics Press, Beijing.

In terms of innovation activities and efforts, heterogeneity exists across sectors as well as among firms. The National Bureau of Statistics (NBS) conducted the first national survey of firm innovation activities in 2007. Detailed information 
about firm-level innovation activities was collected over a three-year period (2004-06). The survey covered all large and medium firms and a sample of small firms. ${ }^{7}$ Among the 299995 firms surveyed, there were 2674 large firms (0.9 per cent), 29622 medium firms (9.9 per cent) and 267699 small firms (89.2 per cent). Only 86342 firms - less than one-third of the total - were in fact engaged in innovation activities (NBS 2008). According to the survey, large firms were found to have the highest rate (83.5 per cent) of participation in research and development activities, followed by small (25.2 per cent) and medium (55.9 per cent) firms. At the industry level, the top five sectors in terms of participation rates were pharmaceuticals (63.7 per cent), instruments and office machines (60.7 per cent), tobacco (55.2 per cent), communication and other electronic equipment (46.8 per cent) and special measuring instruments ( 46.5 per cent). ${ }^{8}$ All of these sectors other than tobacco belong to the so-called high-technology sector. ${ }^{9}$

On average, innovative firms in 2006 spent about 1.9 per cent of their business income on innovation. Though this figure is larger than China's research and development intensity, there is huge disparity among firms. Large firms on average invested about 2.7 per cent of their business income on research and development, which is well ahead of the medium (1.8 per cent) and small firms (1 per cent) (NBS 2008). The large and medium enterprises (LMEs) as a group accounted for 81.1 per cent of total expenditure on innovation in 2006. They also had a value share of 78.7 per cent in the output of new products, which could be used as an alternative indicator of innovation outcome. For this reason, most studies of innovation at the firm level in China focus on LMEs (such as Jefferson et al. 2003; Girma et al. 2009).

The analysis below provides a study of research and development determinants, strategies and intensity in Chinese firms using panel data for 19880 LMEs for the period 2005-07. ${ }^{10}$ Three different yet related models are estimated. These models in turn deal with three issues - namely, the determinants of innovation, the choice of research and development strategies and the intensity of research and development spending in Chinese firms. The baseline model can be presented as Equation 16.1.

\footnotetext{
7 According to the official Enterprise Classification Standards adopted in 2003, Chinese firms are grouped using three criteria: the number of employees, sale revenue and value of assets. For example, the number of employees is above 2000 for the large firms, between 300 and 2000 for the medium firms and below 300 for the small firms in the manufacturing sector $(<w w w . s t a t s . g o v . c n>)$.

8 The percentage figures in parentheses are the rates of participation in research and development activities according to NBS (2008).

9 The National Bureau of Statistics (NBS) released a circular to introduce the Catalogue for High-technology Industrial Statistics Classification in July 2002 (<www.stats.org.cn $>$ ).

10 See $\mathrm{Wu}(2010)$ for a more detailed presentation and discussion.
} 
China: The Next Twenty Years of Reform and Development

\section{Equation 16.1}

$Y_{i t}^{*}=\alpha_{0}+\Sigma \beta_{j} X_{i j(t-1)}+\Sigma \gamma_{j} Z_{i j t}+\varepsilon_{i t}$

In Equation 16.1, $Y^{*}$ is a latent variable that has a value of unity or zero for the first two models (that is, the determinants of innovation and choice of research and development strategy models) and measures firm-level research and development intensity in the third model (that is, the intensity of research and development spending model). The lagged variables $(X)$ capture the effects of the age and size of each firm, its level of liability or debt burden, level of production technology, intangible assets and long-term investment. The $X$ variables are lagged one period to avoid potential simultaneity problems in the models. Specifically, these variables $(X)$ are defined as follows

- $A G E$ is simply the age of the firm (years in existence)

- $S I Z E$ reflects the size of the firm, measured using the number of employees ${ }^{11}$

- $D E B T$ measures the degree of liability, defined as the ratio of total liability over the total value of assets

- $T E C H$ captures the level of technology in production, measured by the ratio of the net value of assets over employment (that is, the capital-labour ratio)

- INTANG reflects whether a firm has intangible assets (such as patents); it is defined as 1 if the firm has intangible assets and zero otherwise

- INVEST takes the value of 1 if a firm has long-term investment and zero otherwise.

Other independent variables - namely, the $Z$ variables in Equation 16.1-are introduced to reflect firms' productivity performance and exporting status, industry concentration and variations across firms with regard to ownership, location, industry and time. These variables $(Z)$ include

- EFF, which is an indicator of firm efficiency, measured simply by the firms' labour productivity - that is, the ratio of output value over total employment

- EXP, which is a binary variable and has a value of 1 if a firm is engaged in exporting and zero otherwise

- the Herfindahl index (HERFINDAHL), which is computed to measure the level of competition or concentration of business activities in a sector; the calculation is based on the four-digit classification of Chinese industrial sectors

- four ownership dummy variables, which are included to represent firms owned or controlled through majority shareholding by the State, investors

11 There are, of course, other measures of firm size such as total output value, the value of total sales and so on. The number of employees is chosen so that few observations are dropped due to missing data. 
from Hong Kong, Macau and Taiwan (HMT), foreign investors and shareholders (versus all other firms)

- five dummy variables, which capture variations among firms located in the areas of Beijing, Shanghai, Pearl River Delta, the six 'middle' provinces, the three north-eastern provinces and western China, with the north-eastern provinces being chosen as the reference region ${ }^{12}$

- 11 sector dummy variables to reflect potential sectoral differences among the firms, which are categorised into 12 industry sectors on the basis of the official Standard Industry Classification (SIC) grouping.

The estimation results of the three models are presented in Table 16.2. According to the results of Model 1, large or old firms are more likely than others to invest in innovation. Exporters and capital-intensive firms also have higher probabilities of spending on research and development - as are firms with longterm investments, intangible assets and better performance (in terms of labour productivity). The probability of innovation tends to increase over time and that more competition increases initially and then reduces the probability of innovation. This is consistent with evidence from other economies (Aghion et al. 2005; Tingvall and Poldahl 2006). Firms that are less likely to invest in research and development are often burdened with heavy debt or owned by offshore investors - in particular, investors from Hong Kong, Macau and Taiwan. The latter have a large presence in the Pearl River Delta region. This finding implies that the country's foreign investment policies might not be providing incentives for foreign firms to invest in research and development in China.

Table 16.2 Econometric estimation results

\begin{tabular}{lcccccc}
\hline & \multicolumn{2}{c}{ Model 1 } & \multicolumn{2}{c}{ Model 2 } & \multicolumn{2}{c}{ Model 3 } \\
Variables & Coefficients & $\boldsymbol{p}$-values & Coefficients & $\boldsymbol{p}$-values & Coefficients & $\boldsymbol{p}$-values \\
\hline & & & & & & \\
Intercept & -2.2088 & 0.000 & -1.3537 & 0.000 & 0.1013 & 0.025 \\
AGE & 0.0098 & 0.000 & 0.0087 & 0.000 & 0.0024 & 0.000 \\
AGE2 & & & & & -0.00005 & 0.000 \\
SIZE & 0.0000 & 0.051 & 0.0000 & 0.000 & 0.0000 & 0.543 \\
EXP & 0.3319 & 0.000 & 0.2535 & 0.000 & 0.0321 & 0.000 \\
DEBT & -0.1763 & 0.000 & -0.2149 & 0.001 & -0.6026 & 0.000 \\
TECH & 0.0001 & 0.000 & 0.0000 & 0.009 & 0.0000 & 0.832
\end{tabular}

12 Specifically, China's 31 administrative regions are partitioned into six groups and represented by six dummy variables: REG1 (Beijing, Tianjin, Hebei and Shandong), REG2 (Shanghai, Jiangsu and Zhejiang), REG3 (Guangdong, Fujian, Guangxi and Hainan), REG4 (Shanxi, Anhui, Jiangxi, Hubei, Hunan and Henan), REG5 (Liaoning, Jilin and Heilongjiang) and REG6 (Inner Mongolia, Ningxia, Tibet, Xinjiang, Gansu, Guizhou, Qinghai, Shaanxi, Sichuan, Yunnan and Chongqing). 
China: The Next Twenty Years of Reform and Development

\begin{tabular}{lcccccc} 
EFF & 0.0000 & 0.011 & 0.0000 & 0.771 & -0.0001 & 0.000 \\
INTANG & 0.2223 & 0.000 & 0.1789 & 0.000 & -0.0358 & 0.000 \\
INVEST & 0.4580 & 0.000 & 0.3566 & 0.000 & 0.2252 & 0.000 \\
HERFINDAHL & 3.0130 & 0.000 & 2.6715 & 0.000 & 3.8713 & 0.000 \\
HERFINDAHL2 & -9.6779 & 0.000 & -8.3931 & 0.004 & & \\
Region dummies & yes & & yes & & yes & \\
Ownership & & & yes & & yes \\
dummies & yes & & no & & yes & \\
Year dummies & yes & & 0.6091 & \\
Seudo-R & 0.1480 & & 0.0842 & & 13446 & \\
Sample size & 59640 & & 27102 & & & \\
\hline
\end{tabular}

Notes: Models 1 and 2 are estimated using quadratic hill-climbing optimisation algorithm and quasimaximum likelihood (Huber-White) robust standard errors and co-variance. Model 3 is estimated using panel EGLS with cross-section weights and White cross-section standard errors and co-variance provided in Eview 6.

Source: Authors' own estimations.

The estimated coefficients (not reported in the table) of the dummy variables also show that firms engaged in manufacturing pharmaceuticals, machinery, transport equipment, communication and other electronic equipment are more likely than others to invest in innovation. These products are mainly in the high-tech sectors. In fact, at the aggregate level, on average, research and development intensity in the high-tech sectors is much higher than the national average of 1.4 per cent in 2007 (see Figure 16.1). For example, the percentage share of research and development expenditure over sectoral value added in 2007 was 4.7 in pharmaceuticals, 15.4 in aircraft and spacecraft, 6.8 in electronic and telecommunication equipment, 3.9 in computers and office equipment and 6.3 in medical equipment and meter manufacturing (YHT 2008). The estimation results also imply that state-owned and shareholding firms are more likely than others to be innovators. ${ }^{13}$ It is also interesting to note that firms located in the central and western regions - in particular, the western region - are more likely than others to spend on research and development. This could reflect the fact that state-owned enterprises (SOEs) play a more important role in the economies of the central and western regions - accounting for 25.1 per cent and 30 per cent of firms in the two regions respectively, compared with a share of 15.6 per cent in the coastal area. These findings about the role of SOEs in innovation suggest that privatisation is not always conducive to innovation (at least before China's private firms can play a more prominent role in innovation).

According to the estimation results of Model 2 in Table 16.2, persistent innovators - defined as firms that invested in research and development every year during the period surveyed - are more likely to be associated with large-

13 The detailed results are reported in $\mathrm{Wu}(2010)$. 
scale production, old age in terms of commencement date, exporting status and high capital-labour ratios (or capital-intensive technology). Persistent innovators are also likely to have long-term investments or intangible assets. We found high indebtedness to be negatively linked with the probability of being a persistent innovator (Table 16.2). Relatively efficient firms are not necessarily more likely than others to be persistent innovators. Firms controlled by investors from Hong Kong, Macau and Taiwan or located in the Pearl River Delta region are less likely than others to be persistent innovators. In general, SOEs and shareholding firms are more likely to be persistent innovators, as are firms located in western China or involved in manufacturing pharmaceuticals, machinery, transport equipment, communication and other electronic equipment. These products once again are produced mainly in the high-tech sectors, as expected.

We found that firms' research and development intensity was negatively related to the age of the firm (Wu 2010). Further analysis, however, demonstrates that firms' research and development intensity increases initially and then falls as their capital ages (Model 3, Table 16.2); the estimated turning point is about 25 years. Since the average age of the firms in the sample is 17, most Chinese enterprises are still on the upward (left) side of the inverted-U shape. As for the relationship between competition and research and development intensity, there is no evidence of an inverted U-shaped relation, as argued by Aghion et al. (2005) and Tingvall and Poldahl (2006). Instead it is shown in Table 16.2 that research and development intensity and competition are negatively related. This supports the argument that dominant firms tend to be more innovative than non-dominant ones (Blundell et al. 1995).

It is further shown in Table 16.2 (Model 3) that firms' research and development intensity is associated positively with the existence of long-term investments, exporting status, large size and high capital intensity, although the last two have insignificant coefficients. It is also found that firms' research and development intensity is linked negatively with firm liability, efficiency and the existence of intangible assets. If a firm possesses intangible assets, it could imply that the firm is well established in the field (with new products or patents, for instance) and needs research and development investment only to maintain the leading edge. The negative relationship between efficiency and research and development intensity is a puzzle. It could reflect the role of SOEs in innovation. Chinese SOEs are generally less efficient than others, but they are the key players in research and development activities in China. This is consistent with the positive sign of the coefficient of the dummy variable representing SOEs. These findings imply that China is facing a dilemma. While the need for further economic reform calls for the withdrawal or privatisation of SOEs, China's private firms are not 
ready to take over the risky business of research and development investment. Thus, as far as innovation is concerned, specific policies are required to help the transition from SOEs to private firms.

\section{International perspective}

Among the world's major spenders on research and development, China was ranked third in 2007-behind only the United States and Japan (Table 16.3). It should be pointed out, however, that there is still a large gap between China and the world's top-two research and development investors. For example, in 2007, China's total research and development spending was about 28 per cent and 70 per cent of that in the United States and Japan, respectively. In terms of research and development intensity, although China is still behind the world's top spenders, it is well ahead of major economies at a similar stage of development - as is clearly demonstrated in Figure 16.5. If current growth in research and development spending is maintained, we speculate that China will follow the innovation paths of South Korea and Japan and become one of the most innovative countries in the world.

Table 16.3 World's top five research and development spenders, 2007

\begin{tabular}{|c|c|c|c|c|c|}
\hline \multicolumn{6}{|c|}{ Shares (\%) } \\
\hline Country & $\begin{array}{l}\text { Research and } \\
\text { development expenditure } \\
\text { (PPP\$ billion in } 2000 \\
\text { prices) }\end{array}$ & Business & Government & Others & $\begin{array}{l}\text { Research and } \\
\text { development } \\
\text { personnel } \\
\text { (million people) }\end{array}$ \\
\hline US & 311.4 & 66.2 & 28.3 & 5.5 & 1.426 \\
\hline Japan & 124.6 & 77.7 & 15.7 & 6.7 & 0.938 \\
\hline China & 87.1 & 70.4 & 24.6 & 5.1 & 1.736 \\
\hline Germany & 58.7 & 68.0 & 27.8 & 4.3 & 0.506 \\
\hline France & 35.6 & 52.0 & 38.2 & 9.8 & 0.372 \\
\hline $\begin{array}{l}\text { United } \\
\text { Kingdom }\end{array}$ & 33.3 & 46.5 & 30.0 & 23.4 & 0.349 \\
\hline
\end{tabular}

$\mathrm{PPP}=$ purchasing power parity

Note: Research and development personnel figures for the United States are 2006 data.

Sources: Research and development expenditure and personnel data are drawn from the OECD online database (<www.oecd.org $>$ ). 
Figure 16.5 Research and development intensity and per capita GDP of major economies, 2007

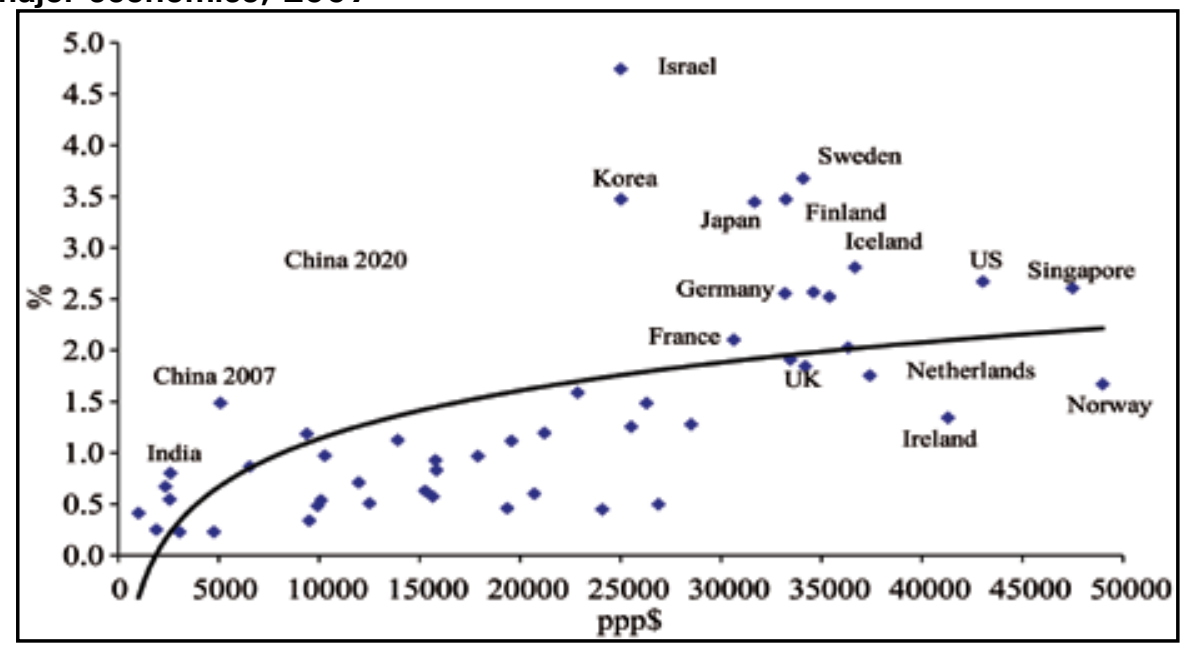

Note: Research and development intensity is the percentage share of research and development expenditure over GDP in each country. GDP per capita is expressed in 2005 constant international prices.

Source: World Bank 2010, World Development Indicators, The World Bank, Washington, DC.

Furthermore, the combined share of basic and applied research expenditure over total research and development spending maintained a declining trend in recent years. It was only 17.2 per cent in 2008 , while this ratio is much higher and rising or relatively stable over time in the major industrialised economies (Figure 16.6). Thus, the pattern of China's research and development spending deviates from the global trend and is biased towards investment in 'development' research. As discussed above, this could have long-term implications for the country's innovation capacity building. For instance, an emerging trend is that, among the patents granted, only 22.7 per cent belonged to the 'inventions' category in 2008. The structure and quality of China's research and development are therefore changing as investment increases over time.

In 2006, China for the first time overtook the United States to have the world's largest number of researchers. ${ }^{14}$ By 2008, China's research and development sector had more than 1.9 million employees, of which more than 84 per cent (about 1.6 million) were scientists and engineers. ${ }^{15}$ Meanwhile, in the same year, there were about 6.1 million students, including 759000 postgraduate students, who were enrolled in the schools of science, engineering and medical sciences in Chinese universities (NBS 2009). Thus, China's potential in research and development human resources will undoubtedly be the largest in the world in the coming

14 This is based on data from the OECD online database (<www.oecd.org $>$ ).

15 These numbers are drawn from the Annual Statistics of Science and Technology, National Bureau of Statistics of China (www.stats.gov.cn). 
decades. The country's comparative advantage in human resources is also reflected in the research and development cost structure. Labour compensation accounted for about 25 per cent of total research and development costs in 2007, which was much lower than that in many Organisation for Economic Cooperation and Development (OECD) countries such as Japan (39 per cent), South Korea (44 per cent), the United Kingdom (48 per cent), the United States (57 per cent), France (57 per cent) and Germany (60 per cent) in the same year. ${ }^{16}$ This suggests that China still enjoys a considerable comparative advantage in labour costs. There are, however, risks associated with low compensation paid to scientists and engineers. Skilled labour is very mobile in today's world and low wages could make China less competitive in the international talent market.

\section{Figure 16.6 Research and development spending shares (basic and applied research) in selected economies}

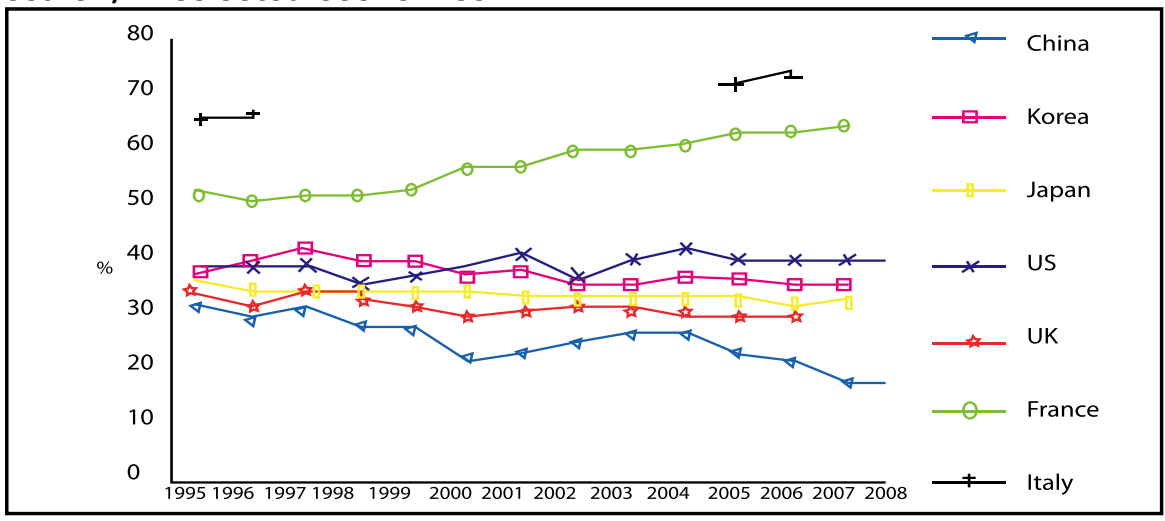

Sources: National Bureau of Statistics (NBS) 2009, China Statistical Yearbook 2009, China Statistics Press, Beijing; OECD online database (<www.oecd.org $>$ ).

Another important factor closely related to innovation is the development of the high-tech sector. During 1996-2007, the average real growth rate of value added in this sector was 18.7 per cent, which was twice as fast as the growth rate of the Chinese economy. Computer and office equipment manufacturing led this growth, with a real rate of growth of 28.8 per cent, followed by the electronic and telecommunications equipment sector, with 18.8 per cent, and medical equipment and meter manufacturing, with 18 per cent (Figure 16.7). In 2008, the high-tech industry as a group amounted to 12.9 per cent of total manufacturing output in China (DPD 2009). The value of exports in this sector has achieved an average rate of growth of 44.9 per cent during 2002-08. ${ }^{17}$ In comparison with major high-tech exporters in the world, China has the largest global market share (Table 16.4). In 2007, China's high-tech sector also accounted for 29.7 per cent of total manufacturing exports from the country. This figure is compatible

16 Labour compensation shares over total research and development costs are estimated using data from the OECD online database $(<$ www.oecd.org $>$ ). 
with that in the United States, which is the world's second-largest exporter, but is well behind other East Asian economies such as the Philippines (68.9 per cent), Malaysia (51.7 per cent), Singapore (46.4 per cent) and South Korea (33.4 per cent) (Table 16.4). It will be interesting to see whether China is able to follow its Asian neighbours in terms of the development of the high-technology sector.

\section{Figure 16.7 High-technology sector value added (in 1995 constant prices)}

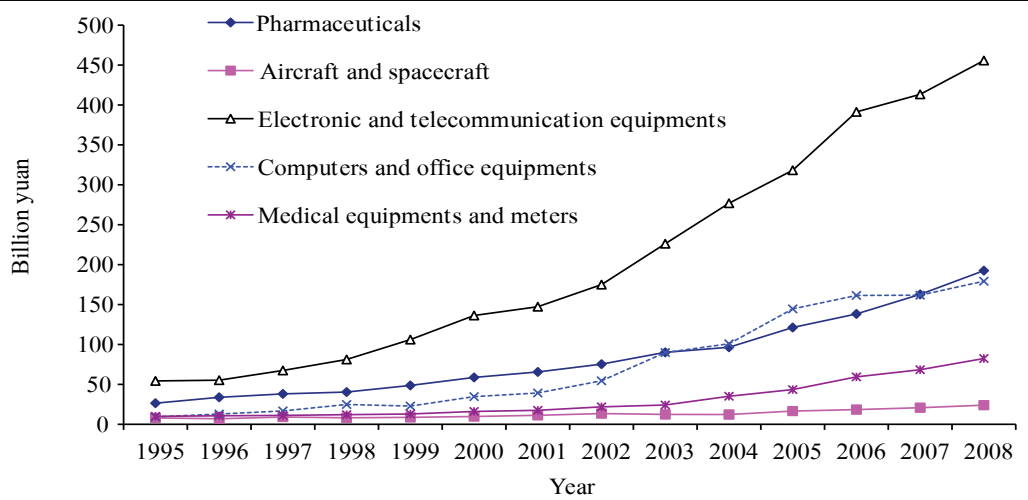

Sources: YHT 2002, China Statistical Yearbook of High Technology Industry 2002, National Bureau of Statistics and Ministry of Science and Technology, China Statistics Press, Beijing; YHT 2008, China Statistical Yearbook of High Technology Industry 2008, National Bureau of Statistics and Ministry of Science and Technology, China Statistics Press, Beijing.

Table 16.4 High-technology sector exports in selected economies, 2007

\begin{tabular}{lcc}
\hline Countries & $\begin{array}{c}\text { Percentage of manufactured } \\
\text { exports }\end{array}$ & World shares (\%) \\
\hline China & 29.7 & 18.6 \\
United States & 28.5 & 12.7 \\
Germany & 14.2 & 8.6 \\
Japan & 19.0 & 6.7 \\
South Korea & 33.4 & 6.1 \\
Singapore & 46.4 & 5.8 \\
France & 18.9 & 4.5 \\
Netherlands & 25.7 & 4.1 \\
Malaysia & 51.7 & 3.6 \\
United Kingdom & 19.5 & 3.5 \\
Mexico & 17.1 & 1.8 \\
Philippines & 68.9 & 1.6 \\
Brazil & 11.9 & 0.5 \\
India & 5.3 & 0.3 \\
Russian Federation & 6.9 & 0.2 \\
\hline
\end{tabular}

Source: World Bank 2010, World Development Indicators, The World Bank, Washington, DC. 


\section{Implications for future economic growth}

A precise assessment of the contribution of innovation to China's growth is technically and conceptually challenging. The empirical literature is dominated by growth-accounting exercises and has focused on the analysis of the traditional Solow-type innovation or total factor productivity (TFP) growth. Wu (forthcoming) reviews more than 70 studies with more than 150 estimates of TFP growth rates and finds that TFP growth on average accounted for about one-third of China's economic growth during the 1990s and the first decade of this century. The same figure for more industrialised economies is, however, much higher. For example, according to Dougherty and Jorgenson (1996), productivity growth accounted for 49.8 and 57.6 per cent of output growth during 1960-89 in Japan and Germany, respectively. Therefore, there is considerable scope for improvement in China's productivity growth in general and in innovation in particular.

The modest contribution of innovation to economic growth in the past three decades is consistent with the country's innovation conditions. As shown in the preceding sections, evidence at the macro and micro levels illustrates that there is still a considerable gap between China and the advanced economies in terms of innovation resources and capacity. China is, however, catching up rapidly with industrialised economies in terms of its innovation capacity measured using various criteria such as the number of patents registered, scientific publications and citations and hi-tech commodity exports. The driving forces for the catchup are the increasing research and development inputs in capital and human resources. The catch-up will make it possible for the country to realise its innovation potential, which will be vital for China's sustainable growth in the coming decades. To reach this goal, several emerging issues must be resolved by Chinese policymakers.

First, in terms of aggregate investment in research and development, China is ahead of other countries at a similar stage of development and the country is also rapidly catching up with OECD economies. There are, however, areas where China could do much better. For example, China's research and development intensity in the high-tech sector is lagging behind the major players in the world (Table 16.5). In four of the five high-tech sectors (the exception being the aircraft and spacecraft sector), there is a huge gap in research and development intensity. Even in the aircraft and spacecraft industry, China's research and development intensity was about half that in Germany, France and the United Kingdom in 2007 (Table 16.5). 
Indigenous innovation for sustainable growth

Table 16.5 High-technology sector research and development intensity in selected economies, 2006 (per cent)

\begin{tabular}{|c|c|c|c|c|c|c|c|c|}
\hline Industries & China & US & Japan & Germany & France & $\begin{array}{c}\text { United } \\
\text { Kingdom }\end{array}$ & Italy & Korea \\
\hline $\begin{array}{l}\text { Manufacturing } \\
\text { total }\end{array}$ & 3.4 & 10.2 & 11.0 & 7.6 & 9.9 & 7.0 & 2.4 & 9.3 \\
\hline $\begin{array}{l}\text { High-tech sector } \\
\text { otal }\end{array}$ & 5.7 & 39.8 & 28.9 & 21.5 & 31.9 & 26.6 & 11.1 & 21.3 \\
\hline Pharmaceuticals & 4.7 & 46.2 & 37.1 & 23.9 & 33.4 & 42.3 & 5.0 & 6.3 \\
\hline $\begin{array}{l}\text { Aircraft and } \\
\text { spacecraft }\end{array}$ & 14.9 & 24.1 & 11.5 & 32.9 & 31.1 & 31.1 & 45.2 & 26.1 \\
\hline $\begin{array}{l}\text { Electronic and } \\
\text { telecommunication } \\
\text { equipment }\end{array}$ & 6.4 & 43.3 & 13.4 & 28.8 & 50.9 & 23.9 & 11.6 & 25.1 \\
\hline $\begin{array}{l}\text { Computers and } \\
\text { office equipment }\end{array}$ & 3.8 & 34.7 & n.a. & 14.9 & 27.7 & 1.4 & 8.4 & 14.2 \\
\hline $\begin{array}{l}\text { Medical equipment } \\
\text { and meters }\end{array}$ & 5.2 & 48.3 & 31.9 & 13.6 & 19.0 & 7.8 & 6.7 & 10.3 \\
\hline
\end{tabular}

n.a. not available

Sources: YHT 2008, China Statistical Yearbook of High Technology Industry 2008, National Bureau of Statistics and Ministry of Science and Technology, China Statistics Press, Beijing; YHT 2009, China Statistical Yearbook of High Technology Industry 2009, National Bureau of Statistics and Ministry of Science and Technology, China Statistics Press, Beijing.

Second, with the expansion of research and development activities it is important not to neglect the quality of research and development in China. The preceding sections presented evidence of relative declines in investment in basic and applied research in recent years. This is also reflected in the small share of 'invention' patents among total domestic patents in China. If this trend continues, China's long-term capacity in innovation-and hence the sustainability of economic growth in the future - could be compromised.

Third, the role of privately owned enterprises, including foreign firms, in innovation should be strengthened through more stringent enforcement of intellectual property rights protection laws and regulations and the provision of incentives via appropriate innovation policies. As shown in the preceding sections, the enterprise sector plays the leading role in innovation in the world's major economies. Although China's privately owned firms are expanding rapidly, in terms of innovation, they are lagging behind their state-owned counterparts, not to mention privately owned firms in other countries. This could be due to institutional constraints in China such as limited access to finance and government grants for non-SOEs. 
Finally, there is considerable regional disparity in innovation. This not only contributes to China's overall regional disparity, but it is also detrimental to the diffusion of knowledge and technology within China. There should be institutional mechanisms to ensure a more even distribution of innovation resources across the Chinese regions.

\section{Conclusions}

In summary, China has made considerable progress in developing indigenous innovation skills and capacity in the past three decades. This trend has been strengthened through the implementation of the 2020 program of science and technology development since 2006. It also lays the foundation for the possible transformation of China's economic growth model from a resource-intensive one to an innovation-oriented model. China's investment in innovation has already grown rapidly, with innovation outcomes expanding as a consequence.

An important development in recent years is the expanded role of Chinese enterprises in innovation. Chinese firms are now the dominant investors in research and development in the country. In terms of innovation-related firm characteristics, however, there is heterogeneity across firms with different ownership and scale as well as in different industries and locations. It is shown in this study that SOEs perform much better than foreign-invested firms and privately owned Chinese firms as far as research and development propensity and efforts are concerned. This is a dilemma for China. As economic reform deepens, SOEs are under pressure to privatise. In the meantime, non-SOEs (including foreign and indigenous private firms) are not ready to take risks associated with research and development activities. This situation calls for specific policies encouraging the participation of non-state firms in innovation and improvement of the legal system to provide effective protection of intellectual property rights in China.

This study has also demonstrated the gap between China and the world's leading innovators. To close the gap, Chinese policymakers could pay more attention to several issues in the coming decades. First, while China is the world's largest exporter of high-tech products, China's research and development intensity in the high-tech sector is lagging behind the world's major players. Second, as the role of enterprises in innovation is strengthened, there is the danger of neglecting basic and applied research, which is vital for the country's innovation capacity building in the longer term. Finally, both the quantity and quality of innovation investments and products should be monitored during the process of economic transformation. Growth should not compromise the quality of innovation. 


\section{References}

Aghion, P., Bloom, N., Blundell, R., Griffith, R. and Howitt, P. 2005, ‘Competition and innovation: an inverted-U relationship', Quarterly Journal of Economics, vol. 120, no. 2, pp. 701-28.

Blundell, R., Griffith, R. and van Reenen, J. 1995, ‘Dynamic count data models of technological innovation', Economic Journal, vol. 105, pp. 333-44.

Dougherty, C. and Jorgenson, D. W. 1996, 'International comparisons of the sources of economic growth', American Economic Review (Papers and Proceedings), vol. 86, no. 2, pp. 25-9.

Development and Planning Division (DPD) 2009, An analysis of China's hi-tech industrial development in 2008, Science and Technology Statistics Report, no. 25, Development and Planning Division, Ministry of Science and Technology, Beijing.

Gao, J. and Jefferson, G. 2007, 'Science and technology take-off in China: sources of rising R\&D intensity', Asia Pacific Business Review, vol. 13, no. 3, pp. $357-71$.

Girma, S., Gong, Y. and Görg, H. 2009, 'What determines innovation activities in Chinese state-owned enterprises? The role of foreign direct investment', World Development, vol. 37, no. 4, pp. 866-73.

Jefferson, G., Hu, A. G., Guan, X. and Yu, X. 2003, 'Ownership, performance, and innovation in China's large- and medium-size industrial enterprise sector', China Economic Review, vol. 14, no. 1, pp. 89-113.

Jin, F., Lee, K. and Kim, Y.-K. 2008, 'Changing engines of growth in China: from exports, FDI and marketization to innovation and exports', China and World Economy, vol. 16, no. 2, pp. 31-49.

Kuo, C.-C. and Yang, C.-H. 2008, 'Knowledge capital and spillover on regional economic growth: evidence from China', China Economic Review, vol. 19, no. 4, pp. 594-604.

Liu, X., Wang, C. and Wei, Y. 2009, 'Do local manufacturing firms benefit from transactional linkages with multinational enterprises in China?', Journal of International Business Studies, vol. 40, pp. 1113-30.

Ministry of Science and Technology (MST) 2010, China Science \& Technology Statistics, Ministry of Science and Technology, Beijing, <www.most.gov.cn> 
China: The Next Twenty Years of Reform and Development

National Bureau of Statistics (NBS) 2008, Statistics of 2007 Innovation Survey of Industrial Firms, China Statistics Press, Beijing.

National Bureau of Statistics (NBS) 2009, China Statistical Yearbook 2009, China Statistics Press, Beijing.

National Bureau of Statistics (NBS) 2010, 2009 Statistical Communiqué of National Economic and Social Development, National Bureau of Statistics, Beijing.

Organisation for Economic Cooperation and Development (OECD) 2009, Measuring China's innovation system: national specificities and international comparisons, STI Working Paper 2009/1, Statistical Analysis of Science, Technology and Industry, Organisation for Economic Cooperation and Development, Paris.

Tian, X. 2007, 'Accounting for sources of FDI technology spillovers: evidence from China', Journal of International Business Studies, vol. 38, no. 1, pp. 14759.

Tingvall, P. G. and Poldahl, A. 2006, 'Is there really an inverted U-shaped relation between competition and R\&D?', Economics of Innovation and New Technology, vol. 15, no. 2, pp. 101-18.

Wei, Y. and Liu, X. 2006, 'Productivity spillovers from R\&D, exports and FDI in China's manufacturing sector', Journal of International Business Studies, vol. 37, pp. 544-57.

World Bank 2010, World Development Indicators, The World Bank, Washington, DC.

Wu, Y. 2010, Are Chinese enterprises innovative? R\&D determinants, strategies and intensity, Economics Discussion Papers, University of Western Australia, Perth.

Wu, Y. (forthcoming), 'What do we really know about productivity growth in China?', in L. Xu (ed.), China's Economy in the Post-WTO Environment: Stock markets, FDI and challenges of sustainability, Edward Elgar, Cheltenham.

YHT 2002, China Statistical Yearbook of High Technology Industry 2002, National Bureau of Statistics and Ministry of Science and Technology, China Statistics Press, Beijing.

YHT 2008, China Statistical Yearbook of High Technology Industry 2008, National Bureau of Statistics and Ministry of Science and Technology, China Statistics Press, Beijing. 
YHT 2009, China Statistical Yearbook of High Technology Industry 2009, National Bureau of Statistics and Ministry of Science and Technology, China Statistics Press, Beijing.

YST 2009, China Statistical Yearbook of Science and Technology 2009, National Bureau of Statistics and Ministry of Science and Technology, China Statistics Press, Beijing.

Zhang, C., Zeng, D. Z., Mako, W. P. and Seward, J. 2009, Promoting EnterpriseLed Innovation in China, The World Bank, Washington DC. 



\section{China's health system and the next 20 years of reform}

\section{Ryan Manuel}

\section{Introduction}

Health care in China remains a topic of great popular discontent, particularly in rural areas, despite a raft of recent reforms and an unprecedented splurge in government health spending, The common phrase 'kanbing nan, kanbing gui' (seeing a doctor is hard, and expensive) summarises succinctly the issues facing many Chinese citizens with regard to health care.

Analysing the future of the Chinese healthcare system requires some historical context. This chapter will divide the Chinese healthcare reform experience into three distinct periods. The first is the collective period, defined as the period 1950-79. Due to its efficient public finance system and 'step-up, step-down' delivery mechanisms, China's public health system was a world leader in terms of its high levels of 'bang for your buck'.

The second, post-collectivisation period (approximately 1980-2003) saw the Chinese system remain efficient compared with other developing countries of comparable per capita income. Yet it was highly inequitable in terms of access. The end of the collective within China has seen a constantly high rate of cost inflation, caused largely by physician-induced demand and the overprescription of drugs and high-tech services, a disturbingly high level of inequity of access and falling rates of healthcare security. Providers and users alike were confronted with flawed institutions and incentives. Rural and urban differences and an ineffective public finance system that reinforces inequities have exacerbated these problems and hindered reform.

The beginning of the third period (2003 onwards), along with the introduction of the Harmonious Society Program, saw considerable debate about how to reform China's health system. The introduction of the New Cooperative Medical Scheme (NCMS) and the beginning of the 'Cover the countryside' campaign of public finance in 2003 also led to far greater public funds being introduced 
into the healthcare system. A number of demand-side social health insurance projects were introduced, and these will be major drivers of the next 20 years of health reform in China.

These reform proposals can, on the whole, be divided into two major camps. The first camp looks largely at using demand-side strategies based on social health insurance schemes to increase the funds available in the system. The other camp concentrates on increasing spending to develop a Chinese system based on publicly funded outpatient institutions acting as a gatekeeper and referrer to public hospitals - similar to Britain's National Health Service (NHS).

Each of these reforms appear to be insufficient. An institutional model reveals some of the problems facing the Chinese government. Increases in public spending appear to be unable to change the flawed incentives that exist for individual providers. Issues remain, stemming from a lack of supervision, coordination and governance that hinder the imposition of social welfare objectives from the central government, in spite of the addition of greater funds. The most recent health plan, released in 2009, has made some progress towards resolving the theoretical conundrums facing the Chinese health sector, but leaving structural problems. The effectiveness of the next 20 years of reform looks most likely to be determined by how effectively the Chinese government addresses the structural problems and flawed incentives hindering the system.

\section{History of the Chinese health sector}

There are three distinct phases of healthcare provision in China. The first phase-built within the socialist planned economy-was characterised by public provision of health services at all government levels with public financing in urban areas and community financing in rural areas (Liu 2004:149-156). This egalitarian social model used strong government structures in order to provide health benefits. The collective (in rural areas) and the work unit - or danwei - in urban areas both made provisions for health care for their members. Compulsory health insurance and primary-care provision could be provided through either the collective or the danwei. This situation provided a number of different tiers of treatment, which, combined with the innovative use of part-time doctors to provide localised primary health care (Smith 1974:429-35), led to extraordinary improvements in population health measurements across Chinese society. These achievements occurred in a low-budget environment and in a society that spent a disproportionately small amount of gross domestic product (GDP) on public health. Much of this improvement was attributed to the use of preventive and primary care and to the wide entitlement and access to health care present in the 'egalitarian society period' (Liu 2004:533). 
Many authors argue that the structural features of China's public health system were instrumental to China's excellent health outcomes. ${ }^{1}$ Under this system, village health stations, township health centres (THCs) and county hospitals were integrated within the three-tier system by a vertical administrative system. The county health bureau was responsible for the performance of local health services. It prepared plans and allocated the annual government budget. County institutions supervised township and village facilities and provided referral services, training and high-level tertiary care.

More importantly, social health insurance schemes organised at the village level funded more than 50 per cent of total health expenditures. At the peak of popularity of the Cooperative Medical Scheme (CMS), it covered 90 per cent of the rural population. Health services financed through the CMS were able to rely on prepayment plans. Hence, during this period, the State played an important role in funding providers (particularly at the secondary and tertiary levels), while the commune provided mandatory community health insurance to individuals.

Figure 17.1 Levels of healthcare provision in pre-1978 rural China

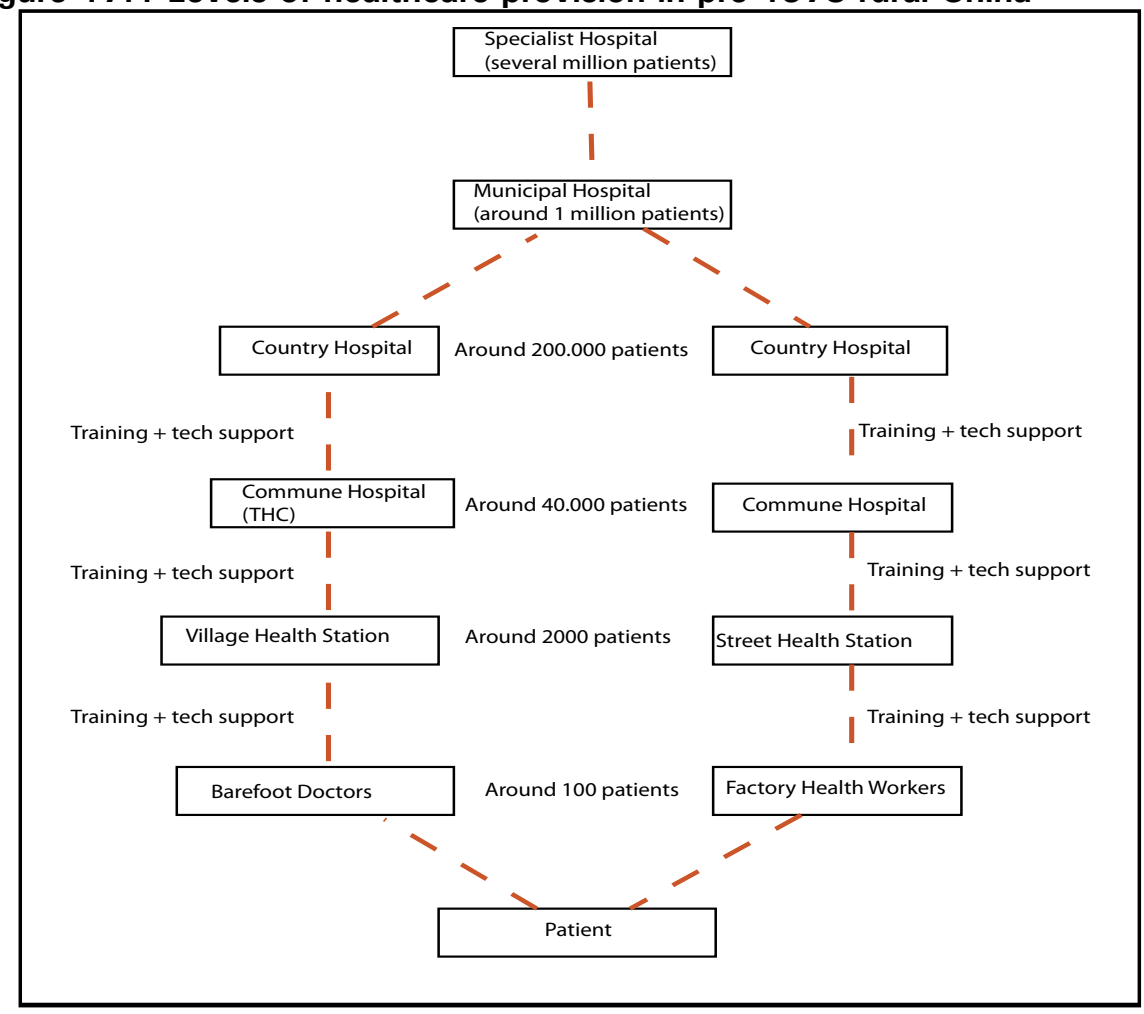

1 See, for example, Bloom and Tang (2000); Liu (2004); and Smith (1974). 
By the mid-1970s, China had established an effective rural health system, supported by institutional arrangements including a network of appropriate facilities and personnel, social financing of a large proportion of health expenditure and mechanisms to coordinate service providers and to encourage health workers to act in the community's interest (Chernichovsky 1995). The incentives in this three-tier, 'step-up, step-down' system were highly effective, encouraging high levels of primary care.

Similarly, in urban areas an efficiently organised and managed system was married with state funding and a vertical administrative system. Unlike the rural areas, this system relied on the worker's employer, the danwei, to organise health care. Patients had to pay a very small fee; however, the danwei acted as the major purchaser and provider of health services. Like the barefoot doctors in rural areas, factory workers were given work points for performing basic primary healthcare tasks and for referring patients upwards when required. Above that level of treatment was a healthcare system staffed with full-time employees.

In both of these systems, major hospitals acted as the highest point of care and the public health mechanisms acted as gatekeepers for these hospitals. Before 1980, public hospital service fees were mandated by the government to be at very low levels (about 20 per cent of the costs) and the government protected against deficits in the hospital through a flexible government budget in which patients were subsidised for hospital care (Jing 2004). Hospitals had no incentive to provide unnecessary care or drugs that could increase the economic burden of patients, as budgetary constraints were largely soft.

This system laid the foundations for much of China's modern healthcare infrastructure. Although today there are no factory workers acting as primarycare providers, and barefoot doctors and village health stations are now private providers, the structure of the state system and the expectation of patient flow through the system remain much the same as during the collective period.

\section{The end of communes and socialised medicine}

Following the rise to power of Deng Xiaoping, China dramatically shifted the structure of its economy and the provision of public services. The fundamental role of the State itself changed. This change involved far greater application of competition and a varying degree of decentralisation to provincial, township and village levels of government. With shifts in models of governance - and the changes this led to in China's employment structure and taxation system-came a shift in the nature of health services. Social sector development including health care became low on the public policy agenda. 
In spite of this - although somewhat unsurprisingly given China's economic growth - the health status of China's people, measured by broad population health indicators, continuously improved. Life expectancy at birth increased from 67.9 years in 1981 to 71.8 years in 2003. From 1991 to 2005, the infant mortality rate fell from 50.2 to 19 per 1000 live births and the maternal mortality rate declined from 88.9 to 47.7 per 100000 (WHO 2009).

Moreover, China's primary healthcare system was, by per capita international standards, relatively comprehensive. The coverage rates of access to safe drinking water, antenatal care, hospital delivery and childhood vaccinations were 99, 96, 93 and 95 per cent for urban areas and 80, 86, 62 and 85 per cent for rural areas, respectively (Ministry of Health 2004).

In spite of these improvements in broad primary health objectives, this period also saw growing dissatisfaction with the healthcare sector within China. Selfreported morbidity rates and bedridden days increased remarkably from 1993 to $2003 .^{2}$ By 2003, hospital dissatisfaction rates in patients living in urban and rural areas increased to 61 per cent and 54 per cent, respectively, compared with 8 per cent and 14 per cent in 1993 (Ministry of Health 2004). This dissatisfaction with the hospital system appeared to be related largely to cost inflation and access.

This shift seemed to be the result of a broader shift of strategy, based on the Chinese government's acceptance of the principle referred to as the 'family responsibility system' for the rural sector in particular (Saich 2003: 18-30). At its heart, this principle holds that the family is the first line of social protection. As a corollary, the government becomes involved only 'when the family cannot take care of its own, and when government action can be effective' (Lin 2005:1). Most importantly, the burden of spending for social services falls initially on the individual.

Corresponding with the rise in private spending was a considerable fall in public spending. Between 1978 and 2004, the annual growth rate of health expenditure in China was 12 per cent, which was higher than the 9.4 per cent growth of GDP. Despite rapid growth in healthcare costs, the percentage of government spending as a proportion of total health expenditure declined from 32 per cent in 1978 to 17 per cent in 2004 (NBS 2005). In the overall government budget, health expenditure accounted for 2.4 per cent in 1980, decreasing to 1.9 per cent in 2004 (Ministry of Health 2010).

Thus, before the introduction of the Harmonious Society campaign, China's public spending on health care was far lower than that of most developing

2 Based on the three national household health surveys done in 1993, 1998 and 2003; see Ministry of Health (2004). 
countries (Figure 17.2). This financial structure created significant shortfalls in government funding for healthcare providers. Hospitals were nominally publicly funded, yet needed to raise significant amounts of their own revenue. The end of the collective saw a dismantling of central government soft budgets, and in 1985 institutional health providers such as hospitals had to submit to hard budgetary constraints. This resulted in the rapid reduction in public funds available to the system. A World Bank (1997) survey estimated that overall government subsidies to total hospital operating costs amounted to no more than 15 per cent. This has had enormous ramifications for hospitals and doctors.

Even nominally fully funded public health institutions have suffered from severe budget shortages. ${ }^{3}$ At the beginning of the 1980s, all of the public health institutions' revenue was from government budgets, yet by 1992 the contribution from the government had dwindled to only 35 per cent of the total revenue. The rest of the budget was made up from service charges. By the end of 1996, the government budget covered only 50 per cent of the cost for basic salaries, or some 25 per cent of the public health institutions' total revenue (Xu 1997).

The result was to push responsibility for funding public health care onto the individual during this post-collectivisation period.

Figure 17.2 Public spending in the post-collectivisation period, 1990-2003

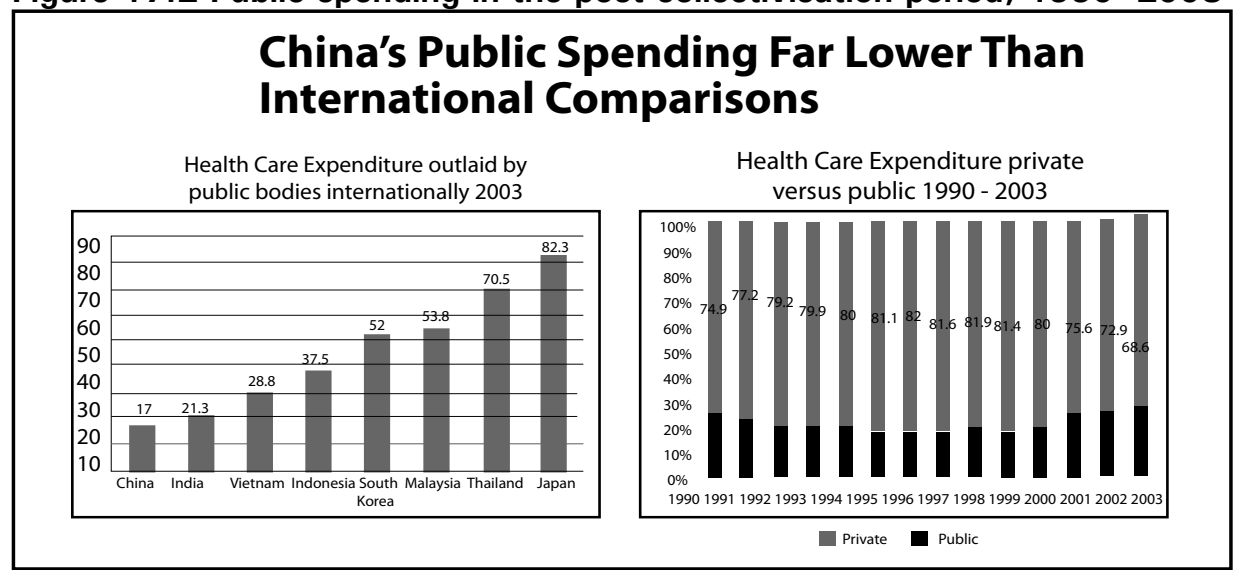

Major questions, which are still being asked today, arose about whether or not the individual could afford this larger burden. The 2003 Chinese National Health Survey showed that in type-four rural areas about 68 per cent of the population reported that they refused to seek medical assistance for reasons of cost. ${ }^{4}$ Yip and

3 Public health institutions here refers to bodies whose job is solely to provide public goods such as immunisations or primary health monitoring, as opposed to a normal hospital or Township Health Centre (THC), which provides a mix of public, private and merit goods.

4 Type four is the lowest relative socioeconomic status rural area. Areas are classified one to four according to socioeconomic stratification using average income measures (Ministry of Health 2004). 
Hsiao's (2008) retrospective study showed that 3 per cent of Chinese households per annum were pushed into poverty due to healthcare costs. Moreover, the real figures could be even more distressing, as many people fail to report illnesses even to their family due to concerns about the economic burden or a belief that the services provided will not be effective. Thus, it appears that there are many situations in which families are currently not 'able to take care of their own'. Worryingly, the increased number of people who did not have access to health services was due largely to a decrease in the perceived affordability of outpatient care, which should be the most affordable level of care.

Figure 17.3 People declining hospitalisation in the post-collectivisation period, $1990-2003$

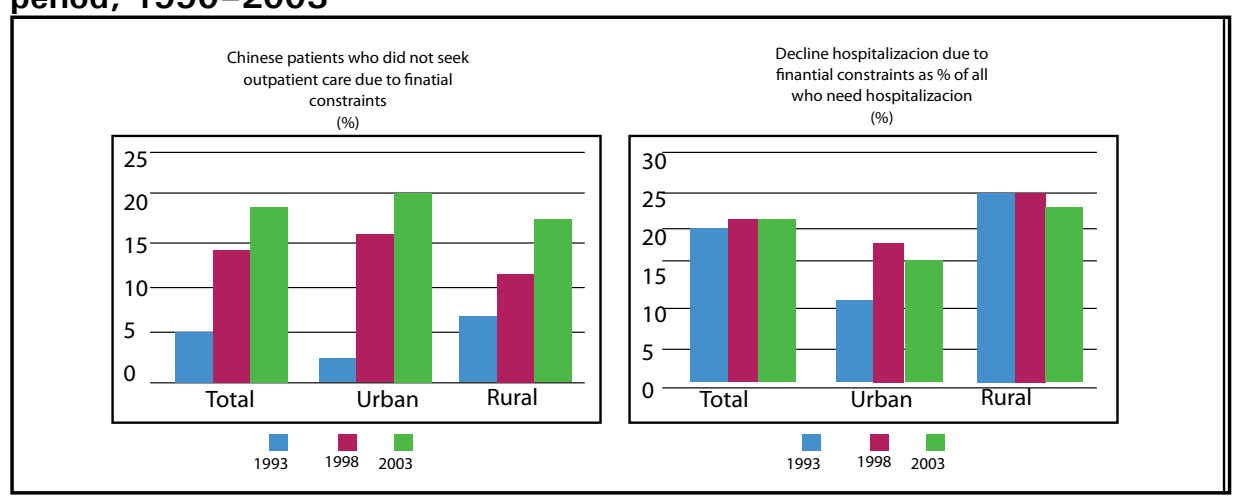

The impact of this rise in the amount of personal funds needed to access health care was exacerbated by a shortage of insurance available to Chinese citizens. Rural social health insurance coverage dropped from about 90 per cent in 1980 to 10 per cent in 1989 (World Bank 1993:28). This low coverage continued until the advent of the NCMS program. Likewise, coverage in urban areas dropped to about 2-3 per cent in 1993-95 (NBS 2006:125, 908-9). This led to patients accessing healthcare self-funding.

The effects of this period remain today. Much of the current debate is shaped by a desire to ameliorate the negative impacts of this period.

\section{Structural problems}

Central to understanding how and why this system developed when it did is an appreciation of the public finance system that funds health, and this appreciation is also crucial for understanding the future of Chinese healthcare reforms. This section therefore provides a brief introduction to the impact of public finance mechanisms on the Chinese health system, particularly during this post-collectivisation period. 
Figure 17.4 Sources of healthcare spending in the post-collectivisation period, 1990-2003

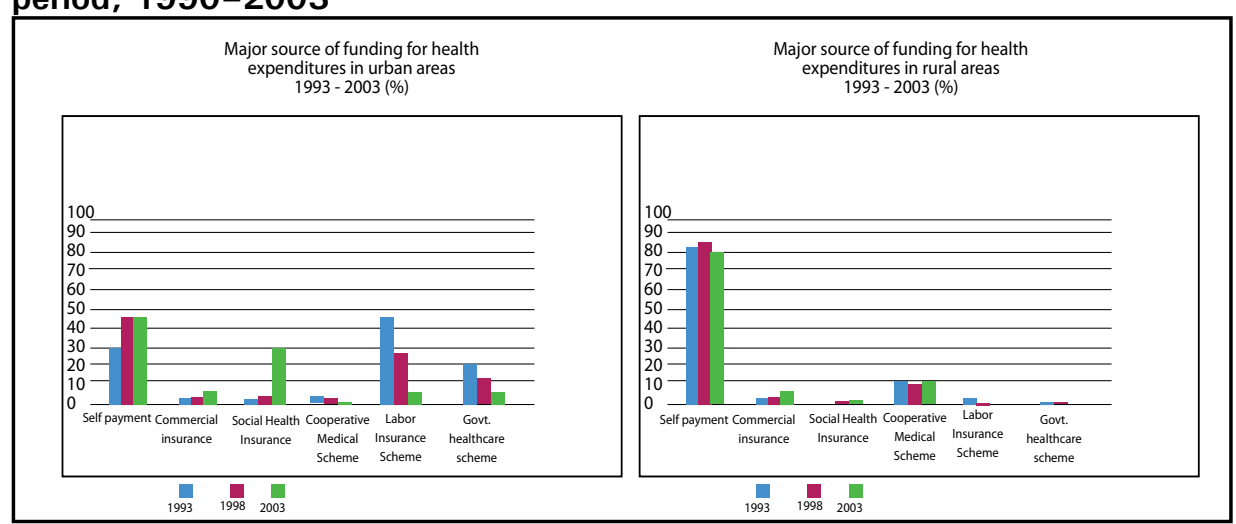

Following the end of the communes, a system of fiscal responsibility was introduced in the early 1980s, which lasted until 1994 (Wong 2007). This reform pertained mainly to the relationship between the central and provincial governments. Due to incentives to stimulate local industry, lower-level governments focused funds almost solely on local industry. This encouraged the hoarding of funds at the provincial level while reinforcing existing vertical and horizontal inequalities (Wong 20072). Moreover, it led to the near bankruptcy of the Chinese State as its tax revenue dwindled (World Bank 2005; Wong 2007; Fock and Wong 2008) and social spending withered.

In 1994, a 'tax-sharing' system, which formally delineated local and central taxes, was introduced. The main aims of this tax reform were to strengthen the centre's financial position and to sever the direct link between the revenues of the local government and those of the enterprises located within their respective geographical jurisdictions. The system theoretically enabled the central government to play a redistributive role through the usage of fiscal transfers, ensuring that adequate funds were available throughout all levels of the Chinese political system.

This system, however, failed to solve the underlying structural imbalances of the Chinese taxation system. The central government increased its revenues more than twofold (Wong 2007:7). These gains in revenue came, however, from passing shortages in funding down to lower levels - as shown in Figure 17.5.

This is significant for public health as these lower levels of government are then mandated to pay for social goods. Figure 17.5 demonstrates which level of government is responsible for each social good. It clearly shows that distribution of revenues is not proportional to the allocation of mandates. Each level of government has therefore been under progressively more pressure to raise revenues to fund social programs. This puts considerable pressure on the finances 
of smaller counties. The inability to raise rural informal fees and charges (due to the 2002 mandate outlawing rural informal fees and charges) and the increase of top-down 'matched fund' transfers from above also reinforce horizontal and vertical inequities in spending to the detriment of service providers at lower levels, particularly within disadvantaged areas.

Figure 17.5 Changes in tax revenues versus expenditures, 1993-2004 (per cent)

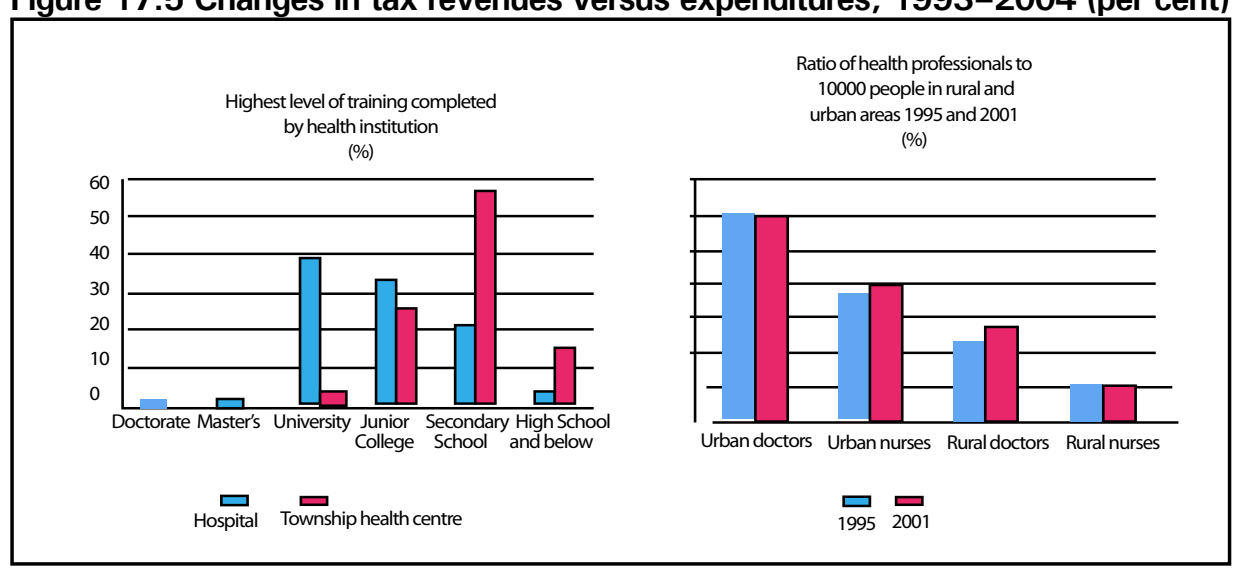

Gaps in spending power are critical to understanding health care in China. A lack of taxation revenue makes it difficult to fund healthcare providers, healthcare policies or bodies to regulate healthcare provision. As Chou and Wang (2009:694) show, government budget deficits have a significant longrun impact on regional healthcare expenditures. An inability to raise funds imposes a considerable constraint on public health expenditures. Indeed, Chou and Wang argue that, all other things equal and on average, for every RMB10 million increase in budget deficits, health expenditure will be decreased by 26.3 per cent.

Apart from being vertically unbalanced among different levels of government, China's economic growth has also been horizontally unbalanced across regions, with much higher growth rates in the coastal provinces, on the whole, than in the inland provinces. With the shift to the tax-sharing system in 1994, the distribution of fiscal resources came to resemble more closely that of regional incomes, reinforcing the effect of income inequalities. Thus, Liu et al (2009:978979) note, transfers often reinforce rather than reduce horizontal revenue disparities. The more economically successful a province is, the more likely it is to benefit from tax-based transfer methods.

As a result, effective demand for health care shifts to those who can readily afford it, making citizens in the far wealthier coastal regions more likely to visit doctors when sick (Zhang and Kanbur 2005:194). This shift in demand has caused an enormous shortage of secondary and tertiary-level medical professionals in 
rural areas. Larger and better-equipped facilities can generate more profits and thus pay more bonuses, so there is a strong financial incentive for qualified personnel in district hospitals to leave for larger city hospitals and for trained health workers in rural areas to seek employment in county or city hospitals. The negative impact of this on the skills of doctors in rural areas is marked.

Gong et al.'s (1997) study, for example, showed that more than 80 per cent of qualified doctors sampled from eight Chinese provinces left poor counties for more lucrative positions in urban facilities. As a result, while about threequarters of Chinese people live in rural areas, only about one-third of medical professionals work there. This, when combined with the higher skill levels present in urban hospitals, makes it difficult for rural areas to assure the same quality of standards as those present in urban areas - as shown in Figure 17.6.

\section{Figure 17.6 Urban and rural health profession skills and ratios}

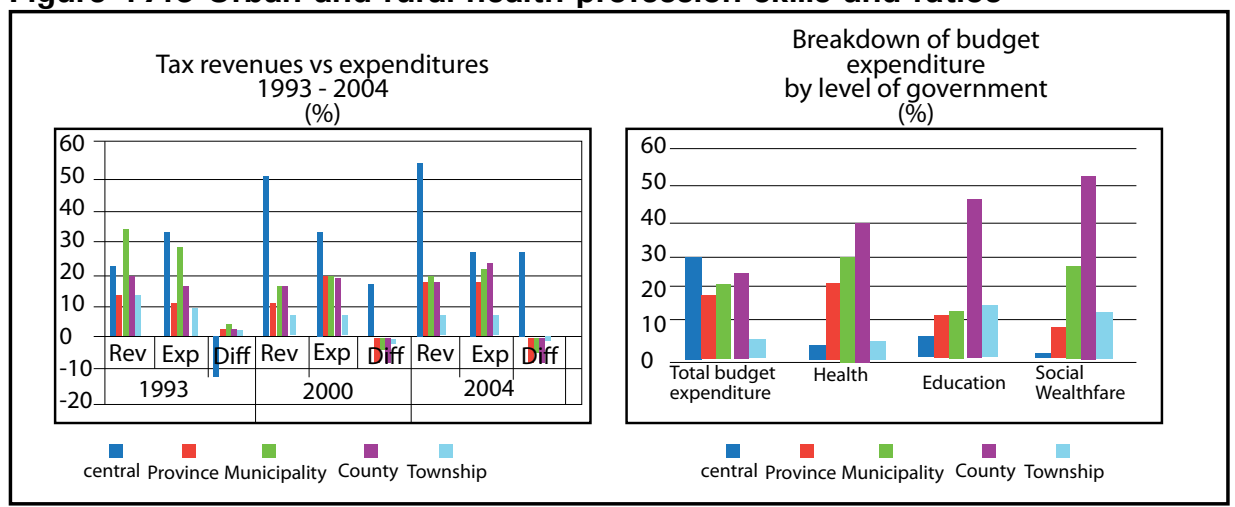

Shortages in skilled staff have deleterious outcomes for patients. For example, the low proportion of health workers to residents in China's rural areas has serious repercussions. The recent study by Liu et al. (2009) showed the impacts of these structural problems on the amounts of coverage in China's health system. There were significant differences between provinces and between urban and rural areas. On average, coverage in urban areas (61 per cent) was 15 per cent higher than in rural areas. This low coverage is also reflected in poor health outcomes. As an example, wider research shows clearly that the density of health workers physicians, nurses and midwives per 1000 population) is negatively correlated with maternal, infant and under-five mortality rates (Anand et al. 2008; Chen et al. 2004). In 2005, the infant mortality rate in rural areas was 2.4 times higher than in urban areas and the maternal mortality rate in rural areas was 2.5 times that of the urban population. Another study of health outcomes showed that in poorer areas, life expectancy was four years shorter than the country's average (Liu 2004). 


\section{The negative cycle of Chinese health care}

The Chinese health system has reacted to these structural problems and has developed flawed incentives for medical providers. On the supply side, the attempt by the Chinese government to effectively subsidise the provision of basic services through allowing overcharging on more complex services forces physicians to choose between treating low or high-cost patients. On the demand side, patient responses to this system indicate that instead of having an efficient 'step-up, step down' system, the Chinese system is more of a 'doughnut' system in which demand is squeezed to the lowest and highest rungs within the system.

The incentives embedded in this system lead to a vicious cycle. Average hospital bills are nearly equal to the average annual rural salary and are about two-thirds the average urban disposable income (Ministry of Health 2009; NBS 2009). These high medical bills often contribute directly to poverty. Thus, farmers and workers alike avoid healthcare institutions.

Yet healthcare institutions - underfunded by the public purse - also suffer from revenue shortages. Their best staff often leave for higher-level institutions. They have incentives to raise prices, employ more high-tech machinery and oversupply medical care. Yet then, as noted above, poor citizens have an even greater disincentive not to seek medical care, and thus the cycle continues.

This then exacerbates the shortage of effective demand that exists because people are unable to afford health care. Underfunded public health providers are forced to charge for poor-quality care or fail to have sufficient supplies. This makes patients who can afford health care services to leave lower levels of provider such as those working in a village clinic or Township Health Centre (THC), and to join instead higher-level providers of care, who are more highly trained and have better resources. These higher-level providers are, however, also stretched for funds, and there is also an incentive to obtain extra funds by oversupplying care, through such means as excessive over-prescription, overordering of tests and forced repeat visits.

Hence, within the Chinese health system there is a paradox centred on demand. Many regions suffer acute problems of inadequate supply. Many more areas, however, suffer from chronic under-utilisation due to low effective demand. ${ }^{5}$ Although people want health care, they cannot afford it, or when they can they are pushed upwards towards county and municipal providers. These providers are not only more expensive, they are likely to be further away.

\footnotetext{
5 To give a simple measure, the average bed occupancy rate in hospitals is about 60 per cent; it is about 40
} per cent in THCs (Ministry of Health 2009). 
This price barrier affects access to health care. Those who are unable to pay remain ill, often becoming even more ill, necessitating even more expensive tertiary care. This leads to a dynamic whereby patients, if unable to obtain access providers as a low-cost patient, return as a high-cost patient, leading to both access and cost-inflation problems. ${ }^{6}$

\section{Breaking this cycle through insurance}

The Chinese government announced its first major response to these problems in the early 2000s through a number of demand-side initiatives designed to boost the overall coverage of Chinese health insurance schemes. These initiatives use basic social medical insurance schemes as a country-wide government system that was designed to be a third-party payer and a new mechanism for financing health care. ${ }^{7}$

The reforms in demand-side policy seek to break the cycle described above through altering the effective demand for health care. By providing subsidised, government-organised social health insurance, the government reduces the risk of catastrophic medical expenses and tries to make necessary health care affordable through risk pooling. The aim at initiation was to expand the programs to cover all citizens within 10 years. Although the programs still do not yet provide universal coverage, the program has been expanding rapidly into rural and urban areas in China in the past five years. The government has already proclaimed that universal coverage will be achieved by 2011 , and almost all its targets for the coverage through the NCMS program have so far been achieved ahead of time.

Although the reimbursement rates differ, urban and rural social health insurance (SHI) schemes use co-contributions. In rural areas, funding is divided between the individual, a mandatory local government contribution and a matching central government contribution. As an example, early iterations of the NCMS policy (2003-05) used a subsidy of RMB10 per person, an RMB10 local government subsidy and an RMB10 central government matching subsidy. The subsidies have been progressively increased through central government mandate to the point where today government subsidies are at a minimum of RMB80, and the minimum total fund contribution is RMB120.

6 Liu (2009) has two good recent examples, showing that only about half of urban and almost 60 per cent of rural patients who were treated for tuberculosis completed the treatment protocol. Similarly, only 12 per cent and 7 per cent of patients with hypertension living in urban and rural areas, respectively, had their blood pressure lowered to normal values as a result of treatment.

7 Dong (2009:595) has a good overview of the strategic implications of this policy. 
In urban areas, the Urban Employees' Healthcare Insurance Scheme (usually referred to as Basic Medical Insurance, or BMI) is designed to cover all employees and retirees in urban areas. It is financed by employee ( 2 per cent of total salary) and employer ( 6 per cent of total salary) contributions. The local government is able to top-up the BMI funds if required; however, its role remains mainly one of governance and fund management. Users have two accounts: the individual account pays for outpatient expenses, emergency services and drug costs, while the social pooling account (70 per cent of the employer's contribution) pays for some inpatient costs within a predefined band. The patients pay upfront and are then reimbursed by the fund.

Urban residents without a danwei or employer had been left uninsured since the abolition of free urban medical services in the 1980s. In the mid to late 2000s, the State Council carried out pilot reforms for a special basic social medical insurance program for urban residents that covered these groups in 79 cities in China, which was then expanded to more than 300 cities in 2007. The structure of this program is similar to the NCMS in that there are contributions from the individual and from the government. Total coverage today is estimated to be about 40 million citizens. It is expected that this program will be further rolled out soon.

All of the new systems are catastrophic-event insurance funds the main aim of which is to reimburse patients for expenditure costs after inpatient episodes. In the case of the NCMS, these funds provide an account for 'serious illness and manpower fees' for the consumer, which is pooled into a cooperative medical fund at the county level (Zhongguo Weisheng Bu 2006). The consumer pays for the episode and is subsequently reimbursed post-treatment by the townshiplevel administration body, which is reimbursed by the county-level CMS fund. The bulk of reimbursement by the NCMS is for inpatient expenses, even in counties where outpatient expenses are covered. ${ }^{8}$

\section{Reform effectiveness}

Early evaluations suggest that despite its relatively short life and limited financing, the NCMS has improved access. A number of Chinese studies find that the implementation of the NCMS has improved overall healthcare utilisation and access and to some extent has reduced the financial burden of diseases for the insured. A study in pilot counties in Shandong Province revealed that the rural population covered by the NCMS had an average of 10-15 per cent higher

8 A 2006 World Bank survey noted that in the 27 counties for which data were available, the share of reimbursements accounted for by inpatient care varied from 100 per cent to 66 per cent, depending on the coverage mode (Wagstaff 2007). 
healthcare utilisation than the uninsured (Jackson et al 2005). Wagstaff and Lindelow (2008), utilising a number of data-sets, find that the BMI in urban areas has increased the utilisation rate.

A number of problems remain. The inpatient focus of the insurance schemes means that the system of health security is geared towards more expensive tertiary care. The focus on the individual paying upfront and then being reimbursed encourages both adverse selection and moral hazard. ${ }^{9}$

Perhaps more significant are recent findings that the incidence of catastrophic spending appears to have increased since the introduction of the demand-side reforms. Thus, the early assessment of the NCMS in particular seems to show an increase in demand for services due to the lowering of costs through insurance. ${ }^{10}$ Yet the real cost of health care itself could still be increasing - in contrast with previous international evidence. ${ }^{11}$

There is a notable theoretical gap here, which is that a causal relationship between health insurance and health outcomes requires health institutions to act as the intermediary. The reason for the distinct increase in cost inflation could lie on the supply-side - the fact that providers in China are paid by feefor-service and face a fee schedule that strongly encourages demand shifting to drugs and high-tech care on which the margins are higher. ${ }^{12}$ If physicians and insurance users already face flawed incentives and more funds are added to the system, the extra inflow of public funds into the health system runs the risk of merely fuelling cost inflation rather than changing behaviour in a favourable way.

9 See Manuel (2008) for a more in-depth description of this problem.

10 For more on the impacts of the demand-side reforms, see Lei and Lin (2009).

11 Wagstaff and Lindelow's study noted the cases of Vietnam and Mexico specifically.

12 Liu and Mills (1999) remains the classic study of this. 


\section{Demand-side strategies and structural problems}

If we treat the demand-side reforms as increases in funds that do not change the incentives or the structure of healthcare provision, it is reasonable to assume that the structural problems of urban-rural and inter-provincial divides will also continue, and hence we will also expect to see similarly inequitable outcomes stemming from these divides.

There is some research currently emerging on these matters. Yip and Hsiao (2009), using the data from the 2003 Health Services Survey and their own data, report that government spending in urban areas is five to six times higher than in rural areas. Demand-side spending drives much of this: city hospitals absorbed 50 per cent of supply-side subsidies in 2002 and county hospitals 9 per cent; THCs, in contrast, received just 7 per cent.

Moreover, inherent regressive biases remain within the current demand-side policies. The city Basic Medical Insurance program, for example, is based on payments of a percentage of salary; however, the risk pooling for this program occurs at the city level rather than on broader county or provincial levels. There is no ability to transfer resources between cities. Hence, cities with advantageous demographic or public health endowments or with high revenues are able to provide more generous support packages than cities with higher actuarial risks or less well-paid workers.

This reinforces the fact that spending is often distributed unequally horizontally and vertically. The NCMS scheme, for example, can also receive extra contributions at the household or local government's discretion. World Bank studies of the 2005 iteration of the NCMS program showed the total NCMS budget tended to be higher than the RMB50 minimum mandated amount per person (RMB62.9 on average in a sample of 189 counties from 17 provinces), and it varied considerably once local income and coverage mode were factored in (Wagstaff 2007). More economically developed counties are thus able to provide greater funds to the scheme.

Establishing demand-side reforms requires the institutions running the reforms to have sufficient authority and skills for fund collection and risk transfer. ${ }^{13}$ Yet in the NCMS program there is a distinct lack of funding for institutional capacity building. For example, the central Ministry of Health declared that the management cost of pilot counties paid by the finance departments of local governments in 2004 was CNY85 million, or approximately CNY1 per capita

13 Bloom and Xingyuan (1997) have a comprehensive overview of this need for capacity in rural areas; their survey provides an extensive overview of the structure of payment in under-capacity areas. 
(Hu 2004:2). The problem here is that the management costs for the poorer counties are likely to be relatively far more significant, due to their lower budgets. Meng (2005) notes that management costs account for 9.8 per cent, 5.1 per cent and 3 per cent of budgetary costs in the western, central and eastern areas, respectively. Thus, the very regions that need the extra revenue are far more likely to have a shortfall. Moreover, central government regulations forbid the use of funds from the NCMS to support management costs.

The manifestation of this precarious situation is that county governments often become more unwilling to spend even the funds they have raised through the NCMS. Poorer governments, concerned about budgetary shortfalls, are likely to contain costs and avoid overspending through designing very conservative plans that limit coverage and benefits (Wong 2007).

Depending on when measurements were taken, the minimum level of financing per beneficiary generally represented only about one-fifth of average per capita total health spending in rural areas. ${ }^{14}$ Hence, coverage of medical expenses tends to be shallow, many services are not covered or are covered only partially, deductibles are high, ceilings are low and co-insurance rates are high.

It is further revealed by a number of studies that the NCMS has not been effective in improving healthcare access and reducing the financial burden of disease, as expected, for the poor. Compared with the high-income insured, the low-income insured utilised less health care and received less reimbursement from the NCMS (Mao 2006).

\section{How structural problems hinder reform}

The current inequities in funding do not affect just the provision of services; they also affect the incentives for institutions. ${ }^{15}$ The impacts of the demandside reforms outlined above provide an excellent case study. The administrative responsibilities for the NCMS fund are fairly clearly outlined. ${ }^{16}$ The central government - in a quest to improve social welfare and general health service provision-commits funds and gives targets to provinces. Provincial-level

\footnotetext{
14 Zhang (2005:20) uses 2004 calculations; Wagstaff et al. (2009) make similar assumptions for 2007. The data themselves each year are available from <http://www.moh.gov.cn/publicfiles//business/htmlfiles/ zwgkzt/pwstj/index.htm>

15 This section follows the methodological principle of Wilson (1989) in arguing that bureaucracies can also act as self-interested units and that this self-interest is directed to assuring its own survival through the maintenance of funding.

16 This outline can be found in Zhongguo Weisheng Bu (2006); any translations and abbreviation mistakes are the fault of the author of this chapter.
} 
responsibilities largely amount to target setting and analysis, and they decide the relative effectiveness of the counties, as well as exerting influence over annual decisions regarding fund allocation and spending. ${ }^{17}$

Counties bear most of the responsibility for the management and administration of the NCMS funds. They 'outline the level of cooperative medical care to be funded, set reasonable rebate guidelines and then calculate the ceiling payments, compensation and the proportion of the scope of compensation' (Zhongguo Weishengbu 2006). County governments, however, are allowed to loosely set NCMS reimbursement ranges and criteria according to 'funds raising and local conditions' (Zhongguo Weishengbu 2006).

Township responsibilities centre on the efficient management of the THC, which is generally considered the lynchpin of the NCMS model (Wu 2007). Most of these responsibilities focus on ensuring supplies of drugs and basic medical equipment and that 'medical institutions are functional'. Thus the THC, under the management of the township government, is the hub of the delivery system, performing outreach and connecting all preventive services for the township residents including child vaccination, disease control, prevention of infectious disease, maternal and child health and family planning, while also providing a link to more advanced tertiary services. THCs receive no subsidy, however, for the services of their time and administration. Funding to THCs is expected to come from cash-strapped local governments. Not surprisingly, their relative funding is lower than other tiers of treatment.

Physicians in THCs face a difficult situation. They do not have the same levels of training or access to resources and supplies that larger hospitals have in order to treat their patients. Their envisaged role is as a gatekeeper and primary health provider. Under this THC usage system, however, prices tend to be set below cost for simple and non-invasive care and above cost for more complex care. Hence, the incentive for the physicians in the THC is to treat the complex patients themselves, in order to gain greater revenue.

Similarly, in a situation in which they face funding shortages, THC administrators' expected behaviour for more difficult cases is to contain THC costs by encouraging physicians to transfer patients to hospitals at the county or municipal level. This utilisation mode, however, gives THCs lesser income from the absence of more complex cases that act as a de facto subsidy.

In this way, the behaviour of THC administrators and township government officials is aligned. As the township government officials are measured for

17 Provincial governments are required to 'establish CMS essential drug list, formulate survey basis and analyse hospital admissions, fiscal balances and fund payouts', balance the books and 'strive to improve the level of benefit for the farmers of the Senate' (Zhongguo Weishengbu 2006). 
effectiveness through ensuring that THCs do not become bankrupt, they have no incentive to force THC physicians or administrators to attempt to act as gatekeepers.

For the system to work, the county government would need to be able to force the township government officials to influence the behaviour of the THC. Yet the county government has very little incentive to do this. This is because county government officials have conflicting incentives. The performance of officials is measured, with some provincial variations, according to

1. whether or not institutions under their command become bankrupt

2. whether or not their NCMS fund is financially viable

3. the rate of enrolment in the NCMS program

4. the number of staff working on health care

5. general public health measurements including vaccinations and so on.

The information asymmetries present in treatment mean that measurements such as treatment protocols, prescription rates and use of medical testing are unable to be used to assess the performance of government officials. Unlike health outcomes, enrolment in NCMS is measured and can thus influence the provincial government's assessment of the country officials' performance. Hence, there is an incentive to make sure that all citizens are enrolled - in spite of the scheme being voluntary - yet there is no incentive for government administrators to take account of service delivery, in spite of the healthcare system being public.

Moreover, the inability to measure outcomes means that government officials need to rely on hospital administrators to ensure that physicians behave in a way that is socially beneficial. Although county hospitals and THCs are public, they have incentive schemes similar to the private sector. Local governments can provide some funding to hospitals and provide them with targets for specific public health interventions, such as vaccination targets. Yet, simultaneously, the major role of the hospital is to survive in spite of funding shortages.

Hospitals do this through ensuring an adequate supply of high-cost treatment patients. More importantly, hospitals have a controlling mechanism over the behaviour of physicians through the payment of bonuses. These bonuses are supplementary to salary and are generally not formally contracted - or available on the public record. A study done by the World Bank (2005:43) indicates that there appears to be a link between hospital revenue and physician bonuses, but data to prove this hypothesis have been difficult to access.

Finally, local governments and hospitals/THCs have incentives to increase the number of staff. As the base salary of staff is mandated by central decree, and there are generally soft budget constraints only, extra staff is useful for the 
hospitals/THCs (who can use them to generate extra revenue) or for the local government (for whom they are a source of support, power and influence) (Shih et al. 2008. Capital grants or targeted transfers from the central or provincial government can similarly be used for purchasing or upgrading expensive equipment, which tends to allow for more complicated revenue-generating medical procedures to be performed.

Patients are then forced to respond to these incentives. The patient pays upfront and thus the patient decides which level of provider to visit as well as bearing all the financial risk. The post-visit repayment structures of the NCMS encourage the patient to be treated at the THC level. The THC has an incentive to treat the patient as high rather than low cost, and there are the usual asymmetries of information problems present in models of fee-for-service health systems. The THC workers are, however, less qualified than county hospital staff. ${ }^{18}$

Patients not only have to ascertain which level of provision is most suitable for them to be treated and pay upfront for the treatment, they are supposed to discipline provider behaviour. Theoretically, providing individual consumers with greater funds allows them to have a measure of voice, exit or loyalty. ${ }^{19}$ Yet patients are unlikely to have much voice since information asymmetry between patient and doctor makes it difficult for individuals to discipline providers one-on-one. Moreover, as patients have no say in the running of the NCMS or its purchasing behaviour, their choice becomes one of exit or loyalty. As the majority of the health system is publicly owned and managed, options for exit are also limited. Hence, it appears difficult for individuals to discipline provider behaviour.

Due to pushing the risks back onto the patient, and not having effective, aligned incentives for bureaucrats, the demand-side strategies of the Chinese government appear to be insufficient on their own. The social medical insurance system does not provide mechanisms for improving flawed incentives and fails to ameliorate or monitor agency problems between physicians. The conflicting incentives for government bureaucrats, hospital administrators and physicians force patients to attempt to navigate, fund and discipline the healthcare system themselves - a role for which they are ill equipped.

18 As discussed in the schematic of the collectivisation period supply, there is also a very low-level private alternative available to the patient - the village doctor - but as these doctors are unregulated and do not officially access public funds they have been left out of this model for the sake of maintaining reader interest. 19 Based on Hirschman's classic characterisation of consumer options for public providers (Hirschman 1970:17-37 outlines the model). 


\section{Supply-side reforms also hindered by flawed incentives}

Significantly, these conflicting incentives also affect the Chinese government's ability to make supply-side reforms to the system. Take, for example, the idea of 'government leadership' - a supply-side theory that has gained considerable traction in the media and, according to some reports, within the government itself. ${ }^{20}$ According to this theory, the government should be responsible for as much of the development of 'basic health care' as possible. Public community healthcare providers at the primary-care level will provide highly subsidised care, with a small co-payment from the users. These providers should improve their skills through greater, publicly funded training and are expected to also upgrade the skills of village doctors within the area. At higher tiers of treatment, public health insurance schemes such as the NCMS and BMI should be 'enhanced' and this enhanced funding should be used to provide social health insurance cover for hospitalisation costs.

There are two major problems with this proposed strategy of reform. The first relates to cost. The total revenue of public healthcare providers in China at the time was equal to about one-seventh of total government expenditure, and China lacked the fiscal capacity to introduce full supply. ${ }^{21}$ Rather, these supply-side strategies focused on creating a sort of 'mini-NHS' system in which the government attempted to focus its spending on community centres, including extensive training programs to ensure there were enough employees for the centres. Yet this does not deal with the problems of what to do with the hospitals. Supply-side reforms thus far have concentrated on intensifying the SHI programs in order to deal with 'non-basic care'.

Moreover, this exacerbates the problems with poor incentives currently faced by the Chinese healthcare system. Public hospitals would be able to use excess revenues to pay bonuses to staff. For this and other reasons such as prestige, it would be hard to retain community health workers in THCs or to ensure quality of health services within this area. The conflict in incentives for THCs, county hospitals and bureaucrats therefore continues.

$20 \mathrm{Gu}(2009: 124)$ has far more on the internal politics of this, although his preference for demand-side reforms is clear.

$21 \mathrm{Gu}(2009: 125)$ does the calculations, based on Ministry of Health (2007) and NBS (2007). 


\section{The April 2009 health reforms}

Perhaps the best indication of how the Chinese government sees the next 20 years of reform can be seen in its most recent health plan. ${ }^{22}$ The plan-the Opinions on Deepening Healthcare System Reform (2009-10) - was adopted in January 2009 and released in early April. ${ }^{23}$ This plan promises to 'effectively solve the problem of difficult and costly access to health care services' - a problem, the plan notes, 'arouses intense public concerns'.

Much of the plan appears to be embracing supply-side reform proposals. Funding standards for basic public health services will be increased ('in 2009, the average per capita public health funding shall be no less than 15 Yuan, and no less than 20 yuan by $2011^{\prime}$ ), with the expectation that this greater funding be used for improving public health and grassroots services. The central government also proposes to place more drugs on the essential medicine list.

Over and above this, there appears to be a commitment by the central government to 'lead' healthcare reforms on the supply side. It promises to 'rationally determine the payment criteria for drugs, healthcare services and medical materials'; to check that the 'salary level of healthcare workers is in line with the average salary level of staff of local public institutions'; to set the 'service charges of grassroots healthcare institutions according to the costs after deduction of government subsidy'; and finally, to ensure that drugs are 'sold at zero price margin'. It is thought that this will stop drug revenue from being the 'major compensation source' for funding grassroots healthcare institutions. Rather, the government thinks that it will 'provide rational subsidies to rural doctors for providing public health services'. Crucially, local governments will regulate the criteria for these measures. There is no mention of which level of government will pay the providers themselves, but it is presumed from the choice of regulatory body that it will be local governments.

On the demand side, the subsidy on SHI programs will be increased so that the funds reach a minimum of RMB120 per capita per annum. Greater focus will be put on outpatient expenses and the reimbursement range will be increased.

22 The most recent bout of reform was intended to be a seminal reform. It was anointed by the State Council and Li Keqiang himself led the project. Many multinational consulting firms, foreign and local universities and think tanks also consulted on the project. The full details of the reform can be found at $<$ http://shs.ndrc. gov.cn/ygjd/ygwj/>

23 The following section is taken from details of the plan, which can be found at <http://shs.ndrc.gov.cn/ ygjd/ygwj/> Any translation mistakes are the fault of the author. 
The scope and proportion of reimbursement for outpatient expenses will be expanded. In rural areas, county governments are mandated to reimburse a higher amount of NCMS funds. ${ }^{24}$

The most radical part of the reform is a promise to shift away from public ownership. The government has pledged to compensate healthcare non-profit organisations for any 'grassroots' work they do. It has also encouraged 'qualified' physicians to run clinics or establish their own clinics or practices. The envisaged compensation mechanism is through SHI reimbursement, although providers will be forced to sign a 'designated insurance contract'. Similarly, 'efforts will be made' to transfer ownership of public hospitals to non-public institutions.

Finally, governance reforms are promised. These reforms include trying to 'encourage' local governments to 'actively explore effective formats of separating government agencies and public institutions' and to try to separate 'government administration and business operations'. The most significant of these is a mooted 'negotiation mechanism between medical insurance handling institutions and providers of healthcare services'. This, if done effectively, would undoubtedly be a major step forward.

\section{Future paths and conclusions}

Overall, however, the Chinese government appears to be caught in a bind in which it is trying to do too many things at once. It wishes to 'rationally determine the payment criteria for drugs, healthcare services and medical materials', yet simultaneously commits massive amounts of funding to demand-side programs in which individuals are forced to navigate flawed government incentives.

Clearly, as insurance coverage widens and the funds devoted to insurance increase, the ability to use these demand-side programs to reform the payment systems of providers will also increase. The current model, however, requires tweaking in order to change the behaviour of providers. The insurance mechanism would benefit from moving from a post-hoc reimbursement model to a more contractual model in which insurance bodies act as genuine third-party purchasers and in which insurance bodies are able to use mixed-method purchasing techniques. A number of studies in China across different geographical areas and service providers have all reported considerable improvements in affordability, access and patient satisfaction following shifts to mixed-method models (Yip and Eggleston 2001; Yip and Eggleston 2004; Wang et al. 2005; Hsiao 2007a, 2007b; Wagstaff et al. 2009).

24 This is the so-called ' $85-93$ rule', whereby county governments are mandated to reimburse no less than 85 per cent of the NCMS fund from the year but to not reimburse more than 93 per cent. 
A shift such as this will also require the Chinese government to clarify its own political structure and strategy at a number of levels. For example, the responsibilities for the current insurance schemes at the central government level itself are divided between the Ministry of Health and the Ministry of Labour and Social Security. Reform proposals are often bitterly contested between these two ministries at the central level. ${ }^{25}$

This lack of clarity is a problem that reinforces itself within China's governance structure both horizontally and vertically. For example, the central government thinks that it will 'provide rational subsidies to rural doctors for providing public health services', yet the local (most probably county) government will regulate the criteria for these measures. The very same local government, however, has considerable incentives to ensure that hospitals and community centres - underfunded by the public purse for a lengthy period - do not go out of business. As such, allowing the continuance of a distorted system in which providers are forced to choose between providing low and high-cost health services makes any sort of reforms difficult.

Changing this system is not merely administratively and fiscally difficult. It also runs parallel to recent political trends that point to the greater centralisation of Chinese governance. As Barry Naughton (2010) observed so perceptively about the 2010 National People's Congress, the current central government line following the global financial crisis is the effect of what Wen Jiabao called 'macro-control'. Macro-control is defined as continuing

to make use of both market mechanisms and macro-control, that is, at the same time as we keep our reforms oriented toward a market economy, let market forces play their basic role in allocating resources, and stimulate the market's vitality, we must make best use of the socialist system's advantages, which are making decisions efficiently, organizing effectively, and concentrating resources to accomplish large undertakings. (Wen 2010)

It is difficult to see how concentrating resources can accomplish large improvements in health care. For example, more generous earmarked transfers for public health programs have been mooted for the provincial level in order to attempt to reduce the horizontal fiscal inequities present in the current Chinese system. Yet the current vertical inequities indicate that 50 per cent of these extra funds would be directed into urban demand-side programs and would do very little to change the incentives for bureaucrats and providers at lower levels. It is hard to see how concentrating resources at the central level would not merely reinforce the current flawed incentives. 
A truly promising course of reform for the next 20 years of Chinese health care would be a shift away from macro-control towards what we can term 'microcontrol'. Any program of reform would need to consider supply and demandside issues.

True supply-side reforms would embrace sector neutrality. The government would need to eliminate the high-cost/low-cost patient distinction, decide the ownership status of health institutions and examine reform of the incentives for local bureaucrats. Similarly, attempts would need to be made to secure far higher levels of funding for township and county governments to act as effective monitors, measurers and regulators and to secure greater funding for public health providers to ensure more efficient 'gatekeeping'. There would need to be horizontal and vertical intergovernmental fiscal reform in order to ameliorate the current incentives for providers and patients to move to more developed areas. Finally, there would need to be some concessions to 'losers' from these reforms ${ }^{26}$ - and they would undoubtedly come at considerable fiscal cost and administrative difficulty.

The other option for the next 20 years is to truly embrace demand-side reform. Making demand-side institutions such as the BMI or NCMS agencies accountable to the populations they serve (and that fund them) would create huge incentives for improving service delivery. This would be particularly true if these demand-side institutions are allowed to embrace new payment mechanisms and active purchasing. Vital to this occurring would be to not only ensure universal coverage by 2011, as planned, but to counteract problems of portability and inequity. Allowing transfers between cities with basic medical insurance, for example, would be a good start. Better yet would be to continue and even expand the large funding increases for the demand-side programs; to make health insurance part of a single central government ministry's mandate; to merge urban unemployed and rural schemes and ensure they are aligned with the BMI program; and finally, to make health insurance packages fully portable.

When considering the next 20 years of reform, it is difficult to avoid the problems of today - and these problems are firmly anchored by events in the past. Specifically, inequalities in the fiscal and public good system were linked to inequality in service provision. Moreover, the intersection of these inequalities created flawed incentives that led to poorer outcomes for Chinese citizens and that today hinder reform. Reform proposals such as the most recent April 2009 plan must navigate the same flawed institutions that brought about discontent with the health sector. Without attacking these incentives, systemic reform remains highly difficult. As such, it is difficult not to feel somewhat cautious about the next 20 years of reform. 
The Chinese central government has, however, shown a considerable, and laudable, commitment to healthcare spending throughout the past decade. Although much remains to be done, a marrying of this commitment to funding with a commitment to redressing the flawed incentives in the system could have a dramatic impact in the next two decades.

\section{References}

Anand, S. Fan, V., Zhang, J., Zhang, L., Ke, L., Dong, Z. and Chen, L. 2008, 'China's human resources for health: quantity, quality, and distribution', The Lancet, October.

Bloom, G. and Tang, S. 2000, 'Decentralizing rural health services: a case study in China', The International Journal of Health Planning and Management, vol. 15, no. 3 (January), pp. 189-200.

Bloom, G. and Xingyuan, G. 1997, 'Health sector reform: lessons from China', Social Science \& Medicine, vol. 45, no. 3 (January), pp. 351-60.

Chen, L., Evans, T., Anand, S., Boufford, J. and Brown, H. 2004, 'Human resources for health: overcoming the crisis', The Lancet, January.

Chernichovsky, D. 1995, 'What can developing economies learn from health system reforms of developed economies?' Health Policy vol. 32, January, pp 79-91.

Chou, W. L. and Wang, Z. 2009, 'Regional inequality in China's health care expenditures', Health Economics, vol. 18, no. S, pp. 137-46.

Dong, K. 2009, 'Medical insurance system evolution in China', China Economic Review, January.

Eggleston, K., Ling, L., Qingyue, M., Lindelow, M. and Wagstaff, A. 2008, 'Health service delivery in China: a literature review', Health Economics, vol. 17, no. 2 (January), pp. 149-65.

Fock, A. and Wong, C. 2008, Financing rural development for a harmonious society in China, World Bank Policy Research Working Papers, no. 4693 (January), The World Bank, Washington, DC.

Gu, E. 2009, 'Towards Universal Coverage: China's New Healthcare Insurance Reforms', in China's Reforms at 30: Challenges and Prospects (edited by Dali Yang and Litao Zhao), World Scientific Publishing, Singapore, pp. 115-164.

Hirschman, A. 1970, 'Exit, voice and loyalty', Harvard University Press, Connecticut. 
Hsiao, W. C. 2007a, 'The political economy of Chinese health reform', Health Economics, Policy and Law, vol. 2, no. 1, pt 3 (June), pp. 241-9.

Hsiao, W. C. 2007b, 'Why is a systemic view of health financing necessary?', Health Affairs, vol. 26, no. 4 (July), pp. 950-62.

$\mathrm{Hu}, \mathrm{T} .2004$, 'Financing and organization of China's health care', Bulletin of the World Health Organization, January.

Jing, F. 2004, 'Health sector reform and reproductive health services in poor rural China', Health Policy and Planning, vol. 19, no. 1 (October), pp. 140-9.

Gong, Y. Bloom, G. and Wilkes, A., 1997. Health human resources in rural China. IDS Bulletin vol. 28, no. 1, pp. 71-79.

Lei, X. and Lin, W. 2009, 'The new cooperative medical scheme in rural China: does more coverage mean more service and better health?', Health Economics, vol. 18, no. S, pp. 25-46.

Lin, S. 2005, 'Excessive government fee collection in China', Contemporary Economic Policy, vol. 23, no. 1 (January), pp. 91-106.

Liu, M., Wang, J., Tao, R. and Murphy, R. 2009, 'The political economy of earmarked transfers in a state-designated poor county in western China: central policies and local responses', China Quarterly, no. 200 (December), pp. 973-94.

Liu, X. and Mills, A. 1999, 'Evaluating payment mechanisms: how can we measure unnecessary care?', Health Policy and Planning, vol. 14, no. 4 (January), pp. 408-13.

Liu, Y. 2004, 'Development of the rural health insurance system in China', Health Policy and Planning, vol. 19, no. 3 (May), pp. 159-65.

Manuel, R. 2008, The Political Economy of Health Care in China: Henan and the new CMS system. Unpublished MPhil Dissertation, University of Oxford, pp. 1-100.

Mao, Z. (2006). Health System of China Overview of Challenges and Reforms. United Nations Health Partners Group in China working paper, Beijing.

Ministry of Health 2004, An Analysis Report of National Health Services Survey in 2003, Center for Health Statistics and Information, Ministry of Health, Chinese Academy of Science and Peking Union Medical College Press, Beijing.

Ministry of Health 2007, Chinese Health Statistical Yearbook, Ministry of Health, Beijing. 
Ministry of Health 2009, Chinese Health Statistical Yearbook, Ministry of Health, Beijing.

Ministry of Health 2010, Chinese Health Statistical Yearbook, Ministry of Health, Beijing.

National Bureau of Statistics (NBS) 2005, China Statistical Yearbook 2005, China Statistics Press, Beijing.

National Bureau of Statistics (NBS) 2006, China Statistical Yearbook 2006, China Statistics Press, Beijing.

National Bureau of Statistics (NBS) 2007, China Statistical Yearbook 2007, China Statistics Press, Beijing.

National Bureau of Statistics (NBS) 2009, China Statistical Yearbook 2009, China Statistics Press, Beijing.

Naughton, B. 2010, 'Understanding the Chinese stimulus package', China Leadership Monitor, vol. 28, no. 2, pp. 1-12.

Saich, T. (2003). Enhancing economic security in transition: Pluralism in service delivery. International Labor Organization Working Paper, no. 32 (SES Paper), pp. 1-33.

Shih, V., Zhang, L. and Liu, M. 2008, When the autocrat gives, Working Paper Department of Political Science, Northwestern University, accessed online 24/1/2010, available at: http://faculty.wcas.northwestern.edu/ vsh853/ papers/shih_zhang_liu_autocratgives08.pdf

Smith, A. 1974, 'Barefoot doctors and the medical pyramid', British Medical Journal, vol. 2, pp. 429-32.

Wagstaff, A. 2007, Extending health insurance to the rural population: an impact evaluation of China's new cooperative, World Bank Policy Briefing Impact Evaluation Series, no. 12, The World Bank, Washington, DC.

Wagstaff, A. and Lindelow, M. 2008, 'Can insurance increase financial risk? The curious case of health insurance in China', Journal of Health Economics, vol. 27, no. 4 (June), pp. 990-1005.

Wagstaff, A., Yip, W., Lindelow, M., \& Hsiao, W. 2009, 'China's health system and its reform: A review of recent studies.' Health Economics, vol. 18 (S), pp. 7-23. 
Wang, H., Yip, W., Zhang, L., Wang, L. and Hsiao, W. 2005, 'Community-based health insurance in poor rural China: the distribution of net benefits', Health Policy and Planning, vol. 10, no. 3 (January), pp. 361-74.

Wen, J. 2010, Report on the work of the government (2010), Third Session of the Eleventh National People's Congress, 5 March 2010, <http://www.npc.gov. cn/englishnpc/Speeches/2010- 03/19/content_1564308.htm>

Wilson, J. 1989, Bureaucracy: What government agencies do and why they do it, Basic Books, New York.

Wong, C. 2007, Fiscal management for a harmonious society: assessing the central government's capacity to implement national policies, BICC Working Paper Series 4, August, British Inter-University China Centre, Oxford, pp. 1-20.

World Bank 1993, Country Study. China: long term issues and options in the health transition 1992. The World Bank, Washington, DC, pp. 1-132.

World Bank 1997, Financing Health Care: Issues and options for China. Volume 4, January, The World Bank, Washington, DC, pp. 1-83.

World Bank 2005, China deepening public service unit reform to improve service delivery, World Bank Policy Briefing, no. 32341-CHA, August, The World Bank, Washington, DC, pp. 1-65.

World Health Organisation 2009, International health indicators, accessed online 23/3/2010, available at: www.who.org

Xu, J. 1997, 'Historical review and perspective of our country's health economic policies', Chinese Health Economics [in Chinese], vol. 16, issue 177, pp. 7-9.

Yip, W. and Eggleston, K. 2001, 'Provider payment reform in China: the case of hospital reimbursement in Hainan province', Health Economics, vol. 10, no. 4 (June), pp. 325-39.

Yip, W. and Eggleston, K. 2004, 'Addressing government and market failures with payment incentives: hospital reimbursement reform in Hainan, China', Social Science \& Medicine, vol. 58, no. 2 (January), pp. 267-77.

Yip, W. and Hsiao, W. C. 2008, 'The Chinese health system at a crossroads', Health Affairs (Project Hope), vol. 27, no. 2 (December), pp. 460-8.

Yip, W. and Hsiao, W. C. 2009, 'China's health care reform: a tentative assessment', China Economic Review, vol. 20, no. 4 (December), pp. 613-19.

Zhang, X., \& Kanbur, R. 2005, 'Spatial inequality in education and health care in China.' China Economic Review vol. 16, no. 2, pp. 189-204. 
Zhang, Z. (2005). 'Henan shen Xinxing Nongcun Hezuo Shidian Ceng Jizhao Diaocha Yanjiu (The investigation report of the base-line survey of the Experimental Counties of the New CMS in Henan)'. Chinese Health Economics, vol. 24, no.5, pp. 51-55.

Zhongguo Weisheng Bu (2006). Gongbu 2006 nian Zhongguo Weisheng Shida Xinjian. Zhonghua Renmin Gonghe Guo Zhongyang Renmin Zhengfu Zhiwu Yaojian. 



\section{Index}

agricultural

underemployment $28,145,244$,

260, 261

wages $9,172,173,321$

agriculture $31,32,41,47-8,172,173$,

$174,243,263,298,301,303,315,322$

as pool of surplus labour 12, 321, 322,

$324,326,336$

anti-dumping 213

Asia

currencies 181

economies 10, 80, 184n.19, 193-4,

195, 201, 209, 295, 355

foreign direct investment (FDI) 221-

37,239

trade 184, 193-215

Association of South-East Asian Nations

(ASEAN) 106, 141, 195, 196-204, 206, 207, 209, 210, 214, 234

Association of South-East Asian

Nations (ASEAN)-China Free Trade

Agreement (ACFTA) 234

balance of payments 168n.5, 169, 179, 184,271

bank

central, see People's Bank of China

credits 46

commercial 175, 177, 178, 185, 301,

302,314

deposits 160

loans 274,283

private $281-2,283$

reserves 177,178

state-controlled (SCBs) 43, 273-4,

275n.10, 281, 282, 283

state-owned (SOBs) 275n.9

system 269, 270, 273, 283, 305

'Beijing Consensus' 31, 39-41

bio-power 107, 285

capital 304-5, 307, 309, 311, 356

account 43, 166, 168-70, 184

accumulation 1, 23, 143, 156, 157, 235

controls 9, 158, 160, 164, 169, 175,
$177,179-81,185$

cross-border flows 2, 158, 159, 161

flow 77n.3, 144, 157, 168, 169, 221

formation 84, 221

inflows 154, 158, 160, 331

investment 42, 50, 144

outflow 48, 154, 161, 296-7

requirement 300, 312, 314, 315

returns on 182

shortage $77 \mathrm{n} .3$

stock 12, 24, 48, 79n.6, 82n.9, 144,

179, 180, 224, 294, 303

capital-intensive goods 26, 33, 34

capital-intensive industry 136, 142, 145,

$308,349,351$

capital-labour ratio 322, 348, 351

catch-up 9, 35, 144, 159, 160, 163, 285 ,

288,356

centrally planned economy 1, 270n.1

China inter-bank offered rate (CHIBOR)

305,311

China Investment Company (CIC) 178, 179

Chinese Communist Party (CCP) 41, 44-

$51,65,128,147,270$

climate change $4,5,8,94,99,100,106$,

$110,112,119,120,278,285,293,302$, 316

coal

'clean' 286

consumption 102-3, 107, 114, 285

dependence on 99

prices 118, 306

production 114, 137, 139, 277n.15,

313, 315

Coastal Development Strategy 127

Commonwealth of Independent States

(CIS) 8, 75, 84

comparative advantage $2,3,23,26,30$,

$33,34,74,82,94,141,235,281,354$

consumer price index (CPI) 158, 172,

173n.10, 272, 299

consumption $24,27,50,74,156,182-3$,

$283,295,302,308,310-11,316$ 
China: The Next Twenty Years of Reform and Development

basket 75

domestic 4-5, 9, 27, 33, 158, 330

durable goods 94

efficiency 160

household 73, 295, 301, 310, 315

patterns 76

preferences 89

private 176,213

rate $23,295,296$

share 22, 33, 293, 294, 299

corruption 59, 65, 66, 146, 223, 227, 270, $271,277,284,285,293,311$

currency appreciation 9, 10, 34, 153, $154-5,156,158,160-1,163,164,165$, $170,177-8,179,181-5,305,289$ n.29, 302,305

debt 159, 175, 333, 348, 349, 315

government $65,178,274$

national 153

public 33, 212

decentralisation 2, 53-4, 55-60, 100, 366

fiscal 7, 42, 47, 53, 273n.6, 330

decoupling thesis 10, 193-217

democracy 39, 40, 47, 51, 56, 58, 65, 67, $159,270,284,289$

democratisation 7,51

Deng Xiaoping 1, 127, 128, 142, 366

desertification 279, 280, 286

disparity, rural-urban 45, 212, 298, 299, 377

drought 278, 280, 285

East Asia 21, 48, 79, 85, 288, 295, 319

dollar 181

economies 10, 226, 230, 231, 295, 355

financial crisis 169, 175, 222, 243,

249, 305

trade 193-217

education 2, 3, 26, 27, 28, 173, 213, 223,

277,372

compulsory 336

expansion 35, 143

expenditure 116, 144, 156, 171

investment 30, 32, 147

overseas 157

primary 41, 43, 330

products 137,139

provision $28,60,65,75$

quality 30 rural 49,156

tertiary 144, 336

electricity consumption 83,85

energy $73,157,285,342$

conservation 8, 99-120, 302, 313,

$314,315,316$

consumption 3, 99, 101, 102, 113,

$114,115,118,119,301,313,314$

demand 3, 107, 113

efficiency 101-6, 110, 117, 293

intensity 3, 100, 101, 102, 111, 112,

$113,115,119,293,302,314$

-intensive production $3,8,101,111$,

$117,120,300,301,313,315$

pricing 3, 79n.6, 101, 120, 306, 308,

309, 311

projects 146

reliability 8

research 286

resources 143, 305, 307n.2, 308

-saving technologies 3,4

supply 102

use 100, 101, 103, 110-11, 112, 114,

$115,118,119,314$

environmental

amenity 94

consequences of growth $8,99,101$,

341

costs 106, 116, 294, 305, 306-7

degradation (see also pollution) 4, 11 , 12, 99, 106, 109, 270, 271, 278, 279,

$280,285-6$

friendly industry 4, 300

policy $8,100,116,285$

protection 100, 117, 118, 127, 313-16, 342

standards 103, 302

technology 4

Europe 74, 84, 153n.2, 158, 159, 181n.17

European Union (EU) 57, 104, 106, 107, 115, 180, 195, 196-7, 198, 199-200,

203-4, 205, 209, 210, 214, 224, 288

exchange rate 33, 163-193, 227, 287, 296,

305, 311

adjustment 156, 158

appreciation 25, 35, 155, 165, 168,

$170-4,213$

debate 9,153 
fixed 34, 305

floating 43

nominal 25, 35, 213n.10

policy 153-61, 297

real 9, 25, 35, 154-6, 163-85, 213

regime 3, 5, 289n.29, 311

stability $155-9$

unified 41

exports 10, 46, 79, 82, 84, 130, 193-5, 199, 200, 201-5, 208-10, 217, 221,

$228,233,235,341,348,351$

agricultural 184

capital 296, 297

commodity 23, 356

competition 213

constraints on 164

contraction 11, 184, 208-9, 241, 247,

250, 271, 272

costs 155

demand 20, 178, 212

disincentives 10

distortions 310, 311

expansion 19, 34, 184

growth 23, 41, 42, 45, 174, 195, 196,

210, 212, 216, 293, 296

high-technology 355-6, 358

industrial 183

investment 316

labour-intensive 3, 241, 304

manufacturing 185, 196-7, 198, 199,

200, 201, 205, 215, 354, 355

merchandise 200, 207, 209-10, 211,

212

orientation $8,31,34,74,213,226,309$

prices 34

promotion 289n.29, 305, 309, 214

reliance on $4,212,214$

revenue 177

sector 157, 184, 185, 213

factor inputs 94

factor market

distortions 12, 294, 303-10

domestic 3, 217

reform 6, 12, 294, 311, 312

factor prices $79 \mathrm{n} .6$

Five-Year Plan (eleventh) 100, 101, 115,

118, 212-13, 217, 293

'flying geese' model 141, 142 food 136, 137, 139, 243, 276

prices 29

supply 73,275

forced labour 276, 277

foreign direct investment (FDI) 1-2, 130, $157,169,216,221,225,272,341$

approved 175

attracting 10, 215

barriers to 41

inflows 10, 175, 221, 222-4, 225-30,

232, 234-7, 239, 269

outflows 10, 229, 232, 235

free elections $11,47,56,57,64,65,66$, 285

free trade $215,287,288$

free-trade agreements (FTAs) 214, 215,

216,234

fuel economy standards 105

G20 214

GDP growth 1, 50, 87, 91, 95, 99, 101, $116,118,130-1,132,176,226,239$, 241, 269, 270, 271-2, 289n.29, 309, $312,314,320,342$

General Agreement on Tariffs and Trade (GATT) 287, 288

Gini coefficient 48, 49, 277, 298

globalisation 2, 214, 287

Great Depression, the 60, 61, 205, 206, 213

Great Leap Forward 41

health care 46, 60, 75, 171

access to 5

expenditure 41

interventions 277

reform 13, 49, 363-87

rural 213

system 3, 5, 270

see also insurance-medical

homeownership 11, 281, 282

Hong Kong 57, 58, 129, 130, 141, 154,

155, 160, 169, 179, 180, 195, 198, 202, 204, 207, 209-10, 222, 229, 233, 234,

$282,284,349,351$

Hu Jintao 46, 128, 284, 285

hukou (household registration system) 12, 13, 46, 163, 173, 174, 258, 259, 263, $328,329,336,337$

human capital 3, 144, 277 
hydropower 107, 300, 315n.6

imports 42, 79, 82, 84, 153, 155, 157, $168,194,195,198,199,200,202$, 203-5, 206-7, 208, 209-10, 211, 212, 216, 233, 288, 296, 309, 316

competing 173, 215

components 184, 185

contraction 184

costs 161,177

cutting 185

demand 5

manufacturing 198, 201, 205

raw materials 231

technology 75

India 79n.8, 84, 106, 108, 147, 158, 179, 180, 181, 193n.1, 198, 214, 229, 230, $231,234,280,285,288,356,368$

Indonesia 106, 198, 202, 207, 209-10, $222,229,230,231,243,249,368$

inequality

income 5, 12, 19, 23, 24, 25, 33, 48, 79-80, 142, 277, 284, 297-8, 371

regional 9, 127, 132, 141, 143, 144, $146,147,148$

social 3, 34, 47, 48, 271, 386

information and communication technology (ICT) 196, 208, 209, 210

Information Technology Agreement 214 insurance 171,369

medical 171, 185, 243, 249, 302, 304, $364,365,369,374-8,381,382,384-6$ retirement 171, 175, 243, 249, 332 social 252 unemployment 243, 249, 332, 334, 335

welfare 249

work injury 249, 304

intellectual property rights 13, 43, 227, $342,357,358$

interest rates $9,33,41,43,154,157-8$, $159,160,178,182,183,282,302$, $304-5,311$

Japan 8, 74, 75, 156, 195, 234, 284, 319, $327,352,354,357,368$

currency 154

economic development 21

economy 158, 159, 179, 183 energy 103

exports 196-7, 207, 208-10, 355-6

foreign ownership 180-1

GDP 288, 309

Gini coefficient 49

growth 2, 155, 172

Imperial 48

imports 207

industry 141, 239n.215

metal intensity 84, 85, 87, 89, 91, 95

pollution 279,286

trade 198-205, 214

vehicle standards 104

Jiang Zemin 127

labour

agricultural 11, 19, 32, 213, 241-64, 268, 260, 261, 262, 304, 323, 324-9

leaving industry 12-13, 19, 213,

$242,322,323,327,328-30,337$

mobility 2, 5, 26, 46, 141, 168, 244,

304, 334, 335

surplus 3, 6, 12, 19-35, 142, 143, 145, $147,174,304,321,322,324-6,336$

land classification 277, 282-4, 306, 312 law of one price $164,168,184$

leapfrogging $8,75,76,77,79,81,85,88$, 92, 93, 94, 95, 331

legislation

Criminal Law 276

Employment Contract Law 332, 334 environmental 306

Interim Measures on the Transfer of Continuation of Basic Pension for Urban Enterprises Employees 334

Labour Law 331

Land Administration Law 305-6

New Labour Contract Law 241

Property Law 43, 49

Regulation on Minimum Wages in

Enterprises 331

Regulations on strengthening control of investment in fixed assets and newly started projects 301, 314

Renewable Energy Law 108

Lewis, Arthur 6, 20, 21, 26, 87, 141

Lewisian turning point' 6, 12, 142, 145, $320-2,324-7,330,331,332,336,337$ 
liberalisation 2, 214, 289n.29, 308

capital account 42

financial 41, 43, 179, 283, 305

foreign direct investment (FDI) 42

market 12, 294, 302-8, 311, 312

programs 1

trade $11,30,42,172,215,216,222$,

288, 302

see also price liberalisation

'liquidity tango' 273, 274

Macau 129, 130, 349, 351

Mao Zedong 278, 280

market economy 1, 6, 7, 12, 40-1, 43, 45, 58, 65, 66, 144, 147, 159, 193, 270n.1, $275,303,305,312,336,385$

markets

capital 22, 179, 184, 185, 304, 307,

311

energy 306

see also factor market

metal consumption 73, 78, 85, 88, 93, 94

Mexico 180, 181, 198, 355, 376n.11

migration, rural-urban 5, 11, 12, 21,

30, 172, 241-64, 299, 304, 307, 319,

$321-5,326,328$

Ministry of Environmental Protection 315

Ministry of Finance 176n.15, 302, 304n.1

Ministry of Health 377, 385

Ministry of Human Resources and Social

Security (MoHRSS) 242

Ministry of Labour and Social Security 385

Ministry of Public Security 276

'monetary mercantilism' 175-7, 181

National Bureau of Statistics (NBS) 306, 323, 332

National Development and Reform

Commission (NDRC) 102, 109, 117,

273, 300, 306, 309, 313

National People's Congress 272, 385

neoclassical economics 7, 41, 43, 44, 141, 144

neo-liberal 39, 43

New Countryside Movement 49

newly industrialised economies (NIEs)

195 non-performing loans (NPLs) 273, 274, 281, 282, 283

North American Free-Trade Agreement (NAFTA) 195, 196-7, 198, 199-200, 203, 204-5

One-Child Policy 3

Open-Door Policy 1, 45, 127, 142

Organisation for Economic Cooperation and Development (OECD) 60, 84, 224, 354, 356

pensions 304, 332, 333-4 see also insurance

People's Bank of China (PBOC) 154, 175$9,181,182,183,184,185,296,301$, 302,305

pollution 99, 280, 285, 293-4, 306, 309, 310

air 278n.16

coal 114

industrial 8, 120, 301, 313, 314

reducing 100, 101-6, 116, 118, 293,

302, 314

vehicle emissions 105-6

water 278,279

population 4, 10, 42, 45, 48-9, 77-8, 130,

132,333

ageing 3, 235

control 320

growth 25, 28, 278

migrant 246

pressures 270

projections 32

rural $23,365,368-9,376$

shift in 87,320

urban 2, 82, 84, 328, 329-30, 373

working-age $2,30,32,145,320$

poverty 1, 5, 21, 130, 145, 146, 147, 277,

283-4, 297, 310, 319, 326, 369, 372,

373,378

price liberalisation 155, 303, 306

agricultural 303

privatisation $9,13,41,42,45,156,171$, $274,282,283,312,351,352,358$

productivity $44,80,94,226,341,348$

agricultural 29, 116, 213, 244, 263,

319,321

capital 141 
catch-up 9, 160, 163-4

gains 1, 28, 87, 143-4, 153, 154-5

growth 4, 5, 11, 21, 24, 35, 154, 159,

160-1, 165-6, 168-9, 173, 184-5, 271,

$275,281,282,356$

labour 3, 23, 142, 156, 165, 227, 236,

$321,322,348$

raising 21,29

urban 46, 299

property rights $11,42,43$

protectionism 153, 183, 213-14, 278,

286-8

purchasing power parity (PPP) 352

recapitalisation $274 n .9,275,283 n .25$

re-employment programs 45, 49, 245n.2,

$254 \mathrm{n} .3$

regional imbalances 128,270

renewable energy 100, 106-10, 113, 118

'Revive the Northeast' scheme 128, 143

'Rise of the Central Region' scheme 128

rule of law 7, 57, 58, 60, 65-8, 270, 275, 285

rules-of-origin (ROO) 215, 216

Rural-Urban Migration in China and Indonesia (RUMiCI) Project 11, 241-2, 244, 245, 251-2, 258

Singapore 49, 106, 141, 179, 180, 195, 198, 199, 202, 207, 209-10, 222, 223, $229,231,233,234,282,295,306,355$ social unrest $11,46,47,48,49,50,51$, $176,241,271,277,284$

soft-budget constraint 175, 273, 283, 366, 368,380

South Korea 8, 48, 85, 319, 352, 357, 368 economy $77 n .3$

exports 207, 208, 209, 355-6

foreign direct investment (FDI) 222-3, 229-31

foreign ownership 179-81

Gini coefficient 49

growth 2, 155, 172

imports 210

income 80

industry 141, 215n.15

labour costs 29,354

pollution 279, 286 steel intensity 74, 84, 87, 89, 91, 93, 95 trade 195, 197, 198, 199-200, 201-4, $214,233,234$

Soviet Union 45, 57, 58, 270n.1

special economic zones (SEZs) 42, 45, 222

State Council 102, 146, 284, 301, 306, $342 \mathrm{n} .2,375,383 \mathrm{n} .22$

state-controlled enterprises (SCEs) 273, $274,281,282,287$

State-Owned Assets Supervision and Administration Commission 63 state-owned enterprises (SOEs) 13, 30, $42,45,46,47,49,63,130,143,156$, $171,175-6,185,273 n .5,274,311-12$, $333,350-2,357-8$

statistics agricultural 73, 139

consumption 114 energy 100, 113-16, 119 reliability issues $8,100,111,113-16$, 119

steel consumption $77,81,84,87,89,90$, 93

stimulus program $50,157,212,272,273-$ $5,281,282,283,316,327$

structural adjustment 2, 6, 34, 45, 287, 295, 296

structural imbalance 3, 12, 293, 294, 308, $309,310,370$

subsidies

agricultural 173n.9, 174, 288, 293

energy 120

export 12, 214, 293, 294, 215, 302, $310,314,315$

Taiwan 47, 48, 80, 84, 91, 95, 130, 141, $155,169,172,179,180-1,195,197$, 198, 199-200, 201, 202, 207, 208, 209-10, 222, 229, 230, 231-3, 234 tariffs

agricultural 172n.8 import 183 taxation $42,52,54,55,59,61,63,64$, $114,116-17,176,227,310,311-12$, $342,366,370,371-2$ exemptions 309 reform 7, 41, 370 
taxes

agricultural 173n.9, 302, 306, 312, 313,326

arable land occupation 117

coal 101, 118

consumption 104, 116

contract 117

corporate 42, 223

development 117

export 101, 173, 183, 184, 185, 293,

$302,314,315$

income 42, 116, 302

inflation 41

property 118

resource 118

trade 183-5

urban land-use 117

vehicle excise 104

vehicle purchase 116, 315

see also value-added tax (VAT)

Tax-Sharing System (TSS) 57, 62, 63, 64, $65,67,116,117,118,370,371$

Todaro dogma 12, 321, 325-30, 334

'Top 1000 Enterprises Energy

Conservation Action Program' 102, 117

total factor productivity (TFP) 144, 323 growth 24, 34, 144, 356

town and village enterprises (TVEs) 41 , 46

trade sanctions 213, 214, 286

transfer payments, intergovernmental 5 , 53-60, 62-4, 67, 68, 370, 371, 372, 381,385

United Nations (UN) 57, 91, 92

United States 6, 33, 35, 45, 58, 60, 79, 80, $84,113,145,183,213,214,352,353$, 354

consumption 94, 153, 157, 287

currency 153, 154, 155, 163, 181, 297

dollar peg 154, 161, 170, 181-2

economy 156, 157-60, 163, 164, 165, $167,170,181,274,275,285,287$

energy 103

exchange rate $34,153,154,167,287$,

305

exports 153, 355 exports to 208, 209-10

foreign direct investment (FDI) 224

foreign ownership 180-1

fuel economy 104

GDP 270, 271, 309

labour costs 29,213

metal intensity $80,84,85,87,89,91$,

95

pollution 279,286

productivity 184, 212

renewable energy 107-8

trade 184, 213, 269, 287, 288, 289n.29

urbanisation 2, 3, 4, 11, 12, 73, 78, 80,

$82,84-5,87,88-9,90,91,153,159$,

281, 282, 283, 289n.29, 311, 319-37

value-added tax (VAT) 42, 63, 108, 116 , 173

Washington Consensus 31, 39-41, 43

water $138,139,278-81,284-6,302,311$,

$313,342,367$

transfer 280, 281, 285, 286, 289n.29

Wen Jiabao 46, 153n.2, 273, 275, 281,

284-5, 293, 300, 310, 385

West-East Gas Pipeline project 127

West-East Power Transmission Project 127

Western Regional Development Program (WRDP) 127, 128, 129, 141, 146

wind power 107-10, 120

World Bank 278n.16, 377

World Trade Organisation (WTO) 5, 172, 287, 289n.29

China's accession to $20,30,42,45$, $101,143,164,166,169,171,172,183$, $184,221,222,269,299$

Zhu Rongji 273 
